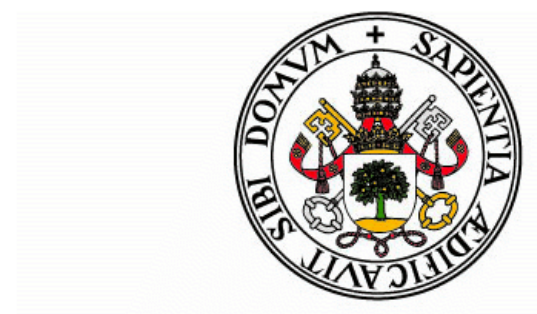

Universidad deValladolid

FACULTAD DE MEDICINA

DEPARTAMENTO

DE MEDICINA, DERMATOLOGÍA Y TOXICOLOGÍA

TESIS DOCTORAL:

\title{
REPERCUSIONES DE LA CIRUGÍA DE MINI BYPASS GÁSTRICO EN PACIENTES OBESOS (ReCiMB)
}

\author{
Presentada por D. José $M^{a}$ Jiménez Pérez para \\ optar al grado de \\ Doctor por la Universidad de Valladolid
}

\author{
Dirigida por: \\ Dr. Daniel de Luis Román \\ Dra. Ma José Castro Alija \\ Dr. Miguel Ángel Carbajo Caballero
}





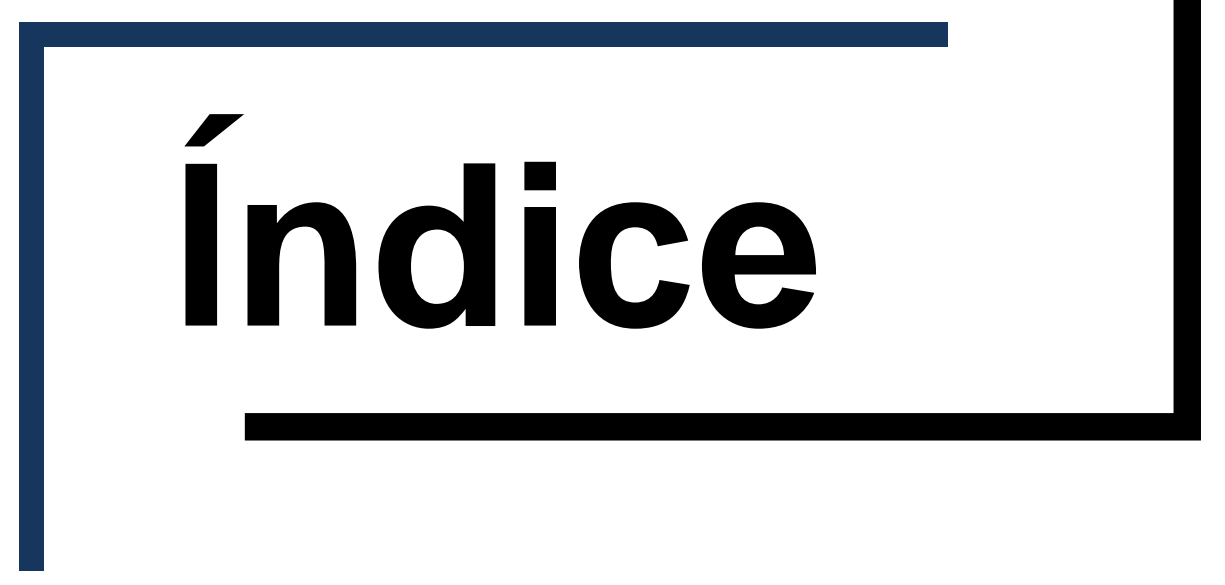




\section{Índice}

Índice de figuras

1. Evolución de la obesidad y estado actual

1.1. Antecedentes históricos

1.1.1. Edad Media

1.1.2. Edad Moderna

1.1.3. Edad Contemporánea

1.1.4. La obesidad como epidemia del siglo XXI

2. Diagnóstico y clasificación de la obesidad

2.1. Concepto

2.2. Clasificación

3. Etiopatogenia

3.1. Factores socioeconómicos y estilo de vida

3.2. Factores psicológicos

3.3. Factores neuroendocrinos

3.4. Factores genéticos

4. Epidemiología

4.1. Epidemiología de la obesidad en el mundo

4.2. Epidemiología de la obesidad en España

5. Patologías asociadas a la obesidad

5.1. Alteraciones metabólicas

5.2. Síndrome metabólico

5.3. Alteraciones cardiovasculares 
5.4. Alteraciones respiratorias

5.5. Enfermedades digestivas

5.5.1. Reflujo gastroesofágico

5.5.2. Colelitiasis

5.6. Enfermedades del aparato genitourinario

5.7. Alteraciones osteoarticulares

5.8. Enfermedades neoplásicas

5.9. Alteraciones de la salud mental

6. Tratamiento de la obesidad

6.1. Tratamiento dietético

6.2. Ejercicio físico

6.3. Tratamiento farmacológico

6.4. Terapia cognitivo-conductual

6.5. Tratamiento quirúrgico

6.5.1. Evolución histórica en el tratamiento quirúrgico

6.5.2. Técnicas restrictivas

6.5.2.1. Gastroplastia vertical anillada.

6.5.2.2. Banda gástrica ajustable.

6.5.2.3. Gastrectomía tubular.

6.5.3. Técnicas restrictivas-malabsortivas

6.5.3.1. Derivación biliopancreática y cruce duodenal

6.5.3.2. Bypass gástrico

6.5.4. Cirugías emergentes mínimamente invasivas

II. Objetivos

III. Material y métodos 65

3. Metodología 66

3.1. Diseño del estudio y ámbito de realización

3.2. Población y periodo de estudio

3.3. Procedimiento quirúrgico: Bypass gástrico de una sola anastomosis (BAGUA)

3.3.1. Evaluación preoperatoria 
3.3.2. Procedimiento quirúrgico

3.3.3. Protocolo de seguimiento postquirúrgico

3.4. Variables analizadas

3.4.1. Características generales

3.4.2. Evaluación clínica

3.4.3. Evaluación antropométrica

3.4.4. Características de la cirugía

3.4.5. Estilo de vida

3.4.6. Autovaloración de la tolerancia alimentaria postquirúrgica

3.4.7. Tratamiento farmacológico postquirúrgico

3.4.8. Evaluación bioquímica

3.5. Análisis estadístico

3.6. Aspectos éticos

3.7. Búsqueda bibliográfica

\section{Resultados}

4.1. Características generales de la muestra 85

4.1.1. Sexo y edad

4.1.2. País de nacimiento

4.1.3. Ocupación profesional

4.1.4. Estado civil

4.1.5. Número de hijos y embarazo

4.1.6. Origen de la obesidad

4.1.7. Clasificación de la muestra según la SEEDO

4.1.8. Hábito en la conducta alimentaria

4.2. Antecedentes clínicos de la muestra 100

4.3. Antecedentes quirúrgicos de la muestra 106

4.4. Hábitos tóxicos 110

4.4.1. Hábito tabáquico

4.4.2. Consumo de alcohol

\subsection{Preparación dietético-nutricional previa a la} cirugía 
4.6. Características generales de la cirugía

4.7. Valoración antropométrica.

4.7.1. Altura

4.7.2. Peso

a) Pérdida de peso entre las revisiones evaluadas

b) Pérdida de peso diario entre las revisiones evaluadas

c) Porcentaje de Sobrepeso Perdido. PSP

4.7.3. Índice de Masa Corporal (IMC)

a) Porcentaje de IMC Perdido. PIMCP

b) Porcentaje de Exceso de IMC Perdido. PEIMCP

c) Categorización de la pérdida de peso según el PEIMCP

d) Evolución de la obesidad por IMC. Criterios SEEDO

4.7.4. Perímetro de cintura

a) Obesidad abdominal asociada al perímetro de cintura

4.7.5. Perímetro de cadera

4.7.6. Índice de cintura/cadera. ICC

\subsection{Cuantificación del riesgo relativo de presentar} comorbilidades mayores. Criterios SEEDO

4.8.1. Riesgo relativo de presentar comorbilidades mayores en pacientes con obesidad abdominal

4.8.2. Riesgo relativo de presentar comorbilidades mayores en pacientes sin obesidad abdominal

\subsection{Autovaloración y tolerancia del consumo alimentario} postquirúrgico 201

4.9.1. Número de comidas diarias

4.9.2. Comer entre horas, picoteo

4.9.3. Autovaloración de la tolerancia alimentaria

4.10. Actividad física postquirúrgica............................ 209

4.11. Evolución de los valores bioquímicos

plasmáticos

4.11.1. Glucemia

4.11.2. Perfil lipídico

a) Colesterol total 

b) HDL-colesterol
c) LDL-colesterol
d) Triglicéridos

4.11.3. Perfil renal
a) Ácido úrico
b) Urea
c) Creatinina

4.11.4. Perfil hepático
a) GOT
b) GPT
c) GGT
d) Fosfatasa alcalina

4.11.5. Parámetros proteicos
a) Albúmina
b) Proteínas totales
c) Ferritina

4.11.6. Vitaminas
a) Vitamina $B_{12}$.
b) Ácido fólico.

4.11.7. Minerales
a) Hierro
b) Calcio
c) Fósforo

5.1.1. Características generales de la muestra

5.1.2. Antecedentes clínicos de la muestra

5.1.3. Antecedentes quirúrgicos de la muestra

5.2. Hábitos tóxicos 295

5.2.1. Hábito tabáquico

5.2.2. Consumo de alcohol

5.3. Preparación dietético-nutricional previa a la cirugía 
5.4. Características específicas de la cirugía 299

5.5. Valoración antropométrica

5.5.1. Evolución de la pérdida ponderal

5.5.2. Evolución del patrón de distribución de la grasa abdominal

5.6. Evaluación de la adaptación alimentaria

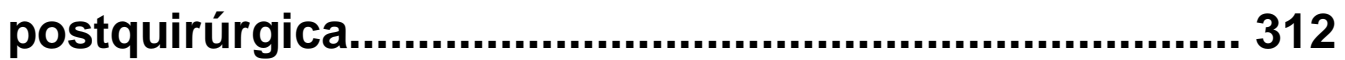

5.7. Actividad física postquirúrgica.............................. 315

5.8. Evolución de los valores bioquímicos plasmáticos

\subsubsection{Glucemia}

5.8.2. Perfil lipídico

5.8.3. Perfil renal

5.8.4. Perfil hepático

5.8.5. Proteínas

5.8.6. Micronutrientes

5.8.6.1. Vitaminas

5.8.6.2. Minerales

5.9. Limitaciones del estudio e implicaciones de futuro 330

VI. Conclusiones 331

VII. Bibliografía 335 


\section{ÍNDICE DE FIGURAS}

Figura 1.1. Prevalencia mundial del sobrepeso en edad adulta. Fuente: OMS. Base de datos mundial sobre el IMC. Disponible en: http://apps.who.int/bmi/index.jsp

Figura 1.2. Prevalencia mundial de la obesidad en edad adulta. Fuente:

OMS. Base de datos mundial sobre el IMC. Disponible en: http://apps.who.int/bmi/index.jsp

Figura 1.3. Prevalencia de la obesidad. Fuente: OECD Health Statistics 2014. Disponible en: www.oecd.org/health/healthdata

Figura 1.4. Prevalencia mundial de la obesidad. Fuente: OECD Health

Statistics 2014. Disponible en: www.oecd.org/health/healthdata

Figura 1.5. Índice relativo de sobrepeso por nivel de educación. Fuente:

OECD Health $2014 . \quad$ Disponible en: www.oecd.org/health/healthdata .................................................................. 24

Figura 1.6. Prevalencia de obesidad en España por nivel de educación y sexo. Fuente: OECD Health Statistics 2014. Disponible en: www.oecd.org/health/healthdata

Figura 1.7. Tendencia del número de cirugías bariátricas a nivel mundial y europeo ${ }^{108}$ 50

Figura 1.8. Banda gástrica ajustable. Imagen de D.M. Herron, MD, New York, NY. (c) 2007 Daniel M. Herron

Figura 1.9. Gastrectomía tubular. Imagen de D.M. Herron, MD, New York, NY. (C) 2007 Daniel M. Herron

Figura 1.10. Derivación biliopancreática y cruce duodenal. Imagen de D.M. Herron, MD, New York, NY. (C) 2007 Daniel M. Herron

Figura 1.11. Bypass gástrico en Y de Roux. Imagen de D.M. Herron, MD, New York, NY. (c) 2007 Daniel M. Herron

Figura 3.1. Distribución esquemática del acceso laparoscópico empleado. Imagen de M.A. Carbajo, MD.PhD, CTO Valladolid. (c) 2008 M.A. Carbajo..... 68 
Figura 4.1.1. Descripción de la edad de la muestra estudiada. 85

Figura 4.1.2. Distribución de los pacientes intervenidos por CCAA de origen

Figura 4.1.3. Ocupación profesional de la muestra estudiada 89

Figura 4.1.4. Distribución por número de hijos de las mujeres de la muestra

Figura 4.1.5. Clasificación según el tipo de parto de las mujeres con hijos ..... 93

Figura 4.1.6. Clasificación de la muestra según el IMC prequirúrgico.

SEEDO 2007 95

Figura 4.1.7. Distribución del consumo de alimentario por la frecuencia de hábitos 98

Figura 4.1.8. Distribución porcentual respecto al sexo por frecuencia de hábitos alimentarios 99

Figura 4.4.1. Clasificación del hábito tabáquico de la muestra....................... 110

Figura 4.4.2. Clasificación del consumo de alcohol de la muestra.................. 112

Figura 4.5.1. Diferencia entre el peso objetivo estimado en la cirugía según el sexo .

Figura 4.5.2. Descripción del peso objetivo estimado en la cirugía según el grado de obesidad

Figura 4.5.3. Descripción del porcentaje aplicado en la reducción ponderal prequirúrgica según el sexo

Figura 4.5.4. Descripción del porcentaje aplicado en la reducción ponderal prequirúrgica según el grado de obesidad

Figura 4.5.5. Descripción de la variación ponderal $(\mathrm{kg})$ respecto al peso objetivo en la cirugía

Figura 4.5.6. Descripción en días del tiempo de preparación prequirúrgico... 121

Figura 4.5.7. Tiempo de preparación prequirúrgico según el grado de obesidad.

Figura 4.6.1. Tiempo quirúrgico según el grado de obesidad. 
Figura 4.7.1. Descripción de la altura según el sexo mediante diagrama de cajas

Figura 4.7.2. Descripción de la altura según la mediana de edad de la muestra

Figura 4.7.3. Representación en histogramas del peso en las diferentes revisiones evaluadas

Figura 4.7.4. Gráfico de barras de error (IC 95\%) del peso en los controles evaluados

Figura 4.7.5. Tendencia en la evolución del peso medio por sexo

Figura 4.7.6. Representación en histogramas del peso perdido en las diferentes revisiones evaluadas

Figura 4.7.7. Gráfico de barras de error (IC 95\%) del peso perdido en los controles evaluados

Figura 4.7.8. Representación en histogramas del peso perdido diario en las diferentes revisiones evaluadas.

Figura 4.7.9. Gráfico de barras de error (IC 95\%) del peso perdido al día en los diferentes controles evaluados

Figura 4.7.10. Representación en histogramas del PSP en las diferentes revisiones evaluadas

Figura 4.7.11. Gráfico de barras de error (IC 95\%) del PSP en los diferentes controles evaluados

Figura 4.7.12. Representación en histogramas del IMC en las diferentes revisiones evaluadas

Figura 4.7.13. Gráfico de barras de error (IC 95\%) del IMC en los diferentes controles evaluados

Figura 4.7.14. Representación en histogramas del PIMCP en las diferentes revisiones evaluadas

Figura 4.7.15. Gráfico de barras de error (IC 95\%) del PIMCP en los diferentes controles evaluados. 
Figura 4.7.16. Representación en histogramas del PEIMCP en las diferentes revisiones evaluadas

Figura 4.7.17. Gráfico de barras de error (IC 95\%) del PEIMCP en los diferentes controles evaluados

Figura 4.7.18. Clasificación de los pacientes en cada uno de los controles evaluados según los criterios de calidad basados en el PEIMCP

Figura 4.7.19. Evolución del criterio de calidad basado en el PEIMCP según el sexo, en cada uno de los controles evaluados

Figura 4.7.20. Evolución del criterio de calidad basado en el PEIMCP según el grupo de edad, en cada uno de los controles evaluados

Figura 4.7.21. Distribución de los pacientes por criterios de clasificación SEEDO en los diferentes controles evaluados

Figura 4.7.22. Representación en histogramas del perímetro de cintura en las diferentes revisiones evaluadas

Figura 4.7.23. Gráfico de barras de error (IC 95\%) del perímetro de cintura en los controles evaluados

Figura 4.7.24. Representación en histogramas del perímetro de cadera en las diferentes revisiones evaluadas

Figura 4.7.25. Gráfico de barras de error (IC 95\%) del perímetro de cadera en los controles evaluados

Figura 4.7.26. Representación en histogramas del ICC en las diferentes revisiones evaluadas

Figura 4.7.27. Gráfico de barras de error (IC 95\%) del ICC en los controles evaluados

Figura 4.8.1. Clasificación de los pacientes según el riesgo relativo de presentar comorbilidades mayores en los pacientes con obesidad abdominal, en cada uno de los controles evaluados

Figura 4.8.2. Riesgo de presentar comorbilidades mayores en los pacientes con obesidad abdominal según el sexo, en los diferentes controles evaluados 
Figura 4.8.3. Riesgo de presentar comorbilidades mayores en los pacientes con obesidad abdominal, según el grupo de edad, en los diferentes controles evaluados

Figura 4.8.4 Clasificación de los pacientes según el riesgo relativo de presentar comorbilidades mayores en los pacientes sin obesidad abdominal, en cada uno de los controles evaluados

Figura 4.8.5. Riesgo de presentar comorbilidades mayores en los pacientes sin obesidad abdominal según el sexo, en los diferentes controles evaluados

Figura 4.8.6. Riesgo de presentar comorbilidades mayores en los pacientes sin obesidad abdominal según el grupo de edad, en los diferentes controles evaluados...

Figura 4.9.1. Tolerancia por grupo alimentario en los diferentes controles postquirúrgicos 205

Figura 4.10.1. Actividad física en los diferentes controles postquirúrgicos .... 210

Figura 4.11.1.1. Diagrama de caja de la glucemia plasmática en los diferentes controles evaluados representando los valores de referencia en el eje de ordenadas

Figura 4.11.1.2. Evolución de la diabetes según criterios ADA 2015

Figura 4.11.1.3. Gráfico de barras de la glucemia plasmática en los diferentes controles evaluados según el sexo y el grupo de edad correspondiente en cada uno de ellos

Figura 4.11.2.1. Diagrama de caja del Colesterol Total (Col-Total) plasmático en los diferentes controles evaluados representando los valores de referencia en el eje de ordenadas

Figura 4.11.2.2. Diagrama de caja del HDL-Colesterol plasmático en los diferentes controles evaluados representando los valores de referencia en el eje de ordenadas

Figura 4.11.2.3. Diagrama de caja del LDL-Colesterol plasmático en los diferentes controles evaluados representando los valores de referencia en el eje de ordenadas 
Figura 4.11.2.4. Diagrama de caja de los triglicéridos plasmáticos en los diferentes controles evaluados representando los valores de referencia en el eje de ordenadas

Figura 4.11.2.5. Gráfico de barras del perfil lipídico plasmático en los diferentes controles evaluados según el sexo y el grupo de edad correspondiente en cada uno de ellos

Figura 4.11.3.1. Diagrama de caja del ácido úrico plasmático en los diferentes controles evaluados representando los valores de referencia en el eje de ordenadas

Figura 4.11.3.2. Diagrama de caja de la urea plasmática en los diferentes controles evaluados representando los valores de referencia en el eje de ordenadas

Figura 4.11.3.3. Diagrama de caja de la creatinina plasmática en los diferentes controles evaluados representando los valores de referencia en el eje de ordenadas

Figura 4.11.3.4. Gráfico de barras del perfil renal plasmático en los diferentes controles evaluados según el sexo y el grupo de edad correspondiente en cada uno de ellos

Figura 4.11.4.1. Diagrama de caja de la transaminasa glutámico oxalacética (GOT) plasmática en los diferentes controles evaluados representando los valores de referencia en el eje de ordenadas

Figura 4.11.4.2. Diagrama de caja de la transaminasa glutámico-pirúvica (GPT) plasmática en los diferentes controles evaluados representando los valores de referencia en el eje de ordenadas

Figura 4.11.4.3. Diagrama de caja de la transaminasa gamma glutamil transpeptidasa (GGT) plasmática en los diferentes controles evaluados representando los valores de referencia en el eje de ordenadas

Figura 4.11.4.4. Diagrama de caja de la Fosfatasa Alcalina (FA) plasmática en los diferentes controles evaluados representando los valores de referencia en el eje de ordenadas. 
Figura 4.11.4.5. Gráfico de barras del perfil hepático plasmático en los diferentes controles evaluados según el sexo y el grupo de edad correspondiente en cada uno de ellos.

Figura 4.11.5.1. Diagrama de caja de la Vitamina $\mathrm{B}_{12}\left(\mathrm{Vit}_{12}\right)$ plasmática en los diferentes controles evaluados representando los valores de referencia en el eje de ordenadas

Figura 4.11.5.2. Diagrama de caja de la Ácido fólico plasmático en los diferentes controles evaluados representando los valores de referencia en el eje de ordenadas

Figura 4.11.6.1. Diagrama de caja de las proteínas totales (Prot.T) plasmáticas en los diferentes controles evaluados representando los valores de referencia en el eje de ordenadas

Figura 4.11.6.2. Diagrama de caja de la albúmina plasmática en los diferentes controles evaluados representando los valores de referencia en el eje de ordenadas

Figura 4.11.6.3. Gráfico de barras de las proteínas totales y la albúmina plasmática en los diferentes controles evaluados según el sexo y el grupo de edad correspondiente en cada uno de ellos.

Figura 4.11.6.4. Diagrama de caja de la ferritina plasmática en los diferentes controles evaluados representando los valores de referencia en el eje de ordenadas

Figura 4.11.7.1. Diagrama de caja del hierro plasmático en los diferentes controles evaluados representando los valores de referencia en el eje de ordenadas

Figura 4.11.7.2. Diagrama de caja del calcio plasmático en los diferentes controles evaluados representando los valores de referencia en el eje de ordenadas

Figura 4.11.7.3. Diagrama de caja del fósforo plasmático en los diferentes controles evaluados representando los valores de referencia en el eje de ordenadas 


\section{ÍNDICE DE TABLAS}

Tabla 1.1. Técnicas de valoración de la composición corporal 10

Tabla 1.2. Clasificación del sobrepeso y la obesidad según el IMC (OMS 2000)

Tabla 1.3. Clasificación del sobrepeso y la obesidad según el IMC (SEEDO 2007)

Tabla 1.4. Prevalencia del sobrepeso y obesidad. Fuente: ENS 2011-12.

Disponible en:

http://www.ine.es/jaxi/menu.do?type=pcaxis\&path=/t15/p419\&file=inebase .... 23

Tabla 1.5. Criterios diagnósticos del Síndrome Metabólico. Para poblaciones caucásicas se pueden tomar como referencia los criterios de la IDF (donde el perímetro de la cintura en hombres debe de ser $\geq 94 \mathrm{~cm}$ y en mujeres $\geq 80 \mathrm{~cm}$ ) o los de la AHA/NHLBI (donde el perímetro de cintura debe de ser $\geq 102 \mathrm{~cm}$ en los hombres y $\geq 88 \mathrm{~cm}$ en las mujeres), éste último coincide con las directrices sobre obesidad del National Institute of

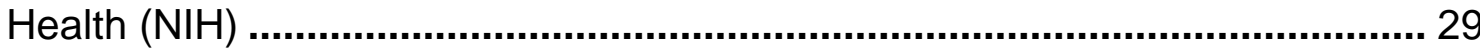

Tabla 3.1. Resumen de variables analizadas................................................. 72

Tabla 3.2. Clasificación del sobrepeso y la obesidad según el IMC (SEEDO 2007)

Tabla 3.3. Clasificación del riesgo relativo de presentar comorbilidades mayores según el peso y la presencia de obesidad abdominal. SEEDO......... 78

Tabla 3.4. Parámetros bioquímicos de referencia. Laboratorio de Análisis Clínicos del Hospital Universitario Río Hortega, Valladolid .............................. 79

Tabla 4.1.1. Clasificación de la muestra por grupos de edad y sexo ................ 86

Tabla 4.1.2. Clasificación de las diferentes ocupaciones profesionales por

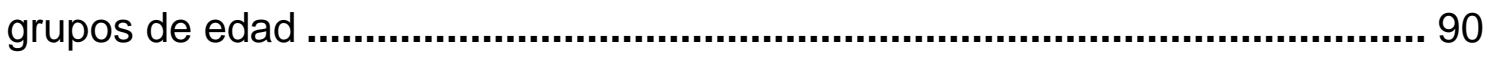

Tabla 4.1.3. Estado civil de la muestra según el sexo..................................... 91

Tabla 4.1.4. Estado civil de la muestra clasificada por grupos de edad ............ 91

Tabla 4.1.5. Número de hijos de las mujeres por grupo de edad ...................... 92

Tabla 4.1.6. Origen de la obesidad de la muestra según el sexo...................... 94 
Tabla 4.2.1. Distribución del tratamiento de la DM según el sexo 104

Tabla 4.3.1. Porcentaje de pacientes con cirugía traumatológica previas según el sexo. 106

Tabla 4.3.2. Porcentaje de pacientes con apendicectomía previa según el sexo 108

Tabla 4.4.1. Hábito tabáquico de la muestra según el sexo 111

Tabla 4.4.2. Consumo de alcohol de la muestra según el sexo

Tabla 4.5.1. Descripción del peso objetivo estimado en la cirugía

Tabla 4.5.2. Descripción del porcentaje aplicado en la reducción ponderal prequirúrgica

Tabla 4.5.3. Cumplimiento del peso objetivo en la cirugía según el grado de obesidad

Tabla 4.6.1. Tiempo quirúrgico según la longitud del asa biliopancreática .... 125

Tabla 4.6.2. Tiempo quirúrgico según la longitud del asa común 125

Tabla 4.7.1. Descripción de la altura de los pacientes estudiados 127

Tabla 4.7.2. Descripción del peso en las diferentes revisiones evaluadas. 129

Tabla 4.7.3. Descripción del peso medio según el sexo en las diferentes revisiones evaluadas

Tabla 4.7.4. Descripción del peso medio según el grupo de edad en las diferentes revisiones evaluadas

Tabla 4.7.5. Descripción del peso perdido en las diferentes revisiones evaluadas

Tabla 4.7.6. Descripción del peso perdido medio según el sexo en las diferentes revisiones evaluadas

Tabla 4.7.7. Descripción del peso perdido medio según el grupo de edad en las diferentes revisiones evaluadas. 
Tabla 4.7.8. Descripción del peso perdido al día en las diferentes revisiones evaluadas

Tabla 4.7.9. Descripción del peso perdido al día según el sexo en las diferentes revisiones evaluadas

Tabla 4.7.10. Descripción del peso perdido al día según el grupo de edad en las diferentes revisiones evaluadas.

Tabla 4.7.11. Descripción del PSP en las diferentes revisiones evaluadas ... 144

Tabla 4.7.12. Descripción del PSP según el sexo en las diferentes revisiones evaluadas.

Tabla 4.7.13. Descripción del PSP según el grupo de edad en las diferentes revisiones evaluadas

Tabla 4.7.14. Descripción del IMC en las diferentes revisiones evaluadas.... 149

Tabla 4.7.15. Descripción del IMC según el sexo en las diferentes revisiones evaluadas

Tabla 4.7.16. Descripción del IMC según el grupo de edad en las diferentes revisiones evaluadas

Tabla 4.7.17. Descripción del PIMCP en las diferentes revisiones evaluadas.

Tabla 4.7.18. Descripción del PIMCP según el sexo en las diferentes revisiones evaluadas

Tabla 4.7.19. Descripción del PIMCP según el grupo de edad en las diferentes revisiones evaluadas

Tabla 4.7.20 Descripción del PEIMCP en las diferentes revisiones evaluadas

Tabla 4.7.21. Descripción del PEIMCP según el sexo en las diferentes revisiones evaluadas. 
Tabla 4.7.22. Descripción del PEIMCP según el grupo de edad en las diferentes revisiones evaluadas

Tabla 4.7.23. Seguimiento del PEIMCP en los pacientes evaluados en cada una de las revisiones

Tabla 4.7.24. Seguimiento del PEIMCP en los pacientes evaluados en cada una de las revisiones según el sexo.

Tabla 4.7.25. Seguimiento del PEIMCP en los pacientes evaluados en cada una de las revisiones según la edad

Tabla 4.7.26. Distribución de los pacientes por criterios de IMC en las diferentes revisiones evaluadas

Tabla 4.7.27. Distribución de los pacientes por criterios de IMC según el sexo en la revisión de los 18 meses.

Tabla 4.7.28. Descripción del perímetro de cintura en las diferentes revisiones evaluadas

Tabla 4.7.29. Descripción del perímetro de cintura según el sexo en las diferentes revisiones evaluadas

Tabla 4.7.30. Descripción del perímetro de cintura según el grupo de edad en las diferentes revisiones evaluadas.

Tabla 4.7.31. Descripción de la obesidad abdominal según el sexo en los controles evaluados

Tabla 4.7.32. Descripción de la obesidad abdominal por grupos de edad en los controles evaluados

Tabla 4.7.33. Descripción del perímetro de cadera en las diferentes revisiones evaluadas.

Tabla 4.7.34. Descripción del perímetro de cadera según el sexo en las diferentes revisiones evaluadas 
Tabla 4.7.35. Descripción del perímetro de cadera según el grupo de edad en las diferentes revisiones evaluadas.

Tabla 4.7.36. Descripción del ICC en las diferentes revisiones evaluadas .... 182

Tabla 4.7.37. Descripción del ICC según el sexo en las diferentes revisiones evaluadas

Tabla 4.7.38. Descripción del ICC según el grupo de edad en las diferentes revisiones evaluadas

Tabla 4.8.1. Clasificación del riesgo relativo de presentar comorbilidades mayores según el peso y la presencia de obesidad abdominal. SEEDO

Tabla 4.8.2.Distribución de pacientes con obesidad abdominal en los controles evaluados

Tabla 4.8.3. Pacientes sin obesidad abdominal evaluados según el sexo y el riesgo de presentar comorbilidades mayores, en cada una de las revisiones evaluadas

Tabla 4.8.4. Pacientes con obesidad abdominal evaluados según la edad y el riesgo de presentar comorbilidades mayores, en cada una de las revisiones evaluadas

Tabla 4.8.5 Distribución de pacientes sin obesidad abdominal en los controles evaluados

Tabla 4.8.6. Pacientes sin obesidad abdominal evaluados según el sexo y el riesgo de presentar comorbilidades mayores, en cada una de las revisiones evaluadas.

Tabla 4.8.7. Pacientes sin obesidad abdominal evaluados según la edad y el riesgo de presentar comorbilidades mayores, en cada una de las revisiones evaluadas.

Tabla 4.9.1. Número De comidas diarias en los diferentes controles trimestrales 
Tabla 4.9.2. Frecuencia de comidas diarias en los controles postquirúrgicos

Tabla 4.9.3. Distribución de pacientes picoteadores en los controles postquirúrgicos

Tabla 4.9.4. Frecuencia de comidas entre horas en los controles postquirúrgicos

Tabla 4.9.5. Nivel de autovaloración de la tolerancia alimentaria postquirúrgica

Tabla 4.9.6. Número de respuestas observadas en la autovaloración de los alimentos peor tolerados.

Tabla 4.9.7. Descripción de vómitos en los controles postquirúrgicos 206

Tabla 4.9.8. Descripción de RGE en los controles postquirúrgicos 206

Tabla 4.9.9. Descripción de diarrea en los controles postquirúrgicos 207

Tabla 4.9.10. Descripción del número de deposiciones diarias en los controles postquirúrgicos

Tabla 4.10.1. Frecuencia de la actividad física en los controles postquirúrgicos

Tabla 4.11.1.1 Descripción de la glucemia plasmática en las diferentes revisiones evaluadas

Tabla 4.11.1.2. Descripción de la glucemia plasmática en las diferentes revisiones evaluadas según el sexo

Tabla 4.11.1.3. Descripción de la glucemia plasmática en las diferentes revisiones evaluadas según el grupo de edad

Tabla 4.11.2.1. Descripción del Colesterol Total (Col-Total) plasmático en las diferentes revisiones evaluadas

Tabla 4.11.2.2. Descripción del Colesterol Total (Col-Total) plasmático en las diferentes revisiones evaluadas según el sexo. 
Tabla 4.11.2.3. Descripción del Colesterol Total (Col-Total) plasmático en las diferentes revisiones evaluadas según el grupo de edad

Tabla 4.11.2.4. Descripción del HDL-Colesterol (HDL-Col) plasmático en las diferentes revisiones evaluadas

Tabla 4.11.2.5. Descripción del HDL-Colesterol (HDL-Col) plasmático en las diferentes revisiones evaluadas según el sexo.

Tabla 4.11.2.6. Descripción del HDL-Colesterol (HDL-Col) plasmático en las diferentes revisiones evaluadas según el grupo de edad

Tabla 4.11.2.7. Descripción del LDL-Colesterol (LDL-Col) plasmático en las diferentes revisiones evaluadas

Tabla 4.11.2.8. Descripción del LDL-Colesterol (LDL-Col) plasmático en las diferentes revisiones evaluadas según el sexo.

Tabla 4.11.2.9. Descripción del LDL-Colesterol (LDL-Col) plasmático en las diferentes revisiones evaluadas según el grupo de edad

Tabla 4.11.2.10. Descripción de los triglicéridos (TG) plasmáticos en las diferentes revisiones evaluadas

Tabla 4.11.2.11. Descripción de los triglicéridos (TG) plasmáticos en las diferentes revisiones evaluadas según el sexo

Tabla 4.11.2.12. Descripción de los triglicéridos (TG) plasmáticos en las diferentes revisiones evaluadas según el grupo de edad

Tabla 4.11.3.1. Descripción del ácido úrico (Ácd.Úrico) plasmático en las diferentes revisiones evaluadas

Tabla 4.11.3.2. Descripción del ácido úrico (Ácd.Úrico) plasmáticos en las diferentes revisiones evaluadas según el sexo

Tabla 4.11.3.3. Descripción del ácido úrico (Ácd.Úrico) plasmáticos en las diferentes revisiones evaluadas según el grupo de edad. 
Tabla 4.11.3.4. Descripción de urea plasmática en las diferentes revisiones evaluadas

Tabla 4.11.3.5. Descripción de la urea plasmática en las diferentes revisiones evaluadas según el sexo.

Tabla 4.11.3.6. Descripción de la urea plasmática en las diferentes revisiones evaluadas según el grupo de edad

Tabla 4.11.3.7. Descripción de la creatinina (Creat) plasmática en las diferentes revisiones evaluadas

Tabla 4.11.3.8. Descripción de la creatinina (Creat) plasmática en las diferentes revisiones evaluadas según el sexo

Tabla 4.11.3.9. Descripción de la creatinina (Creat) plasmática en las diferentes revisiones evaluadas según el grupo de edad

Tabla 4.11.4.1. Descripción de la transaminasa glutámico oxalacética (GOT) en las diferentes revisiones evaluadas

Tabla 4.11.4.2. Descripción de la transaminasa glutámico oxalacética (GOT) plasmática en las diferentes revisiones evaluadas según el sexo ..... 242

Tabla 4.11.4.3. Descripción de la transaminasa glutámico oxalacética (GOT) plasmática en las diferentes revisiones evaluadas según el grupo de edad

Tabla 4.11.4.4. Descripción de la transaminasa glutámico-pirúvica (GPT) en las diferentes revisiones evaluadas

Tabla 4.11.4.5. Descripción de la transaminasa glutámico-pirúvica (GPT) plasmática en las diferentes revisiones evaluadas según el sexo

Tabla 4.11.4.6. Descripción de la transaminasa glutámico-pirúvica (GPT) plasmática en las diferentes revisiones evaluadas según el grupo de edad.. 246

Tabla 4.11.4.7. Descripción de la transaminasa gamma glutamil transpeptidasa (GGT) en las diferentes revisiones evaluadas 
Tabla 4.11.4.8. Descripción de la transaminasa gamma glutamil transpeptidasa (GGT) plasmática en las diferentes revisiones evaluadas según el sexo

Tabla 4.11.4.9. Descripción de la transaminasa gamma glutamil transpeptidasa (GGT) plasmática en las diferentes revisiones evaluadas según el grupo de edad

Tabla 4.11.4.10. Descripción de la Fosfatasa Alcalina (FA) en las diferentes revisiones evaluadas

Tabla 4.11.4.11. Descripción de la Fosfatasa Alcalina (FA) plasmática en las diferentes revisiones evaluadas según el sexo.

Tabla 4.11.4.12. Descripción de la Fosfatasa Alcalina (FA) plasmática en las diferentes revisiones evaluadas según el grupo de edad

Tabla 4.11.5.1. Descripción de Vitamina $\mathrm{B}_{12}\left(\right.$ Vit $\left.\mathrm{B}_{12}\right)$ plasmática en las diferentes revisiones evaluadas

Tabla 4.11.5.2. Descripción de la Vitamina $\mathrm{B}_{12}$ (Vit $\mathrm{B}_{12}$ ) plasmática en las diferentes revisiones evaluadas según el sexo

Tabla 4.11.5.3. Descripción de la Vitamina $\mathrm{B}_{12}$ (Vit $\mathrm{B}_{12}$ ) plasmática en las diferentes revisiones evaluadas según el grupo de edad

Tabla 4.11.5.4. Descripción del ácido fólico (Ácd.Fol) plasmático en las diferentes revisiones evaluadas

Tabla 4.11.5.5. Descripción del ácido fólico (Ácd.Fol) plasmático en las diferentes revisiones evaluadas según el sexo

Tabla 4.11.5.6. Descripción del ácido fólico (Ácd.Fol) plasmático en las diferentes revisiones evaluadas según el grupo de edad

Tabla 4.11.6.1. Descripción de las proteínas totales (Prot.T) plasmáticas en las diferentes revisiones evaluadas.

Tabla 4.11.6.2. Descripción de las proteínas totales (Prot.T) plasmáticas en las diferentes revisiones evaluadas según el sexo. 
Tabla 4.11.6.3. Descripción de las proteínas totales (Prot.T) plasmáticas en las diferentes revisiones evaluadas según el grupo de edad

Tabla 4.11.6.4. Descripción de la albúmina (Alb) plasmática en las diferentes revisiones evaluadas

Tabla 4.11.6.5. Descripción de la albúmina (Alb) plasmática en las diferentes revisiones evaluadas según el sexo

Tabla 4.11.6.6. Descripción de la albúmina (Alb) plasmática en las diferentes revisiones evaluadas según el grupo de edad.

Tabla 4.11.6.7. Descripción de la ferritina plasmática en las diferentes revisiones evaluadas

Tabla 4.11.6.8. Descripción de ferritina plasmática en las diferentes revisiones evaluadas según el sexo

Tabla 4.11.6.9. Descripción de ferritina plasmática en las diferentes revisiones evaluadas según el grupo de edad

Tabla 4.117.1. Descripción del hierro plasmático en las diferentes revisiones evaluadas.

Tabla 4.11.7.2. Descripción del hierro plasmático en las diferentes revisiones evaluadas según el sexo

Tabla 4.11.7.3. Descripción del hierro plasmático en las diferentes revisiones evaluadas según el grupo de edad

Tabla 4.11.7.4. Descripción calcio plasmático en las diferentes revisiones evaluadas

Tabla 4.11.7.5. Descripción del calcio plasmático en las diferentes revisiones evaluadas según el sexo

Tabla 4.11.7.6. Descripción del calcio plasmático en las diferentes revisiones evaluadas según el grupo de edad 
Tabla 4.11.7.7. Descripción fósforo plasmático en las diferentes revisiones evaluadas

Tabla 4.11.7.8. Descripción del fósforo plasmático en las diferentes revisiones evaluadas según el sexo.

Tabla 4.11.7.9. Descripción del fósforo plasmático en las diferentes revisiones evaluadas según el grupo de edad

Tabla 5.1. Características generales de las publicaciones del metaanálisis "mini bypass gástrico" ${ }^{\text {"28 }}$ y el estudio ReCiMB

Tabla 5.2. Características quirúrgicas de las publicaciones del metaanálisis "mini bypass gástrico" ${ }^{\text {"228 }}$ y el estudio ReCiMB

Tabla 5.3. Resultados de PSP del metaanálisis publicado por Lynch et $\mathrm{al}^{182}$, comparados con el estudio ReCiMB

Tabla 5.4. Evolución del IMC publicaciones del metaanálisis "mini bypass gástrico" ${ }^{\prime 28}$ y el estudio ReCiMB

Tabla 5.5. PEIMCP a 12 meses por grupos de edad comparando los resultados del estudio de Contreras et $\mathrm{al}^{134}$ y ReCiMB

Tabla 5.6. Comparativo de las variables: peso, IMC, perímetro de cintura y cadera de los pacientes del estudio de Jastrzębska et $\mathrm{al}^{200}$ y el estudio ReCiMB

Tabla 5.7. Valores prequirúrgicos del perfil lipídico plasmático del estudio de Milone et $a^{214}$ y el estudio ReCiMB

Tabla 5.8. Evolución del perfil lipídico plasmático del estudio de Søvik et $\mathrm{al}^{189}$ y el estudio ReCiMB

Tabla 5.9. Evolución de la Vit $B_{12}$ en el estudio de Vargas-Ruiz et $a^{240}$ y el estudio ReCiMB

Tabla 5.10. Evolución de Ácd.Fol en el estudio de Vargas-Ruiz et $\mathrm{al}^{240}$ y el estudio ReCiMB 
Tabla 5.11. Evolución de hierro sérico en el estudio de Worm et $\mathrm{al}^{242} \mathrm{y}$ el estudio ReCiMB 328 


\section{ABREVIATURAS}

$\mu \mathrm{g}$

Ácd. Fol

Ácd. Úrico

ADA

ADO

AHA / NHLBI

Alb

AMPK

ASMBS

ATP III

BAGUA

BGYR

BIA

BIG

BOD-POD

CCAA

$C D$

$\mathrm{cm}$
Microgramo

Ácido fólico plasmático

Ácido úrico plasmático

Asociación de Diabetes Americana

Antidiabéticos orales

American Heart Association / National Heart, Lung, and Blood Institute

Albúmina plasmática

Proteína quinasa dependiente de AMP

Sociedad Americana de Cirugía Bariátrica y Metabólica

National Cholesterol Education Program Adult

Treatment Panel III

Bypass Gástrico de Una Anastomosis

Bypass gástrico en Y Roux

Impedancia bioeléctrica

Balón intragástrico

Pletismografía por intercambio de aire

Comunidades Autónomas

Cruce duodenal

Centímetro 
Col-Total Colesterol total plasmático

CPAP Dispositivo de presión positiva continua en las vías respiratorias

Creat Creatinina plasmática

CTO Centro de Excelencia para el Estudio y Tratamiento de la Obesidad

DBP Derivación biliopancreática

DEXA Densitometría de doble fotón dual

DHP Dietas hiperproteicas

DI Decilitro

DM Diabetes Mellitus

DMBC Dietas muy bajas en calorías

EAC-BS Registro Europeo de Cirugía Bariátrica

EMA Agencia Europea de Medicamentos

Endobarrier Bypass duodenoyeyunal endoscópico

EndoCinch Gastroplastia vertical endoluminal

ENS Encuesta Nacional de Salud

FA Fosfatasa Alcalina

FDA Agencia de Drogas y Alimentos de Estados Unidos

FESNAD Federación Española de Sociedades de Nutrición, Alimentación y Dietética

9

Gramo 
GOT

GPT

HbA1c

HDL

HTA

IASO

IC

ICC

IDF

IFSO

IMC

IOTF

Kcal

$\mathrm{Kg}$

I

LDL

LPL

m

MBG

MBSAQIP
Transaminasa glutámico oxalacética

Transaminasa glutámico-pirúvica

Hemoglobina glicosilada

Lipoproteína de alta densidad

Hipertensión Arterial

Asociación Internacional para el Estudio de la Obesidad

Intervalo de Confianza

Índice Cintura-Cadera

International Diabetes Federation

Federación Internacional de la Cirugía de la Obesidad

Índice de Masa Corporal

Equipo Internacional de Trabajo de la Obesidad

Kilocaloría

Kilogramo

Litro

Lipoproteína de baja densidad

Lipoprotein lipasa

Metro

Mini bypass gástrico

Metabolic and Bariatric Surgery Accreditation and Quality Improvement Program 
milímetro

NAOS Estrategia para la Nutrición, Actividad Física y Prevención de la Obesidad

ng

Nanogramo

NHANES

Encuesta Nacional de Salud y Nutrición

$\mathrm{NIH}$

National Institute of Health

OCDE

Organización para la Cooperación y el Desarrollo

Económicos

OMS

Organización Mundial de la Salud

PEIMCP

Porcentaje de Exceso de Índice de Masa Corporal Perdido

PIMCP Porcentaje de Índice de Masa Corporal Perdido

Prot.T Proteínas totales

PSP Porcentaje de Sobrepeso Perdido

PTH Hormona paratiroidea en sangre

RGE Reflujo gastroesofágico

RI Resistencia a la insulina

RMN Resonancia Magnética Nuclear

SAOS Síndrome de apnea obstructiva del sueño

SECO Sociedad Española de Cirugía de la Obesidad Mórbida y de las Enfermedades Metabólicas

SEEDO Sociedad Española para el Estudio de la Obesidad

SEEN Sociedad Española de Endocrinología y Nutrición 
SEMERGEN Sociedad Española de Médicos de Atención Primaria

SING Scottish Intercollegiate Guidelines Network

SM

Síndrome Metabólico

TAC

Tomografía Axial Computerizada

TG

Triglicéridos plasmáticos

TOGA

Gastroplastia transoral

Vit $B_{12}$

Vitamina $\mathrm{B}_{12}$ plasmática 


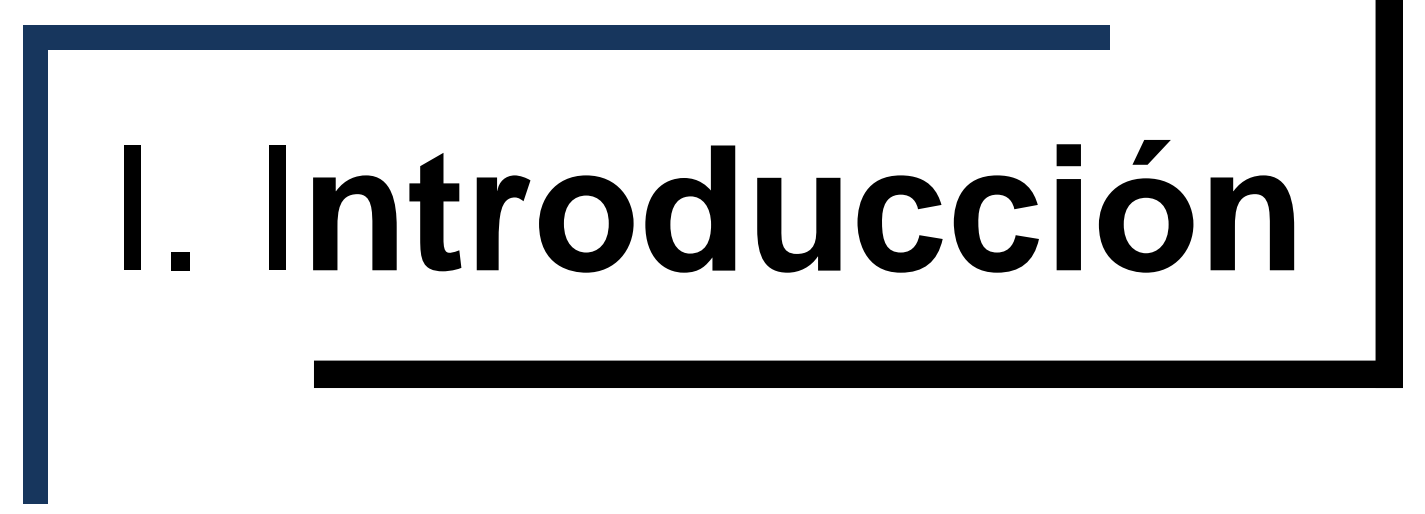


La obesidad se ha ido convirtiendo de manera progresiva en un problema sociosanitario con una gran incidencia en las sociedades desarrolladas, alcanzando un carácter epidémico. El sobrepeso y la obesidad son el sexto factor principal de riesgo de muerte en el mundo, cada año mueren alrededor de 3,4 millones de personas adultas por esta causa según los datos ofrecidos por la Organización Mundial de la Salud (OMS). Constituye un problema de salud pública, que según los datos de la última Encuesta Nacional de Salud (ENS) del 2012, afecta al 17,03\% de la población adulta en España y el sobrepeso al 36,65\%. Su etiología es multifactorial y está asociada a comorbilidades que suponen una disminución de la esperanza y calidad de vida de los pacientes que la sufren. Es por ello que la obesidad ejerce un gran impacto en el consumo de recursos económicos de los sistemas sanitarios. A lo largo de sus vidas los pacientes obesos sin tratamiento, generan unos gastos de atención sanitaria por lo menos del $25 \%$ más que las personas con normopeso ${ }^{1}$.

Las opciones de tratamiento para la obesidad incluyen el tratamiento no quirúrgico y la cirugía bariátrica. El tratamiento no quirúrgico suele estar basado en un enfoque de múltiples componentes que comprende modificaciones en la dieta, la terapia conductual, cambios en el estilo de vida, aumento de la actividad física, y farmacoterapia. Las técnicas de cirugía bariátrica más comúnmente utilizados son el bypass gástrico, la gastrectomía tubular y la banda gástrica ajustable.

En este apartado se describirá la evolución de la obesidad en la sociedad a lo largo de la historia, las formas de clasificación y definición de esta enfermedad según diferentes criterios. Del mismo modo se detallarán los factores causales de esta enfermedad, su epidemiología a nivel nacional y mundial, las patologías asociadas y su repercusión en el estado de salud del paciente, y las posibles alternativas terapéuticas prestando especial interés a las técnicas quirúrgicas. Más profundamente se analizará la modalidad quirúrgica de mini bypass gástrico de una sola anastomosis (BAGUA), siendo ésta la técnica aplicada a la muestra de pacientes implicados en nuestro trabajo. 


\section{Evolución de la obesidad y estado actual}

\subsection{Antecedentes históricos}

Desde la antigüedad es conocido que el ser humano ha vivido con una conducta de cazador-recolector, con la finalidad de resistir los periodos de escasez de alimentos. Este hecho a través del proceso de selección favoreció la configuración del genoma humano de aquellos "genes ahorradores" que permitían a los individuos disfrutar de una mayor supervivencia.

Hace unos 12000 años, algunos grupos de humanos modificaron ese hábito cazador-recolector e iniciaron a producir alimentos, ese cambio requirió el cultivo de plantas y la domesticación de animales, proceso en el que los humanos actuaron como agentes de selección de los fenotipos domésticos $^{2}$. Esta transformación económica, conocida como revolución neolítica, se considera un lejano antecedente de las sociedades modernas que favorecería la obesidad en la población, ya que permitió el crecimiento de la población y la evolución hacia sociedades más complejas y civilizadas.

El único hecho constatable en la prehistoria de la presencia de humanos obesos, es el descubrimiento de figuras que representan humanos obesos desde el sur de Francia hasta el sur de Rusia. Estas estatuillas del paleolítico se produjeron hace 23000 a 25000 años con terracota, piedra caliza y marfil. La más conocida es la venus de Willendorf, expuesta en el Museo de Historia de Viena, que representa probablemente un símbolo de fertilidad o maternidad ${ }^{3}$.

Las tradiciones médicas de muchas culturas antiguas dejaron registro de la obesidad y sus consecuencias. En el antiguo Egipto, la obesidad se consideraba propia de un rango social alto, en contraste con los campesinos o artesanos, a quienes el exceso y la rudeza del trabajo mantenían en un estado más atlético. Como consecuencia de la obesidad que prevalecía en estratos sociales altos, la arterioesclerosis generalizada 
fue un hallazgo muy frecuente en los cadáveres como Amenhotep III, Ramsés III y Menerptah ${ }^{4}$. Sin embargo, la obesidad fue también un problema de la población general, como demuestran distintos relieves tallados en piedra que la simbolizan como una circunstancia usual entre los egipcios.

Por otro lado, uno de los ideales de la Grecia clásica era el cuerpo atlético, ya que se buscaba la belleza en todos los elementos sociales. Hipócrates desarrolló varias teorías sobre el funcionamiento del cuerpo basadas en los elementos y humores. La salud era concebida como el estado en el que había un adecuado equilibrio entre estos humores, mientras que en la enfermedad se producía un estado de desequilibrio ${ }^{3}$.

Galeno, médico romano y una de las figuras más dominantes en la historia de la medicina, fue uno de los primeros en establecer métodos científicos para describir y tratar la obesidad ${ }^{5}$. Describió la polisarquia, reconocida en la actualidad como obesidad mórbida, y fue quién clasificó la enfermedad por primera vez distinguiendo la obesidad moderada y grave.

\subsubsection{Edad Media}

El representante de la medicina árabe fue Avicena, uno de los médicos más prestigiosos de la época. Su enciclopedia médica, traducida al latín con el título de Canon, fue el texto básico para la enseñanza de la medicina durante siglos, en la cual hace mención a la obesidad y los daños que provoca en la salud.

En esta época en la cultura asiática, como en China e India, describieron los principios de la armonía entre el ser humano y el mundo como la llave para la larga vida y actividades físicas como el yoga y el consumo de alimentos y dietas específicas ${ }^{6}$.

Avanzada la Edad Media, el poder eclesiástico influyó en diversas áreas de la vida cotidiana. La obesidad era poco frecuente debido a la escasez habitual de alimentos, por lo que se consideraba una bendición de Dios. Sin embargo, se creía que la gula era un pecado capital. En el infierno de Dante se describe a los golosos como merecedores de un castigo 
ejemplar ${ }^{7}$. En contradicción, a reyes, papas y cardenales se les permitía ser obesos, lo cual se percibía como un símbolo de poder y bienestar económico. Aún se pueden observar pinturas de monarcas como Luis XVI o Enrique VIII que los retratan como individuos obesos que disfrutan de los opulentos banquetes con gran felicidad.

\subsubsection{Edad Moderna}

Las primeras monografías dedicadas a la obesidad aparecieron durante el siglo XVIII: en sus trabajos, Thomas Short (1727) y Malcolm Flemyng (1760) utilizaron la palabra corpulencia para hacer mención a la obesidad. Las primeras palabras del trabajo de Short fueron: "A mi parecer, ninguna era había presentado tantos casos de corpulencia como la nuestra". Este médico consideraba que el tratamiento de la obesidad requería el restablecimiento del balance natural del cuerpo, así como el retiro de causas secundarias, pudiendo lograrse evitando climas húmedos, ciudades o bosques, al igual que la dieta y el ejercicio eran necesarios para tratar la obesidad.

Flemyng mencionó las cuatro causas de la corpulencia. En primer lugar la ingesta de grandes cantidades de comida, especialmente grasas. También comentó que no todas las causas de la obesidad son secundarias a la ingesta abundante de alimento; así sugirió que la segunda causa de la corpulencia era una membrana muy laxa en los adipocitos, lo cual permitía que las vesículas en su interior pudieran distenderse con gran facilidad. La tercera causa era un estado anormal de la sangre que permitía el almacenamiento. Finalmente, describió como cuarto mecanismo "evacuaciones anómalas". Pensaba que el sudor, la orina y el excremento de la gente corpulenta contenía aceite, por lo que el tratamiento para eliminar el exceso de este compuesto podía consistir en la administración de laxantes, diuréticos y diaforéticos.

En esta segunda mitad del siglo XVIII se produce un hecho trascendental en la historia de la medicina: Joannes Baptista Morgagni publica en 1765 su ingente obra en 5 tomos: De Sedibus et Causis Morborum per Anatomen Indagata. Con ella se inicia la teoría 
anatomopatológica de la enfermedad, ya que Morgagni realiza una minuciosa observación de las vísceras e intenta relacionar estos hallazgos con la presentación clínica de las enfermedades. En el De Sedibus existen dos descripciones de obesidad visceral con comorbilidades asociadas que podían ser consideradas un antecedente histórico de la obesidad androide o central, casi 200 años antes de su descripción inicial por Jean Vague ${ }^{8}$.

\subsubsection{Edad Contemporánea}

Una de las figuras destacadas de esta época fue Bichat, con su teoría tisular de la enfermedad, y a Laennec, con sus estudios sobre la auscultación y su descubrimiento del estetoscopio. En esta época, el interés por la obesidad o polisarcia (como era también denominada la acumulación adiposa) se demuestra por el número de publicaciones que tratan el tema. Las ideas sobre la obesidad, propias de este periodo de auge de la medicina francesa, quedan resumidas en el texto dedicado a la "polisarcia" en el Textbook of Medicine de Hufteland (1842).

En este texto persisten elementos culpabilizadores para el obeso y entre consejos muy razonables, quedan recomendaciones absurdas, que por otra parte se encuentran presentes en "remedios milagrosos" de la actualidad.

El estadístico, belga Adolphe Quételet (1796-1874) fue uno de los primeros en crear y validar medidas matemáticas para la obesidad. Quételet fue el responsable de la creación del concepto "hombre promedio", y sugirió que la razón del peso dividido sobre la talla al cuadrado podía utilizarse como medida de la obesidad corregida para la estatura. Este índice de medida, es conocido hoy en día como Índice de Masa Corporal (IMC) y absolutamente generalizado como medición de la obesidad en estudios epidemiológicos y clínicos.

El libro más interesante sobre obesidad en lengua inglesa publicado en el siglo XIX es "Corpulence, or excess of fat in the human body". En esta obra, el autor desarrolla interesantes ideas en distintas áreas. En la de la antropometría discute el concepto de "normalidad" y de "sobrepeso" a 
través de los valores obtenidos en 2.560 varones sanos. Aparece el concepto del desequilibrio calórico con los experimentos de calorimetría de Lavoisier y la primera ley de termodinámica de Helmholtz ${ }^{3}$.

En el área clínica, Chambers clasifica la obesidad según la edad de aparición y define certeramente que, en la mayoría de los casos, la obesidad en los primeros años de vida es reversible, pero no así en la edad prepuberal. En el área terapéutica, el citado autor aconseja caminar y una dieta con una ingesta moderada de grasa.

Hasta 1863 no apareció la primera dieta popular para adelgazar; fue un pequeño panfleto de 21 páginas publicado por William Banting y titulado " $A$ letter on corpulence addressed to the public", que alcanzó gran popularidad por todo el mundo.

En la primera mitad del siglo XX, la obesidad suele ser clasificada como endógena o exógena, según predominen los factores genéticos, muy pocos conocidos, o los exógenos (exceso de ingesta y sedentarismo). Al mismo tiempo se identifican las características de algunos tipos especiales de obesidad, sobre todo, de tipo hormonal (Síndrome de Cushing, hipotiroidismo).

En España, Gregorio Marañón (1887-1960) el creador de la Endocrinología en nuestro país, trató la obesidad, en su monografía "Gordos y flacos" entre otros textos ${ }^{9}$. En esta obra, Marañón repasa los conocimientos etiopatogénicos de la obesidad de la época. Admite la multifactorialidad, aunque da demasiada importancia al factor endocrino, influido por el prestigio de la reciente especialidad.

En Francia, en relación con el tema de obesidad destaca la figura del endocrinólogo Jean Vague, quien realizó una precisa descripción del que muchos años después sería más conocido como síndrome $X$, metabólico o plurimetabólico, vinculado a la distribución topográfica androide o central de la grasa ${ }^{8}$. 
Tras el fin de la Segunda Guerra Mundial (1945), Estados Unidos lidera el campo de la investigación biomédica. Se inician en esta época los primeros estudios experimentales sobre la obesidad y su tratamiento al igual que la profundización en los conceptos etiopatogénicos de la misma. Del mismo modo se observaron los primeros tratamientos de la obesidad basados en la modificación de la conducta alimentaria y en el control de la ingesta de alimentos. Tras la II Guerra Mundial la moda de la delgadez se afianza y extiende hasta nuestros días ${ }^{10}$.

Durante la segunda mitad del siglo $X X$ se ha hecho un mantenido $y$ creciente esfuerzo para mejorar los resultados terapéuticos en la necesaria lucha para tratar la obesidad. Pese a los esfuerzos realizados, los resultados han sido muy modestos y se ha constatado la reganancia del peso perdido en todos los métodos empleados a excepción de la cirugía bariátrica más agresiva.

Las primeras cirugías bariátricas fueron ideadas a partir de los resultados obtenidos después de la resección del intestino delgado, con la premisa que un paciente con intestino delgado más corto adelgaza respecto a otro que mantenga la longitud intestinal primitiva. La primera intervención bariátrica descrita es del año 1952 y estaba basada en un bypass yeyunoileal. En el último apartado sobre el tratamiento de la obesidad, describiremos de manera detallada la evolución de las diferentes técnicas a lo largo de la historia incidiendo en las características de cada una de ellas. Muy lejos de ser la cirugía bariátrica de lo que en la actualidad conocemos, los consejos alimentarios y el aumento del ejercicio seguían siendo las recomendaciones indispensables para tratar la obesidad.

En el año 1994 se produce un descubrimiento de gran importancia en la investigación básica sobre la obesidad, la revista Nature publica el artículo Positional cloning of the mouse obese gene and its human homologue, por el grupo liderado por J. Friedman de la Rockefeller University (Estados Unidos) $)^{11}$. Describen el gen ob en el ratón, la proteína que codifica, la leptina, y el gen homólogo en el ser humano. El descubrimiento del grupo 
de Friedman estimuló de forma ingente la investigación en biología molecular y en genética en relación a la obesidad.

\subsubsection{La obesidad como epidemia del siglo XXI}

En el año 1999 se publicó la Declaración de Milán ${ }^{12}$, en la que los países pertenecientes a la Unión Europea asumieron que la obesidad constituye un trastorno básico a partir del que se desarrollan comorbilidades de todo tipo (cardiacas, reumatológicas, digestivas, endocrinas, etc.). En 2002, la OMS, en su resolución WHA 55.23, desarrolló la Estrategia Mundial sobre Régimen Alimentario, Actividad Física, y Salud, que fue aprobada por los estados miembros en mayo de 2004, momento en el que se etiquetó a la obesidad como la "epidemia del siglo XXI"13.

En este inicio del siglo XXI los datos relativos al incremento de la prevalencia de obesidad resultan preocupantes. En países de nuestro entorno, la prevalencia de obesidad aumenta en la población adulta, y lo que es peor, también lo hace en la población infantojuvenil. Este hecho conlleva un incremento de las comorbilidades asociadas, especialmente la diabetes mellitus tipo 2, con el consiguiente aumento de los costos sanitarios y económicos. Por los citados motivos, la OMS ha considerado a la obesidad como una epidemia del siglo XXI y lidera junto a diversas instituciones y sociedades científicas una llamada internacional para luchar contra el sobrepeso y la obesidad.

\section{Diagnóstico y clasificación de la obesidad}

\subsection{Concepto}

La obesidad es una enfermedad crónica que se caracteriza por un aumento de grasa corporal, que suele ir asociado a un aumento del peso ${ }^{14}$. Existe un aumento de las reservas energéticas del organismo en forma de grasa, aunque no todo aumento de peso se debe a un incremento del tejido $\operatorname{adiposo}^{15}$. Siendo necesario un término para expresar la cantidad de grasa en el cuerpo, el más aceptado es adiposidad. La adiposidad se expresa 
como el porcentaje total de la masa corporal que supone la grasa. El exceso de peso puede asociarse a un exceso de grasa o de otros tejidos (muscular, esquelético) con relación a la talla.

Desde un punto de vista antropométrico, que es el más utilizado en clínica, se considera obesa a una persona con un IMC $\geq 30$. En la actualidad, el empleo de diferentes técnicas de valoración de la grasa corporal (tabla 1.1) se pueden agrupar fundamentalmente en las técnicas de medición antropométrica y en otros sistemas como el análisis de la composición corporal o como las técnicas de imagen, pero por su complejidad técnica o por su coste económico, algunos sólo suelen utilizarse en trabajos de investigación.

Técnicas para el estudio de la composición corporal

Antropometría (IMC, perímetros de cintura y cadera, pliegues
cutáneos)
Impedancia bioeléctrica (BIA)
Densitometría de doble fotón dual (DEXA)
Tomografía Axial Computerizada (TAC)
Resonancia Magnética Nuclear (RMN)
Pletismografía por intercambio de aire (BOD-POD)
Ultrasonidos (Ecografía)
Densitometría

Tabla 1.1. Técnicas de valoración de la composición corporal

En función del porcentaje graso corporal, podríamos definir como sujetos obesos dentro de la población adulta a aquellos que presentan porcentajes de grasa por encima de los valores considerados normales, que son del 12 al $20 \%$ en varones y del 20 al $30 \%$ en mujeres adultas, como consenso se define la obesidad en el hombre con valores $>25 \%$ de grasa corporal y en la mujer $>33 \%{ }^{16}$.

Los comités internacionales de expertos y los consensos recomiendan el empleo de datos antropométricos para la clasificación corporal. La antropometría (peso, pliegues cutáneos, perímetro de cintura) es el método más utilizado tanto en la práctica clínica como en la investigación epidemiológica por ser un método sencillo y fiable ${ }^{17}$, aunque su precisión 
en la evaluación de la distribución de la grasa es controvertida. El cálculo del IMC, se considera el método de referencia para el diagnóstico de la obesidad y aunque múltiples estudios han demostrado la aceptable correlación entre la medición del IMC con la composición de grasa corporal, hay que tener en cuenta que existen limitaciones en su medición en los sujetos deportistas o musculosos y en los ancianos ${ }^{18}$.

\subsection{Clasificación}

Existen diferentes formas de clasificar la obesidad según el criterio seleccionado. Los criterios de clasificación de la obesidad más utilizados se basan en una clasificación etiológica, según el IMC y por la distribución de la grasa corporal.

\section{- Clasificación etiológica:}

Destaca la obesidad esencial, aproximadamente el $90 \%$ de los casos en España de obesidad, debido a una alteración de la regulación del ajuste de peso. La otra causa es la endocrina, con patologías como: hiperinsulinemia, hiperfunción suprarrenal, obesidad ovárica, hipotiroidismo.

\section{- Clasificación según IMC:}

Es el criterio más utilizado en la clínica para diferenciar el grado de obesidad de los pacientes. Diferentes instituciones de carácter oficial elaboran tablas que reflejan los puntos de categorización. En la tabla 1.2, se muestra la clasificación ofrecida por la $\mathrm{OMS}^{19}$. En España, la Sociedad Española para el Estudio de la Obesidad (SEEDO) ${ }^{15}$ ofrece una clasificación más detallada delimitando distintos grados de sobrepeso y obesidad (tabla 1.3).

Los criterios de obesidad de la OMS son los más aceptados internacionalmente y presentan buenas correlaciones para las poblaciones europeas y norteamericanas. 


\begin{tabular}{|c|c|}
\hline \multicolumn{2}{|c|}{ Grados de obesidad según OMS 2000} \\
\hline Valores límites del IMC (kg/m²) & Categoría \\
\hline$<18,5$ & Peso insuficiente \\
\hline $18,5<24,9$ & Peso normal \\
\hline $25,0-29,9$ & Sobrepeso (preobesidad) \\
\hline $30,0-34,9$ & Obesidad grado I \\
\hline $35,0-39,9$ & Obesidad grado II \\
\hline $40,0-49,9$ & Obesidad grado III (mórbida) \\
\hline
\end{tabular}

Tabla 1.2. Clasificación del sobrepeso y la obesidad según el IMC (OMS 2000)

\begin{tabular}{|c|c|}
\hline \multicolumn{2}{|c|}{ Grados de obesidad según SEEDO 2007} \\
\hline Valores límites del IMC (kg/m²) & Categoría \\
\hline$<18,5$ & Peso insuficiente \\
\hline $18,5<24,9$ & Peso normal \\
\hline $25,0-26,9$ & Sobrepeso grado I \\
\hline $27,0-29,9$ & Sobrepeso grado II (preobesidad) \\
\hline $30,0-34,9$ & Obesidad de tipo I \\
\hline $35,0-39,9$ & Obesidad de tipo II \\
\hline $40,0-49,9$ & Obesidad de tipo III (mórbida) \\
\hline$\geq 50,0$ & Obesidad de tipo IV (extrema) \\
\hline
\end{tabular}

Tabla 1.3. Clasificación del sobrepeso y la obesidad según el IMC (SEEDO 2007)

- Clasificación según la disposición topográfica de la acumulación de grasa:

En el estudio del paciente obeso no sólo interesa saber la cantidad total de grasa corporal del sujeto, sino también su distribución, ya que ésta adquiere una especial trascendencia al estar relacionada independientemente con la morbilidad y riesgo cardiovascular. Por este motivo el estudio de la distribución del tejido graso adquiere un interés especial. Se han descrito cuatro tipos distintos de distribución de grasa corporal ${ }^{20}$ :

1. Homogénea o generalizada: cuando se acumula la grasa tanto en la región abdominal como en caderas, necesitando para su diagnóstico, técnicas de imagen y antropométricas.

2. Abdominal o androide: cuando se acumula la grasa en la región abdominal y existe un cociente cintura/cadera 
superior a 1 en el hombre y 0,9 en la mujer, o cuando la circunferencia de la cintura es superior a $102 \mathrm{~cm}$ en el hombre o a $88 \mathrm{~cm}$ en la mujer ${ }^{19,21}$.

3. Visceral: cuando existe un exceso de grasa alrededor de las vísceras abdominales, requiriendo para su diagnóstico técnicas de imagen como son la ecografía, TAC o RMN.

4. Glúteo-femoral o ginoide: cuando se acumula la grasa en la cadera y existe un cociente cintura/cadera inferior a 1 en el hombre y a 0,9 en la mujer ${ }^{19}$.

\section{Etiopatogenia}

La obesidad es una enfermedad multifactorial, determinada por factores ambientales, endógenos o de tipo genético. Aunque fundamentalmente la obesidad se atribuye al excesivo aporte calórico por los alimentos respecto a la disminución del gasto energético de forma crónica ${ }^{22}$, no sólo se debe atribuir a la sobrealimentación la única causa de esta enfermedad. En ella influyen las distintas situaciones culturales, ambientales, demográficas, socioeconómicas, psicológicas y genéticas. Hoy es posible analizar los genes determinantes de la obesidad, entre el $40-70 \%$ de la variación en los fenotipos obesos está mediada genéticamente ${ }^{23}$.

\subsection{Factores socioeconómicos y estilo de vida}

Los cambios producidos que justifican el aumento de peso en la población en los últimos años son debidos a los cambios del estilo de vida durante el proceso de modernización, las nuevas tecnologías, la reestructuración económica y el ocio pasivo, que han modificado los modelos dietéticos y de actividad física ${ }^{24}$.

En los países en vía de desarrollo, la obesidad predomina en los grupos con mejor situación socioeconómica, sin embargo no es exclusiva de estos grupos y también aparece en las clases menos favorecidas. Estas clases están más protegidas frente al padecimiento de obesidad debido a que 
entre la población con bajos recursos es común la escasez de alimentos y el elevado gasto energético ${ }^{25}$.

La falta de ejercicio o sedentarismo es un factor cada vez de mayor importancia al ir ligado al desarrollo de las nuevas tecnologías, asociado a la evolución de la sociedad en busca de la comodidad y del mínimo esfuerzo físico, al ser sustituido éste por el trabajo de las máquinas o aparatos de la sociedad del bienestar ${ }^{26}$.

En los países desarrollados, la obesidad predomina en los sectores de la sociedad con niveles culturales más bajos y las clases sociales más desfavorecidas que tienen menores posibilidades de consumir alimentos de mayor calidad nutricional y de menor densidad energética como son las frutas, verduras, hortalizas y cereales. La población con un mayor nivel socioeconómico tiene más flexibilidad para elegir su dieta y diferentes patrones de ejercicio ${ }^{19}$. Por otra parte, la presión laboral hace que disminuya la disponibilidad de tiempo libre, lo que dificulta la realización de ejercicio físico.

\subsection{Factores psicológicos}

Existen diversas alteraciones emocionales y psicológicas que pueden llevar asociados trastornos del comportamiento alimentario y preceder a la ganancia de peso y a la aparición de obesidad ${ }^{27}$. Son muchos los estudios que han tratado de establecer un perfil de personalidad del individuo obeso, o que se han centrado en la relación entre obesidad y diversas variables de personalidad; así se ha señalado que los obesos presentan más problemas psicológicos que la población general ${ }^{28}$, que son más inmaduros y recelosos, que son más pasivos, dependientes y hostiles en sus relaciones interpersonales, inseguros y emocionalmente inestables. Sin embargo, la interpretación de estos resultados es controvertida y es necesario tener en cuenta la posible bidireccionabilidad de la relación entre aspectos psicológicos y diversos trastornos de salud, como la obesidad. La relación entre variables psicológicas y obesidad, como las funciones de la actividad emocional en la determinación de conductas de ingesta y sobreingesta, 
tienen una mayor importancia en el estudio del paciente obeso, como lo es en el trastorno por atracón.

\subsection{Factores neuroendocrinos}

El sistema nervioso central regula el balance energético y el peso corporal mediante tres mecanismos: 1) efectos sobre el comportamiento, incluyendo la ingesta y la actividad física; 2) efectos sobre el sistema nerviosos autónomo, que regula el gasto energético y otros aspectos del metabolismo; y 3) efectos sobre el sistema neuroendocrino, incluyendo la secreción de hormonas.

Es de gran relevancia la implicación del hipotálamo en la regulación de la ingesta de alimentos y la homeostasis energética, y es por ello que daños en su estructura determina un tipo de obesidad puesto que en él se encuentran el centro de la saciedad y el centro que controla la conducta alimentaria. Dentro de la obesidad de origen endocrino destaca el síndrome de Cushing, síndrome de ovario poliquístico, insulinoma, hipogonadismo e hipotiroidismo ${ }^{29}$.

\subsection{Factores genéticos}

La asociación de factores hereditarios como causa de la obesidad no es algo reciente, existen diversos trabajos que intentan estudiar la heredabilidad de esta enfermedad. Han sido relacionados con la obesidad en humanos más de 250 genes $^{30}$. La magnitud de la contribución genética en el desarrollo de la obesidad se ha analizado en múltiples estudios sobre agregación familiar, estudiando los casos de gemelos y personas adoptadas, y en diversas poblaciones entre las cuales se espera que exista variabilidad genética ${ }^{31}$.

En la actualidad se considera que entre un $40-70 \%$ de la variación en el IMC puede atribuirse a factores genéticos ${ }^{23}$, se ha determinado que el riesgo de obesidad extrema es 7-8 veces mayor en familias con algún pariente con dicho grado de obesidad ${ }^{32}$. Los individuos están genéticamente programados para el almacenamiento de grasa según un 
patrón particular, y esa programación es difícilmente superable, si bien la interacción de los factores ambientales y los genéticos modulan su expresión ${ }^{33}$.

Numerosos estudios apuntan a una conexión entre la obesidad y defectos genéticos que afectan a la ruta lipolítica ${ }^{34}$, en este sentido cabe destacar los siguientes polimorfismos genéticos:

- Que produzcan desequilibrios entre músculo y tejido adiposo en el transporte de glucosa (GLUT4).

- Que influyan en las alteraciones de la lipoprotein lipasa (LPL).

- Genes cuya capacidad lipogénica dependa de la actividad de factores de transcripción como ChREBP y SREBP-1.

- Otros como los implicados en la regulación del metabolismo intracelular de los ácidos grasos, como es el caso de la proteína quinasa dependiente de AMP $(\mathrm{AMPK})^{35}$, proteína que media los efectos catabólicos de la leptina y la adiponectina ${ }^{36}$.

- Variaciones genéticas que afecten a las hormonas estimulantes de la adipogénesis como la insulina, la hormona de crecimiento, los glucocorticoides o las hormonas tiroideas.

- Polimorfismos que inhiben la adipogénesis como el factor de necrosis tumoral (TNFa) o la resistina ${ }^{37}$.

- Genes relacionados con otros factores adipogénicos como en el PPAR $\beta$, PPAR $\alpha$ y PAR $\gamma^{38}$.

Se ha identificado una raza de ratones en los que aparece un tipo de obesidad aislada en forma recesiva. Los ratones homocigotos para el gen causante se denominan ob/ob. La herencia se transmite de forma autosómica y recesiva. Al gen ob también se le conoce como gen Lep y se encuentra ubicado en el cromosoma 6 del ratón ${ }^{39}$. En el ser humano, el equivalente del gen ob ha podido identificarse mediante hibridación in situ en el cromosoma 7q3116. Se ha encontrado que los mecanismos 
reguladores del gen son complejos, por lo que sólo se conoce una parte de su regulación. El principal regulador es el estado nutricional de manera que la expresión génica del gen aumenta con la ingesta y disminuye con el ayuno en una vía metabólica mediada por la insulina ${ }^{40}$.

En los últimos años, los estudios genéticos en obesidad asocian el gen conocido como FTO al riesgo de padecer sobrepeso y obesidad ${ }^{41}$. El mecanismo que determinaba esa asociación era desconocido, hasta que el grupo de investigadores de la Universidad de Chicago ha descubierto que los elementos asociados a la obesidad dentro de FTO interactúan con el gen IRX3 situado a mil unidades de distancia. Algunas regiones no codificantes de un gen denominadas intrones, son las encargadas de regular la expresión de los genes. Éste grupo de investigadores observó en ratones que las mutaciones en los intrones de FTO que se relacionan con la obesidad no afectan a su expresión, sino a la del nuevo gen lejano IRX3. Para verificar el papel del IRX3, los investigadores diseñaron ratones con el gen eliminado y comprobaron que dichos ratones eran significativamente más delgados que los normales. También comprobaron que la disminución en la ganancia de peso se producía a pesar de que los niveles de consumo de alimentos y de actividad física eran normales. Sin embargo, los ratones normales alimentados con una dieta alta en grasas duplicaron su peso ${ }^{42}$. Tras estudiar esta relación en ratones, encontraron un patrón similar de interacciones en humanos al analizar los datos del proyecto ENCODE ${ }^{43}$, que se confirmaron con experimentos en células humanas.

La etiología de la obesidad es multicausal, pero la predisposición genética incluiría genes que interaccionarían con los cambios nutricionales y del estilo de vida. Este aspecto multifactorial es lo que dificulta la identificación de genes implicados en el desarrollo de la obesidad. 


\section{Epidemiología}

A nivel mundial, casi tres millones de personas mueren cada año debido a las complicaciones de la obesidad. El exceso de peso está directamente relacionado con el aumento de riesgo de diabetes tipo 2, accidentes cerebrovasculares, enfermedades del corazón, y algunas formas de cáncer. Durante los últimos 30 años, la obesidad se ha convertido en una epidemia mundial y un factor contribuyente en el aumento de las tasas de enfermedades no transmisibles, una tendencia que amenaza con disminuir la esperanza de vida ${ }^{44}$.

Incluso en países de rentas per cápitas bajas y muy bajas, la prevalencia de la obesidad está aumentando a un ritmo alarmante. La globalización está transformando diariamente la vida de millones de personas en todo el mundo. Desafortunadamente, muchos de estos cambios promueven estilos de vida poco saludables, contribuyendo así directamente a la pandemia de la obesidad. En la actualidad, las elevadas tasas de prevalencia de la obesidad están garantizadas por igual en países ricos y pobres.

La pandemia de la obesidad y sus complicaciones asociadas registran tasas de mortalidad que exceden a las obtenidas por el número de muertes a causas de enfermedades infeccionas. Entre 1990 y 2020, las muertes por enfermedades infecciosas se prevé que disminuyan de 17,2 millones a 10,3 millones al año. Durante el mismo período, las muertes a causa de las enfermedades no infecciosas se prevé que aumenten un $77 \%{ }^{45}$.

La obesidad es un problema mundial que no sólo afecta a los adultos, sino también a niños y adolescentes, en los que la tasa de incremento de la prevalencia es aún mayor, siendo ya evidente en la edad preescolar. La obesidad infantil, afecta a ambos sexos y de forma especial a determinados grupos étnicos y de población, los cuales presentan un riesgo elevado de desarrollar enfermedades crónicas relacionadas con la obesidad ${ }^{46}$.

\subsection{Epidemiología de la obesidad en el mundo}

Desde el año 2002, la Asociación Internacional para el Estudio de la Obesidad (IASO) y el Equipo Internacional de Trabajo de la Obesidad 
(IOTF) se fusionaron para convertirse en una única entidad capaz de hacer frente a los retos que plantea la epidemia mundial de obesidad en el siglo XXI, denominada World Obesity. Según sus últimos análisis, en el 2010 estimaron que aproximadamente un billón de adultos en el mundo tenían sobrepeso, y cerca de 475 millones tenían obesidad. En cuanto a la población infantil, se estimó en cerca de 200 millones el número de niños en edad escolar con sobrepeso u obesidad, y de ellos, 40 millones con obesidad. En lo que respecta a la población europea, aproximadamente el $60 \%$ de los adultos y más del $20 \%$ de la población en edad escolar tienen sobrepeso u obesidad, lo que supone alrededor de 260 millones de adultos y 20 millones de niños con sobrepeso y obesidad ${ }^{47}$.

La prevalencia de sobrepeso entre los diferentes países es muy variable, como se aprecia en la figura 1.1. Las estimaciones realizadas por la OMS respecto a la prevalencia del sobrepeso muestran una variabilidad menor que las observadas en las tasas de prevalencia de la obesidad (figura 1.2). Aunque las estimaciones que se muestran son orientativas, no se pueden comparar, puesto que el análisis de muestreo, rangos de edad de la muestra y la de recogida de los datos difiere en cada país evaluado.

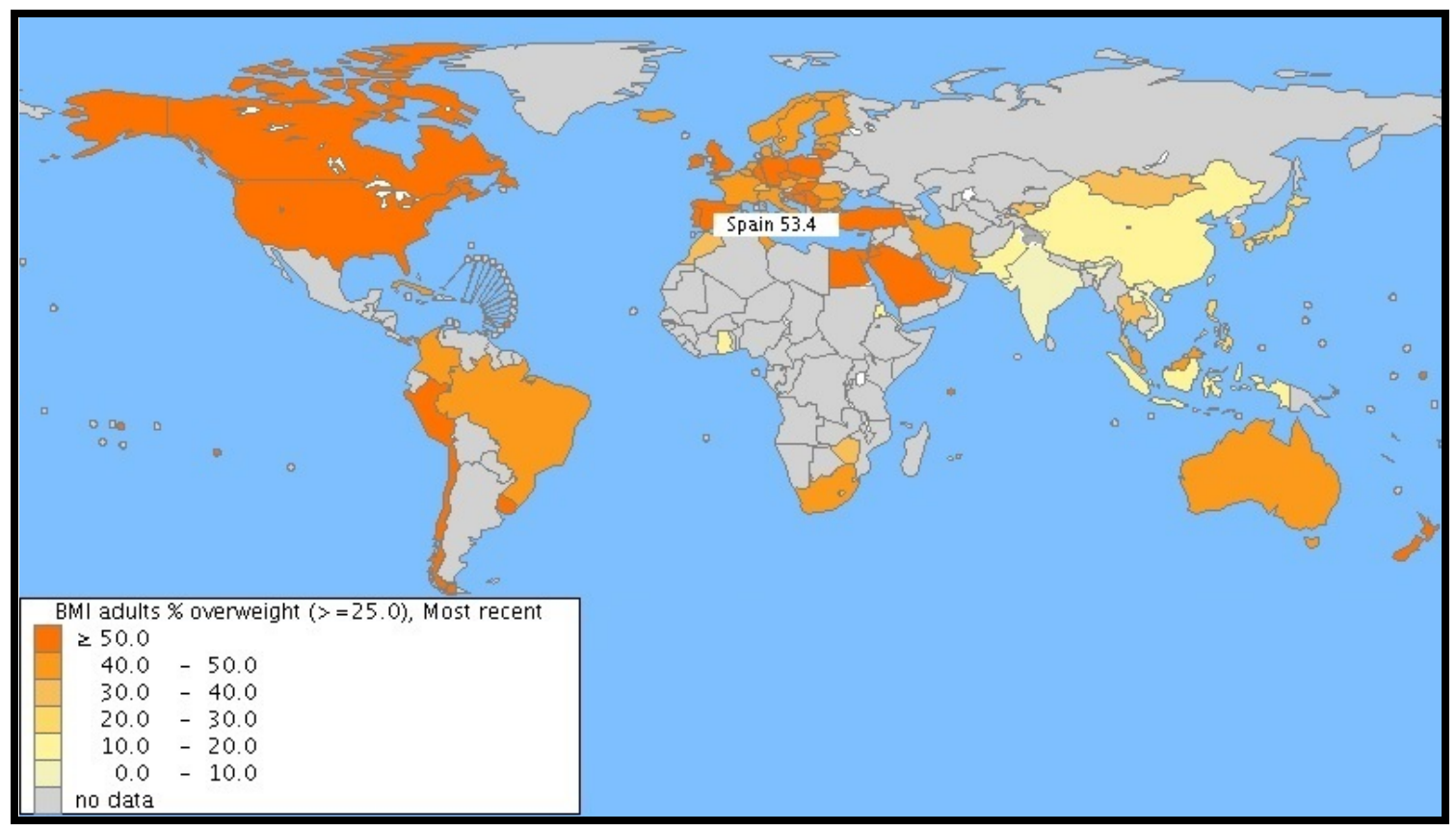

Figura 1.1. Prevalencia mundial del sobrepeso en edad adulta. Fuente: OMS. Base de datos mundial sobre el IMC. Disponible en: http://apps.who.int/bmi/index.jsp 


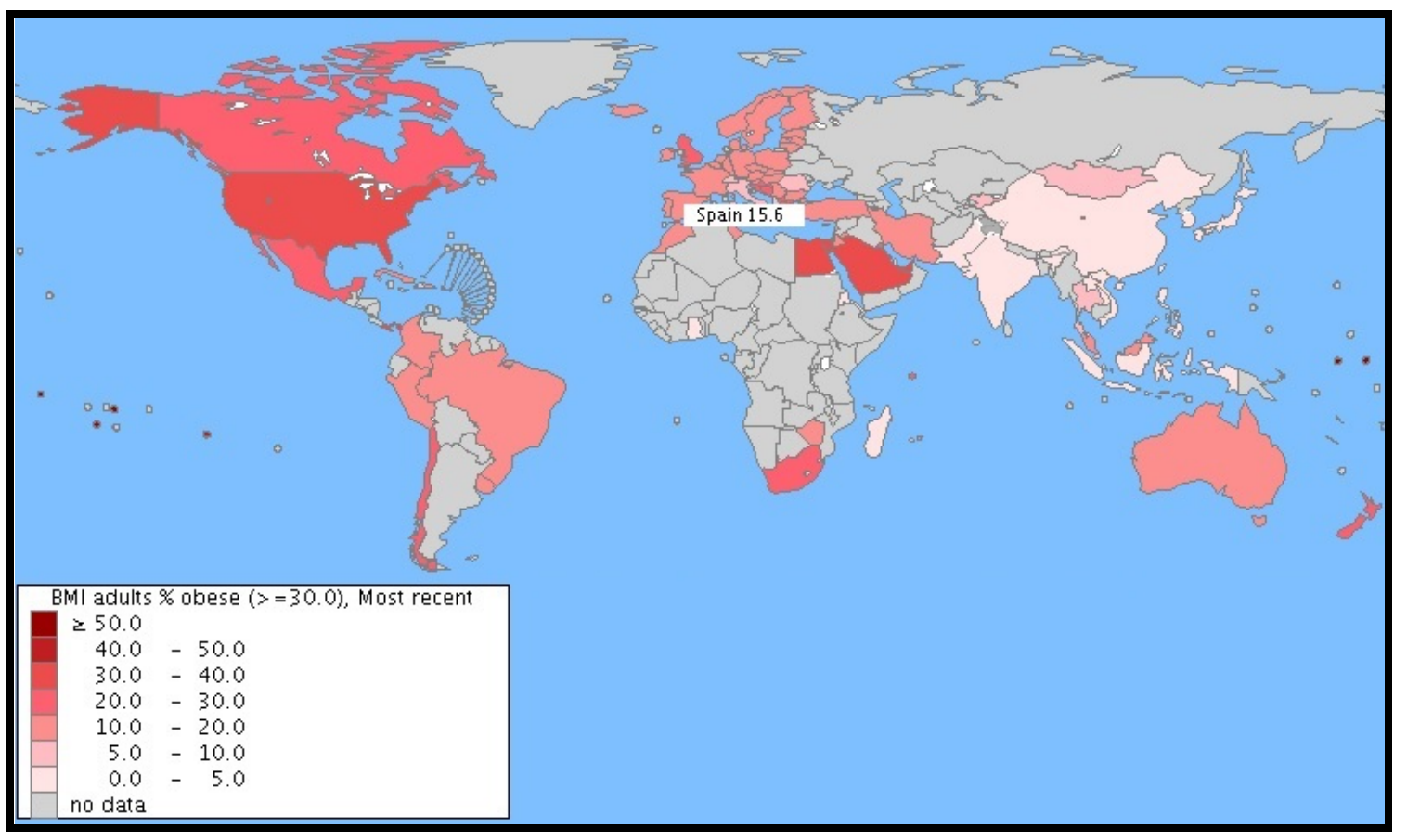

Figura 1.2. Prevalencia mundial de la obesidad en edad adulta. Fuente: OMS. Base de datos mundial sobre el IMC. Disponible en: http://apps.who.int/bmi/index.jsp

La Organización para la Cooperación y el Desarrollo Económicos (OCDE), elabora informes periódicos en los que reporta información de los costes y magnitud del problema que supone la obesidad. Hasta 1980, menos de 1 de cada 10 personas eran obesas, desde entonces, las tasas se han duplicado o triplicado en muchos países y en casi la mitad de los integrantes de la OCDE, se aprecia a 1 de cada 2 personas con sobrepeso u obesidad ${ }^{1}$ (figura 1.3).

En la figura 1.3 se puede apreciar como Estados Unidos sigue siendo el país con mayor número de obesos en el mundo ${ }^{48}$, seguido de cerca por México, donde la prevalencia de obesidad se ha triplicado en las dos últimas décadas, y sigue creciendo a un ritmo alarmante, especialmente en la población infantil. 


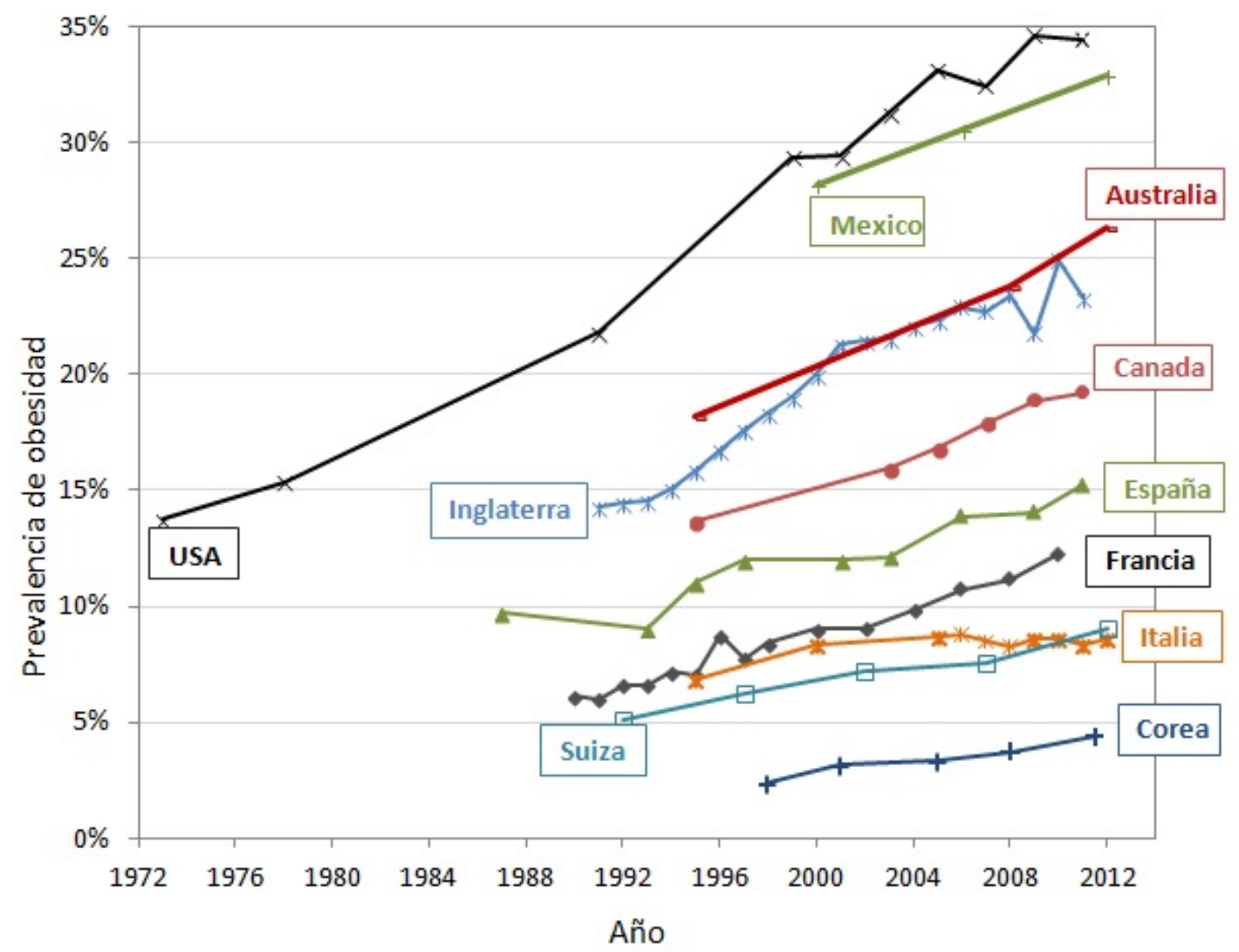

Figura 1.3. Prevalencia de la obesidad. Fuente: OECD Health Statistics 2014. Disponible en: www.oecd.org/health/healthdata.

De manera más detallada se muestra en la figura 1.4 la prevalencia de la obesidad mundial según el sexo en los diferentes países comparados con los datos de la OCDE. La pirámide muestra la prevalencia de la obesidad en los diferentes países que han sido medidos directamente y en los que se reportan a través de las encuestas nacionales (columna izquierda) y según el sexo (columna derecha), en España se observa un 15,6\% de obesidad en mujeres y $17,5 \%$ en hombres. En cambio la media de los países que forman la OCDE registra una tasa de prevalencia superior a la española, siendo $18,7 \%$ en las mujeres y $17,9 \%$ en los hombres. 


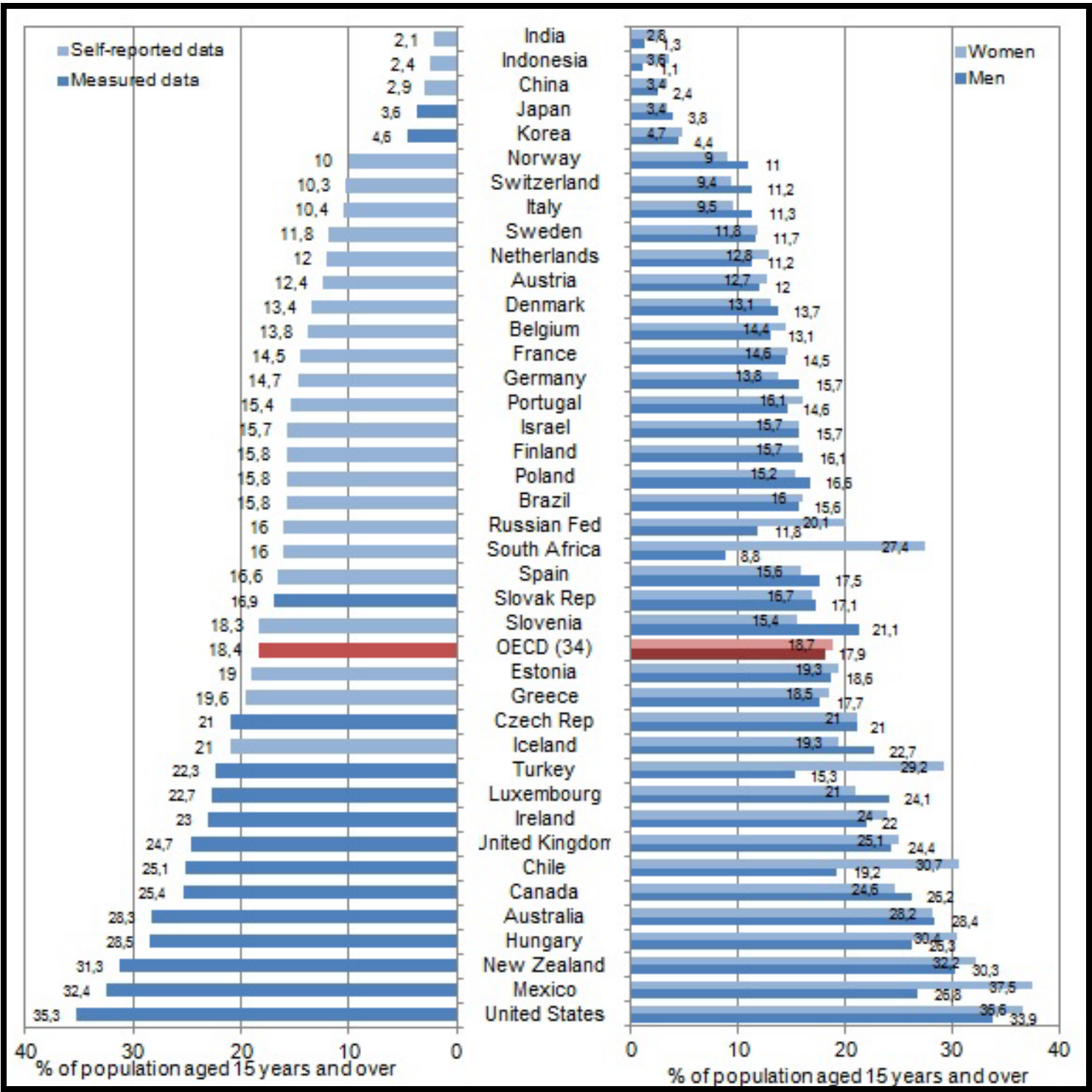

Figura 1.4. Prevalencia mundial de la obesidad. Fuente: OECD Health Statistics 2014. Disponible en: www.oecd.org/health/healthdata.

La Encuesta Nacional de Salud y Nutrición NHANES 2009-10 estima una prevalencia de obesidad y sobrepeso en Estados Unidos superior al $60 \%$, y una prevalencia de la obesidad del $36 \%$ en ambos sexos.

\subsection{Epidemiología de la obesidad en España}

Los resultados recogidos por la ENS en España del año 2011-12, permiten estimar una prevalencia de la obesidad en el 17,03\% a nivel nacional y una prevalencia de sobrepeso del 36,65\%. El bajo nivel cultural y socioeconómico, el vivir en poblaciones pequeñas aumenta el riesgo de ser obeso, tanto en varones como en mujeres. 
Castilla y León presenta una prevalencia del sobrepeso en ambos sexos superior a la media nacional, en cambio en la prevalencia de la obesidad las cifras son menores que la media nacional. Tabla 1.4.

\begin{tabular}{lcccccc}
\hline \multicolumn{1}{c}{ Comunidad } & \multicolumn{3}{c}{ Sobrepeso (\%) } & \multicolumn{3}{c}{ Obesidad (\%) } \\
\cline { 2 - 6 } Autónoma & Mujeres & Hombres & Total & Mujeres & Hombres & Total \\
Andalía & 29,32 & 42,94 & 36,21 & 19,40 & 22,85 & 21,15 \\
\hline Aragón & 24,25 & 46,46 & 35,75 & 14,82 & 16,42 & 15,65 \\
\hline Asturias & 29,64 & 48,45 & 38,52 & 19,33 & 17,89 & 18,65 \\
\hline Islas Baleares & 30,81 & 42,79 & 36,95 & 10,33 & 19,62 & 15,09 \\
\hline Islas Canarias & 30,48 & 39,58 & 35,05 & 18,62 & 17,83 & 18,22 \\
\hline Cantabria & 32,26 & 52,64 & 42,35 & 10,45 & 11,81 & 11,12 \\
\hline Castilla y León & 31,24 & 45,42 & 38,43 & 11,63 & 15,98 & 13,84 \\
\hline Castilla La Mancha & 25,46 & 45,01 & 35,69 & 18,66 & 22,35 & 20,59 \\
\hline Cataluña & 26,37 & 46,04 & 36,12 & 13,92 & 14,58 & 14,25 \\
\hline Valencia & 28,4 & 44,84 & 36,66 & 17,66 & 17,01 & 17,33 \\
\hline Extremadura & 31,44 & 48,29 & 40,17 & 19,70 & 23,44 & 21,64 \\
\hline Galicia & 32,50 & 48,18 & 40,53 & 18,37 & 19,96 & 19,18 \\
\hline Madrid & 24,88 & 45,41 & 34,88 & 12,71 & 15,93 & 14,28 \\
\hline Murcia & 28,70 & 45,13 & 36,76 & 20,69 & 19,93 & 20,32 \\
\hline Navarra & 30,26 & 46,46 & 38,24 & 9,65 & 12,70 & 11,15 \\
\hline País Vasco & 27,02 & 46,68 & 36,65 & 15,32 & 15,19 & 15,26 \\
\hline La Rioja & 26,54 & 49,25 & 38,13 & 12,54 & 17,12 & 14,88 \\
\hline Ceuta & 32,75 & 37,10 & 34,78 & 19,64 & 30,86 & 24,88 \\
\hline Melilla & 27,13 & 36,95 & 32,43 & 13,55 & 12,12 & 12,78 \\
\hline Media nacional & 28,14 & 45,14 & 36,65 & 16,04 & 18,01 & 17,03 \\
\hline
\end{tabular}

Tabla 1.4. Prevalencia del sobrepeso y obesidad. Fuente: ENS 2011-12. Disponible en: http://www.ine.es/jaxi/menu.do?type=pcaxis\&path=/t15/p419\&file=inebase.

En España, las diferencias sociales con respecto a la obesidad afectan de manera importante a las mujeres, quienes con un nivel de educación más bajo tienen una probabilidad 3,5 veces mayor de tener sobrepeso, respecto a las mujeres con un nivel educativo más alto. En contrapartida, las diferencias sociales son menores entre los hombres como se observa en la figura 1.5. 


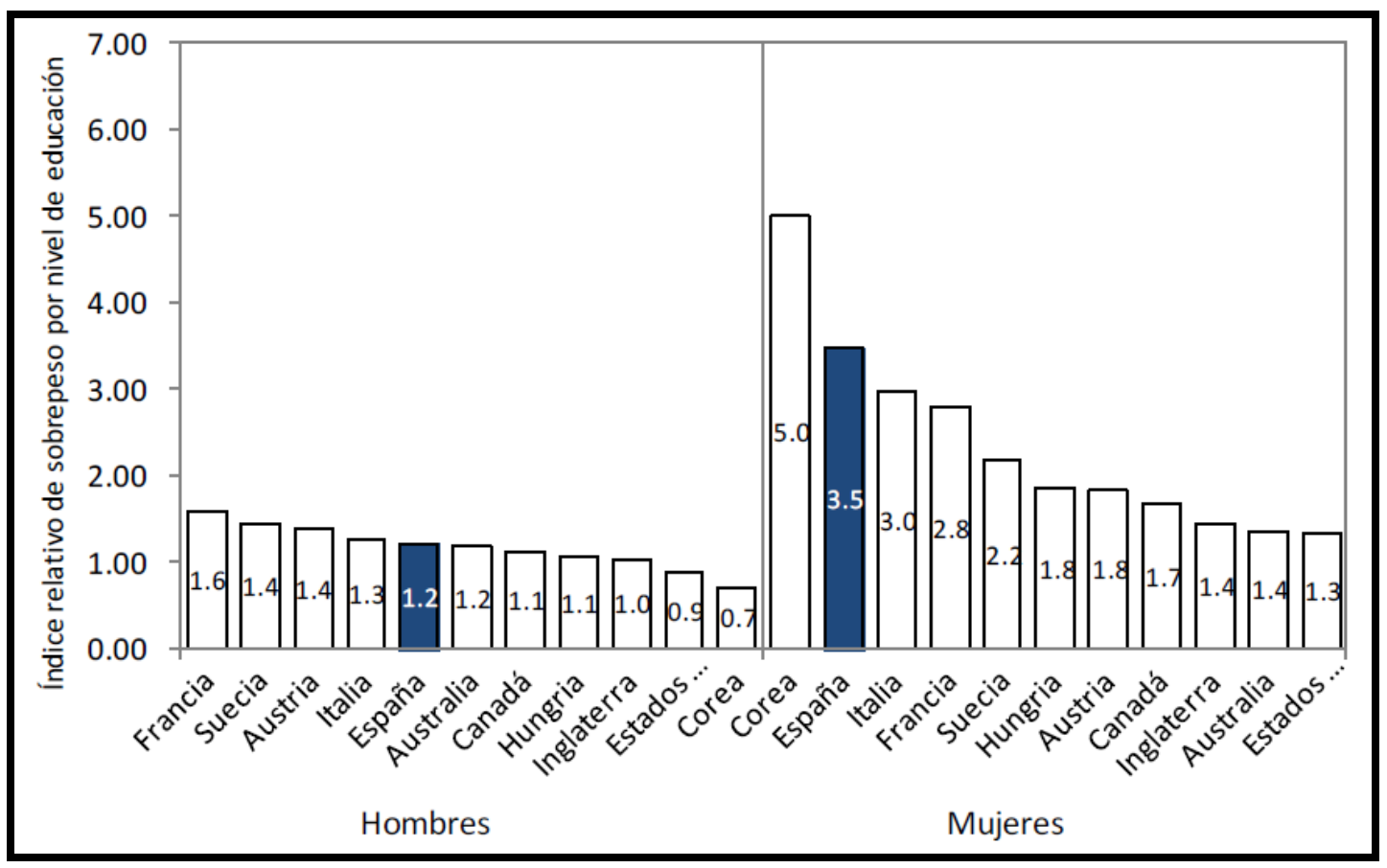

Figura 1.5. Índice relativo de sobrepeso por nivel de educación. Fuente: OECD Health Statistics 2014. Disponible en: www.oecd.org/health/healthdata.

La evolución de la obesidad en España según el nivel educativo ha aumentado a todos los niveles tanto en hombres como en mujeres, figura 1.6, observando un ascenso menor en las mujeres en comparación con los hombres en 10 años, aunque existe una mayor variabilidad entre el nivel educativo y la prevalencia de la obesidad en las primeras.

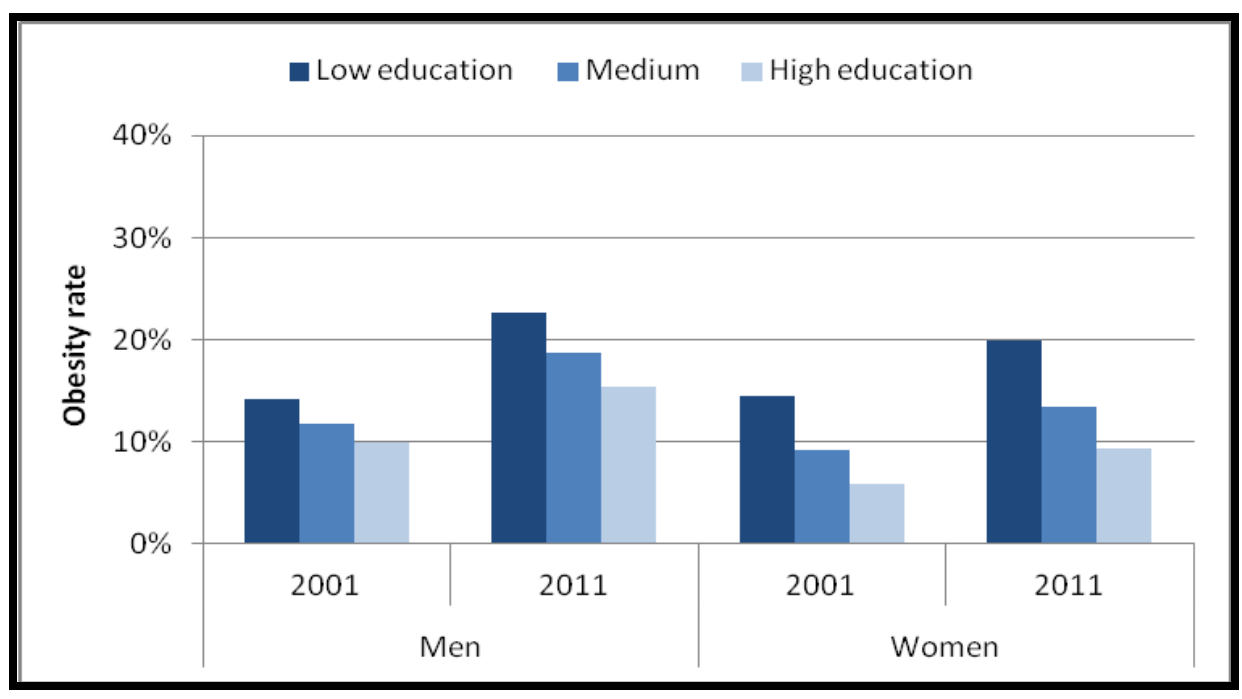

Figura 1.6. Prevalencia de obesidad en España por nivel de educación y sexo. Fuente: OECD Health Statistics 2014. Disponible en: www.oecd.org/health/healthdata. 
La obesidad es considerada un factor de riesgo común a muchas enfermedades crónicas, más del $70 \%$ de los individuos obesos tienen al menos un problema de salud relacionado con su obesidad. Guh et $\mathrm{al}^{49}$, ponen de manifiesto que el riesgo relativo de presentar enfermedades en los individuos obesos es de: 6,74 en hombres y 12,41 en mujeres para la diabetes de tipo 2; de 1,84 en hombres y 2,42 en mujeres para la hipertensión arterial; de 1,72 en hombres y 3,10 en mujeres para la enfermedad coronaria; de 4,20 en hombres y 2,64 en mujeres para la osteoartritis; de 1,82 en hombres y 2,64 en mujeres para el cáncer de riñón y de 3,22 para el cáncer de endometrio. Según datos de la OMS, el sobrepeso y la obesidad suponen la quinta causa de muerte a nivel mundial, de forma que cada año fallecen como consecuencia de ello 2,8 millones de personas en la edad adulta.

\section{Patologías asociadas a la obesidad}

Las patologías asociadas a la obesidad afectan en esencia a todos los sistemas orgánicos ${ }^{50}$ : cardiovascular (hipertensión, arterioesclerosis, enfermedades vasculares, accidentes cerebrovasculares, infartos de miocardio), respiratorio (asma, apnea obstructiva del sueño, síndrome de obesidad-hipoventilación), síndrome metabólico (diabetes tipo 2, intolerancia a la glucosa, dislipidemia), musculo esqueléticos (esguince vertebral, enfermedad de los discos de la columna, artrosis por sobrecarga de caderas, rodillas, tobillos y pies), digestivo (colelitiasis, reflujo gastroesofágico, esteatosis hepática, cirrosis hepática, hepatocarcinoma), urinario (incontinencia urinaria de esfuerzo), endocrino y reproductivo (síndrome de ovario poliquístico, mayor riesgo de patologías durante el embarazo y para el feto, hipogonadismo masculino, cáncer de endometrio, ovario, mama, próstata y páncreas), dermatológico (dermatitis intertriginosa), neurológico (pseudotumor cerebral, síndrome de túnel carpiano) y psicológico (depresión). A continuación destacaremos las más importantes. 


\subsection{Alteraciones metabólicas}

La diabetes mellitus (DM) tipo 2, se asocia a un incremento del peso del individuo, casi el 90\% de los casos de DM tipo 2 se pueden atribuir a la obesidad. Pero no sólo el grado de obesidad actúa como un factor de riesgo sino también la distribución de la grasa corporal. La resistencia a la insulina (RI) precede al desarrollo de la hiperglucemia y la aparición de la DM en aquellos individuos en los que las células $\beta$-pancreáticas no son capaces de compensar la $\mathrm{RI}^{51}$.

A medida que aumenta la RI, las células $\beta$-pancreáticas deben incrementar su actividad para mantener estable la glucemia. Así pues, se podría definir la RI como aquel estado en el que se requiere más insulina para obtener los efectos biológicos que se consiguen con menos insulina en un individuo sano.

La DM se caracteriza por la reducción, con el paso del tiempo, tanto de la masa como de la capacidad secretora de las células $\beta$. Esta reducción progresiva en la secreción de insulina da lugar a un aumento de los niveles de glucosa en sangre (hiperglucemia). Hay evidencias que demuestran que el deterioro de la función $\beta$-pancreática precede la hiperglucemia; así pues, se ha descrito que la función de los islotes $\beta$-pancreáticos en el momento del diagnóstico se encuentra reducida en un 50\%, independientemente del grado de $\mathrm{RI}^{51}$.

Las alteraciones del perfil lipídico en los pacientes con obesidad se deben a la alteración en la homeostasis de la glucosa y la insulina, por una parte debido a la sensibilidad de la lipoproteinlipasa a los niveles de insulina. La menor actividad de esta proteína genera un aumento de los triglicéridos, existiendo un aumento en los niveles de colesterol en sangre, con elevación de las concentraciones de LDL-colesterol y una disminución de los valores plasmáticos de HDL-colesterol, lo que condiciona un mayor riesgo aterogénico. Respecto otros factores lipídicos, se ha observado incrementos de las apoliproteínas B y C-III, y una disminución de la apolipoproteína $A^{15}$. 
La enfermedad del hígado graso no alcohólico representa un amplio espectro de enfermedades que van desde la esteatosis benigna, pasando por la esteatohepatitis, hasta la cirrosis y el cáncer hepatocelular, en los casos más graves. Aunque tiene similitudes con el daño hepático provocado por el consumo excesivo de alcohol, esta enfermedad se desarrolla en pacientes que consumen cantidades de alcohol muy pequeñas o nulas. La enfermedad del hígado graso no alcohólico se caracteriza histológicamente por una acumulación de grasa en el hígado superior al 5-10\% de su peso, la aparición de focos de inflamación, fibrosis e incluso cirrosis ${ }^{52}$.

La prevalencia del hígado graso no alcohólico, ha aumentado en paralelo con el incremento de casos de obesidad y DM, y se está convirtiendo en la causa más frecuente de enfermedad hepática en el mundo occidental ${ }^{53}$. Entre el 8-26\% de pacientes con hígado graso no alcohólico evolucionan hacia cirrosis y finalmente entre el 4-7\% de los casos desarrollas cáncer hepatocelular ${ }^{54}$.

\subsection{Síndrome metabólico}

Desde hace más de 90 años, se describió la existencia de un conjunto de desórdenes metabólicos como la hipertensión arterial, hiperglucemia y gota que conferían un mayor riesgo para padecer enfermedad cardiovascular. Más adelante, Vague $^{8}$ destacó que la adiposidad de tipo androide se encontraba frecuentemente asociada con desórdenes metabólicos que conllevaban mayor riesgo de padecer DM y enfermedades cardiovasculares.

Sin embargo, no fue hasta 1988 cuando se describió el Síndrome X como la confluencia de hipertensión arterial (HTA), DM y dislipemia. Con el paso de los años también se le ha denominado como síndrome de resistencia insulínica. Ya en el año 1998, la OMS fijó unos criterios para definir lo que llamaron el Síndrome Metabólico (SM). En esta primera descripción se consideraba la resistencia a la insulina como factor desencadenante del síndrome, y por tanto la contemplaban como condición 
indispensable para el diagnóstico. Además, se debían tener dos de los siguientes factores de riesgo: obesidad, HTA, hipertrigliceridemia o microalbuminuria ${ }^{55}$. En la descripción de 2001 del National Cholesterol Education Program Adult Treatment Panel III (ATPIII), se modifican los requisitos para diagnosticar el SM: la RI ya no era un factor indispensable para el diagnóstico del síndrome, había suficiente con tener 3 de los 5 primeros citados anteriormente, RI incluida ${ }^{56}$. En el año 2005, la International Diabetes Federation (IDF) junto con la American Heart Association / National Heart, Lung, and Blood Institute (AHA / NHLBI) consensuaron una descripción del SM.

Acordaron que la obesidad visceral, con el perímetro de cintura como indicador, era una condición indispensable para el diagnóstico del síndrome, aunque no establecieron unos perímetros de circunferencia fijos sino que los fijaron en función del grupo étnic ${ }^{57}$. De esta manera se daba una importancia clave en el desarrollo del SM a la obesidad. Finalmente, en 2009, la agrupación de varias entidades internacionales lograron consensuar una definición de SM que recogieron en el documento "Harmonizing the Metabolic Syndrome"58. A continuación en la tabla 1.5 se muestra de manera comparada y a modo de resumen la definición de SM entre los diferentes organismos más representativos.

A tener en cuenta que para definir el SM según la OMS 1998 era indispensable la presencia de la resistencia a la insulina y 2 de los 5 factores que se describen. La ATPIII 2001 lo definía con la presencia de 3 de los 5 criterios de la tabla. La IDF 2005 define SM con la presencia de obesidad abdominal acompañada de 2 de los 4 factores restantes. Por último el Consenso del 2009, define el SM en presencia de 3 de los 5 parámetros especificados en la tabla al igual que el ATP III. 


\begin{tabular}{|c|c|c|c|c|}
\hline & OMS $1998^{55}$ & ATPIII $2001^{56}$ & IDF $2005^{57}$ & $\begin{array}{c}\text { Consenso } \\
2009^{58}\end{array}$ \\
\hline $\begin{array}{c}\text { Glucemia en } \\
\text { ayunas }\end{array}$ & $\geq 110 \mathrm{mg} / \mathrm{dl}$ & $\geq 110 \mathrm{mg} / \mathrm{dl}$ & $\geq 100$ mg/dl & $\geq 100 \mathrm{mg} / \mathrm{dl}$ \\
\hline $\begin{array}{l}\text { Obesidad } \\
\text { abdominal }\end{array}$ & $\begin{array}{c}\text { IMC } \geq 30 \text { y/o } \\
\text { índice } \\
\text { cintura/cader } \\
a>0,9 \text { en } \\
\text { hombres y } \\
>0,85 \text { en } \\
\text { mujeres }\end{array}$ & $\begin{array}{c}\text { Perímetro de } \\
\text { cintura >102 } \\
\text { cm en } \\
\text { hombres y >88 } \\
\text { cm en mujeres }\end{array}$ & $\begin{array}{l}\text { Según grupo } \\
\text { étnico }\end{array}$ & $\begin{array}{l}\text { Según grupo } \\
\text { étnico }\end{array}$ \\
\hline $\begin{array}{l}\text { Triglicéridos } \\
\text { plasmáticos }\end{array}$ & $\geq 150 \mathrm{mg} / \mathrm{dl}$ & $\geq 150 \mathrm{mg} / \mathrm{dl}$ & $\begin{array}{c}\geq 150 \mathrm{mg} / \mathrm{dl} \text { o } \\
\text { en } \\
\text { tratamiento }\end{array}$ & $\begin{array}{c}\geq 150 \mathrm{mg} / \mathrm{dl} \text { o } \\
\text { en } \\
\text { tratamiento }\end{array}$ \\
\hline $\begin{array}{c}\text { HDL- } \\
\text { Colesterol }\end{array}$ & $\begin{array}{c}<35 \mathrm{mg} / \mathrm{dl} \text { en } \\
\text { hombres o } \\
<39 \mathrm{mg} / \mathrm{dl} \text { en } \\
\text { mujeres }\end{array}$ & $\begin{array}{c}<40 \mathrm{mg} / \mathrm{dl} \text { en } \\
\text { hombres o } \\
<50 \mathrm{mg} / \mathrm{dl} \text { en } \\
\text { mujeres }\end{array}$ & $\begin{array}{c}<40 \mathrm{mg} / \mathrm{dl} \text { en } \\
\text { hombres o } \\
<50 \mathrm{mg} / \mathrm{dl} \text { en } \\
\text { mujeres o en } \\
\text { tratamiento }\end{array}$ & $\begin{array}{c}<40 \mathrm{mg} / \mathrm{dl} \text { en } \\
\text { hombres o } \\
<50 \mathrm{mg} / \mathrm{dl} \text { en } \\
\text { mujeres o en } \\
\text { tratamiento }\end{array}$ \\
\hline $\begin{array}{l}\text { Tensión } \\
\text { arterial }\end{array}$ & $\begin{array}{l}\geq 140 / 90 \\
\text { mmHg o en } \\
\text { tratamiento }\end{array}$ & $\begin{array}{l}\geq 130 / 85 \\
\text { mmHg o en } \\
\text { tratamiento }\end{array}$ & $\begin{array}{l}\geq 130 / 85 \\
\text { mmHg o en } \\
\text { tratamiento }\end{array}$ & $\begin{array}{c}\geq 130 / 85 \\
\text { mmHg o en } \\
\text { tratamiento }\end{array}$ \\
\hline Albuminuria & $\begin{array}{c}\geq 20 \\
\mu \mathrm{g} / \mathrm{minuto} \text { o } \\
\text { albúmina/cre } \\
\text { atinina } \geq 30 \\
\mathrm{mg} / \mathrm{g}\end{array}$ & - & - & - \\
\hline
\end{tabular}

Tabla 1.5. Criterios diagnósticos del Síndrome Metabólico. "Para poblaciones caucásicas se pueden tomar como referencia los criterios de la IDF (donde el perímetro de la cintura en hombres debe de ser $\geq 94 \mathrm{~cm}$ y en mujeres $\geq 80 \mathrm{~cm}$ ) o los de la AHA/NHLBI (donde el perímetro de cintura debe de ser $\geq 102 \mathrm{~cm}$ en los hombres $y \geq 88 \mathrm{~cm}$ en las mujeres), éste último coincide con las directrices sobre obesidad del National Institute of Health (NIH).

\subsection{Alteraciones cardiovasculares}

La obesidad constituye un factor de riesgo en el desarrollo de las patologías cardiovasculares a través de factores clásicos como son la HTA, diabetes o dislipemia y otros no tan comunes como las alteraciones de la coagulación y la presencia de citoquinas inflamatorias ${ }^{59}$.

El riesgo de desarrollar una insuficiencia cardiaca en el paciente obeso se duplica ${ }^{60}$, se produce una hipertrofia de ventrículo izquierdo debido al aumento del volumen telediastólico y de la presión de llenado. Esta hipertrofia ventricular se asocia a insuficiencia cardiaca, arritmias ventriculares, infarto agudo de miocardio, así como muerte súbita ${ }^{61}$. 
Numerosos estudios en humanos y en animales ${ }^{62}$, confirman la existencia de una fuerte relación entre la obesidad y la HTA como factores de riesgo en el desarrollo de la obesidad visceral. La HTA en obesos se produce principalmente por un aumento del volumen vascular debido a la retención de sodio y expansión del volumen plasmático, así como por el estímulo del sistema renina-angiotensina-aldosterona y por el aumento de la actividad simpática ${ }^{59}$. Entre los hombres, la prevalencia de la hipertensión arterial es del $15 \%$ para aquellos con un IMC $<25$, y del $42 \%$ para un IMC > 30; a las mujeres estos porcentajes son del 15\% y del 38\%, respectivamente $^{63}$.

\subsection{Alteraciones respiratorias}

El exceso de peso puede llegar a alterar la mecánica ventilatoria, el intercambio de gases y la respiración a nivel central y periférico. En los individuos obesos el volumen respiratorio de reserva disminuye como consecuencia de la presión que ejerce sobre el diafragma la grasa acumulada en la región abdominal. En casos de obesidad extrema, también se pueden ver disminuidas la capacidad vital y la capacidad pulmonar total. Las capacidades y volúmenes inspiratorios son normales. Los obesos dedican a la función respiratoria un porcentaje de consumo de oxígeno muy elevado (ineficiencia respiratoria) que les confiere una predisposición a la insuficiencia respiratoria ante cualquier problema pulmonar añadido. Además, el patrón respiratorio se encuentra alterado, aumentando la frecuencia respiratoria en un $40 \%$ más en los individuos obesos y hasta un $60 \%$ en el caso de pacientes con obesidad mórbida ${ }^{64}$. El trastorno respiratorio más característico en el paciente obeso es el síndrome de apnea obstructiva del sueño (SAOS).

\section{- Síndrome de apnea obstructiva del sueño (SAOS)}

Este síndrome se caracteriza por colapsos intermitentes, totales o parciales, de la vía respiratoria superior que producen frecuentes episodios de apneas o hipopnea, debido a una hipotonía de la musculatura palatina en la fase del sueño REM. A esta, se suma el estrechamiento de las vías aéreas superiores debida a la 
acumulación de grasa cervical. Provoca ronquidos nocturnos, sueño superficial e hipersomnia diurna compensatoria. La obesidad es el factor de riesgo más importante para desarrollar esta enfermedad $y$, aunque la prevalencia depende del grado de obesidad se ha descrito que en sujetos de IMC $>30$, la prevalencia en los hombres es del $50 \%$ y en las mujeres del $8 \%$; y en la obesidad mórbida del $80 \%$ en hombres y del $50 \%$ en mujeres ${ }^{64}$.

Las pausas respiratorias producen efectos adversos agudos, como desaturaciones de hemoglobina, fluctuaciones en la presión arterial y en la frecuencia cardiaca, aumento de la actividad simpática, fragmentación del sueño ${ }^{65}$. El tratamiento de elección es la aplicación de presión continua positiva por vía nasal (CPAP). El síndrome está asociado a HTA y enfermedad cardiovascular.

\subsection{Enfermedades digestivas}

Los individuos obesos presentan una mayor disposición a desarrollar diversos tipos de trastornos digestivos, entre los que destacan el reflujo gastroesofágico (RGE) y la colelitiasis.

\section{- Reflujo gastroesofágico (RGE)}

En la población general esta patología tiene una prevalencia del 8-26\%. En el estudio NHANES ${ }^{66}$ indicaron que por cada incremento de 5 puntos en el IMC, el riesgo de desarrollar reflujo aumentaba 1,2 veces. Aunque los datos de la prevalencia son controvertidos, estudios realizados en la población en general describen que el $39 \%$ de los individuos con un IMC >30 presentan síntomas; y si el IMC se encuentra entre 35-40, los síntomas aparecen en el 53-61\% de los $\operatorname{casos}^{67}$. La obesidad central (medida como índice cintura/cadera) puede llegar a ser más importante como factor predictivo que el mismo IMC, ya que en este tipo de obesidad aumentaría la presión intragástrica, predisponiendo al individuo al reflujo. Al mismo tiempo, en la obesidad central se secretan numerosas citoquinas que podrían afectar la motilidad 
esofagogástrica. Además, patologías que a menudo se presentan en el individuo obeso como la hernia de hiato, un vaciado gástrico irregular o una mayor relajación del esfínter esofágico, que propiciaría el reflujo de ácido hacia el esófago ${ }^{68}$.

\section{- Colelitiasis}

Las personas obesas tienen una mayor predisposición a la litiasis vesicular debido a la relación directa entre la grasa corporal y el colesterol, a mayor grasa corporal mayor síntesis de colesterol, este aumento de colesterol es eliminado por la bilis, la cual tiene un alto contenido en ácidos biliares y fosfolípidos. Además, esto genera un aumento del tamaño de la vesícula biliar y una menor contractibilidad de la vesícula. La obesidad presenta una fuerte asociación con la formación de cálculos en la vesícula biliar, así pues, mientras que en la población general la prevalencia de la enfermedad oscila entre el $2 \%$ y el $15 \%$, en los obesos aumenta hasta el $21-41 \%$ (medido por ultrasonografía) ${ }^{69}$.

\subsection{Enfermedades del aparato genitourinario}

Multitud de trabajos describen la asociación entre infertilidad y sobrepeso, en las mujeres obesas se han descrito disfunciones menstruales debido a que el hiperinsulinismo favorece la producción de andrógenos ováricos (testosterona y androstendiona) ${ }^{70}$.

Otras de las alteraciones observadas es el síndrome de ovarios poliquísticos, prácticamente característico de mujeres con exceso de peso $^{59}$. Respecto a la fertilidad de una pareja, tanto en hombres como en mujeres, está en relación con el IMC, de forma que se ha descrito que la subfecundidad es mayor cuando existe sobrepeso u obesidad en cualquier miembro de la pareja ${ }^{71}$. En el caso de los hombres, existe una mayor prevalencia de oligospermia, impotencia, niveles bajos de testosterona y disminución de la líbido ${ }^{72}$. Además se han descrito otras alteraciones como el exceso de vello, la incontinencia urinaria y complicaciones obstétricas ${ }^{73}$. 


\subsection{Alteraciones osteoarticulares}

La obesidad está asociada a la presencia de patologías músculoesqueléticas (osteoartritis de rodilla, cadera y mano, osteoporosis, túnel carpiano, fascitis plantar, lumbalgias, hernias discales, etc) ${ }^{74}$, afectando principalmente a las articulaciones de carga (regiones intervertebrales, rodillas, tobillos, etc) por una sobrecarga mecánica. Aunque también aparecen en otras articulaciones que no sostienen peso, lo que hace pensar que existe algún componente de la obesidad que afecta directamente al cartílago y al metabolismo óseo ${ }^{72}$. La enfermedad puede manifestarse de forma inflamatoria aguda (artritis) o en forma crónica (artrosis) $^{74}$.

Frecuentemente la gravedad de la enfermedad se correlaciona con el nivel de obesidad, recientemente el Centro de Control de Enfermedades de los EEUU ha publicado que el $31 \%$ de los obesos adultos habían sido diagnosticados de artritis en comparación con el 16\% de los individuos con normopeso ${ }^{75}$.

\subsection{Enfermedades neoplásicas}

La obesidad ha sido relacionada con un incremento de la mortalidad y morbilidad por distintos tipos de cáncer, describiendo una mortalidad en obesos del $33 \%$ en los hombres y del $55 \%$ en mujeres con obesidad ${ }^{59}$.

La asociación en el desarrollo de diferentes tipos de cáncer y la presencia de obesidad es causa de variedad de estudios ${ }^{76}$ que han demostrado la correlación entre adiposidad e incremento en el riesgo de cáncer de endometrio, riñón, vesícula biliar (con predominio en mujeres), mama (principalmente en mujeres postmenopaúsicas) y colón (particularmente en hombres).

\subsection{Alteraciones de la salud mental}

Las personas obesas presentan con mayor frecuencia trastornos afectivos relacionados con la baja autoestima, con una distorsión de la imagen corporal, y con dificultades en las relaciones sociales y laborales. 
Del 20 al 30\% de los obesos tratados padecen depresión y otras alteraciones psicológicas como ansiedad, sobre todo los obesos caucásicos con mayor nivel educativo y económico ${ }^{77}$.

En consecuencia, las personas obesas tienen menor probabilidad de completar los estudios, presentan menores ingresos, mayores índices de pobreza y menos probabilidad de contraer matrimonio. Respecto a la calidad de vida, se ha podido comprobar a través del test de calidad de vida SF-36, que los sujetos que presentan obesidad tienen una menor calidad de vida que los normopeso y se sienten desplazados del resto de la sociedad $^{78}$.

\section{Tratamiento de la obesidad}

El abordaje terapéutico de la obesidad conlleva en la actualidad dificultades en la práctica clínica diaria. El objetivo principal es el de disminuir la masa grasa de los pacientes obesos, aunque también se plantean tratamientos que reduzcan las complicaciones asociadas a la obesidad, mantener la reducción de peso alcanzada, mejorar la calidad de vida, implementar hábitos y mejorar conductas saludables.

Los resultados en el abordaje terapéutico de los sujetos obesos en la mayoría de los casos se producen de manera lenta, con logros en salud escasos, con la necesidad de realizar cambios de manera permanente en el hábito y conducta de estas personas.

En España en el año 2005 se inicia la Estrategia NAOS (Estrategia para la Nutrición, Actividad Física y Prevención de la Obesidad) desde el Ministerio de Sanidad y Consumo. Su objetivo era sensibilizar a la población del problema que supone la obesidad para la salud e impulsar iniciativas que contribuyan a promocionar hábitos de vida saludables ${ }^{79}$.

En 2007 la Sociedad Española de Médicos de Atención Primaria (SEMERGEN), la SEEDO y la Sociedad Española de Endocrinología y Nutrición (SEEN) publicaron una estrategia, en forma de tríptico, diseñada 
con el objetivo de prevenir (aunque también de diagnosticar y tratar) el sobrepeso y la obesidad en la población general ${ }^{80}$.

A nivel internacional, se formularon recomendaciones según el método propuesto en 2008 por la Asociación Europea para el Estudio de la Obesidad $^{81}$ y que consiste en una versión simplificada del sistema propugnado por la Scottish Intercollegiate Guidelines Network (SING) (Red Escocesa Intercolegiada sobre Guías de Práctica Clínica ${ }^{82}$.

En líneas generales los objetivos en el abordaje terapéutico de la obesidad se fundamentan $\mathrm{en}^{15}$ :

a) Favorecer la pérdida de peso o evitar un mayor incremento de peso.

b) Controlar los factores de riesgo o enfermedades asociadas.

c) Prevenir la recuperación del peso a largo plazo.

d) Estimular un estilo de vida activo.

e) Mejorar la calidad de vida de los pacientes.

Los pilares fundamentales del tratamiento son la intervención dietética y el aumento en la actividad física. Como herramientas para mejorar el cambio de hábito alimentario y de actividad física, se enfatiza la necesidad de apoyo psicológico y social, pudiendo elaborarse estrategias de terapia conductual y farmacológica.

A largo plazo estos tratamientos pueden tener resultados desalentadores en sujetos con obesidad mórbida y deben recurrir a la cirugía bariátrica para mantener la pérdida de peso, la cual ha demostrado ser un tratamiento eficaz a largo plazo respecto a otras medidas convencionales en el tratamiento de la obesidad mórbida, reduciendo de manera significativa las comorbilidades asociadas a la misma ${ }^{83}$.

A continuación describiremos las principales estrategias utilizadas para el tratamiento de la obesidad profundizando en el tratamiento dietético y la cirugía bariátrica. 


\subsection{Tratamiento dietético}

El documento más representativo de las sociedades internacionales, es el de la $\mathrm{OMS}^{13}$, en el que consideraba que existía suficiente evidencia que acreditaba la eficacia, en la pérdida de peso, de las dietas hipocalóricas, las dietas hipograsas con reducción calórica o las dietas hipograsas sin reducción de calorías. Por otro lado reconoce la eficacia de las dietas muy bajas en calorías (DMBC) para la pérdida de peso a corto plazo en pacientes seleccionados.

Las sociedades científicas estadounidenses como la North American Association for the Study of Obesity, el National Heart, Lung, and Blood Institute y el National Institutes of Health ${ }^{84}$, en el año 2000 recomendaban de forma conjunta, un abordaje dietético con una reducción en la ingesta calórica de 500 a 1000 kcal respecto a las necesidades calóricas siguiendo el esquema de una dieta hipocalórica convencional.

La Guía Dietética Americana $2010^{85}$ aconseja que para el tratamiento inicial de la obesidad lo adecuado es pautar una dieta con un déficit energético de 500 kcal, considerando que lo importante es el déficit calórico total, sin que la proporción de nutrientes tenga apenas repercusión sobre el peso. Asume las recomendaciones de Institute of Medicine sobre la distribución de macronutrientes (hidratos de carbono 45-65\%, proteínas 10$35 \%$ y grasas $20-35 \%$ ) aunque reconoce que resulta muy difícil cubrir las recomendaciones de ingesta de fibra dietética en el rango inferior de recomendaciones para hidratos de carbono.

En Europa, la European Association for the Study of Obesity en su Guía de Prácticas Clínicas de $2008^{81}$ aboga por una reducción del contenido calórico de la dieta entre 500 y 1.000 kcal. No considera que posibles variaciones en la proporción de los principios inmediatos de la dieta ofrezcan ninguna ventaja sobre la dieta hipocalórica convencional, excepto en el caso de las dietas de bajo índice glucémico a corto plazo. Reserva el empleo de las DMBC para casos muy específicos y siempre dentro de un programa global de pérdida de peso supervisado por un especialista. 
En España tras el último Consenso en el año 2011 entre la Federación Española de Sociedades de Nutrición, Alimentación y Dietética (FESNAD), y la SEEDO establecen unas condiciones que se deberían cumplir en el tratamiento dietético de la obesidad ${ }^{86}$ :

- Disminuir la grasa corporal preservando al máximo la masa magra.

- Realizable por un espacio de tiempo prolongado.

- Eficaz a largo plazo, esto es, manteniendo el peso perdido.

- Prevenir futuras ganancias de peso.

- Conllevar una función de educación alimentaria que destierre errores y hábitos de alimentación inadecuados.

- Disminuir los factores de riesgo cardiovasculares asociados a la obesidad (hipertensión arterial, dislipemia, prediabetes 0 diabetes mellitus).

- Mejorar otras comorbilidades vinculadas al exceso de peso (apnea del sueño, artrosis, riesgo neoplásico, etc...).

- Inducir una mejoría psicosomática con recuperación de la autoestima.

- Aumentar la capacidad funcional y la calidad de vida.

Las dietas hipocalóricas, origina un déficit calórico entre 500-1000 $\mathrm{kcal} /$ día, con un aporte calórico total superior a $800 \mathrm{kcal}$ diarias, con el objetivo de alcanzar una pérdida de peso de aproximadamente 0,5-1 kg por semana. Este tipo de dietas contienen habitualmente entre 1000-1200 kcal/día en mujeres y 1500-2000 kcal/día en varones. Se debe tener en cuenta que cuando se realiza una dieta hipocalórica es necesario aumentar el porcentaje del aporte calórico total que corresponde a las proteínas, situándose al menos en $1 \mathrm{~g} / \mathrm{kg} /$ día. El plan de alimentación propuesto debe adaptarse a las características clínicas y a las preferencias de cada paciente y debe estar planificado para facilitar la adherencia a largo plazo ${ }^{87}$.

Las dietas de muy bajo contenido calórico (DMBC), aportan entre 450 y $800 \mathrm{kcal}$ al día, incluyendo además 0,8-1,5 g/Kg/día de proteínas. Las 
indicaciones se basan ante la necesidad de una pérdida de peso rápida, como por ejemplo una insuficiencia respiratoria severa o a causa de patologías graves asociada a la obesidad que responde a la reducción ponderal, como la DM tipo 2, HTA, dislipemia o SAOS, en los que se obtiene una mejoría rápida de los síntomas y los valores de laboratorio ${ }^{88}$. Habitualmente se produce una reducción ponderal importante al inicio del programa, unos 12 a $35 \mathrm{~kg}$, en las primeras 8-16 semanas, con posterior recuperación en un tiempo variable. Los resultados en un año de seguimiento son similares a los de las Dietas hipocalóricas tradicionales, por lo que hay autores ${ }^{89}$ que desaconsejan las DMBC argumentando la posibilidad de efectos secundarios.

Las dietas hiperproteicas (DHP), se basan en la modificación de la proporción de macronutrientes de la dieta, teniendo gran popularidad la opción de cambiar los hidratos de carbono de la dieta por proteínas buscando un mayor efecto sobre la pérdida de peso. Esta propuesta se basa en una serie de características atribuidas a las proteínas, como su posible efecto saciante, superior al de los hidratos de carbono o al de las grasas, que favorecería la limitación del consumo energético incluso en una dieta sin restricción calórica ${ }^{90}$. Teniendo en cuenta que las proporciones habitualmente recomendadas de ingesta proteica se sitúan en torno al 10$15 \%$ del aporte calórico total, las DHP se encuadrarían en aquellas que suponen un aporte proteico de al menos el 20 o el 30\% del contenido calórico total de la dieta, habitualmente superiores al 25\%. Tras la evidencia de los estudios realizados al respecto, el Consenso FESNADSEEDO $^{86}$ afirma que la DHP favorece la preservación de la masa magra mejor que una dieta rica en hidratos de carbono y puede inducir a corto plazo (menos de 6 meses) mayor pérdida de peso que una dieta convencional rica en hidratos de carbono. Por el contrario, los resultados difieren cuando se establece la DHP a más de 12 meses.

\subsection{Ejercicio físico}

El ejercicio físico afecta en el balance de los macronutrientes, ayuda a establecer el gasto energético negativo necesario para la reducción 
ponderal. Durante la realización de ejercicio a una intensidad moderada se produce una mayor utilización de la grasa como combustible energético ${ }^{91}$.

Un grupo de trabajo de La Colaboración Cochrane ${ }^{92}$ encontró que el ejercicio por sí solo conlleva una pérdida de peso limitado, sin embargo al combinarlo con la dieta observaron una pérdida de peso de 1,5 $\mathrm{kg}$ superior comparado con la pérdida de peso ofrecida sólo con la dieta.

Es recomendable desarrollar un ejercicio físico semanal que supere los 150 minutos con una tasa de consumo de energía de 1200 a $1800 \mathrm{Kcal}$, pues se consigue una reducción de alrededor de $2 \mathrm{~kg}$ y aproximadamente un $6 \%$ de pérdida de grasa abdominal entre 6 y 12 meses $^{93}$.

El aumento en la actividad física puede promoverse indicando ejercicios de baja intensidad, incluyendo actividades de la vida diaria, como caminar, arreglar el jardín, subir escaleras, o actividades estructuradas como realizar caminatas, montar en bicicleta, bailar o nadar con braceo lento. En general, estas actividades requieren mayor dedicación diaria (al menos 1 hora/día), pero tienen la ventaja de no requerir mayor supervisión y ser factibles de mantener a largo plazo.

\subsection{Tratamiento farmacológico}

Los fármacos para el tratamiento de la obesidad tienen unos antecedentes muy desfavorables en cuanto a seguridad y eficacia, ya sea por el mal uso o abuso de estos fármacos, y por la falta previa de estudios a su utilización clínica. La farmacoterapia de la obesidad ha cambiado ya que muchos de los fármacos que se utilizaban en los últimos 50 años han sido retirados, y por la aparición de nuevas moléculas que pueden ser utilizadas en pautas farmacológicas a largo plazo.

Debemos señalar que el tratamiento farmacológico de la obesidad no debería ser ni la primera ni la única opción terapéutica. Deberían utilizarse fármacos, si después de un período de tratamiento sólo con dieta no se hubiera conseguido una pérdida equivalente al $10 \%$ del peso inicial. En tal 
caso, los fármacos anti-obesidad estarían indicados con un control y ajuste de dosis específicos por cada caso clínico.

Los tratamientos farmacológicos de los que se dispone en la actualidad son para tratamientos a largo plazo, ya que se ha visto que si se interrumpe el tratamiento se recupera el peso perdido ${ }^{94}$. Es por ello que se recomienda que no se utilice como terapia aislada, sino acompañada de cambios en el estilo de vida, dieta y ejercicio. Algunos de los fármacos más utilizados se pueden clasificar según su mecanismo de acción ${ }^{95}$ :

1. Fármacos anorexígenos. Inhibidores apetito y/o estimulantes de saciedad:

a) Adrenérgicos controlados: dietilpropión, mazindol, fentermina.

b) Adrenérgicos no controlados: fenilpropanolamina, efedrina.

c) Inhibidores selectivos de la recaptación de serotonina: fluoxetina, fenfluramina, dexfenfluramina, sertralina.

d) Acción dual (adrenérgico-serotoninérgico): sibutramina.

e) Antagonistas del receptor cannabinoide CB1: rimonabant.

2. Fármacos que aumentan el gasto energético. Termogénicoslipolíticos: efedrina, cafeína.

3. Fármacos que interfieren con la absorción o el metabolismo de los nutrientes.

a) Inhibidores de la absorción de grasas: orlistat.

Desde la década de 1950, varios fármacos anorexígenos de la clase feniletilamina se utilizaron como elección en el tratamiento de la obesidad (anfetamina, fentermina, dietilpropión y fenilpropanolamina). Estos agentes actúan mediante la liberación de noradrenalina y dopamina a partir de vesículas presinápticas en el hipotálamo lateral.

Mazindol es un fármaco simpaticomimético que actúa bloqueando la recaptación de noradrenalina por las neuronas presinápticas. El aumento de noradrenalina está asociado a la estimulación de receptores beta2adrenérgicos desencadenándose una inhibición del apetito ${ }^{96}$. En abril del 
año 2000, la Agencia Europea de Medicamentos (EMA) recomienda la retirada de varios medicamentos para bajar de peso, incluyendo la fentermina, dietilpropión y mazindol.

La fenfluramina y dexfenfluramina, elevan los niveles séricos de serotonina $(5 \mathrm{HT})$ en el sistema nervioso central mediante la liberación de serotonina y la inhibición en su recaptación. El aumento del nivel de 5HT parece estimular el hipotálamo, activando el receptor 4 de melanocortina provocando una disminución en el apetito y anorexia. El empleo de estos fármacos demostró como la acumulación de serotonina en los tejidos provocaba efectos secundarios graves asociados a enfermedades cardiacas e hipertensión pulmonar ${ }^{97}$. Ambos medicamentos fueron retirados del mercado desde el año 1997.

La sibutramina inhibe selectivamente la recaptación de serotonina, noradrenalina y dopamina en el hipotálamo. La estimulación de los receptores alfa1-adrenérgicos y beta1-adrenérgicos inducen un aumento de la saciedad, mientras que la estimulación de los receptores beta3adrenérgicos inducen un modesto incremento de la termogénesis.

Diversos estudios han publicado la efectividad de este fármaco como tratamiento de la obesidad describiendo una pérdida de peso en un año de duración, que oscila entre $4,7 \%$ y un $7,3 \%$, mejorando comorbilidades asociadas a la obesidad como la HTA, dislipemia e hiperuricemia ${ }^{98}$. Sin embargo la aparición de efectos cardiovasculares adversos asociados a la administración de este fármaco provocaron su retirada del mercado en el año 2010.

Rimonabant, es un fármaco antagonista del receptor cannabinoide CB1. Fue desarrollado como resultado de observaciones sobre la estimulación del apetito asociado al consumo de cannabis. El fármaco posee una serie de efectos metabólicos centrales y periféricos que también ayudaba a dejar de fumar. En el estudio RIO-Diabetes ${ }^{99}$, tras 12 meses de tratamiento con rimonabant, determinó una pérdida de peso de $5,3 \mathrm{Kg}$ en comparación con los $1,4 \mathrm{Kg}$ del grupo placebo. A finales de 2008, los fabricantes de 
rimonabant anunciaron el cese de todas sus investigaciones clínicas de manera permanente. Este anuncio se produjo tras la decisión previa de EMA para retirar la comercialización del fármaco debido a los riesgos principalmente los efectos secundarios de carácter psiquiátrico.

La efedrina es un fármaco que estimula los receptores beta1, 2 y 3 adrenérgicos, su efecto termogénico conduce a un incremento en el gasto energético y utilización de grasas como combustible energético y su efecto supresor del apetito reduce la ingesta. Pero por mecanismos de adaptación de receptores, su efecto disminuye al cabo de algunas semanas. En dosis altas aparecen efectos secundarios adrenérgicos como aumento de la presión arterial y temblores. Por este motivo y porque se incrementa también su eficacia, se suele asociar a cafeína para potenciar sus efectos sin aumentar su dosis ${ }^{98}$.

Orlistat, es una droga sintética derivada de una lipasa de origen natural. No actúa directamente sobre el apetito sino que disminuye la absorción de la grasa que se ingiere en la dieta mediante la unión a la lipasa pancreática, principal enzima implicada en hidrolizar los triglicéridos ${ }^{100}$. Numerosos estudios han demostrado la efectividad de orlistat a largo plazo (entre 2 y 4 años) en la pérdida ponderal, así como mejoras en la presión arterial, resistencia a la insulina, y los niveles de lípidos en suero ${ }^{101}$.

Uno de los inconvenientes es la elevada frecuencia de efectos adversos gastrointestinales, especialmente cuando el paciente no sigue una dieta baja en grasas, en este caso el paciente puede sufrir de un molesto aumento en el número de defecaciones y urgencia fecal (con evacuaciones aceitosas o manchadas, dolor de estómago, mayor número de evacuaciones). A estos efectos hay que añadir los nuevos casos publicados de daño hepático asociados al consumo de este fármaco, lo que ha provocado una modificación en el etiquetado y advertencias del mismo revisado por la Agencia de Drogas y Alimentos de Estados Unidos (FDA) en 2010. Otro inconveniente es que puede provocar malabsorción de vitaminas liposolubles, siendo recomendable, ante su uso prolongado, la utilización de suplementos orales de vitaminas A, D, E y K. Considerando 
que reduce la absorción intestinal de colesterol y que produce una disminución significativa del colesterol LDL, independientemente de la reducción del peso corporal, se está considerando su utilización como agente hipolipemiante ${ }^{95}$.

Otros fármacos como la fluoxetina o bupropión, actúan como inhibidores de la recaptación de serotonina, demostrando sus efectos en la pérdida de peso a corto plazo (6 meses), aunque después de ese período el peso se recupera incluso manteniendo la medicación. Al no haber demostrado su eficacia en el tratamiento de la obesidad a largo plazo, su uso ha quedado restringido al tratamiento de la depresión y conductas bulímicas que a menudo se asocian a ésta ${ }^{97,98}$.

Aunque el bupropión no está aprobado para disminuir el peso, se ha utilizado fuera de esa prescripción y está actualmente bajo evaluación como terapia de combinación con naltrexona, un antagonista del receptor $\mu$-opioide, y la zonisamida, un activador del receptor GABA ${ }^{102}$.

Hasta la fecha, tan solo cuatro medicamentos para reducir el peso han sido aprobados por la FDA: Xenical, Contrave, Qsymia y Lorcaserin. Xenical actúa como un inhibidor de lipasa, Contrave es una combinación de bupropión y naltrexona, Qsymia formado por fentermina y topiramato, y Lorcaserin (inhibidores selectivo de la recaptación de serotonina) compartiendo características similares a fenfluraminas.

En España, actualmente la Agencia Española del Medicamento sólo ha aprobado la comercialización de Orlistat como fármaco para el tratamiento de la obesidad. En el boletín del mes de diciembre de 2014 tras una valoración favorable proceden a la indicación del fármaco Mysimba (Naltrexona/Bupropión) junto con una dieta hipocalórica y una actividad física incrementada, para el manejo del peso en pacientes adultos ( $\geq 18$ años) con un IMC $\geq 30$, o IMC $\geq 27<30$ con factores de riesgo asociados con el peso. 


\subsection{Terapia cognitivo-conductual}

Partiendo de la base en la que se defiende la implicación psicogénica como una de las causas de obesidad, la conducta de las personas en las que el acto de comer se realiza de manera inconsciente y descontrolada provoca una mayor predisposición en el aumento de peso y por tanto a padecer obesidad. Entre estas conductas patológicas, las más frecuentes son adicciones a determinados alimentos, como el chocolate, café, frutos secos, refrescos, etc., picar entre horas durante todo el día, atracones de comida, levantarse por la noche a comer y permanecer en ayuno durante el día (síndrome del comedor nocturno), entre otras. De hecho, hasta un 34\% de los obesos que acuden a programas de adelgazamiento presentan conductas de este tipo y cumplen criterios de trastorno por atracón ${ }^{103}$.

El tratamiento que se ha demostrado más eficaz en este tipo de trastornos es la psicoterapia cognitivo-conductual, aunque faltan estudios con resultados a largo plazo ( $\geq 5$ años). Lo que sí se ha observado es que, puesto que este trastorno es más frecuente en la obesidad, además de este tipo de psicoterapia hay que utilizar técnicas conductuales encaminadas al adelgazamiento, puesto que es lo que solicitan los pacientes y así se conseguiría un mayor cumplimiento terapéutico ${ }^{104}$.

La mayoría de los programas de terapia conductual constan de elementos modulares que incluyen, entre otros, automonitorización por parte de los pacientes, control de los estímulos, autocontrol, modificación del comportamiento cognitivo, establecimiento de objetivos, apoyo social, autoestima, práctica de la asertividad, ejercicios de relajación, educación nutricional, programación mental.

El tratamiento psicológico (terapia cognitivo-conductual), tiene como objetivo modificar el estilo de vida y adoptar unos hábitos saludables que reduzcan y mantengan el peso de los pacientes obesos a largo plazo, tarea que en la mayoría de las ocasiones no se cumple y es necesario plantear intervenciones más agresivas, como la cirugía bariátrica. No por ello a los pacientes intervenidos quirúrgicamente se les excluye de tratamiento psicológico, con el objetivo de adoptar un comportamiento en el consumo 
alimentario, adaptado a las necesidades de cada paciente consiguiendo mantener y optimizar los resultados de la cirugía bariátrica.

\subsection{Tratamiento quirúrgico}

\subsubsection{Evolución histórica en el tratamiento quirúrgico}

En la actualidad el abordaje quirúrgico de la obesidad está teniendo una mayor repercusión e influencia debido a los resultados esperanzadores a largo plazo en la reducción ponderal y mejora de las comorbilidades asociadas a la misma. La cirugía bariátrica no es una técnica nueva, las primeras intervenciones datan del año 1952 y estaban basadas en la resección del intestino delgado con la premisa de que toda persona con una menor longitud del intestino delgado adelgazaba.

Con el paso de los años esas cirugías de bypass yeyunocólico y yeyunoileal se fueron modificando para reducir las complicaciones y las graves consecuencias metabólicas que originaban en los pacientes, entre las que destacaban:

a) Alteraciones hidroeléctricas.

b) Malnutrición calórico-proteica.

c) Complicaciones entéricas.

d) Colelitiasis.

e) Alteraciones extraintestinales: Artritis, fallo hepático, renal, neuropatía periférica, etc.

En los años setenta y ochenta la cirugía bariátrica se simplificó mediante la introducción de intervenciones gástricas puramente restrictivas (gastroplastias, gastroplastias verticales y bandas gástricas). Estas técnicas presentaban menores complicaciones a largo plazo, siendo la principal preocupación en tal contexto los problemas externos. Al final de los años noventa se introdujo el marcapasos gástrico, el cual no pertenecía al ámbito de la malabsorción ni al de la restricción. 
Con el paso de los años, determinadas intervenciones bariátricas han fracasado en su efectividad a largo plazo y se han dejado de emplear, otras se utilizan actualmente y aún pueden dar lugar a nuevas líneas en el campo de la cirugía bariátrica. La introducción de técnicas laparoscópicas ha ampliado dicho campo, no sólo en el número de intervenciones realizadas anualmente sino también la variedad de los procedimientos y posibilidades que ofrecen.

La SECO en la Declaración de Salamanca ${ }^{105}$, considera "ideal" la técnica que beneficia a más del $75 \%$ de los pacientes a largo plazo, con una morbilidad que no supere el $10 \%$ y una mortalidad menor del 1\%, así como con un número de revisiones o reintervenciones por debajo del 2\% anual. Asimismo, la técnica ideal debe ser reproducible, proporcionar una buena calidad de vida y conllevar pocos efectos secundarios.

Los criterios iniciales para establecer una indicación quirúrgica del tratamiento de la obesidad fueron tradicionalmente establecidos cuando el peso excedía $45 \mathrm{~kg}$ o el 100\% del peso ideal. A partir de 1991, el comité de expertos del Instituto Nacional de Salud (NIH) americano considero que un paciente con obesidad debería ser candidato a cirugía bariátrica cuando el IMC fuese $\geq 40 \quad 0 \geq 35$, que coexistieran con problemas médicos serios. Además de estas condiciones mínimas, los pacientes deben reunir una serie de requisitos adicionales que garanticen el éxito a largo plazo de la cirugía $^{106}$.

En la actualidad, los criterios de indicación de cirugía bariátrica adoptados por las diferentes Sociedades de cirugía bariátrica de los diferentes países están basadas en el Consenso de la Sociedad Americana de Cirugía Bariátrica y Metabólica $(A S M B S)^{107}$, en el que se especifican los siguientes requisitos:

- Un equipo multidisciplinario que incluye: un cirujano, anestesista, nutricionista, enfermero y personal administrativo con experiencia. Equipo clínico colaborador que deberá estar 
disponible si fuera preciso que cuente con un cardiólogo, neumólogo, psiquiatra y psicólogo.

- Los candidatos deben haber intentado perder peso haciendo dieta, haber seguido consejos de nutrición, y programas de pérdida de peso, pero no es necesario como condición previa a la operación.

- Los candidatos deben tener una evaluación médica completa antes de la cirugía.

- Los procedimientos quirúrgicos actualmente recomendados incluyen: bypass gástrico, banda gástrica ajustable; gastroplastia vertical anillada, derivación biliopancreática y el cruce duodenal.

- En el tratamiento quirúrgico se incluye el uso de la laparoscopia y la cirugía abierta.

- La experiencia adicional debe obtenerse con la ampliación de los beneficios de la cirugía bariátrica para los adolescentes en condiciones cuidadosamente definidas por un equipo multidisciplinario, con la capacidad de realizar seguimiento a largo plazo.

- Se debería considerar la posibilidad de ampliar los beneficios de la cirugía bariátrica para pacientes con obesidad tipo I, que tienen una condición clínica que puede ser curada o mejorada notablemente por el sustancial pérdida de peso mantenido en el tiempo. $Y$ que presentan un estilo de vida inadecuado acompañado de tratamiento farmacológico

- Debido a que la cirugía bariátrica puede ser rentable en menos de 4 años, en comparación con el tratamiento conservador, la cirugía bariátrica también estaría indicada en su relación costebeneficio. 
La SECO, junto con otras Sociedades españolas, ha matizado las propuestas de la ASMBS especificando los criterios de cirugía metabólica y ampliando las indicaciones reflejadas en el último Consenso FESNAD-SEEDO ${ }^{86}$, de las que destacan:

- La cirugía metabólica está indicada en pacientes con obesidad (IMC $\geq 35)$, especialmente si está acompañado de comorbilidades difíciles de controlar con cambios en el estilo de vida y tratamiento farmacológico.

- No recomendar de manera indiscriminada la cirugía metabólica en DM tipo 2 con IMC 30-35, debido a insuficientes datos a largo plazo sobre reducción de morbimortalidad cardiovascular y/o disminución de complicaciones microvasculares, se puede plantear su aplicación en ciertas situaciones.

- Analizando la experiencia positiva de algunas series de casos y ensayos clínicos pequeños a corto y medio plazo en la mejoría del control glucémico y de las comorbilidades asociadas, consideran que podrían ser candidatos a cirugía metabólica los pacientes con DM tipo 2 e IMC 30-35 que cumplan los siguientes requisitos:

a) Pacientes en los que, habiendo sido evaluados por un endocrinólogo en el contexto de un equipo interdisciplinar, se haya descartado otras formas de diabetes diferentes de la DM tipo 2 (diabetes tipo 1, LADA, MODY ...).

b) Que muestren un deterioro progresivo del control glucémico $(\mathrm{HbA} 1 \mathrm{c}>7,5 \%)$ a pesar del tratamiento convencional optimizado y en los que, especialmente, coexistan otras comorbilidades mayores no controladas adecuadamente (dislipemia aterogénica, HTA, SAOS). 
- La inclusión de pacientes fuera de estos criterios debería formar parte de protocolos de investigación bien diseñados y controlados, confrontados a tratamientos convencionales basados en cambios del estilo de vida y tratamiento farmacológico habitual.

- Señalan que las tasas de remisión son menores cuando el diagnóstico de la diabetes supera los 10 años, el paciente sigue tratamiento con insulina y existe evidencia de escasa reserva pancreática.

La Federación Internacional de la Cirugía de la Obesidad (IFSO), cada 3 años realiza un cuestionario entre los diferentes centros de cirugía bariátrica a nivel internacional, describiendo las tendencias quirúrgicas. En su último informe publicado en el $2013^{108}$ se observa en Europa un total de 340000 cirugías de las que el 46\% eran bypass gástrico, seguido de la gastrectomía tubular o también conocida como manga gástrica en un 27\%. En España se reportaron 7800 cirugías, el $58 \%$ aproximadamente bypass gástrico, seguido de la gastrectomía tubular en un $18 \%$.

En la figura 1.7 se muestra la evolución de las diferentes técnicas bariátricas empleadas a nivel mundial y europeo, en la que se aprecia un aumento de la gastrectomía tubular, superando en Europa por primera vez en el año 2013 al bypass gástrico. A nivel mundial, aunque el número de todos estos procedimientos quirúrgicos ha aumentado, el bypass gástrico sigue prevaleciendo al resto. 


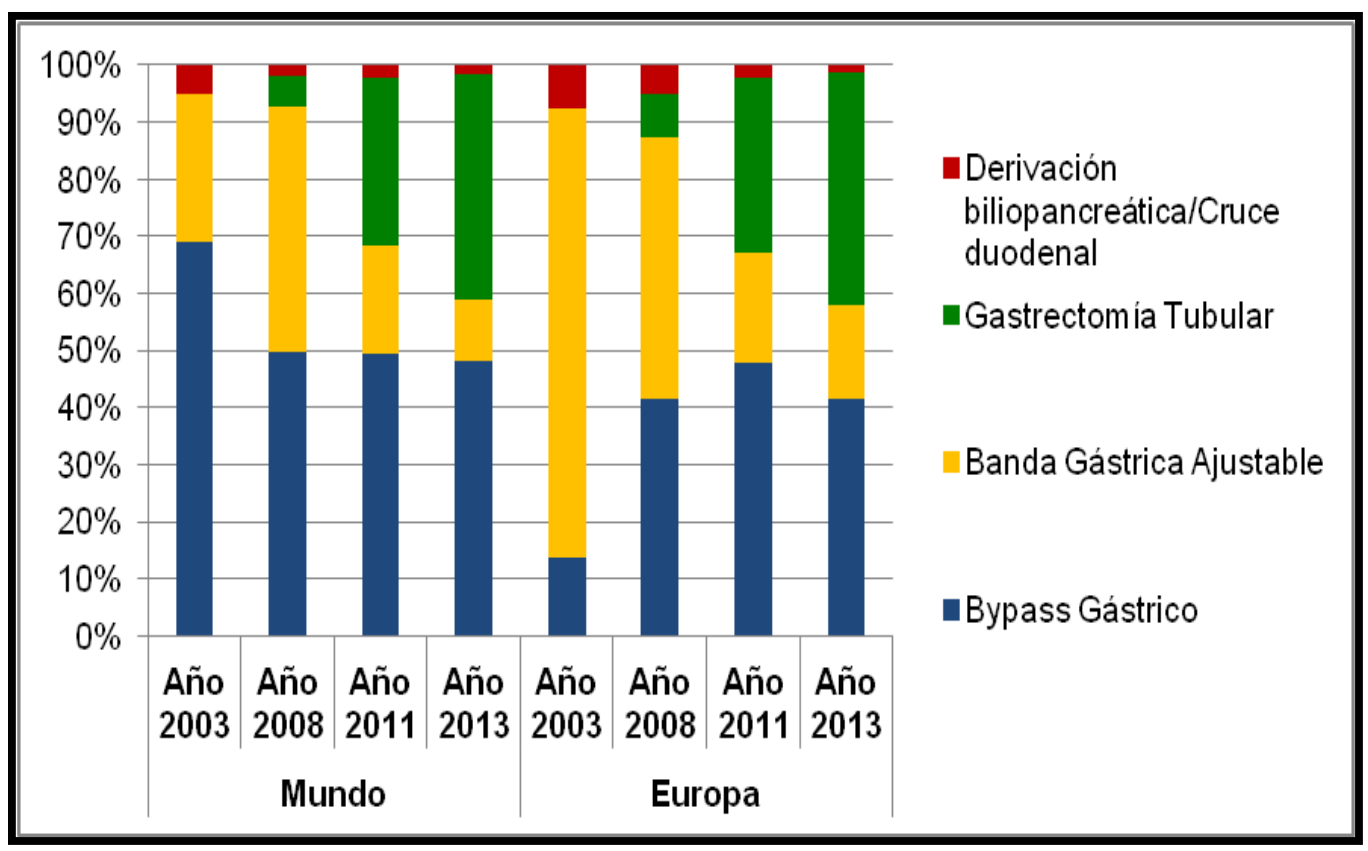

Figura 1.7. Tendencia del número de cirugías bariátricas a nivel mundial y europeo ${ }^{108}$.

A continuación describiremos las técnicas que en la actualidad perduran definiendo sus características y efectos reportados sobre la evolución de la obesidad y las comorbilidades asociadas en los pacientes sometidos a cirugía.

\subsubsection{Técnicas restrictivas}

Este tipo de técnicas implican la creación de una reducida bolsa gástrica también denominado reservorio, con una pequeña salida que cuando se distiende por acción de la comida, causa la sensación de saciedad.

\subsubsection{Gastroplastia vertical anillada}

La primera cirugía de este tipo fue descrita por Mason en 1971, una gastroplastia horizontal con el objetivo de evitar los efectos indeseables del bypass gástrico y realizar un procedimiento más fisiológico sin excluir ninguna parte del tubo digestivo ${ }^{109}$. Con el paso de los años diferentes cirujanos realizan variaciones a la técnica primitiva, como la gastroplastia vertical con banda basada en la perforación completa de ambas paredes del estómago creando una ventana utilizada para la inserción de una grapadora en el ángulo de His, hasta formar una pequeña bolsa vertical grapada. La innovación 
más reciente incorporada a esta técnica por Mason implica un menor número de complicaciones de tipo malabsortivo, no genera síndrome de dumping y los déficits de vitamina $B_{12} \quad 0$ anemia son excepcionales. El uso de esta técnica actualmente está disminuyendo por los malos resultados a largo plazo, debido a la reganancia del peso perdido, especialmente en pacientes superobesos, aquellos que no siguen de manera rigurosa las pautas alimentarias postquirúrgicas, etc.

\subsubsection{Banda gástrica ajustable}

Es la cirugía menos agresiva de los procedimientos restrictivos. Consiste en crear una pequeña bolsa y un reducido estoma mediante una banda colocada alrededor de la parte superior del estómago. En esta técnica, el estómago no se secciona, ni se grapa ni se realizan en él anastomosis.

Este dispositivo consta de un globo de goma de silicona que se coloca alrededor de la porción superior del estómago, justo distal a la unión gastroesofágica. El dispositivo se conecta, mediante un tubo flexible de silicona, a un puerto de acceso subcutáneo montado habitualmente en el músculo de la pared abdominal (figura 1.8).

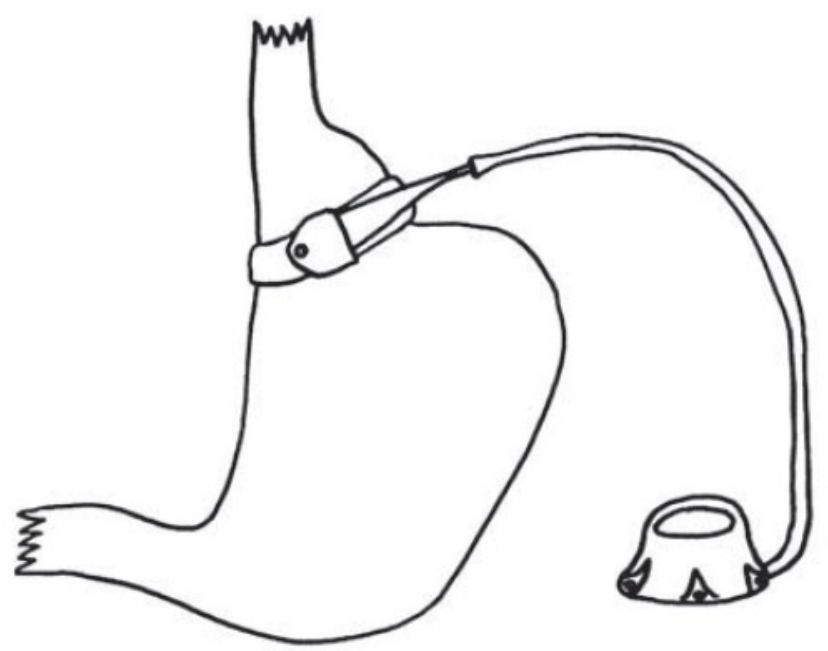

Figura 1.8. Banda gástrica ajustable. Imagen de D.M. Herron, MD, New York, NY. (c) 2007 Daniel M. Herron. 
A diferencia del bypass gástrico, la banda gástrica ajustable permite una restricción gástrica de volumen ajustable. Al inyectar suero salino en el puerto subcutáneo, el globo se expande, y se estrecha la luz gástrica de la banda. Idealmente, la banda se ajusta para proporcionar aproximadamente una pérdida de 0,5 a $1 \mathrm{~kg}$ de peso por semana ${ }^{110}$. Es importante evitar un ajuste excesivo de la banda, que puede producir vómitos y dilatación esofágica frecuentes. Aún así los resultados de pérdida de peso y fracasos son muy similares a los de la gastroplastia vertical anillada.

\subsubsection{Gastrectomía tubular o manga gástrica}

Recientemente, ha aumentado el interés por la gastrectomía tubular laparoscópica. Esta intervención es la porción restrictiva de la técnica malabsortiva Derivación biliopancreática-Cruce duodenal que posteriormente se describirá (figura 1.9).

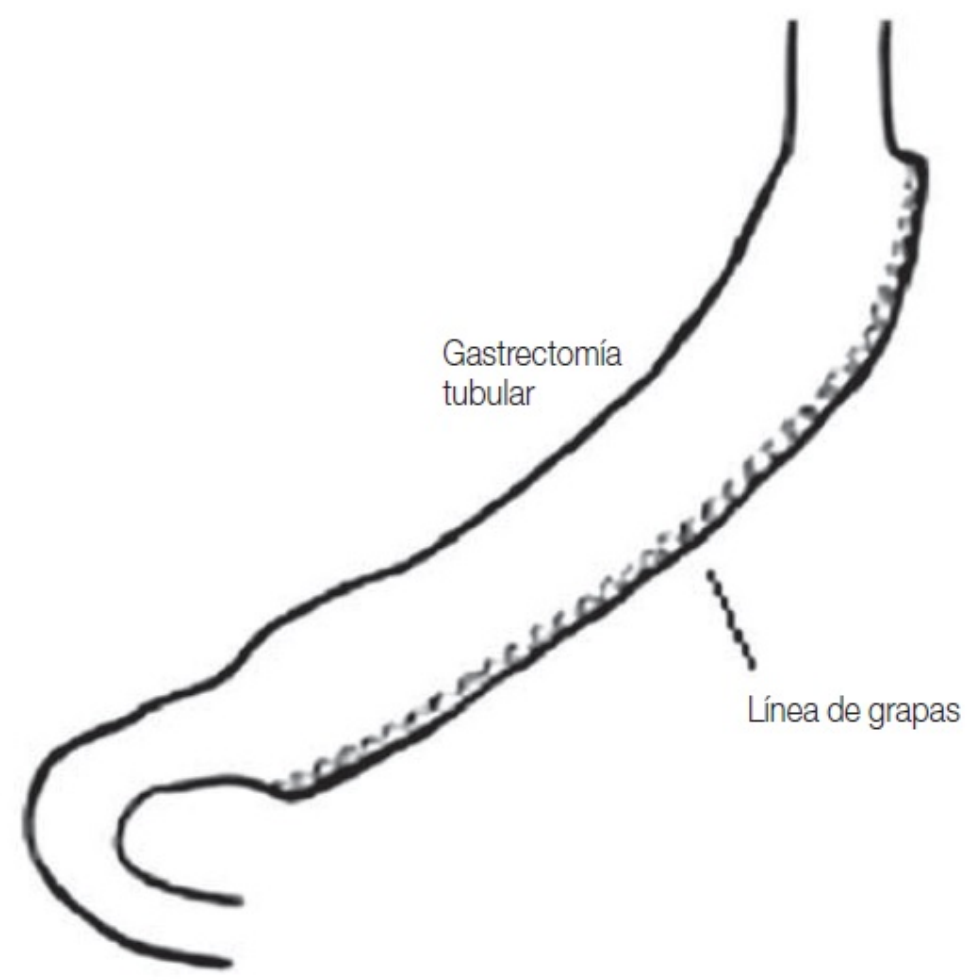

Figura 1.9. Gastrectomía tubular. Imagen de D.M. Herron, MD, New York, NY. (c) 2007 Daniel M. Herron.

En una serie de 216 pacientes sometidos a gastrectomía vertical, Lee et $\mathrm{al}^{111}$ mostraron una pérdida del 59\% del peso excesivo inicial al 
año, en comparación con el $47 \%$ en los pacientes con banda gástrica y el $75 \%$ en los pacientes con bypass gástrico. Algunos investigadores son optimistas en cuanto a que este procedimiento puede ofrecer una pérdida de peso tan buena o mejor que la obtenida con la banda gástrica ajustable, sin la necesidad de implantar un dispositivo médico, ni de los frecuentes ajustes. Por el momento, se esperan datos de resultados a largo plazo.

\subsubsection{Técnicas restrictivas-malabsortivas}

Mediante una derivación gastrointestinal se genera el componente malabsortivo de la técnica, la extensión de la derivación del tracto intestinal determina el grado de malabsorción. La cantidad mínima de tracto intestinal derivado consta de estómago distal, el duodeno completo y el primer segmento del yeyuno proximal.

\subsubsection{Derivación biliopancreática (DBP) y cruce duodenal (CD)}

Surge como desencadenante de técnicas quirúrgicas como el bypass yeyunoileal, pero a diferencia de este en el DBP-CD no existe el intestino delgado desfuncionalizado, en todos sus segmentos hay tránsito.

La intervención es una modificación de una operación muy malabsortiva realizada por primera vez por Scopinaro ${ }^{112}$ en la década de 1970. La técnica consta de un componente restrictivo mediante gastrectomía horizontal y el efecto malabsortivo con un asa alimentaria, un asa biliopancreática larga y un corto canal común. Aunque en lo referente a la pérdida de peso los resultados son excelentes, presenta complicaciones de carácter grave con casos de malnutrición proteica severa de por vida y úlceras de la anastomosis.

En 1998, Hess ${ }^{113}$ aporta una variante a esta técnica mediante una sección duodenal y anastomosis termino-terminal del asa alimentaria al duodeno proximal. Estas modificaciones a la técnica de Scopinaro eliminaban el síndrome de dumping y las úlceras marginales en los pacientes intervenidos (figura 1.10). 


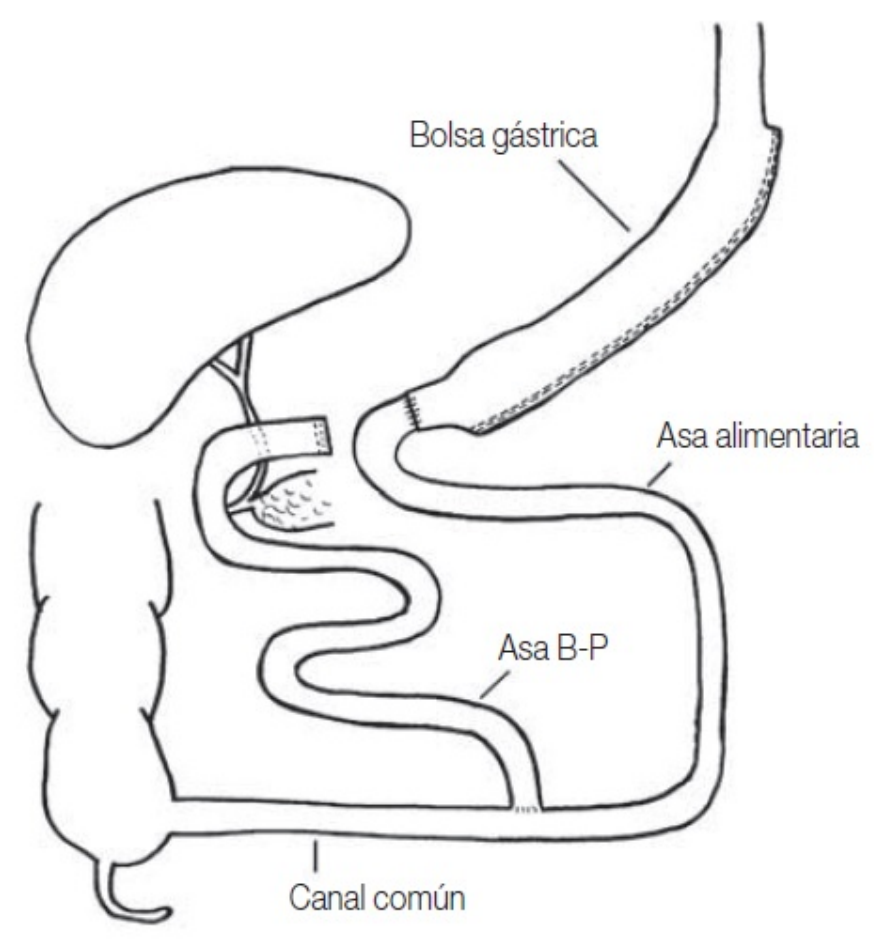

Figura 1.10. Derivación biliopancreática y cruce duodenal. Imagen de D.M. Herron, MD, New York, NY. (C) 2007 Daniel M. Herron.

La pérdida de peso después del procedimiento de cruce duodenal es excelente, en la serie de Marceau ${ }^{114}$, de 457 pacientes, los sujetos perdieron el $73 \%$ del exceso de peso inicial. Sin embargo, como cabe esperar en una intervención muy malabsortiva, los pacientes presentan efectos secundarios por la malabsorción de proteínas y grasas. La mayoría de los pacientes presenta de tres a cinco deposiciones blandas al día y tiene un meteorismo importante. Presenta una mayor incidencia de morbilidad mayor (15\%) y mortalidad $(0,5-2,5 \%)$ en comparación con otras intervenciones bariátricas.

\subsubsection{Bypass gástrico}

El primer bypass descrito por Mason es del 1967, el cual consistía en una división horizontal del estómago y una gastroyeyunostomía en asa, con un estoma. La intervención realizada al principio era exclusivamente por un abordaje abierto, hoy se realiza con mayor frecuencia por vía laparoscópica, reduciendo las estancias 
hospitalarias y las complicaciones postquirúrgicas. Muchos cirujanos bariátricos consideran que esta intervención es el método de referencia frente al que comparar las demás intervenciones para perder peso ${ }^{115}$.

Desde el inicio, el bypass gástrico ha sufrido una importante evolución. La mayoría de cirujanos utilizan una cortadora quirúrgica para crear una pequeña bolsa gástrica en la curvatura menor del estómago. Esta bolsa suele tener un volumen de 15-20 ml habitualmente. La bolsa se anastomosa a un segmento de intestino delgado, conocido como asa de Roux (figura 1.11). El alimento pasa de la bolsa gástrica al asa de Roux, que suele medir de 50 a $150 \mathrm{~cm}$ de longitud.

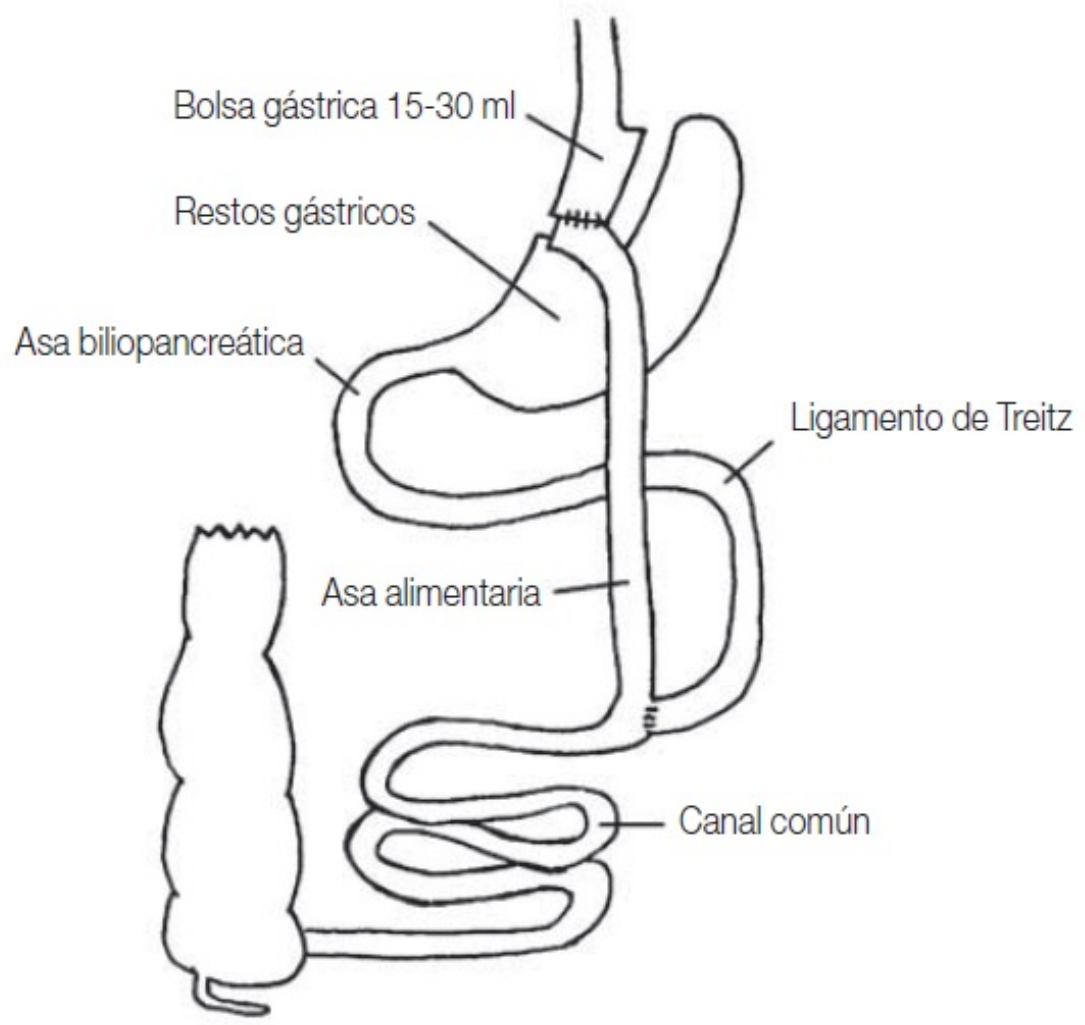

Figura 1.11. Bypass gástrico en $Y$ de Roux. Imagen de D.M. Herron, MD, New York, NY. () 2007 Daniel M. Herron.

Aunque todavía no se comprende totalmente el mecanismo de acción del bypass gástrico, muchos cirujanos creen que la intervención es principalmente restrictiva. Debido a que la bolsa 
gástrica es tan pequeña, los pacientes notan una sensación de saciedad después de tomar una pequeña comida. El bypass gástrico también produce un grado de malabsorción por la separación del recorrido de los alimentos (asa alimentaria) de las secreciones biliopancreáticas (asa biliopancreática). El grado de malabsorción que causa la intervención está directamente relacionado con la longitud de las asas alimentaria y biliopancreática ${ }^{116}$.

Se aconseja a los pacientes portadores de un bypass gástrico que no tomen dulces, por el síndrome de dumping o evacuación gástrica rápida, acompañada de sudoración, escalofríos y sofocos, causada por el paso rápido de azúcares simples y alimentos de osmolaridad elevada del reservorio gástrico al asa de Roux. Los pacientes con un síndrome de dumping habitualmente se notan fríos y sudorosos o calurosos y sofocados.

El grado de pérdida de peso después de la cirugía bariátrica es variable y está determinado en gran parte por la conducta del paciente después de la intervención. La pérdida de peso suele producirse durante los 6-12 meses posteriores a la intervención, tras los que el peso tiende a estabilizarse. Si bien el apetito tiende a estar muy disminuido durante los primeros meses después del bypass gástrico, tiende a recuperarse después del primer año. Algunos pacientes, especialmente si no siguen las recomendaciones postoperatorias de dieta y ejercicio, probablemente recuperen parte del peso perdido. En términos generales, los pacientes suelen perder el $75 \%$ del exceso de peso inicial ${ }^{116}$.

En 1994 se realizó el primer bypass por laparoscopia demostrando los beneficios sobre la técnica abierta con una mayor recuperación postoperatoria, la disminución de alteraciones pulmonares y complicaciones perioperatorias. Normalmente, los pacientes pueden volver a realizar las actividades normales a las 2-3 semanas de la intervención. 
La complicación más habitual después del bypass gástrico es la estenosis de la anastomosis gastroyeyunal, que se produce en el 2$15 \%$ de los pacientes y se trata habitualmente por dilatación con globo endoscópico ${ }^{117}$. Pueden producirse úlceras anastomóticas justo distales a la anastomosis en el 1\% o menos de los pacientes. La incidencia de obstrucción intestinal postoperatoria varía ${ }^{116}$. Cuando se cierran los defectos mesentéricos, la incidencia es aproximadamente del $1 \%$.

A pesar del hecho de que el bypass gástrico laparoscópico es una intervención mayor realizada en pacientes obesos, con comorbilidades cardíacas, pulmonares y endocrinas considerables, la mortalidad perioperatoria se mantiene baja: 0\%- 0,4\% ${ }^{115,116}$.

\subsubsection{Cirugías emergentes mínimamente invasivas}

La cirugía bariátrica se ha convertido en un tratamiento extensamente aceptado para la obesidad mórbida, sin embargo un gran número de pacientes evita la cirugía por temor a las posibles complicaciones operatorias y a las consecuencias a largo plazo de los procedimientos quirúrgicos actuales, del mismo modo que el largo tiempo de las listas de espera que en España provoca que la mayoría de los pacientes acudan a centros bariátricos privados. El avance de nuevas técnicas menos costosas y agresivas en el tratamiento de la obesidad, buscan alcanzar resultados equiparables a las técnicas anteriormente descritas de las cuales existen resultados a largo plazo, demostrando su efectividad ${ }^{116}$.

\subsubsection{Balón intragástrico (BIG)}

- Balón intragástrico ajustable: Desarrollado desde 2004 por Brooks en Nueva York, esta nueva modalidad de BIG se basa en dos innovaciones: un sistema de anclaje que previene la migración del balón al intestino, y en $2^{\circ}$ lugar, un catéter acoplado al mismo que permite regular el volumen en el transcurso del tratamiento. No hay publicaciones hasta la 
fecha relativas a resultados y/o complicaciones de este nuevo BIG.

- Protesis intragástrica (ATIIP): Se trata de un BIG que se implanta bajo control endoscópico y se fija vía percutánea la pared gástrica. Se conecta con un reservorio que permite regular su volumen. Con ello se pretende evitar los efectos indeseables del balón clásico durante los primeros días al demorar el inflado inicial, y, por otra parte, regular el volumen en función de la respuesta del paciente. Su fijación a la pared impediría la migración, con lo que no ha de retirarse antes de los 6 meses aconsejándose mantener unos 2 años. El estudio preliminar de Gaggiotti ${ }^{118}$ muestra un porcentaje de exceso de peso perdido a 12 meses del 39,2\%, describiendo como complicaciones: infección subcutánea en el 35\% de los casos, y en un $15 \%$ explantación del reservorio.

- Gastroplastia vertical endoluminal (EndoCinch): Se diseñó inicialmente para el tratamiento del reflujo gastroesofágico, FOGEL ${ }^{119}$, en 2008 describió por primera vez el uso de este procedimiento para el tratamiento de la obesidad. Se realizan 7 suturas entrecruzadas desde fundus hacia zona distal, de modo que se limita mucho la capacidad de distensión gástrica. La duración de la técnica es de unos 45 minutos, con pérdida media de 58,1\% del exceso ponderal al año. No hay datos aún respecto a durabilidad y estabilidad de las suturas.

- Gastroplastia transoral (TOGA): Esta técnica difiere de la anterior en que las suturas son transmurales y mecánicas. Se obtiene así una manga gástrica a lo largo de la curvatura menor $\mathrm{y}$, mediante plicaturas sucesivas puede estrecharse la luz gástrica a voluntad.

- Toxina botulínica antral: La toxina botulínica tiene un potente efecto inhibidor y de larga duración (2 a 4 meses) de las contracciones musculares, tanto de los músculos lisos como estriados. Esta prolongada parálisis es considerada como ideal 
para el tratamiento de ciertos desórdenes de la tonicidad muscular. Aunque la utilización de toxina con fines terapéuticos en otras enfermedades ha demostrado ser efectiva, en el tratamiento de la obesidad aún no hay resultados contundentes y son necesarios más estudios con mayor número de pacientes. Los principales problemas para ello son el coste de la toxina y la duración limitada de su efecto.

- Bypass duodenoyeyunal endoscópico (Endobarrier): Consiste en implantar una manga que recubre $60 \mathrm{~cm}$ de luz duodenoyeyunal. De este modo, el bolo alimenticio sin sufrir desviación de su trayecto, eludirá el contacto con los $60 \mathrm{~cm}$ proximales de la pared intestinal. Con ello, se obtiene un efecto de bypass similar al de la técnica quirúrgica, aunque sin su componente restrictivo. Su colocación se realiza bajo anestesia, al igual que su retirada meses más tarde. Recientemente, el concepto del bypass duodenoyeyunal endoscópico sufre una modificación que le aporta un carácter restrictivo: se induce una restricción del flujo mediante un diafragma a nivel del extremo proximal del dispositivo dejando un orificio de paso de $4 \mathrm{~mm}$. Gracias a esta modificación, la pérdida media del exceso ponderal alcanzó el 40\% frente a los datos previos de 11,9-22\%. Cabe destacar que el $70 \%$ de los pacientes requirió una o más dilataciones del orificio por náuseas y/o vómitos ${ }^{120}$.

- Estimulación gástrica implantable (marcapasos gástrico): Esta técnica está basada en la modificación de la motilidad gástrica, reduciendo las contracciones de manera coordinada, modificando el vaciamiento normal del estómago y por tanto, prolongando la sensación de saciedad. La estimulación gástrica consiste en la aplicación de una corriente eléctrica al estómago para alterar su funcionamiento.

Los primeros estudios descritos de la utilización del marcapasos gástrico en el tratamiento de la obesidad son de 
1992 por Cigaina, describiendo que la pérdida ponderal obtenida con este método es similar a la que confieren las técnicas quirúrgicas restrictivas, aunque más lenta.

Sus dos limitaciones principales estarían relacionadas con el marcapasos en sí, por problemas de exteriorización del mismo y con la adecuada selección del paciente, en concreto con aspectos psicológicos, siendo poco eficaz en los casos de trastorno por atracón.

Los resultados de un estudio multicéntrico europeo ${ }^{121}$ así como de la experiencia americana, concluyen que el marcapaso es un procedimiento seguro con el que se obtiene una pérdida del exceso ponderal rondando el $20 \%$ a los 6 meses. En la actualidad se están perfeccionando este dispositivo y empezando a emplear marcapasos que detectan los alimentos y emiten los impulsos eléctricos, describiendo un porcentaje de exceso de peso perdido a 12 meses mayor. 


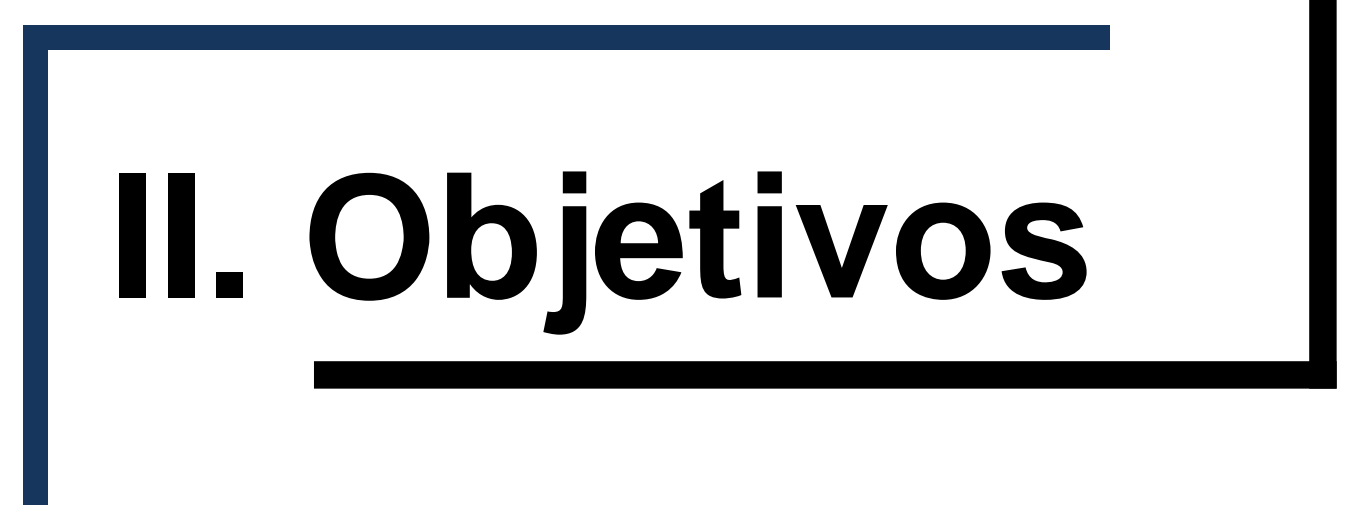


Los pacientes intervenidos de cirugía bariátrica mediante técnicas mixtas (malabsortiva y restrictiva) pierden más del 50\% del sobrepeso a medio-largo plazo. Después de someterse a la cirugía bariátrica, el $80 \%$ de los pacientes que padecían comorbilidades asociadas a la obesidad como el síndrome de apnea obstructiva del sueño, diabetes y dislipidemia consiguen resolverlas ${ }^{107}$.

El bypass gástrico es la técnica más utilizada ya que combina unos buenos resultados a largo plazo, con mejoría de la calidad de vida y de las comorbilidades y una baja morbimortalidad postoperatoria.

Los pacientes que se someten a este tipo de cirugía bariátrica, pueden presentar alteraciones digestivas como diarreas, vómitos, malabsorción de macro y micronutrientes, provocando cuadros clínicos que necesitan ser tratados bajo supervisión clínica y de manera individualizada, mediante un seguimiento postquirúrgico exhaustivo intensificando la periodicidad de las revisiones durante el primer año puesto que es la etapa con mayores efectos adversos descritos.

\section{OBJETIVOS:}

1. Valorar las características generales y el perfil del paciente sometido a cirugía bariátrica de la muestra a estudio. Describiendo los antecedentes clínicos y quirúrgicos previos de los pacientes de la muestra.

2. Conocer las variables del estilo de vida, hábitos dietéticos, consumo de tabaco y alcohol de la muestra.

3. Evaluar la preparación dietético-nutricional previa a la cirugía bariátrica.

4. Valorar la pérdida y mantenimiento del peso en los pacientes intervenidos de mini bypass gástrico de una sola anastomosis a los 2 años de la cirugía. Determinar el porcentaje de sobrepeso 
perdido y el porcentaje de exceso de IMC perdido después de someterse al procedimiento quirúrgico.

5. Valorar la modificación en el riesgo de presentar comorbilidades mayores desde el control prequirúrgico hasta los 2 años posteriores a la cirugía bariátrica.

6. Evaluar la adaptación alimentaria postquirúrgica.

7. Describir la evolución de las variables analíticas en los diferentes controles de evolución postquirúrgicos de la muestra de pacientes sometidos a mini bypass gástrico. 


\section{Material y}

métodos 


\section{Metodología}

Para lograr los objetivos fijados en el presente trabajo se requirió la siguiente metodología.

\subsection{Diseño del estudio y ámbito de realización}

- Estudio descriptivo transversal prospectivo de pacientes intervenidos de mini bypass gástrico de una sola anastomosis (BAGUA) en el Centro de Excelencia para el Estudio y Tratamiento de la Obesidad (СTO), durante un periodo de 2 años de seguimiento.

\subsection{Población y periodo de estudio}

Los pacientes que formaban parte del Registro Europeo de Cirugía Bariátrica (EAC-BS) entre enero del 2010 y diciembre del 2012 eran 501 pacientes obesos intervenidos de BAGUA que cumplían los criterios de indicación de cirugía aceptados por IFSO. De los cuales 185 pacientes a 1 de diciembre del 2012 cumplían un seguimiento a 24 meses, y de los que se seleccionó la muestra estudiada atendiendo a los criterios de inclusión.

Se recogieron, previo consentimiento informado (ANEXO I), datos demográficos, de exploración y clínicos incluidos en la historia clínica de cada paciente. Los datos fueron tratados de manera confidencial y siguiendo los criterios del programa de Excelencia en Cirugía Bariátrica en Europa coordinado por IFSO, por el que se encuentra acreditado de manera favorable CTO Valladolid desde el año 2010.

Se realizaron revisiones periódicas de carácter trimestral en las que se incluyó el registro de evaluación (ANEXO II) y control analítico, desde la cirugía hasta los 12 meses, desde este momento los controles se realizaron cada 6 meses siguiendo las directrices en el seguimiento del paciente bariátrico según las pautas establecidas por IFSO hasta alcanzar los 24 meses de seguimiento postquirúrgico.

Los controles postquirúrgicos se llevaron a cabo mediante el seguimiento de todo el equipo multidisciplinar de CTO, a través de un seguimiento online y presencial, aplicando los criterios de revisión clínica, 
acompañados de una muestra sanguínea en cada uno de los controles postquirúrgicos.

- Paciente

o Criterios de inclusión:

-Pacientes obesos IMC $\geq 30$, con patología metabólica y un inadecuado control en el estilo de vida y tratamiento médico (criterios IFSO).

-Consentimiento informado cumplimentado y firmado.

-Seguimiento postquirúrgico superior al 75\% a los 24 meses de la cirugía, del total de los casos seleccionados.

o Criterios de exclusión:

-Aquellos pacientes sin alcanzar los 24 meses postquirúrgicos durante el periodo de tiempo descrito.

-Pacientes con una tasa de seguimiento inferior del 75\% a los 24 meses de seguimiento postquirúrgico.

-Rechazo a participar o colaborar en el seguimiento postquirúrgico.

-Contraindicación anestésica.

-Patología clínica asociada que contraindique la intervención como cardiopatías o neuropatías severas, neoplasias activas.

-Consentimiento informado no cumplimentado y/o firmado por el paciente.

- Tamaño muestral: Pacientes que cumplen los criterios de inclusión y no han sido excluidos durante el periodo estudiado. La muestra cumpliendo estos criterios es de 100 sujetos, 71 mujeres y 29 varones.

- Muestreo: Se ha realizado mediante reclutamiento de casos consecutivos, estudiando todos los que cumplían criterios de inclusión para la cirugía bariátrica en el periodo mencionado. 


\subsection{Procedimiento quirúrgico: mini bypass gástrico de una sola anastomosis (BAGUA)}

\subsubsection{Evaluación preoperatoria}

El protocolo preoperatorio incluyó tanto los criterios de selección para la cirugía bariátrica como la evaluación psicológica, los estudios analíticos y radiológicos habituales, de función cardiorrespiratoria y otros complementarios en relación con las comorbilidades existentes. Los pacientes fueron sometidos a fisioterapia respiratoria preoperatoria, ejercicio físico y de deambulación activa, así como un protocolo dietético diseñado específicamente para la preparación preoperatoria de 20 días de duración: doce días de dieta hiperproteica pura con bricks de 200 kcal cada 6 horas, a razón de 800 kcal/día, (Vegefast-Complet®; Vegenat, España), y dieta líquida completa durante los ocho días previos a la cirugía. Dicho protocolo se indicó como resultado de un estudio prospectivo randomizado Vegefast vs dieta hiperproteica natural ${ }^{122}$.

\subsubsection{Procedimiento quirúrgico ${ }^{123,124}$}

La técnica quirúrgica se encuentra esquemáticamente descrita en la figura 3.1. Seis trócares son habitualmente empleados: uno de $10 \mathrm{~mm}$ para la cámara, 2 de $12 \mathrm{~mm}$ para el paso de las endograpadoras y 3 de $5 \mathrm{~mm}$ para la retracción hepática y el manejo del segmento intestinal.
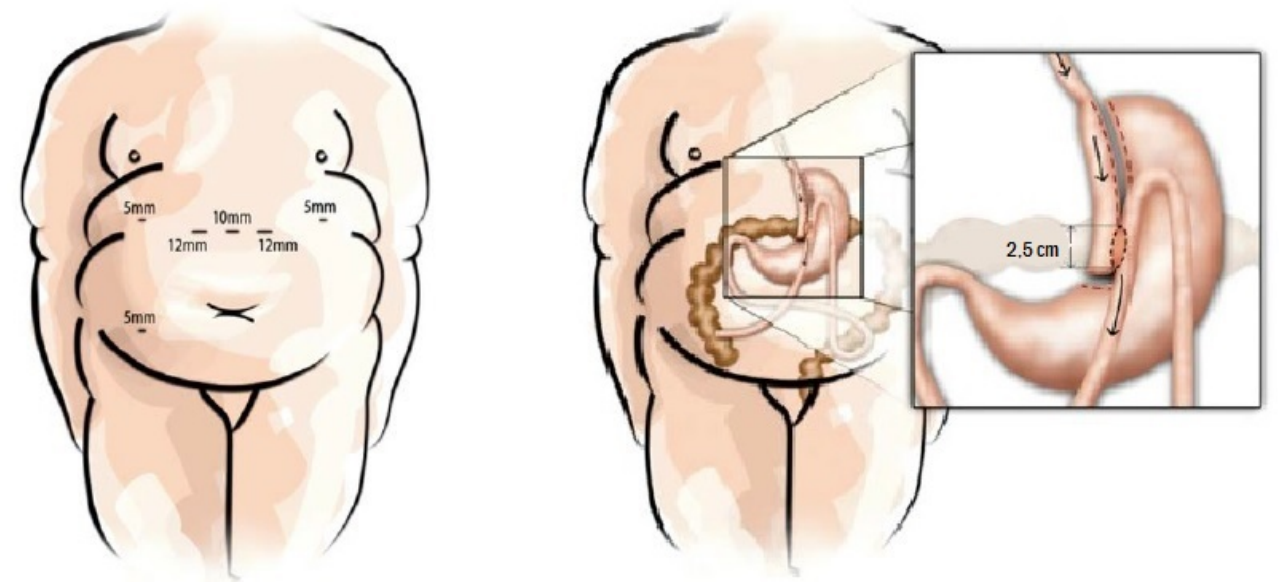

Figura 3.1. Distribución esquemática del acceso laparoscópico empleado. Imagen de M.A. Carbajo, MD.PhD, CTO Valladolid. (C) 2008 M.A. Carbajo. 
Un robot auxiliar se conecta al sistema óptico (Lap Man, Medsys, Belgium) y manejado por control remoto por láser para mantener el trabajo de la cámara de forma independiente.

El primer paso de la intervención consiste en la localización del ángulo de Treitz y la medición del asa yeyunal a excluir, entre 200 a 350 $\mathrm{cm}$ distales al Treitz, en función de la longitud intestinal y del IMC. Posteriormente se coloca al paciente en posición de antitrendelenburg $30^{\circ}$ y se libera ampliamente el ángulo de Hiss, disecando la unión esofagogástrica y visualizando por completo el pilar izquierdo. En pacientes con hernia hiatal asociada, este paso debe incluir una reducción de la hernia y una apertura total de la membrana gastrofrénica, con control del pilar derecho del diafragma.

A continuación se realiza la colocación del robot en el lugar apropiado y con ayuda del dispositivo control-láser se sitúa el brazo robótico en la posición adecuada para efectuar la conexión y anclaje con el sistema óptico. Una vez efectuada esta maniobra, el cirujano asistente pasa a tener el control del robot con el mando a distancia anclado sobre el soporte del separador hepático y a partir de ese momento todo el movimiento de la cámara dependerá de las órdenes emitidas por el mismo hasta la finalización de la intervención quirúrgica.

Posteriormente, se seccionan con tijeras ultrasónicas (Autosonix, Covidien, USA) los vasos sanguíneos de la curvatura menor gástrica a nivel del extremo inferior de la "pata de ganso", abriendo el paso a la cara posterior del estómago. Esta maniobra debe cuidar en extremo el mantenimiento de la máxima vascularización al reservorio gástrico. A continuación, una Endo-Gia Roticulator de 45 mm, 3,5 mm (Covidien, USA), secciona el estómago horizontalmente a ese nivel. Se introduce una sonda orogástrica de 36 french para la calibración del reservorio gástrico, se liberan todas las adherencias grasas y fibrosas de la cara posterior del estómago y se aplican 3 Endo-Gias de $60 \mathrm{~mm}, 3,5 \mathrm{~mm}$, completamente ajustadas entre la sonda y la curvatura menor gástrica, hasta tener acceso al orificio que inicialmente se abrió a nivel de la unión 
esofagogástrica y realizar la completa sección del estómago en la misma unión gastroesofágica. El reservorio gástrico que se obtiene es largo, estrecho, bien vascularizado y fácil de movilizar en sentido caudal.

Después se retira la sonda y el intestino es movilizado y traccionado en el lugar elegido para colocarlo en posición antecólica y antegástrica, frente al reservorio gástrico. La transección del epiplón mayor y/o del epiplón gastrocólico debe realizarse en caso de necesidad. A continuación se realiza una sutura continua en posición latero-lateral fijando el asa ileal a la línea de grapado del reservorio gástrico en unos 8-10 cm de longitud. Una enterotomía de 3-4 $\mathrm{mm}$ y una pequeña gastrostomía efectuada con las tijeras ultrasónicas y una carga de $30 \mathrm{~mm}$, introduciendo $3,5 \mathrm{~mm}$ al $50 \%$ entre ambos lados, realizando la anastomosis gastroileal con una longitud de $2,5 \mathrm{~cm}$. Los orificios abiertos en la cara anterior de la anastomosis, se suturan con puntos sueltos polisorb No. 0 (Covidien, USA); el asa intestinal biliopancreática se sutura en sentido ascendente al estómago excluido, así como el asa común, manteniendo el mecanismo antirreflujo y descargando tensión a la anastomosis.

Finalmente, se efectúa una prueba de control con aire a presión intraluminal bajo suero salino para comprobar la estanqueidad anastomótica. Después de esto, la anastomosis se sella con cola sintética (Glubran-2, Cardiolink, Italia), el omento mayor adherido a la misma, y un drenaje de silicona es aplicado bajo el lóbulo izquierdo hepático y extraído por el orificio del trócar subcostal derecho de $5 \mathrm{~mm}$.

En el control postoperatorio inmediato todos los pacientes son desintubados en el quirófano y trasladados a su habitación, salvo aquellos que padezcan cardiopatía o broncopatía grave no controlada, que son trasladados a la unidad de reanimación. La sonda nasogástrica es retirada en el quirófano. La sonda vesical se retira a las 10-12 horas siguientes, favoreciendo la movilización activa y deambulación precoz del paciente. A continuación, se realiza un control radiográfico con 
contraste hidrosoluble para un nuevo chequeo de la anastomosis y visualización radiográfica de la cavidad abdominal.

Si los resultados son satisfactorios, se inicia la tolerancia oral con agua e infusiones, y posteriormente se retira el drenaje y catéter venoso, siendo el paciente dado de alta hospitalaria en las primeras $24 \mathrm{~h}$ postoperatorias. Durante los 2-3 días ambulatorios hasta la primera revisión en consulta se mantiene control telefónico y si fuera preciso visita presencial hasta la primera revisión en consulta.

\subsubsection{Protocolo de seguimiento postquirúrgico}

Los pacientes mantienen una dieta líquida la primera semana postquirúrgica, semilíquida la segunda semana, triturada (turmix), las tres semanas siguientes y se inicia la dieta semisólida en la sexta semana y sólida progresiva en las dos semanas posteriores de forma controlada, todo ello en base a un protocolo nutricional adaptado a cada paciente por el equipo de nutrición del Centro. El proceso de adaptación intestinal completo suele mantenerse durante los tres primeros meses, pero puede prolongarse hasta el sexto mes en casos de transgresiones alimentarias. A partir del sexto mes, usualmente todos los pacientes toleran cualquier tipo de alimentos.

Respecto a la prescripción farmacológica postquirúrgica protocolizada, durante el primer mes se pauta pantoprazol y sucralfato a diario. Calcio durante los tres primeros meses y un complejo polivitamínico-mineral, durante el primer año, con dosis de recuerdo recomendadas de por vida. El resto de medicación administrada a cada paciente dependerá de las comorbilidades asociadas, el grado de resolución de las mismas y las pautas médicas prescritas por los especialistas si fuese el caso.

Los controles postquirúrgicos o revisiones se realizan cada 3 meses después de la cirugía, aconsejando un examen anual continuado presencial en la consulta. 


\subsection{Variables analizadas}

Las variables cuantitativas se expresan mediante la unidad de medición correspondiente, y las cualitativas mediante categorías. En la tabla 3.1, se expresan el resumen de las variables empleadas, las unidades de medida y la forma de medición.

\begin{tabular}{|c|c|c|}
\hline Nombre de la variable & Unidad & Forma de medición \\
\hline \multicolumn{3}{|c|}{ VARIABLES CLÍNICAS } \\
\hline Sexo & $\begin{array}{c}\text { Hombre }(ð) \\
\text { Mujer }(\phi)\end{array}$ & \multirow{14}{*}{ Historia clínica } \\
\hline Edad & Años & \\
\hline Nacionalidad & País & \\
\hline Ocupación profesional & Tipo & \\
\hline Estado civil & Tipo & \\
\hline Número de hijos & Numérica & \\
\hline Origen de la obesidad & Tipo & \\
\hline Patologías & Tipo & \\
\hline Hábitos alimentarios & Tipo & \\
\hline $\begin{array}{l}\text { Antecedentes quirúrgicos } \\
\text { previos }\end{array}$ & Tipo & \\
\hline $\begin{array}{c}\text { Hábitos tóxicos: Tabaco y } \\
\text { alcohol }\end{array}$ & Tipo & \\
\hline $\begin{array}{c}\text { Autovaloración de la } \\
\text { tolerancia alimentaria } \\
\text { postquirúrgica }\end{array}$ & Tipo & \\
\hline $\begin{array}{l}\text { Actividad física } \\
\text { postquirúrgica }\end{array}$ & Tipo & \\
\hline $\begin{array}{l}\text { Tratamiento } \\
\text { farmacológico } \\
\text { postquirúrgico }\end{array}$ & Tipo & \\
\hline \multicolumn{3}{|c|}{ VARIABLES ANTROPOMÉTRICAS } \\
\hline Altura & $\mathrm{m}$ & Estadómetro \\
\hline Peso & $\mathrm{Kg}$ & Báscula manual \\
\hline IMC & $\mathrm{kg} / \mathrm{m}^{2}$ & Peso/talla ${ }^{2}$ \\
\hline PSP & $\%$ & $\begin{array}{c}\text { (Peso inicial }- \text { peso } \\
\text { actual/peso inicial }- \text { peso } \\
\text { ideal) } \times 100\end{array}$ \\
\hline PIMCP & $\%$ & $\begin{array}{c}(\mathrm{IMC} \text { inicial }-\mathrm{IMC} \text { final/IMC } \\
\text { inicial) } \times 100\end{array}$ \\
\hline PEIMCP & $\%$ & $\begin{array}{l}100-([\text { IMC final }-25 / \text { IMC } \\
\text { inicial }-25] \times 100)\end{array}$ \\
\hline Perímetro de cintura & $\mathrm{cm}$ & Cinta métrica \\
\hline Perímetro de cadera & $\mathrm{cm}$ & Cinta métrica \\
\hline ICC & - & $\begin{array}{c}\text { Perímetro de } \\
\text { cintura/Perímetro de cadera }\end{array}$ \\
\hline
\end{tabular}




\begin{tabular}{|c|c|c|}
\hline Nombre de la variable & Unidad & Forma de medición \\
\hline \multicolumn{3}{|c|}{ VARIABLES BIOQUÍMICAS } \\
\hline Glucemia & mg/dL & \multirow{20}{*}{$\begin{array}{l}\text { Laboratorio de análisis clínico } \\
\text { seleccionado por el paciente }\end{array}$} \\
\hline Colesterol total & $\mathrm{mg} / \mathrm{dL}$ & \\
\hline HDL-Colesterol & $\mathrm{mg} / \mathrm{dL}$ & \\
\hline LDL-Colesterol & $\mathrm{mg} / \mathrm{dL}$ & \\
\hline Triglicéridos & $\mathrm{mg} / \mathrm{dL}$ & \\
\hline Ácido úrico & $\mathrm{mg} / \mathrm{dL}$ & \\
\hline Urea & $\mathrm{mg} / \mathrm{dL}$ & \\
\hline Creatinina & $\mathrm{mg} / \mathrm{dL}$ & \\
\hline GOT & $\mathrm{U} / \mathrm{L}$ & \\
\hline GPT & $\mathrm{U} / \mathrm{L}$ & \\
\hline GGT & $U / L$ & \\
\hline Fosfatasa Alcalina & $U / L$ & \\
\hline Hierro & $\mu \mathrm{g} / \mathrm{dL}$ & \\
\hline Ferritina & $\mathrm{ng} / \mathrm{mL}$ & \\
\hline Vitamina $B_{12}$ & $\mathrm{pg} / \mathrm{mL}$ & \\
\hline Ácido Fólico & $\mathrm{ng} / \mathrm{mL}$ & \\
\hline Proteínas totales & $\mathrm{g} / \mathrm{L}$ & \\
\hline Albúmina & g/L & \\
\hline Calcio & $\mathrm{mg} / \mathrm{dL}$ & \\
\hline Fósforo & $\mathrm{mg} / \mathrm{dL}$ & \\
\hline
\end{tabular}

Tabla 3.1. Resumen de variables analizadas

\subsubsection{Características generales}

- Se registró la edad y sexo de cada paciente. En el análisis comparativo por edad se dividió la población de estudio en igual o menor a 42 años y mayor a 42 años, por ser esta la mediana de edad de la muestra.

- País de nacimiento.

- Ocupación profesional, mediante la clasificación nacional de ocupaciones Ministerio de Trabajo y Seguridad Social, división de estudios ocupacionales (ANEXO III).

- Estado civil: Soltero, casado o viudo.

- Número de hijos.

- Origen de la obesidad: Infancia, adolescencia, embarazo, cirugías previas.

- Hábitos de conducta alimentaria. tomando como referencia las recomendaciones IFSO, se determinó la preferencia de los pacientes en los siguientes patrones de consumo alimentario: 
-Goloso, preferencia por alimentos con alto contenido en azúcares de rápida absorción.

-Picoteador, consumo de pequeñas cantidades de manera reiterada durante el día.

-Comilón, consumo de gran cantidad de alimentos en las tres principales comidas del día (desayuno, comida y cena).

-Comilón emocional, cuando el paciente expresa un deseo insaciable de comer que tiene que ser correspondido para calmar la ansiedad.

\subsubsection{Evaluación clínica}

A cada uno de los pacientes incluidos en el estudio se le realizó una historia clínica y una exploración física para determinar las patologías asociadas a la obesidad, identificadas en el apartado de antecedentes clínicos. Del mismo modo se registraron los antecedentes quirúrgicos previos.

\subsubsection{Evaluación antropométrica}

La valoración antropométrica de los sujetos se realizó mediante determinación del peso, la talla mediante estadómetro y báscula calibrada y el Índice de Masa Corporal (IMC); así como perímetro de cintura, perímetro de cadera e índice cintura-cadera (ICC).

- Peso, talla e IMC

El peso se midió sin ropa con una precisión de $\pm 0,5 \mathrm{~kg}$, empleando una báscula manual hasta el 0,1 kg más cercano. La altura se midió con el paciente en posición erguida hasta el centímetro más cercano, empleando un estadómetro. Se calculó el índice de masa corporal (IMC) mediante la fórmula:

$$
\text { IMC }=\frac{\text { peso }(\mathrm{kg})}{\operatorname{talla}^{2}\left(\mathrm{~m}^{2}\right)}
$$


A partir del IMC, según el Consenso SEEDO 2007 para la evaluación del sobrepeso y la obesidad se utiliza la siguiente clasificación (tabla 3.2).

\begin{tabular}{|c|c|}
\hline \multicolumn{2}{|c|}{ Grados de obesidad según SEEDO 2007} \\
\hline Valores límites del IMC (kg/m²) & Categoría \\
\hline$<18,5$ & Peso insuficiente \\
\hline $18,5<24,9$ & Peso normal \\
\hline $25,0-26,9$ & Sobrepeso grado I \\
\hline $27,0-29,9$ & Sobrepeso grado II (preobesidad) \\
\hline $30,0-34,9$ & Obesidad de tipo I \\
\hline $35,0-39,9$ & Obesidad de tipo II \\
\hline $40,0-49,9$ & Obesidad de tipo III (mórbida) \\
\hline$\geq 50,0$ & Obesidad de tipo IV (extrema) \\
\hline
\end{tabular}

Tabla 3.2. Clasificación del sobrepeso y la obesidad según el IMC (SEEDO 2007)

- Pérdida de peso entre revisiones y pérdida de peso diario: Se cuantificó el peso perdido al restar el peso entre un control trimestral con el anterior. Del mismo modo dividido entre los días transcurridos entre cada control, se calculó la pérdida de peso diaria expresada en g/día. Los valores representados en negativo suponen ganancia de peso respecto al control anterior.

- Porcentaje de Sobrepeso Perdido (PSP), Porcentaje de IMC Perdido (PIMCP), y Porcentaje de Exceso de IMC Perdido (PEIMCP) $)^{125}$

En la valoración de la pérdida ponderal se utilizaron los siguientes indicadores que son utilizados por las diferentes Organizaciones Internacionales de cirugía bariátrica para determinar el éxito o fracaso de la cirugía en la pérdida ponderal.

a) $P S P=($ Peso inicial - peso actual/peso inicial - peso ideal $) \times 100$

b) $\mathrm{PIMCP}=(\mathrm{IMC}$ inicial $-\mathrm{IMC}$ actual/IMC inicial $) \times 100$

c) $P E I M C P=100-([I M C$ actual $-25 / I M C$ inicial -25$] \times 100)$

El peso e IMC inicial es el correspondiente al registrado en la $1^{\text {a }}$ consulta, previa a la cirugía bariátrica. El peso e IMC actual hace referencia al periodo específico donde se mide de manera trimestral 
en cada una de las revisiones. El peso ideal se obtiene a través de la fórmula Metropolitan Life Insurance Company. PI $=50+[0,75 X$ (Talla (cm) - 150)].

A propuesta de los criterios de Baltasar et $\mathrm{al}^{125}$, se utilizó el PEIMCP por su correlación en la determinación del resultado en la valoración de la pérdida ponderal postquirúrgica, considerando los resultados:

- Excelentes. PEIMCP >65\%

- Buenos. PEIMCP 50-65\%

- Fracasos. PEIMCP $<50 \%$

- Cintura, cadera e ICC

El perímetro de la cintura se determinó con el sujeto en bipedestación, sin ropa y relajado. Se localizó el borde superior de las crestas ilíacas y, por encima de ese punto, se rodeó la cintura del individuo con una cinta métrica. La lectura se realizó al final de una espiración normal. Se midió en centímetros (cm). El perímetro de la cadera se determinó de la misma manera, pero eligiendo como puntos anatómicos ambos trocánteres. El índice cintura- cadera se determinó con la siguiente fórmula:

$$
\text { Índice Cintura-Cadera: } \frac{\text { Cintura }(\mathrm{cm})}{\text { Cadera }(\mathrm{cm})}
$$

La relación cintura-cadera es un método utilizado para describir la distribución, tanto subcutánea como intraabdominal, del tejido adiposo. Resulta de dividir el perímetro de la cintura (en centímetros) por el perímetro de la cadera (también en centímetros).

\subsubsection{Objetivo ponderal previo a la cirugía}

La evidencia científica actual hace recomendable la pérdida de peso preoperatoria en aquellos pacientes candidatos a cirugía bariátrica con la finalidad de favorecer el acto quirúrgico, pues disminuye el tamaño hepático y la grasa intraabdominal. Con esta premisa el cirujano 
aplicó un objetivo ponderal a todos los pacientes de manera individualizada según su estado clínico, basado en una reducción entre el $10-12 \%$ sobre el peso inicial para evitar posibles complicaciones perioperatorias y favorecer el acto quirúrgico. Del mismo modo se describe en días, el tiempo de duración de dicha preparación.

Se estudia el peso objetivo marcado por el equipo quirúrgico, el porcentaje aplicado para lograr el objetivo marcado y el grado del cumplimiento comparando el peso marcado como objetivo, con el peso real del día de la cirugía.

\subsubsection{Características de la cirugía}

Se analizó el tiempo de duración de la cirugía, la combinación con otras técnicas simultáneamente como la reducción de la hernia hiatal y la colecistectomía, el tiempo de estancia hospitalaria, la longitud de las asas biliopancreática y común, y las complicaciones quirúrgicas.

\subsubsection{Estilo de vida}

Se recogieron datos sobre los hábitos tóxicos de los pacientes como el hábito tabáquico y el consumo de alcohol prequirúrgico. Se clasificaron a los pacientes por su consumo habitual de alcohol en cuatro grupos según las recomendaciones de IFSO: No bebedor, ex-alcohólico, bebedor diario, bebedor semanal, y bebedor mensual.

Del mismo modo se hizo con el consumo de tabaco clasificándoles en: no fumador, ex-fumador, <20 cigarros/día, 20 cigarros/día, y >20 cigarros/día.

También se encuestó a los pacientes por el ejercicio físico que realizaban después de la cirugía, pudiendo ser: ninguno, 1 vez/semana, 2 veces/semana, o a diario.

\subsubsection{Cuantificación del riesgo relativo de presentar comorbilidades mayores}

SEEDO evalúa el riesgo de morbimortalidad que comporta el exceso de peso y que depende especialmente del exceso de peso, la distribución de la grasa corporal, la presencia de factores de riesgo 
cardiovascular y otras comorbilidades. Es por ello la determinación del riesgo desde ninguno, ligeramente aumentado, aumentado, alto y muy alto. Se clasificó a los pacientes de la muestra atendiendo a los siguientes criterios especificados en la tabla 3.3.

\begin{tabular}{|c|c|c|c|}
\cline { 2 - 4 } & \multirow{2}{*}{ IMC } & \multicolumn{2}{c|}{$\begin{array}{c}\text { Riesgo relativo a partir del perímetro } \\
\text { de cintura }\end{array}$} \\
\cline { 2 - 4 } & & Mujeres $\leq 88 \mathrm{~cm}$ & Mujeres $>88 \mathrm{~cm}$ \\
\cline { 2 - 4 } & Varones $\leq 102 \mathrm{~cm}$ & Varones $>102 \mathrm{~cm}$ \\
\hline Peso normal & $18,5-24,9$ & Ninguno & $\begin{array}{c}\text { Ligeramente } \\
\text { aumentado }\end{array}$ \\
\hline Sobrepeso & $25-29,9$ & $\begin{array}{c}\text { Ligeramente } \\
\text { aumentado }\end{array}$ & Aumentado \\
\hline Obesidad & $30-34,9$ & Aumentado & Alto \\
\cline { 2 - 4 } & $35-39,9$ & Alto & Muy alto \\
\hline Obesidad mórbida & $\geq 40$ & Muy alto & Muy alto \\
\hline
\end{tabular}

Tabla 3.3. Clasificación del riesgo relativo de presentar comorbilidades mayores según el peso y la presencia de obesidad abdominal. SEEDO

\subsubsection{Autovaloración de la tolerancia alimentaria postquirúrgica}

Siguiendo las recomendaciones de IFSO, se registraron las variables exigidas para el control y seguimiento en la valoración y adaptación a la alimentación postquirúrgica según este organismo. En él se incluye el número de comidas al día, si "picotea" entre horas, autovaloración de la tolerancia a los alimentos (regular, buena, óptima), síntomas gastrointestinales entre los que se incluyen vómitos, reflujo gastroesofágico y diarrea (ANEXO II).

\subsubsection{Evaluación bioquímica}

Se determinaron los siguientes parámetros bioquímicos de la muestra sanguínea correspondiente a la primera consulta previa a la cirugía y de manera trimestral hasta los 12 meses, continuando cada 6 meses hasta los 24 meses de seguimiento postquirúrgico:

-Glucosa.

-Perfil lipídico: HDL-Colesterol, LDL-Colesterol, colesterol total y triglicéridos.

-Perfil hepático: GOT, GPT, GGT y fosfatasa alcalina.

-Perfil renal: ácido úrico, urea, creatinina.

-Metabolismo del hierro: hierro, ferritina. 
-Proteínas plasmáticas: proteínas totales y albúmina.

-Vitaminas* : ácido fólico, vitamina $\mathrm{B}_{12}$.

-lonograma: calcio y fósforo.

*Las determinaciones plasmáticas de vitaminas se llevaron a cabo desde el primer control postquirúrgico de los 3 meses.

Debido a la dispersión geográfica de los pacientes se dejó a su criterio la elección del laboratorio de análisis clínico para determinar la bioquímica sanguínea. Por ello se muestra en la tabla 3.4 los valores de referencia utilizados en la descripción de los resultados que corresponde a los del Laboratorio del Hospital Universitario Río Hortega de Valladolid.

\begin{tabular}{|c|c|}
\hline Parámetro & Valores de referencia \\
\hline Glucemia & $\begin{array}{c}74-115 \mathrm{mg} / \mathrm{dL} \\
\text { Colesterol total } \\
\text { III<200 } 20 \mathrm{mg} / \mathrm{dL}\end{array}$ \\
\hline HDL-Colesterol & $\begin{array}{c}\text { Recomendación ATP } \\
\text { III):40 }-60 \mathrm{mg} / \mathrm{dL}\end{array}$ \\
\hline LDL-Colesterol & $\begin{array}{c}\text { Recomendaciones ATP } \\
\text { III< } 100 \mathrm{mg} / \mathrm{dL}\end{array}$ \\
\hline Triglicéridos & $\begin{array}{c}\text { Recomendación ATPIII: } \\
<150 \mathrm{mg} / \mathrm{dL}\end{array}$ \\
\hline GOT & $0-50 \mathrm{U} / \mathrm{L}$ \\
\hline GPT & $1-50 \mathrm{U} / \mathrm{L}$ \\
\hline GGT & $0-55 \mathrm{U} / \mathrm{L}$ \\
\hline Fosfatasa alcalina & $30-120 \mathrm{U} / \mathrm{L}$ \\
\hline Ácido úrico & $2,6-7,2 \mathrm{mg} / \mathrm{dL}$ \\
\hline Urea & $10,7-49,2 \mathrm{mg} / \mathrm{dL}$ \\
\hline Creatinina & $0,6-1,3 \mathrm{mg} / \mathrm{dL}$ \\
\hline Hierro & $50-175 \mu \mathrm{g} / \mathrm{dL}$ \\
\hline Ferritina & $10-300 \mathrm{ng} / \mathrm{mL}$ \\
\hline Proteínas totales & $4,1-6,3 \mathrm{~g} / \mathrm{L}$ \\
\hline Albúmina & $3,5-5,2 \mathrm{~g} / \mathrm{L}$ \\
\hline Ácido fólico & $4,6-18,7 \mathrm{ng} / \mathrm{mL}$ \\
\hline Vitamina B 12 & $211-946 \mathrm{pg} / \mathrm{mL}$ \\
\hline Calcio & $8,6-10,2 \mathrm{mg} / \mathrm{dL}$ \\
\hline Fósforo & $2,3-4,2 \mathrm{mg} / \mathrm{dL}$ \\
\hline 3
\end{tabular}

Tabla 3.4. Parámetros bioquímicos de referencia. Laboratorio de Análisis Clínicos del Hospital Universitario Río Hortega, Valladolid. 


\subsection{Análisis estadístico}

Para la recogida de los datos se confeccionó una base de datos en el programa Excel (Microsoft Office 2007). Los datos fueron introducidos por una sola persona y revisados por un experto. Tras su depuración se analizaron utilizando el programa estadístico SPSS v. 15.0 (SPSS Inc. 1989-2006). La pérdida de valores superior al $15 \%$ en una determinada variable fue considerada como un posible sesgo del estudio.

Las variables cuantitativas se describieron como media \pm desviación estándar (DE) y su normalidad se estableció con la prueba de KolmogorovSmirnov. Por su parte, las variables cualitativas fueron descritas mediante frecuencias absolutas y relativas (porcentajes). Se calcularon los Intervalos de Confianza al 95\% (IC 95\%) de los parámetros obtenidos y se informa el porcentaje de valores perdidos. Finalmente, se utilizaron histogramas de frecuencia, barras de error o diagramas de cajas para representar las variables cuantitativas y gráficos de barras o de sectores para las cualitativas.

Para estudiar la asociación entre variables cualitativas se utilizó la prueba de Chi cuadrado con test exacto de Fisher o razón de verosimilitud, dependiendo de sus condiciones de aplicación. Para estudiar las diferencias entre medias se utilizó la prueba de la t de Student o la U de Mann-Whitney, dependiendo de las condiciones de aplicación, para 2 grupos, y el ANOVA o la $\mathrm{H}$ de Kruskal-Wallis, dependiendo asimismo de las condiciones de aplicación, para más de 2 grupos.

El nivel de significación para todas las pruebas se consideró para una $P$ $\leq 0,05$.

\subsection{Aspectos éticos}

Este trabajo se realizó siguiendo las recomendaciones de la Declaración de Helsinki de 1964 (última enmienda, 2013). Se cuenta con la aprobación de la Comisión de Investigación de la Facultad de Enfermería de Valladolid.

Se obtuvo el Consentimiento Informado para la participación en el estudio y para la obtención de muestras biológicas destinadas a la investigación (ANEXO I). 
No existe conflicto de intereses ni se dispone de financiación por organismos públicos o privados.

\subsection{Búsqueda bibliográfica}

http://www.ncbi.nlm.nih.gov/pubmed?otool=iesbscllib

Se realizó una búsqueda bibliográfica en la base de datos MEDLINE, uno de los componentes de PubMed, un recurso gratuito que es desarrollado y mantenido por el Centro Nacional de Información Biotecnológica (NCBI), en la Biblioteca Nacional de Medicina de Estados Unidos (NLM), ubicado en el Instituto Nacional de Salud (NIH).

La búsqueda inicial se planteó utilizando términos libres y la definitiva a través de términos MeSH, utilizando los operadores booleanos y los límites de tiempo (5 últimos años) e idioma (español e inglés), para confeccionar la estrategia más adecuada. Estos límites no han sido considerados para trabajos históricos de referencia.

Se ha completado con la consulta de libros de texto actualizados y la comunicación con expertos. 

obesos (ReCiMB) 


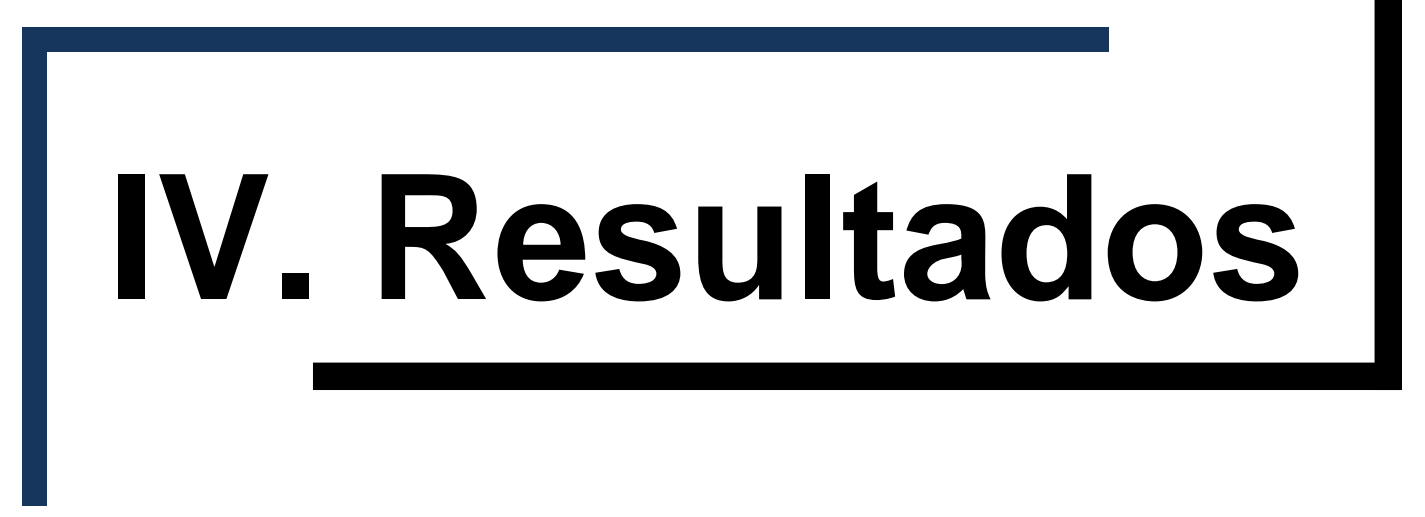


En el siguiente apartado se describen los resultados obtenidos del análisis de la muestra de pacientes obesos intervenidos de bypass gástrico de una sola anastomosis (BAGUA) desde el momento de la primera consulta hasta los 24 meses después de la cirugía según el sexo y por grupos de edad. Al comienzo se detallan las características generales de la muestra, hábitos alimentarios, antecedentes clínicos y quirúrgicos, hábitos tabáquico y consumo de alcohol, previos a la cirugía bariátrica. Posteriormente se analiza la preparación dietético-nutricional previa a la cirugía, las características propias del procedimiento quirúrgico y las variables utilizadas en la valoración de la pérdida ponderal y tipos de obesidad en los 2 años de seguimiento.

También se estudia la autovaloración del consumo alimentario postquirúrgico y la actividad física en los pacientes intervenidos. Finalmente se describe la evolución de las variables bioquímicas sanguíneas desde la primera consulta precirugía, hasta los 24 meses posteriores a la misma. 


\subsection{Características generales de la muestra}

\subsubsection{Sexo y edad}

La muestra estudiada está constituida por 100 pacientes intervenidos de BAGUA con seguimiento a 24 meses, de la cual 71 eran mujeres y 29 hombres.

La edad en ambos sexos se encuentra comprendida entre los 13 y 65 años. La edad media es de 42,61 $\pm 11,33$ años. La media de edad de las mujeres es de 42,56 \pm 11,02 años, y 42,72 \pm 12,25 años en los hombres. Entre ambos sexos no se observan diferencias estadísticamente significativas respecto a la edad. En la figura 4.1.1 se muestra la distribución normal de la edad mediante un histograma.

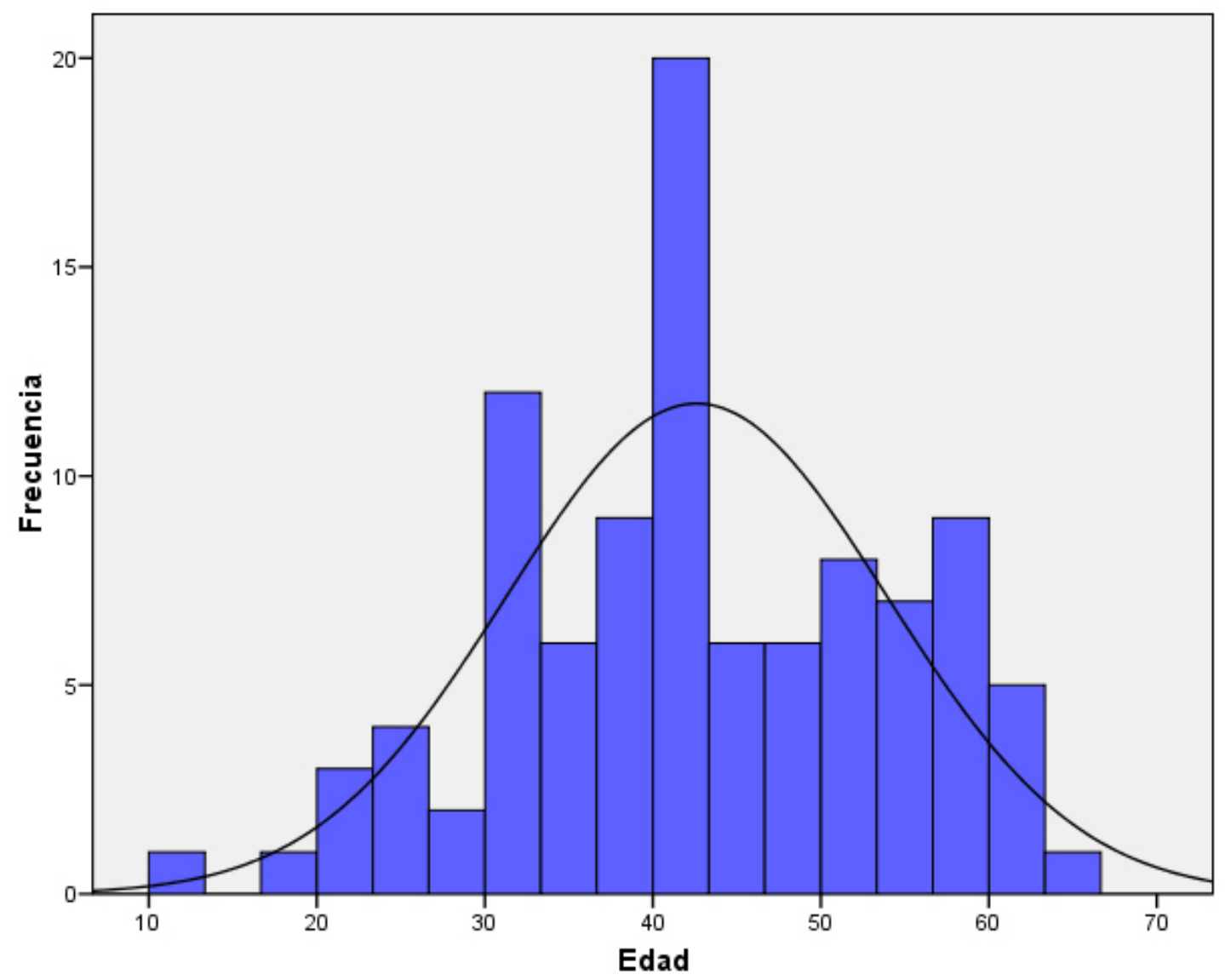

Figura 4.1.1. Descripción de la edad de la muestra estudiada 
Tomando como referencia la edad de 42 años por ser el percentil 50, se agrupó a la muestra en 2 grupos etarios: $<42$ años (48\% de la muestra) y $\geq$ 42 años (52\% de la muestra).

El número de pacientes varones y mujeres en cada uno de los grupos de edad estudiado es homogéneo, como se describe en la tabla 4.1.1.

\begin{tabular}{|c|c|c|c|c|c|}
\hline & & & \multicolumn{2}{|c|}{ Grupos de edad } & \multirow{2}{*}{ Total } \\
\hline & & & $<42$ años & $\geq$ 42años & \\
\hline \multirow{2}{*}{ Sexo } & Mujer & $\%$ de sexo $(\mathrm{N})$ & $\begin{array}{c}49,3 \% \\
(35)\end{array}$ & $\begin{array}{c}50,7 \% \\
(36)\end{array}$ & $\begin{array}{c}100 \% \\
(71)\end{array}$ \\
\hline & Hombre & $\%$ de sexo $(\mathrm{N})$ & $\begin{array}{c}44,8 \% \\
(13)\end{array}$ & $\begin{array}{c}52,2 \% \\
(16)\end{array}$ & $\begin{array}{c}100 \% \\
(29)\end{array}$ \\
\hline Total & \multicolumn{2}{|c|}{$\%$ de sexo $(\mathrm{N})$} & $\begin{array}{l}48 \% \\
(48)\end{array}$ & $\begin{array}{l}52 \% \\
(52)\end{array}$ & $\begin{array}{l}100 \% \\
(100)\end{array}$ \\
\hline \multicolumn{6}{|r|}{$P>0,05$} \\
\hline
\end{tabular}

Tabla 4.1.1. Clasificación de la muestra por grupos de edad y sexo

\subsubsection{País de nacimiento}

El origen de nacimiento de todos los pacientes de la muestra sometidos a estudio fue España. En la figura 4.1.2 a página completa, se detalla por Comunidades Autónomas (CCAA) la procedencia de los pacientes intervenidos. Las tres CCAA con más proporción de pacientes fueron País Vasco, seguido de Cantabria y Andalucía. 


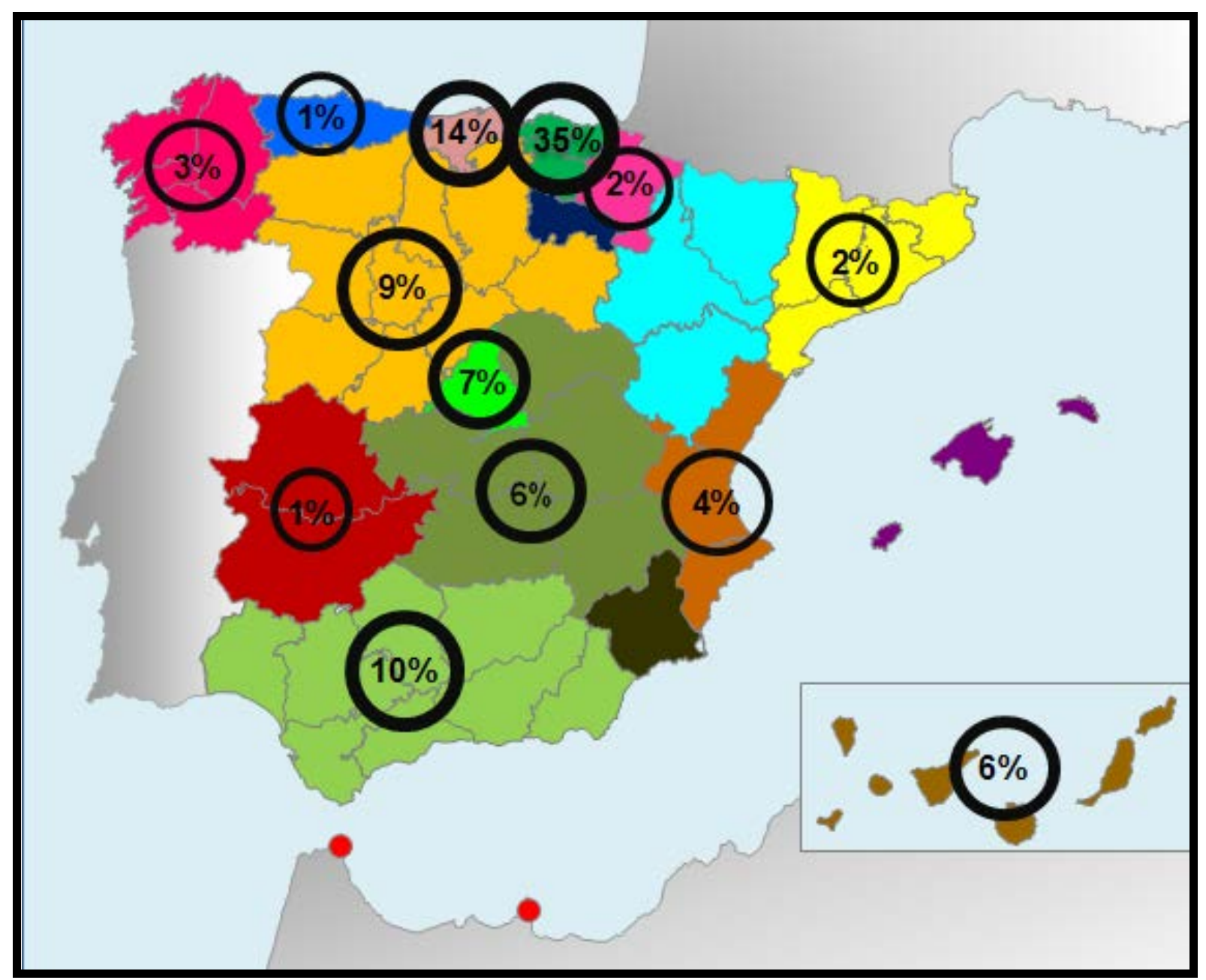

Figura 4.1.2. Distribución de los pacientes intervenidos por CCAA de origen 


\subsubsection{Ocupación profesional}

Se tomó como referencia la clasificación nacional de ocupaciones desarrollada por el Servicio Nacional de Aprendizaje y Dirección de Empleo dependiente del Ministerio de Trabajo y Seguridad Social (ANEXO III) como se muestra en la figura 4.1.3. También se describe el porcentaje de pacientes estudiantes que no desempeñaban actividad profesional remunerada.

Existen diferencias significativas entre ambos sexos $(P<0,001)$ respecto a la ocupación profesional desempeñada. Destacando un 20,7\% de los varones en el sector de "Ciencias naturales aplicadas y relacionadas" y ninguna mujer. Por el contrario en el sector "Arte, cultura, recreación y deporte" sólo hay mujeres, constituyendo el $36,6 \%$ de las mujeres de la muestra este sector profesional. En el sector "oficios, operadores de equipos y transporte" no hay mujeres, forman este sector el $24,1 \%$ de los varones de la muestra. 


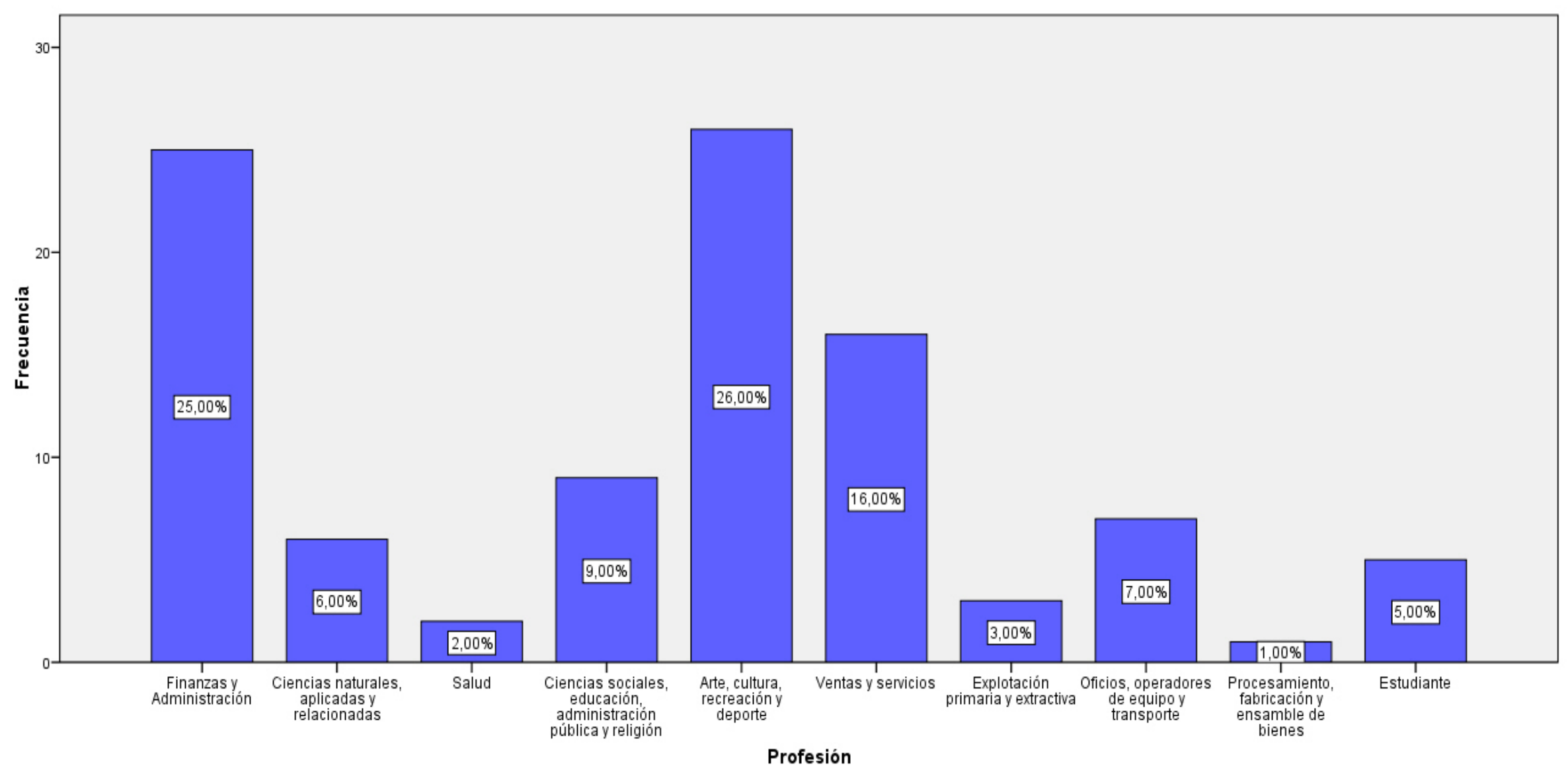

Figura 4.1.3. Ocupación profesional de la muestra estudiada 
En la clasificación de las diferentes ocupaciones profesionales por grupos de edad, sí se observan diferencias estadísticamente significativas $(P<0,001)$. Destacando un $37,5 \%$ del grupo de pacientes $<42$ años en el sector de "Finanzas y administración", y un 40,4\% de pacientes del grupo de $\geq 42$ años en el sector "Arte, cultura, recreación y deporte". Tabla 4.1.2.

\begin{tabular}{|c|c|c|c|}
\hline \multirow{3}{*}{ Profesión } & \multicolumn{2}{|c|}{ Grupos de edad } & \multirow{3}{*}{$\begin{array}{l}\text { \% de grupo } \\
\text { de edad } \\
(\mathrm{N})\end{array}$} \\
\hline & \multirow{2}{*}{\begin{tabular}{|c}
$<42$ años \\
$\%$ de \\
grupo de \\
edad $(N)$
\end{tabular}} & \multirow{2}{*}{$\begin{array}{c}\begin{array}{c}\geq 42 \\
\text { años }\end{array} \\
\text { \% de } \\
\text { grupo de } \\
\text { edad }(\mathrm{N})\end{array}$} & \\
\hline & & & \\
\hline Finanzas y Administración & $\begin{array}{c}37,5 \% \\
(18)\end{array}$ & $\begin{array}{l}13,5 \% \\
(7)\end{array}$ & $\begin{array}{l}25 \% \\
(25)\end{array}$ \\
\hline $\begin{array}{l}\text { Ciencias naturales, aplicadas y } \\
\text { relacionadas }\end{array}$ & $\begin{array}{c}4,2 \% \\
(2)\end{array}$ & $\begin{array}{c}7,7 \% \\
(4)\end{array}$ & $\begin{array}{l}6 \% \\
(6)\end{array}$ \\
\hline Salud & $\begin{array}{c}4,2 \% \\
(2)\end{array}$ & - & $\begin{array}{l}2 \% \\
(2)\end{array}$ \\
\hline $\begin{array}{l}\text { Ciencias sociales, educación, } \\
\text { administración pública y religión }\end{array}$ & $\begin{array}{l}8,3 \% \\
(4)\end{array}$ & $\begin{array}{c}9,6 \% \\
(5)\end{array}$ & $\begin{array}{l}9 \% \\
(9)\end{array}$ \\
\hline Arte, cultura, recreación y deporte & $\begin{array}{l}10,4 \% \\
(5)\end{array}$ & $\begin{array}{c}40,4 \% \\
(21)\end{array}$ & $\begin{array}{l}26 \% \\
(26)\end{array}$ \\
\hline Ventas y servicios & $\begin{array}{l}18,8 \% \\
(9)\end{array}$ & $\begin{array}{l}13,5 \% \\
(7)\end{array}$ & $\begin{array}{l}16 \% \\
(16)\end{array}$ \\
\hline Explotación primaria y extractiva & $\begin{array}{c}2,1 \% \\
(1)\end{array}$ & $\begin{array}{c}3,8 \% \\
(2)\end{array}$ & $\begin{array}{l}3 \% \\
(3)\end{array}$ \\
\hline $\begin{array}{l}\text { Oficios, operadores de equipo y } \\
\text { transporte }\end{array}$ & $\begin{array}{l}4,2 \% \\
(2)\end{array}$ & $\begin{array}{l}9,6 \% \\
(5)\end{array}$ & $\begin{array}{l}7 \% \\
(7)\end{array}$ \\
\hline $\begin{array}{l}\text { Procesamiento, fabricación y } \\
\text { ensamble de bienes }\end{array}$ & - & $\begin{array}{c}1,9 \% \\
(1)\end{array}$ & $\begin{array}{l}1 \% \\
(1)\end{array}$ \\
\hline Estudiante & $\begin{array}{l}10,4 \% \\
(5)\end{array}$ & - & $\begin{array}{l}5 \% \\
(5)\end{array}$ \\
\hline Total & $\begin{array}{c}100 \% \\
(48)\end{array}$ & $\begin{array}{c}100 \% \\
(52)\end{array}$ & $\begin{array}{l}100 \% \\
(100)\end{array}$ \\
\hline & & & $P<0,001$ \\
\hline
\end{tabular}

Tabla 4.1.2. Clasificación de las diferentes ocupaciones profesionales por grupos de edad

\subsubsection{Estado civil}

En el estado civil de la muestra se observa un $77 \%$ de los pacientes casados, el $20 \%$ solteros, y el $3 \%$ viudos. Las diferencias en el estado civil respecto al sexo no fueron estadísticamente significativas $(P=0,13)$. En la tabla 4.1.3 se describe el estado civil de la muestra según el sexo. 


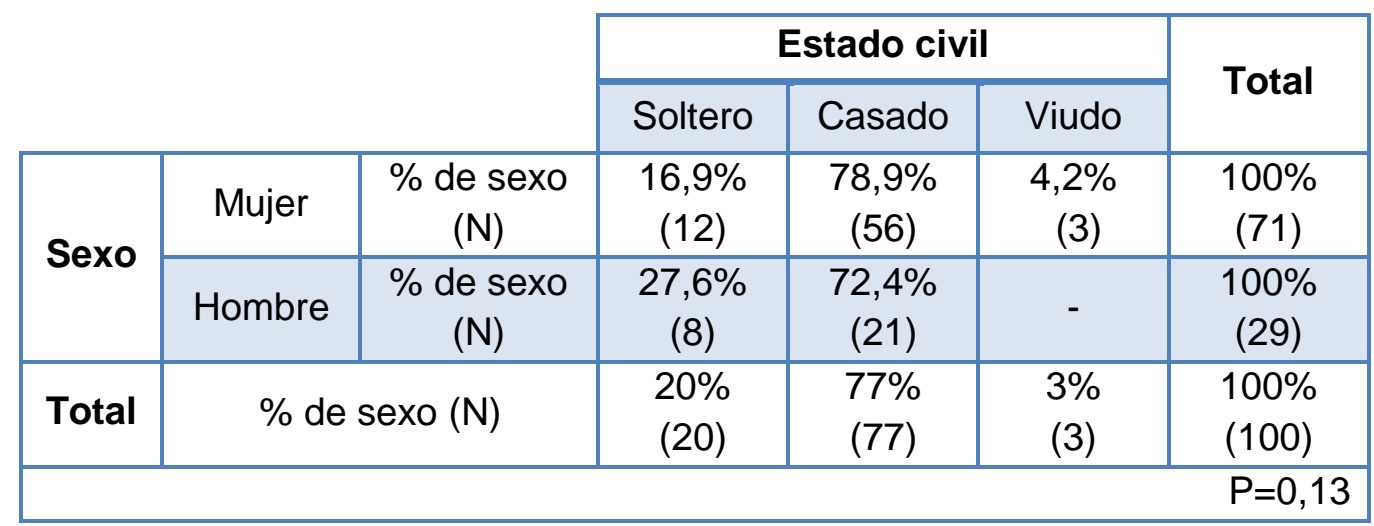

Tabla 4.1.3. Estado civil de la muestra según el sexo

Al agrupar a la muestra por grupos de edad, se observan diferencias estadísticamente significativas $(P=0,004)$ entre los pacientes solteros, casados y viudos (tabla 4.1.4). En el grupo de $<42$ años y el de los $\geq 42$ años, predominan los pacientes casados, constituyendo el 77\% del total de los pacientes. Se observa un mayor número de pacientes solteros en el grupo de menos edad ( $15 \%$ de la muestra), que en el grupo de los $\geq 42$ años (5\% de la muestra).

\begin{tabular}{|c|c|c|c|c|c|c|}
\hline & & & \multicolumn{3}{|c|}{ Estado civil } & \multirow{2}{*}{ Total } \\
\hline & & & Soltero & Casado & Viudo & \\
\hline \multirow{2}{*}{$\begin{array}{l}\text { Grupos } \\
\text { de edad }\end{array}$} & $<42$ años & $\begin{array}{c}\% \text { de } \\
\text { grupo de } \\
\text { edad }(\mathrm{N})\end{array}$ & $\begin{array}{c}31,3 \% \\
(15)\end{array}$ & $\begin{array}{c}68,8 \% \\
(33)\end{array}$ & - & $\begin{array}{c}100 \% \\
(48)\end{array}$ \\
\hline & 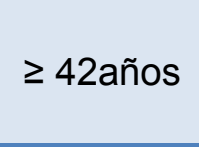 & $\begin{array}{c}\% \text { de } \\
\text { grupo de } \\
\text { edad }(\mathrm{N})\end{array}$ & $9,6 \%(5)$ & $\begin{array}{c}84,6 \% \\
(44)\end{array}$ & $\begin{array}{c}5,8 \% \\
(3)\end{array}$ & $\begin{array}{c}100 \% \\
(52)\end{array}$ \\
\hline \multicolumn{2}{|c|}{ Total } & $\begin{array}{c}\% \text { de } \\
\text { grupo de } \\
\text { edad }(\mathrm{N})\end{array}$ & $\begin{array}{l}20 \% \\
(20)\end{array}$ & $\begin{array}{l}77 \% \\
(77)\end{array}$ & $\begin{array}{l}3 \% \\
(3)\end{array}$ & $\begin{array}{l}100 \% \\
(100)\end{array}$ \\
\hline
\end{tabular}

Tabla 4.1.4. Estado civil de la muestra clasificada por grupos de edad

\subsubsection{Número de hijos y embarazo}

El 60\% de la muestra contestó que tenían uno o más hijos. De esos 60 pacientes que contestaron si tenían hijos, 48 eran mujeres $(67,6 \%)$ y 12 $(41,4 \%)$ hombres $(P=0,015)$. De las mujeres que tienen hijos, se observa 
una tendencia a tener más hijos en edades superiores de los 40 años: 21 mujeres $(43,75 \%)<42$ años, y 27 mujeres $(56,25 \%) \geq 42$ años.

Se estudió la frecuencia en el número de hijos de las mujeres de la muestra estudiada. Clasificándolas por grupos, si tuvieron: uno, dos o tres hijos, como se detalla en la figura 4.1.4.

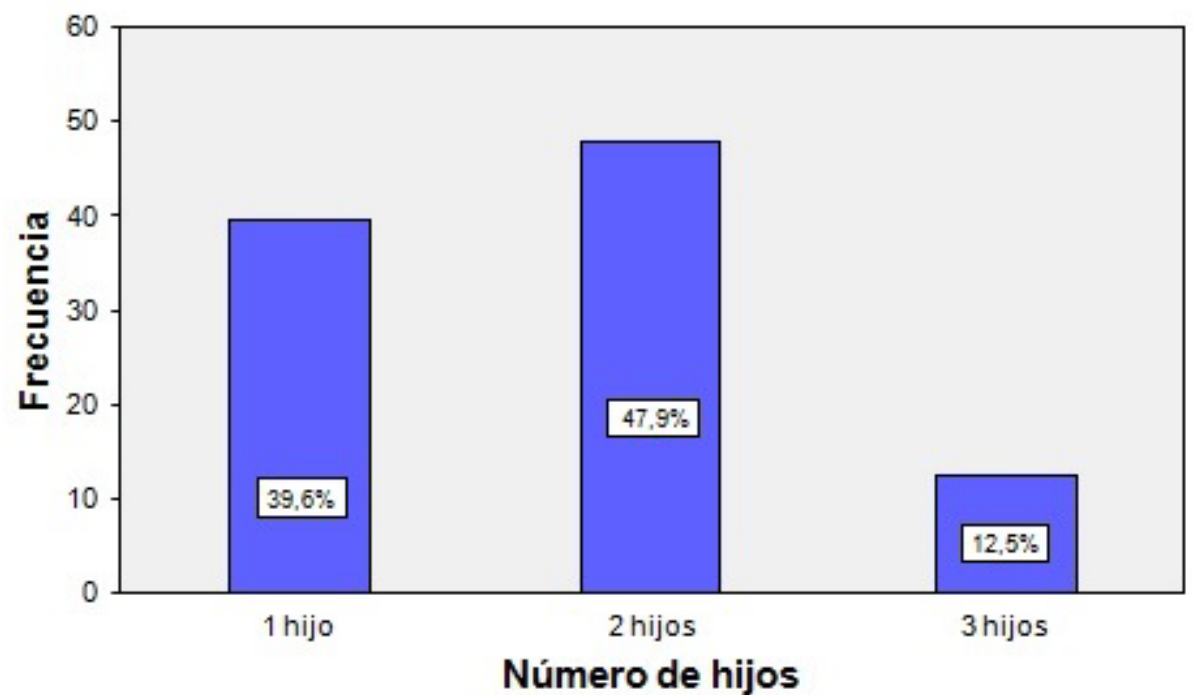

Figura 4.1.4. Distribución por número de hijos de las mujeres de la muestra

En la tabla 4.1.5, se clasifica a las mujeres por el número de hijos que han tenido según el grupo de edad, observando diferencias estadísticamente significativas $(P<0,05)$, predominando en el grupo de $<42$ años, las mujeres con un solo hijo $(66,7 \%)$ y en el grupo de $\geq 42$ años las mujeres con 2 hijos (59,3\%).

\begin{tabular}{|c|c|c|c|c|c|c|}
\hline & & & \multicolumn{3}{|c|}{ Número de hijos } & \multirow{2}{*}{ Total } \\
\hline & & & Uno & Dos & Tres & \\
\hline \multirow{2}{*}{$\begin{array}{l}\text { Grupos } \\
\text { de edad }\end{array}$} & $<42$ años & $\begin{array}{c}\% \text { de } \\
\text { grupo de } \\
\text { edad (N) }\end{array}$ & $\begin{array}{c}66,7 \% \\
(14)\end{array}$ & $\begin{array}{c}33,3 \% \\
(7)\end{array}$ & - & $\begin{array}{c}100 \% \\
(21)\end{array}$ \\
\hline & $\geq$ 42años & $\begin{array}{c}\% \text { de } \\
\text { grupo de } \\
\text { edad }(\mathrm{N})\end{array}$ & $\begin{array}{c}18,5 \% \\
(5)\end{array}$ & $\begin{array}{c}59,3 \% \\
(16)\end{array}$ & $\begin{array}{c}22,2 \% \\
(6)\end{array}$ & $\begin{array}{c}100 \% \\
(27)\end{array}$ \\
\hline \multicolumn{2}{|c|}{ Total } & $\begin{array}{c}\% \text { de } \\
\text { grupo de } \\
\text { edad }(\mathrm{N})\end{array}$ & $\begin{array}{c}39,6 \% \\
(19)\end{array}$ & $\begin{array}{c}47,9 \% \\
(23)\end{array}$ & $\begin{array}{c}12,5 \% \\
(6)\end{array}$ & $\begin{array}{c}100 \% \\
(48)\end{array}$ \\
\hline
\end{tabular}

Tabla 4.1.5. Número de hijos de las mujeres por grupo de edad 
De las 48 mujeres que tenían hijos, se estudiaron a aquellas a las que se les realizó el parto por cesárea, puesto que la técnica obstétrica se realiza por laparotomía y es de interés conocerlo para el abordaje quirúrgico en la cirugía bariátrica (figura 4.1.5). De las 48 mujeres, el 50\% tuvo un parto vaginal, seguido del 31,3\% de cesáreas horizontales.

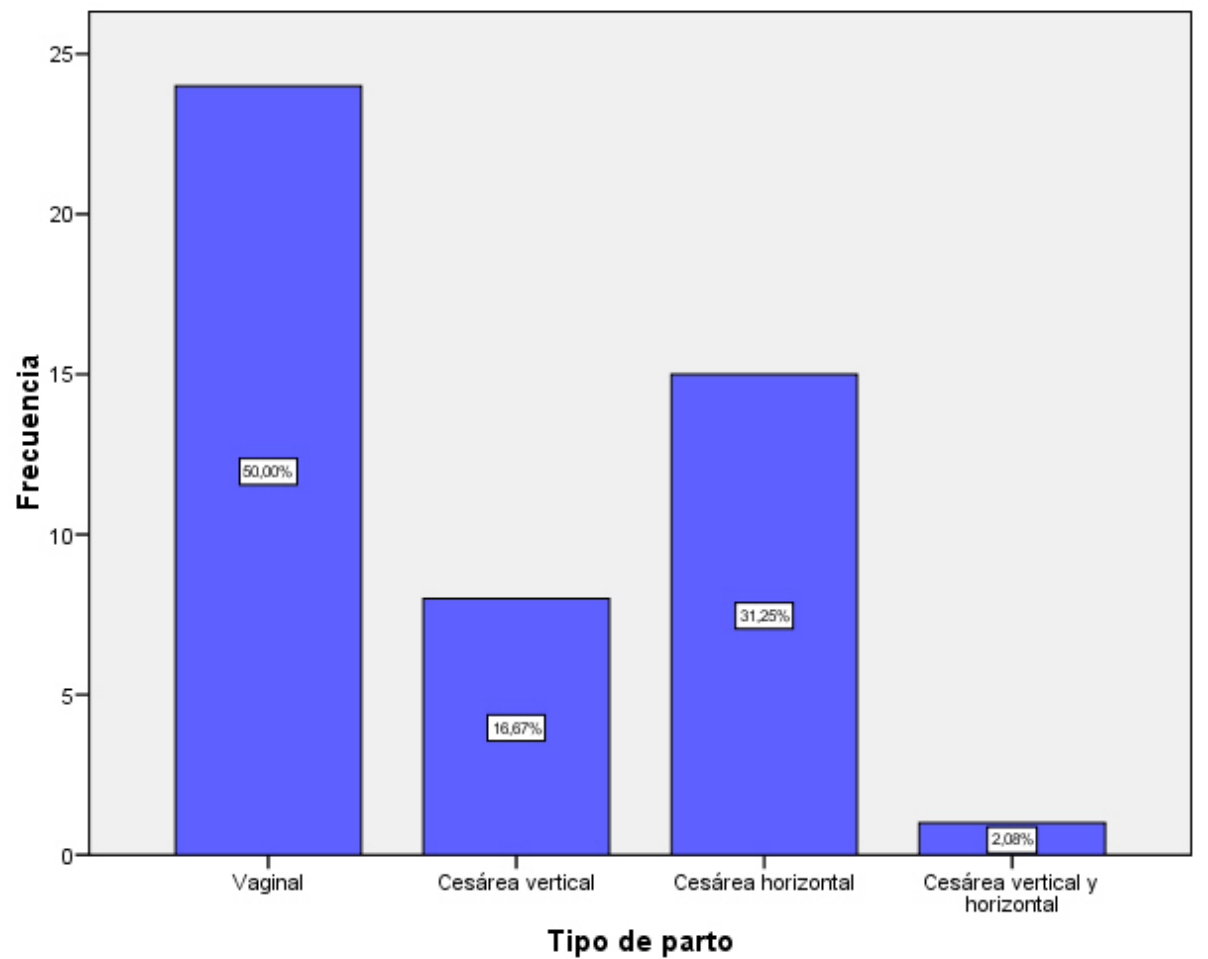

Figura 4.1.5. Clasificación según el tipo de parto de las mujeres con hijos

\subsubsection{Origen de la obesidad}

A los pacientes sometidos a estudio se les preguntó si asociaron algún momento de su periodo de crecimiento o proceso concreto de su vida que fuera el desencadenante en la ganancia ponderal descontrolada como origen de la obesidad que padecían. El resultado expresado por los pacientes de la muestra según el sexo se detalla en la tabla 4.1.6, siendo estadísticamente significativa $(P<0,001)$ la diferencia en el origen de la obesidad respecto al sexo. Observando que 56,33\% de las mujeres asociaron el embarazo con el origen de su obesidad, en cambio en los varones predomina un origen de la obesidad en la etapa de la adolescencia. 


\begin{tabular}{|c|c|c|c|c|c|c|c|}
\hline & \multicolumn{4}{|c|}{ Origen de la obesidad } & \multirow[b]{2}{*}{ Total } \\
\hline & & & Infancia & Adolescencia & Embarazo & $\begin{array}{c}\text { Cirugías } \\
\text { previas }\end{array}$ & \\
\hline \multirow{2}{*}{ Sexo } & Mujer & $\begin{array}{c}\% \text { de } \\
\text { sexo } \\
(\mathrm{N})\end{array}$ & $\begin{array}{c}22,53 \% \\
(16)\end{array}$ & $\begin{array}{c}16,90 \% \\
(12)\end{array}$ & $\begin{array}{c}56,33 \% \\
\quad(40)\end{array}$ & $\begin{array}{c}4,22 \% \\
(3)\end{array}$ & $\begin{array}{c}100 \% \\
(71)\end{array}$ \\
\hline & Hombre & $\begin{array}{c}\% \text { de } \\
\text { sexo } \\
(\mathrm{N})\end{array}$ & $\begin{array}{c}41,37 \% \\
(12)\end{array}$ & $\begin{array}{c}51,72 \% \\
(15)\end{array}$ & - & $\begin{array}{c}6,89 \% \\
(2)\end{array}$ & $\begin{array}{c}100 \% \\
(29)\end{array}$ \\
\hline Total & \multicolumn{2}{|c|}{$\%$ de sexo $(\mathrm{N})$} & $\begin{array}{l}28 \% \\
(28) \\
\end{array}$ & $\begin{array}{l}27 \% \\
(27) \\
\end{array}$ & $\begin{array}{l}40 \% \\
(40) \\
\end{array}$ & $\begin{array}{l}5 \% \\
(5)\end{array}$ & $\begin{array}{l}100 \% \\
(100) \\
\end{array}$ \\
\hline & & & & & & & $<0,001$ \\
\hline
\end{tabular}

Tabla 4.1.6. Origen de la obesidad de la muestra según el sexo

Al diferenciar a los pacientes por la mediana de la edad de la muestra, la distribución en el grupo de $<42$ años con respecto al de $\geq 42$ años no presenta diferencias estadísticamente significativas siguiendo una distribución casi idéntica en ambos grupos, siendo las cirugías previas al BAGUA la causa del origen de la obesidad la menos frecuente.

\subsubsection{Clasificación de la muestra según la SEEDO}

De los 100 pacientes obesos que componen la muestra se han clasificado por grupos de IMC según las definiciones de la SEEDO 2007, tomando como referencia el peso prequirúrgico, como se muestra en la figura 4.1.6. 


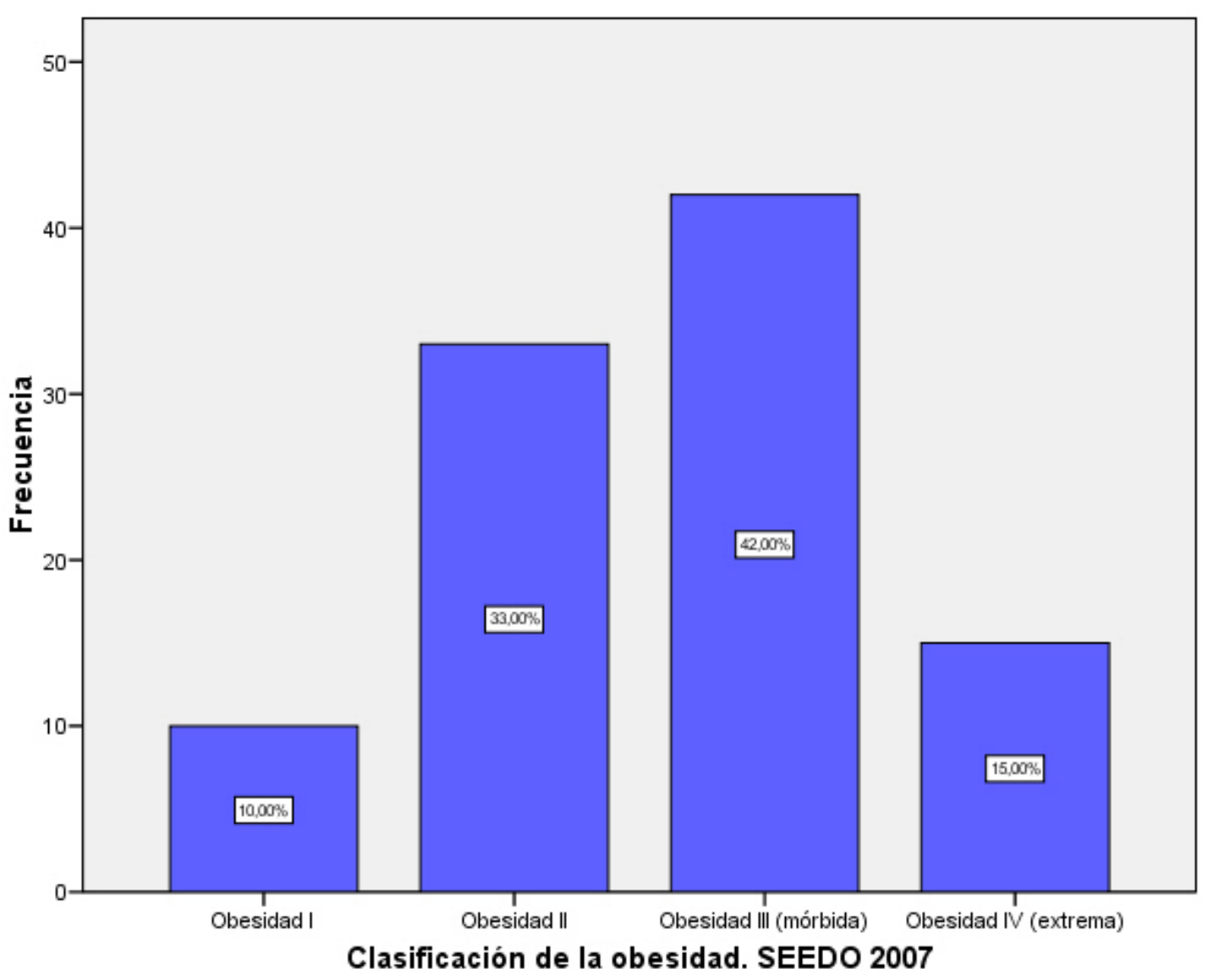

Figura 4.1.6. Clasificación de la muestra según el IMC prequirúrgico. SEEDO 2007

No existen diferencias estadísticamente significativas entre los diferentes grupos de clasificación de la obesidad según la SEEDO 2007, presentando un $42 \%$ de los pacientes antes de la cirugía de BAGUA una obesidad III o mórbida $(\mathrm{IMC}>40 \leq 49,9)$.

En relación al sexo tampoco se evidencian diferencias significativas entre los diferentes grupos de clasificación de la obesidad, pero sí se observa una mayoría de las mujeres con obesidad tipo II y III. Tampoco se observan diferencias significativas al agrupar los pacientes con obesidad tipo I y II y contrastarles estadísticamente con el conjunto de pacientes de obesidad III y IV según el sexo.

La clasificación de los pacientes por grupos de edad tampoco muestra diferencias estadísticamente significativas y en los cuatro tipos de obesidad se aprecia prácticamente por igual la distribución de los pacientes. Aunque en el grupo de obesos mórbidos, se observa una mayor concentración de 
pacientes $\geq 42$ años $(25 \%$ de la muestra), que $<42$ años $(17 \%$ de la muestra).

\subsubsection{Hábito en la conducta alimentaria}

En la primera consulta, tomando como referencia las recomendaciones de la International Federation for the Surgery of Obesity and Metabolic Disorders (IFSO), se determinó la preferencia de los pacientes en los siguientes patrones de consumo alimentario:

-Goloso, preferencia por alimentos con alto contenido en azúcares de rápida absorción.

-Picoteador, consumo de pequeñas cantidades de manera reiterada durante todo el día.

-Comilón, consumo de gran cantidad de alimentos en las tres principales comidas del día (desayuno, comida y cena).

-Comilón emocional, cuando el paciente expresa un deseo insaciable de comer que tiene que ser correspondido para calmar la ansiedad.

Un mismo paciente podía pertenecer a más de uno de los criterios de clasificación.

\section{-Goloso.}

El 73\% de los pacientes presentaba este tipo de conducta alimentaria, el $27 \%$ no. En referencia al sexo, se muestra una mayor afinidad a este comportamiento en el grupo de las mujeres (Recuento: 55. Porcentaje del sexo: $77,5 \%$ ) con respecto al de los hombres (Recuento: 18. Porcentaje del sexo: $62,1 \%$ ) sin ser estadísticamente significativo.

Por grupos de edad tampoco se muestran diferencias estadísticamente significativas, observando un menor número de pacientes en el grupo de $<42$ años (Recuento: 33. Porcentaje del grupo de edad: $68,8 \%$ ), respecto de los $\geq 42$ años (Recuento: 40 . Porcentaje del grupo de edad: $76,9 \%)$. 


\section{-Picoteador.}

El $77 \%$ era picoteador respecto al 23\% que no lo era. En relación al sexo se muestra como la mayoría de mujeres de la muestra picotean (Recuento: 57. Porcentaje del sexo: 80,3\%), en comparación con los hombres (Recuento: 20. Porcentaje del sexo: 69\%)

Al comparar los dos grupos de edad, la distribución de pacientes picoteadores es casi idéntica, 38 pacientes $<42$ años $(79,2 \%)$ y 39 pacientes $\geq 42$ años (75\%).

\section{-Comilón.}

Es el hábito alimentario más repetido entre los pacientes estudiados, afirmando este tipo de conducta el $90 \%$ de los pacientes evaluados.

Al observar este patrón por sexos, no se aprecian diferencias relevantes: en el grupo de las mujeres (Recuento: 63. Porcentaje del sexo: 88,7\%) ni en el de los hombres (Recuento: 27. Porcentaje del sexo: 93,1\%\%). Por grupos de edad el porcentaje de pacientes en cada uno de los grupos es prácticamente el mismo: 43 pacientes en el grupo de los < 42 años (89,6\%), y 47 pacientes en el grupo de $\geq 42$ años $(90,4 \%)$.

\section{-Comilón emocional.}

El $36 \%$ de los pacientes manifestaba esta conducta. Sin ser estadísticamente significativo, se aprecia un mayor número de las mujeres con este comportamiento (Recuento: 28. Porcentaje del sexo: $39,4 \%$ ) que en el grupo de los hombres (Recuento: 8. Porcentaje del sexo: 27,6\%). Por grupos de edad no se observan diferencias, describiendo a 18 pacientes < 42 años $(37,5 \%)$ y otros 18 pacientes $\geq 42$ años $(36,4 \%)$.

Se midió la presencia de uno, dos, tres o los cuatro patrones alimentarios en los pacientes estudiados, dando lugar a la distribución que se muestra en la figura 4.1.7. El 41\% de la muestra tiene 3 de estos hábitos, siendo ésta la frecuencia en hábitos alimentarios más repetida. 


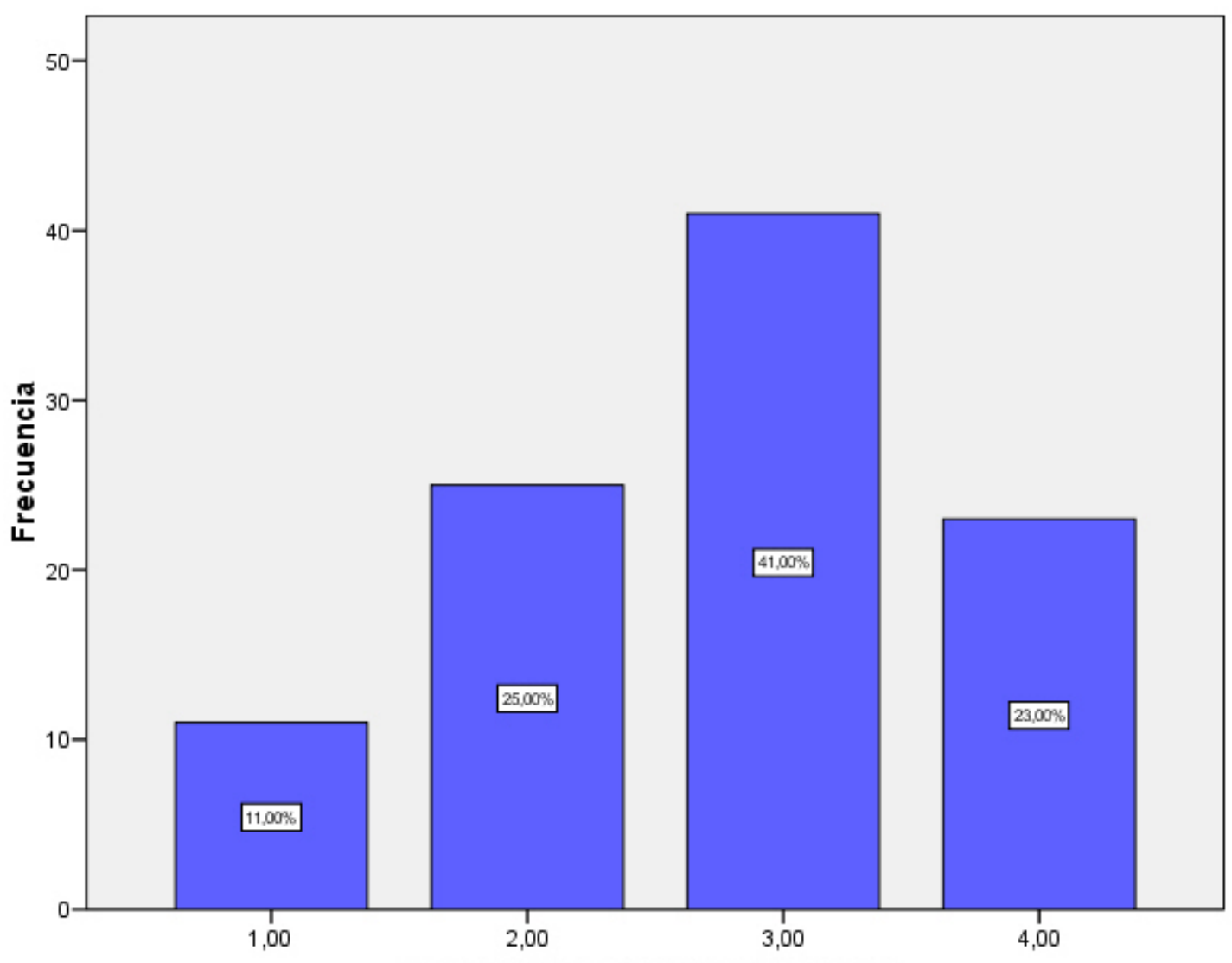

Habitos en el consumo alimentario

Figura 4.1.7. Distribución del consumo de alimentario por la frecuencia de hábitos

Por sexos se aprecia como las mujeres presentan una mayor frecuencia simultánea de estos hábitos alimentarios observando 2,85 $\pm 0,91$, a diferencia del grupo de los hombres con 2,51 $\pm 0,94$, sin ser esta una diferencia significativa estadísticamente.

Del mismo modo, al estudiar lo mismo por grupos de edad no se observan diferencias significativas en la frecuencia simultánea de estos hábitos alimentarios.

En la relación entre el número de hábitos alimentarios que tenían los pacientes respecto al sexo, la presencia de 3 de esos hábitos alimentarios de manera simultánea, es el más repetido en ambos sexos.

La distribución de los pacientes según la presencia de 1, 2, 3 o los 4 hábitos alimentarios según el sexo, se muestra en la figura 4.1.8. Se aprecia un mayor porcentaje de varones con 1, 2 o 3 hábitos simultáneos, en cambio es mayor el porcentaje de mujeres con 4 de estos patrones alimentarios. 


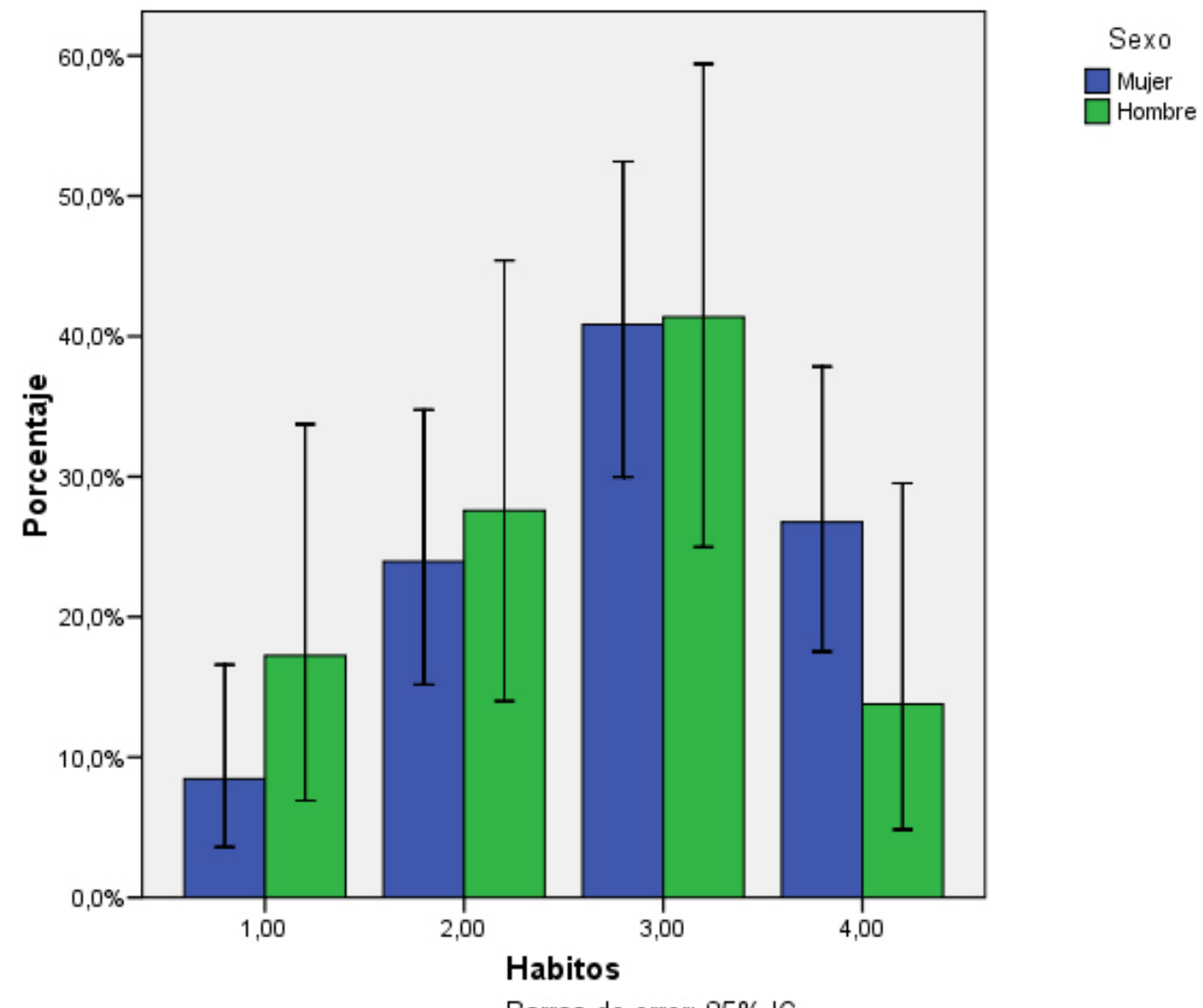

Barras de error: $95 \%$ IC

Figura 4.1.8. Distribución porcentual respecto al sexo por frecuencia de hábitos alimentarios 


\subsection{Antecedentes clínicos de la muestra}

En este apartado se describirá la prevalencia de las comorbilidades que sufren los pacientes de la muestra estudiada.

\section{- Obesidad troncal}

El $70 \%$ de los pacientes presentaba obesidad troncal, 19 de ellos eran mujeres $(26,8 \%)$ y 11 hombres $(37,9 \%)$. Por grupos de edad, se aprecia un mayor número de pacientes con obesidad troncal en el grupo de $\geq 42$ años (Recuento: 21. Porcentaje del grupo de edad: 40,4\%) que en el grupo de < 42 años (Recuento: 9 pacientes. Porcentaje del grupo de edad: 18,8\%). $\mathrm{P}=0,018$

\section{- Megaestómago}

En el $77 \%$ de los pacientes se observó un estómago que superaba las dimensiones normales. Respecto al sexo sí se observan diferencias estadísticamente significativas, siendo mayor el número de las mujeres con megaestómago (Recuento: 61. Porcentaje del sexo: 85,9\%), respecto a los hombres (Recuento 16. Porcentaje del sexo: 55,2\%). $P=0,001$.

Por grupos de edad la distribución en la presencia de megaestómago es homogénea y no se observan grandes diferencias; 35 pacientes $<42$ años $(72,9 \%)$ y 42 pacientes $\geq 42$ años $(80,8 \%)$.

\section{- Enfermedad tiroidea}

Sólo se aprecia un 9\% de los pacientes con patología tiroidea previa a la cirugía bariátrica. En función del sexo es notable la diferencia $(P<0,05)$, siendo en total 9 mujeres $(12,7 \%)$.

Por grupos de edad, las 9 mujeres se dividen en los dos grupos prácticamente de la misma forma. En el grupo de $<42$ años se describen 5 mujeres $(10,4 \%)$, y en el grupo de $\geq 42$ años a 4 mujeres $(7,7 \%)$.

\section{- Artropatías}

El 88\% de los pacientes padecían alguna artropatía. En función del sexo, las mujeres muestran una mayor tendencia a sufrir artropatías (Recuento: 
65. Porcentaje del sexo: 91,5\%) respecto a los hombres (Recuento: 23. Porcentaje del sexo: $79,3 \%)$.

La distribución de pacientes con patología articular en función de la edad no es estadísticamente significativa, observándose en 42 pacientes de los < 42 años $(87,5 \%)$, y en 46 de los $\geq 42$ años $(88,5 \%)$.

- Enfermedad vascular periférica. Varices

El $40 \%$ de los pacientes presentaba enfermedad vascular periférica previa a la cirugía. Se observa una mayor frecuencia de varices en las mujeres (Recuento: 30. Porcentaje del sexo: 42,3\%), que en los hombres (Recuento: 10. Porcentaje del sexo: 34,5\%).

Se describe una mayor presencia de pacientes con varices en el grupo de mayor edad: 17 pacientes de < 42 años $(35,4 \%)$ sufría de varices, y 23 de los pacientes de $\geq 42$ años $(44,2 \%)$.

\section{- Dislipemia}

El 68\% de los pacientes presentaba alterado alguno de los parámetros que definen el perfil lipídico. En ambos sexos la distribución era homogénea, 49 mujeres (69\%) y 19 hombres $(65,5 \%)$.

Por grupos de edad, en las personas más jóvenes se observa un menor porcentaje en la alteración del patrón lipídico: 29 pacientes < 42 años $(60,4 \%)$, y 39 pacientes $\geq 42$ años $(75 \%)$.

De los pacientes con alguno de los parámetros del perfil lipídico alterados, 25 de ellos $(36,76 \%)$ estaba en tratamiento con hipolipemieantes.

\section{- Esteatosis hepática}

El $81 \%$ de los pacientes estaba diagnosticado de esteatosis hepática antes de la cirugía de BAGUA. La distribución de esta patología es prácticamente igual en relación al sexo, observándose en 57 mujeres $(80,3 \%)$, y en 24 hombres $(82,8 \%)$.

Del mismo modo se observa por grupos de edad, siendo mínima la diferencia entre grupos. 39 pacientes $<42$ años (81,3\%), y 42 pacientes $\geq 42$ años (80,8\%), padecían esteatosis hepática. 


\section{- Reflujo gastroesofágico}

Se observó reflujo gastroesofágico previamente a la cirugía bariátrica en el $53 \%$ de los pacientes. Las diferencias por sexos fueros estadísticamente significativas $(P<0,05), 42$ mujeres lo padecían $(59,2 \%)$ y 11 varones $(37,9 \%)$.

Por grupos de edad no se muestran diferencias estadísticamente significativas pero sí existe una mayor tendencia en la presencia de reflujo en el grupo de $\geq 42$ años (31 pacientes. 59,6\%), que en el de los $<42$ años (22 pacientes. $45,8 \%$ ).

\section{- Hernia hiatal}

El $61 \%$ de los pacientes presentaba hernia hiatal. Describiendo un porcentaje homogéneo respecto al sexo; representando el $62 \%$ de los pacientes con hernia hiatal en el grupo de las mujeres (Recuento: 44), y el $58,6 \%$ en el grupo de los hombres (Recuento: 17 ).

En cuanto a la mediana de edad de la muestra, no se observa un mayor número de esta patología por pertenecer a un grupo de edad u otro. Describiendo a 30 pacientes $<42$ años $(62,5 \%)$ y a 31 pacientes $\geq 42$ años $(59,6 \%)$.

\section{- Colelitiasis}

Tan solo el 14\% de los pacientes manifiesta padecer colelitiasis, y todos ellos son mujeres. No se observa a ningún varón con colelitiasis. $(P=0,009)$.

Por grupos de edad la distribución es homogénea, 5 mujeres $<42$ años $(10,4 \%)$ y 9 mujeres $\geq 42$ años $(17,3 \%)$.

\section{- Horizontalización gástrica}

Esta deformidad del estómago se aprecia en el $26 \%$ de los pacientes de la muestra estudiada. Por sexos la diferencia es estadísticamente significativa $(P<0,05)$, estando presente en 15 varones $(51,7 \%)$ y en 11 mujeres $(15,5 \%)$.

En cuanto a las diferencias por grupos de edad; de los 26 pacientes, 11 eran $<42$ años $(22,9 \%)$ y $15 \geq 42$ años $(28,8 \%)$. 


\section{- Insuficiencia respiratoria}

En el $99 \%$ de los pacientes se observó la presencia de insuficiencia respiratoria previa a la intervención, siendo ésta la patología más recurrente entre los pacientes de la muestra estudiada. No se evidencias diferencias estadísticamente significativas por sexo: 70 mujeres $(98,6 \%)$ y 29 hombres (100\%) presentaron insuficiencia respiratoria. Por grupos de edad se apreciaron 47 pacientes $<42$ años $(97,9 \%)$ y 52 pacientes $\geq 42$ años (100\%).

\section{- Síndrome de Apnea Obstructiva del Sueño (SAOS)}

El 81\% de los pacientes padecía SAOS, 57 mujeres (80,3\%) frente a 24 hombres (82,8\%). Por grupos de edad, 36 pacientes < 42 años (75\%) y 45 pacientes $\geq 42$ años $(86,5 \%)$.

Se midió el número de pacientes que utilizaban un dispositivo domiciliario de CPAP (presión positiva continua en la vía aérea), instrumento de elección en el tratamiento del SAOS. En total fueron 5 pacientes de la muestra los que lo utilizaban CPAP domiciliaria observando diferencias significativas en función del sexo $(P=0,024)$ : 1 mujer $(1,4 \%)$ y 4 hombres $(13,8 \%)$. Los 5 pacientes eran $\geq 42$ años.

\section{- Hipertensión arterial}

El 37\% de los pacientes estaban diagnosticados de hipertensión arterial previamente al BAGUA. La correlación por sexos muestra una diferencia estadísticamente significativa, observando esta patología en 19 varones $(65,5 \%)$ y 18 mujeres $(25,4 \%)$.

Por grupos de edad se aprecian diferencias estadísticamente significativas $(P<0,001)$ en la presencia de hipertensión arterial en 10 pacientes de los < 42 años (20,8\%), y 27 pacientes $\geq 42$ años $(51,9 \%)$.

Los pacientes en tratamiento con antihipertensivos orales constituían el $27 \%$ de la muestra, en función del sexo las diferencias eran significativas $(P=0,010): 13$ hombres $(44,8 \%)$ y 14 mujeres $(19,7 \%)$. 
Por grupos de edad, también se observan diferencias significativas $(\mathrm{P}<0,001): 4$ pacientes $(8,3 \%)<42$ años con tratamiento antihipertensivo oral previo a la intervención, y 23 pacientes $\geq 42$ años $(44,2 \%)$.

\section{- Diabetes Mellitus}

El $18 \%$ de los pacientes de la muestra antes de la cirugía refería Diabetes Mellitus (DM). La distribución por sexo fue homogénea, 10 mujeres $(14,1 \%)$ y 8 hombres $(27,6 \%)$.

Al observar la presencia de DM por edad las diferencias fueron significativas $(P=0,003)$, en el grupo de $\geq 42$ años 15 pacientes $(28,8 \%)$ padecían DM, y tan solo 3 en el grupo de $<42$ años $(6,3 \%)$.

Los pacientes en tratamiento de la DM eran el $12 \%$ de la muestra, distribuidos de la siguiente manera: $8 \%$ con antidiabéticos orales (ADO), 2\% con insulina, y $2 \%$ ambos tratamientos combinados. El $6 \%$ restante mantenían un tratamiento dietético no farmacológico.

En relación al sexo y tipo de tratamiento antidiabético, tabla 4.2.1, se observaron diferencias estadísticamente significativas, describiéndose en cada uno de los tratamientos una mayor presencia en los hombres respecto a las mujeres.

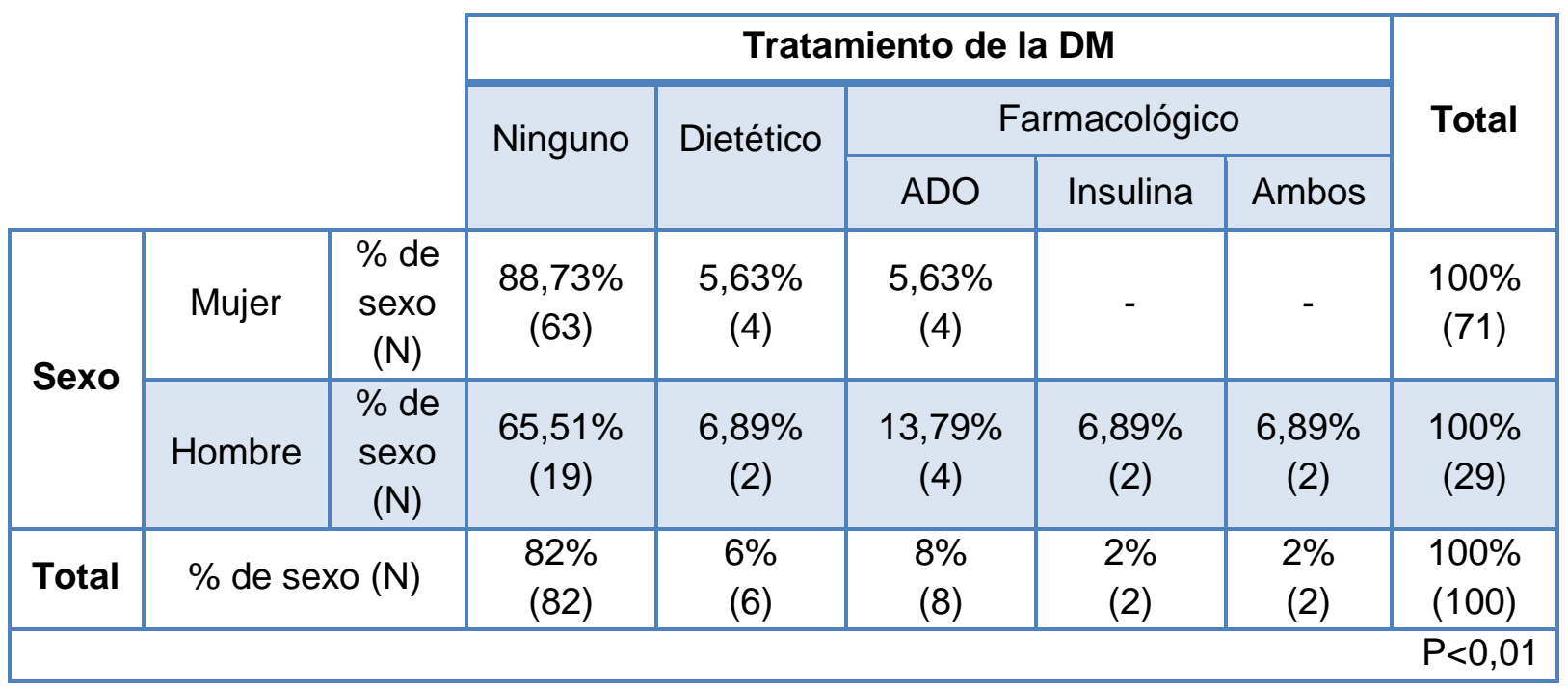

Tabla 4.2.1. Distribución del tratamiento de la DM según el sexo 
Se observa un mayor número de pacientes en tratamiento farmacológico en el grupo más longevo ( $P=0,013)$, con ADO 7 pacientes $(13,5 \%), 2$ con insulina $(3,8 \%)$, y 2 con la combinación de ambos tratamientos $(3,8 \%)$.

\section{- Alteraciones mentales: depresión}

Previamente al BAGUA se observó en el 39\% de los pacientes la presencia de alteraciones mentales relacionadas con el estado anímico.

De los pacientes diagnosticados de depresión se aprecian diferencias estadísticamente significativas $(P=0,016)$ entre ambos sexos, observándose en 33 mujeres $(46,5 \%)$ y en 6 hombres $(20,7 \%)$.

En ambos grupos de edad, la distribución es homogénea y no se diferencia entre ellos la presencia o no de alteraciones mentales. Siendo 17 pacientes $<42$ años $(35,4 \%)$, y 22 pacientes $\geq 42$ años $(42,3 \%)$.

Sólo el 21\% de los pacientes estaban en tratamiento psiquiátrico, observando 18 pacientes con alteraciones mentales sin tratamiento farmacológico.

Por sexo no se aprecia una diferencia estadísticamente significativa entre hombres y mujeres a la hora de consumir medicación psiquiátrica; 16 mujeres $(22,5 \%)$ y 5 hombres $(17,2 \%)$ con tratamiento psiquiátrico.

El consumo de fármacos psiquiátricos es prácticamente igual en el grupo de $<42$ años (10 pacientes. 20,8\%), que en el grupo de los $\geq 42$ años (11 pacientes. $21,2 \%)$. 


\subsection{Antecedentes quirúrgicos de la muestra}

A continuación se detallan las cirugías previas al BAGUA a las que se ha sometido la muestra estudiada. Clasificando las cirugías por grupos y como en los puntos anteriores observando las diferencias por sexo y grupo de edad.

\section{- Safenectomía}

El 2\% de los pacientes tenía una safenectomía previa, siendo los 2 casos mujeres $(2,8 \%)$ y $\geq 42$ años $(3,8 \%)$.

\section{- Cirugía traumatológica}

El $81 \%$ de los pacientes no se sometió a una cirugía traumatológica previa, por el contrario el 19\% si.

Clasificándoles por sexo, se observan diferencias estadísticamente significativas $(P<0,05)$, siendo mayor el porcentaje de varones intervenidos como se detalla en la tabla 4.3.1.

\begin{tabular}{|c|c|c|c|c|c|}
\hline & \multicolumn{2}{|c|}{$\begin{array}{c}\text { Cirugía } \\
\text { traumatológica }\end{array}$} & \multirow[t]{2}{*}{ Total } \\
\hline & & & NO & Sí & \\
\hline \multirow{2}{*}{ Sexo } & Mujer & $\begin{array}{c}\% \text { de } \\
\text { sexo }(N)\end{array}$ & $\begin{array}{c}85,9 \% \\
(61)\end{array}$ & $\begin{array}{c}14,1 \% \\
(10)\end{array}$ & $\begin{array}{c}100 \% \\
(71)\end{array}$ \\
\hline & Hombre & $\begin{array}{c}\% \text { de } \\
\operatorname{sexo}(N)\end{array}$ & $\begin{array}{l}69 \% \\
(20)\end{array}$ & $\begin{array}{l}31 \% \\
(9)\end{array}$ & $\begin{array}{c}100 \% \\
(29)\end{array}$ \\
\hline Total & \multicolumn{2}{|c|}{$\%$ de sexo $(N)$} & $\begin{array}{l}81 \% \\
(81)\end{array}$ & $\begin{array}{l}19 \% \\
(19)\end{array}$ & $\begin{array}{l}100 \% \\
(100)\end{array}$ \\
\hline
\end{tabular}

Tabla 4.3.1. Porcentaje de pacientes con cirugía traumatológica previas según el sexo

Por grupos de edad no se observan diferencias estadísticamente significativas. Entre los pacientes con cirugía traumatológica previa destacan el grupo de los < 42 años 6 pacientes (12,5\%), y en el grupo de los $\geq 42$ años 13 pacientes (25\%). 


\section{- Cirugía cardiaca}

Sólo se describen 4 pacientes intervenidos de cirugía cardiaca, de los cuales 2 eran hombres $(6,9 \%)$ y 2 mujeres $(2,8 \%)$.

Por grupos de edad, 1 paciente tenía $<42$ años $(2,1 \%)$ y los otros 3 pacientes $\geq 42$ años $(5,8 \%)$.

- Cirugía ocular

Se describieron 3 pacientes intervenidos, 2 mujeres (12,5\%) y 1 hombre $(14,3 \%)$. Los 3 eran < 42 años $(27,3 \%)$.

- Fístula sacra

Se observaron 3 pacientes, 2 mujeres (12,5\%) y 1 hombre (14,3\%). 1 de ellos $<42$ años $(9,1 \%)$, y los 2 restantes $\geq 42$ años $(16,7 \%)$.

\section{- Amigdalectomía}

El 6\% de la muestra presentaba una amigdalectomía previa. 4 pacientes mujeres (25\%) y 2 hombres (28,6\%). Por grupos de edad: 5 pacientes < 42 años $(45,5 \%)$ y 1 pacientes $\geq 42$ años $(8,3 \%)$.

- Tiroidectomía

Se observan 2 pacientes con esta cirugía, siendo ambas mujeres $(12,5 \%)$ del grupo de $\geq 42$ años $(16,7 \%)$.

\section{- Liposucción}

Considerada como una técnica de cirugía estética, se describen 7 pacientes en su totalidad mujeres $(9,9 \%), 4$ de ellas $<42$ años $(8,3 \%)$ y las 3 restantes $\geq 42$ años $(5,8 \%)$.

\section{- Hernia inguinal y umbilical}

Agrupadas en un mismo punto debido a que en ambas patologías existe una protusión del contenido de la cavidad abdominal. Observamos a 2 varones $\geq 42$ años $(16,7 \%)$ con hernia umbilical. Con hernia inguinal se observó 1 mujer < 42 años $(9,1 \%)$ y 1 hombre $\geq 42$ años $(8,3 \%)$. 


\section{- Balón gástrico previo}

Es considerada una técnica endoscópica, no como cirugía. 4 pacientes antes de someterse al BAGUA mantuvieron un balón intragástrico, en su totalidad mujeres (5,6\%). De las 4 mujeres, 2 tenían $<42$ años $(4,2 \%)$ y $2 \geq$ 42 años (3,8\%).

\section{- Cirugías del aparato digestivo}

De las intervenciones relacionadas con el aparato digestivo, previas al BAGUA destaca el 13\% con apendicectomía previa (tabla 4.3.2.), y el 5\% con colecistectomía. En ninguno de los pacientes estudiados se observaron cirugías bariátricas previas.

En lo referente a la cirugía de colecistectomía anterior al BAGUA se describe en su totalidad a 5 mujeres (7\%), 3 de ellas < 42 años $(6,3 \%)$ y las 2 restantes $\geq 42$ años $(3,8 \%)$.

\begin{tabular}{|c|c|c|c|c|c|}
\hline & \multicolumn{2}{|c|}{ Apendicectomía } & \multirow{2}{*}{ Total } \\
\hline & & & NO & sí & \\
\hline \multirow{2}{*}{ Sexo } & Mujer & $\begin{array}{c}\% \text { de } \\
\text { sexo }(N)\end{array}$ & $\begin{array}{c}88,7 \% \\
(63)\end{array}$ & $\begin{array}{c}11,3 \% \\
(8)\end{array}$ & $\begin{array}{c}100 \% \\
(71)\end{array}$ \\
\hline & Hombre & $\begin{array}{c}\% \text { de } \\
\text { sexo }(N)\end{array}$ & $\begin{array}{c}82,8 \% \\
(24)\end{array}$ & $\begin{array}{c}17,2 \% \\
(5)\end{array}$ & $\begin{array}{c}100 \% \\
(29)\end{array}$ \\
\hline Total & \multicolumn{2}{|c|}{$\%$ de sexo $(\mathrm{N})$} & $\begin{array}{l}87 \% \\
(87)\end{array}$ & $\begin{array}{l}13 \% \\
(13)\end{array}$ & $\begin{array}{l}100 \% \\
(100)\end{array}$ \\
\hline \multicolumn{6}{|c|}{$P>0,0$} \\
\hline
\end{tabular}

Tabla 4.3.2. Porcentaje de pacientes con apendicectomía previa según el sexo

No existen diferencias estadísticamente significativas según el sexo en ninguna de las dos intervenciones, pero en la apendicectomía al igual que en la colecistectomía predominan más las mujeres que los hombres.

Por grupos de edad, se observaron a 5 pacientes < 42 años $(10,4 \%)$ y 8 pacientes $\geq 42$ años $(15,4 \%)$ con apendicetomía previa al BAGUA. 


\section{- Cirugías ginecológicas}

Entre las cirugías ginecológicas previas al BAGUA, destacan: 7 histerectomías (9,9\%), 1 ovaricectomía (6,3\%) y 4 ligaduras de trompas (25\%).

En la histerectomía previa, las 7 son mujeres $\geq 42$ años (13,5\%), sin observar a ninguna mujer en el grupo de menor edad $(P<0,05)$.

En la ovaricectomía, sólo se describe 1 mujer $\geq 42$ años (8,3\%). En la ligadura de trompas se aprecian a 4 mujeres, 1 de ellas $<42$ años $(9,1 \%)$ y el resto $\geq 42$ años (25\%). En relación al grupo de edad en estas dos cirugías no se observaron diferencias estadísticamente significativas. 


\subsection{Hábitos tóxicos}

\subsubsection{Hábito tabáquico}

En la primera consulta previa a la cirugía se determinó el consumo de tabaco siguiendo una clasificación en cuanto al hábito tabáquico aprobada y utilizada por IFSO.

En la figura 4.4.1 se distinguen a los pacientes fumadores de los no fumadores y también a los que dejaron de fumar antes de la primera consulta (exfumadores). A su vez, a los pacientes fumadores se les clasificó por la cantidad de cigarrillos consumidos diariamente: menos de 20 cigarrillos al día, 20 cigarrillos al día, y más de 20 cigarrillos al día.

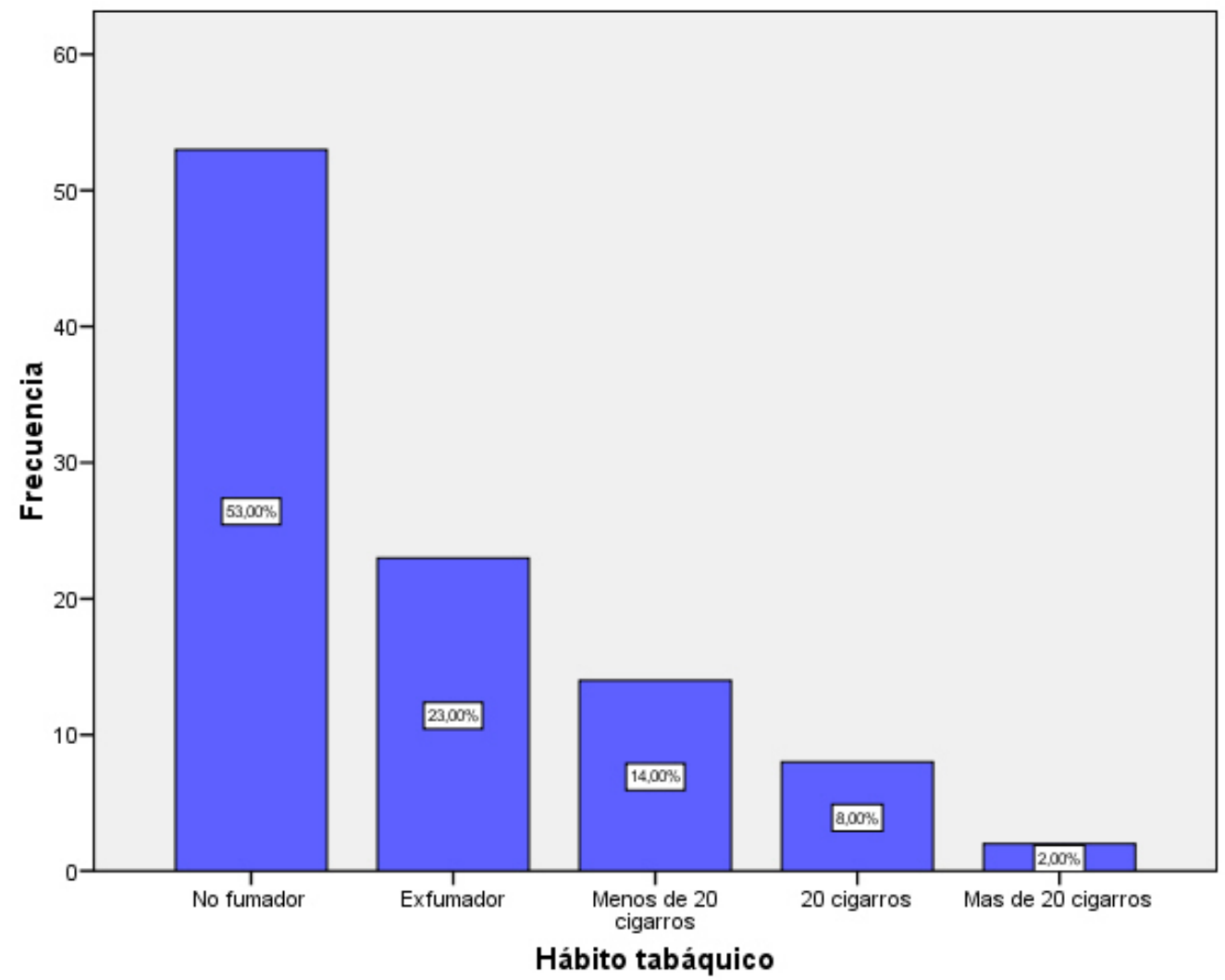

Figura 4.4.1. Clasificación del hábito tabáquico de la muestra

La mayoría de los pacientes (53\%) en la primera consulta, manifiesta no haber fumado nunca, seguido del $24 \%$ de pacientes fumadores y un $23 \%$ que expresa haber dejado de fumar. 
Al estudiar el hábito de consumo de tabaco en relación al sexo no se observan diferencias estadísticamente significativas, tampoco entre el grupo de los fumadores y los no fumadores. Tampoco se observan diferencias estadísticamente significativas entre fumadores y no fumadores en función del grupo de edad. En la tabla 4.4.1, se describe la frecuencia del consumo de tabaco de la muestra en relación al sexo.

\begin{tabular}{|c|c|c|c|c|c|c|c|c|}
\hline & \multicolumn{5}{|c|}{ Hábito tabáquico } & \multirow[b]{2}{*}{ Total } \\
\hline & & & $\begin{array}{c}\text { No } \\
\text { fumador }\end{array}$ & Exfumador & $\begin{array}{c}<20 \text { cig/ } \\
\text { día }\end{array}$ & $\begin{array}{l}\text { 20cig/ } \\
\text { día }\end{array}$ & $\begin{array}{c}>20 \text { cig/ } \\
\text { día }\end{array}$ & \\
\hline \multirow{2}{*}{ Sexo } & Mujer & $\begin{array}{c}\% \text { de } \\
\text { sexo }(N)\end{array}$ & $\begin{array}{c}56,3 \% \\
(40)\end{array}$ & $\begin{array}{c}18,3 \% \\
(13)\end{array}$ & $\begin{array}{c}15,5 \% \\
(11)\end{array}$ & $\begin{array}{r}7 \% \\
(5)\end{array}$ & $\begin{array}{c}2,8 \% \\
(2)\end{array}$ & $\begin{array}{c}100 \% \\
(71)\end{array}$ \\
\hline & Hombre & $\begin{array}{c}\% \text { de } \\
\text { sexo }(\mathrm{N})\end{array}$ & $\begin{array}{c}44,8 \% \\
(13)\end{array}$ & $\begin{array}{c}34,5 \% \\
(10)\end{array}$ & $\begin{array}{c}10,3 \% \\
\text { (3) }\end{array}$ & $\begin{array}{c}10,3 \% \\
(3)\end{array}$ & - & $\begin{array}{c}100 \% \\
(29)\end{array}$ \\
\hline Total & \multicolumn{2}{|c|}{$\%$ de sexo $(\mathrm{N})$} & $\begin{array}{l}53 \% \\
(53)\end{array}$ & $\begin{array}{l}23 \% \\
(23)\end{array}$ & $\begin{array}{l}14 \% \\
(14)\end{array}$ & $\begin{array}{l}8 \% \\
(8)\end{array}$ & $\begin{array}{l}2 \% \\
(2)\end{array}$ & $\begin{array}{l}100 \% \\
(100)\end{array}$ \\
\hline
\end{tabular}

Tabla 4.4.1. Hábito tabáquico de la muestra según el sexo

\subsubsection{Consumo de alcohol}

Del mismo modo que la determinación del hábito tabáquico en la primera consulta, se realizó un cuestionario de consumo de alcohol según las recomendaciones de IFSO, figura 4.4.2, en el que se clasificó a los pacientes en: ex-alcohólicos, los que nunca han consumido alcohol, y a los consumidores de alcohol. A estos últimos, se les dividió en: bebedor diario, semanal y mensual.

La mayoría de los pacientes en la primera consulta (78\%) fueron considerados no bebedores. En contraposición se encuentra el 21\% de los pacientes que toman alcohol, destacando un $15 \%$ de los consumidores de alcohol en los fines de semana.

Entre los pacientes consumidores de alcohol, se observan 10 mujeres $(14,1 \%$ del total de las mujeres de la muestra) y 12 hombres ( $41 \%$ del total de los hombres de la muestra) $\mathrm{P}=0,004$. 


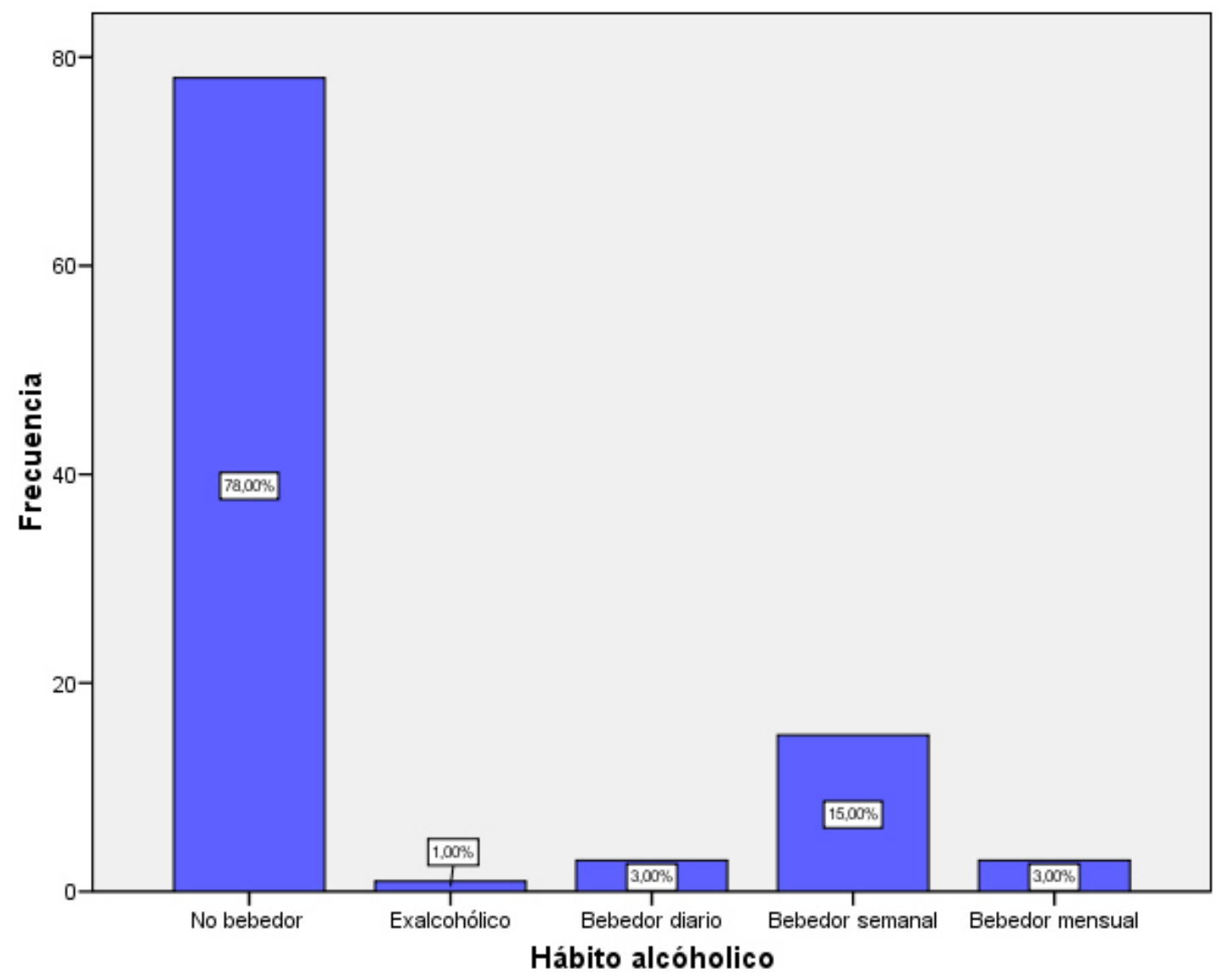

Figura 4.4.2. Clasificación del consumo de alcohol de la muestra

En relación al sexo, también se aprecian diferencias estadísticamente significativas $(P=0,007)$ entre los diferentes grupos de clasificación según el consumo de alcohol como se muestra en la tabla 4.4.2.

No se han observado diferencias estadísticamente significativas entre bebedores y no bebedores en función del grupo de edad al que pertenecían.

\begin{tabular}{|c|c|c|c|c|c|c|c|c|}
\hline & \multicolumn{5}{|c|}{ Consumo de alcohol } & \multirow[b]{2}{*}{ Total } \\
\hline & & & $\begin{array}{c}\text { No } \\
\text { bebedor }\end{array}$ & $\begin{array}{c}\text { Ex- } \\
\text { alcohólico }\end{array}$ & $\begin{array}{c}\text { Bebedor } \\
\text { diario }\end{array}$ & $\begin{array}{l}\text { Bebedor } \\
\text { semanal }\end{array}$ & $\begin{array}{l}\text { Bebedor } \\
\text { mensual }\end{array}$ & \\
\hline \multirow{2}{*}{ Sexo } & Mujer & $\begin{array}{c}\% \text { de } \\
\text { sexo }(N)\end{array}$ & $\begin{array}{c}85,9 \% \\
(61)\end{array}$ & - & $\begin{array}{c}2,8 \% \\
(2)\end{array}$ & $\begin{array}{c}11,3 \% \\
(8)\end{array}$ & - & $\begin{array}{c}100 \% \\
(71)\end{array}$ \\
\hline & Hombre & $\begin{array}{c}\% \text { de } \\
\text { sexo }(N)\end{array}$ & $\begin{array}{c}58,6 \% \\
(17)\end{array}$ & $\begin{array}{c}3,4 \% \\
(1)\end{array}$ & $\begin{array}{c}3,4 \% \\
(1)\end{array}$ & $\begin{array}{c}24,1 \% \\
(7)\end{array}$ & $\begin{array}{c}10,3 \% \\
(3)\end{array}$ & $\begin{array}{c}100 \% \\
(29)\end{array}$ \\
\hline Total & \multicolumn{2}{|c|}{$\%$ de sexo $(\mathrm{N})$} & $\begin{array}{l}78 \% \\
(78)\end{array}$ & $\begin{array}{l}1 \% \\
(1)\end{array}$ & $\begin{array}{l}3 \% \\
(3)\end{array}$ & $\begin{array}{l}15 \% \\
(15)\end{array}$ & $\begin{array}{l}3 \% \\
\text { (3) }\end{array}$ & $\begin{array}{l}100 \% \\
(100)\end{array}$ \\
\hline \multicolumn{9}{|c|}{$P=0,007$} \\
\hline
\end{tabular}

Tabla 4.4.2. Consumo de alcohol de la muestra según el sexo 


\subsection{Preparación dietético-nutricional previa a la cirugía}

El paciente previamente a la cirugía se somete a un protocolo dietéticonutricional con el objetivo de reducir los riesgos perioperatorios y modificar los hábitos alimentarios inadecuados, reduciendo a su vez el peso inicial. A continuación se estudia el peso objetivo para la cirugía estimado por el equipo quirúrgico, aplicando una reducción porcentual al peso inicial. También se determinará el grado de cumplimiento del peso objetivo estimado para la cirugía, y el tiempo transcurrido desde la consulta inicial hasta el día de la cirugía.

\section{- Peso objetivo estimado en la cirugía}

En la tabla 4.5.1 se describe el peso objetivo estimado en la cirugía, expresado en $\mathrm{Kg}$. Al $75 \%$ de la muestra se le estima un peso objetivo en la cirugía > $90 \mathrm{Kg}$, teniendo en cuenta que todos los pacientes de la muestra eran obesos.

\begin{tabular}{|c|c|}
\hline & $\begin{array}{c}\text { Peso objetivo estimado } \\
\text { en la cirugía (Kg) }\end{array}$ \\
\hline $\mathbf{N}$ & 100 \\
\hline Media & 102,93 \\
\hline D.Típica & 16,64 \\
\hline Mediana & 98,95 \\
\hline $\begin{array}{c}\text { Rango } \\
\text { intercuartílico } \\
\text { (P25-P75) }\end{array}$ & $90-114,95$ \\
\hline
\end{tabular}

Tabla 4.5.1. Descripción del peso objetivo estimado en la cirugía

En la figura 4.5 .1 se muestran las diferencias en el peso objetivo estimado en la cirugía según el sexo. El peso objetivo medio en las mujeres fue de $98,51 \pm 14,48 \mathrm{Kg}$, a diferencia del de los hombres que fue de 113,75 $\pm 16,87 \mathrm{Kg}(\mathrm{P}<0,001)$. 


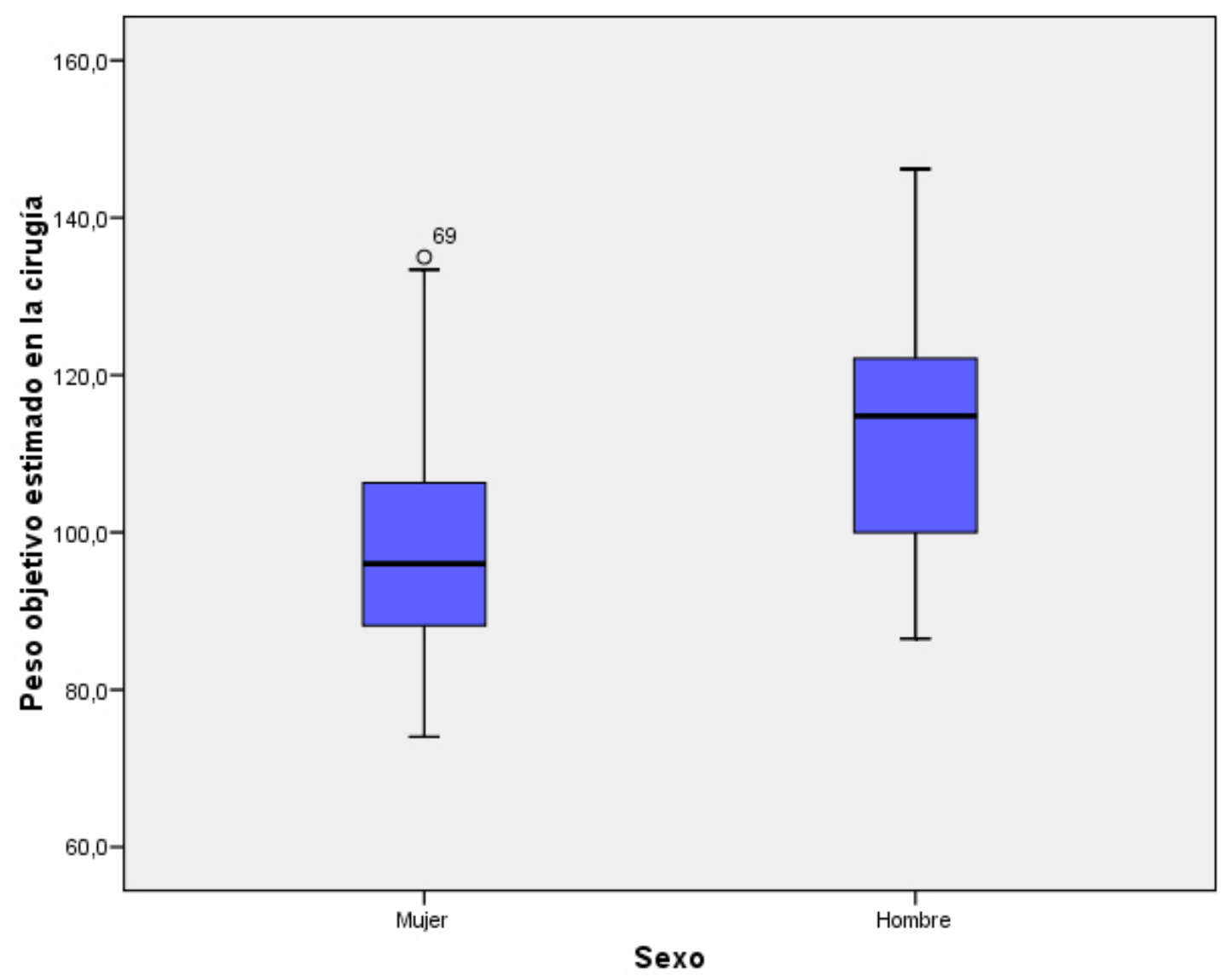

Figura 4.5.1. Diferencia entre el peso objetivo estimado en la cirugía según el sexo

El peso medio objetivo estimado en la cirugía, no presenta diferencias estadísticamente significativas entre el grupo de los $<42$ años $(104,58 \pm$ $17,39)$ y el de los $\geq 42$ años $(101,41 \pm 15,94 \mathrm{Kg})$.

En la figura 4.5.2 se muestra el peso objetivo estimado en la cirugía según el grado de obesidad en la consulta inicial. Las diferencias entre el peso medio objetivo estimado para la cirugía es mayor conforme aumenta el grado de obesidad $(P<0,001)$. 


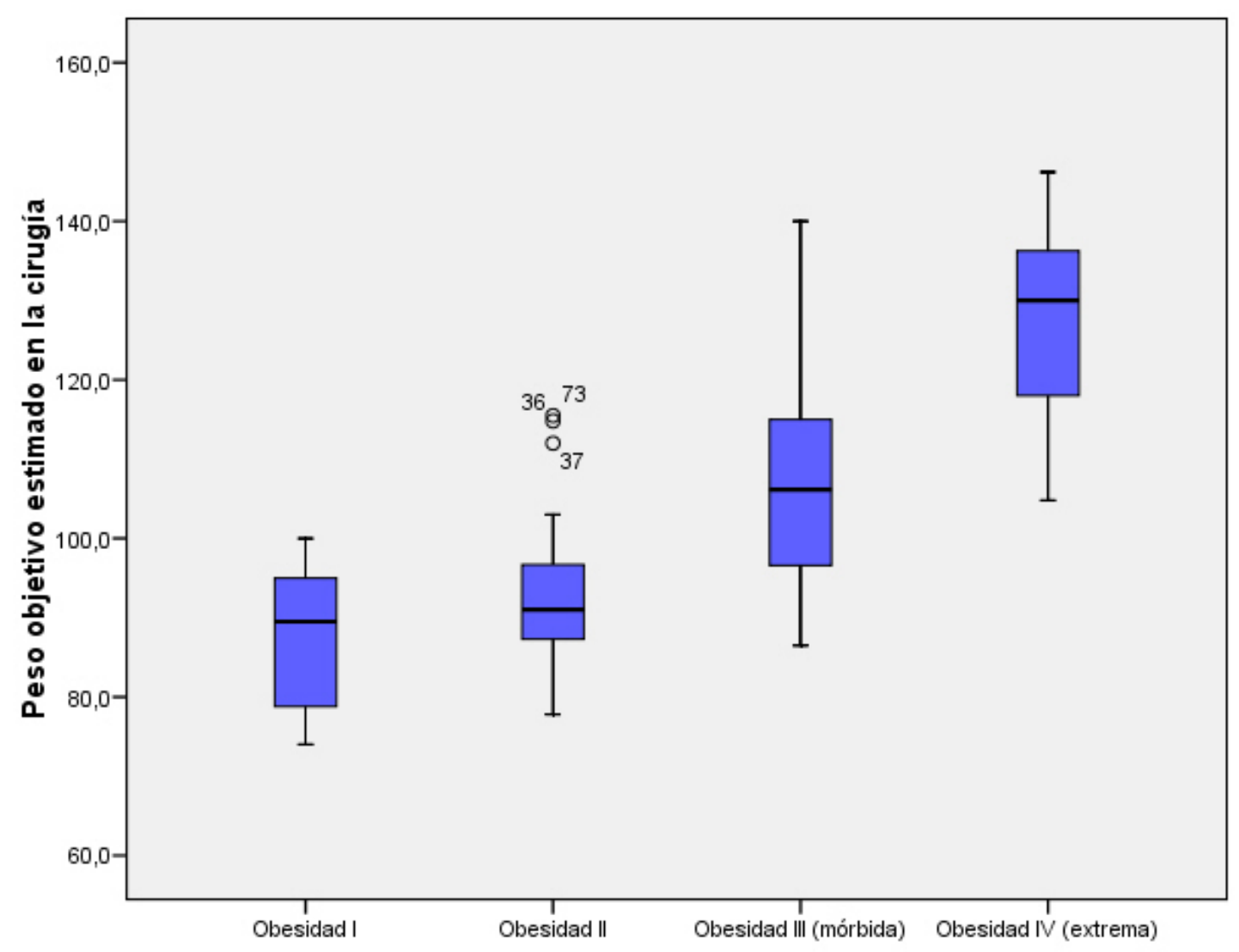

Figura 4.5.2. Descripción del peso objetivo estimado en la cirugía según el grado de obesidad

- Porcentaje aplicado en la reducción ponderal prequirúrgica

En la tabla 4.5.2, se describe el porcentaje aplicado al peso inicial para lograr la reducción ponderal prequirúrgica a consenso del equipo quirúrgico.

\begin{tabular}{|c|c|}
\hline & $\begin{array}{c}\text { Porcentaje aplicado en la } \\
\text { reducción ponderal prequirúrgica }\end{array}$ \\
\hline $\mathbf{N}$ & 100 \\
\hline Media & 11,33 \\
\hline D.Típica & 3,98 \\
\hline Mediana & 10,58 \\
\hline $\begin{array}{c}\text { Rango } \\
\text { intercuartílico } \\
\text { (P25-P75) }\end{array}$ & $8,85-14,41$ \\
\hline
\end{tabular}

Tabla 4.5.2. Descripción del porcentaje aplicado en la reducción ponderal prequirúrgica

Sí se observan diferencias estadísticamente significativas $(P<0,001)$ entre los dos sexos, figura 4.5.3, siendo en los hombres en los que se aplica 
un mayor porcentaje medio de pérdida ponderal prequirúrgica $(13,68 \pm 3,34$

$\%)$ respecto a las mujeres $(10,37 \pm 3,84 \%)$.

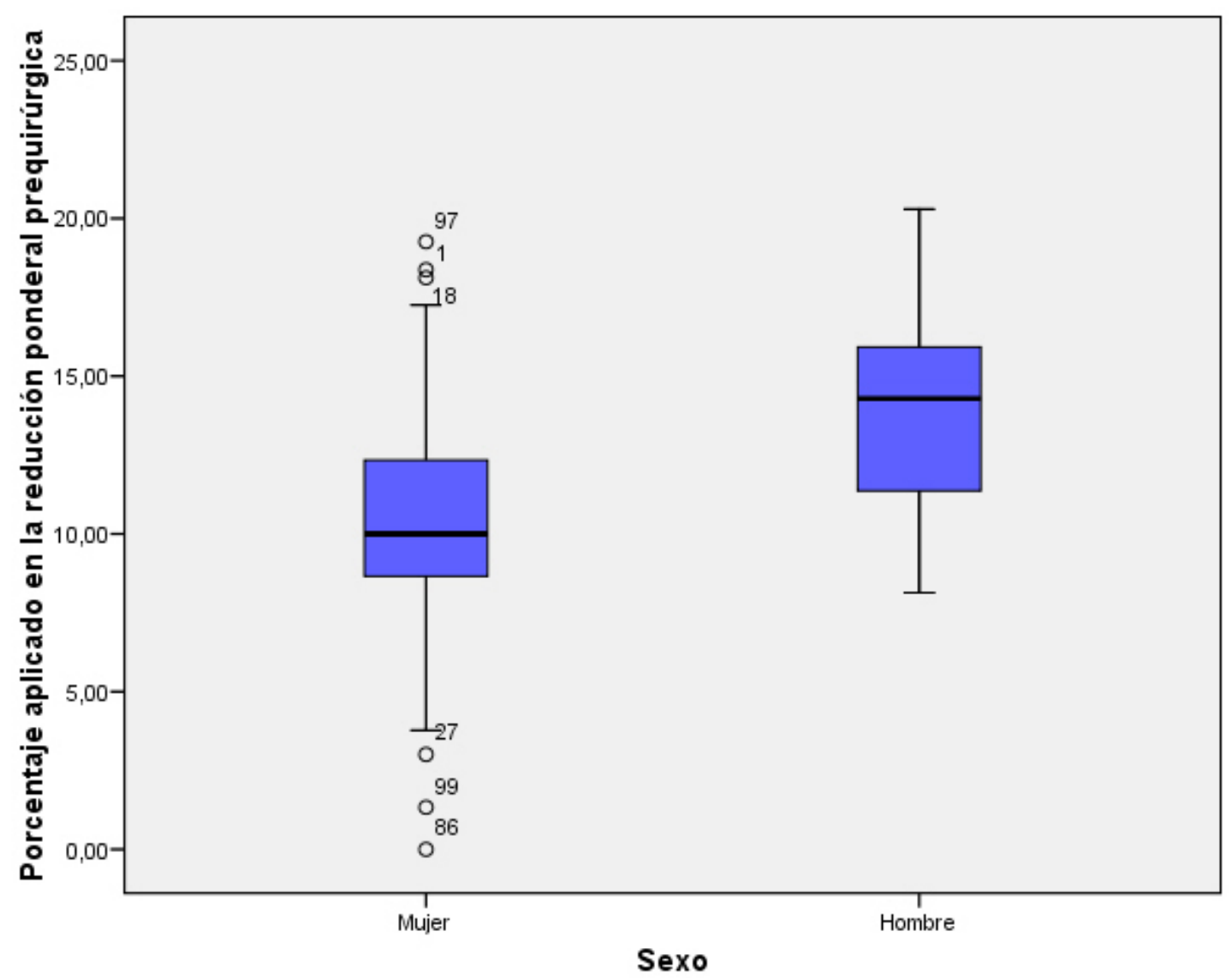

Figura 4.5.3. Descripción del porcentaje aplicado en la reducción ponderal prequirúrgica según el sexo

Por grupos de edad no se observan diferencias estadísticamente significativas en el porcentaje medio aplicado en la reducción ponderal prequirúrgica. Siendo el porcentaje medio aplicado algo superior en los $\geq 42$ años (11,84 $\pm 3,82 \%)$, en comparación con los < 42 años $(10,78 \pm 4,12 \%)$.

En la figura 4.5.4 se muestra el porcentaje aplicado en la reducción ponderal prequirúrgica, en función del grado de obesidad, siendo mayor el porcentaje aplicado en los pacientes con mayor grado de obesidad $(P<0,001)$. La diferencia más elevada en la aplicación del porcentaje en el peso inicial al compararlo entre cada uno de los grupos de obesidad definidos, se observa en el grupo de obesos extremos a los que se les aplica en la mitad de los casos una reducción porcentual del 17\% sobre el peso inicial. 


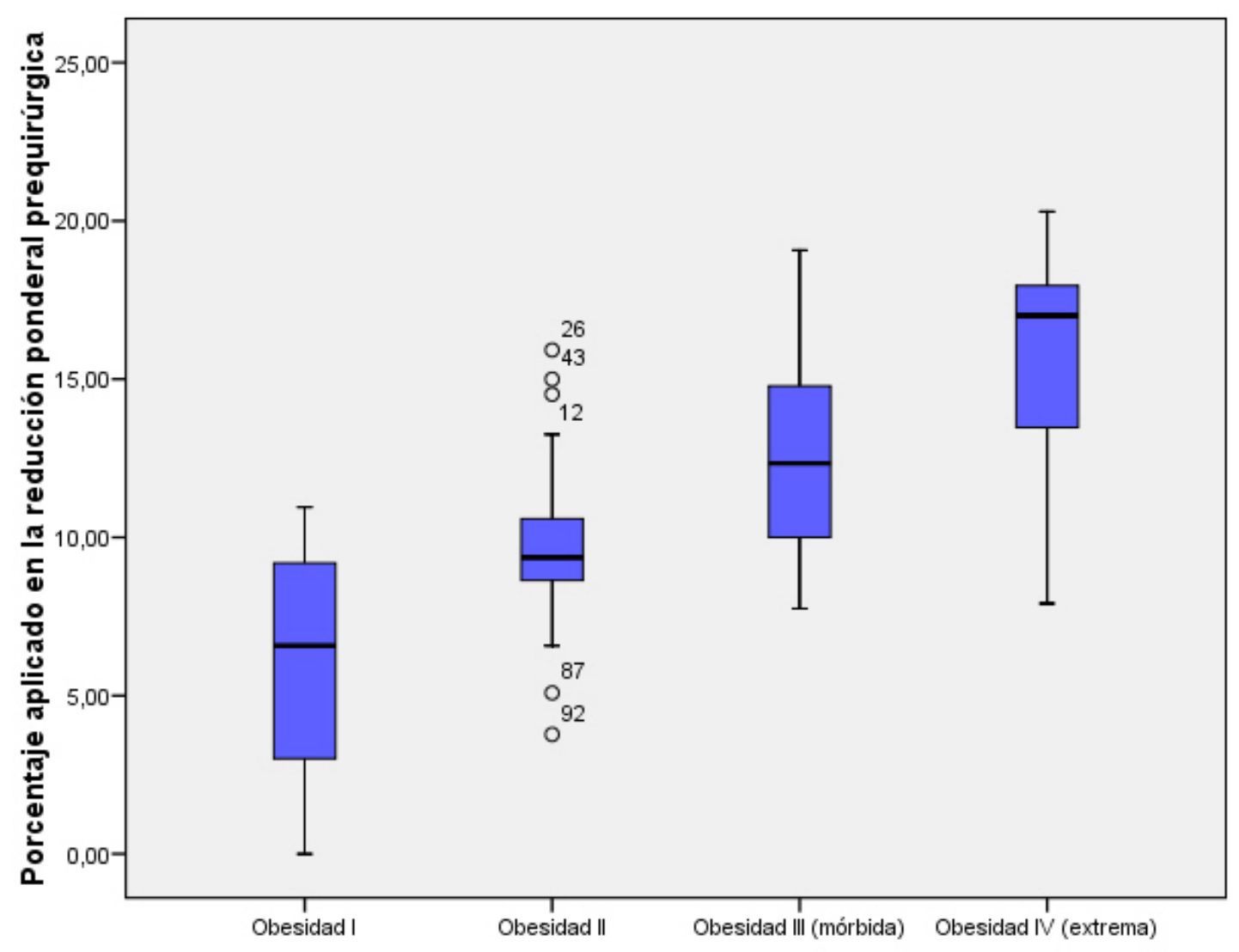

Figura 4.5.4. Descripción del porcentaje aplicado en la reducción ponderal prequirúrgica según el grado de obesidad

- Cumplimiento del peso objetivo marcado para la cirugía

Todos los pacientes que no alcanzaron el peso marcado como objetivo para la cirugía, no cumplieron el objetivo. Aunque se quedaron a 500 gramos de lograr el peso objetivo también se les incluyó, siendo 74 pacientes los que lograron el peso objetivo con estos criterios. Los 26 pacientes restantes no lo consiguieron.

Respecto al sexo, predominan en los dos grupos el número de pacientes con el cumplimiento del objetivo sin presentar diferencias estadísticamente significativas. El $70,4 \%$ de las mujeres logra el objetivo, y el $82,8 \%$ de los hombres.

Por grupos de edad se observa una mayor proporción en el cumplimiento del peso objetivo en el grupo de los $<42$ años $(77,1 \%)$ que en el grupo de los $\geq 42$ años $(71,2 \%)$. 
En el cumplimiento del peso objetivo en los pacientes según el grado de obesidad, no se observaron diferencias estadísticamente significativas entre los dos grupos, predominando en ambos el porcentaje de pacientes con el peso objetivo cumplido. Como se muestra en la tabla 4.5.3, el número de pacientes según el grado de obesidad que cumplieron el peso objetivo en la cirugía.

\begin{tabular}{|c|c|c|c|c|c|c|}
\hline & \multicolumn{4}{|c|}{ Grado de obesidad } & \multirow[b]{2}{*}{ Total } \\
\hline & & $\begin{array}{c}\text { Obesidad } \\
\text { | }\end{array}$ & $\begin{array}{c}\text { Obesidad } \\
\text { II }\end{array}$ & $\begin{array}{l}\text { Obesidad } \\
\text { III }\end{array}$ & $\begin{array}{c}\text { Obesidad } \\
\text { IV }\end{array}$ & \\
\hline \multirow{2}{*}{$\begin{array}{l}\text { Objetivo } \\
\text { cumplido }\end{array}$} & Sí (N) & 7 & 23 & 32 & 12 & 74 \\
\hline & No $(N)$ & 3 & 10 & 10 & 3 & 26 \\
\hline \multicolumn{2}{|c|}{ Total } & 10 & 33 & 42 & 15 & 100 \\
\hline
\end{tabular}

Tabla 4.5.3. Cumplimiento del peso objetivo en la cirugía según el grado de obesidad

En apartados siguientes se mostrará la evolución ponderal de los pacientes en cada uno de los controles trimestrales hasta los 2 años de la cirugía, pero es objeto de este apartado describir el grado de cumplimiento o no del objetivo ponderal en la cirugía de manera cuantificada. En la figura 4.5.5 se detalla la variación de peso tomando como referencia el peso marcado como objetivo en la cirugía (valor 0). Los valores expresados en negativo indican una pérdida de peso superior a la establecida al peso objetivo, y por el contrario los valores en positivo no lograron alcanzar el peso objetivo en la cirugía. 


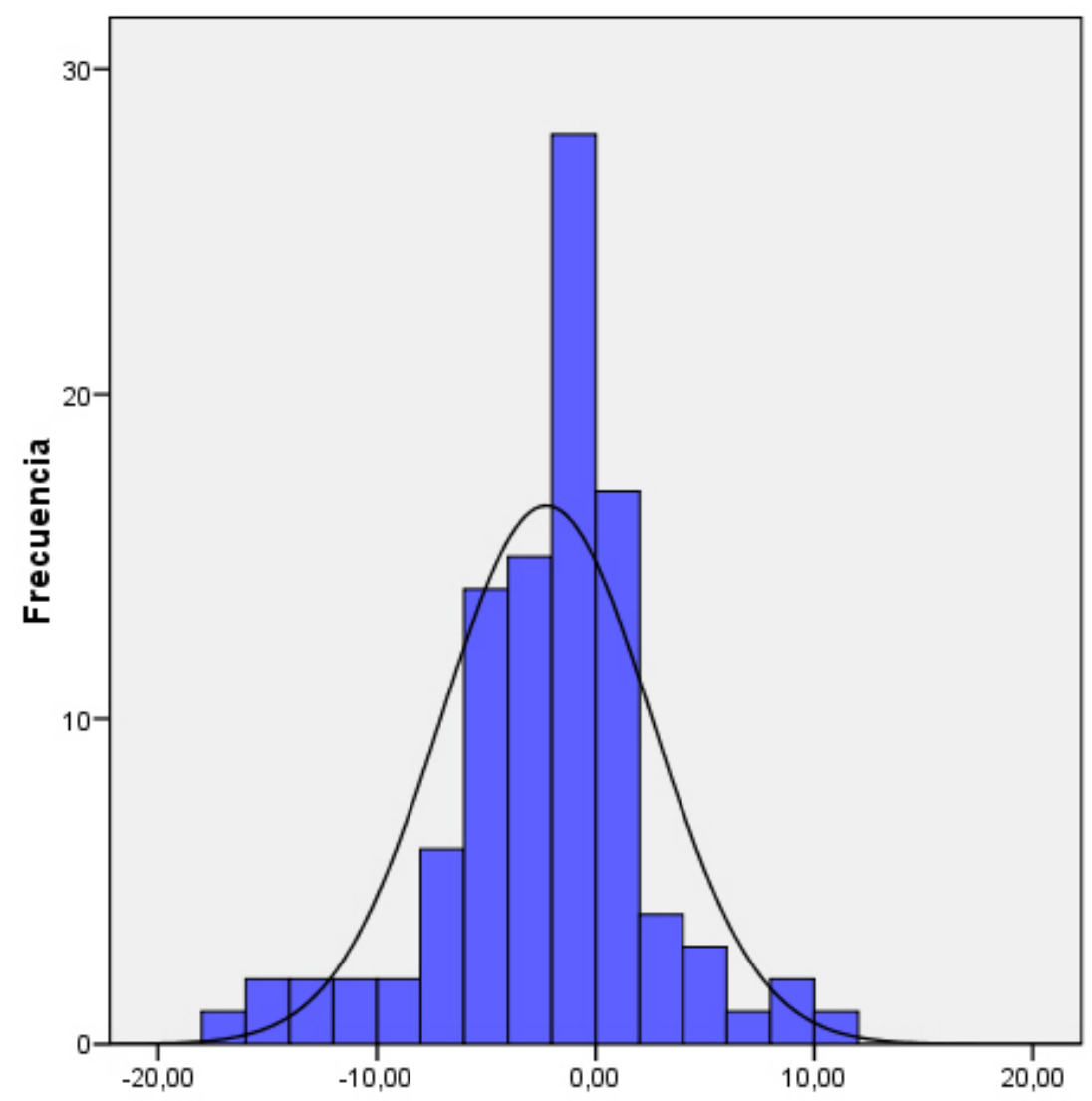

Figura 4.5.5. Descripción de la variación ponderal $(\mathrm{kg})$ respecto al peso objetivo en la cirugía

Entre hombres y mujeres no se observaron diferencias estadísticamente significativas en la variación ponderal respecto al peso objetivo en la cirugía siendo en las mujeres una variación media de $-1,73 \pm 4,47 \mathrm{Kg}$, y en los hombres de $-3,51 \pm 5,44$. Por grupos de edad esta diferencia es aún menor, en los $<42$ años $-2,19 \pm 3,99 \mathrm{Kg}$, y en los $\geq 42$ años $-2,30 \pm 5,50 \mathrm{Kg}$.

Por el grado de obesidad estas variaciones respecto al peso marcado como objetivo, tampoco mostraron diferencias estadísticamente significativas entre los diferentes grupos de pacientes obesos. Los pacientes con obesidad extrema en un 50\% de los casos, lograron superar el peso marcado como objetivo en $2,20 \mathrm{Kg}$, siendo el grupo de obesos que describe un mejor cumplimiento del peso marcado como objetivo en el 50\% de los casos.

De los 26 pacientes que no lograron el peso objetivo en la cirugía, 5 pacientes superaron los $5 \mathrm{Kg}$ de diferencia respecto al marcado como objetivo. El paciente que más lejos se queda de alcanzar el peso objetivo es un varón de 47 años, con obesidad mórbida, insuficiencia respiratoria 
crónica, con apnea obstructiva del sueño tratada con un dispositivo de presión positiva continua en las vías aéreas respiratorias (CPAP). A este paciente, el equipo quirúrgico le aplicó un porcentaje de reducción ponderal prequirúrgica del 15,76\%, llegando a la cirugía con un incumplimiento de 11 Kg sobre el peso pautado como objetivo.

\section{- Tiempo de preparación prequirúrgica}

Se midió el tiempo en días de duración de la preparación dietéticonutricional previa a la cirugía. Ese tiempo varía en función de la consecución del peso objetivo marcado para la cirugía y la lista de espera quirúrgica del СТO. El tiempo de preparación del paciente antes de la intervención se describió en el 50\% de los casos en 89 días, y en el 75\% en 108 días.

El tiempo medio de preparación prequirúrgica de la muestra fueron 94,27 $\pm 53,75$ días, observando un tiempo mínimo de preparación de 14 días y un máximo de 450 días, como se detalla en la figura 4.5.6. Estos valores se ven determinados por la cantidad de peso que deben de perder antes de la intervención para que ésta pueda ser segura y cumpla con los criterios recomendados por la SECO. 


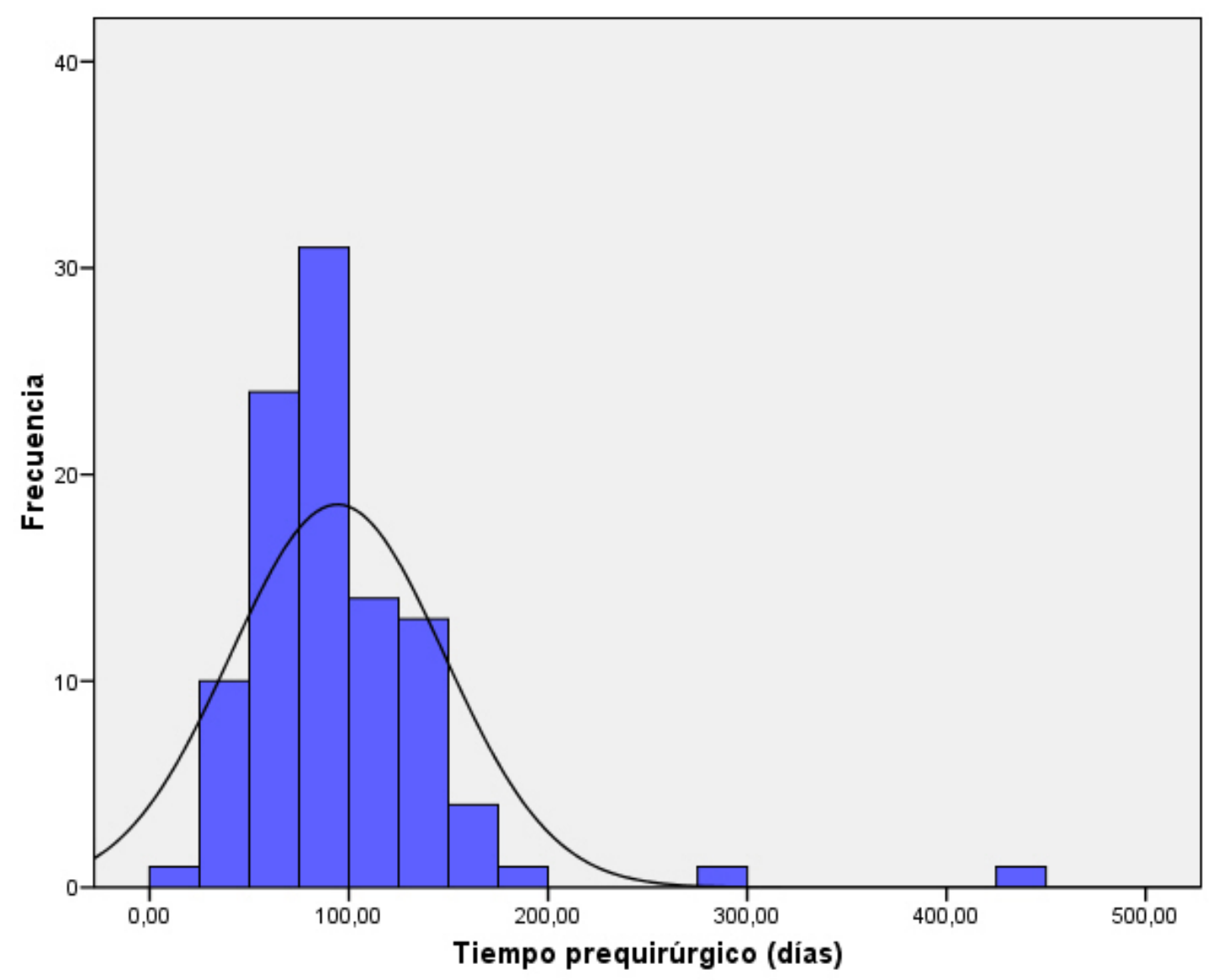

Figura 4.5.6. Descripción en días del tiempo de preparación prequirúrgico

Se observan diferencias estadísticamente significativas en el tiempo de preparación previo a la cirugía por sexo, las mujeres necesitaron menos días de preparación antes de la cirugía (79,97 \pm 30,56 días) que los hombres $(129,27 \pm 78,06$ días $)$. $P=0,002$.

Por grupos de edad, los pacientes < 42 años precisaron de un tiempo menor en la preparación prequirúrgica con una media de $88,27 \pm 61,88$ días, respecto a los $\geq 42$ años que necesitaron una media de 99,80 \pm 44,88 días $(P<0,05)$.

En los pacientes con un mayor grado de obesidad, el tiempo necesario de preparación prequirúrgica aumentó sin ser estadísticamente significativo. En la figura 4.5.7 se muestra el paulatino aumento de los días necesarios de preparación prequirúrgica en función de un mayor grado de obesidad. 


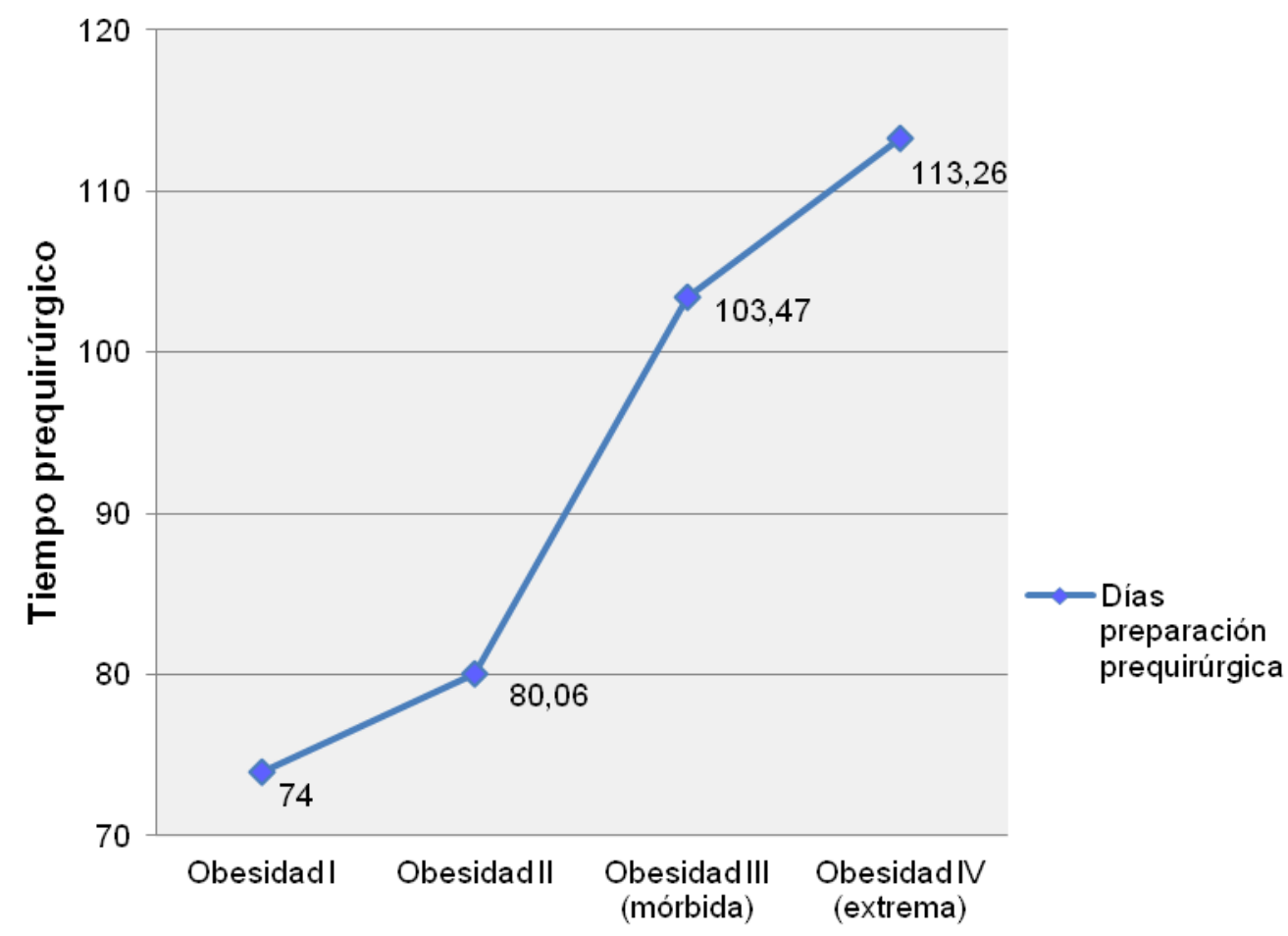

Figura 4.5.7. Tiempo de preparación prequirúrgico según el grado de obesidad

Si agrupamos a los pacientes de obesidad tipo I y II, y los relacionamos con el conjunto de pacientes con obesidad III y IV; se observa un tiempo medio de preparación prequirúrgica menor en el primero de los casos de $78,65 \pm 35,54$ días, y en el segundo grupo de 106,05 $\pm 60,90$ días $(P<0,05)$. 


\subsection{Características generales de la cirugía}

- Medidas de las asas intestinales

La técnica BAGUA implica la exclusión de un área intestinal denominada asa biliopancreática, a criterio del cirujano en función del IMC y longitud intestinal total del paciente, por el que no circularán los alimentos ingeridos pero al que se vierten los jugos pancreáticos y gástricos. El asa común será el resultante desde la unión de la anastomosis hasta el intestino grueso, en el que confluirán los alimentos digeridos desde el reservorio gástrico, y los jugos del asa biliopancreática.

La longitud media del asa biliopancreática de la muestra fue de 274,95 \pm 23,69 cm. La longitud media de las mujeres fue de 269,08 $\pm 22,15 \mathrm{~cm}$, y en los hombres $289,31 \pm 21,36 \mathrm{~cm}(\mathrm{P}<0,001)$.

Respecto a la mediana de edad no se observaron diferencias estadísticamente significativas siendo prácticamente la misma longitud del asa biliopancreática. En los $<42$ años $274,48 \pm 28,15 \mathrm{~cm}$, y en los $\geq 42$ años $275,38 \pm 18,93 \mathrm{~cm}$.

De manera inversa y por anatomía del intestino los pacientes con mayor longitud de asa biliopancreática portarán un asa común más corta. En el asa común la longitud media fue 226,60 $\pm 25,39 \mathrm{~cm}$. La diferencia de longitud entre hombres y mujeres fue estadísticamente significativa $P<0,001$, siendo más largo el asa común en las mujeres $(232,96 \pm 23,86 \mathrm{~cm})$ que en los hombres $(211,03 \pm 22,41 \mathrm{~cm})$. Por grupos de edad, la longitud del asa común observada es la misma.

\section{- Combinación de técnicas simultáneas al BAGUA}

La cirugía de BAGUA y a criterio del cirujano tiene la posibilidad de reducir la hernia hiatal, y combinarse con colecistectomía aprovechando el propio acto quirúrgico del bypass.

A 55 pacientes se les realizó una reducción de la hernia hiatal, de los cuales 41 eran mujeres y 14 hombres. Por grupos de edad, la distribución es prácticamente la misma, 28 pacientes $<42$ años y 27 pacientes $\geq 42$ años. 
Respecto a la combinación de la colecistectomía junto al BAGUA sólo se describe en 12 pacientes y todos mujeres $(P=0,017)$. La distribución por edad es similar, siendo 5 mujeres $<42$ años y 7 mujeres $\geq 42$ años.

\section{- Duración de la técnica quirúrgica}

La cirugía tuvo una duración media de 97,84 \pm 12,54 minutos, sin ser estadísticamente significativa la diferencia de tiempo entre hombres y mujeres. La duración media en las mujeres fue de 97,97 \pm 13,09 minutos, y en los hombres $97,52 \pm 11,30$ minutos.

Por grupos de edad, los pacientes con $\geq 42$ años mantuvieron un mayor tiempo quirúrgico $(99,67 \pm 13,38$ minutos) que los $<42$ años $(95,85 \pm 11,38$ minutos), sin ser esta diferencia significativa.

En la figura 4.6.1 se muestran agrupados los pacientes por IMC, siendo los obesos tipo IV los pacientes con mayor tiempo de cirugía respecto a los otros pacientes obesos $(P=0,036)$.

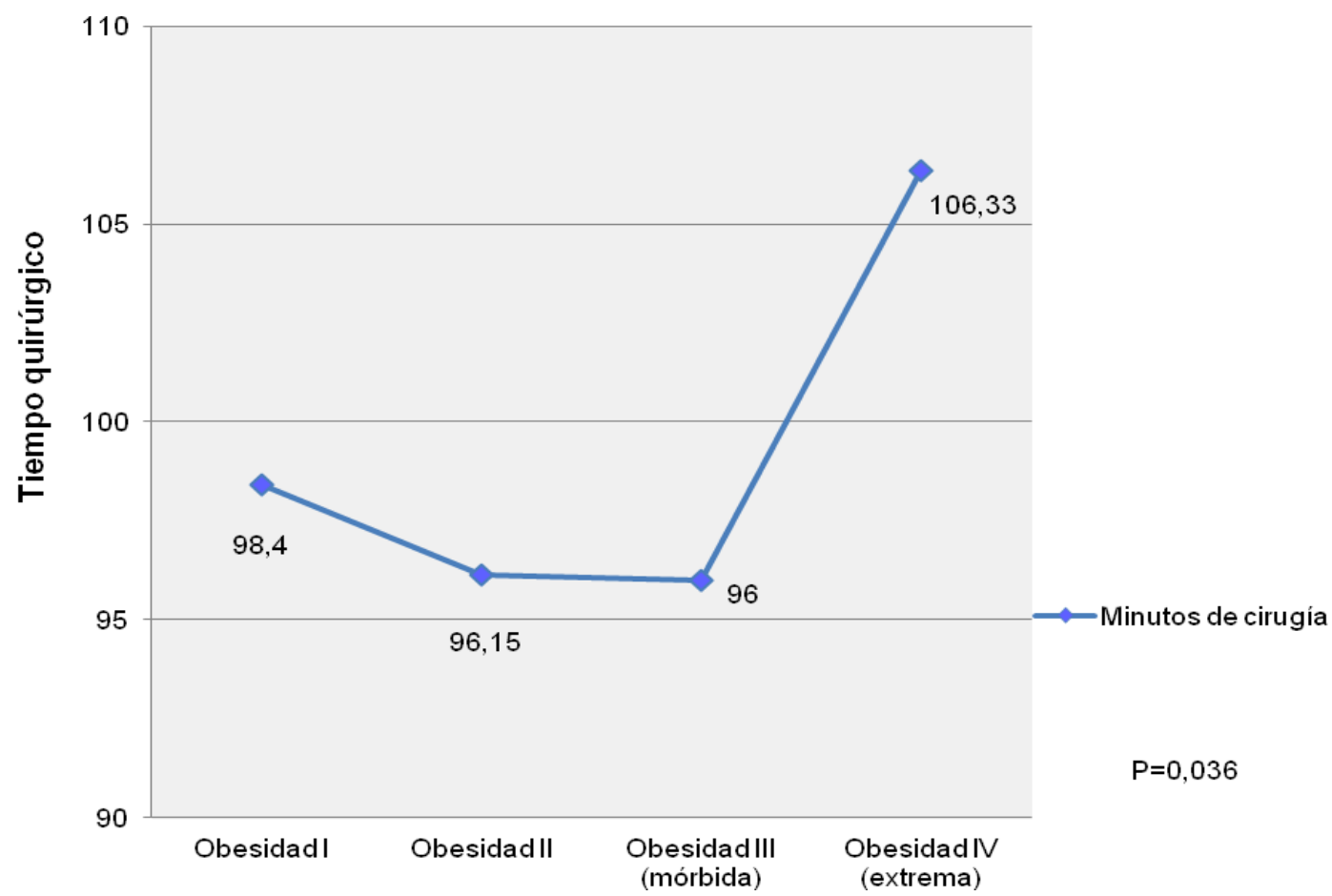

Figura 4.6.1. Tiempo quirúrgico según el grado de obesidad

La duración media de la intervención cuando se realizó la reducción de hernia hiatal fue de 97,38 \pm 10,51 minutos, cuando no se realizó el tiempo 
medio fue de 98,40 \ 14,76 minutos. La combinación de BAGUA y reducción de hernia hiatal no modificó de manera estadísticamente significativa la media del tiempo de duración de la cirugía.

De manera contraria, la combinación de BAGUA y colecistectomía modificó la duración media de la cirugía, siendo de 121,58 \pm 2,35 minutos en los pacientes con la combinación de colecistectomía, y 94,60 \pm 9,49 minutos en los que no se les practicó colecistectomía de manera simultánea $(P<0,001)$.

Al estudiar la correlación entre la longitud de las asas intestinales resultantes en el BAGUA y el tiempo de duración de la cirugía, no se observaron diferencias estadísticamente significativas. Si tomamos como referencia la mediana de las asas intestinales, siendo en el asa biliopancreática $P 50=270 \mathrm{~cm}$ y en el asa común $P 50=230 \mathrm{~cm}$, no se determinaron diferencias estadísticamente significativas entre la duración de la cirugía respecto al P50 del asa biliopancreática, tabla 4.6.1.

\begin{tabular}{|c|c|c|c|c|}
\hline & Asa biliopancreática & $\mathbf{N}$ & Media & D. Típica \\
\hline \multirow{3}{*}{$\begin{array}{c}\text { Tiempo } \\
\text { quirúrgico } \\
\text { (minutos) }\end{array}$} & $\leq 270 \mathrm{~cm}$ & 58 & 98,19 & 13,47 \\
\hline & $>270 \mathrm{~cm}$ & 42 & 101,87 & 11,29 \\
\hline & & & & $P=0,738$ \\
\hline
\end{tabular}

Tabla 4.6.1. Tiempo quirúrgico según la longitud del asa biliopancreática

En cambio el P50 de la longitud del asa común respecto al tiempo quirúrgico si modificó la duración de la misma $(P=0,021)$ como se observa en la tabla 4.6.2.

\begin{tabular}{|c|c|c|c|c|}
\hline & Asa común & N & Media & D. Típica \\
\hline Tiempo & $\leq 230 \mathrm{~cm}$ & 61 & 95,26 & 9,35 \\
\cline { 2 - 5 } quirúrgico & $>230 \mathrm{~cm}$ & 39 & 101,87 & 15,64 \\
\cline { 2 - 6 } (minutos) & & & & $\mathrm{P}=0,021$ \\
\hline
\end{tabular}

Tabla 4.6.2. Tiempo quirúrgico según la longitud del asa común

\section{- Estancia hospitalaria}

Los días de hospitalización de los 100 pacientes intervenidos de BAGUA, en el $98 \%$ de los casos fue de 1 día. Tan solo 2 pacientes 
estuvieron 2 días ingresados. En ninguno de los 100 pacientes estudiados el tiempo de hospitalización supera las 48 horas.

\section{- Complicaciones quirúrgicas}

No se observaron complicaciones intraoperatorias ni las consideradas como tempranas (antes de los 30 días postquirúrgicos) ni tampoco tardías (posteriores a los 30 días postquirúrgicos). Aquellas complicaciones que no precisaron ingreso hospitalario derivadas por las carencias en la absorción de los nutrientes propias de las cirugías de tipo malabsortivo, fueron evaluadas y tratadas por el equipo nutricional de CTO. 


\subsection{Valoración antropométrica}

En este apartado se describirá cada una de las variables antropométricas evaluadas en las diferentes revisiones desde la consulta inicial hasta los 2 años de la cirugía. En cada uno de los controles cada variable se describirá en función del sexo y la mediana de edad de la muestra.

\subsubsection{Altura}

En la consulta prequirúrgica se midió la altura de todos los pacientes que posteriormente se sometieron a la cirugía. En la tabla 4.7.1 se describe la altura expresada en metros, la media, desviación típica, mediana, y rango intercuartílico (P25-P75).

\begin{tabular}{|c|c|}
\hline & Altura consulta inicial (m) \\
\hline $\mathbf{N}$ & 100 \\
\hline Media & 1,65 \\
\hline D.Típica & 0,09 \\
\hline Mediana & 1,64 \\
\hline $\begin{array}{c}\text { Rango } \\
\text { intercuartílico } \\
\text { (P25-P75) }\end{array}$ & $1,59-1,70$ \\
\hline
\end{tabular}

Tabla 4.7.1. Descripción de la altura de los pacientes estudiados

Existe una mayor concentración de los pacientes respecto a la altura en el primer cuartil. La altura más elevada corresponde a un varón de 1,86 m y la más baja también a un hombre de 1,49 m. Sólo 25 pacientes superaban el $1,70 \mathrm{~m}$ de altura.

Respecto al sexo, en la figura 4.7.1 se muestra mediante un diagrama de cajas la diferencia en altura entre hombre y mujeres, siendo más elevada en el primero $(P<0,001)$. 


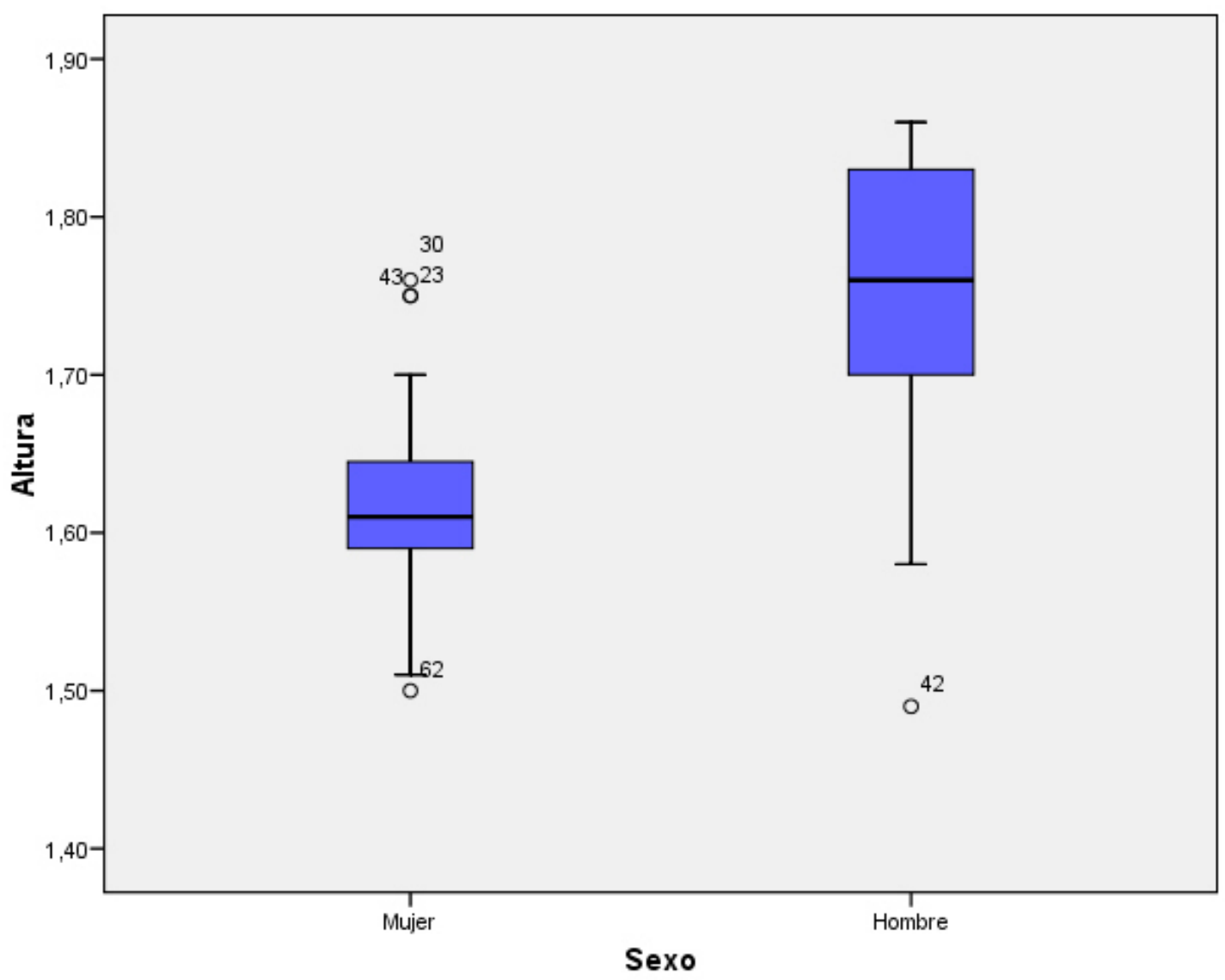

Figura 4.7.1. Descripción de la altura según el sexo mediante diagrama de cajas

La altura máxima observada en el grupo de las mujeres fue de 1,76 m, y la más baja de 1,50 m. El 50\% de los hombres tenía una altura de 1,76 m, mientras que las mujeres de 1,61 m. $(P<0,001)$.

Al observar la altura por grupos de edad, no se observaron diferencias estadísticamente significativas, como muestra la figura 4.7.2. 


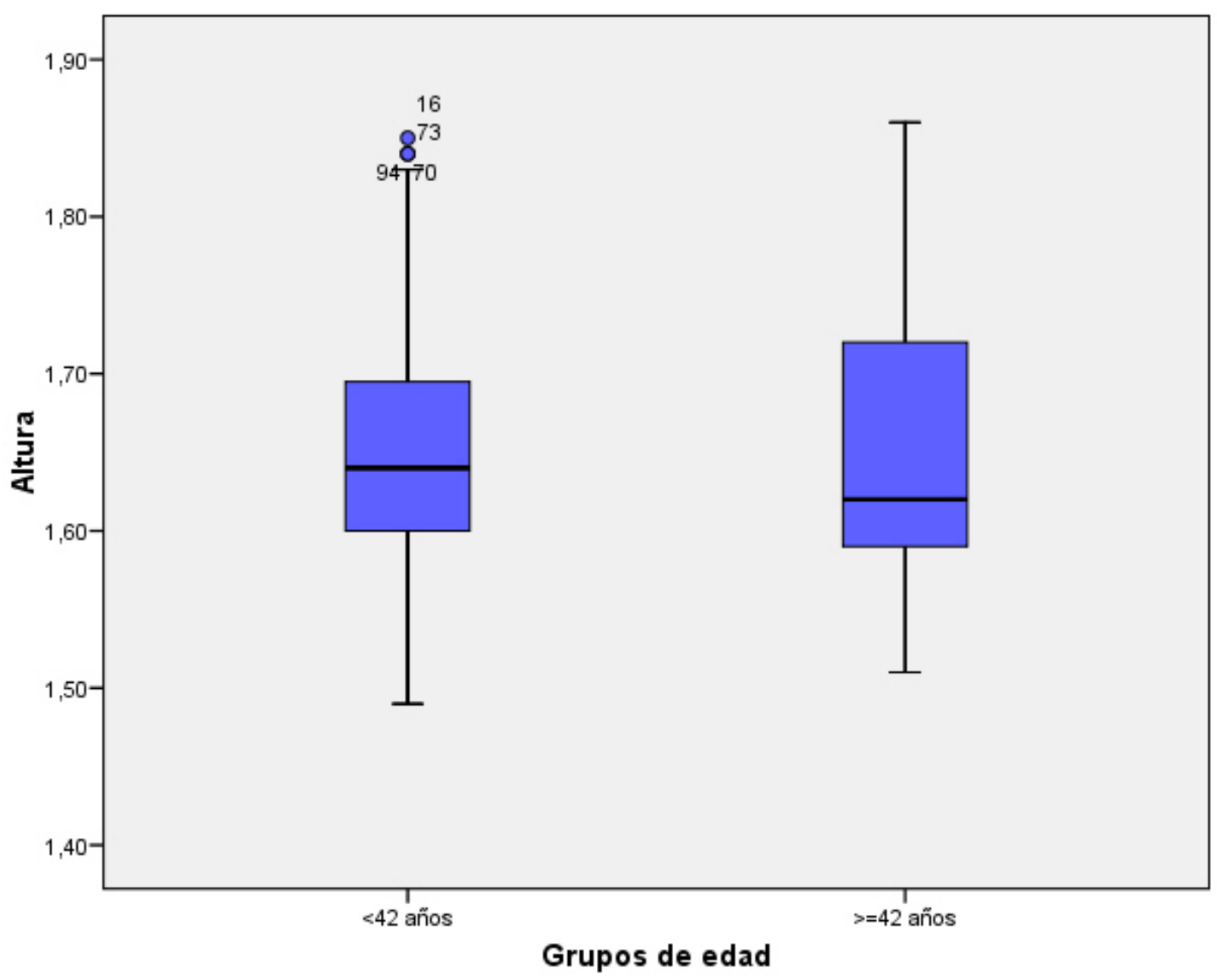

Figura 4.7.2. Descripción de la altura según la mediana de edad de la muestra

El grupo de < 42 años están más concentrados respecto a la altura, en cambio en el grupo de los $\geq 42$ años existe una mayor dispersión entre el P50-P75.

\subsubsection{Peso}

En la tabla 4.7.2 se describen los pesos en $\mathrm{Kg}$, la media, desviación típica, mediana, y rango intercuartílico (P25-P75), en cada uno de los controles evaluados, acompañados de la proporción de pacientes que contestaron en cada uno de ellos.

\begin{tabular}{|c|c|c|c|c|c|c|c|c|}
\cline { 2 - 9 } & $\begin{array}{c}\text { Peso } \\
\text { consulta } \\
\text { inicial } \\
\mathbf{( K g )}\end{array}$ & $\begin{array}{c}\text { Peso } \\
\text { cirugía } \\
\mathbf{( K g )}\end{array}$ & $\begin{array}{c}\text { Peso 3 } \\
\text { meses } \\
\mathbf{( K g )}\end{array}$ & $\begin{array}{c}\text { Peso 6 } \\
\text { meses } \\
\mathbf{( K g )}\end{array}$ & $\begin{array}{c}\text { Peso 9 } \\
\text { meses } \\
\mathbf{( K g )}\end{array}$ & $\begin{array}{c}\text { Peso } \\
\mathbf{1 2} \\
\text { meses } \\
\mathbf{( K g )}\end{array}$ & $\begin{array}{c}\text { Peso } \\
\mathbf{1 8} \\
\text { meses } \\
\mathbf{( K g )}\end{array}$ & $\begin{array}{c}\text { Peso } \\
\mathbf{2 4} \\
\text { meses } \\
\mathbf{( K g )}\end{array}$ \\
\hline $\mathbf{N}$ & 100 & 100 & 93 & 83 & 58 & 82 & 63 & 100 \\
\hline Media & 116,75 & $100,75^{\star^{\dagger}}$ & $81,55^{\star^{\dagger}}$ & $74,02^{*^{\dagger}}$ & $72,13^{\star^{\dagger}}$ & $68,56^{\star^{\dagger}}$ & $69,67^{\dagger}$ & $69,66^{*^{\dagger}}$ \\
\hline D.Típica & 22,19 & 15,79 & 15,22 & 14,11 & 14,78 & 13,10 & 14,40 & 13,07 \\
\hline Mediana & 110,70 & 97,8 & 82 & 73 & 70,35 & 66,25 & 67 & 67 \\
\hline
\end{tabular}




\begin{tabular}{|c|c|c|c|c|c|c|c|c|}
\hline & $\begin{array}{c}\text { Peso } \\
\text { consulta } \\
\text { inicial } \\
(\mathrm{Kg})\end{array}$ & $\begin{array}{l}\text { Peso } \\
\text { cirugía } \\
(\mathrm{Kg})\end{array}$ & $\begin{array}{c}\text { Peso } 3 \\
\text { meses } \\
(\mathrm{Kg})\end{array}$ & $\begin{array}{c}\text { Peso } 6 \\
\text { meses } \\
(\mathrm{Kg})\end{array}$ & $\begin{array}{c}\text { Peso } 9 \\
\text { meses } \\
(\mathrm{Kg})\end{array}$ & $\begin{array}{c}\text { Peso } \\
12 \\
\text { meses } \\
(\mathrm{Kg})\end{array}$ & $\begin{array}{c}\text { Peso } \\
18 \\
\text { meses } \\
(\mathrm{Kg})\end{array}$ & $\begin{array}{c}\text { Peso } \\
24 \\
\text { meses } \\
(\mathrm{Kg})\end{array}$ \\
\hline $\begin{array}{c}\text { Rango } \\
\text { intercuartílico } \\
\text { (P25-P75) }\end{array}$ & $\begin{array}{l}99,48- \\
130,33\end{array}$ & $\begin{array}{c}89- \\
110,95\end{array}$ & $\begin{array}{c}69,50- \\
90\end{array}$ & $63-82$ & $\begin{array}{c}62- \\
80,60\end{array}$ & $59-78$ & $\begin{array}{l}58,70- \\
78,50\end{array}$ & $\begin{array}{c}59,78- \\
78,45\end{array}$ \\
\hline
\end{tabular}

Tabla 4.7.2. Descripción del peso en las diferentes revisiones evaluadas

Se observa una tasa de respuesta de los pacientes no homogénea entre los diferentes controles, siendo el control de los 9 meses en el que menos pacientes enviaron los datos de evolución, seguido del de los 18 meses. El resto de revisiones las respondieron más del $80 \%$ de la muestra estudiada.

En la primera consulta, el 25\% de los pacientes superaban los $130 \mathrm{Kg}$. La disminución ponderal media entre controles será objeto de estudio en apartados posteriores. Destaca la desaceleración en la disminución ponderal media desde el control de los 12 meses hasta los 2 años, siendo prácticamente el mismo peso en los 3 controles posteriores.

La diferencia del peso medio entre cada control evaluado es estadísticamente significativa excepto entre el control de los 12 a los 18 meses $(P>0,05)$.

El peso medio más bajo obtenido en los diferentes controles evaluados se describe a los 12 meses postcirugía $(P<0,001)$. Desde el control de los 12 meses el $75 \%$ de la muestra tiene un peso medio $<80 \mathrm{Kg}$.

En la figura 4.7.3 se describen en histogramas el peso en los diferentes controles evaluados. 

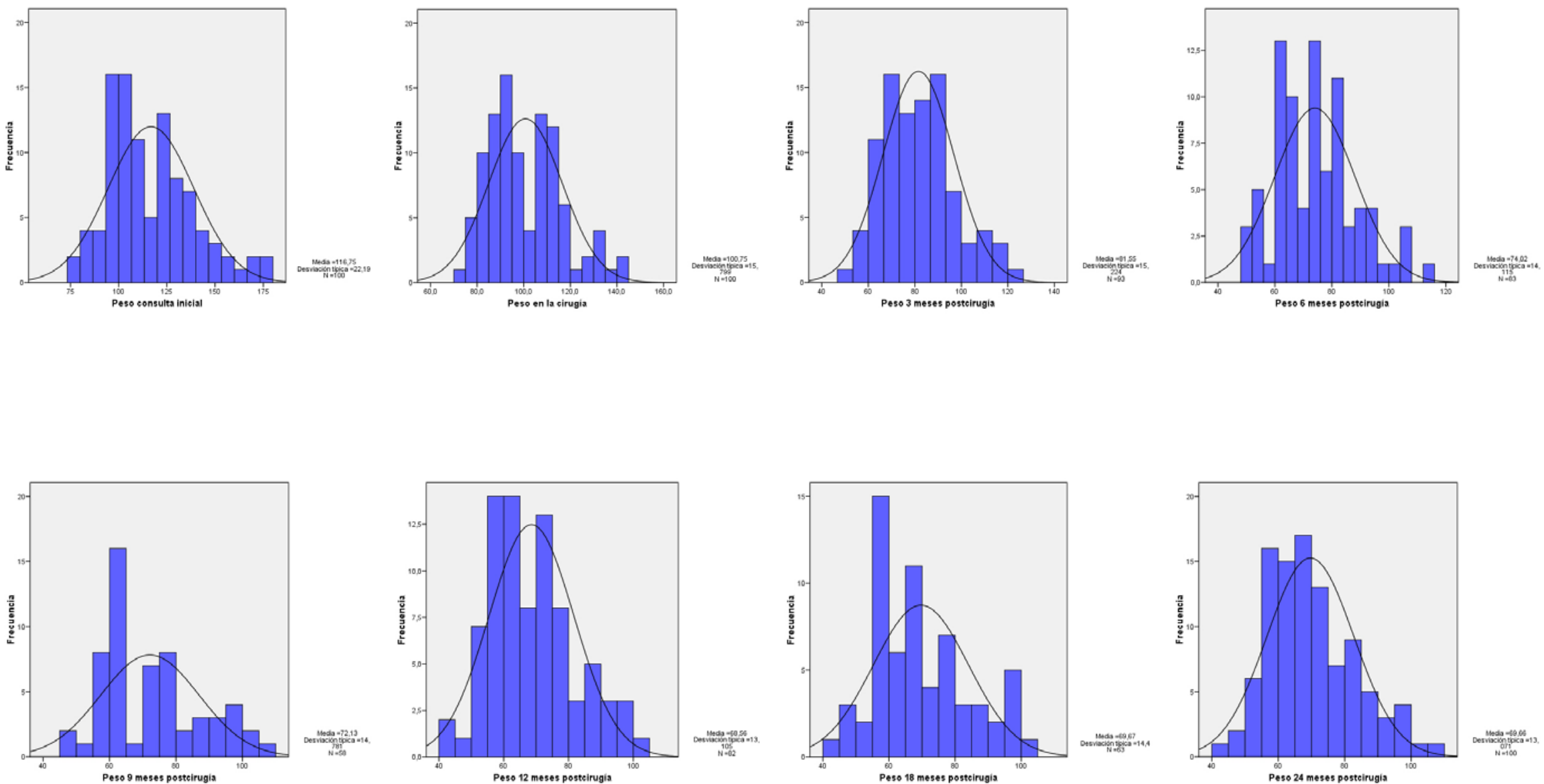

Figura 4.7.3. Representación en histogramas del peso en las diferentes revisiones evaluadas 
En la figura 4.7.4 se representa la media de peso en los diferentes controles evaluados en un gráfico de barras de error.

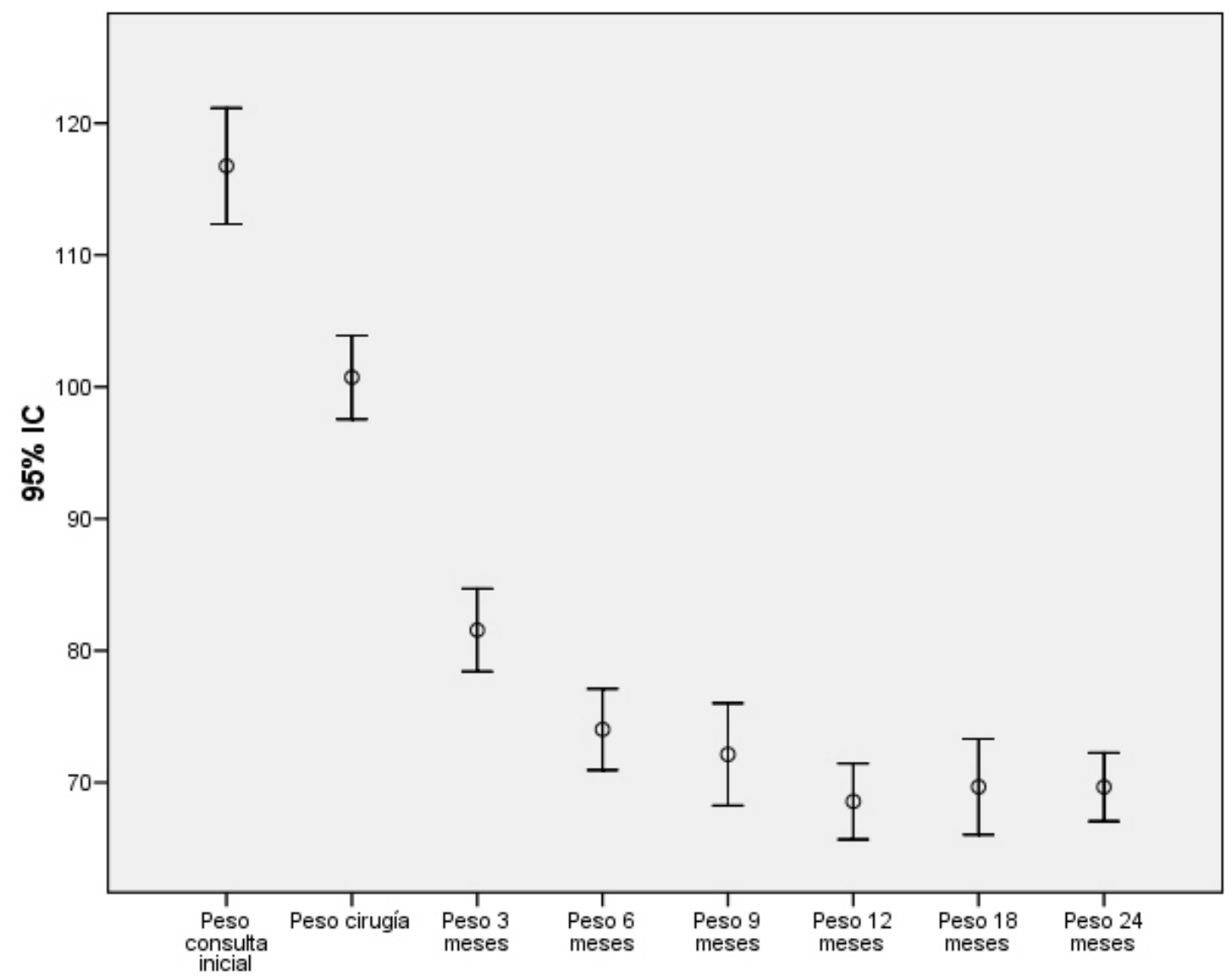

Figura 4.7.4. Gráfico de barras de error (IC 95\%) del peso en los controles evaluados

En la tabla 4.7.3, se describe el peso medio según el sexo en los diferentes controles evaluados. Se observan en todos los controles un peso medio más elevado en los varones $(P<0,001)$, del mismo modo ocurre al comparar cada uno de los controles con el peso de la consulta inicial $(P<0,001)$.

\begin{tabular}{|l|c|c|c|c|c|c|c|}
\cline { 2 - 8 } \multicolumn{1}{c|}{} & \multicolumn{3}{c|}{ Mujer } & \multicolumn{3}{c|}{ Hombre } & \multirow{2}{*}{ P } \\
\cline { 2 - 8 } & $\mathbf{N}$ & Media & D.Típica & N & Media & D.Típica & \\
\hline $\begin{array}{l}\text { Peso consulta inicial } \\
\text { (Kg) }\end{array}$ & 71 & 110,43 & 18,99 & 29 & 132,23 & 22,13 & $<0,001$ \\
\hline Peso cirugía (Kg) & 71 & $96,87^{\dagger}$ & 13,64 & 29 & $110,23^{\dagger}$ & 16,91 & $<0,001$ \\
\hline Peso 3 meses (Kg) & 66 & $78,33^{\dagger}$ & 14,42 & 27 & $89,44^{\dagger}$ & 14,45 & $<0,001$ \\
\hline Peso 6 meses (Kg) & 61 & $70,11^{\dagger}$ & 11,83 & 22 & $84,86^{\dagger}$ & 14,50 & $<0,001$ \\
\hline Peso 9 meses (Kg) & 39 & $67,65^{\dagger}$ & 12,34 & 19 & $81,33^{\dagger}$ & 15,41 & $<0,001$ \\
\hline Peso 12 meses (Kg) & 60 & $64,75^{\dagger}$ & 11 & 22 & $78,96^{\dagger}$ & 12,94 & $<0,001$ \\
\hline
\end{tabular}




\begin{tabular}{|c|c|c|c|c|c|c|c|}
\hline & \multicolumn{3}{|c|}{ Mujer } & \multicolumn{3}{|c|}{ Hombre } & \multirow{2}{*}{$\mathbf{P}$} \\
\hline & $\mathbf{N}$ & Media & D.Típica & $\mathbf{N}$ & Media & D.Típica & \\
\hline Peso 18 meses $(\mathrm{Kg})$ & 42 & $63,57^{\dagger}$ & 10,96 & 21 & $81,87^{\dagger}$ & 12,72 & $<0,001$ \\
\hline Peso 24 meses $(\mathrm{Kg})$ & 71 & $64,75^{\dagger}$ & 10 & 29 & $81,69^{\dagger}$ & 11,95 & $<0,001$ \\
\hline
\end{tabular}

Tabla 4.7.3. Descripción del peso medio según el sexo en las diferentes revisiones evaluadas

En todos los controles se observa una media de peso superior en los hombres respecto a las mujeres, siendo la mayor diferencia de medias entre ambos sexos en el control de la consulta inicial y a los 18 meses de la intervención.

El peso medio más bajo en las mujeres se registró a los 18 meses con un peso medio de 63,57 $\pm 10,96 \mathrm{Kg}$. En cambio en los varones es al año de la intervención cuando consiguen un peso medio más bajo $(78,96 \pm 12,94$ $\mathrm{Kg}$ ) respecto al resto de controles.

En la figura 4.7.5 se representa la evolución del peso medio de las mujeres y el de los hombres. Se observa que en todos los controles evaluados, tanto las mujeres como los hombres disminuyen el peso medio conforme pasan los meses desde la cirugía, hasta los 12 meses en el que los hombres suben el peso medio y lo mantienen hasta los 24 meses. Las mujeres descienden el peso medio en todos los controles, excepto a los 24 meses que registra un peso medio igual que el de los 12 meses $(64,75 \mathrm{Kg})$.

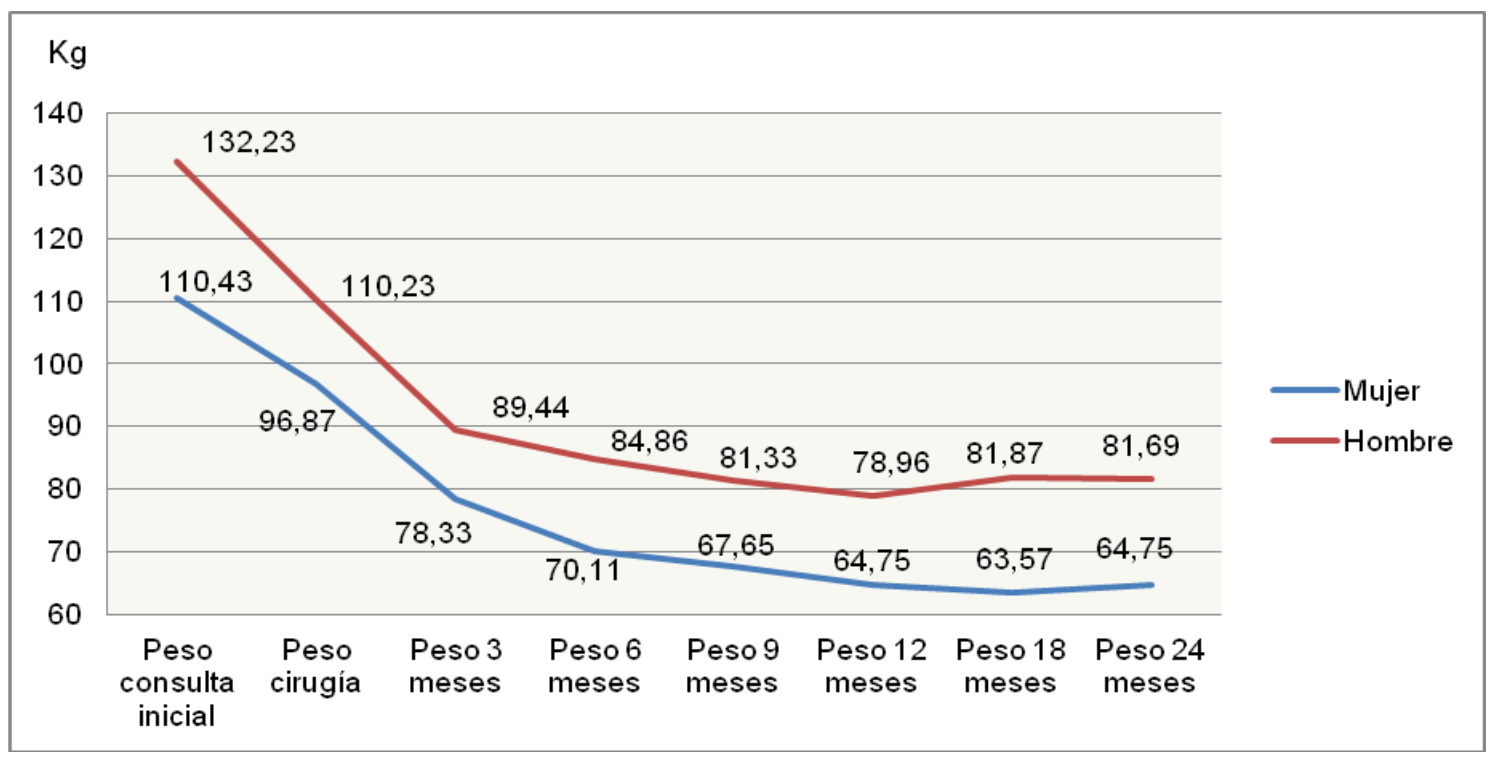

Figura 4.7.5. Tendencia en la evolución del peso medio por sexo 
Por grupos de edad, como se detalla en la tabla 4.7.4, en ningún control evaluado se observan diferencias estadísticamente significativas entre el peso medio y los grupos de $<42$ años de edad $y \geq 42$ años.

\begin{tabular}{|c|c|c|c|c|c|c|c|}
\hline & \multicolumn{3}{|c|}{$<42$ años } & \multicolumn{3}{|c|}{$\geq 42$ años } & \multirow{2}{*}{$\mathbf{P}$} \\
\hline & $\mathbf{N}$ & Media & D.Típica & $\mathbf{N}$ & Media & D.Típica & \\
\hline $\begin{array}{l}\text { Peso consulta inicial } \\
(\mathrm{Kg})\end{array}$ & 48 & 118,05 & 23,75 & 52 & 115,55 & 20,79 & NS \\
\hline Peso cirugía (Kg) & 48 & $102,38^{\dagger}$ & 16,26 & 52 & $99,23^{\dagger}$ & 15,35 & NS \\
\hline Peso 3 meses $(\mathrm{Kg})$ & 45 & $82,28^{\dagger}$ & 14,26 & 48 & $80,88^{\dagger}$ & 16,19 & NS \\
\hline Peso 6 meses $(\mathrm{Kg})$ & 39 & $72,62^{\dagger}$ & 13,58 & 44 & $75,26^{\dagger}$ & 14,61 & NS \\
\hline Peso 9 meses $(\mathrm{Kg})$ & 24 & $75,26^{\dagger}$ & 14,61 & 24 & $71,27^{\dagger}$ & 15,48 & NS \\
\hline Peso 12 meses (Kg) & 39 & $69,20^{\dagger}$ & 13,47 & 43 & $67,99^{\dagger}$ & 12,89 & NS \\
\hline Peso 18 meses $(\mathrm{Kg})$ & 28 & $69,65^{\dagger}$ & 14,88 & 35 & $69,69^{\dagger}$ & 14,21 & NS \\
\hline Peso 24 meses $(\mathrm{Kg})$ & 48 & $69,15^{\dagger}$ & 12,50 & 52 & $70,13^{\dagger}$ & 13,68 & NS \\
\hline
\end{tabular}

Tabla 4.7.4. Descripción del peso medio según el grupo de edad en las diferentes revisiones evaluadas

\section{a) Pérdida de peso entre las revisiones evaluadas}

En la tabla 4.7.5 se muestra la pérdida ponderal entre los controles evaluados desde el momento de la cirugía expresado en $\mathrm{Kg}$. El primer control evaluado corresponde al peso perdido medio previo a la cirugía, en los controles posteriores se hace referencia a la diferencia de peso medio perdido respecto al control anterior. Los valores expresados en negativo suponen ganancia de peso respecto al control anterior.

\begin{tabular}{|c|c|c|c|c|c|c|c|}
\hline & $\begin{array}{c}\text { Peso } \\
\text { perdido } \\
\text { precirugía } \\
(\mathrm{Kg})\end{array}$ & $\begin{array}{c}\text { Peso } \\
\text { perdido } \\
3 \\
\text { meses } \\
(\mathrm{Kg})\end{array}$ & $\begin{array}{c}\text { Peso } \\
\text { perdido } \\
6 \\
\text { meses } \\
(\mathrm{Kg})\end{array}$ & $\begin{array}{c}\text { Peso } \\
\text { perdido } \\
9 \\
\text { meses } \\
(\mathrm{Kg})\end{array}$ & $\begin{array}{c}\text { Peso } \\
\text { perdido } \\
12 \\
\text { meses } \\
(\mathrm{Kg})\end{array}$ & $\begin{array}{c}\text { Peso } \\
\text { perdido } \\
18 \\
\text { meses } \\
(\mathrm{Kg})\end{array}$ & $\begin{array}{c}\text { Peso } \\
\text { perdido } \\
24 \\
\text { meses } \\
(\mathrm{Kg})\end{array}$ \\
\hline $\mathbf{N}$ & 100 & 92 & 77 & 44 & 50 & 55 & 63 \\
\hline Media & 16 & $19,65^{\star^{\dagger}}$ & $7,44^{*^{\dagger}}$ & $4,04 *^{\dagger}$ & $2,35^{*^{\dagger}}$ & $-0,03^{*^{\dagger}}$ & $-0,77^{\dagger}$ \\
\hline D.Típica & 7,99 & 7,28 & 7 & 3,51 & 3,15 & 2,75 & 1,84 \\
\hline Mediana & 14,80 & 18,85 & 6 & 3,75 & 2 & 0 & $-0,5$ \\
\hline $\begin{array}{c}\text { Rango } \\
\text { intercuartílico } \\
\text { (P25-P75) }\end{array}$ & $\begin{array}{l}9,90- \\
22,10\end{array}$ & $\begin{array}{l}15,92- \\
24,47\end{array}$ & $3,4-10,4$ & $1,85-6$ & $\begin{array}{c}0,47- \\
4,12\end{array}$ & $\begin{array}{c}(-1,70)- \\
(1,30)\end{array}$ & $\begin{array}{c}(-1,80)- \\
(0,50)\end{array}$ \\
\hline
\end{tabular}

Tabla 4.7.5. Descripción del peso perdido en las diferentes revisiones evaluadas 
La pérdida de peso medio aumenta entre la cirugía y los 3 meses de manera significativa $(P<0,001)$, observando una disminución de esa pérdida de peso entre los controles sucesivos. Desde los 18 meses de la cirugía el balance en la pérdida de peso es negativa puesto que es desde este control cuando los pacientes modifican la tendencia y aumentan ligeramente su peso

La pérdida de peso medio más pronunciada se observa en el periodo comprendido desde la cirugía hasta los 3 meses. Desde este momento la pérdida de peso desciende hasta que en el control de los 18 meses en el que se detiene, con una ligera ganancia ponderal de 30 gramos de media. A los 18 meses, la mitad de los pacientes no sufrieron cambios de peso respecto al control anterior.

A los 24 meses la ganancia ponderal media de la muestra sobrepasa los $1,8 \mathrm{Kg}$ en el $25 \%$ de los pacientes evaluados. El $50 \%$ de los pacientes a los 24 meses aumentaron $0,5 \mathrm{Kg}$ de media.

En la figura 4.7.6 se describe mediante histogramas el peso perdido en los diferentes controles evaluados. 

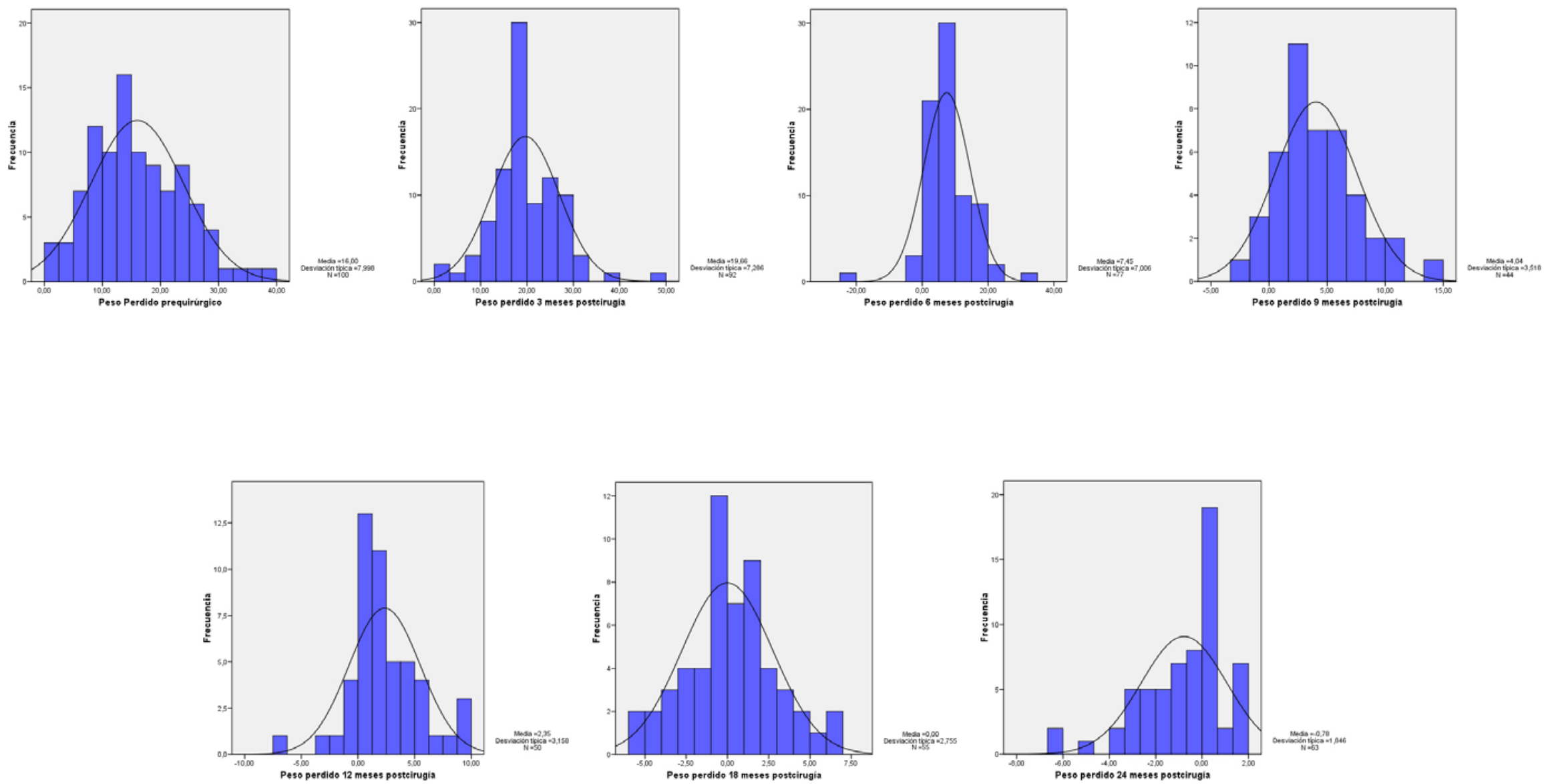

Figura 4.7.6. Representación en histogramas del peso perdido en las diferentes revisiones evaluadas 
En la figura 4.7.7 se representa la pérdida de peso en los diferentes controles evaluados en un gráfico de barras de error. Se aprecia de manera más visual como a partir del control de los 18 meses no hay pérdida de peso sino aumento del mismo hasta el último control evaluado a los 24 meses.

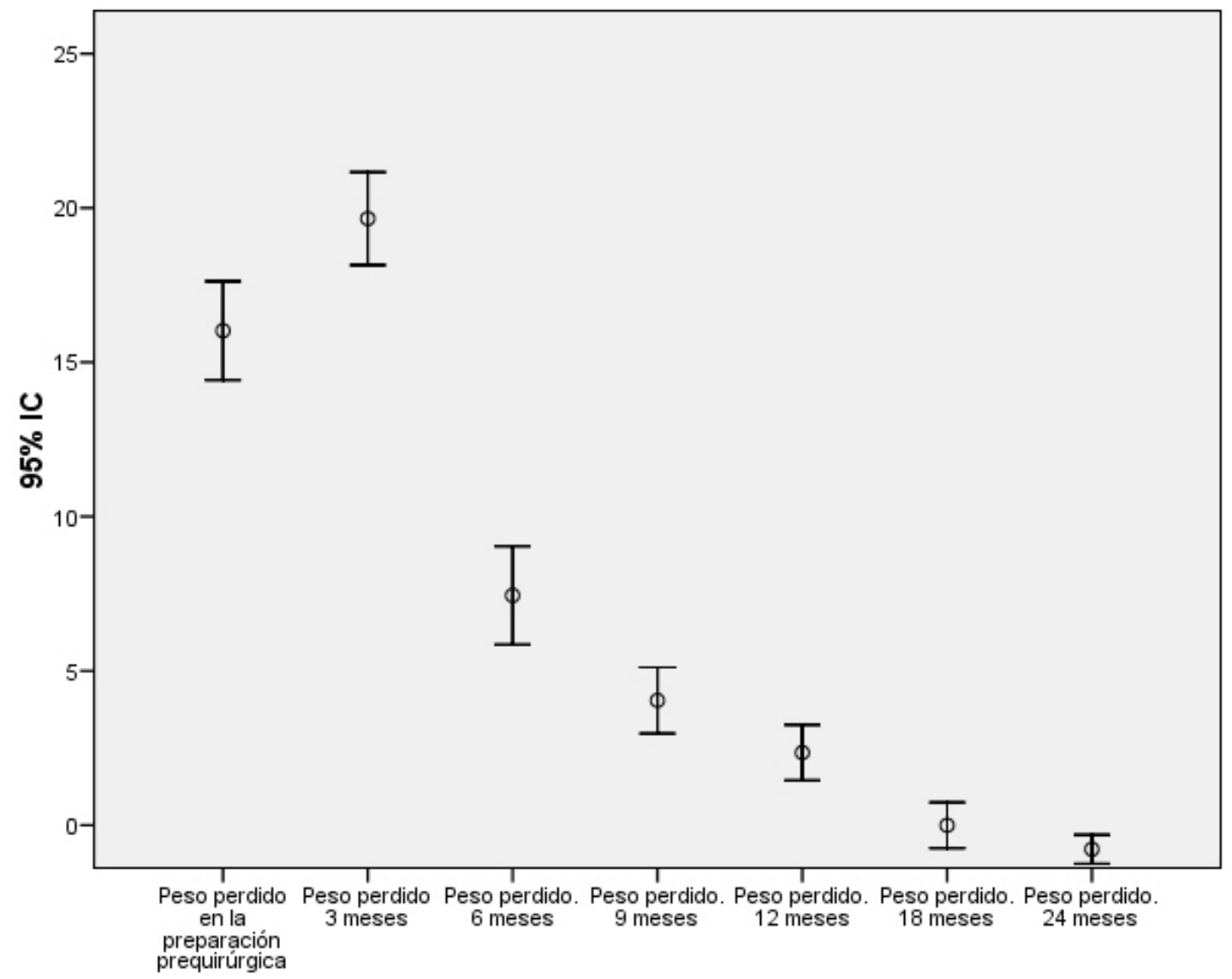

Figura 4.7.7. Gráfico de barras de error (IC 95\%) del peso perdido en los controles evaluados

En la tabla 4.7.6 se muestra la distribución de los pacientes estudiados en los diferentes controles evaluados según el sexo y el peso medio perdido. Los valores con signo negativo indican ganancia de peso y no disminución, como se observa desde los 18 meses.

\begin{tabular}{|c|c|c|c|c|c|c|c|}
\hline & \multicolumn{3}{|c|}{ Mujer } & \multicolumn{3}{|c|}{ Hombre } & \multirow{2}{*}{$\mathbf{P}$} \\
\hline & $\mathbf{N}$ & Media & D.Típica & $\mathbf{N}$ & Media & D.Típica & \\
\hline $\begin{array}{c}\text { Peso perdido } \\
\text { preparación } \\
\text { prequirúrgica } \\
\text { (Kg) }\end{array}$ & 71 & 13,55 & 6,84 & 29 & 21,98 & 7,53 & $<0,001$ \\
\hline $\begin{array}{c}\text { Peso perdido } 3 \\
\text { meses }(\mathrm{Kg})\end{array}$ & 65 & $18,88^{\dagger}$ & 6,98 & 27 & 21,50 & 7,78 & NS \\
\hline
\end{tabular}




\begin{tabular}{|c|c|c|c|c|c|c|c|}
\hline & \multicolumn{3}{|c|}{ Mujer } & \multicolumn{3}{|c|}{ Hombre } & \multirow{2}{*}{$\mathbf{P}$} \\
\hline & $\mathbf{N}$ & Media & D.Típica & $\mathbf{N}$ & Media & D.Típica & \\
\hline $\begin{array}{c}\text { Peso perdido } 6 \\
\text { meses }(\mathrm{Kg})\end{array}$ & 57 & $8,18^{\dagger}$ & 7,68 & 20 & $5,35^{\dagger}$ & 4,02 & $<0,05$ \\
\hline $\begin{array}{c}\text { Peso perdido } 9 \\
\text { meses }(\mathrm{Kg})\end{array}$ & 31 & $4,14^{\dagger}$ & 3,73 & 13 & $3,78^{\dagger}$ & 3,06 & NS \\
\hline $\begin{array}{l}\text { Peso perdido } 12 \\
\text { meses }(\mathrm{Kg})\end{array}$ & 34 & $2,90^{\dagger}$ & 2,87 & 16 & $1,17^{\dagger}$ & 3,50 & NS \\
\hline $\begin{array}{l}\text { Peso perdido } 18 \\
\text { meses }(\mathrm{Kg})\end{array}$ & 38 & $0,41^{\dagger}$ & 2,78 & 17 & $-0,94^{\dagger}$ & 2,52 & NS \\
\hline $\begin{array}{c}\text { Peso perdido } 24 \\
\text { meses }(\mathrm{Kg})\end{array}$ & 42 & $-0,81^{\dagger}$ & 1,55 & 21 & $-0,70^{\dagger}$ & 2,36 & NS \\
\hline
\end{tabular}

Tabla 4.7.6. Descripción del peso perdido medio según el sexo en las diferentes revisiones evaluadas

En la preparación prequirúrgica y en la revisión de los 6 meses, son los periodos en los que se aprecia una diferencia significativa en la pérdida ponderal en función del sexo, siendo el control prequirúrgico en el que los hombres alcanzan una mayor pérdida de peso. En cambio a los 6 meses postcirugía son las mujeres las que pierden más peso medio respecto a los hombres. En el resto de controles la pérdida ponderal en ambos sexos es similar. En la tabla 4.7.7, se muestran los pacientes agrupados por la mediana de edad.

\begin{tabular}{|c|c|c|c|c|c|c|c|}
\cline { 2 - 7 } \multicolumn{1}{c|}{} & \multicolumn{3}{c|}{$<\mathbf{4 2 \text { años }}$} & \multicolumn{3}{c|}{$\geq \mathbf{4 2 \text { años }}$} & \multirow{2}{*}{ P } \\
\cline { 2 - 7 } & $\mathbf{N}$ & Media & D.Típica & $\mathbf{N}$ & Media & D.Típica & \\
\hline $\begin{array}{c}\text { Peso perdido } \\
\text { preparación } \\
\text { prequirúrgica } \\
\text { (Kg) }\end{array}$ & 48 & 15,66 & 8,41 & 52 & 16,31 & 7,66 & NS \\
\hline $\begin{array}{c}\text { Peso perdido 3 } \\
\text { meses (Kg) }\end{array}$ & 45 & $21,30^{\dagger}$ & 6,68 & 47 & 18,08 & 7,55 & $<0,05$ \\
\hline $\begin{array}{c}\text { Peso perdido 6 } \\
\text { meses (Kg) }\end{array}$ & 37 & $7,60^{\dagger}$ & 5,26 & 40 & $7,30^{\dagger}$ & 8,36 & NS \\
\hline $\begin{array}{c}\text { Peso perdido 9 } \\
\text { meses (Kg) }\end{array}$ & 16 & $5,37^{\dagger}$ & 2,88 & 28 & $3,27^{\dagger}$ & 3,66 & $<0,05$ \\
\hline $\begin{array}{c}\text { Peso perdido 12 } \\
\text { meses (Kg) }\end{array}$ & 21 & $2,38^{\dagger}$ & 3,26 & 29 & $2,32^{\dagger}$ & 3,14 & NS \\
\hline $\begin{array}{c}\text { Peso perdido 18 } \\
\text { meses (Kg) }\end{array}$ & 25 & $0,22^{\dagger}$ & 2,56 & 30 & $-0,19^{\dagger}$ & 2,93 & NS \\
\hline $\begin{array}{c}\text { Peso perdido 24 } \\
\text { meses (Kg) }\end{array}$ & 28 & $-0,25^{\dagger}$ & 1,84 & 35 & $-1,20^{\dagger}$ & 1,75 & $<0,05$ \\
\hline
\end{tabular}

Tabla 4.7.7. Descripción del peso perdido medio según el grupo de edad en las diferentes revisiones evaluadas 
En los controles postquirúrgicos de los 3 y 9 meses se observa como el grupo de pacientes de menor edad pierde más peso que el de los $\geq 42$ años $(P<0,05)$.

A los 2 años de la intervención, ambos grupos suben de peso medio respecto al control anterior pero son los pacientes $<42$ años quienes ganan menos peso respecto al grupo de los $\geq 42$ años que aumentan de media $1,20 \mathrm{Kg}(P<0,05)$.

En el resto de controles, los dos grupos de edad evaluados no presentan diferencias estadísticamente significativas en la pérdida de peso medio. A los 18 meses los más jóvenes reflejan una pérdida ponderal media de 0,22 $\mathrm{Kg}$, frente al aumento de peso observado en el grupo de los $\geq 42$ años de $0,19 \mathrm{Kg}$, sin ser estadísticamente significativo.

\section{b) Pérdida de peso diario entre las revisiones evaluadas}

En la tabla 4.7.8, se describe la pérdida de peso medio al día expresado en gramos en los diferentes controles evaluados, como en el apartado anterior los valores expresados en negativo suponen aumento de peso.

\begin{tabular}{|c|c|c|c|c|c|c|c|}
\hline & $\begin{array}{c}\text { Peso } \\
\text { perdido } \\
\text { día } \\
\text { precirugía } \\
\text { (g/día) }\end{array}$ & $\begin{array}{l}\text { Peso } \\
\text { perdido } \\
\text { día } \\
3 \text { meses } \\
\text { (g/día) }\end{array}$ & $\begin{array}{l}\text { Peso } \\
\text { perdido } \\
\text { día } \\
6 \text { meses } \\
\text { (g/día) }\end{array}$ & $\begin{array}{c}\text { Peso } \\
\text { perdido } \\
\text { día } \\
9 \text { meses } \\
\text { (g/día) }\end{array}$ & $\begin{array}{c}\text { Peso } \\
\text { perdido } \\
\text { día } \\
12 \\
\text { meses } \\
\text { (g/día) }\end{array}$ & $\begin{array}{c}\text { Peso } \\
\text { perdido } \\
\text { día } \\
18 \\
\text { meses } \\
\text { (g/día) }\end{array}$ & $\begin{array}{c}\text { Peso } \\
\text { perdido } \\
\text { día } \\
24 \\
\text { meses } \\
\text { (g/día) }\end{array}$ \\
\hline $\mathbf{N}$ & 100 & 92 & 77 & 44 & 50 & 55 & 63 \\
\hline Media & 187,3 & $163,8^{*^{\dagger}}$ & $62^{*^{\dagger}}$ & $33,7^{*^{\dagger}}$ & $19,6^{*^{\dagger}}$ & $0^{*^{\dagger}}$ & $-6,5^{\dagger}$ \\
\hline D.Típica & 90,35 & 60,72 & 58,39 & 29,32 & 26,32 & 22,96 & 15,38 \\
\hline Mediana & 181,1 & 157,1 & 50 & 31,3 & 16,7 & 0 & 4,2 \\
\hline $\begin{array}{c}\text { Rango } \\
\text { intercuartílico } \\
\text { (P25-P75) }\end{array}$ & $\begin{array}{l}133,8- \\
241,2\end{array}$ & $\begin{array}{c}132,7- \\
204\end{array}$ & $\begin{array}{c}28,3- \\
86,7\end{array}$ & $15,4-50$ & $4-34,4$ & $\begin{array}{c}(-14,2)- \\
(10,8)\end{array}$ & $\begin{array}{c}(-15)- \\
(4,2)\end{array}$ \\
\hline
\end{tabular}

Tabla 4.7.8. Descripción del peso perdido al día en las diferentes revisiones evaluadas

Se describe una pérdida de peso medio diaria gradual estadísticamente significativa desde la primera revisión hasta los 18 meses, que tiene su punto de inflexión a los 18 meses. Siendo éste, el control desde el que se aprecia un aumento ponderal diario de 6,5 g hasta los 2 años postquirúrgicos 
evaluados $(P>0,05)$. El $25 \%$ de los pacientes evaluados a los 18 meses aumentaron el peso diario respecto al control anterior por encima de los 14,2 g/día.

En la figura 4.7.8 se describe mediante histogramas el peso perdido al día en los diferentes controles evaluados, expresado en gramos. 

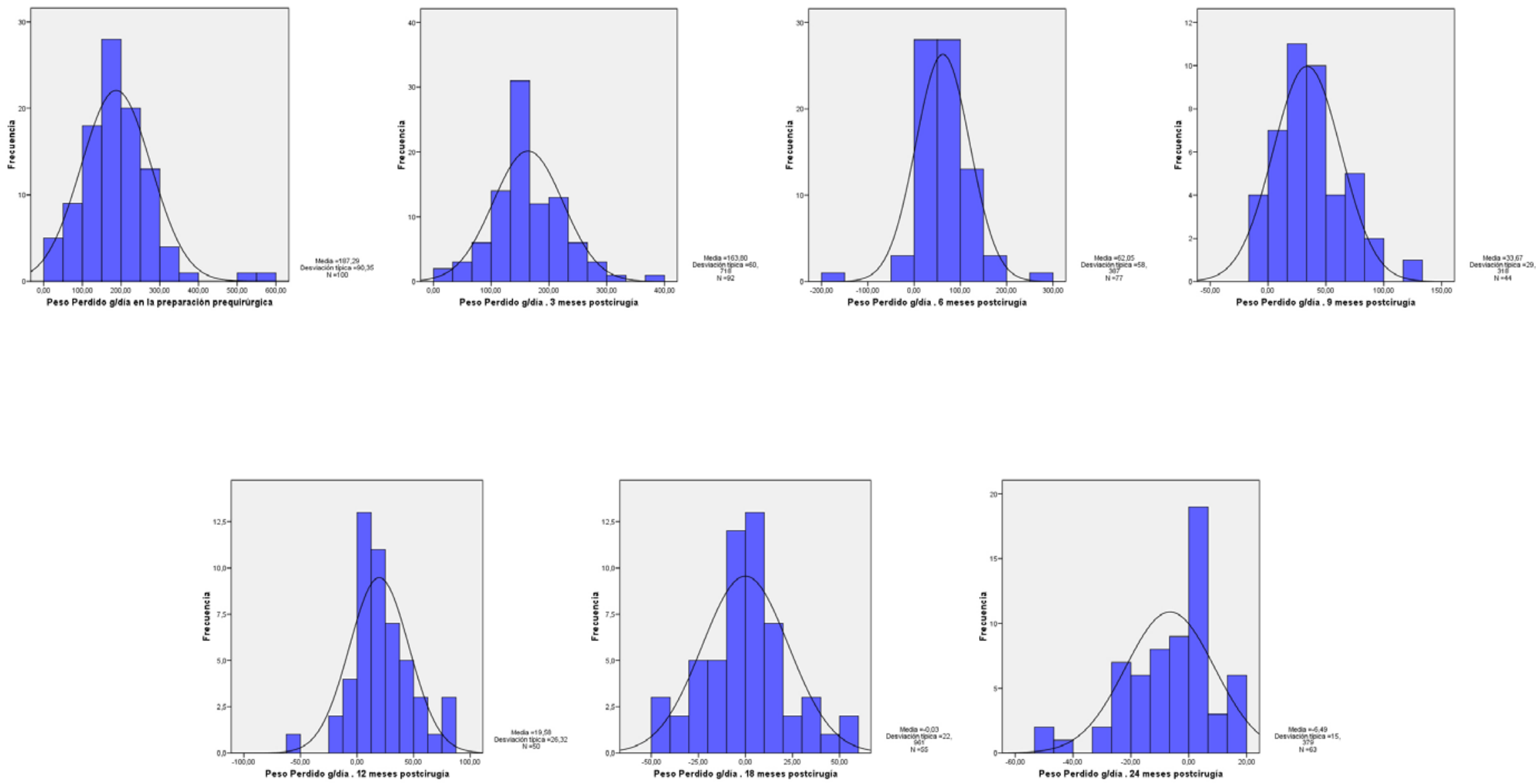

Figura 4.7.8. Representación en histogramas del peso perdido diario en las diferentes revisiones evaluadas 
En la figura 4.7.9, se muestra en un diagrama de barras de error la evolución de las media de peso perdido al día, expresado en gramos desde la primera consulta hasta los 2 años de la cirugía. Se observa una diferencias significativa $(P<0,001)$ en el peso perdido diario entre el primer control posterior a la cirugía y la revisión de los 24 meses.

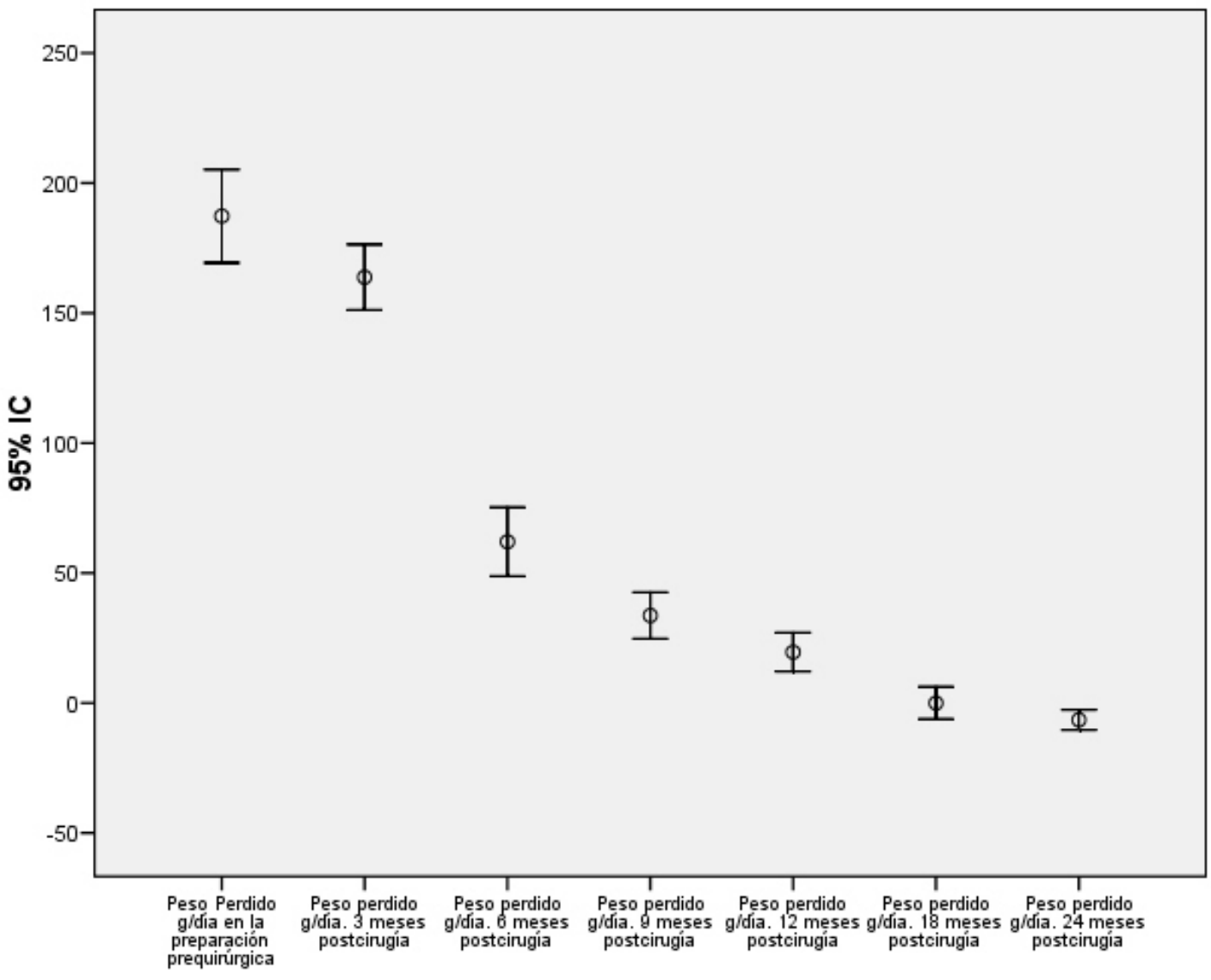

Figura 4.7.9. Gráfico de barras de error (IC 95\%) del peso perdido al día en los diferentes controles evaluados

En la tabla 4.7.9 se describe la pérdida ponderal media diaria expresada en gramos, en los diferentes controles evaluados según el sexo. Los valores en negativo manifiestan aumento de peso. Sólo en el control de los 6 meses postcirugía la diferencia del peso medio perdido al día es estadísticamente significativa, siendo la pérdida ponderal más alta en las mujeres $(P<0,05)$. 


\begin{tabular}{|c|c|c|c|c|c|c|c|}
\hline & \multicolumn{3}{|c|}{ Mujer } & \multicolumn{3}{|c|}{ Hombre } & \multirow{2}{*}{$\mathbf{P}$} \\
\hline & $\mathbf{N}$ & Media & D.Típica & $\mathbf{N}$ & Media & D.Típica & \\
\hline $\begin{array}{c}\text { Peso perdido día } \\
\text { preparación } \\
\text { prequirúrgica } \\
\text { (g/día) }\end{array}$ & 71 & 182,4 & 95,88 & 29 & 199,3 & 75,31 & NS \\
\hline $\begin{array}{l}\text { Peso perdido día } \\
3 \text { meses (g/día) }\end{array}$ & 65 & $157,44^{\dagger}$ & 58,23 & 27 & 179,2 & 64,85 & NS \\
\hline $\begin{array}{l}\text { Peso perdido día } \\
6 \text { meses (g/día) }\end{array}$ & 57 & $68,2^{\dagger}$ & 64,01 & 20 & 44,6 & $33,56^{\dagger}$ & $<0,05$ \\
\hline $\begin{array}{l}\text { Peso perdido día } \\
9 \text { meses (g/día) }\end{array}$ & 31 & $34,6^{\dagger}$ & 31,12 & 13 & 31,5 & $25,52^{\dagger}$ & NS \\
\hline $\begin{array}{l}\text { Peso perdido día } \\
12 \text { meses (g/día) }\end{array}$ & 34 & $24,2^{\dagger}$ & 23,92 & 16 & 9,8 & $29,22^{\dagger}$ & NS \\
\hline $\begin{array}{l}\text { Peso perdido día } \\
18 \text { meses (g/día) }\end{array}$ & 38 & $3,5^{\dagger}$ & 23,19 & 17 & $-7,8$ & $21,01^{\dagger}$ & NS \\
\hline $\begin{array}{l}\text { Peso perdido día } \\
24 \text { meses (g/día) }\end{array}$ & 42 & $-6,8^{\dagger}$ & 12,95 & 21 & $-5,8$ & $19,72^{\dagger}$ & NS \\
\hline
\end{tabular}

Tabla 4.7.9. Descripción del peso perdido al día según el sexo en las diferentes revisiones evaluadas

En los demás controles evaluados no se aprecian diferencias estadísticamente significativas en la pérdida de peso diaria, entre hombres y mujeres. En el control inicial y el de los 3 meses pierden más peso al día los hombres, esta diferencia desde los 6 meses cambia y son las mujeres quien pierden más peso diario hasta el control de los 18 meses. En la revisión de los 24 meses los dos grupos aumentan ligeramente el peso diario prácticamente por igual: 6,8 g/día las mujeres y 5,8 g/día los hombres.

Respecto a la pérdida de peso diario según el grupo de edad, en la tabla 4.7.10, apreciando diferencias significativas en el control de los 3, 9, y 24 meses postquirúrgicos $(P<0,05)$.

\begin{tabular}{|c|c|c|c|c|c|c|c|}
\cline { 2 - 8 } \multicolumn{1}{c|}{} & \multicolumn{3}{c|}{$<42$ años } & \multicolumn{3}{c|}{$\geq 42$ años } & \multirow{2}{*}{ P } \\
\cline { 2 - 7 } & $\mathbf{N}$ & Media & D.Típica & $\mathbf{N}$ & Media & D.Típica & \\
\hline $\begin{array}{c}\text { Peso perdido día } \\
\text { preparación } \\
\text { prequirúrgica } \\
\text { (g/día) }\end{array}$ & 48 & 198,7 & 98,23 & 52 & 176,8 & 81,97 & NS \\
\hline $\begin{array}{c}\text { Peso perdido día } \\
\text { 3 meses (g/día) }\end{array}$ & 45 & 177,5 & 55,73 & 47 & 150,7 & 62,95 & $<0,05$ \\
\hline $\begin{array}{c}\text { Peso perdido día } \\
\text { 6 meses (g/día) }\end{array}$ & 37 & $63,4^{\dagger}$ & 43,86 & 40 & $60,8^{\dagger}$ & 69,74 & NS \\
\hline $\begin{array}{c}\text { Peso perdido día } \\
\text { 9 meses (g/día) }\end{array}$ & 16 & $44,8^{\dagger}$ & 24,01 & 28 & $27,3^{\dagger}$ & 30,56 & $<0,05$ \\
\hline
\end{tabular}




\begin{tabular}{|c|c|c|c|c|c|c|c|}
\hline & \multicolumn{3}{|c|}{$<42$ años } & \multicolumn{3}{|c|}{$\geq 42$ años } & \multirow{2}{*}{$\mathbf{P}$} \\
\hline & $\mathbf{N}$ & Media & D.Típica & $\mathbf{N}$ & Media & D.Típica & \\
\hline $\begin{array}{l}\text { Peso perdido día } \\
12 \text { meses (g/día) }\end{array}$ & 21 & $19,8^{\dagger}$ & 27,17 & 29 & $18,4^{\dagger}$ & 26,17 & NS \\
\hline $\begin{array}{l}\text { Peso perdido día } \\
18 \text { meses (g/día) }\end{array}$ & 25 & $1,8^{\dagger}$ & 21,34 & 30 & $-1,6^{\dagger}$ & 24,48 & NS \\
\hline $\begin{array}{l}\text { Peso perdido día } \\
24 \text { meses (g/día) }\end{array}$ & 28 & $-2,1^{\dagger}$ & 15,40 & 35 & $-10^{\dagger}$ & 14,64 & $<0,05$ \\
\hline
\end{tabular}

Tabla 4.7.10. Descripción del peso perdido al día según el grupo de edad en las diferentes revisiones evaluadas

El grupo de los $<42$ años pierden más peso al día que los $\geq 42$ años, en todos los controles evaluados hasta los 18 meses. En el control de los 24 meses se observa un aumento del peso medio diario, siendo mayor en el grupo de los $<42$ años $(P<0,05)$.

\section{c) Porcentaje de Sobrepeso Perdido. PSP}

La descripción de la pérdida de peso en términos absolutos como se ha descrito en los puntos anteriores no es aceptable como único medio en la medición de la pérdida de peso, para ello se utilizan porcentajes de sobrepeso perdido (PSP) y variaciones en el IMC como se desarrollará en los apartados siguientes.

En la tabla 4.7.11 se describe el PSP expresado en \% en los diferentes controles evaluados. El seguimiento de los pacientes es el mismo que en las variables previamente estudiadas.

\begin{tabular}{|c|c|c|c|c|c|c|c|}
\hline & $\begin{array}{c}\text { PSP } \\
\text { cirugía } \\
(\%)\end{array}$ & $\begin{array}{l}\text { PSP 3 } \\
\text { meses } \\
(\%)\end{array}$ & $\begin{array}{c}\text { PSP } 6 \\
\text { meses } \\
(\%)\end{array}$ & $\begin{array}{c}\text { PSP 9 } \\
\text { meses } \\
(\%)\end{array}$ & $\begin{array}{c}\text { PSP 12 } \\
\text { meses } \\
(\%)\end{array}$ & $\begin{array}{c}\text { PSP 18 } \\
\text { meses } \\
(\%)\end{array}$ & $\begin{array}{c}\text { PSP 24 } \\
\text { meses } \\
(\%)\end{array}$ \\
\hline $\mathbf{N}$ & 100 & 93 & 83 & 58 & 82 & 63 & 100 \\
\hline Media & 28,05 & $66,86^{*^{\dagger}}$ & $81,05^{\star^{\dagger}}$ & $83,31^{*^{\dagger}}$ & $89,70^{\star^{\dagger}}$ & $88,40^{\star^{\dagger}}$ & $88,10^{\star^{\dagger}}$ \\
\hline D.Típica & 9,89 & 17,49 & 17,64 & 15,37 & 16,57 & 16,93 & 16,99 \\
\hline Mediana & 29,11 & 66,60 & 78,50 & 84,89 & 87,35 & 86,52 & 87,22 \\
\hline $\begin{array}{c}\text { Rango } \\
\text { intercuartílico } \\
\text { (P25-P75) }\end{array}$ & $\begin{array}{l}21,83- \\
32,63\end{array}$ & $\begin{array}{l}55,10- \\
76,49\end{array}$ & $\begin{array}{l}67,09- \\
90,09\end{array}$ & $\begin{array}{l}72,34- \\
93,34\end{array}$ & $\begin{array}{l}80,46- \\
100,85\end{array}$ & $\begin{array}{l}78,87- \\
97,41\end{array}$ & $\begin{array}{c}78,19- \\
98,43\end{array}$ \\
\hline
\end{tabular}

Tabla 4.7.11. Descripción del PSP en las diferentes revisiones evaluadas 
EI PSP registrado en la cirugía hace referencia al peso perdido en la preparación previa a la intervención. La mitad de los pacientes consiguen un PSP superior al 25\%, tan solo 2 pacientes superaron el $50 \%$ del PSP en la preparación prequirúrgica.

Las variaciones del PSP observadas entre cada uno de los controles son significativas, describiendo una línea de tendencia ascendente hasta los 12 meses. Después de este control se observa un ligero descenso del PSP $(P<0,001)$.

En el control de los 3 meses es dónde se observa un mayor aumento del PSP, siendo 13 pacientes los que presentaron un PSP $<50 \%$.

A los 6 meses de la intervención no se obtuvo ningún paciente con PSP $<50 \%$. A los 18 y 24 meses postquirúrgicos se observó como un paciente presentaba un PSP < 50\%, siendo a los 18 meses de 45,28\% y a los 24 meses de 48,62\%. En todos los controles postquirúrgicos se observó un PSP superior en relación al valor prequirúrgicos $(P<0,001)$.

A continuación en la figura 4.7.10 se describe mediante histogramas el PSP en los diferentes controles evaluados, expresado en $\%$. 

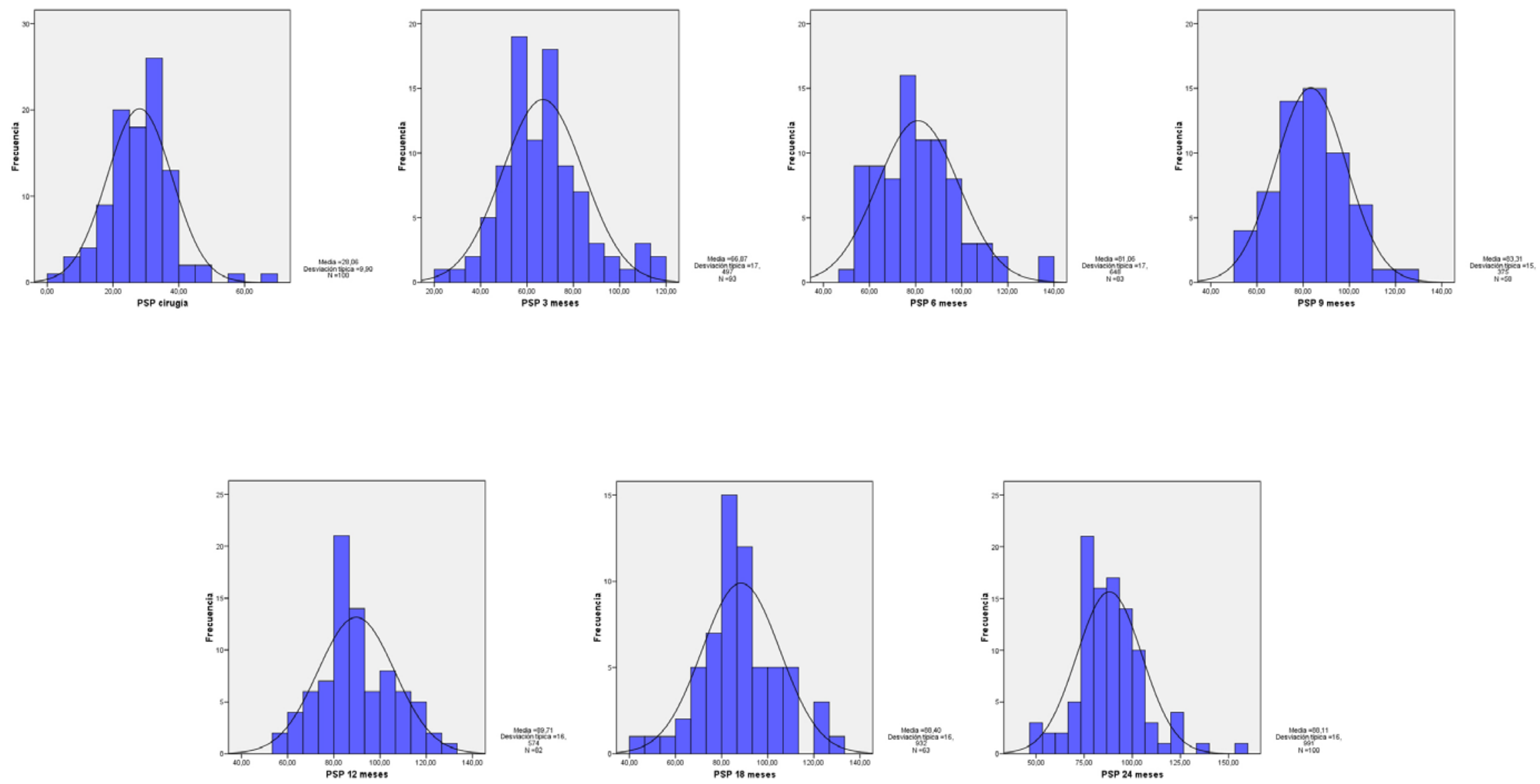

Figura 4.7.10. Representación en histogramas del PSP en las diferentes revisiones evaluadas 
En la figura 4.7.11 se representa mediante un gráfico de barras de error la evolución del PSP en los diferentes controles evaluados. La línea de referencia en el eje de ordenadas hace referencia al valor del 50\% del PSP.

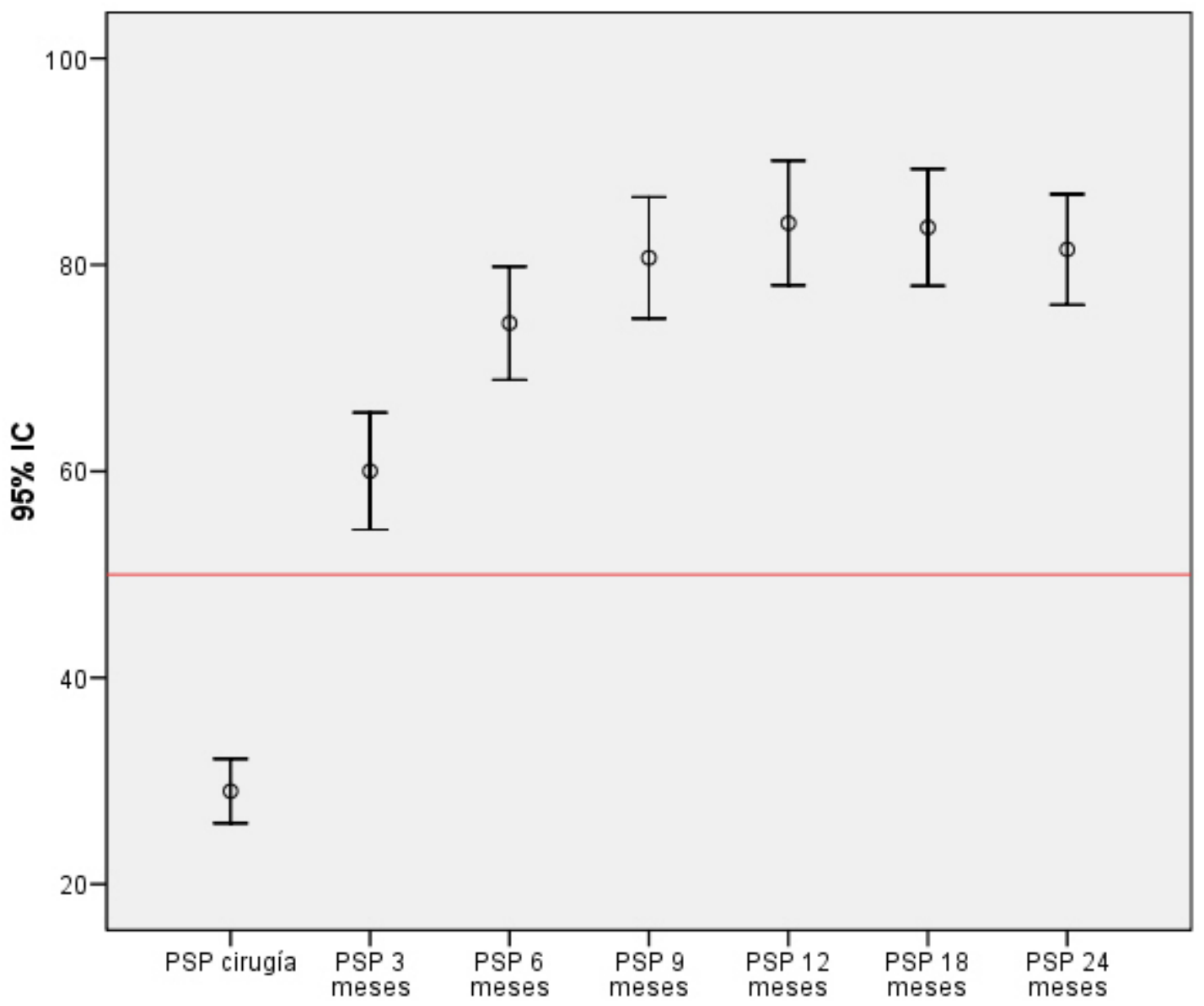

Figura 4.7.11. Gráfico de barras de error (IC 95\%) del PSP en los diferentes controles evaluados

Se estudió la evolución del PSP en función del sexo, en la tabla 4.7.12 se muestran las medias del PSP en los diferentes controles evaluados.

\begin{tabular}{|c|c|c|c|c|c|c|c|}
\hline & \multicolumn{3}{|c|}{ Mujer } & \multicolumn{3}{|c|}{ Hombre } & \multirow{2}{*}{$\mathbf{P}$} \\
\hline & $\mathbf{N}$ & Media & D.Típica & $\mathbf{N}$ & Media & D.Típica & \\
\hline PSP cirugía (\%) & 71 & 25,16 & 8,53 & 29 & 35,15 & 9,54 & $<0,001$ \\
\hline PSP 3 meses (\%) & 66 & $65,30^{\dagger}$ & 18,25 & 27 & 70,68 & $15,13^{\dagger}$ & NS \\
\hline PSP 6 meses (\%) & 61 & $81,87^{\dagger}$ & 18,20 & 22 & 78,78 & $16,17^{\dagger}$ & NS \\
\hline PSP 9 meses (\%) & 39 & $85,12^{\dagger}$ & 15,29 & 19 & 79,58 & $15,25^{\dagger}$ & NS \\
\hline PSP 12 meses (\%) & 60 & $91,86^{\dagger}$ & 17,20 & 22 & 83,82 & $13,36^{\dagger}$ & $<0,05$ \\
\hline PSP 18 meses (\%) & 42 & $92,71^{\dagger}$ & 16,54 & 21 & 79,77 & $14,50^{\dagger}$ & $<0,05$ \\
\hline PSP 24 meses (\%) & 71 & $91,34^{\dagger}$ & 17,53 & 29 & 80,16 & $12,64^{\dagger}$ & $<0,001$ \\
\hline
\end{tabular}

Tabla 4.7.12. Descripción del PSP según el sexo en las diferentes revisiones evaluadas 
Se observa un PSP más elevado en las mujeres respecto a los hombres en todos los controles excepto en el periodo de preparación prequirúrgica. La mayor diferencia entre el PSP de hombres y mujeres se registra en el control de los 24 meses, apreciando un mayor del PSP en los hombres desde el control de los 12 a los 24 meses. En cambio las mujeres entre estos dos controles prácticamente no modifican su PSP medio: 91,86\% (12 meses) y $91,34 \%$ (24 meses).

Los 2 pacientes que superaron un PSP del 50\% en la preparación prequirúrgica fueron varones. En el control de los 18 y 24 meses se observa un paciente varón con un PSP $<50 \%$.

Al agrupar a los pacientes por la mediana de edad, como se muestra en la tabla 4.7.13, no se observan diferencias estadísticamente significativas en ninguno de los controles evaluados.

\begin{tabular}{|c|c|c|c|c|c|c|c|}
\hline & \multicolumn{3}{|c|}{$<42$ años } & \multicolumn{3}{|c|}{$\geq 42$ años } & \multirow{2}{*}{$\mathbf{P}$} \\
\hline & $\mathbf{N}$ & Media & D.Típica & $\mathbf{N}$ & Media & D.Típica & \\
\hline PSP cirugía (\%) & 48 & 26,72 & 8,61 & 52 & 29,29 & 10,89 & NS \\
\hline PSP 3 meses (\%) & 45 & $68,22^{\dagger}$ & 17,92 & 48 & $65,59^{\dagger}$ & 17,17 & NS \\
\hline PSP 6 meses (\%) & 39 & $84,20^{\dagger}$ & 19,16 & 44 & $78,27^{\dagger}$ & 15,88 & NS \\
\hline PSP 9 meses (\%) & 24 & $86,45^{\dagger}$ & 17,10 & 34 & $81,09^{\dagger}$ & 13,85 & NS \\
\hline PSP 12 meses (\%) & 39 & $91,13^{\dagger}$ & 17,37 & 43 & $88,41^{\dagger}$ & 15,90 & NS \\
\hline PSP 18 meses (\%) & 28 & $92,32^{\dagger}$ & 16,75 & 35 & $85,26^{\dagger}$ & 16,64 & NS \\
\hline PSP 24 meses (\%) & 48 & $91,08^{\dagger}$ & 17,22 & 52 & $85,35^{\dagger}$ & 16,45 & NS \\
\hline
\end{tabular}

Tabla 4.7.13. Descripción del PSP según el grupo de edad en las diferentes revisiones evaluadas

Los 2 pacientes registrados que superaron un PSP del 50\% en la preparación prequirúrgica correspondían al grupo de los $\geq 42$ años. El paciente que en el control de los 18 y 24 que no alcanzó un PSP del 50\% pertenecía al grupo de los $\geq 42$ años.

No se observaron diferencias estadísticamente significativas entre los 2 grupos de edad $(P=0,52)$ ni tampoco entre hombres y mujeres $(P=0,29)$ a la hora de alcanzar un PSP > 50\% a los 24 meses de la cirugía. 


\subsection{3. Índice de Masa Corporal. IMC}

Esta variable será estudiada como las anteriores, describiendo la evolución del IMC en los diferentes controles evaluados hasta los 2 años de la cirugía. Posteriormente se analizará la perdida porcentual del IMC respecto al control de la consulta inicial, y se categorizarán los pacientes estudiados según su IMC, describiendo la evolución de los mismos.

En la tabla 4.7.14, se muestra el IMC medio en los controles evaluados, desviación típica, mediana, y rango intercuartílico (P25-P75) como en las variables anteriormente descritas.

\begin{tabular}{|c|c|c|c|c|c|c|c|c|}
\hline & $\begin{array}{c}\text { IMC } \\
\text { consulta } \\
\text { inicial }\end{array}$ & $\begin{array}{l}\text { IMC } \\
\text { cirugía }\end{array}$ & $\begin{array}{c}\text { IMC } \\
3 \\
\text { meses } \\
\end{array}$ & $\begin{array}{c}\text { IMC } \\
6 \\
\text { meses } \\
\end{array}$ & $\begin{array}{c}\text { IMC } \\
9 \\
\text { meses } \\
\end{array}$ & $\begin{array}{l}\text { IMC } 12 \\
\text { meses }\end{array}$ & $\begin{array}{l}\text { IMC } 18 \\
\text { meses }\end{array}$ & $\begin{array}{l}\text { IMC } 24 \\
\text { meses }\end{array}$ \\
\hline $\mathbf{N}$ & 100 & 100 & 93 & 83 & 58 & 82 & 63 & 100 \\
\hline Media & 42,61 & $36,83^{*^{\dagger}}$ & $29,77^{*^{\dagger}}$ & $26,99 *^{\dagger}$ & $26,44^{*^{\dagger}}$ & $25,08^{\star^{\dagger}}$ & $25,27^{\dagger}$ & $25,33^{*^{\dagger}}$ \\
\hline D.Típica & 6,66 & 4,86 & 5,04 & 4,15 & 3,92 & 3,59 & 3,54 & 3,35 \\
\hline Mediana & 41,27 & 36,01 & 28,87 & 26,43 & 25,43 & 25,01 & 25,07 & 25,15 \\
\hline $\begin{array}{c}\text { Rango } \\
\text { intercuartílico } \\
\text { (P25-P75) }\end{array}$ & $\begin{array}{l}38,17- \\
46,96\end{array}$ & $\begin{array}{c}33,35- \\
39,80\end{array}$ & $\begin{array}{l}26,33- \\
33,20\end{array}$ & $\begin{array}{l}23,62- \\
30,46\end{array}$ & $\begin{array}{c}23,57- \\
29,63\end{array}$ & $\begin{array}{l}22,23- \\
27,70\end{array}$ & $\begin{array}{l}22,86- \\
27,23\end{array}$ & $\begin{array}{c}22,71- \\
27,28\end{array}$ \\
\hline
\end{tabular}

Tabla 4.7.14. Descripción del IMC en las diferentes revisiones evaluadas

EI IMC medio en la primera consulta es de 42,61, el cual desciende de manera estadísticamente significativa entre la cirugía y los 3 meses. A partir de este control sigue descendiendo el IMC progresivamente hasta los 12 meses (control con IMC medio más bajo registrado), a partir de este momento el IMC medio aumenta. Desde los 12 a los 18 meses el aumento del IMC no es estadísticamente significativo, por el contrario el aumento del IMC entre los 18 meses y 24 meses si lo es $(P<0,001)$.

En la figura 4.7.12 se muestra mediante histogramas el IMC en los diferentes controles evaluados. 

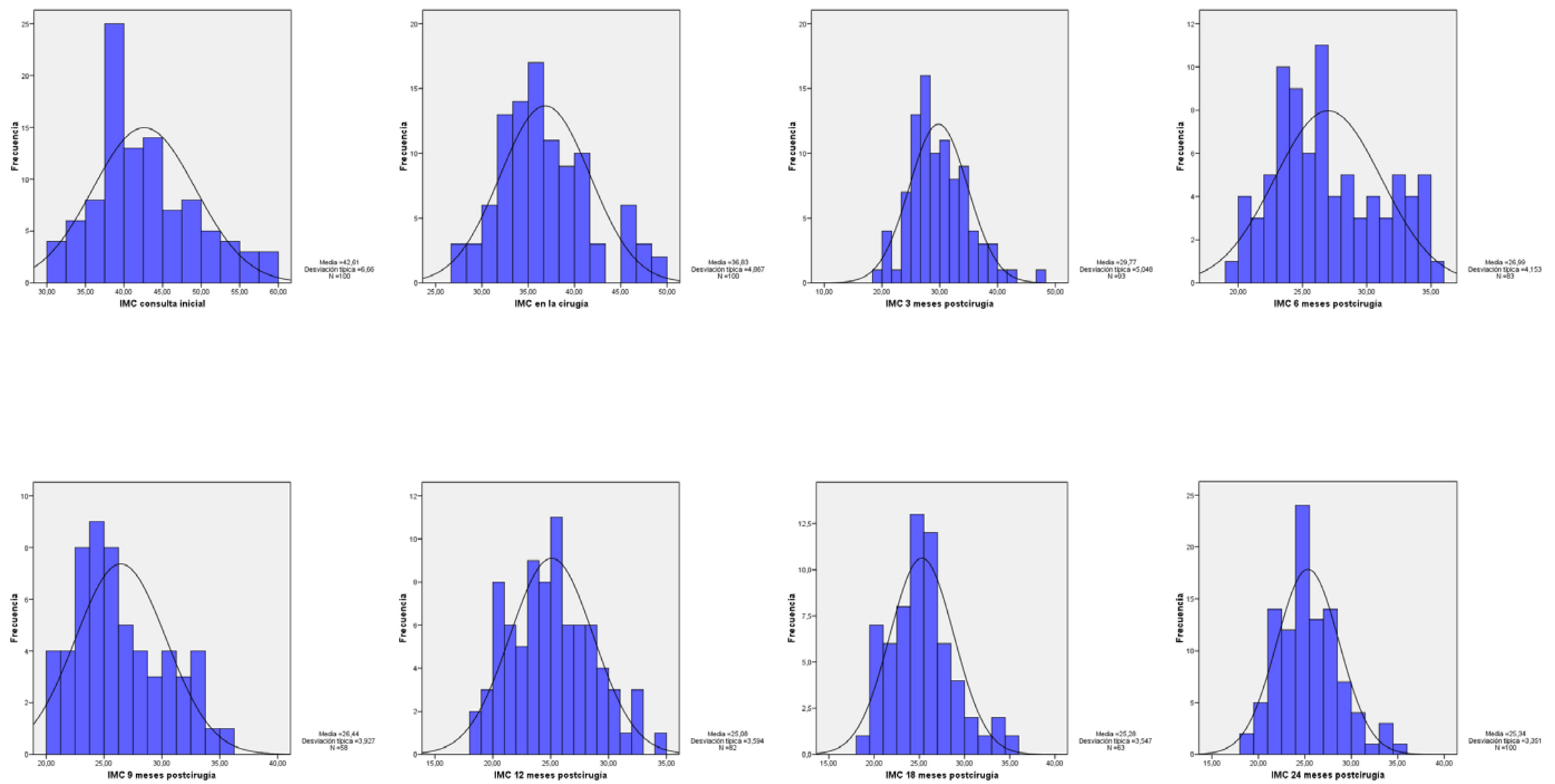

Figura 4.7.12. Representación en histogramas del IMC en las diferentes revisiones evaluadas obesos (ReCiMB) 
La tendencia que sigue el IMC medio en los diferentes controles evaluados, se expresa en la siguiente gráfica de barras de error. Figura 4.7.13. El efecto atribuible a la cirugía en la disminución del IMC fue estadísticamente significativo $(P<0,001)$, al observar una disminución de 11,49 unidades del IMC entre el control de la cirugía y el de los 24 meses.

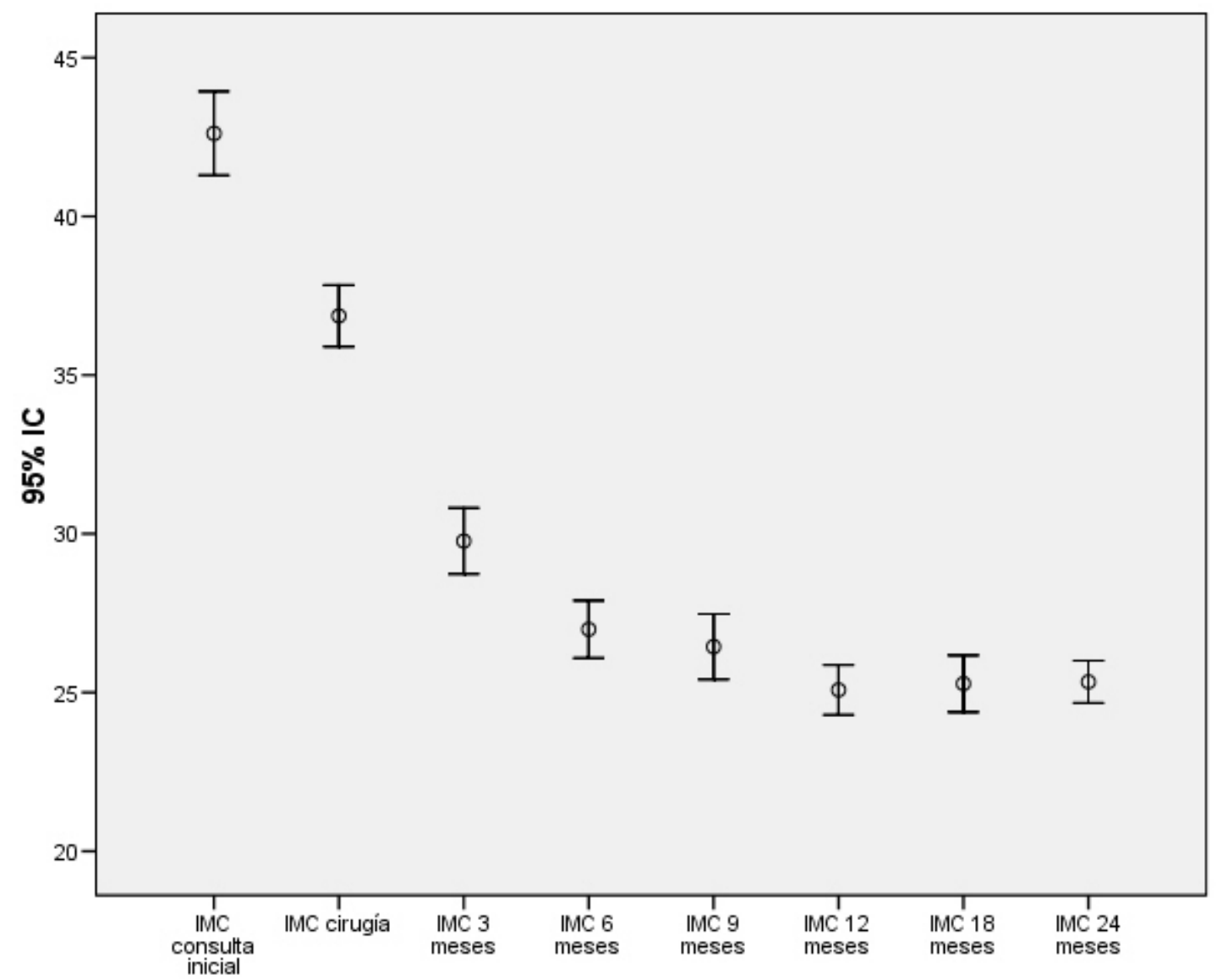

Figura 4.7.13. Gráfico de barras de error (IC 95\%) del IMC en los diferentes controles evaluados

En la tabla 4.7.15, se describe el IMC en los diferentes controles respecto al sexo. Las diferencias en el IMC medio son estadísticamente significativas entre hombres y mujeres en el control de los 18 y 24 meses, siendo más elevado en el primero.

\begin{tabular}{|c|c|c|c|c|c|c|c|}
\hline & \multicolumn{3}{|c|}{ Mujer } & \multicolumn{3}{|c|}{ Hombre } & \multirow{2}{*}{$\mathbf{P}$} \\
\hline & $\mathbf{N}$ & Media & D.Típica & $\mathbf{N}$ & Media & D.Típica & \\
\hline IMC consulta inicial & 71 & 42,32 & 6,75 & 29 & 43,31 & 6,49 & NS \\
\hline IMC cirugía & 71 & $37,12^{\dagger}$ & 4,82 & 29 & $36,11^{\dagger}$ & 4,96 & NS \\
\hline IMC 3 meses & 66 & $30,08^{\dagger}$ & 5,29 & 27 & $29,01^{\dagger}$ & 4,37 & NS \\
\hline IMC 6 meses & 61 & $26,80^{\dagger}$ & 4,15 & 22 & $27,51^{\dagger}$ & 4,20 & NS \\
\hline IMC 9 meses & 39 & $26,07^{\dagger}$ & 4,01 & 19 & $27,19^{\dagger}$ & 3,72 & NS \\
\hline
\end{tabular}




\begin{tabular}{|c|c|c|c|c|c|c|c|}
\hline & \multicolumn{3}{|c|}{ Mujer } & \multicolumn{3}{|c|}{ Hombre } & \multirow{2}{*}{$\mathbf{P}$} \\
\hline & $\mathbf{N}$ & Media & D.Típica & $\mathbf{N}$ & Media & D.Típica & \\
\hline IMC 12 meses & 60 & $24,70^{\dagger}$ & 3,73 & 22 & $26,11^{\dagger}$ & 3,02 & NS \\
\hline IMC 18 meses & 42 & $24,46^{\dagger}$ & 3,41 & 21 & $26,90^{\dagger}$ & 3,31 & $<0,05$ \\
\hline IMC 24 meses & 71 & $24,77^{\dagger}$ & 3,32 & 29 & $26,70^{\dagger}$ & 3,05 & $<0,05$ \\
\hline
\end{tabular}

Tabla 4.7.15. Descripción del IMC según el sexo en las diferentes revisiones evaluadas

EI IMC medio observado es más alto en las mujeres respecto a los hombres, en el control previo a la cirugía, en el quirúrgico y a los 3 meses. Desde el control de los 6 meses son los hombres quienes presentan un IMC medio más elevado en todos los controles posteriores observados hasta los 24 meses postcirugía.

Como muestra la tabla 4.7.16, en el comportamiento de la media de IMC en los controles evaluados respecto a la mediana de edad de la muestra, no se observa prácticamente ninguna variabilidad entre el grupo de los $<42$ años y de los $\geq 42$ años.

\begin{tabular}{|c|c|c|c|c|c|c|c|}
\hline & \multicolumn{3}{|c|}{$<42$ años } & \multicolumn{3}{|c|}{$\geq 42$ años } & \multirow{2}{*}{$\mathbf{P}$} \\
\hline & $\mathbf{N}$ & Media & D.Típica & $\mathbf{N}$ & Media & D.Típica & \\
\hline IMC consulta inicial & 48 & 42,64 & 7,16 & 52 & 42,58 & 6,22 & NS \\
\hline IMC cirugía & 48 & $37,06^{\dagger}$ & 5,20 & 52 & $36,61^{\dagger}$ & 4,57 & NS \\
\hline IMC 3 meses & 45 & $29,67^{\dagger}$ & 4,93 & 48 & $29,86^{\dagger}$ & 5,20 & NS \\
\hline IMC 6 meses & 39 & $26,47^{\dagger}$ & 4,20 & 44 & $27,44^{\dagger}$ & 4,09 & NS \\
\hline IMC 9 meses & 24 & $26,11^{\dagger}$ & 4,20 & 34 & $26,67^{\dagger}$ & 3,76 & NS \\
\hline IMC 12 meses & 39 & $25,02^{\dagger}$ & 3,67 & 43 & $25,13^{\dagger}$ & 3,56 & NS \\
\hline IMC 18 meses & 28 & $24,65^{\dagger}$ & 3,19 & 35 & $25,77^{\dagger}$ & 3,77 & NS \\
\hline IMC 24 meses & 48 & $24,90^{\dagger}$ & 3,05 & 52 & $25,73^{\dagger}$ & 3,58 & NS \\
\hline & & & $\mathrm{P}<0, \mathrm{C}$ & $\pi$ & lo con & ontrol pl & úrgic \\
\hline
\end{tabular}

Tabla 4.7.16. Descripción del IMC según el grupo de edad en las diferentes revisiones evaluadas

\section{a) Porcentaje de IMC Perdido. PIMCP}

Con la descripción del PIMCP, se muestra la evolución del IMC perdido en cada uno de los controles respecto al inicial (IMC consulta inicial). En la tabla 4.7.17 se describen las variaciones del PIMCP en las diferentes revisiones. 


\begin{tabular}{|c|c|c|c|c|c|c|c|}
\hline & $\begin{array}{c}\text { PIMCP } \\
\text { cirugía } \\
\text { (\%) }\end{array}$ & $\begin{array}{c}\text { PIMCP } \\
3 \\
\text { meses } \\
(\%)\end{array}$ & $\begin{array}{c}\text { PIMCP } \\
6 \\
\text { meses } \\
(\%)\end{array}$ & $\begin{array}{c}\text { PIMCP } \\
9 \\
\text { meses } \\
(\%)\end{array}$ & $\begin{array}{c}\text { PIMCP } \\
12 \\
\text { meses } \\
(\%)\end{array}$ & $\begin{array}{c}\text { PIMCP } \\
18 \\
\text { meses } \\
(\%)\end{array}$ & $\begin{array}{c}\text { PIMCP } \\
24 \\
\text { meses } \\
(\%)\end{array}$ \\
\hline $\mathbf{N}$ & 100 & 93 & 83 & 58 & 82 & 63 & 100 \\
\hline Media & 13,14 & $30,22^{*^{\dagger}}$ & $36,69 *^{\dagger}$ & $38,86^{*^{\dagger}}$ & $41,33^{\star^{\dagger}}$ & $40,64^{\dagger}$ & $39,90^{*^{\dagger}}$ \\
\hline D.Típica & 4,89 & 6,55 & 6,13 & 6,98 & 7,38 & 7,38 & 7,26 \\
\hline Mediana & 13,57 & 29,53 & 36,25 & 39,62 & 42,18 & 42,08 & 40,80 \\
\hline $\begin{array}{c}\text { Rango } \\
\text { intercuartílico } \\
\text { (P25-P75) }\end{array}$ & $\begin{array}{l}9,48- \\
16,88\end{array}$ & $\begin{array}{l}26,24- \\
34,84\end{array}$ & $\begin{array}{c}32,61- \\
40,61\end{array}$ & $\begin{array}{c}33,55- \\
44,07\end{array}$ & $\begin{array}{c}35,88- \\
46,40\end{array}$ & $\begin{array}{c}34,84- \\
45,45\end{array}$ & $\begin{array}{c}33,93- \\
44,45\end{array}$ \\
\hline
\end{tabular}

Tabla 4.7.17. Descripción del PIMCP en las diferentes revisiones evaluadas

EI PIMCP aumenta de manera significativa entre los controles evaluados hasta los 12 meses de la cirugía. Entre los 12 y 18 meses posquirúrgicos, el descenso no fue significativo, pero sí entre los 18 y 24 meses $(P<0,001)$.

EI PIMCP medio más elevado, es a los 12 meses de la cirugía, desde entonces disminuye progresivamente hasta los 24 meses evaluados $(P<0,001)$

En la figura 4.7.14 se muestra mediante histogramas el PIMCP en los diferentes controles evaluados. 

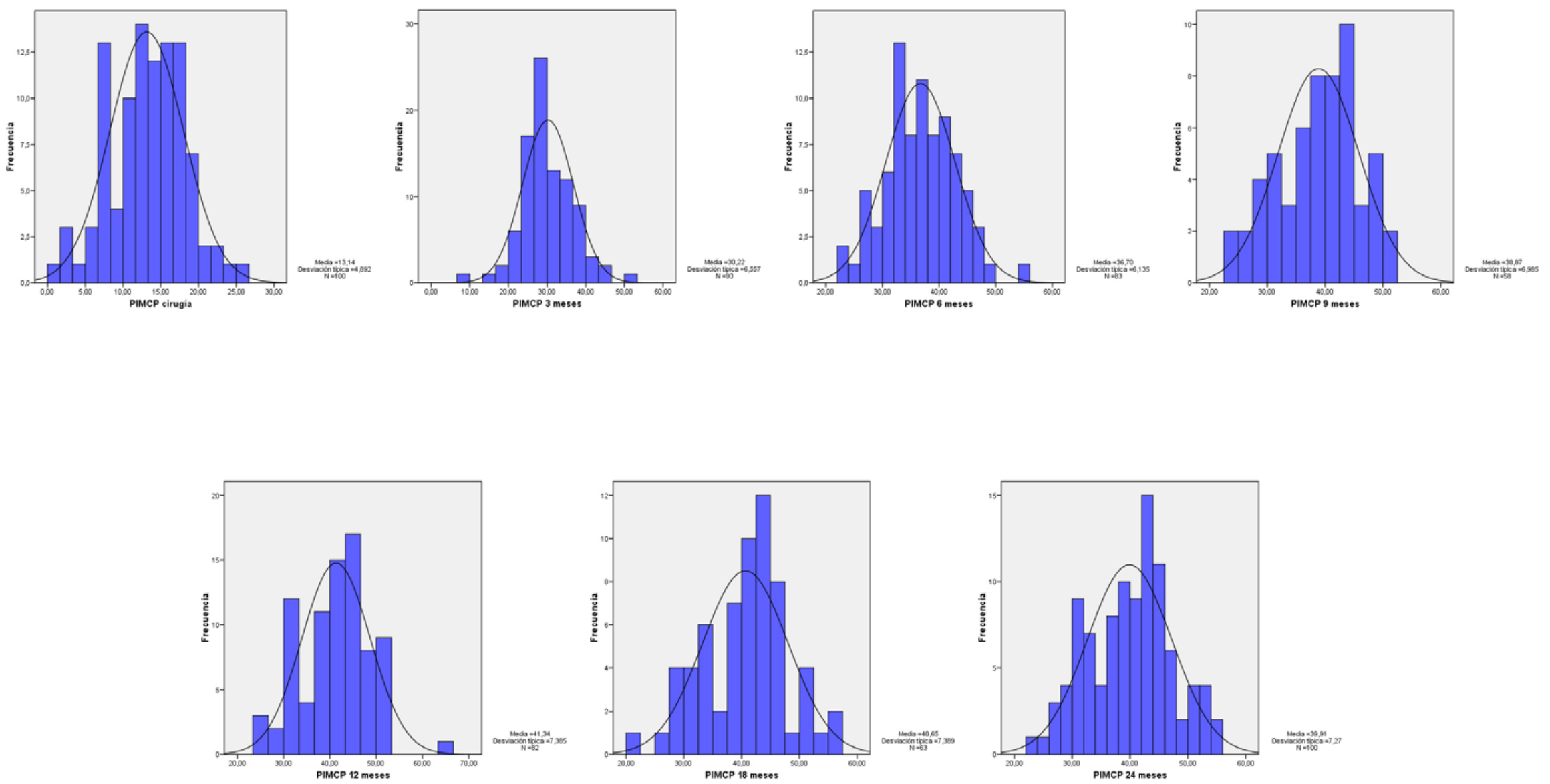

Figura 4.7.14. Representación en histogramas del PIMCP en las diferentes revisiones evaluadas 
En la figura 4.7.15 se representa mediante un gráfico de barras de error la evolución del PIMCP entre los diferentes controles evaluados. El aumento experimentado en el PIMCP desde la cirugía hasta los 24 meses es estadísticamente significativo $(P<0,001)$.

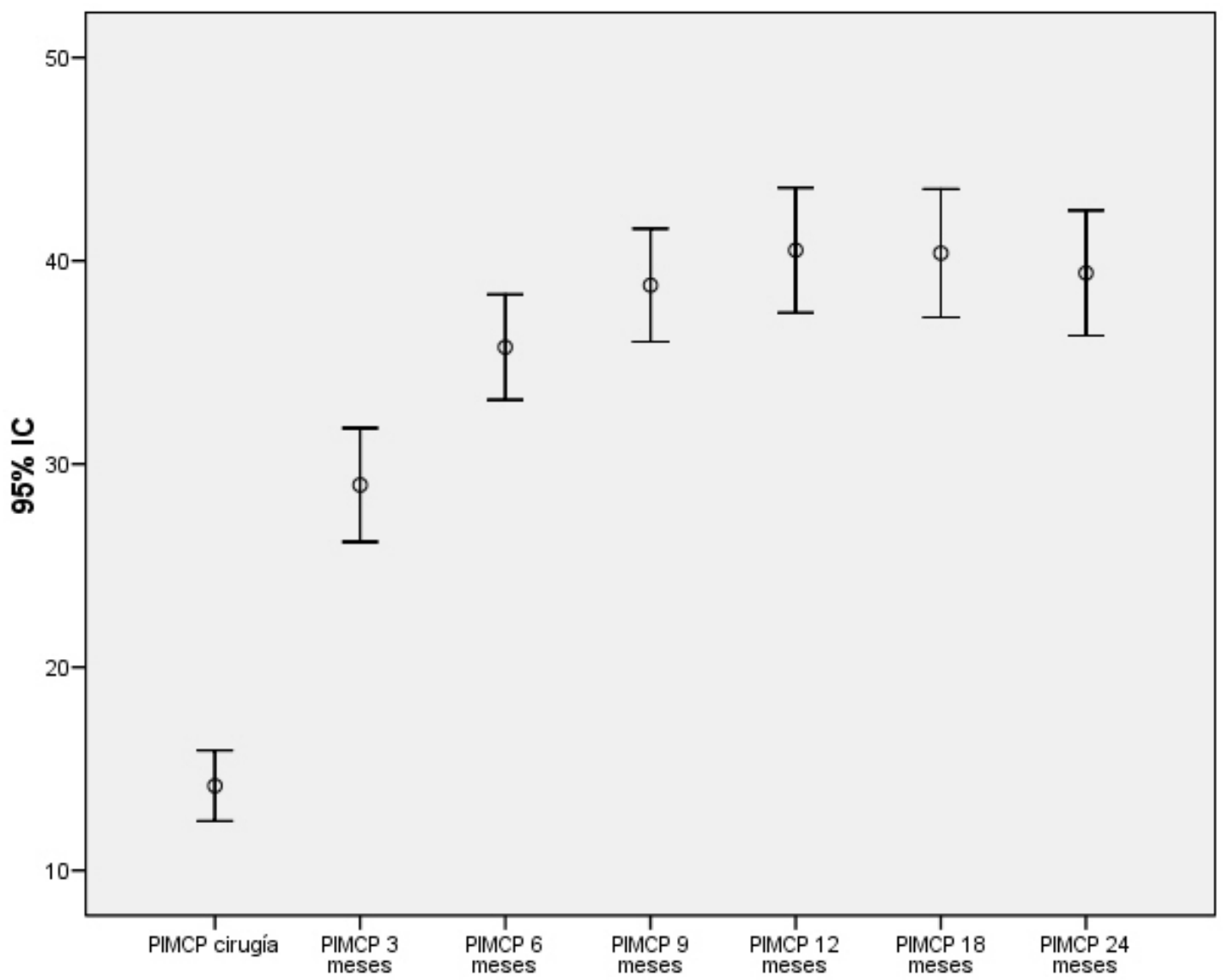

Figura 4.7.15. Gráfico de barras de error (IC 95\%) del PIMCP en los diferentes controles evaluados

En la tabla 4.7.18 se muestran las diferencias en la evolución del PIMCP en los diferentes controles según el sexo.

\begin{tabular}{|c|c|c|c|c|c|c|c|}
\hline & \multicolumn{3}{|c|}{ Mujer } & \multicolumn{3}{|c|}{ Hombre } & \multirow{2}{*}{$\mathbf{P}$} \\
\hline & $\mathbf{N}$ & Media & D.Típica & $\mathbf{N}$ & Media & D.Típica & \\
\hline PIMCP cirugía (\%) & 71 & 11,81 & 4,55 & 29 & 16,38 & 4,17 & $<0,001$ \\
\hline PIMCP 3 meses (\%) & 66 & $29,29^{\dagger}$ & 6,54 & 27 & $32,49^{\dagger}$ & 6,11 & $<0,05$ \\
\hline PIMCP 6 meses (\%) & 61 & $36,81^{\dagger}$ & 6,23 & 22 & $36,36^{\dagger}$ & 5,98 & NS \\
\hline PIMCP 9 meses (\%) & 39 & $39,08^{\dagger}$ & 6,46 & 19 & $38,41^{\dagger}$ & 8,12 & NS \\
\hline PIMCP 12 meses (\%) & 60 & $41,90^{\dagger}$ & 7,15 & 22 & $39,79^{\dagger}$ & 7,94 & NS \\
\hline PIMCP 18 meses (\%) & 42 & $41,93^{\dagger}$ & 6,72 & 21 & $38,07^{\dagger}$ & 8,12 & $<0,001$ \\
\hline PIMCP 24 meses (\%) & 71 & $40,86^{\dagger}$ & 6,81 & 29 & $37,57^{\dagger}$ & 7,91 & $<0,05$ \\
\hline
\end{tabular}

Tabla 4.7.18. Descripción del PIMCP según el sexo en las diferentes revisiones evaluadas 
Hasta el control de los 9 meses las mujeres registran un PIMCP medio más alto que los hombres, siendo esta diferencia estadísticamente significativa en el control de la cirugía y el de los 3 meses. EI PIMCP en los varones aumenta de manera progresiva hasta los 12 meses postquirúrgicos, a diferencia de las mujeres que continúa aumentando hasta los 18 meses.

En la tabla 4.7.19 se muestra la evolución del PIMCP por grupos de edad.

\begin{tabular}{|c|c|c|c|c|c|c|c|}
\hline & \multicolumn{3}{|c|}{$<42$ años } & \multicolumn{3}{|c|}{$\geq 42$ años } & \multirow{2}{*}{$\mathbf{P}$} \\
\hline & $\mathbf{N}$ & Media & D.Típica & $\mathbf{N}$ & Media & D.Típica & \\
\hline PIMCP cirugía (\%) & 48 & 12,59 & 4,66 & 52 & 13,65 & 5,08 & NS \\
\hline PIMCP 3 meses (\%) & 45 & $30,84^{\dagger}$ & 6,13 & 48 & $29,64^{\dagger}$ & 6,94 & NS \\
\hline PIMCP 6 meses (\%) & 39 & $37,07^{\dagger}$ & 5,74 & 44 & $36,36^{\dagger}$ & 6,50 & NS \\
\hline PIMCP 9 meses (\%) & 24 & $40,98^{\dagger}$ & 6,50 & 34 & $37,37^{\dagger}$ & 7,01 & $<0,05$ \\
\hline PIMCP 12 meses (\%) & 39 & $42,60^{\dagger}$ & 7,09 & 43 & $40,19^{\dagger}$ & 7,53 & NS \\
\hline PIMCP 18 meses (\%) & 28 & $41,45^{\dagger}$ & 5,74 & 35 & $40^{\dagger}$ & 8,50 & NS \\
\hline PIMCP 24 meses (\%) & 48 & $40,87^{\dagger}$ & 6,67 & 52 & $39,01^{\dagger}$ & 7,73 & NS \\
\hline & & & ${ }^{\dagger} \mathrm{P}<0$ & om & lo con & ntrol $p$ & Lirúrgicc \\
\hline
\end{tabular}

Tabla 4.7.19. Descripción del PIMCP según el grupo de edad en las diferentes revisiones evaluadas

Los valores del PIMCP son mayores en el grupo de $<42$ años en todos los controles, a excepción del quirúrgico, en el que se muestra un PIMCP más elevado en los $\geq 42$ años, correspondiente a una mayor pérdida ponderal en la preparación prequirúrgica.

\section{b) Porcentaje de Exceso de IMC Perdido. PEIMCP}

EI PEIMCP es otra de las formas de expresión de la pérdida ponderal en términos absolutos, el cual representa la pérdida de IMC por encima del límite normal considerado con un IMC de 25.

A modo de ejemplo, un individuo que tenga un IMC inicial en la primera consulta de 45, las 20 unidades del IMC por encima del límite superior del IMC normal (IMC 25) representan un PEIMCP del 100\%; una pérdida de 10 unidades de IMC (IMC 35) supondría un PEIMCP del 50\%.

En la tabla 4.7.20, se muestra la evolución del PEIMCP medio en los diferentes controles evaluados. 


\begin{tabular}{|c|c|c|c|c|c|c|c|}
\hline & $\begin{array}{l}\text { PEIMCP } \\
\text { cirugía } \\
(\%)\end{array}$ & $\begin{array}{l}\text { PEIMCP } \\
3 \text { meses } \\
(\%)\end{array}$ & $\begin{array}{l}\text { PEIMCP } \\
6 \text { meses } \\
(\%)\end{array}$ & $\begin{array}{l}\text { PEIMCP } \\
9 \text { meses } \\
(\%)\end{array}$ & $\begin{array}{c}\text { PEIMCP } \\
12 \\
\text { meses } \\
(\%)\end{array}$ & $\begin{array}{c}\text { PEIMCP } \\
18 \\
\text { meses } \\
(\%)\end{array}$ & $\begin{array}{c}\text { PEIMCP } \\
24 \\
\text { meses } \\
(\%)\end{array}$ \\
\hline $\mathbf{N}$ & 100 & 93 & 83 & 58 & 82 & 63 & 100 \\
\hline Media & 32,87 & $78,72^{*^{\dagger}}$ & $95,50^{*^{\dagger}}$ & $96,96^{\star^{\dagger}}$ & $104,82^{*^{\dagger}}$ & $103,43^{\dagger}$ & $103,79^{\star}{ }^{\dagger}$ \\
\hline D.Típica & 11,68 & 24,12 & 26,66 & 20,76 & 23,57 & 24,16 & 25,89 \\
\hline Mediana & 32,97 & 76,29 & 91,53 & 97,31 & 99,89 & 99,55 & 99,12 \\
\hline $\begin{array}{c}\text { Rango } \\
\text { intercuartílico } \\
\text { (P25-P75) }\end{array}$ & $\begin{array}{l}25,81- \\
38,38\end{array}$ & $\begin{array}{l}62,22- \\
90,93\end{array}$ & $\begin{array}{l}74,84- \\
111,66\end{array}$ & $\begin{array}{l}80,79- \\
110,02\end{array}$ & $\begin{array}{l}89,18- \\
120,02\end{array}$ & $\begin{array}{l}91,50- \\
116,02\end{array}$ & $\begin{array}{l}88,32- \\
113,65\end{array}$ \\
\hline
\end{tabular}

Tabla 4.7.20 Descripción del PEIMCP en las diferentes revisiones evaluadas

EI PEIMCP desde la cirugía aumenta de manera estadísticamente significativa entre los controles evaluados hasta los 12 meses posteriores a la intervención, desde ese momento el PEIMCP desciende sin ser significativo entre los 12 a 18 meses, pero sí entre los 18 y 24 meses.

El control en el que se alcanza un PEIMCP más elevado es a los 12 meses de la intervención $(P<0,001)$. El periodo en el que se registra un PEIMCP más alto respecto al control anterior es a los 3 meses de la cirugía, con una diferencia de medias del PEIMCP del 45,85\% $(P<0,001)$.

En todos los controles postquirúrgicos el PEIMCP respecto al valor prequirúrgico aumentó de manera significativa $(P<0,001)$.

En la figura 4.7.16 se muestra mediante histogramas el PEIMCP en los diferentes controles evaluados. 

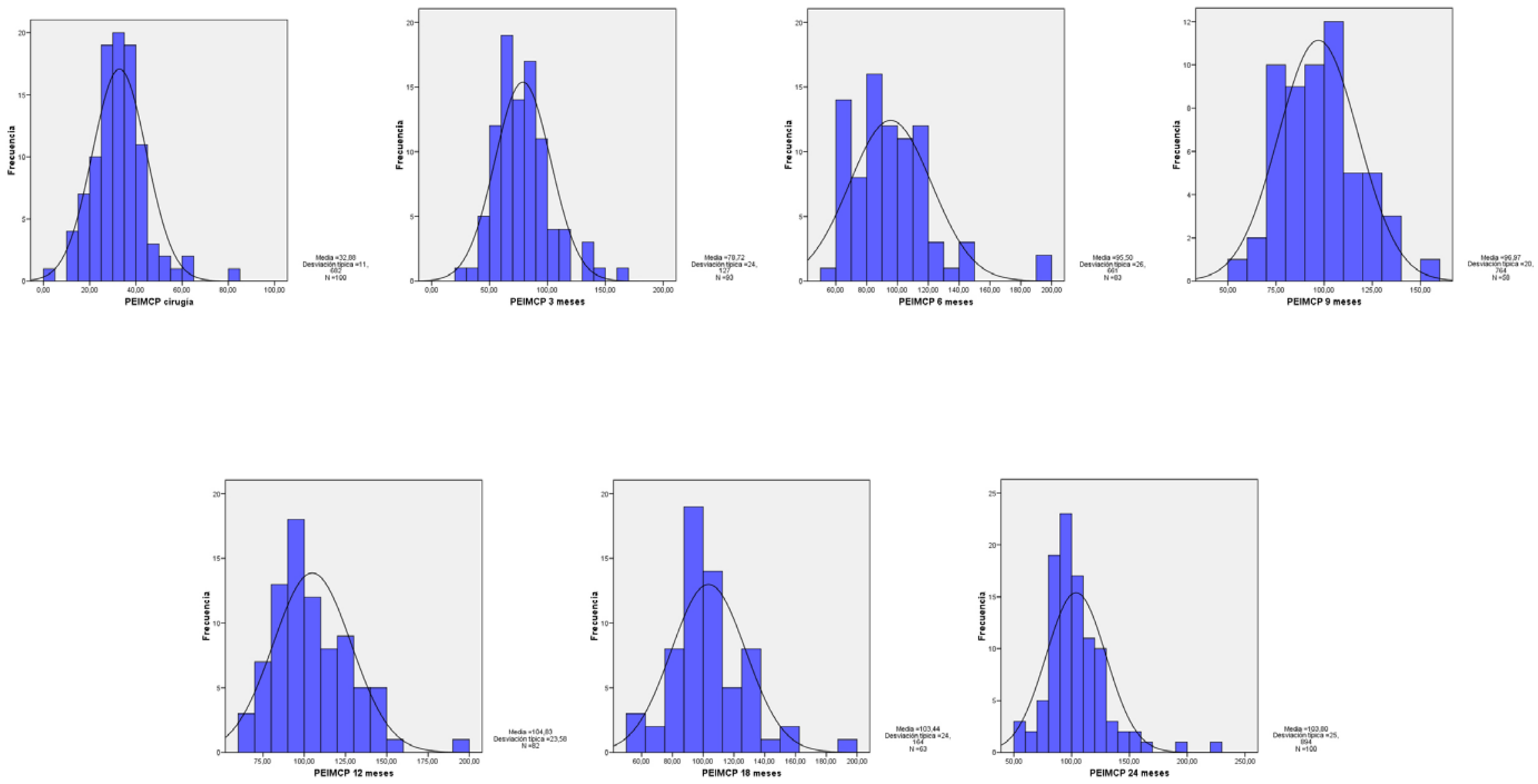

Figura 4.7.16. Representación en histogramas del PEIMCP en las diferentes revisiones evaluadas obesos (ReCiMB) 
En la figura 4.7.17 se representa mediante un gráfico de barras de error la evolución del PEIMCP medio en los diferentes controles. Se observa un aumento del PEIMCP medio significativo $(P<0,001)$ a los 24 meses respecto del PEIMCP de la cirugía.

La línea de referencia en el eje de ordenadas marca el 50\% y 65\% del PEIMCP, que servirá para categorizar el resultado en función del peso conseguido como se especificará en el siguiente apartado.

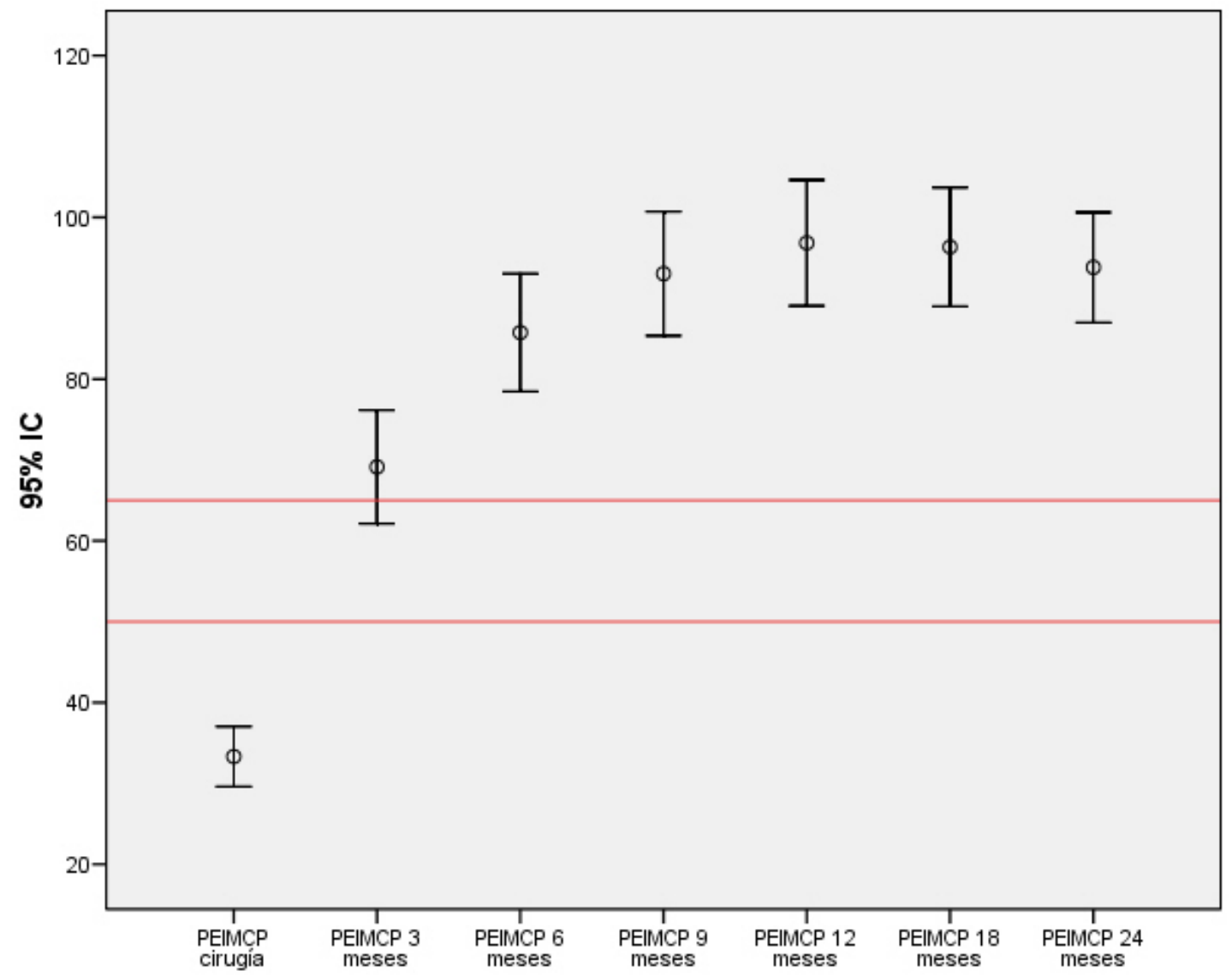

Figura 4.7.17. Gráfico de barras de error (IC 95\%) del PEIMCP en los diferentes controles evaluados

En la tabla 4.7.21 se muestra la evolución del PEIMCP medio respecto al sexo, observando un PEIMCP en la consulta prequirúrgica significativamente mayor en los varones. Por el contrario, el grupo de las mujeres desde los 12 meses hasta el último control presenta un PEIMCP más elevado que en el grupo de los hombres $(P<0,05)$. 


\begin{tabular}{|c|c|c|c|c|c|c|c|}
\hline & \multicolumn{3}{|c|}{ Mujer } & \multicolumn{3}{|c|}{ Hombre } & \multirow{2}{*}{$\mathbf{P}$} \\
\hline & $\mathbf{N}$ & Media & D.Típica & $\mathbf{N}$ & Media & D.Típica & \\
\hline $\begin{array}{c}\text { PEIMCP } \\
\text { cirugía (\%) }\end{array}$ & 71 & 29,53 & 9,67 & 29 & 41,07 & 12,26 & $<0,001$ \\
\hline $\begin{array}{l}\text { PEIMCP } 3 \\
\text { meses (\%) }\end{array}$ & 66 & $76,95^{\dagger}$ & 25,12 & 27 & $83,02^{\dagger}$ & 21,33 & NS \\
\hline $\begin{array}{l}\text { PEIMCP } 6 \\
\text { meses (\%) }\end{array}$ & 61 & $96,54^{\dagger}$ & 27,73 & 22 & $92,62^{\dagger}$ & 23,80 & NS \\
\hline $\begin{array}{l}\text { PEIMCP } 9 \\
\text { meses (\%) }\end{array}$ & 39 & $99,46^{\dagger}$ & 21,07 & 19 & $91,83^{\dagger}$ & 19,64 & NS \\
\hline $\begin{array}{l}\text { PEIMCP } 12 \\
\text { meses (\%) }\end{array}$ & 60 & $107,55^{\dagger}$ & 24,84 & 22 & $97,39^{\dagger}$ & 18,20 & $<0,05$ \\
\hline $\begin{array}{l}\text { PEIMCP } 18 \\
\text { meses (\%) }\end{array}$ & 42 & $108,94^{\dagger}$ & 24,80 & 21 & $92,41^{\dagger}$ & 18,92 & $<0,05$ \\
\hline $\begin{array}{l}\text { PEIMCP } 24 \\
\text { meses (\%) }\end{array}$ & 71 & $107,98^{\dagger}$ & 27,76 & 29 & $93,55^{\dagger}$ & 17,04 & $<0,05$ \\
\hline
\end{tabular}

Tabla 4.7.21. Descripción del PEIMCP según el sexo en las diferentes revisiones evaluadas

Hasta el control de los 3 meses son los hombres quienes registran un PEIMCP medio más elevado que las mujeres. Desde los 6 meses son las mujeres las que presentan un PEIMCP más elevado respecto a los hombres hasta los 24 meses evaluados.

En las mujeres el control en el que se observa mayor PEIMCP es a los 18 meses, en cambio en los hombres es a los 12 meses. Las mujeres alcanzan un PEIMCP medio más elevado que los hombres: 108,94\% . $97,39 \%(P<0,05)$.

En la tabla 4.7.22 se muestra la tendencia del PEIMCP conforme a la mediana de edad de la muestra.

\begin{tabular}{|c|c|c|c|c|c|c|c|}
\cline { 2 - 7 } \multicolumn{1}{c|}{} & \multicolumn{3}{c|}{$<42$ años } & \multicolumn{3}{c|}{$\geq \mathbf{4 2 \text { años }}$} & \multirow{2}{*}{ P } \\
\cline { 2 - 7 } & $\mathbf{N}$ & Media & D.Típica & N & Media & D.Típica & NS \\
\hline $\begin{array}{c}\text { PEIMCP } \\
\text { cirugía (\%) }\end{array}$ & 48 & 31,63 & 9,80 & 52 & 34,03 & 13,16 & NS \\
\hline $\begin{array}{c}\text { PEIMCP 3 } \\
\text { meses (\%) }\end{array}$ & 45 & $80,54^{\dagger}$ & 26,29 & 48 & $77,01^{\dagger}$ & 22,04 & NS \\
\hline $\begin{array}{c}\text { PEIMCP 6 } \\
\text { meses (\%) }\end{array}$ & 39 & $100,56^{\dagger}$ & 31,26 & 44 & $91,01^{\dagger}$ & 21,15 & NS \\
\hline $\begin{array}{c}\text { PEIMCP 9 } \\
\text { meses (\%) }\end{array}$ & 24 & $100,17^{\dagger}$ & 23,50 & 34 & $94,70^{\dagger}$ & 18,62 & NS \\
\hline $\begin{array}{c}\text { PEIMCP 12 } \\
\text { meses (\%) }\end{array}$ & 39 & $106,19^{\dagger}$ & 26,04 & 43 & $103,58^{\dagger}$ & 21,33 & NS \\
\hline $\begin{array}{c}\text { PEIMCP 18 } \\
\text { meses (\%) }\end{array}$ & 28 & $109,11^{\dagger}$ & 26,64 & 35 & $98,89^{\dagger}$ & 21,28 & N \\
\hline
\end{tabular}




\begin{tabular}{|c|c|c|c|c|c|c|c|}
\hline & \multicolumn{3}{|c|}{$<42$ años } & \multicolumn{3}{|c|}{$\geq 42$ años } & \multirow{2}{*}{$\mathbf{P}$} \\
\hline & $\mathbf{N}$ & Media & D.Típica & $\mathbf{N}$ & Media & D.Típica & \\
\hline $\begin{array}{c}\text { PEIMCP } 24 \\
\text { meses (\%) }\end{array}$ & 48 & $108^{\dagger}$ & 28,80 & 52 & $99,91^{\dagger}$ & 22,46 & NS \\
\hline
\end{tabular}

Tabla 4.7.22. Descripción del PEIMCP según el grupo de edad en las diferentes revisiones evaluadas

No se observan diferencias estadísticamente significativas entre el grupo de los $<42$ años y los $\geq 42$ años en ninguno de los controles evaluados. El grupo de los $<42$ años desde el control de los 3 meses registra un PEIMCP medio más elevado en cada uno de los controles siguientes hasta los 24 meses evaluados, siendo el PEIMCP medio más elevado el registrado en el control de los 18 meses en el grupo de los $<42$ años.

\section{c) Categorización de la pérdida de peso según el PEIMCP}

A continuación se desarrolla la evolución del PEIMCP categorizado en criterios de resultados: "excelente", "bueno" y "fracaso", según la clasificación propuesta por A. Larrad ${ }^{125}$.

- Excelente. PEIMCP $>65 \%$

- Bueno. PEIMCP 50-65\%

- Fracaso. PEIMCP $<50 \%$

En la tabla 4.7.23 se muestra la participación de pacientes en cada uno de los controles evaluados que es la misma que la descrita en el apartado anterior.

\begin{tabular}{cc}
\hline Periodo evaluado & N \\
\hline PEIMCP cirugía & 100 \\
\hline PEIMCP 3 meses & 93 \\
PEIMCP 6 meses & 83 \\
PEIMCP 9 meses & 58 \\
PEIMCP 12 meses & 82 \\
PEIMCP 18 meses & 63 \\
\hline PEIMCP 24 meses & 100 \\
\hline
\end{tabular}

Tabla 4.7.23. Seguimiento del PEIMCP en los pacientes evaluados en cada una de las revisiones 
En la figura 4.7.18 a página completa se representa la clasificación de los pacientes en cada uno de los controles evaluados según los criterios de calidad basados en el PEIMCP medio en cada uno de los controles evaluados. 


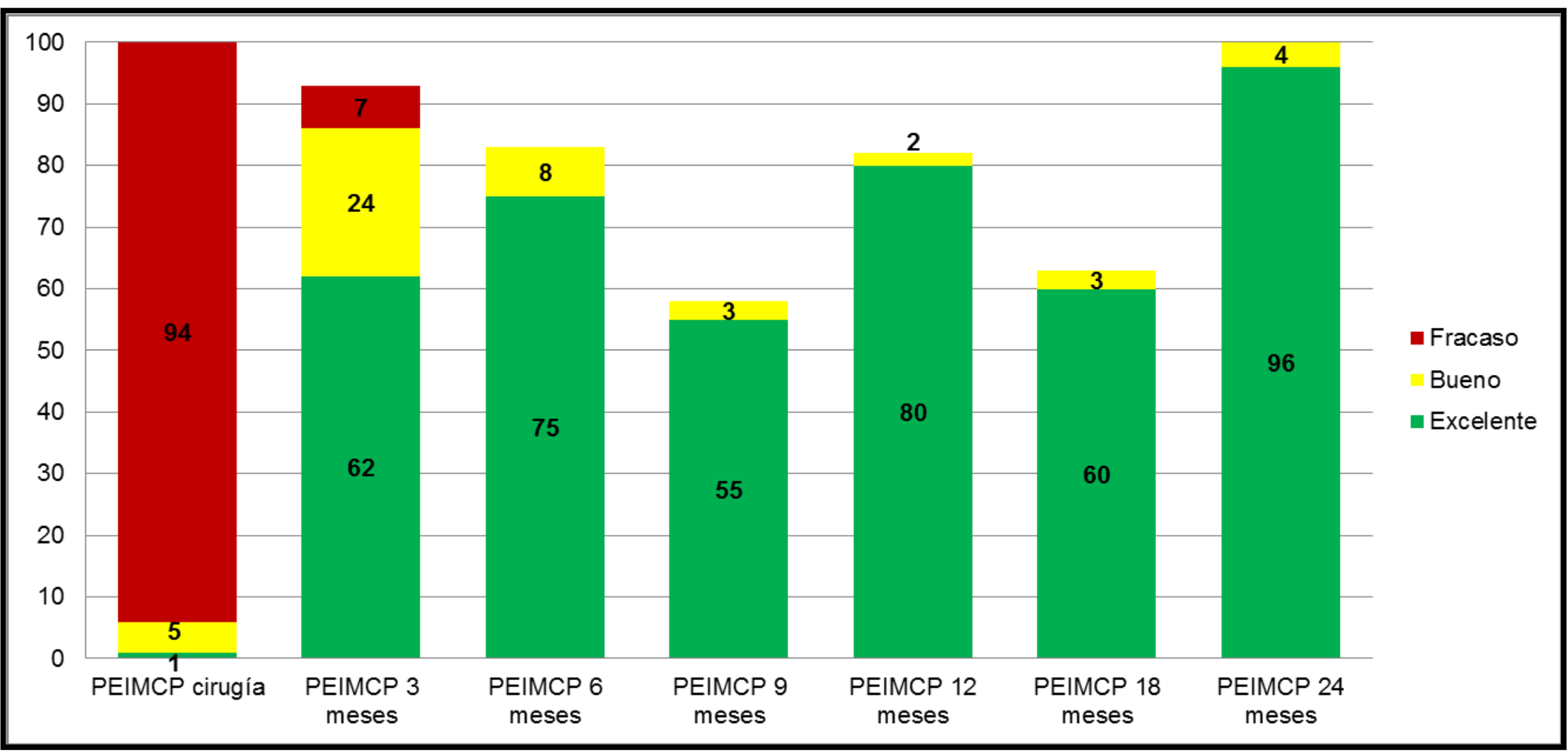

Figura 4.7.18. Clasificación de los pacientes en cada uno de los controles evaluados según los criterios de calidad basados en el PEIMCP 
En el control de la cirugía, se puede apreciar que la preparación prequirúrgica supone en el $94 \%$ de los casos un "fracaso" en cuanto a la pérdida ponderal establecida por el PEIMCP.

A los 3 meses de la cirugía tan solo 7 pacientes presentaban un PEIMCP <50\%, a diferencia de los 62 pacientes con criterios de "excelente". La revisión en la que se observan más pacientes con resultados de "excelente" es a los 24 meses de la cirugía.

Al comparar las variaciones de resultado entre el control inicial y los 24 meses postcirugía, se observa que la modificación en el número de pacientes con "fracaso" se reduce de manera estadísticamente significativa $(P<0,001)$. El número de pacientes con criterio de "bueno" entre el control inicial y a los 24 meses no sufre cambios estadísticamente significativos. Por el contrario, los pacientes con criterio de "excelente" sí aumentan de manera significativa a los 2 años de la cirugía $(P<0,001)$.

En la tabla 4.7.24 se muestra el número de pacientes agrupados por sexo en los diferentes controles, posteriormente se dividen a las mujeres y hombres por criterios de calidad basados en el PEIMCP. En la figura 4.7.19, se muestran los resultados expresados en porcentajes y están calculados sobre el número de mujeres y hombres según sea, de cada control, como se detalla en la tabla 4.7.24.

\begin{tabular}{lcc}
\hline & Mujeres & Hombres \\
\hline Periodo evaluado & N & N \\
\hline PEIMCP cirugía & 71 & 29 \\
PEIMCP 3 meses & 66 & 27 \\
PEIMCP 6 meses & 61 & 22 \\
PEIMCP 9 meses & 39 & 19 \\
PEIMCP 12 meses & 60 & 22 \\
PEIMCP 18 meses & 42 & 21 \\
PEIMCP 24 meses & 71 & 29 \\
\hline
\end{tabular}

Tabla 4.7.24. Seguimiento del PEIMCP en los pacientes evaluados en cada una de las revisiones según el sexo 
- Fracaso

Bueno

Excelente

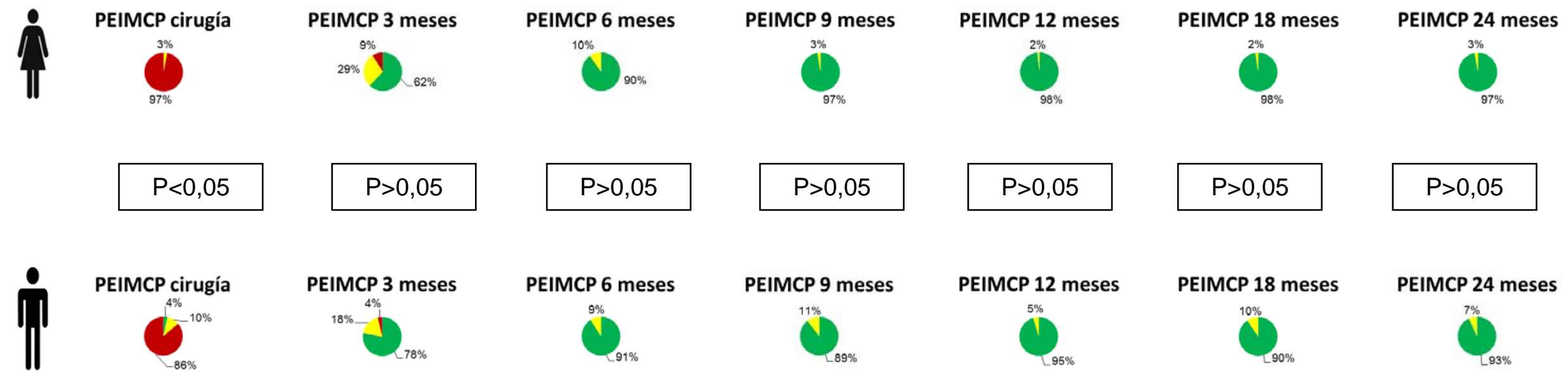

Figura 4.7.19. Evolución del criterio de calidad basado en el PEIMCP según el sexo, en cada uno de los controles evaluados 
Tan solo se observan diferencias estadísticamente significativas entre los hombres y las mujeres respecto al éxito basado en el PEIMCP en el momento quirúrgico. En los controles posteriores hasta los 24 meses evaluados, prácticamente no se aprecian diferencias entre ambos sexos.

Al comparar la evolución en las mujeres desde la cirugía hasta los 24 meses evaluados, se observa que el número de "fracasos" disminuye de manera significativa no observando a ninguna mujer a los 24 meses $(P<0,001)$. El criterio de calidad de "bueno" no sufre modificaciones. El número de mujeres con criterio de "excelente" a los 24 aumenta de manera significativa desde la cirugía $(P<0,001)$.

En los hombres, la modificación de los criterios de calidad basados en el PEIMCP desde la cirugía a los 24 meses, siguen la misma tendencia, siendo significativo el cambio sufrido en la disminución del número de hombres con criterio de "fracaso" y aumentando el número de "excelente" $(P<0,001)$.

En la tabla 4.7.25 se muestra el número de pacientes correspondientes en cada control evaluado según la edad. En la figura 4.7.20 se detalla mediante diagrama de sectores el porcentaje de pacientes de cada grupo de edad que presentaban criterios de "fracaso", "bueno" y "excelente".

\begin{tabular}{lcc}
\hline & $<$ 42 años & $\mathbf{2}$ 42 años \\
\hline Periodo evaluado & $\mathbf{N}$ & $\mathbf{N}$ \\
\hline PEIMCP cirugía & 48 & 52 \\
PEIMCP 3 meses & 45 & 48 \\
PEIMCP 6 meses & 39 & 44 \\
PEIMCP 9 meses & 24 & 34 \\
PEIMCP 12 meses & 39 & 43 \\
PEIMCP 18 meses & 28 & 35 \\
PEIMCP 24 meses & 48 & 52 \\
\hline
\end{tabular}

Tabla 4.7.25. Seguimiento del PEIMCP en los pacientes evaluados en cada una de las revisiones según la edad 
- Fracaso

Bueno

- Excelente

\begin{tabular}{|c|c|c|c|c|c|c|c|}
\hline $\begin{array}{l}<42 \\
\text { años }\end{array}$ & PEIMCP cirugía & PEIMCP 3 meses & PEIMCP 6 meses & PEIMCP 9 meses & PEIMCP 12 meses & PEIMCP 18 meses & PEIMCP 24 meses \\
\hline & $P>0,05$ & $P>0,05$ & $P>0,05$ & $P>0,05$ & $P>0,05$ & $P>0,05$ & $P>0,05$ \\
\hline
\end{tabular}

Figura 4.7.20. Evolución del criterio de calidad basado en el PEIMCP según el grupo de edad, en cada uno de los controles evaluados 
En ninguno de los controles evaluados se observan diferencias estadísticamente significativas entre los dos grupos de edad. Desde el 3 mes de la cirugía, en ambos grupos se describe una mayor presencia de pacientes con criterio de "excelente", observando este criterio en la totalidad de los pacientes < 42 años en el control de los 9,12, y 18 meses.

Al tomar como referencia el cambio experimentado desde la cirugía a los 24 meses apreciando la misma evolución en los dos grupos de edad. Los pacientes con criterio de "fracaso" en la cirugía desaparecen a los 24 meses en los dos grupos de edad $(P<0,001)$. El criterio "bueno" no sufre modificaciones estadísticamente significativas en ninguno de los dos grupos de edad desde la cirugía a los 24 meses estudiados. En cambio, el criterio de "excelente" aumenta de manera significativa desde la cirugía hasta los 24 meses en ambos grupos $(P<0,001)$.

\section{d) Evolución de la obesidad por IMC. Criterios SEEDO}

A continuación se describirán los grados de obesidad de la muestra estudiada en las diferentes revisiones, y las diferencias por sexo y mediana de edad.

En la tabla 4.7.26, se muestra la proporción de pacientes $(\mathrm{N})$ en cada uno de los controles evaluados, con los que se desarrolla a página completa en la figura 4.7.21 la distribución de los pacientes estudiados expresado en porcentajes, según el criterio de la SEEDO de clasificación del IMC.

\begin{tabular}{cc}
\hline Periodo evaluado & N \\
\hline Prequirúrgico & 100 \\
\hline Cirugía & 100 \\
3 meses & 93 \\
6 meses & 83 \\
9 meses & 58 \\
\hline 12 meses & 82 \\
18 meses & 63 \\
\hline 24 meses & 100 \\
\hline
\end{tabular}

Tabla 4.7.26. Distribución de los pacientes por criterios de IMC en las diferentes revisiones evaluadas 


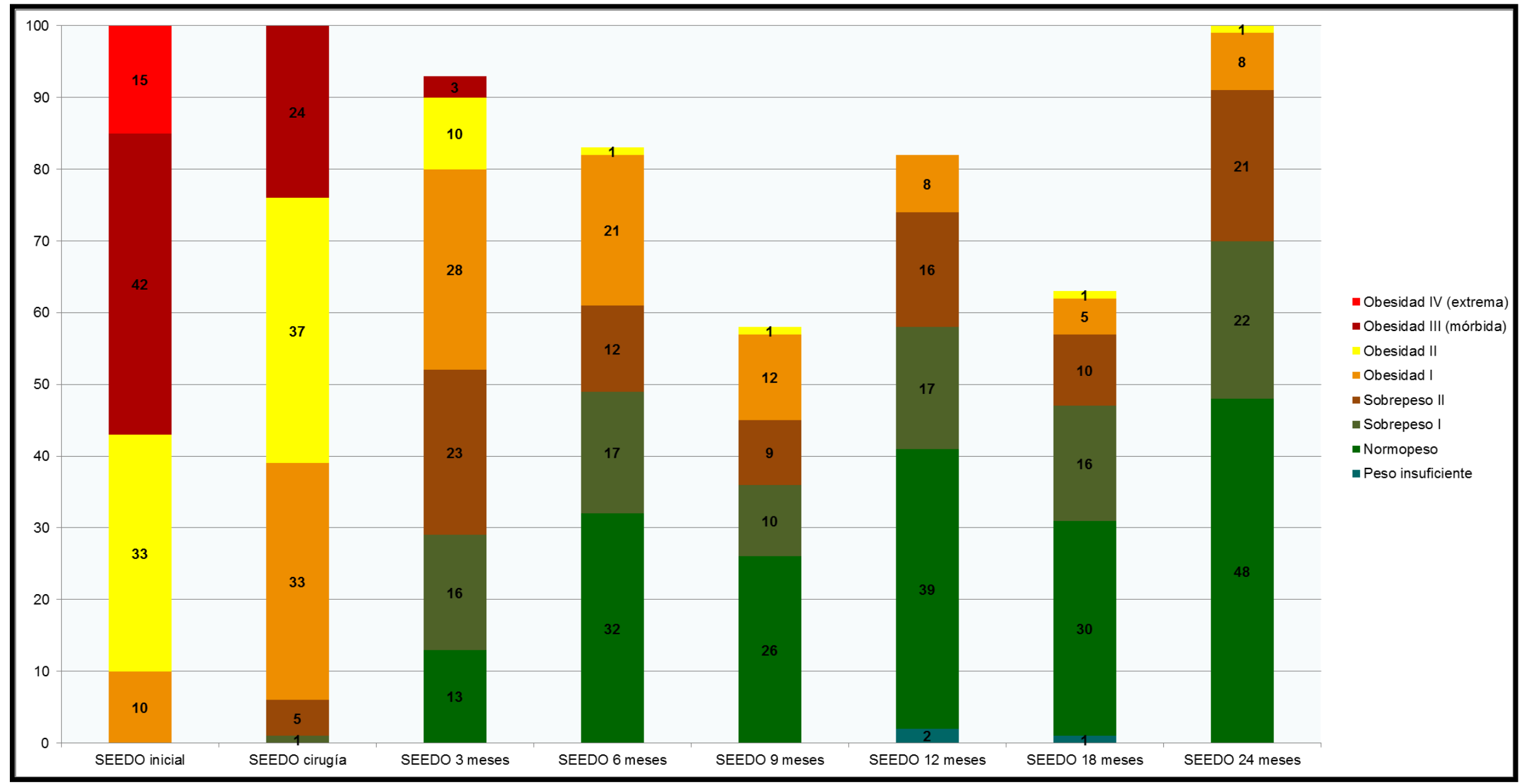

Figura 4.7.21. Distribución de los pacientes por criterios de clasificación SEEDO en los diferentes controles evaluados 
Como se puede apreciar en la figura 4.7.21 en el momento inicial, un $15 \%$ de los pacientes sufre obesidad tipo IV (extrema) que mediante la preparación dietético-nutricional prequirúrgica, consiguiendo llegar a eliminarla en su totalidad.

En el momento quirúrgico, se aprecia una mayor proporción de pacientes con obesidad tipo I y se han reducido los pacientes mórbidos respecto a la consulta inicial $(P<0,001)$.

Después de la cirugía, es en control de los 24 meses donde se observa más proporción de pacientes con normopeso (48\%). Ninguno de los 100 pacientes a los 24 meses presentaba obesidad mórbida. Tan solo 9 pacientes eran obesos, 8 de ellos con obesidad tipo I.

Al estudiar cada una de las clasificaciones del estado nutricional según el IMC desde el momento de la cirugía hasta los 24 meses evaluados, el resultado es estadísticamente significativo en cada uno de los criterios de categorización $(P<0,001)$.

Se observa una disminución significativa del número de pacientes obesos (en cada una de sus variantes) desde la cirugía a los 24 meses de seguimiento $(P<0,001)$. Del mismo modo ocurre a los 24 meses postquirúrgicos en el grupo de pacientes con normopeso, sobrepeso I y sobrepeso II, aumentando respecto al control quirúrgico $(P<0,001)$.

Por sexo, no existen diferencias estadísticamente significativas entre hombres y mujeres en la distribución de los mismos según los criterios SEEDO en ninguno de los controles evaluados excepto a los 18. En la tabla 4.7.27 se muestra la distribución de pacientes en el control de los 18 meses según criterios SEEDO, específicamente. 


\begin{tabular}{|c|c|c|c|}
\hline & \multicolumn{2}{|c|}{ SEXO } & \multirow{2}{*}{$\begin{array}{c}\text { TOTAL } \\
\text { \% de sexo } \\
\text { (N) }\end{array}$} \\
\hline & $\begin{array}{c}\text { Mujer } \\
\% \text { de sexo } \\
\text { (N) }\end{array}$ & $\begin{array}{l}\text { Hombre } \\
\% \text { de sexo } \\
\text { (N) }\end{array}$ & \\
\hline $\begin{array}{c}\text { Peso } \\
\text { insuficiente }\end{array}$ & $\begin{array}{l}2,4 \% \\
(1)\end{array}$ & - & $\begin{array}{c}1,6 \% \\
(1)\end{array}$ \\
\hline Normopeso & $\begin{array}{c}59,5 \% \\
(25)\end{array}$ & $\begin{array}{c}23,8 \% \\
(5)\end{array}$ & $\begin{array}{c}47,6 \% \\
(30)\end{array}$ \\
\hline Sobrepeso I & $\begin{array}{l}21,4 \% \\
(9)\end{array}$ & $\begin{array}{c}33,3 \% \\
(7)\end{array}$ & $\begin{array}{c}25,4 \% \\
(16)\end{array}$ \\
\hline Sobrepeso II & $\begin{array}{l}9,5 \% \\
(4)\end{array}$ & $\begin{array}{c}28,6 \% \\
(6)\end{array}$ & $\begin{array}{c}15,9 \% \\
(10)\end{array}$ \\
\hline Obesidad I & $\begin{array}{l}4,8 \% \\
(2)\end{array}$ & $\begin{array}{c}14,3 \% \\
(3)\end{array}$ & $\begin{array}{l}7,9 \% \\
(5)\end{array}$ \\
\hline Obesidad II & $\begin{array}{l}2,4 \% \\
(1)\end{array}$ & - & $\begin{array}{c}1,6 \% \\
(1)\end{array}$ \\
\hline TOTAL & $\begin{array}{c}100 \% \\
(42)\end{array}$ & $\begin{array}{c}100 \% \\
(21)\end{array}$ & $\begin{array}{c}100 \% \\
(63)\end{array}$ \\
\hline & & & $P=0,013$ \\
\hline
\end{tabular}

Tabla 4.7.27. Distribución de los pacientes por criterios de IMC según el sexo en la revisión de los 18 meses

Observando una mayor proporción de mujeres con normopeso respecto a los hombres. El porcentaje de hombres con sobrepeso y obesidad es más elevado que en el grupo de las mujeres $(P=0,013)$.

Al observar la distribución de los pacientes respecto a la mediana de edad, en ninguno de los controles evaluados se aprecian diferencias estadísticamente significativas, siendo prácticamente el mismo número de pacientes observados en cada categoría según el criterio SEEDO.

\subsubsection{Perímetro de cintura}

El perímetro de la cintura se ha evaluado en el momento previo a la cirugía y en los controles postquirúrgicos. Los resultados se expresan en cm, en la tabla 4.7.28 se muestran los resultados en los diferentes controles.

\begin{tabular}{|c|c|c|c|c|c|c|c|}
\hline & $\begin{array}{c}\text { Cintura } \\
\text { consulta } \\
\text { inicial } \\
\text { (cm) }\end{array}$ & $\begin{array}{c}\text { Cintura } \\
3 \\
\text { meses } \\
(\mathrm{cm})\end{array}$ & $\begin{array}{c}\text { Cintura } \\
6 \\
\text { meses } \\
(\mathrm{cm})\end{array}$ & $\begin{array}{c}\text { Cintura } \\
9 \\
\text { meses } \\
\text { (cm) }\end{array}$ & $\begin{array}{c}\text { Cintura } \\
12 \\
\text { meses } \\
\text { (cm) }\end{array}$ & $\begin{array}{c}\text { Cintura } \\
18 \\
\text { meses } \\
\text { (cm) }\end{array}$ & $\begin{array}{c}\text { Cintura } \\
24 \\
\text { meses } \\
(\mathrm{cm})\end{array}$ \\
\hline $\mathbf{N}$ & 100 & 91 & 82 & 57 & 81 & 63 & 100 \\
\hline Media & 128,49 & $96,84^{*^{\dagger}}$ & $92,04^{*^{\dagger}}$ & $89,86^{*^{\dagger}}$ & $85,98^{*^{\dagger}}$ & $86,59^{\dagger}$ & $88,06^{*^{\dagger}}$ \\
\hline D.Típica & 15,33 & 15,82 & 11,11 & 11,35 & 10,71 & 10,57 & 10,95 \\
\hline Mediana & 125 & 96 & 92 & 88 & 85 & 87 & 86,50 \\
\hline
\end{tabular}




\begin{tabular}{|c|c|c|c|c|c|c|c|}
\hline & $\begin{array}{l}\text { Cintura } \\
\text { consulta } \\
\text { inicial } \\
\text { (cm) }\end{array}$ & $\begin{array}{c}\text { Cintura } \\
3 \\
\text { meses } \\
(\mathrm{cm})\end{array}$ & $\begin{array}{c}\text { Cintura } \\
6 \\
\text { meses } \\
(\mathrm{cm})\end{array}$ & $\begin{array}{c}\text { Cintura } \\
9 \\
\text { meses } \\
(\mathrm{cm})\end{array}$ & $\begin{array}{c}\text { Cintura } \\
12 \\
\text { meses } \\
(\mathrm{cm})\end{array}$ & $\begin{array}{c}\text { Cintura } \\
18 \\
\text { meses } \\
(\mathrm{cm})\end{array}$ & $\begin{array}{c}\text { Cintura } \\
24 \\
\text { meses } \\
\text { (cm) }\end{array}$ \\
\hline $\begin{array}{c}\text { Rango } \\
\text { intercuartílico } \\
\text { (P25-P75) }\end{array}$ & $\begin{array}{c}117,25- \\
140\end{array}$ & 88-104 & $85-99$ & $83-95$ & $\begin{array}{c}79,50- \\
94\end{array}$ & 80-93 & $\begin{array}{c}80,25- \\
95\end{array}$ \\
\hline
\end{tabular}

Tabla 4.7.28. Descripción del perímetro de cintura en las diferentes revisiones evaluadas

La tasa de respuesta es prácticamente la misma que con las variables previamente estudiadas. El perímetro de cintura medio más elevado se registra en el control previo a la cirugía, el cual disminuye progresivamente hasta los 12 meses de manera significativa $(P<0,05)$. Desde el control de los 12 meses a los 18, el perímetro de cintura medio aumenta sin ser estadísticamente significativo. En cambio entre el control de los 18 meses y 24 meses, el perímetro de cintura medio aumenta significativamente 2,50 $\mathrm{cm}$.

Desde el año de la cirugía, se observa cómo un 25\% de pacientes superan los $94 \mathrm{~cm}$ de perímetro de cintura hasta los 24 meses. Del mismo modo ocurre con un 25\% de pacientes que están por debajo de los $80 \mathrm{~cm}$ de perímetro de cintura desde los 12 meses postcirugía y se mantienen hasta los 24 meses estudiados.

En la figura 4.7.22 se representa mediante histogramas la distribución del perímetro de cintura, expresado en $\mathrm{cm}$, en los diferentes controles evaluados. 

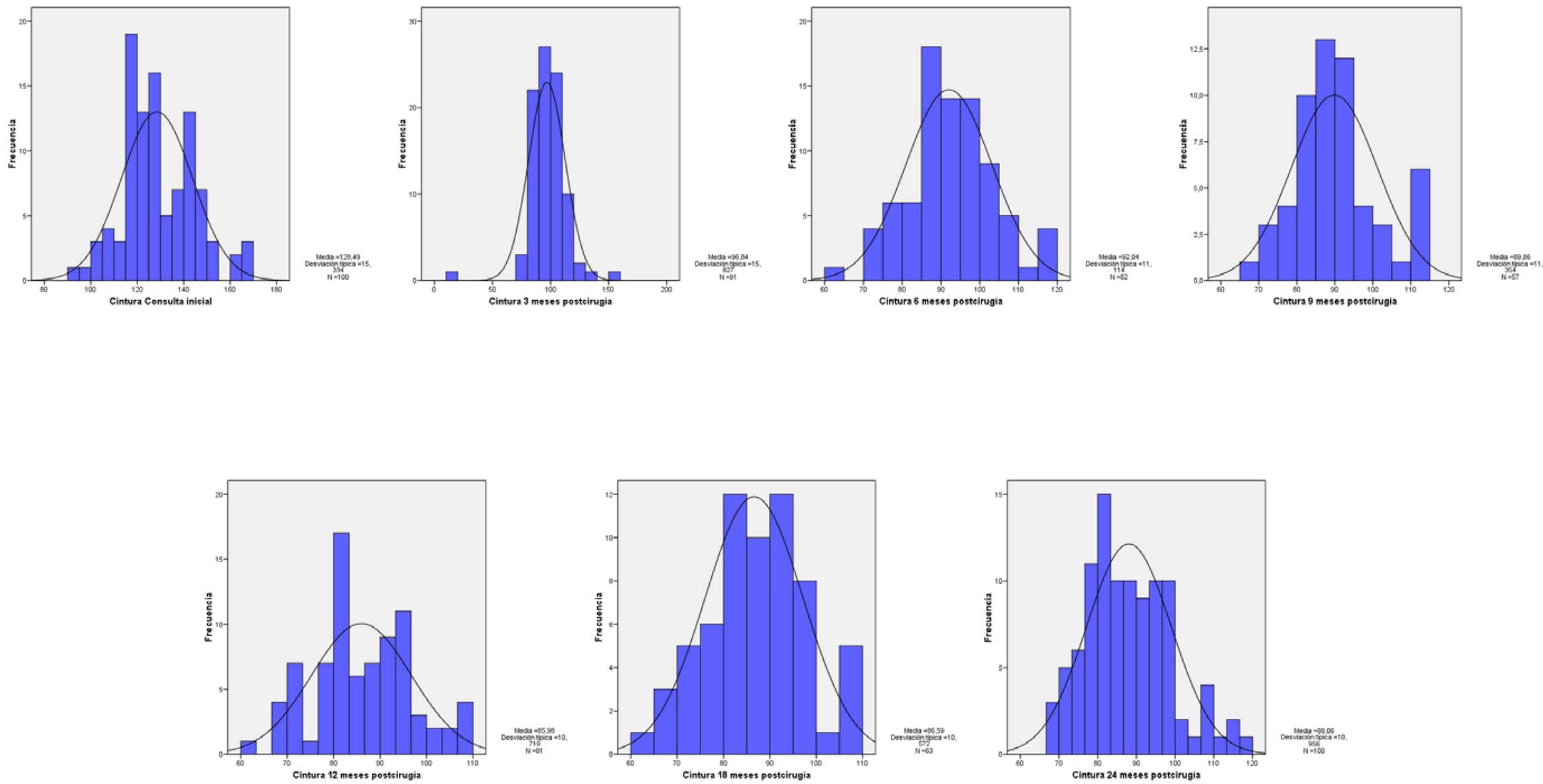

Figura 4.7.22. Representación en histogramas del perímetro de cintura en las diferentes revisiones evaluadas 
En la figura 4.7.23 se describe mediante un gráfico de barras de error la evolución del perímetro de cintura medio en los diferentes controles evaluados. El perímetro de cintura medio entre los 3 meses de la cirugía y el control de los 24 meses, desciende 8,14 cm $(P<0,001)$.

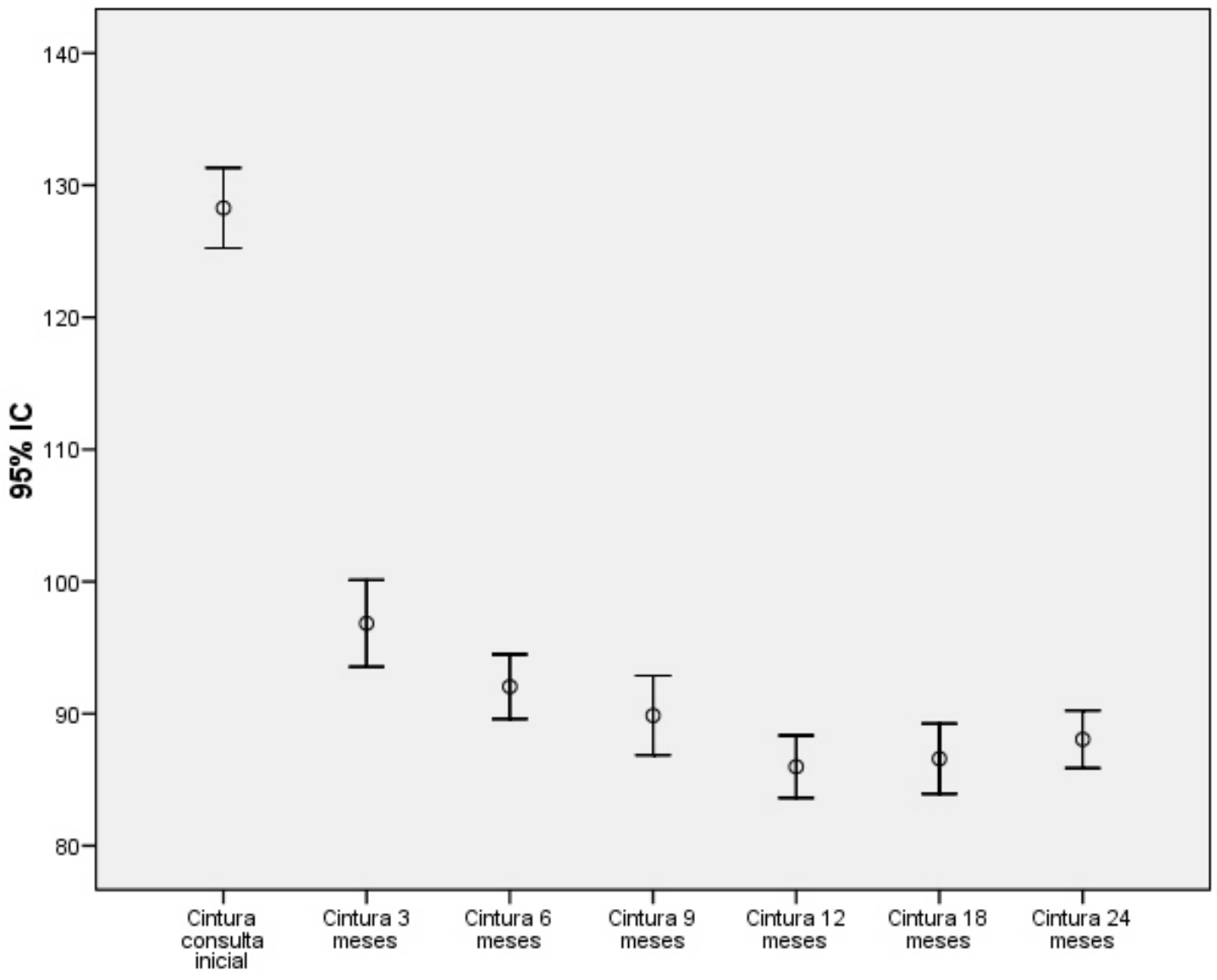

Figura 4.7.23. Gráfico de barras de error (IC 95\%) del perímetro de cintura en los controles evaluados

En la tabla 4.7.29 se observan las diferencias estadísticamente significativas del perímetro de cintura en función del sexo, en cada uno de los controles evaluados, siendo mayor el perímetro en los hombres que en las mujeres en cada uno de ellos.

\begin{tabular}{|c|c|c|c|c|c|c|c|}
\hline & \multicolumn{3}{|c|}{ Mujer } & \multicolumn{3}{|c|}{ Hombre } & \multirow{2}{*}{$\mathbf{P}$} \\
\hline & $\mathbf{N}$ & Media & D.Típica & $\mathbf{N}$ & Media & D.Típica & \\
\hline $\begin{array}{c}\text { Cintura } \\
\text { consulta } \\
\text { inicial (cm) }\end{array}$ & 71 & 124,44 & 14,26 & 29 & 138,41 & 13,37 & $<0,001$ \\
\hline $\begin{array}{c}\text { Cintura } 3 \\
\text { meses }(\mathrm{cm})\end{array}$ & 64 & $94,48^{\dagger}$ & 16,29 & 27 & $102,41^{\dagger}$ & 13,35 & $<0,05$ \\
\hline $\begin{array}{l}\text { Cintura } 6 \\
\text { meses }(\mathrm{cm})\end{array}$ & 60 & $89,84^{\dagger}$ & 10,49 & 22 & $98,05^{\dagger}$ & 10,73 & $<0,05$ \\
\hline
\end{tabular}




\begin{tabular}{|c|c|c|c|c|c|c|c|}
\cline { 2 - 8 } \multicolumn{1}{c|}{} & \multicolumn{5}{c|}{ Mujer } & \multicolumn{3}{c|}{ Hombre } & \multirow{2}{*}{ P } \\
\cline { 2 - 8 } \multicolumn{1}{c|}{} & N & Media & D.Típica & N & Media & D.Típica & \\
\hline $\begin{array}{c}\text { Cintura 9 } \\
\text { meses (cm) }\end{array}$ & 38 & $86,76^{\dagger}$ & 10,35 & 19 & $96,05^{\dagger}$ & 10,94 & $<0,05$ \\
\hline $\begin{array}{c}\text { Cintura 12 } \\
\text { meses (cm) }\end{array}$ & 59 & $83,21^{\dagger}$ & 10,15 & 22 & $83,41^{\dagger}$ & 8,56 & $<0,001$ \\
\hline $\begin{array}{c}\text { Cintura 18 } \\
\text { meses (cm) }\end{array}$ & 42 & $82,71^{\dagger}$ & 9,57 & 21 & $94,33^{\dagger}$ & 8 & $<0,001$ \\
\hline $\begin{array}{c}\text { Cintura 24 } \\
\text { meses (cm) }\end{array}$ & 71 & $84,62^{\dagger}$ & 9,38 & 29 & $96,48^{\dagger}$ & 10,02 & $<0,001$ \\
\hline
\end{tabular}

Tabla 4.7.29. Descripción del perímetro de cintura según el sexo en las diferentes revisiones evaluadas

Respecto a la mediana de edad como se muestra en la tabla 4.7.30, en el perímetro de cintura medio sólo se observan diferencias significativas en el control de los 9 y 18 meses, siendo mayor el perímetro de cintura medio en el grupo de los $\geq 42$ años. En el resto de controles el perímetro de cintura medio es mayor en el grupo de los $\geq 42$ años, que en el de los $<42$ años $(P>0,05)$.

\begin{tabular}{|c|c|c|c|c|c|c|c|}
\hline & \multicolumn{3}{|c|}{$<42$ años } & \multicolumn{3}{|c|}{$\geq 42$ años } & \multirow{2}{*}{$\mathbf{P}$} \\
\hline & $\mathbf{N}$ & Media & D.Típica & $\mathbf{N}$ & Media & D.Típica & \\
\hline $\begin{array}{c}\text { Cintura } \\
\text { consulta } \\
\text { inicial }(\mathbf{c m})\end{array}$ & 48 & 128,19 & 16,15 & 52 & 128,77 & 14,68 & NS \\
\hline $\begin{array}{c}\text { Cintura } 3 \\
\text { meses }(\mathrm{cm})\end{array}$ & 44 & $94,80^{\dagger}$ & 17,89 & 47 & $98,74^{\dagger}$ & 13,52 & NS \\
\hline $\begin{array}{c}\text { Cintura } 6 \\
\text { meses }(\mathrm{cm})\end{array}$ & 38 & $90,38^{\dagger}$ & 11,43 & 44 & $93,48^{\dagger}$ & 10,75 & NS \\
\hline $\begin{array}{c}\text { Cintura } 9 \\
\text { meses (cm) }\end{array}$ & 23 & $85,65^{\dagger}$ & 10,75 & 34 & $92,71^{\dagger}$ & 11 & $<0,05$ \\
\hline $\begin{array}{l}\text { Cintura } 12 \\
\text { meses (cm) }\end{array}$ & 39 & $85,35^{\dagger}$ & 11,01 & 42 & $86,57^{\dagger}$ & 10,53 & NS \\
\hline $\begin{array}{c}\text { Cintura } 18 \\
\text { meses }(\mathrm{cm})\end{array}$ & 28 & $83,32^{\dagger}$ & 11,34 & 35 & $89,20^{\dagger}$ & 9,26 & $<0,05$ \\
\hline $\begin{array}{c}\text { Cintura } 24 \\
\text { meses (cm) }\end{array}$ & 48 & $86,46^{\dagger}$ & 11,65 & 52 & $89,54^{\dagger}$ & 10,16 & NS \\
\hline
\end{tabular}

Tabla 4.7.30. Descripción del perímetro de cintura según el grupo de edad en las diferentes revisiones evaluadas

\section{a) Obesidad abdominal asociada al perímetro de cintura}

La definición de obesidad abdominal según el sexo viene determinada por la longitud en el perímetro de la cintura: $>102 \mathrm{~cm}$ en el hombre y $88 \mathrm{~cm}$ 
en la mujer, según las recomendaciones de la SEEDO, National Cholesterol Education Program Adult Treatment Panel III (ATPIII) y la International Diabetes Federation (IDF) ${ }^{126}$.

En la tabla 4.7.31 se describe la obesidad abdominal según el sexo en los diferentes controles evaluados. El número total de pacientes en cada control es el mismo que el descrito en el apartado anterior del perímetro de cintura.

\begin{tabular}{|c|c|c|c|c|c|c|c|c|c|}
\hline & \multicolumn{7}{|c|}{ Controles evaluados } \\
\hline & & & Precirugía & $\begin{array}{c}3^{*} \\
\text { meses }\end{array}$ & $\begin{array}{c}6 \\
\text { meses }\end{array}$ & $\begin{array}{c}9^{*} \\
\text { meses }\end{array}$ & $\begin{array}{c}12 \\
\text { meses }\end{array}$ & $\begin{array}{c}18 \\
\text { meses }\end{array}$ & $\begin{array}{c}24 \\
\text { meses }\end{array}$ \\
\hline \multirow{2}{*}{ Sexo } & Mujer & $\begin{array}{c}\% \text { de } \\
\text { sexo } \\
(\mathrm{N})\end{array}$ & $\begin{array}{c}100 \% \\
(71)\end{array}$ & $\begin{array}{c}68,8 \% \\
(44)\end{array}$ & $\begin{array}{c}61,7 \% \\
(37)\end{array}$ & $\begin{array}{l}50 \% \\
(19)\end{array}$ & $\begin{array}{c}32,2 \% \\
(19)\end{array}$ & $\begin{array}{l}31 \% \\
(13)\end{array}$ & $\begin{array}{c}33,8 \% \\
(24)\end{array}$ \\
\hline & Hombre & $\begin{array}{c}\% \text { de } \\
\text { sexo } \\
(\mathrm{N})\end{array}$ & $\begin{array}{c}100 \% \\
(29)\end{array}$ & $\begin{array}{c}48,1 \% \\
(13)\end{array}$ & $\begin{array}{c}36,4 \% \\
\quad(8)\end{array}$ & $\begin{array}{c}26,3 \% \\
(5)\end{array}$ & $\begin{array}{c}18,2 \% \\
(4)\end{array}$ & $\begin{array}{c}19 \% \\
(4)\end{array}$ & $\begin{array}{c}20,7 \% \\
\quad(6)\end{array}$ \\
\hline Total & \multicolumn{2}{|c|}{$\%$ de sexo $(\mathrm{N})$} & $\begin{array}{l}100 \% \\
(100)\end{array}$ & $\begin{array}{c}62,6 \% \\
(57)\end{array}$ & $\begin{array}{c}54,9 \% \\
(45)\end{array}$ & $\begin{array}{c}42,1 \% \\
(24)\end{array}$ & $\begin{array}{c}28,4 \% \\
(23)\end{array}$ & $\begin{array}{l}27 \% \\
(17)\end{array}$ & $\begin{array}{l}30 \% \\
(30)\end{array}$ \\
\hline
\end{tabular}

Tabla 4.7.31. Descripción de la obesidad abdominal según el sexo en los controles evaluados

La presencia de obesidad abdominal según el sexo en los controles de los 3 y 6 meses postquirúrgicos es estadísticamente significativa, siendo mucho mayor la presencia de obesidad abdominal en las mujeres. En los controles siguientes, la obesidad abdominal respecto al sexo se observa más en las mujeres sin ser significativo.

En términos generales, sobre el total de los pacientes estudiados la evolución de la obesidad abdominal desde el momento prequirúrgico hasta los 24 meses, desciende significativamente $(P<0,001)$. En el momento prequirúrgico los 100 pacientes presentaban obesidad abdominal y a los 2 años de la cirugía solamente 30 de ellos $(P<0,001)$.

Si observamos esto mismo respecto al sexo, en el momento previo a la cirugía 71 mujeres presentaban obesidad abdominal y al cabo de 24 meses se registraron 24 mujeres $(P<0,001)$. En el caso de los hombres, 29 
pacientes presentaban obesidad abdominal prequirúrgica y a los 24 meses tan solo 6 de ellos $(P<0,001)$.

En la tabla 4.7.32, se describe la presencia de obesidad abdominal por grupos de edad en los diferentes controles evaluados.

\begin{tabular}{|c|c|c|c|c|c|c|c|c|c|}
\hline & \multicolumn{7}{|c|}{ Controles evaluados } \\
\hline & & & Precirugía & $\begin{array}{c}3 \\
\text { meses }\end{array}$ & $\begin{array}{c}6 \\
\text { meses }\end{array}$ & $\begin{array}{c}{ }^{* 9} \\
\text { meses }\end{array}$ & $\begin{array}{c}12 \\
\text { meses }\end{array}$ & $\begin{array}{c}18 \\
\text { meses }\end{array}$ & $\begin{array}{c}24 \\
\text { meses }\end{array}$ \\
\hline \multirow{2}{*}{$\begin{array}{c}\text { Grupo } \\
\text { de } \\
\text { edad }\end{array}$} & $\begin{array}{l}<42 \\
\text { años }\end{array}$ & $\begin{array}{c}\text { \% de } \\
\text { grupo de } \\
\text { edad }(\mathrm{N})\end{array}$ & $\begin{array}{c}100 \% \\
(48)\end{array}$ & $\begin{array}{c}54,5 \% \\
(24)\end{array}$ & $\begin{array}{l}50 \% \\
(19)\end{array}$ & $\begin{array}{c}26,1 \% \\
(6)\end{array}$ & $\begin{array}{c}30,8 \% \\
(12)\end{array}$ & $\begin{array}{c}17,9 \% \\
(5)\end{array}$ & $\begin{array}{l}25 \% \\
(12)\end{array}$ \\
\hline & $\begin{array}{l}\geq 42 \\
\text { años }\end{array}$ & $\begin{array}{c}\text { \% de } \\
\text { grupo de } \\
\text { edad }(\mathrm{N})\end{array}$ & $\begin{array}{c}100 \% \\
(52)\end{array}$ & $\begin{array}{c}70,2 \% \\
\text { (33) }\end{array}$ & $\begin{array}{c}59,1 \% \\
(26)\end{array}$ & $\begin{array}{c}52,9 \% \\
(18)\end{array}$ & $\begin{array}{c}26,2 \% \\
(11)\end{array}$ & $\begin{array}{c}34,3 \% \\
(12)\end{array}$ & $\begin{array}{c}34,6 \% \\
(18)\end{array}$ \\
\hline Total & \multicolumn{2}{|c|}{$\begin{array}{l}\% \text { de grupo de } \\
\text { edad }(N)\end{array}$} & $\begin{array}{l}100 \% \\
(100)\end{array}$ & $\begin{array}{c}62,6 \% \\
(57)\end{array}$ & $\begin{array}{c}54,9 \% \\
(45)\end{array}$ & $\begin{array}{c}42,1 \% \\
(24)\end{array}$ & $\begin{array}{c}28,4 \% \\
(23)\end{array}$ & $\begin{array}{l}27 \% \\
(17)\end{array}$ & $\begin{array}{l}30 \% \\
(30)\end{array}$ \\
\hline
\end{tabular}

Tabla 4.7.32. Descripción de la obesidad abdominal por grupos de edad en los controles evaluados

En el control previo a la cirugía todos los pacientes independientemente de la edad presentaban obesidad abdominal. En los controles postquirúrgicos se observa una mayor proporción de pacientes con obesidad abdominal en el grupo de los $\geq 42$ años, siendo estadísticamente significativa esta diferencia a los 9 meses postcirugía $(P<0,05)$.

La evolución de la obesidad abdominal desde el momento prequirúrgico en referencia a los 24 meses de la cirugía sufre un descenso estadísticamente significativo en los dos grupos de edad estudiados $(P<0,001)$.

\subsubsection{Perímetro de la cadera}

En la tabla 4.7.33 se muestra la evolución del perímetro de la cadera desde la consulta previa a la cirugía, los resultados se expresan en cm.

\begin{tabular}{|c|c|c|c|c|c|c|c|}
\cline { 2 - 7 } & $\begin{array}{c}\text { Cadera } \\
\text { consulta } \\
\text { inicial } \\
\mathbf{( c m )}\end{array}$ & $\begin{array}{c}\text { Cadera } \\
\mathbf{3} \\
\text { meses } \\
\mathbf{( c m )}\end{array}$ & $\begin{array}{c}\text { Cadera } \\
\mathbf{6} \\
\text { meses } \\
\mathbf{( c m )}\end{array}$ & $\begin{array}{c}\text { Cadera } \\
\mathbf{9} \\
\text { meses } \\
\mathbf{( c m )}\end{array}$ & $\begin{array}{c}\text { Cadera } \\
\mathbf{1 2} \\
\text { meses } \\
\mathbf{( c m})\end{array}$ & $\begin{array}{c}\text { Cadera } \\
\mathbf{1 8} \\
\text { meses } \\
\mathbf{( c m})\end{array}$ & $\begin{array}{c}\text { Cadera } \\
\mathbf{2 4} \\
\mathbf{m e s e s} \\
\mathbf{( c m})\end{array}$ \\
\hline $\mathbf{N}$ & 100 & 91 & 82 & 57 & 81 & 63 & 100 \\
\hline Media & 123,43 & $110,56^{\star^{\dagger}}$ & $105,15^{\star^{\dagger}}$ & $102,35^{\star^{\dagger}}$ & $99,99^{\star^{\dagger}}$ & $99,84^{\dagger}$ & $99,31^{\dagger}$ \\
\hline
\end{tabular}




\begin{tabular}{|c|c|c|c|c|c|c|c|}
\hline & $\begin{array}{c}\text { Cadera } \\
\text { consulta } \\
\text { inicial } \\
\text { (cm) }\end{array}$ & $\begin{array}{c}\text { Cadera } \\
3 \\
\text { meses } \\
(\mathrm{cm})\end{array}$ & $\begin{array}{c}\text { Cadera } \\
6 \\
\text { meses } \\
(\mathrm{cm})\end{array}$ & $\begin{array}{c}\text { Cadera } \\
9 \\
\text { meses } \\
(\mathrm{cm})\end{array}$ & $\begin{array}{c}\text { Cadera } \\
12 \\
\text { meses } \\
(\mathrm{cm})\end{array}$ & $\begin{array}{c}\text { Cadera } \\
18 \\
\text { meses } \\
\text { (cm) }\end{array}$ & $\begin{array}{c}\text { Cadera } \\
24 \\
\text { meses } \\
(\mathrm{cm})\end{array}$ \\
\hline D.Típica & 25,24 & 13,86 & 9,58 & 10,10 & 8,70 & 9 & 8,65 \\
\hline Mediana & 130,50 & 109 & 104 & 101 & 100 & 100 & 100 \\
\hline $\begin{array}{c}\text { Rango } \\
\text { intercuartílico } \\
\text { (P25-P75) }\end{array}$ & $92-142$ & $100-120$ & $99-113$ & 95-109 & 94-106 & 93-105 & 93-105 \\
\hline
\end{tabular}

Tabla 4.7.33. Descripción del perímetro de cadera en las diferentes revisiones evaluadas

La tasa de respuesta de pacientes es la misma que la registrada en la determinación del perímetro de cintura, y similar a las anteriores variables descritas. En el control previo a la cirugía el 50\% de los pacientes presentaba un perímetro de cadera medio de 130,50 cm. El perímetro de cadera desciende de manera significativa entre cada uno de los controles evaluados hasta los 12 meses $(P<0,05)$. Las modificaciones del perímetro de cadera medio entre el control de los 12 meses a los 18, y entre los 18 a 24 meses no se mostraron diferencias significativas.

Desde los 12 meses de la cirugía a los 24 meses, un 25\% de pacientes se mantienen con un perímetro de cadera inferior a $94 \mathrm{~cm}$. Desde los 12 meses, el $50 \%$ de los pacientes se mantienen con un perímetro de cadera medio de $100 \mathrm{~cm}$. Por encima de los $105 \mathrm{~cm}$ de perímetro de cadera a los 24 meses de la cirugía se registraron 25 pacientes.

En la figura 4.7.24 se representa mediante histogramas la distribución del perímetro de cadera, expresado en $\mathrm{cm}$, en los diferentes controles evaluados. El control prequirúrgico, es el único que no sigue una distribución normal, aunque se consideró incluirlo en la representación junto con el resto de controles. 

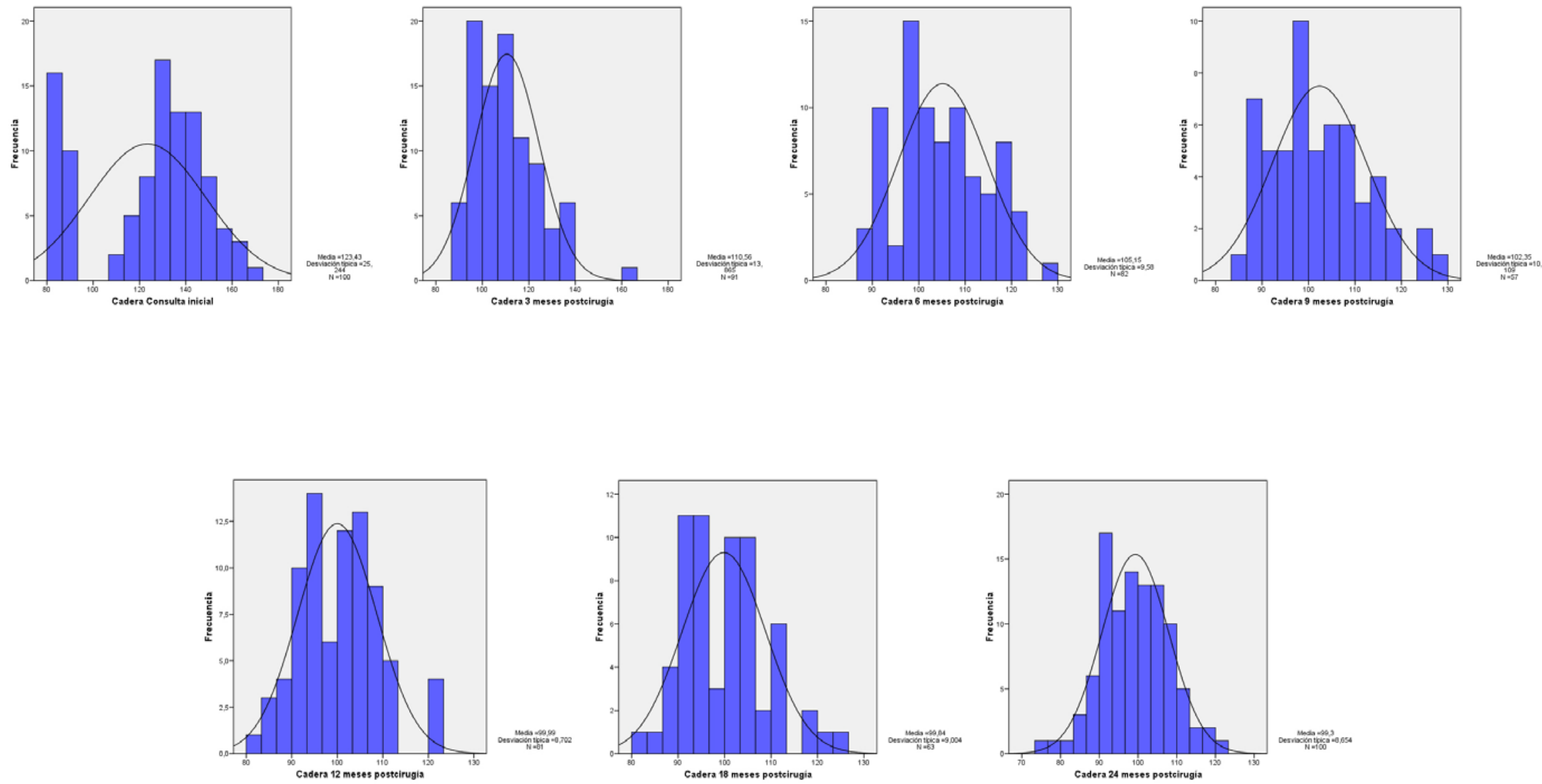

Figura 4.7.24. Representación en histogramas del perímetro de cadera en las diferentes revisiones evaluadas 
En la figura 4.7.25 se describe mediante un gráfico de barras de error la evolución del perímetro de cadera medio en los diferentes controles evaluados. Se observa una reducción del perímetro de cadera medio de $10,74 \mathrm{~cm}$, desde el primer control postquirúrgico de los 3 meses hasta los 24 meses evaluados $(P<0,001)$.

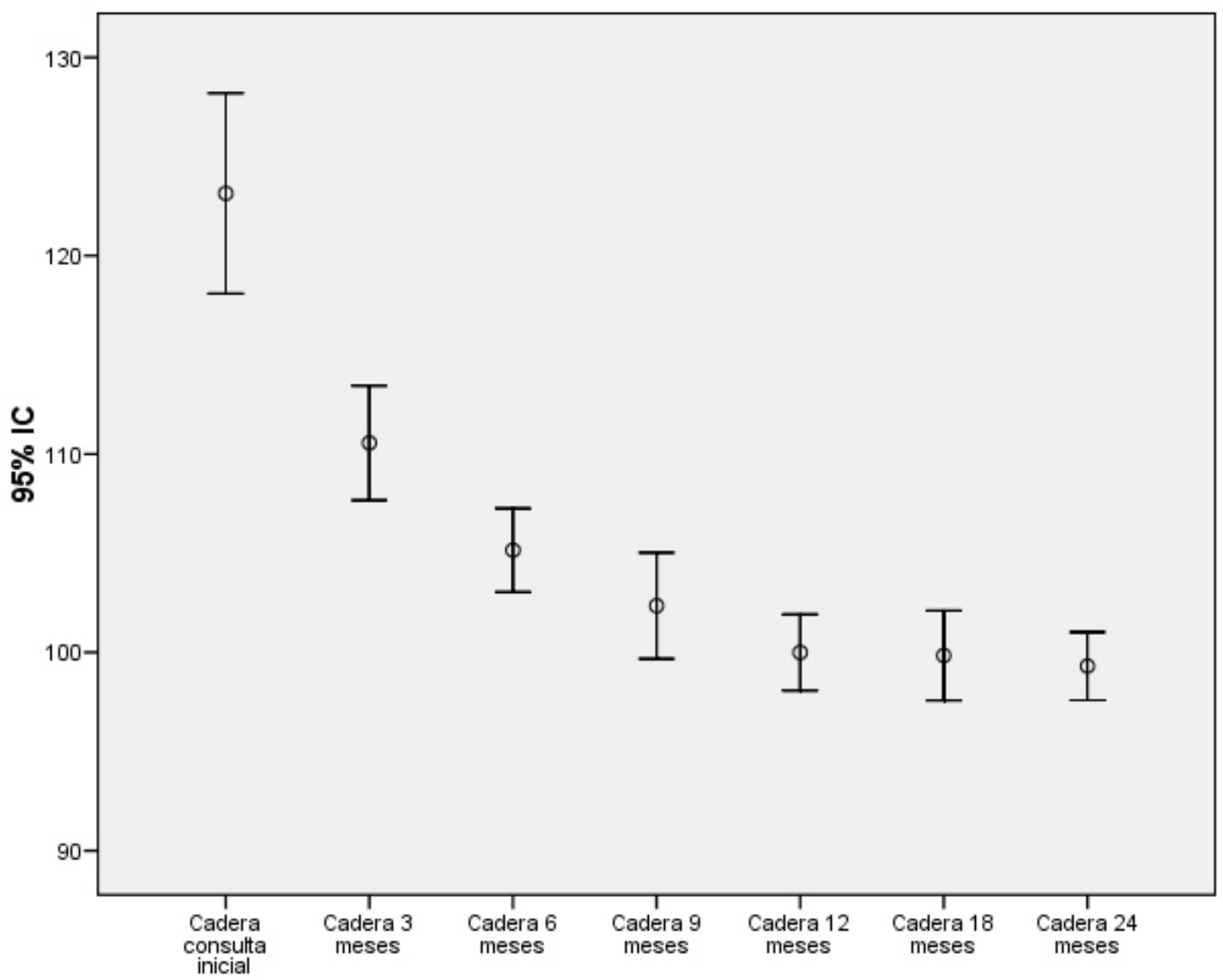

Figura 4.7.25. Gráfico de barras de error (IC 95\%) del perímetro de cadera en los controles evaluados

En la tabla 4.7.34 se muestra la evolución del perímetro de cadera medio según el sexo, sin observarse en ninguno de los controles diferencias estadísticamente significativas entre ambos sexos.

\begin{tabular}{|c|c|c|c|c|c|c|c|}
\hline & \multicolumn{3}{|c|}{ Mujer } & \multicolumn{3}{|c|}{ Hombre } & \multirow{2}{*}{$\mathbf{P}$} \\
\hline & $\mathbf{N}$ & Media & D.Típica & $\mathbf{N}$ & Media & D.Típica & \\
\hline $\begin{array}{c}\text { Cadera } \\
\text { consulta } \\
\text { inicial }(\mathbf{c m})\end{array}$ & 71 & 123,06 & 26,63 & 29 & 124,34 & 21,8 & NS \\
\hline $\begin{array}{c}\text { Cadera } 3 \\
\text { meses }(\mathrm{cm})\end{array}$ & 64 & $111,38^{\dagger}$ & 13,06 & 27 & $108,63^{\dagger}$ & 15,69 & NS \\
\hline
\end{tabular}




\begin{tabular}{|c|c|c|c|c|c|c|c|}
\hline & \multicolumn{3}{|c|}{ Mujer } & \multicolumn{3}{|c|}{ Hombre } & \multirow{2}{*}{$\mathbf{P}$} \\
\hline & $\mathbf{N}$ & Media & D.Típica & $\mathbf{N}$ & Media & D.Típica & \\
\hline $\begin{array}{c}\text { Cadera } 6 \\
\text { meses }(\mathrm{cm})\end{array}$ & 60 & $105,39^{\dagger}$ & 10,11 & 22 & $104,50^{\dagger}$ & 8,12 & NS \\
\hline $\begin{array}{c}\text { Cadera } 9 \\
\text { meses }(\mathrm{cm})\end{array}$ & 38 & $102,26^{\dagger}$ & 10,44 & 19 & $102,53^{\dagger}$ & 9,66 & NS \\
\hline $\begin{array}{l}\text { Cadera } 12 \\
\text { meses }(\mathrm{cm})\end{array}$ & 59 & $99,91^{\dagger}$ & 9,32 & 22 & $100,23^{\dagger}$ & 6,96 & NS \\
\hline $\begin{array}{l}\text { Cadera } 18 \\
\text { meses (cm) }\end{array}$ & 42 & $98,98^{\dagger}$ & 9,62 & 21 & $101,57^{\dagger}$ & 7,52 & NS \\
\hline $\begin{array}{l}\text { Cadera } 24 \\
\text { meses }(\mathrm{cm})\end{array}$ & 71 & $98,55^{\dagger}$ & 9,24 & 29 & $101,16^{\dagger}$ & 6,79 & NS \\
\hline
\end{tabular}

Tabla 4.7.34. Descripción del perímetro de cadera según el sexo en las diferentes revisiones evaluadas

Del mismo modo, al agrupar a los pacientes por la mediana de edad, tabla 4.7.35, tampoco se observan diferencias estadísticamente significativas entre el grupo de los $<42$ años y $\geq 42$ años.

\begin{tabular}{|c|c|c|c|c|c|c|c|}
\hline & \multicolumn{3}{|c|}{$<42$ años } & \multicolumn{3}{|c|}{$\geq 42$ años } & \multirow{2}{*}{$\mathbf{P}$} \\
\hline & $\mathbf{N}$ & Media & D.Típica & $\mathbf{N}$ & Media & D.Típica & \\
\hline $\begin{array}{c}\text { Cadera } \\
\text { consulta } \\
\text { inicial }(\mathbf{c m})\end{array}$ & 48 & 127,25 & 25,91 & 52 & 119,90 & 24,32 & NS \\
\hline $\begin{array}{c}\text { Cadera } 3 \\
\text { meses (cm) }\end{array}$ & 44 & $111,68^{\dagger}$ & 13,43 & 47 & $109,51^{\dagger}$ & 14,32 & NS \\
\hline $\begin{array}{c}\text { Cadera } 6 \\
\text { meses }(\mathrm{cm})\end{array}$ & 38 & $105,12^{\dagger}$ & 10,38 & 44 & $105,18^{\dagger}$ & 8,95 & NS \\
\hline $\begin{array}{c}\text { Cadera } 9 \\
\text { meses }(\mathbf{c m})\end{array}$ & 23 & $101,17^{\dagger}$ & 11,52 & 34 & $103,15^{\dagger}$ & 9,12 & NS \\
\hline $\begin{array}{c}\text { Cadera } 12 \\
\text { meses }(\mathrm{cm})\end{array}$ & 39 & $99,37^{\dagger}$ & 10,04 & 42 & $100,57^{\dagger}$ & 7,31 & NS \\
\hline $\begin{array}{c}\text { Cadera } 18 \\
\text { meses (cm) }\end{array}$ & 28 & $98^{\dagger}$ & 8,68 & 35 & $101,31^{\dagger}$ & 9,10 & NS \\
\hline $\begin{array}{c}\text { Cadera } 24 \\
\text { meses (cm) }\end{array}$ & 48 & $98,21^{\dagger}$ & 8,83 & 52 & $100,32^{\dagger}$ & 8,43 & NS \\
\hline
\end{tabular}

Tabla 4.7.35. Descripción del perímetro de cadera según el grupo de edad en las diferentes revisiones evaluadas

\subsection{6. Índice de cintura/cadera. ICC}

EI ICC, es el obtenido al dividir el perímetro de cintura entre el perímetro de cadera. Ha sido muy utilizado en la valoración de la composición corporal, pero actualmente se ha sustituido fundamentalmente por el perímetro de 
cintura $^{127}$. La OMS establece como criterios de riesgo cardiovascular los valores $>1$ en el hombre, $y>0,85$ en la mujer.

En la tabla 4.7.36 se muestra la evolución del ICC en los controles evaluados de toda la muestra de pacientes estudiados. La tasa de respuesta de pacientes es la misma que en las variables descritas en puntos anteriores.

\begin{tabular}{|c|c|c|c|c|c|c|c|}
\hline & $\begin{array}{c}\text { ICC } \\
\text { consulta } \\
\text { inicial }\end{array}$ & $\begin{array}{c}\text { ICC } \\
3 \\
\text { meses }\end{array}$ & $\begin{array}{c}\text { ICC } \\
6 \\
\text { meses }\end{array}$ & $\begin{array}{c}\text { ICC } \\
9 \\
\text { meses }\end{array}$ & $\begin{array}{c}\text { ICC } \\
12 \\
\text { meses }\end{array}$ & $\begin{array}{c}\text { ICC } \\
18 \\
\text { meses }\end{array}$ & $\begin{array}{c}\text { ICC } \\
24 \\
\text { meses }\end{array}$ \\
\hline $\mathbf{N}$ & 100 & 91 & 82 & 57 & 81 & 63 & 100 \\
\hline Media & 1,09 & $0,87^{\star^{\dagger}}$ & $0,87^{\dagger}$ & $0,87^{\dagger}$ & $0,85^{\dagger}$ & $0,86^{\dagger}$ & $0,88^{*^{\dagger}}$ \\
\hline D.Típica & 0,30 & 0,11 & 0,06 & 0,07 & 0,07 & 0,07 & 0,08 \\
\hline Mediana & 0,94 & 0,87 & 0,87 & 0,88 & 0,86 & 0,87 & 0,88 \\
\hline $\begin{array}{c}\text { Rango } \\
\text { intercuartílico } \\
\text { (P25-P75) }\end{array}$ & $0,89-1,32$ & $\begin{array}{c}0,83- \\
0,95\end{array}$ & $\begin{array}{c}0,87- \\
0,90\end{array}$ & $\begin{array}{c}0,82- \\
0,92\end{array}$ & $\begin{array}{c}0,81- \\
0,90\end{array}$ & $\begin{array}{c}0,83- \\
0,91\end{array}$ & $\begin{array}{c}0,83- \\
0,93\end{array}$ \\
\hline
\end{tabular}

Tabla 4.7.36. Descripción del ICC en las diferentes revisiones evaluadas

En el control previo a la cirugía el $50 \%$ de los pacientes presentaba un ICC medio de 0,94. En los controles posteriores el ICC medio disminuye hasta los 18 meses, aumentando ligeramente hasta los 24 meses postcirugía.

El descenso más significativo entre revisiones, es el comprendido entre el control previo a la cirugía y los 3 meses, y entre los 18 meses y 2 años postcirugía $(P<0,05)$. En el resto de controles las modificaciones del ICC comparado con el control anterior no sufren modificaciones significativas.

Al comparar los valores medios del ICC del control prequirúrgico con los valores a los 24 meses, el descenso en el ICC es significativo $(P<0,001)$.

En la figura 4.7.26 se representa mediante histogramas la distribución del ICC, en los diferentes controles evaluados. Del mismo modo que en la descripción del perímetro de cadera en el control prequirúrgico, el ICC no sigue una distribución normal como se aprecia en el primer histograma representado a continuación. 

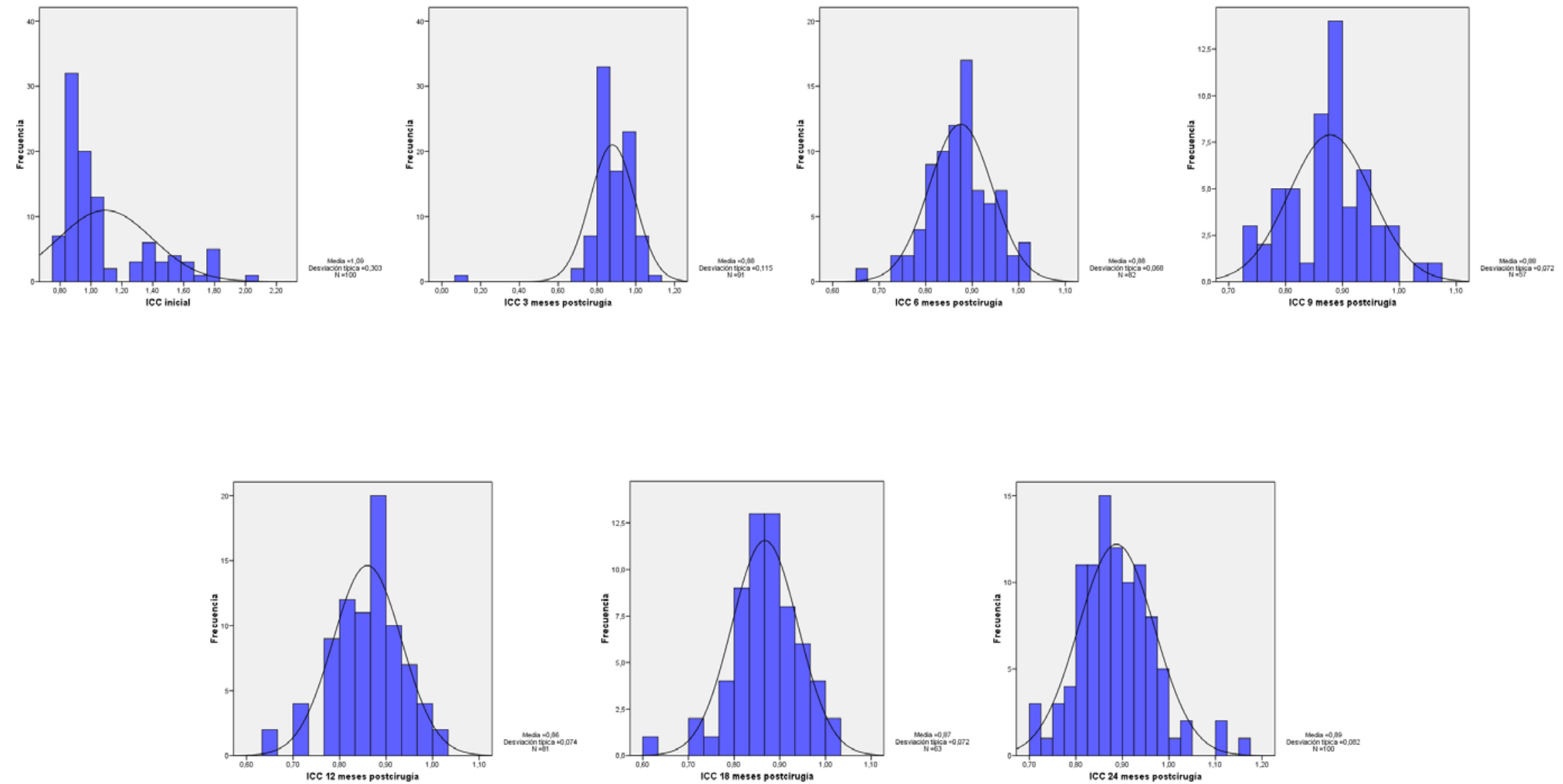

Figura 4.7.26. Representación en histogramas del ICC en las diferentes revisiones evaluadas 
En la figura 4.7.27 se describe mediante un gráfico de barras de error la evolución del ICC medio en los diferentes controles evaluados. La modificación del ICC medio desde el primer control postquirúrgico a los 24 meses no sufre modificaciones estadísticamente significativas, por el contrario la reducción media del ICC sí es estadísticamente significativa al tomar como referencia el control de la primera consulta en referencia a los 24 meses de la cirugía $(P<0,001)$.

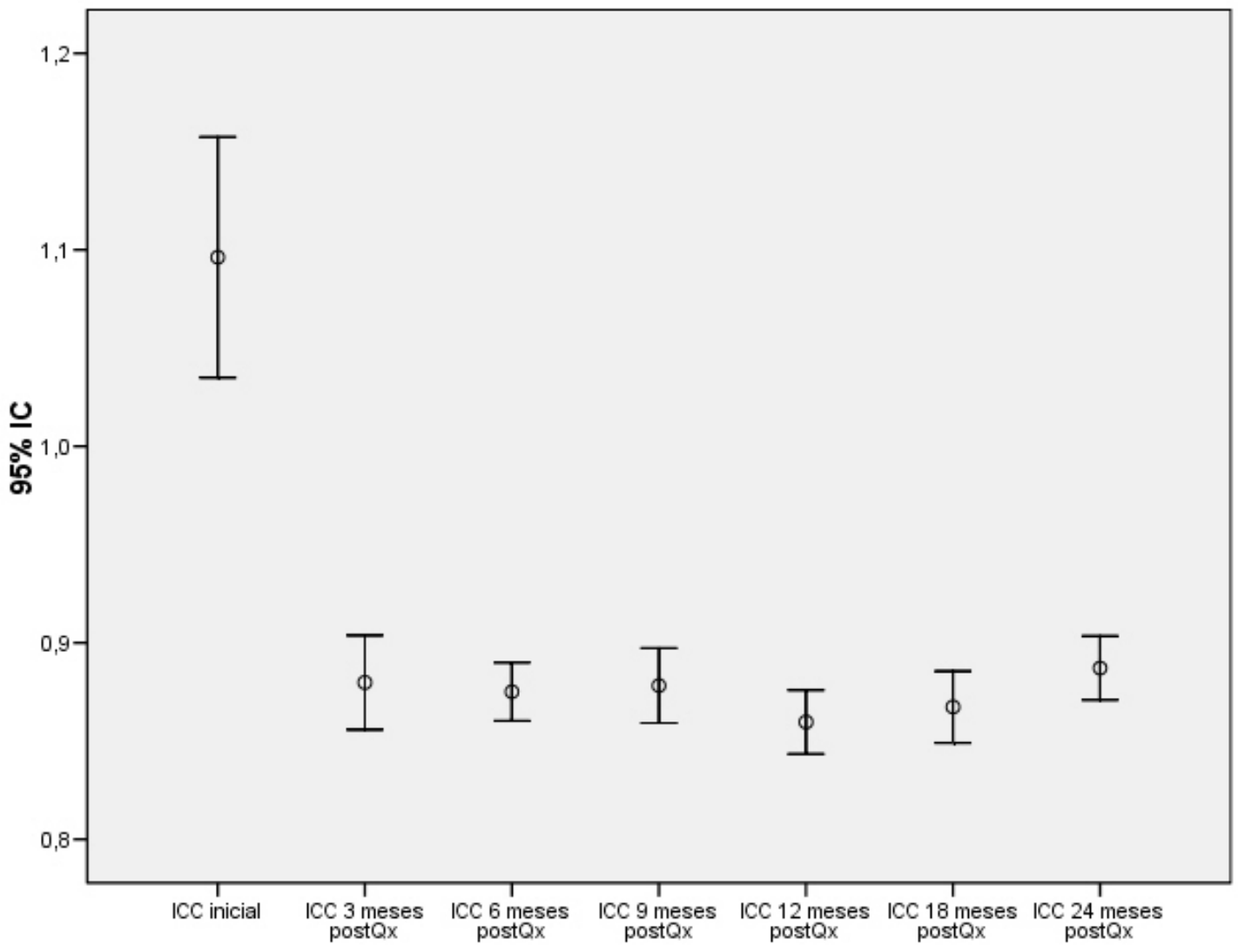

Figura 4.7.27. Gráfico de barras de error (IC 95\%) del ICC en los controles evaluados

En la tabla 4.7.37 se muestra la evolución del ICC medio en los diferentes controles evaluados según el sexo. Las diferencias observadas en el ICC medio entre los dos sexos son estadísticamente significativas en todos los controles evaluados $(P<0,001)$, siendo el ICC mayor en los varones.

\begin{tabular}{|c|c|c|c|c|c|c|c|}
\hline & \multicolumn{3}{|c|}{ Mujer } & \multicolumn{3}{|c|}{ Hombre } & \multirow[b]{2}{*}{$\mathbf{P}$} \\
\hline & $\mathbf{N}$ & Media & D.Típica & $\mathbf{N}$ & Media & D.Típica & \\
\hline $\begin{array}{c}\text { ICC consulta } \\
\text { inicial }\end{array}$ & 71 & 1,07 & 0,32 & 29 & 1,14 & 0,24 & $<0,001$ \\
\hline ICC 3 meses & 64 & $0,85^{\dagger}$ & 0,11 & 27 & $0,94^{\dagger}$ & 0,06 & $<0,001$ \\
\hline
\end{tabular}




\begin{tabular}{|c|c|c|c|c|c|c|c|}
\hline & \multicolumn{3}{|c|}{ Mujer } & \multicolumn{3}{|c|}{ Hombre } & \multirow{2}{*}{$\mathbf{P}$} \\
\hline & $\mathbf{N}$ & Media & D.Típica & $\mathbf{N}$ & Media & D.Típica & \\
\hline ICC 6 meses & 60 & $0,85^{\dagger}$ & 0,05 & 22 & $0,93^{\dagger}$ & 0,05 & $<0,001$ \\
\hline ICC 9 meses & 38 & $0,84^{\dagger}$ & 0,05 & 19 & $0,93^{\dagger}$ & 0,06 & $<0,001$ \\
\hline ICC 12 meses & 59 & $0,83^{\dagger}$ & 0,06 & 22 & $0,93^{\dagger}$ & 0,04 & $<0,001$ \\
\hline ICC 18 meses & 42 & $0,83^{\dagger}$ & 0,06 & 21 & $0,92^{\dagger}$ & 0,04 & $<0,001$ \\
\hline ICC 24 meses & 71 & $0,86^{\dagger}$ & 0,07 & 29 & $0,95^{\dagger}$ & 0,05 & $<0,001$ \\
\hline
\end{tabular}

Tabla 4.7.37. Descripción del ICC según el sexo en las diferentes revisiones evaluadas

En el control prequirúrgico el $85,91 \%$ de las mujeres presentaban un ICC $>0,85$, y el 75,86\% de los hombres un ICC > 1 . A los 24 meses, el 56,33\% de las mujeres presentaba un ICC > 0,85, y el 17,24\% de los hombres un ICC > 1. En ambos sexos disminuyeron de manera estadísticamente significativa el riesgo cardiovascular según los criterios de la OMS $(P<0,001)$.

En la tabla 4.7.38, se describe la evolución del ICC por grupos de edad, siendo el grupo de los < 42 años quienes presentan un ICC medio más bajo en todos los controles evaluados.

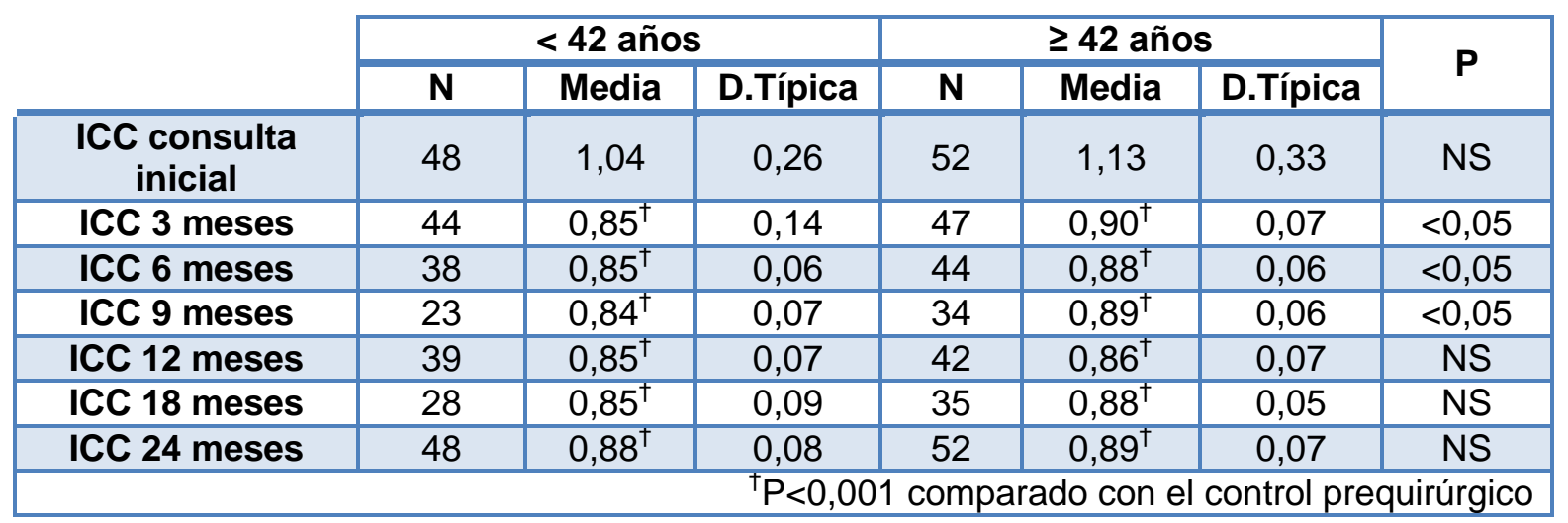

Tabla 4.7.38. Descripción del ICC según el grupo de edad en las diferentes revisiones evaluadas 


\subsection{Cuantificación del riesgo relativo de presentar comorbilidades mayores. Criterios SEEDO}

La SEEDO cuantifica el riesgo relativo de presentar comorbilidades mayores dependiendo de la presencia o no de obesidad abdominal correlacionado con un intervalo de IMC, como se muestra en la tabla 4.8.1. Definiendo la obesidad abdominal por el perímetro de cintura $>88 \mathrm{~cm}$ en la mujer $y>102 \mathrm{~cm}$ en el hombre.

\begin{tabular}{|c|c|c|c|}
\hline & \multirow{3}{*}{ IMC } & \multicolumn{2}{|c|}{$\begin{array}{c}\text { Riesgo relativo a partir del perímetro } \\
\text { de cintura }\end{array}$} \\
\hline & & Mujeres $\leq 88 \mathrm{~cm}$ & Mujeres $>88 \mathrm{~cm}$ \\
\hline & & Varones $\leq 102 \mathrm{~cm}$ & Varones > $102 \mathrm{~cm}$ \\
\hline Peso normal & $18,5-24,9$ & Ninguno & $\begin{array}{l}\text { Ligeramente } \\
\text { aumentado }\end{array}$ \\
\hline Sobrepeso & $25-29,9$ & $\begin{array}{l}\text { Ligeramente } \\
\text { aumentado }\end{array}$ & Aumentado \\
\hline \multirow{2}{*}{ Obesidad } & $30-34,9$ & Aumentado & Alto \\
\hline & $35-39,9$ & Alto & Muy alto \\
\hline Obesidad mórbida & $\geq 40$ & Muy alto & Muy alto \\
\hline
\end{tabular}

Tabla 4.8.1. Clasificación del riesgo relativo de presentar comorbilidades mayores según el peso y la presencia de obesidad abdominal. SEEDO

A continuación se estudia el riesgo cuantificado según criterios SEEDO, dividiendo previamente a los pacientes con obesidad abdominal y sin obesidad abdominal en cada uno de los controles evaluados.

\subsubsection{Riesgo relativo de presentar comorbilidades mayores en pacientes con obesidad abdominal}

En la tabla 4.8.2 se muestra el número de pacientes integrantes en cada control evaluado según los criterios anteriormente mencionados de obesidad abdominal.

\begin{tabular}{lc}
\hline \multicolumn{1}{c}{ Periodo evaluado } & N \\
\hline Riesgo relativo prequirúrgico & 100 \\
Riesgo relativo 3 meses & 57 \\
Riesgo relativo 6 meses & 45 \\
Riesgo relativo 9 meses & 24 \\
Riesgo relativo 12 meses & 23 \\
Riesgo relativo 18 meses & 17 \\
Riesgo relativo 24 meses & 30 \\
\hline
\end{tabular}

Tabla 4.8.2.Distribución de pacientes con obesidad abdominal en los controles evaluados 
En la figura 4.8.1 se describe mediante histogramas apilados, la frecuencia de pacientes en cada uno de los controles evaluados según el riesgo relativo de presentar comorbilidades mayores, en los pacientes con obesidad abdominal. 


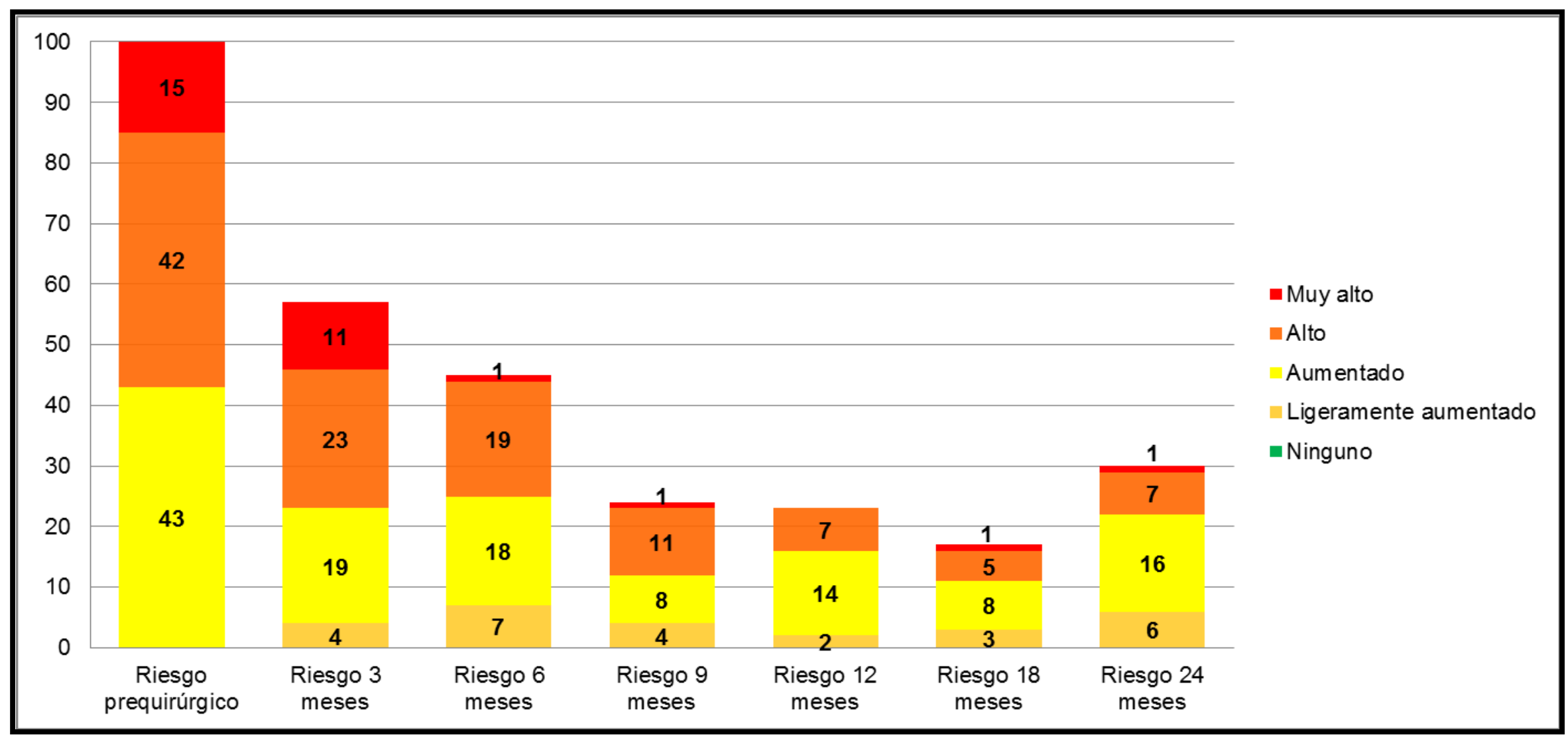

Figura 4.8.1. Clasificación de los pacientes según el riesgo relativo de presentar comorbilidades mayores en los pacientes con obesidad abdominal, en cada uno de los controles evaluados 
En el control prequirúrgico toda la muestra tenía riesgo de presentar comorbilidades mayores: el 43\% "riesgo aumentado", el 42\% "riesgo alto" y el 15\% "riesgo muy alto". A los 24 meses de la intervención, el 30\% de la muestra evaluada continuaba con riesgo de presentar comorbilidades mayores pero éste se redujo de manera estadísticamente significativa desde el control prequirúrgico, en el "riesgo alto" y "riesgo muy alto" $(P<0,05)$.

En la tabla 4.8.3 se muestra la distribución de pacientes con obesidad abdominal estudiados en cada uno de los controles según el sexo, de los cuales se calculará el porcentaje del riesgo en cada control como se muestra en la figura 4.8.2.

\begin{tabular}{lcc}
\hline & Mujeres & Hombres \\
\hline \multicolumn{1}{c}{ Periodo evaluado } & N & N \\
\hline Riesgo relativo prequirúrgico & 71 & 29 \\
Riesgo relativo 3 meses & 44 & 13 \\
Riesgo relativo 6 meses & 37 & 8 \\
Riesgo relativo 9 meses & 19 & 5 \\
Riesgo relativo 12 meses & 19 & 4 \\
Riesgo relativo 18 meses & 13 & 4 \\
Riesgo relativo 24 meses & 24 & 6 \\
\hline
\end{tabular}

Tabla 4.8.3. Pacientes sin obesidad abdominal evaluados según el sexo y el riesgo de presentar comorbilidades mayores, en cada una de las revisiones evaluadas 


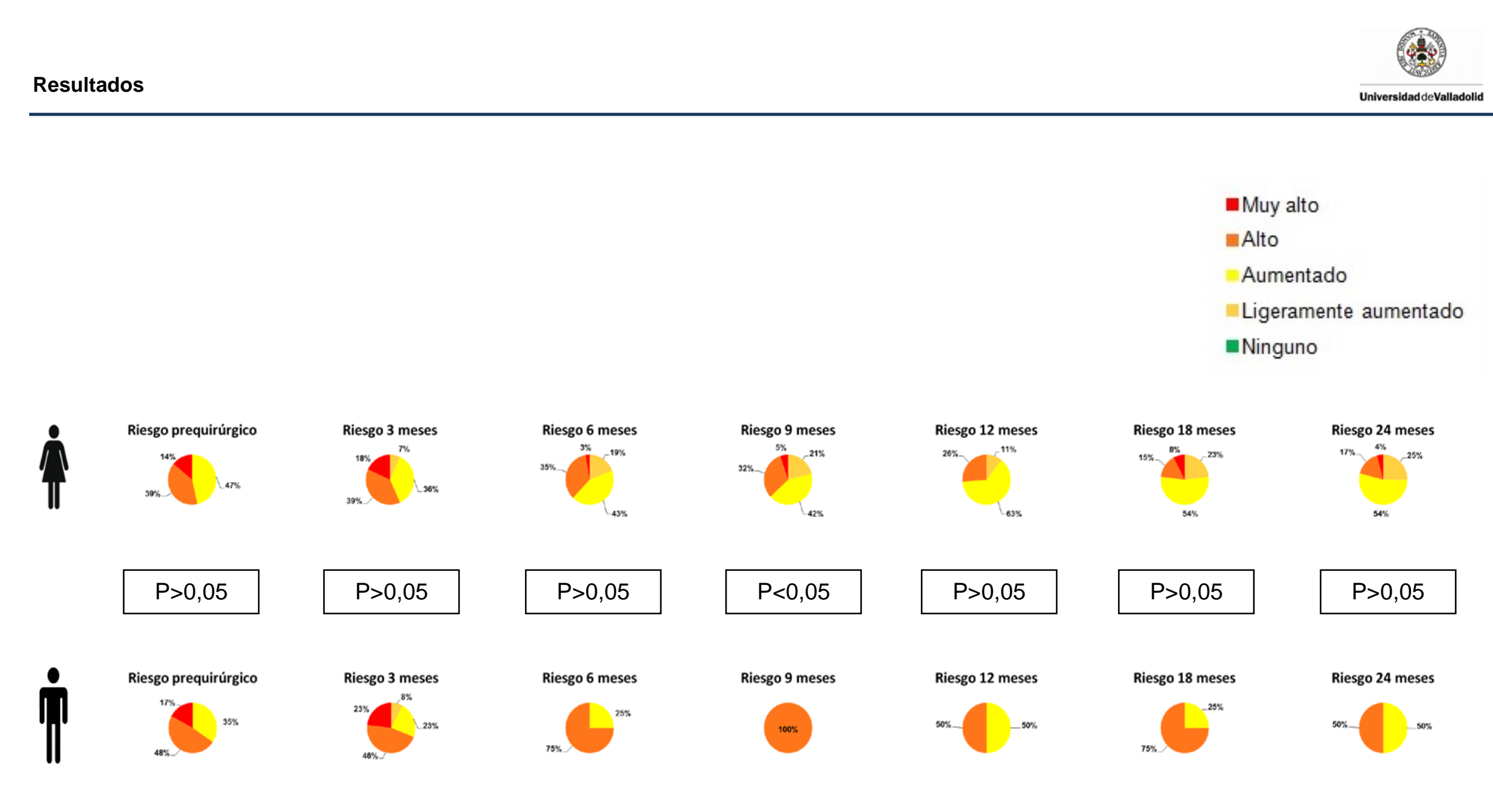


Tan solo se observan diferencias estadísticamente significativas en el riesgo de presentar comorbilidades mayores, según el sexo en el control de los 9 meses, en el que todos los hombres evaluados en ese control presentaban un "riesgo alto" $(\mathrm{P}<0,05)$.

En el resto de controles no se observan diferencias entre hombres y mujeres, pero sí se aprecia una mayor proporción de varones con riesgo de presentar comorbilidades mayores en todos los controles evaluados sin ser estadísticamente significativo.

En el control de los 6, 9, 18, y 24 meses el "riesgo muy alto" se observa en una misma mujer de 51 años con IMC 49,77 en la consulta inicial, el cual desciende a los 6 meses de la cirugía hasta un IMC 34,89, manteniéndose hasta el control de los 18 meses. Desde ese momento aumenta hasta alcanzar un IMC de 35,26 a los 24 meses de la cirugía.

Al estudiar cada uno de los criterios de riesgo, desde el control prequirúrgico a los 24 meses, se observan modificaciones significativas en la reducción del "riesgo alto" $(P<0,05)$, y en el incremento del "riesgo ligeramente aumentado" $(P<0,001)$.

En la tabla 4.8.4 se muestra la distribución de pacientes con obesidad abdominal estudiados en cada uno de los controles según el grupo de edad, de los cuales se calculará el porcentaje del riesgo en cada control como se muestra en la figura 4.8.3.

\begin{tabular}{lcc}
\hline & $<$ 42 años & $\geq$ 42 años \\
\hline \multicolumn{1}{c}{ Periodo evaluado } & $\mathbf{N}$ & $\mathbf{N}$ \\
\hline Riesgo relativo prequirúrgico & 48 & 52 \\
Riesgo relativo 3 meses & 24 & 33 \\
Riesgo relativo 6 meses & 19 & 26 \\
Riesgo relativo 9 meses & 6 & 18 \\
Riesgo relativo 12 meses & 12 & 11 \\
Riesgo relativo 18 meses & 5 & 12 \\
Riesgo relativo 24 meses & 12 & 18 \\
\hline
\end{tabular}

Tabla 4.8.4. Pacientes con obesidad abdominal evaluados según la edad y el riesgo de presentar comorbilidades mayores, en cada una de las revisiones evaluadas 
Resultados

UniversidaddeValladolid

- Muy alto

Alto

Aumentado

Ligeramente aumentado

Ninguno

$$
<42
$$$$
\text { años }
$$
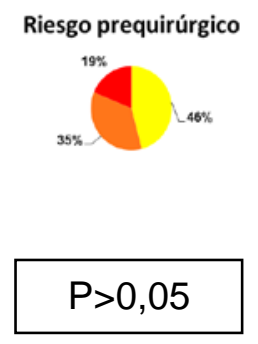

$$
\geq 42
$$

años

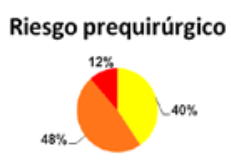

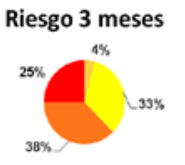
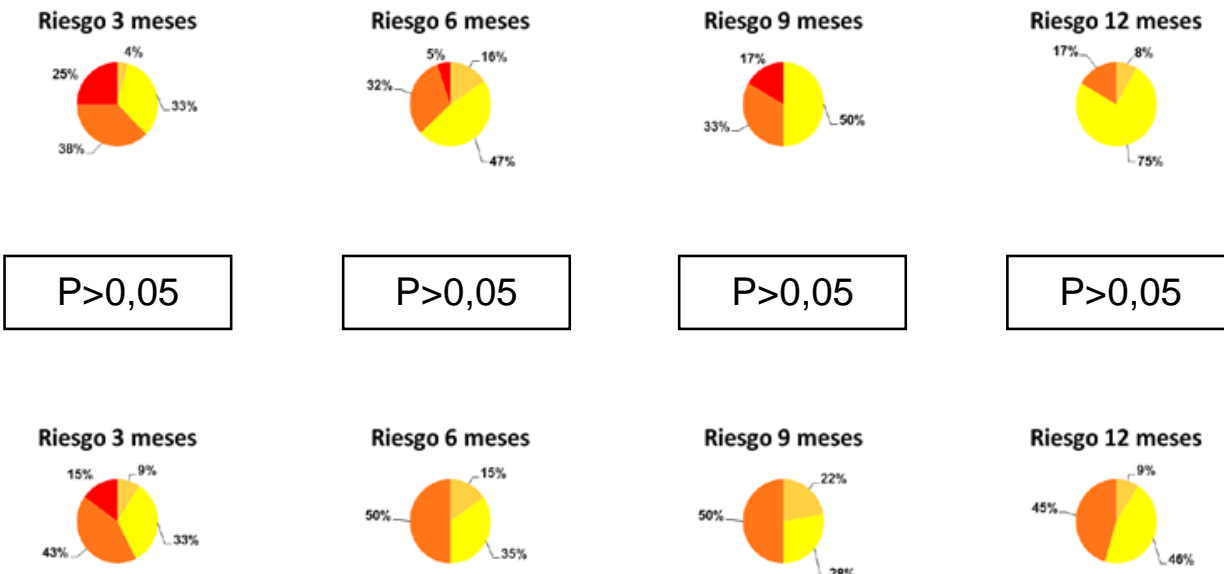

Riesgo 6 meses

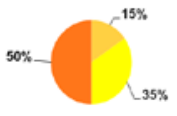

Riesgo 9 meses

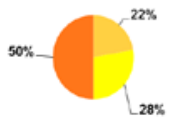

Riesgo 12 meses

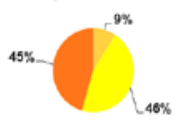

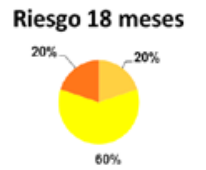

$\mathrm{P}>0,05$
Riesgo 18 meses

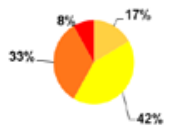

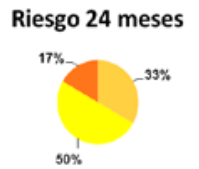

Riesgo 24 meses

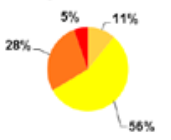

Figura 4.8.3. Riesgo de presentar comorbilidades mayores en los pacientes con obesidad abdominal, según el grupo de edad, en los diferentes controles evaluados

192

Repercusiones de la cirugía de mini bypass gástrico en pacientes obesos (ReCiMB) 
No se observan diferencias estadísticamente significativas en ninguno de los controles evaluados entre los pacientes $<42$ años y los $\geq 42$ años. La presencia de "riesgo muy alto" en el grupo de los $<42$ años disminuye progresivamente. A los 6 y 9 meses el porcentaje expresado de "riesgo muy alto" corresponde a 1 paciente en cada una de las revisiones, los cuales corrigieron el riesgo en la revisión posterior. Por el contrario en los $\geq 42$ años desde los 6 meses postquirúrgicos no se observa "riesgo muy alto", exceptuando a los 18 y 24 meses al paciente varón de 51 años mencionado en el punto anterior en la clasificación según el sexo.

Al tomar como referencia el cambio experimentado desde el momento prequirúrgico hasta los 24 meses de la cirugía, el "riesgo alto" disminuye significativamente $(P<0,05)$, en cambio aumenta significativamente el "riesgo ligeramente aumentado" ( $\mathrm{P}<0,001)$ y el "riesgo aumentado" a los 24 meses disminuye sin ser significativo.

\subsubsection{Riesgo relativo de presentar comorbilidades mayores en pacientes sin obesidad abdominal}

Del mismo modo se evaluó el riesgo relativo de presentar comorbilidades mayores en los pacientes sin obesidad abdominal, con los criterios establecidos por la SEEDO e indicados al inicio del apartado 4.8. En la tabla 4.8 .5 se muestra el número de pacientes en cada uno de los controles evaluados sin presencia de obesidad abdominal. En el control prequirúrgico está libre de obesidad abdominal.

\begin{tabular}{lc}
\hline \multicolumn{1}{c}{ Periodo evaluado } & N \\
\hline Riesgo relativo prequirúrgico & - \\
\hline Riesgo relativo 3 meses & 34 \\
\hline Riesgo relativo 6 meses & 37 \\
Riesgo relativo 9 meses & 33 \\
\hline Riesgo relativo 12 meses & 56 \\
\hline Riesgo relativo 18 meses & 45 \\
\hline Riesgo relativo 24 meses & 70 \\
\hline
\end{tabular}

Tabla 4.8.5 Distribución de pacientes sin obesidad abdominal en los controles evaluados 
En la figura 4.8.4 se describe mediante histogramas apilados, la frecuencia de pacientes en cada uno de los controles evaluados según el riesgo relativo de presentar comorbilidades mayores, en los pacientes con obesidad abdominal. 


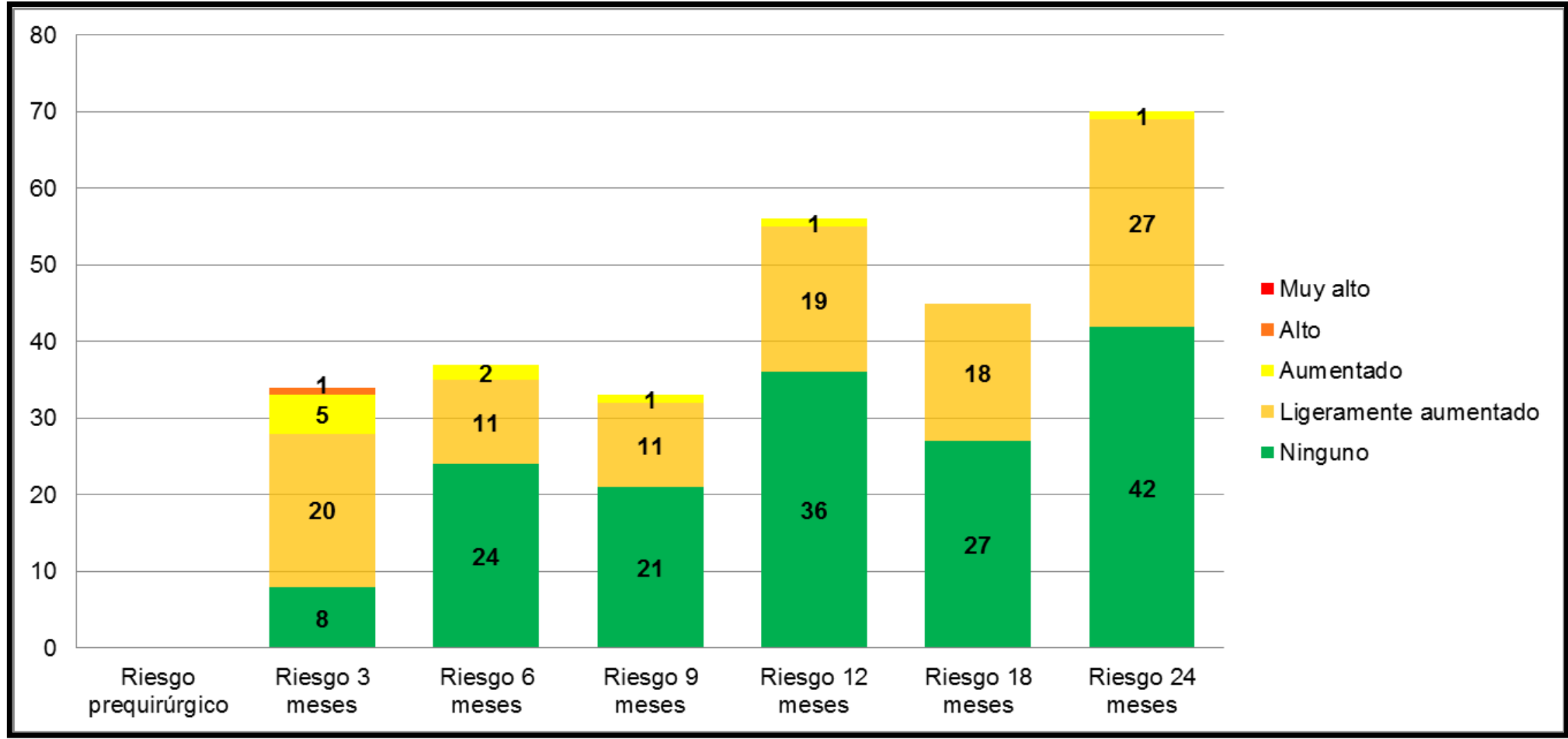

Figura 4.8.4 Clasificación de los pacientes según el riesgo relativo de presentar comorbilidades mayores en los pacientes sin obesidad abdominal, en cada uno de los controles evaluados 
Sólo en la revisión de los 3 meses se observa a un paciente con "riesgo alto" y ningún paciente con "riesgo muy alto". La tendencia del riesgo sufre fluctuaciones hasta los 2 años de la cirugía, pero en términos generales se aprecian dos tipos de pacientes: "riesgo ligeramente aumentado" y "sin riesgo o ninguno".

Al tomar como referencia la revisión de los 3 meses, por ser el primer control dónde observamos a pacientes sin obesidad abdominal, y correlacionarlo con los resultados a los 24 meses se manifiesta un aumento estadísticamente significativo de los pacientes "sin riesgo" $(\mathrm{P}<0,001)$. Por el contrario el "riesgo ligeramente aumentado" asciende en la revisión de los 24 meses $(P<0,05)$, y el "riesgo aumentado" disminuye significativamente $(P<0,05)$.

En la tabla 4.8.6 se muestra la distribución de pacientes con obesidad abdominal estudiados en cada uno de los controles según el sexo, de los cuales se calculará el porcentaje del riesgo en cada control como se muestra en la figura 4.8.5.

\begin{tabular}{lcc}
\hline & Mujeres & Hombres \\
\hline \multicolumn{1}{c}{ Periodo evaluado } & N & N \\
\hline Riesgo relativo prequirúrgico & - & - \\
Riesgo relativo 3 meses & 20 & 14 \\
Riesgo relativo 6 meses & 23 & 14 \\
Riesgo relativo 9 meses & 19 & 14 \\
Riesgo relativo 12 meses & 38 & 18 \\
Riesgo relativo 18 meses & 28 & 17 \\
Riesgo relativo 24 meses & 47 & 23 \\
\hline
\end{tabular}

Tabla 4.8.6. Pacientes sin obesidad abdominal evaluados según el sexo y el riesgo de presentar comorbilidades mayores, en cada una de las revisiones evaluadas 


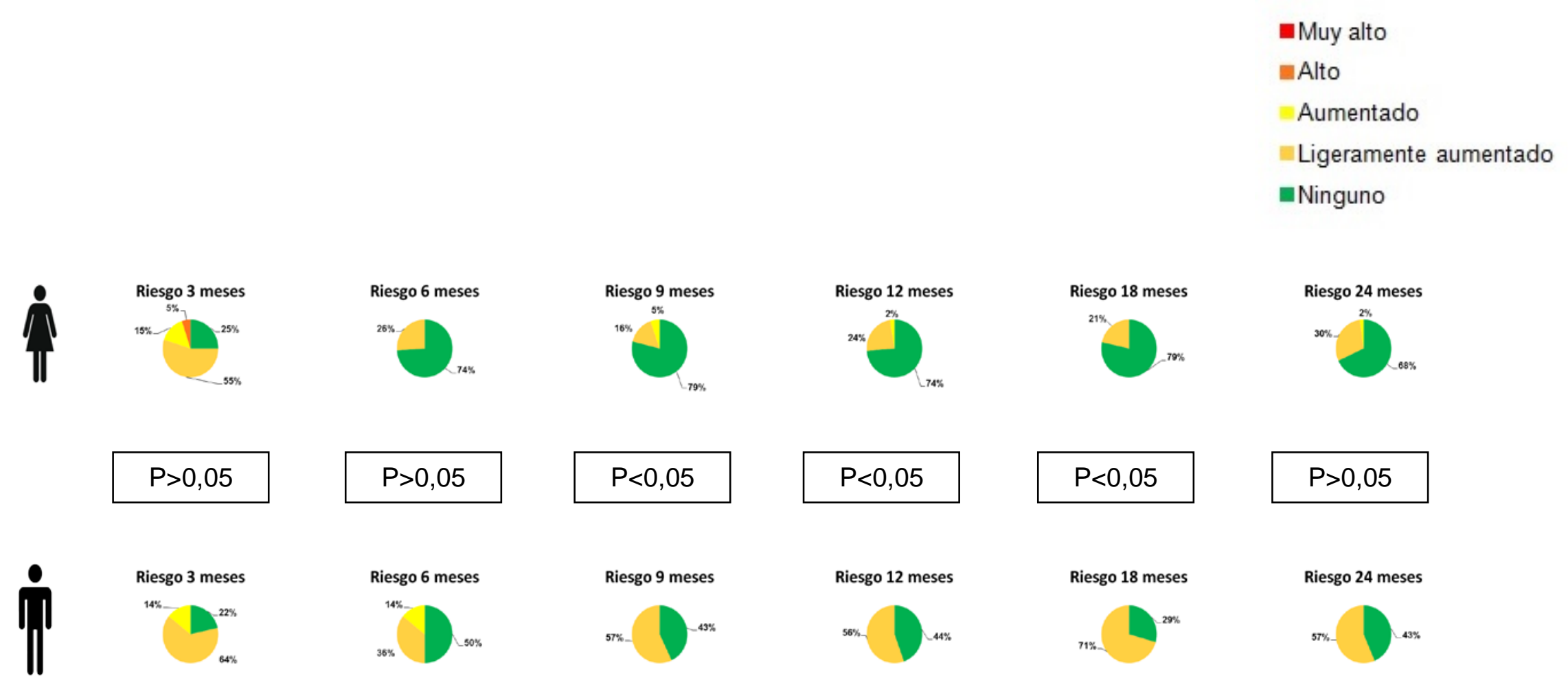

Figura 4.8.5. Riesgo de presentar comorbilidades mayores en los pacientes sin obesidad abdominal según el sexo, en los diferentes controles evaluados 
Las diferencias entre el riesgo mayor de presentar comorbilidades entre hombres y mujeres, es significativa en las revisiones de los 9, 12 y 18 meses. En estas revisiones se observa un mayor porcentaje de mujeres "sin riesgo", a diferencia de los hombres en los que predomina el "riesgo ligeramente aumentado".

En el grupo de las mujeres, desde los 3 meses hasta los 24 meses postquirúrgicos aumenta significativamente el número de pacientes "sin riesgo" $(P<0,001)$, en los hombres también aumenta sin ser significativo.

Por el contrario, sube el "riesgo ligeramente aumentado" en ambos sexos desde los 3 a los 24 meses postquirúrgicos, siendo este cambio significativo en el grupo de mujeres $(P<0,05)$.

En la tabla 4.8.7 se muestra la distribución de pacientes sin obesidad abdominal estudiados en cada uno de los controles según el grupo de edad, de los cuales se calculará el porcentaje del riesgo en cada control como se muestra en la figura 4.8.6.

\begin{tabular}{lcc}
\hline & $<$ 42 años & $\geq$ 42 años \\
\hline \multicolumn{1}{c}{ Periodo evaluado } & $\mathbf{N}$ & $\mathbf{N}$ \\
\hline Riesgo relativo prequirúrgico & - & - \\
Riesgo relativo 3 meses & 20 & 14 \\
Riesgo relativo 6 meses & 19 & 18 \\
Riesgo relativo 9 meses & 17 & 16 \\
Riesgo relativo 12 meses & 26 & 30 \\
Riesgo relativo 18 meses & 23 & 22 \\
Riesgo relativo 24 meses & 36 & 34 \\
\hline
\end{tabular}

Tabla 4.8.7. Pacientes sin obesidad abdominal evaluados según la edad y el riesgo de presentar comorbilidades mayores, en cada una de las revisiones evaluadas 


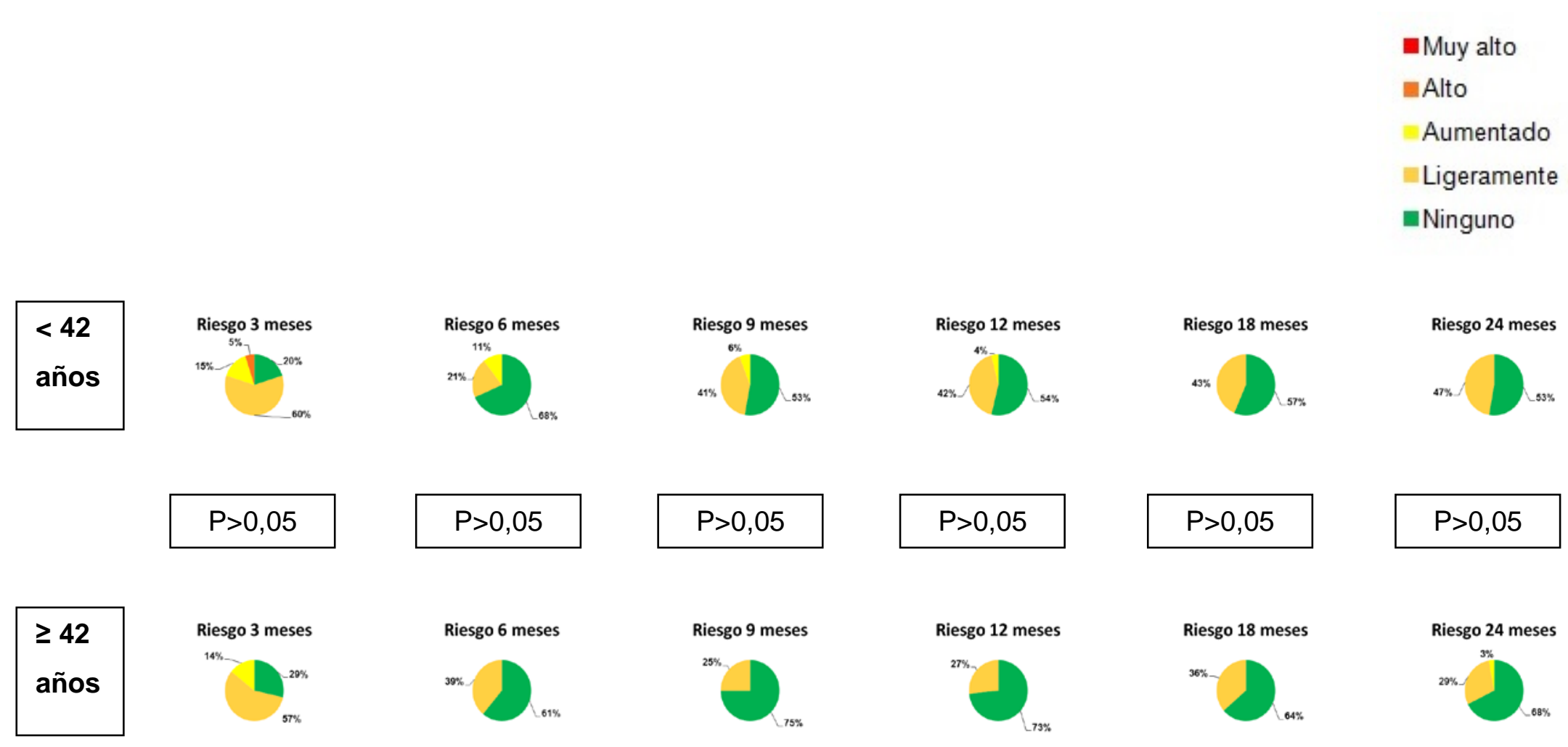

Figura 4.8.6. Riesgo de presentar comorbilidades mayores en los pacientes sin obesidad abdominal según el grupo de edad, en los diferentes controles evaluados 
No se observan diferencias estadísticamente significativas entre los dos grupos de edad respecto al riesgo de presentar comorbilidades mayores en ninguno de los controles evaluados.

Sólo se observa la presencia de "riesgo alto" en los < de 42 años en el control de los 3 meses. En los $\geq 42$ años no se observan pacientes con "riesgo alto" en ninguno de los controles evaluados.

Tomando como referencia los 3 meses de la cirugía y los 24 meses postquirúrgicos, el aumento de pacientes "sin riesgo" es estadísticamente significativo en los dos grupos de edad $(P<0,05)$. En el resto de las categorías de riesgo, el cambio entre los 3 meses y los 24 meses postquirúrgico, no es significativo estadísticamente en ninguno de los dos grupos de edad. 


\subsection{Autovaloración y tolerancia del consumo alimentario postquirúrgico}

Después de la cirugía bariátrica se realizó una autovaloración de la tolerancia y adaptación alimentaria en cada uno de los controles trimestrales postquirúrgicos. En cada variable estudiada en el registro de autovaloración se muestra el porcentaje de respuesta correspondiente.

\subsubsection{Número de comidas diarias}

En la tabla 4.9.1, se detalla el número medio de comidas al día, mediana, y rango intercuartílico (P25-P75) en los diferentes controles trimestrales.

\begin{tabular}{|c|c|c|c|c|c|}
\cline { 2 - 6 } & N & Media & D.Típica & Mediana & $\begin{array}{c}\text { Rango } \\
\text { intercuartílico } \\
\text { (P25-P75) }\end{array}$ \\
\hline 3 Meses & 44 & 4,23 & 0,98 & 4 & $4-5$ \\
\hline 6 Meses & 49 & 4,61 & 0,73 & 5 & $4-5$ \\
\hline 9 Meses & 50 & 4,60 & 0,92 & 5 & $4-5$ \\
\hline 12 Meses & 74 & 4,69 & 0,63 & 5 & $4-5$ \\
\hline 18 Meses & 61 & 4,48 & 0,84 & 5 & $4-5$ \\
\hline 24 Meses & 92 & 4,45 & 0,95 & 5 & $4-5$ \\
\hline
\end{tabular}

Tabla 4.9.1. Número De comidas diarias en los diferentes controles trimestrales

La mayor frecuencia de respuesta de los pacientes se observa en los dos controles anuales postquirúrgicos. En todos ellos, excepto el de los 3 meses, el $50 \%$ de los pacientes que contestaron afirman realizar 5 comidas al día.

En la tabla 4.9.2 se expresa en porcentaje la proporción de pacientes que respondieron a cada una de las variables del registro de autovaloración en cada uno de los controles trimestrales postquirúrgicos, observando mayoritariamente la respuesta de 4 y 5 comidas diarias en todos los controles. 


\begin{tabular}{|c|c|c|c|c|c|c|}
\hline & 3 Meses & 6 Meses & 9 Meses & 12 Meses & 18 Meses & 24 Meses \\
\hline $\mathbf{N}$ & 44 & 49 & 50 & 74 & 61 & 92 \\
\hline 1 comida/día & $2,3 \%$ & - & - & - & - & $1,1 \%$ \\
\hline 2 comidas/día & - & - & $10 \%$ & - & - & $1,1 \%$ \\
\hline 3 comidas/día & $20,5 \%$ & $8,2 \%$ & $26 \%$ & $5,4 \%$ & $16,4 \%$ & $14,1 \%$ \\
\hline 4 comidas/día & $31,8 \%$ & $28,6 \%$ & $52 \%$ & $24,3 \%$ & $26,2 \%$ & $27,2 \%$ \\
\hline 5 comidas/día & $40,9 \%$ & $57,1 \%$ & $8 \%$ & $66,2 \%$ & $50,8 \%$ & $50 \%$ \\
\hline 6 comidas/día & - & $6,1 \%$ & $2 \%$ & $4,1 \%$ & $6,6 \%$ & $5,4 \%$ \\
\hline 7 comidas/día & $4,5 \%$ & - & $2 \%$ & - & - & $1,1 \%$ \\
\hline $\begin{array}{c}\text { Total } \\
\% \text { respuesta }\end{array}$ & $100 \%$ & $100 \%$ & $100 \%$ & $100 \%$ & $100 \%$ & $100 \%$ \\
\hline
\end{tabular}

Tabla 4.9.2. Frecuencia de comidas diarias en los controles postquirúrgicos

\subsubsection{Comer entre horas, picoteo}

En la tabla 4.9.3 se muestra el porcentaje de pacientes que referían comer entre horas.

\begin{tabular}{|c|c|c|c|}
\cline { 2 - 4 } \multicolumn{1}{c|}{} & $\begin{array}{c}\text { Número de } \\
\text { respuestas }\end{array}$ & $\begin{array}{c}\text { Número de pacientes } \\
\text { que comen entre horas }\end{array}$ & $\begin{array}{c}\text { \% de picoteadores por } \\
\text { número de respuesta }\end{array}$ \\
\hline $\mathbf{3}$ Meses & 43 & 28 & $65,1 \%$ \\
\hline $\mathbf{6}$ Meses & 47 & 34 & $72,3 \%$ \\
\hline $\mathbf{9}$ Meses & 51 & 41 & $80,4 \%$ \\
\hline $\mathbf{1 2}$ Meses & 68 & 54 & $79,4 \%$ \\
\hline $\mathbf{1 8}$ Meses & 60 & 48 & $80 \%$ \\
\hline 24 Meses & 90 & 62 & $68,9 \%$ \\
\hline
\end{tabular}

Tabla 4.9.3. Distribución de pacientes picoteadores en los controles postquirúrgicos

Entre los pacientes que contestaron "comer entre horas", se observa un mayor número de picoteadores en los 9 y 18 meses. De forma contraria, en los controles de los 3 y 24 meses se registran un menor número de personas que comían entre horas.

También se les preguntó que indicaran el número de veces que comían entre horas al cabo de un día. El resultado se muestra en la tabla 4.9.4, el cual no sigue un patrón uniforme de respuestas entre los diferentes controles evaluados. En el $6^{\circ}$ mes no respondió ningún paciente. 


\begin{tabular}{|c|c|c|c|c|c|c|}
\cline { 2 - 7 } \multicolumn{1}{c|}{} & $\begin{array}{c}\mathbf{3} \\
\text { Meses }\end{array}$ & $\begin{array}{c}\mathbf{6} \\
\text { Meses }\end{array}$ & $\begin{array}{c}\mathbf{9} \\
\text { Meses }\end{array}$ & $\begin{array}{c}\mathbf{1 2} \\
\text { Meses }\end{array}$ & $\begin{array}{c}\mathbf{1 8} \\
\text { Meses }\end{array}$ & $\begin{array}{c}\mathbf{2 4} \\
\text { Meses }\end{array}$ \\
\hline 1 vez/día & - & - & $\begin{array}{c}2 \\
(100 \%)\end{array}$ & $\begin{array}{c}3 \\
(100 \%)\end{array}$ & $\begin{array}{c}3 \\
(50 \%)\end{array}$ & $\begin{array}{c}1 \\
(20 \%)\end{array}$ \\
\hline veces/día & - & - & - & - & $\begin{array}{c}1 \\
(16,7 \%)\end{array}$ & $\begin{array}{c}1 \\
(20 \%)\end{array}$ \\
\hline 3 veces/día & 1 & - & - & - & $\begin{array}{c}1 \\
(16,7 \%)\end{array}$ & $\begin{array}{c}1 \\
(20 \%)\end{array}$ \\
\hline 4 veces/día & - & - & - & - & - & $\begin{array}{c}2 \\
(40 \%)\end{array}$ \\
\hline $\mathbf{5}$ veces/día & - & - & - & - & $\begin{array}{c}1 \\
(16,7 \%)\end{array}$ & - \\
\hline Total & 1 & - & 2 & 3 & 6 & 5 \\
$(100 \%)$ & - & $(100 \%)$ & $(100 \%)$ & $(100 \%)$ \\
\hline
\end{tabular}

Tabla 4.9.4. Frecuencia de comidas entre horas en los controles postquirúrgicos

\subsubsection{Autovaloración de la tolerancia alimentaria}

En cada uno de las revisiones trimestrales postquirúrgicas se evaluó el nivel de tolerancia alimentaria a criterio del propio paciente en 3 niveles: regular, buena y óptima. En la tabla 4.9.5, se describen los porcentajes de respuesta en cada control y la clasificación por niveles de tolerancia.

\begin{tabular}{|c|c|c|c|c|c|c|c|c|}
\cline { 2 - 9 } \multicolumn{1}{c|}{} & \multicolumn{2}{c|}{ Regular } & \multicolumn{2}{c|}{ Buena } & \multicolumn{2}{c|}{ Óptima } & \multicolumn{2}{c|}{ Total } \\
\cline { 2 - 10 } \multicolumn{1}{c|}{} & $\mathbf{N}$ & $\%$ & $\mathbf{N}$ & $\%$ & $\mathbf{N}$ & $\%$ & $\mathbf{N}$ & $\%$ \\
\hline 3 Meses & 10 & $22,7 \%$ & 25 & $56,8 \%$ & 9 & $20,5 \%$ & 44 & $100 \%$ \\
\hline $\mathbf{6}$ Meses & 3 & $6,4 \%$ & 33 & $70,2 \%$ & 11 & $23,4 \%$ & 47 & $100 \%$ \\
\hline 9 Meses & 5 & $10 \%$ & 28 & $56 \%$ & 17 & $34 \%$ & 50 & $100 \%$ \\
\hline $\mathbf{1 2}$ Meses & 7 & $9,6 \%$ & 40 & $54,8 \%$ & 26 & $35,6 \%$ & 73 & $100 \%$ \\
\hline $\mathbf{1 8}$ Meses & 3 & $5 \%$ & 30 & $50 \%$ & 27 & $45 \%$ & 60 & $100 \%$ \\
\hline 24 Meses & 6 & $6,4 \%$ & 46 & $48,9 \%$ & 42 & $44,7 \%$ & 94 & $100 \%$ \\
\hline
\end{tabular}

Tabla 4.9.5. Nivel de autovaloración de la tolerancia alimentaria postquirúrgica

La mayor tasa de respuesta respecto a la tolerancia alimentaria se registra en el control de los 24 meses y en el de los 12 meses. En cada uno de los controles evaluados se observa una mayor proporción de tolerancia "buena" constituyendo en todas las revisiones más del $50 \%$ de los pacientes que contestaron. 
Es en el control de los 2 años en el que se muestra una respuesta prácticamente igual (48,9\% "tolerancia buena", y 44,7\% "tolerancia óptima") al grado de tolerancia alimentaria.

Del mismo modo se les preguntó qué alimentos les costaba más digerir o los que intentaban evitar comer por las molestias digestivas que les ocasionaban. Entre los pacientes que respondieron se han clasificado los alimentos en: carne, pescado, verduras y cereales.

En la figura 4.9.1, se detallan los alimentos peor tolerados en los diferentes controles trimestrales postquirúrgicos en valores de porcentaje sobre el total de respuestas en cada control. El número de respuestas en cada control fue uniforme, a excepción del control 12 meses en el que se observan más respuestas como se muestra en la tabla 4.9.6.

\begin{tabular}{cc}
\hline $\begin{array}{c}\text { Control } \\
\text { postquirúrgico }\end{array}$ & $\begin{array}{c}\text { Respuestas } \\
\text { observadas }\end{array}$ \\
\hline 3 meses & 10 \\
6 meses & 12 \\
9 meses & 6 \\
12 meses & 15 \\
18 meses & 8 \\
24 meses & 11 \\
\hline
\end{tabular}

Tabla 4.9.6. Número de respuestas observadas en la autovaloración de los alimentos peor tolerados 


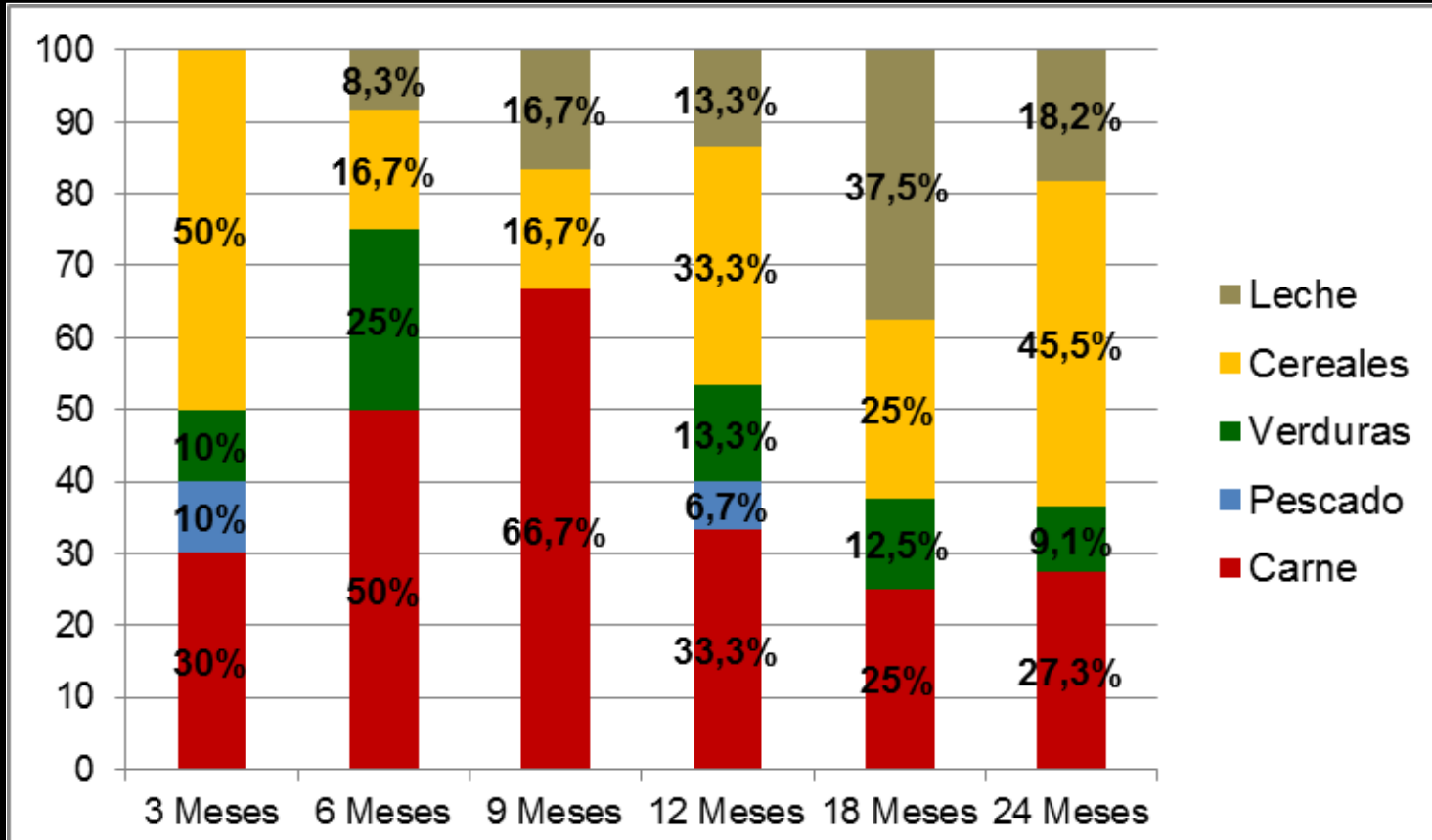

Figura 4.9.1. Tolerancia por grupo alimentario en los diferentes controles postquirúrgicos

Entre los grupos de alimentos peor tolerados se encuentra la carne, seguido de cereales y leche. El pescado es mucho mejor tolerado en todos los controles posteriores a la cirugía. Dentro de los cereales incluimos los preparados de pasta, en los que los pacientes coinciden con mayores problemas de tolerancia.

Dentro de los problemas observados con una mala tolerancia y adaptación alimentaria después de la cirugía, se encuentran los vómitos, reflujo gastroesofágico (RGE) y la diarrea. A continuación, se muestran el número de respuestas afirmativas al preguntarles por alguno de estos síntomas en los controles trimestrales postquirúrgicos, y el porcentaje de estos síntomas entre los pacientes que respondieron.

En la tabla 4.9.7, se detalla la presencia de vómitos con una mayor frecuencia registrada en el control de los 3 meses posteriores a la intervención. La mayor tasa de respuestas al igual que en las variables anteriormente descritas, se da en los 12 y 24 meses. 


\begin{tabular}{|c|c|c|c|c|c|c|}
\hline & \multicolumn{6}{|c|}{ Vómitos } \\
\hline & Sí & $\%$ & No & $\%$ & $\begin{array}{c}\text { Total } \\
\text { Respuestas } \\
\text { (N) }\end{array}$ & $\%$ \\
\hline 3 Meses & 11 & $25 \%$ & 33 & $75 \%$ & 44 & $100 \%$ \\
\hline 6 Meses & 2 & $4,2 \%$ & 46 & $95,8 \%$ & 48 & $100 \%$ \\
\hline 9 Meses & 3 & $6,3 \%$ & 45 & $93,8 \%$ & 48 & $100 \%$ \\
\hline 12 Meses & 4 & $6,6 \%$ & 57 & $93,4 \%$ & 61 & $100 \%$ \\
\hline 18 Meses & 2 & $3,6 \%$ & 53 & $96,4 \%$ & 55 & $100 \%$ \\
\hline 24 Meses & 9 & $10 \%$ & 81 & $90 \%$ & 90 & $100 \%$ \\
\hline
\end{tabular}

Tabla 4.9.7. Descripción de vómitos en los controles postquirúrgicos

Del mismo modo se evaluó la presencia de reflujo gastroesofágico en las revisiones postquirúrgicas. En la tabla 4.9.8, se aprecia, una mayor tasa de respuesta de los pacientes en los controles anuales. La presencia de RGE entre los pacientes que contestaron el cuestionario es mayor en los 3 meses postquirúrgicos que en el resto de controles, aunque el porcentaje de afirmativos entre las respuestas es muy similar y se mantiene incluso en el control bianual.

\begin{tabular}{|c|c|c|c|c|c|c|}
\cline { 2 - 7 } \multicolumn{1}{c|}{} & \multicolumn{6}{c|}{ Reflujo gastroesofágico (RGE) } \\
\cline { 2 - 7 } & Sí & $\%$ & No & $\%$ & $\begin{array}{c}\text { Total } \\
\text { Respuestas } \\
\text { (N) }\end{array}$ & $\%$ \\
\hline 3 Meses & 11 & $25,6 \%$ & 32 & $74,4 \%$ & 43 & $100 \%$ \\
\hline 6 Meses & 5 & $11,1 \%$ & 40 & $88,9 \%$ & 45 & $100 \%$ \\
\hline 9 Meses & 9 & $20 \%$ & 36 & $80 \%$ & 45 & $100 \%$ \\
\hline 12 Meses & 12 & $19 \%$ & 51 & $81 \%$ & 63 & $100 \%$ \\
\hline 18 Meses & 13 & $22,8 \%$ & 44 & $77,2 \%$ & 57 & $100 \%$ \\
\hline 24 Meses & 14 & $15,4 \%$ & 77 & $84,6 \%$ & 91 & $100 \%$ \\
\hline
\end{tabular}

Tabla 4.9.8. Descripción de RGE en los controles postquirúrgicos

También se les preguntó a los pacientes la presencia de diarrea y el número de deposiciones en los diferentes controles postquirúrgicos (tabla 4.9.9). La presencia de diarrea manifestada por los pacientes se distribuye 
de manera uniforme excepto en el control de los 6 y 12 meses, en los que se observa en más del 35\% entre los que respondieron. En el resto de controles la respuesta afirmativa a la presencia de diarrea se sitúa en torno al $20 \%$ de los que respondieron.

\begin{tabular}{|c|c|c|c|c|c|c|}
\cline { 2 - 7 } \multicolumn{1}{c|}{} & \multicolumn{5}{c|}{ Diarrea } \\
\cline { 2 - 7 } \multicolumn{1}{c|}{} & Sí & $\%$ & No & $\%$ & $\begin{array}{c}\text { Total } \\
\text { Respuestas } \\
\text { (N) }\end{array}$ & $\%$ \\
\hline 3 Meses & 9 & $22 \%$ & 32 & $78 \%$ & 41 & $100 \%$ \\
\hline $\mathbf{6}$ Meses & 17 & $37,8 \%$ & 28 & $62,2 \%$ & 45 & $100 \%$ \\
\hline $\mathbf{9}$ Meses & 8 & $19,5 \%$ & 33 & $80,5 \%$ & 41 & $100 \%$ \\
\hline $\mathbf{1 2}$ Meses & 18 & $36,7 \%$ & 31 & $63,3 \%$ & 49 & $100 \%$ \\
\hline $\mathbf{1 8}$ Meses & 7 & $21,9 \%$ & 25 & $78,1 \%$ & 32 & $100 \%$ \\
\hline $\mathbf{2 4}$ Meses & 6 & $10,5 \%$ & 51 & $89,5 \%$ & 57 & $100 \%$ \\
\hline
\end{tabular}

Tabla 4.9.9. Descripción de diarrea en los controles postquirúrgicos

La valoración en el apartado del número de deposiciones diarias, obtiene mejores niveles de respuesta a este apartado de manera progresiva ascendiendo desde el control anual. Como se muestra en la tabla 4.9.10, más del $50 \%$ de las personas que respondieron se encuentra entre 1 y 2 deposiciones diarias, siendo estos valores normales no patológicos.

\begin{tabular}{|c|c|c|c|c|c|c|}
\cline { 2 - 7 } \multicolumn{1}{c|}{} & $\begin{array}{c}\mathbf{3} \\
\text { Meses }\end{array}$ & $\begin{array}{c}\mathbf{6} \\
\text { Meses }\end{array}$ & $\begin{array}{c}\mathbf{9} \\
\text { Meses }\end{array}$ & $\begin{array}{c}\mathbf{1 2} \\
\text { Meses }\end{array}$ & $\begin{array}{c}\mathbf{1 8} \\
\text { Meses }\end{array}$ & $\begin{array}{c}\mathbf{2 4} \\
\text { Meses }\end{array}$ \\
\hline 1 vez/día & 2 & 4 & 2 & 10 & 14 \\
$(66,7 \%)$ & $(57,1 \%)$ & $(22,2 \%)$ & $(47,6 \%)$ & $\begin{array}{c}29 \\
(35 \%)\end{array}$ & $(34,1 \%)$ \\
\hline 2 veces/día & - & $\begin{array}{c}1 \\
(14,3 \%)\end{array}$ & $\begin{array}{c}5 \\
(55,6 \%)\end{array}$ & $\begin{array}{c}8 \\
(38,1 \%)\end{array}$ & $\begin{array}{c}18 \\
(45 \%)\end{array}$ & $\begin{array}{c}34 \\
(40 \%)\end{array}$ \\
\hline 3 veces/día & 1 & - & 1 & 1 & 3 & $\begin{array}{c}12 \\
(14,1 \%)\end{array}$ \\
\hline 4 veces/día & - & 2 & - & - & $\begin{array}{c}2 \\
(5 \%)\end{array}$ & $\begin{array}{c}5 \\
(5,9 \%)\end{array}$ \\
\hline 5 veces/día & - & - & 1 & 2 & $\begin{array}{c}1 \\
(2,5 \%)\end{array}$ & $\begin{array}{c}3 \\
(3,5 \%)\end{array}$ \\
\hline 6 veces/día & - & - & - & - & $\begin{array}{c}1 \\
(2,5 \%)\end{array}$ & $\begin{array}{c}1 \\
(1,2 \%)\end{array}$ \\
\hline
\end{tabular}




\begin{tabular}{|c|c|c|c|c|c|c|}
\cline { 2 - 7 } \multicolumn{1}{c|}{} & $\begin{array}{c}\mathbf{3} \\
\text { Meses }\end{array}$ & $\begin{array}{c}\mathbf{6} \\
\text { Meses }\end{array}$ & $\begin{array}{c}\mathbf{9} \\
\text { Meses }\end{array}$ & $\begin{array}{c}\mathbf{1 2} \\
\text { Meses }\end{array}$ & $\begin{array}{c}\mathbf{1 8} \\
\text { Meses }\end{array}$ & $\begin{array}{c}\mathbf{2 4} \\
\text { Meses }\end{array}$ \\
\hline $\mathbf{7}$ veces/día & - & - & - & - & $\begin{array}{c}1 \\
(2,5 \%)\end{array}$ & $\begin{array}{c}1 \\
(1,2 \%)\end{array}$ \\
\hline Total & 3 & 7 & 9 & 21 & 40 & 85 \\
$(100 \%)$ & $(100 \%)$ & $(100 \%)$ & $(100 \%)$ & $(100 \%)$ & $(100 \%)$ \\
\hline
\end{tabular}

Tabla 4.9.10. Descripción del número de deposiciones diarias en los controles postquirúrgicos 


\subsection{Actividad física postquirúrgica}

Después de la intervención quirúrgica se estudió la actividad física de los pacientes en los diferentes controles trimestrales hasta los 2 años. Antes de la intervención no se registró actividad física por las dificultades y falta de voluntad de realizar actividad física.

A continuación, tabla 4.10.1, se describe la intensidad de actividad física realizada en los diferentes controles postquirúrgicos, entre los pacientes que respondieron a esta variable, especificada en cada uno de los casos.

\begin{tabular}{|c|c|c|c|c|c|c|}
\cline { 2 - 7 } \multicolumn{1}{c|}{} & $\mathbf{3}$ Meses & $\mathbf{6}$ Meses & $\mathbf{9}$ Meses & $\begin{array}{c}\mathbf{1 2} \\
\text { Meses }\end{array}$ & $\begin{array}{c}\mathbf{1 8} \\
\text { Meses }\end{array}$ & $\begin{array}{c}\mathbf{2 4} \\
\text { Meses }\end{array}$ \\
\hline Nunca & 4 & 7 & 7 & 14 & 12 & 19 \\
& $(12,1 \%)$ & $(16,3 \%)$ & $(15,6 \%)$ & $(23 \%)$ & $(25 \%)$ & $(23,5 \%)$ \\
\hline $\begin{array}{c}\mathbf{1} \text { vezl } \\
\text { semana }\end{array}$ & 8 & 8 & 8 & 8 & 4 & 15 \\
$\mathbf{2}$ vecesI & $11,2 \%)$ & $(18,6 \%)$ & $(17,8 \%)$ & $(13,1 \%)$ & $(8,3 \%)$ & $(18,5 \%)$ \\
semana & $(33,3 \%)$ & $(34,9 \%)$ & $(37,8 \%)$ & $(39,3 \%)$ & $(33,3 \%)$ & $(34,6 \%)$ \\
\hline A diario & 10 & 13 & 13 & 15 & 16 & 19 \\
& $(30,3)$ & $(30,2 \%)$ & $(28,9 \%)$ & $(24,6 \%)$ & $(33,3 \%)$ & $(23,5 \%)$ \\
\hline Total & 33 & 43 & 45 & 61 & 48 & 81 \\
& $(100 \%)$ & $(100 \%)$ & $(100 \%)$ & $(100 \%)$ & $(100 \%)$ & $(100 \%)$ \\
\hline
\end{tabular}

Tabla 4.10.1. Frecuencia de la actividad física en los controles postquirúrgicos

De manera más visual en la figura 4.10.1 se muestra una mayor predisposición de los pacientes para realizar actividad física en su rutina postquirúrgica, respondiendo mayoritariamente a una actividad física diaria y bisemanal. Los controles anuales postquirúrgicos fueron dónde más pacientes respondieron al igual que en las otras variables estudiadas anteriormente. 


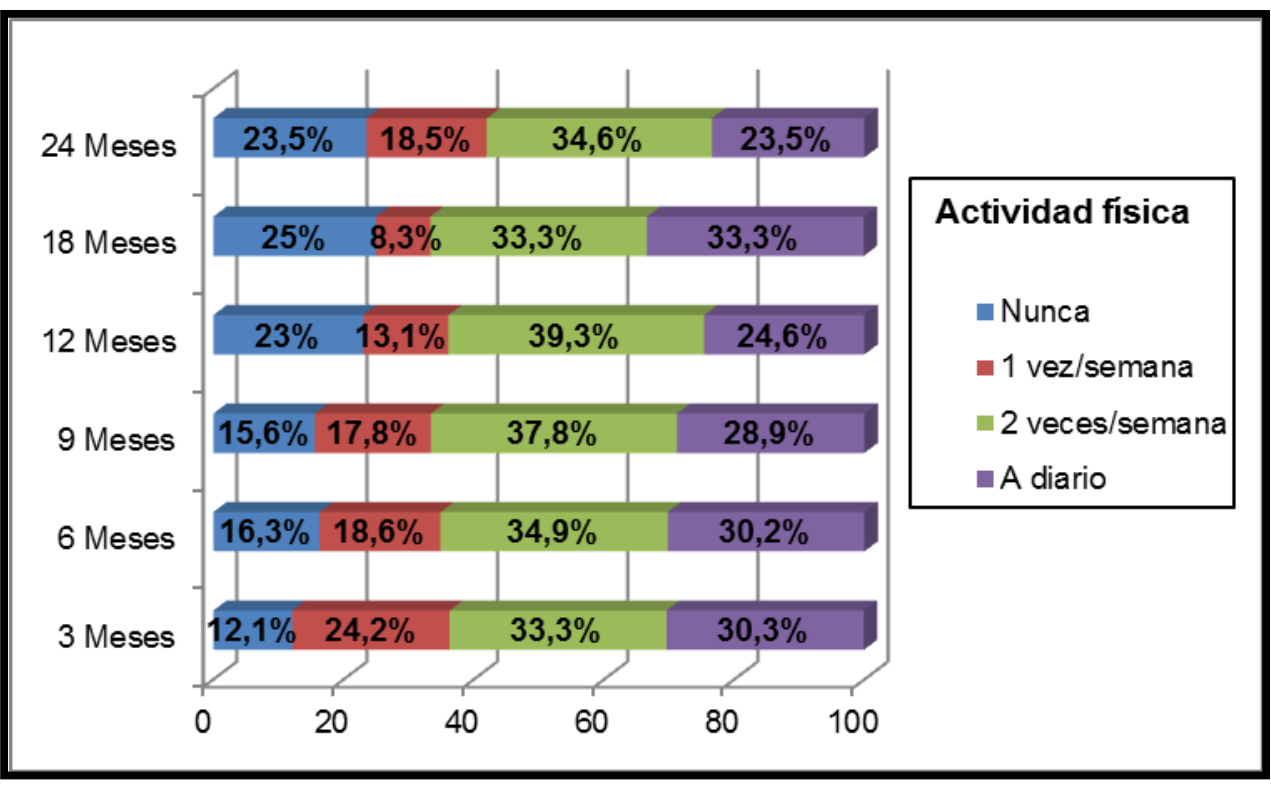

Figura 4.10.1. Actividad física en los diferentes controles postquirúrgicos 


\subsection{Evolución de los valores bioquímicos plasmáticos}

\subsubsection{Glucemia}

En la tabla 4.11.1.1, se detallan las determinaciones de glucosa plasmática en ayunas de los pacientes de la muestra en las diferentes revisiones evaluadas. La glucemia media más elevada se observa en el control previo a la cirugía. Entre las revisiones evaluadas la tendencia es descendente hasta los 12 meses, revisión en la que se describe un aumento de la glucemia de manera significativa respecto al control anterior. En las posteriores revisiones hasta los 24 meses de seguimiento no se observan cambios significativos en los valores medios de la glucemia. En todos los controles postquirúrgicos la glucemia disminuyó de manera significativa respecto al valor precirugía $(\mathrm{P}<0,001)$.

\begin{tabular}{|c|c|c|c|c|c|c|c|}
\hline & $\begin{array}{c}\text { Glucemia } \\
\text { precirugía } \\
\text { (mg/dL) }\end{array}$ & $\begin{array}{c}\text { Glucemia } \\
3 \text { meses } \\
\text { (mg/dL) }\end{array}$ & $\begin{array}{c}\text { Glucemia } \\
6 \text { meses } \\
\text { (mg/dL) }\end{array}$ & $\begin{array}{c}\text { Glucemia } \\
9 \text { meses } \\
\text { (mg/dL) }\end{array}$ & $\begin{array}{l}\text { Glucemia } \\
12 \text { meses } \\
\text { (mg/dL) }\end{array}$ & $\begin{array}{c}\text { Glucemia } \\
18 \text { meses } \\
\text { (mg/dL) }\end{array}$ & $\begin{array}{c}\text { Glucemia } \\
24 \text { meses } \\
\text { (mg/dL) }\end{array}$ \\
\hline $\mathrm{N}$ & 94 & 90 & 77 & 60 & 84 & 75 & 97 \\
\hline Media & 101,10 & $86,87^{*^{\dagger}}$ & $85,28^{\dagger}$ & $82,87^{\dagger}$ & $84,51^{*^{\dagger}}$ & $82,09^{\dagger}$ & $85,17^{\dagger}$ \\
\hline D.Típica & 19,75 & 12,59 & 18,35 & 10,80 & 13,90 & 11,88 & 12,38 \\
\hline Mediana & 98 & 84,50 & 82 & 82 & 82,50 & 81 & 83 \\
\hline $\begin{array}{c}\text { Rango } \\
\text { intercuar } \\
\text { tílico } \\
\text { (P25-P75) }\end{array}$ & $88-112$ & $79-90$ & $78-88$ & $76,13-87$ & $76-88,75$ & $75-87$ & $78-87$ \\
\hline
\end{tabular}

Tabla 4.11.1.1 Descripción de la glucemia plasmática en las diferentes revisiones evaluadas

En la figura 4.11.1.1, se expresan los valores de la glucemia mediante diagrama de cajas marcando los valores límite de referencia (74-115 mg/dL), el $18,08 \%$ de los pacientes en el control prequirúrgico superaban el valor límite superior, a los 3 meses el 2,22\%, en el control de los 6 y 9 meses superan los valores máximos el 1,29\% y el 1,66\% respectivamente. A los 12 meses el $4,76 \%$ de los pacientes superan ese valor máximo reduciéndose en los controles sucesivos a 2,66\% a los 18 meses y 2,06\% a los 24 meses. En todos los controles evaluados el $75 \%$ de los pacientes desde la primera revisión postquirúrgica presenta una glucemia media $<90$ mg/dL. 


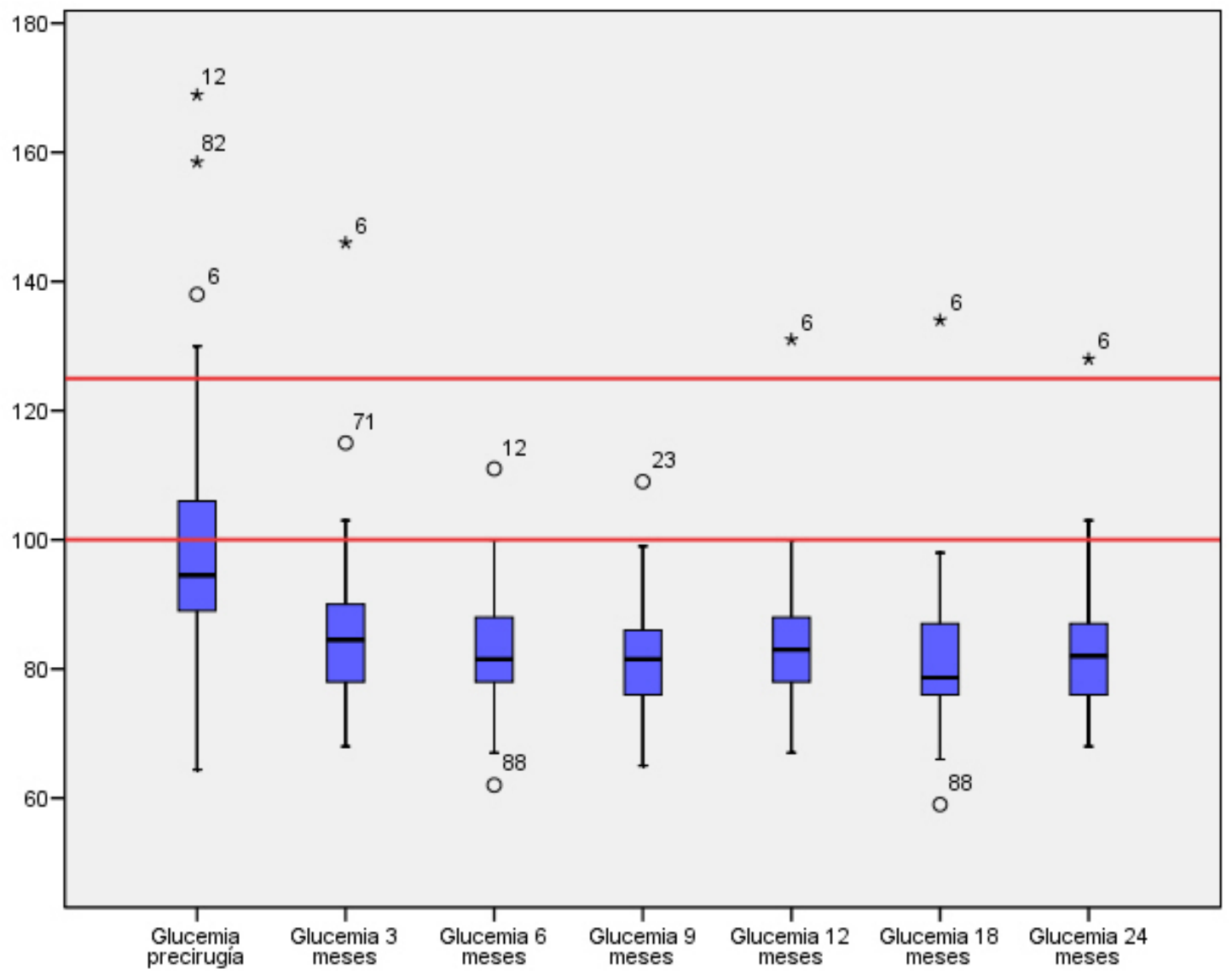

Figura 4.11.1.1. Diagrama de caja de la glucemia plasmática en los diferentes controles evaluados representando los valores de referencia en el eje de ordenadas

El criterio utilizado para el diagnóstico de la diabetes por la Asociación de Diabetes Americana (ADA 2015), establece una determinación de glucemia en ayunas $>126 \mathrm{mg} / \mathrm{dL}$ y la prediabetes o riesgo elevado para el desarrollo de la misma con una glucemia en ayunas entre $\geq 100 \leq 125 \mathrm{mg} / \mathrm{dL}$. En la figura 4.11.1.2 se muestra la evolución de los pacientes diabéticos, prediabéticos y los que no presentaban alteración de la glucemia desde la consulta previa a la cirugía y en las sucesivas revisiones trimestrales.

Inicialmente en el 54,3\% de la muestra no se observan alteraciones de la glucemia, llegando a los 24 meses de la cirugía a alcanzar la normalidad en el $91,8 \%$ de los casos. De los pacientes prediabéticos y diabéticos iniciales $(45,7 \%)$, a los 2 años de la intervención sólo se observa en un 8,3\% de la muestra y de esos pacientes la cifra de diabéticos desciende a un 2,1\%. 


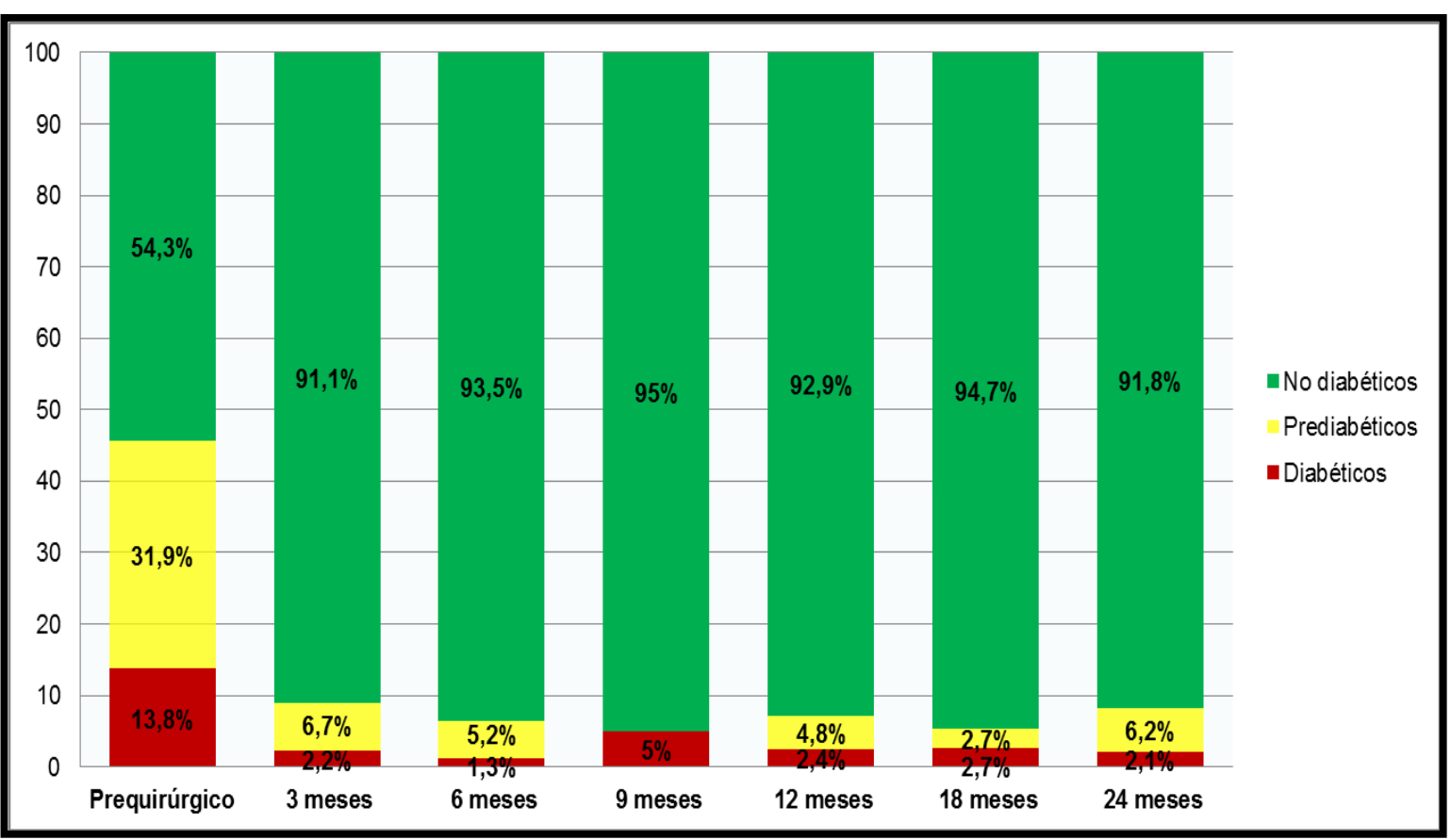

Figura 4.11.1.2. Evolución de la diabetes según criterios ADA 2015

Al comparar los valores medios de glucemia entre las revisiones evaluadas según el sexo, se observan valores superiores en los hombres en todos los controles, siendo esta diferencia estadísticamente significativa a los $6,12,18$ y 24 meses postquirúrgicos.

\begin{tabular}{|c|c|c|c|c|c|c|c|}
\hline & \multicolumn{3}{|c|}{ Mujer } & \multicolumn{3}{|c|}{ Hombre } & \multirow{2}{*}{$\mathbf{P}$} \\
\hline & $\mathbf{N}$ & Media & D.Típica & $\mathbf{N}$ & Media & D.Típica & \\
\hline $\begin{array}{l}\text { Glucemia } \\
\text { precirugía } \\
\text { (mg/dL) }\end{array}$ & 67 & 100,40 & 18,07 & 27 & 102,83 & 23,69 & NS \\
\hline $\begin{array}{c}\text { Glucemia } 3 \\
\text { meses (mg/dL) }\end{array}$ & 64 & $85,38^{\dagger}$ & 9,03 & 26 & $90,54^{\dagger \dagger}$ & 18,41 & NS \\
\hline $\begin{array}{c}\text { Glucemia } 6 \\
\text { meses (mg/dL) }\end{array}$ & 54 & $82,06^{\dagger}$ & 7,62 & 23 & $92,83^{\dagger \dagger}$ & 30,63 & $<0,001$ \\
\hline $\begin{array}{c}\text { Glucemia } 9 \\
\text { meses (mg/dL) }\end{array}$ & 38 & $81,41^{\dagger}$ & 8,97 & 22 & $85,39^{\dagger \dagger}$ & 13,25 & NS \\
\hline $\begin{array}{c}\text { Glucemia } 12 \\
\text { meses (mg/dL) }\end{array}$ & 62 & $81,14^{\dagger}$ & 7,59 & 22 & $94,01^{\dagger \dagger}$ & 21,63 & $<0,001$ \\
\hline $\begin{array}{l}\text { Glucemia } 18 \\
\text { meses (mg/dL) }\end{array}$ & 53 & $79,01^{\dagger}$ & 7,77 & 22 & 89,51 & 16,31 & $<0,001$ \\
\hline $\begin{array}{l}\text { Glucemia } 24 \\
\text { meses (mg/dL) }\end{array}$ & 68 & $82,28^{\dagger}$ & 7,13 & 29 & $91,93^{\dagger \dagger}$ & 18,35 & $<0,001$ \\
\hline
\end{tabular}

Tabla 4.11.1.2. Descripción de la glucemia plasmática en las diferentes revisiones evaluadas según el sexo 
En la tabla 4.11.1.3, se describe la glucemia según el grupo de edad, siendo en todos los controles evaluados la glucemia media más elevada en los $\geq 42$ años. Esta diferencia es estadísticamente significativa en todos los controles excepto a los 6 y 18 meses.

\begin{tabular}{|c|c|c|c|c|c|c|c|}
\hline & \multicolumn{3}{|c|}{$<42$ años } & \multicolumn{3}{|c|}{$\geq 42$ años } & \multirow{2}{*}{$\mathbf{P}$} \\
\hline & $\mathbf{N}$ & Media & D.Típica & $\mathbf{N}$ & Media & D.Típica & \\
\hline $\begin{array}{c}\text { Glucemia } \\
\text { precirugía } \\
\text { (mg/dL) }\end{array}$ & 44 & 93,75 & 16,70 & 50 & 107,56 & 20,10 & $<0,001$ \\
\hline $\begin{array}{c}\text { Glucemia } 3 \\
\text { meses (mg/dL) }\end{array}$ & 44 & $83,09^{\dagger}$ & 6,20 & 46 & $90,48^{\dagger}$ & 15,79 & $<0,05$ \\
\hline $\begin{array}{c}\text { Glucemia } 6 \\
\text { meses (mg/dL) }\end{array}$ & 38 & $82,05^{\dagger}$ & 7,11 & 39 & $88,42^{\dagger}$ & 24,57 & NS \\
\hline $\begin{array}{c}\text { Glucemia } 9 \\
\text { meses (mg/dL) }\end{array}$ & 26 & $79,04^{\dagger}$ & 7,37 & 34 & $85,80^{\dagger}$ & 12,12 & $<0,001$ \\
\hline $\begin{array}{c}\text { Glucemia } 12 \\
\text { meses (mg/dL) }\end{array}$ & 38 & $81,18^{\dagger}$ & 6,14 & 46 & $87,25^{\dagger}$ & 17,56 & $<0,05$ \\
\hline $\begin{array}{c}\text { Glucemia } 18 \\
\text { meses (mg/dL) }\end{array}$ & 37 & $79,54^{\dagger}$ & 7,98 & 38 & $84,57^{\dagger}$ & 14,40 & NS \\
\hline $\begin{array}{c}\text { Glucemia } 24 \\
\text { meses (mg/dL) }\end{array}$ & 46 & $82,52^{\dagger}$ & 6,77 & 51 & $87,55^{\dagger}$ & 15,52 & $<0,05$ \\
\hline
\end{tabular}

Tabla 4.11.1.3. Descripción de la glucemia plasmática en las diferentes revisiones evaluadas según el grupo de edad

Al comparar la evolución de los valores medios de glucemia en cada una de las revisiones desde la cirugía, observamos que en todos los controles se encuentra dentro de los valores de referencia, como muestra la figura 4.11.1.3.

En todas las revisiones evaluadas independientemente del sexo, el grupo de los $\geq 42$ años presentan unos valores medios de glucemia más elevados que el resto. Desde la cirugía en ambos sexos y en los dos grupos de edad, los valores medios de glucemia disminuyen, pero en las mujeres no se observan prácticamente variaciones de la glucemia según el grupo de edad.

Sin embargo en los hombres, la glucemia media disminuye desde el momento de la cirugía. Pero en todos los controles posteriores se muestra como el grupo de mayor edad se mantiene al límite de los criterios ADA de riesgo (100 mg/dL). Por el contrario el grupo de < 42 años no sufre apenas 
variaciones de la glucemia media en los controles postquirúrgicos, mostrando una tendencia similar a las mujeres. 


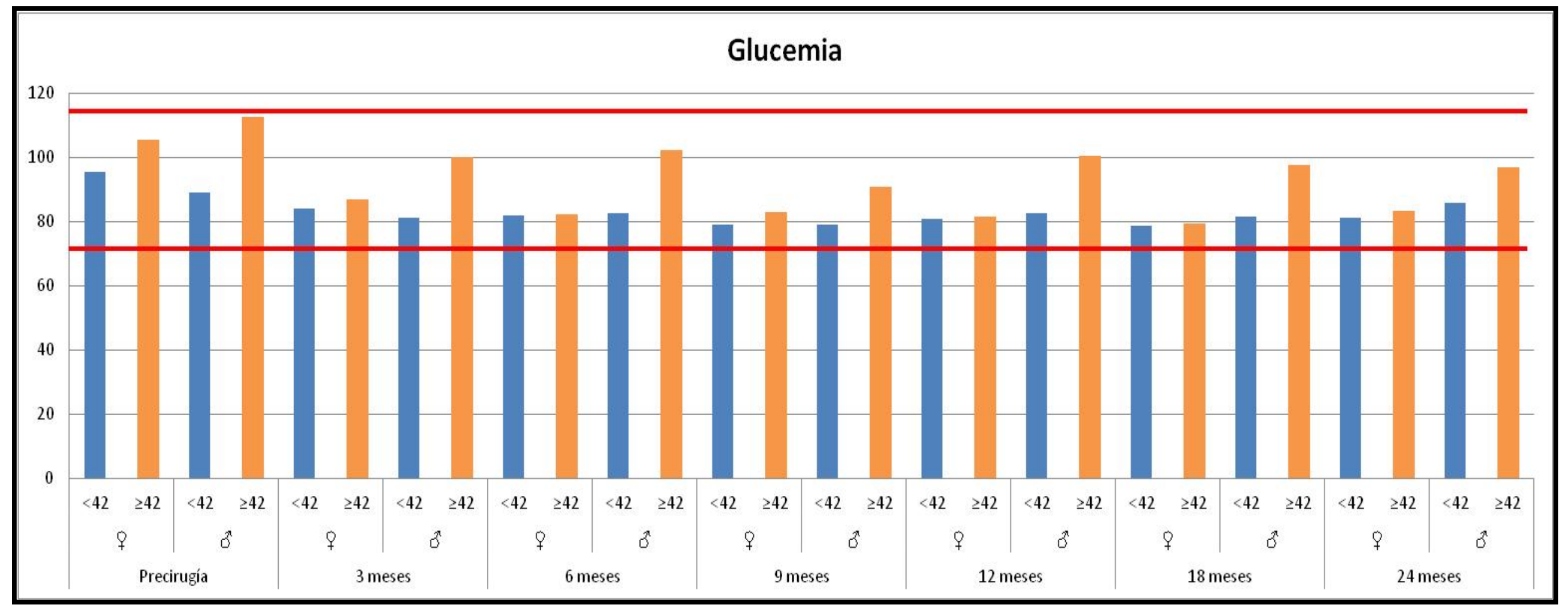

Figura 4.11.1.3. Gráfico de barras de la glucemia plasmática en los diferentes controles evaluados según el sexo y el grupo de edad correspondiente en cada uno de ellos 


\subsubsection{Perfil lipídico}

Los parámetros utilizados en la determinación del perfil lipídico fueron el colesterol total (Col-Total), HDL-Colesterol (HDL-Col), LDL-Colesterol (LDLCol) y triglicéridos (TG). A continuación se describe cada uno de ellos.

\subsubsection{Colesterol total}

En la tabla 4.11.2.1 se detallan las variaciones del colesterol total (ColTotal) desde la primera consulta previa a la cirugía, hasta los 24 meses. El Col-Total medio más elevado se observa en la consulta previa a la cirugía, desde ese momento a los 3 meses disminuye de manera significativa, manteniéndose sin apenas variación hasta los 9 meses donde desciende significativamente respecto al control anterior $(P<0,05)$. Entre la revisión de los 12 y 18 meses no se describen cambios significativos, y sí a los 24 meses respecto al anterior. En todos los controles posteriores a la intervención los niveles de Col-Total se redujeron de manera significativa respecto al valor prequirúrgico $(P<0,001)$, como se aprecia en la tabla 4.11.2.1.

\begin{tabular}{|c|c|c|c|c|c|c|c|}
\hline & $\begin{array}{l}\text { Col-Total } \\
\text { precirugía } \\
\text { (mg/dL) }\end{array}$ & $\begin{array}{c}\text { Col- } \\
\text { Total } 3 \\
\text { meses } \\
\text { (mg/dL) }\end{array}$ & $\begin{array}{c}\text { Col- } \\
\text { Total } 6 \\
\text { meses } \\
\text { (mg/dL) }\end{array}$ & $\begin{array}{c}\text { Col- } \\
\text { Total } 9 \\
\text { meses } \\
\text { (mg/dL) }\end{array}$ & $\begin{array}{c}\text { Col- } \\
\text { Total } 12 \\
\text { meses } \\
\text { (mg/dL) }\end{array}$ & $\begin{array}{c}\text { Col- } \\
\text { Total } 18 \\
\text { meses } \\
\text { (mg/dL) }\end{array}$ & $\begin{array}{c}\text { Col- } \\
\text { Total } 24 \\
\text { meses } \\
\text { (mg/dL) }\end{array}$ \\
\hline $\mathbf{N}$ & 94 & 89 & 80 & 60 & 85 & 75 & 97 \\
\hline Media & 201,86 & $170,60^{*^{\dagger}}$ & $171,01^{\dagger}$ & $166,34^{*^{\dagger}}$ & $164,38^{\dagger}$ & $168,62^{\dagger}$ & $172,99 *^{\dagger}$ \\
\hline D.Típica & 44,60 & 35,99 & 32,65 & 29,48 & 28,25 & 28,59 & 32,26 \\
\hline Mediana & 203 & 167 & 167 & 163,50 & 164 & 164 & 170 \\
\hline $\begin{array}{c}\text { Rango } \\
\text { intercuartílico } \\
\text { (P25-P75) }\end{array}$ & $\begin{array}{l}173,50- \\
230,25\end{array}$ & $\begin{array}{c}149- \\
189,10\end{array}$ & $\begin{array}{l}151,25- \\
190,75\end{array}$ & $\begin{array}{c}147,25- \\
186\end{array}$ & 142-181 & 151-183 & 151-191 \\
\hline \multicolumn{8}{|c|}{$\begin{array}{l}{ }^{*} \mathrm{P}<0,05 \text { comparado con el control anterio } \\
{ }^{\dagger} \mathrm{P}<0,001 \text { comparado con el control prequirúrgico }\end{array}$} \\
\hline
\end{tabular}

Tabla 4.11.2.1. Descripción del Colesterol Total (Col-Total) plasmático en las diferentes revisiones evaluadas

En el control precirugía el $52,12 \%$ de los pacientes superaba el valor marcado como límite en $\geq 200 \mathrm{mg} / \mathrm{dL}$ (ATP III), en el control posterior el $20,22 \%$, a los 6 meses desciende a 13,48\%, manteniéndose sin variaciones a los 9 meses, observando el $13,33 \%$ de los casos. A los 12 meses de la cirugía sólo el 9,41\% de pacientes superan el valor límite máximo, 
aumentando desde ese control al 12\% y $16,49 \%$ de los pacientes en la revisión de los 18 y 24 meses respectivamente. Figura 4.11.2.1.

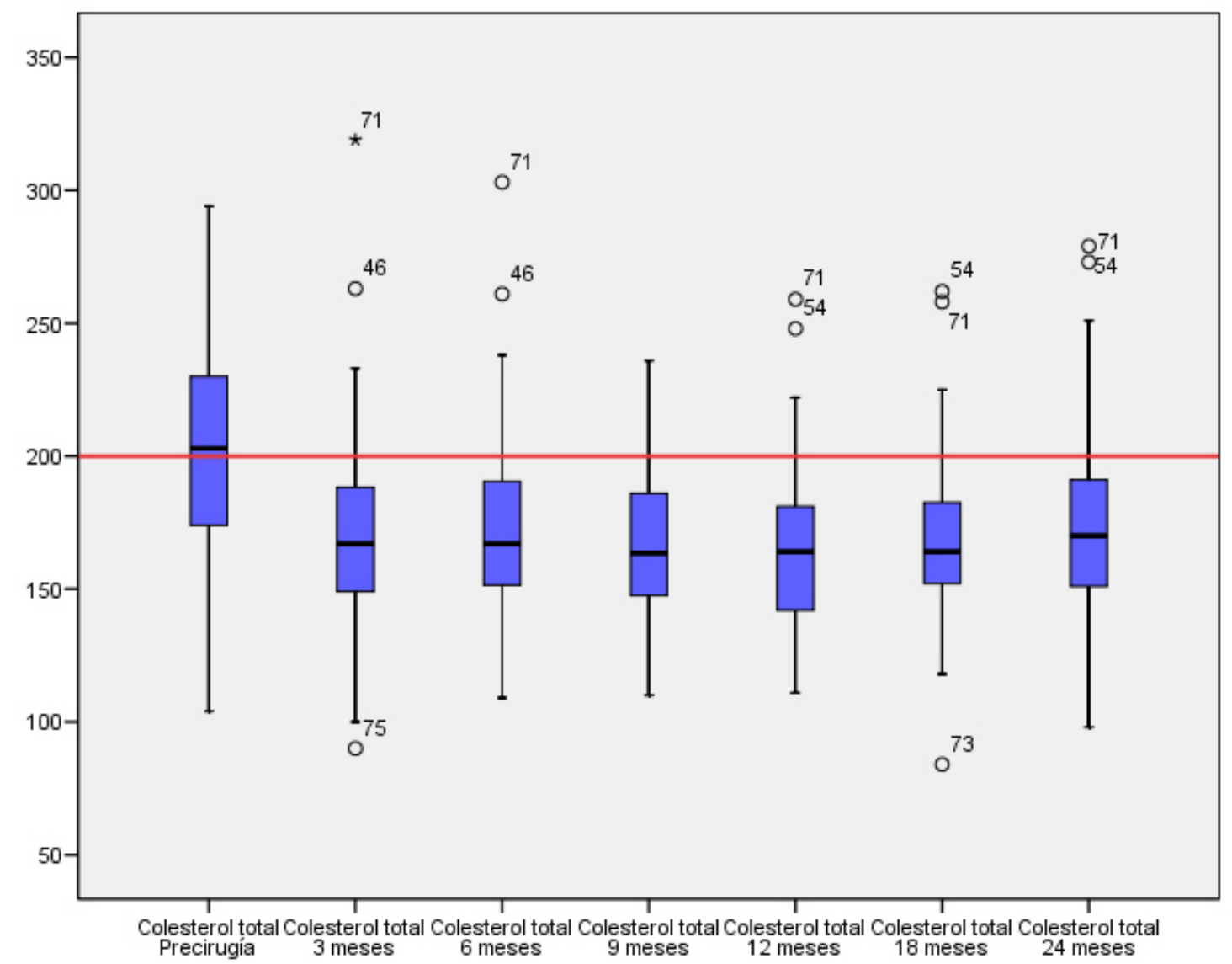

Figura 4.11.2.1. Diagrama de caja del Colesterol Total (Col-Total) plasmático en los diferentes controles evaluados representando los valores de referencia en el eje de ordenadas

Las diferencias entre los valores medios de Col-Total según el sexo, tabla 4.11.2.2, son significativamente más elevados en todos los controles evaluados en las mujeres.

El valor medio de Col-Total precirugía en las mujeres supera el valor límite máximo de referencia (209,38 mg/dL), y no así en los hombres $(183,21$ $\mathrm{mg} / \mathrm{dL})$. En ambos sexos la disminución media del Col-Total se observa hasta los 12 meses postquirúrgicos. Desde ese control aumenta ligeramente hasta los 24 meses, pero siempre manteniéndose por debajo de los valores límite de referencia. 


\begin{tabular}{|c|c|c|c|c|c|c|c|}
\hline & \multicolumn{3}{|c|}{ Mujer } & \multicolumn{3}{|c|}{ Hombre } & \multirow{2}{*}{$\mathbf{P}$} \\
\hline & $\mathbf{N}$ & Media & D.Típica & $\mathbf{N}$ & Media & D.Típica & \\
\hline $\begin{array}{l}\text { Col-Total } \\
\text { precirugía } \\
\text { (mg/dL) }\end{array}$ & 67 & 209,38 & 38,64 & 27 & 183,21 & 53,07 & $<0,05$ \\
\hline $\begin{array}{c}\text { Col-Total } 3 \\
\text { meses (mg/dL) }\end{array}$ & 64 & $175,17^{\dagger}$ & 36,30 & 25 & 158,89 & 33,02 & $<0,05$ \\
\hline $\begin{array}{c}\text { Col-Total } 6 \\
\text { meses (mg/dL) }\end{array}$ & 56 & $176,23^{\dagger}$ & 33,57 & 24 & 158,85 & 27,30 & $<0,05$ \\
\hline $\begin{array}{c}\text { Col-Total } 9 \\
\text { meses (mg/dL) }\end{array}$ & 38 & $173,68^{\dagger}$ & 28,45 & 22 & $153,67^{\dagger \dagger}$ & 27,41 & $<0,001$ \\
\hline $\begin{array}{c}\text { Col-Total } 12 \\
\text { meses (mg/dL) }\end{array}$ & 62 & $168,30^{\dagger}$ & 27,94 & 23 & $153,81^{\dagger \dagger}$ & 26,87 & $<0,05$ \\
\hline $\begin{array}{c}\text { Col-Total } 18 \\
\text { meses (mg/dL) }\end{array}$ & 53 & $173,05^{\dagger}$ & 28,96 & 22 & $157,95^{\dagger \dagger}$ & 25,19 & $<0,05$ \\
\hline $\begin{array}{c}\text { Col-Total } 24 \\
\text { meses (mg/dL) }\end{array}$ & 68 & $177,18^{\dagger}$ & 33,19 & 29 & $163,17^{\dagger \dagger}$ & 28,13 & $<0,05$ \\
\hline
\end{tabular}

Tabla 4.11.2.2. Descripción del Colesterol Total (Col-Total) plasmático en las diferentes revisiones evaluadas según el sexo

Por grupos de edad, en la bioquímica prequirúrgica no se observan variaciones significativas entre el grupo de $<42$ años y el de los $\geq 42$ años. Es a partir del control de los 6 meses y en las sucesivas revisiones cuando se describen cambios estadísticamente significativos entre ambos grupos, siendo en todos ellos la media de Col-Total más elevada en el grupo de mayor edad.

Los valores postquirúrgicos del Col-Total en ambos grupos, descienden significativamente en todos los controles respecto del valor previo a la cirugía $(P<0,001)$. Las variaciones entre controles en cada uno de los grupos de edad apenas sufre variaciones, observando una mejor respuesta de los < 42 años en las cifras de Col-Total, como se detalla en la tabla 4.11.2.3.

\begin{tabular}{|c|c|c|c|c|c|c|c|}
\cline { 2 - 7 } \multicolumn{1}{c|}{} & \multicolumn{3}{c|}{$<42$ años } & \multicolumn{3}{c|}{$\geq \mathbf{4 2 \text { años }}$} & \multirow{2}{*}{ P } \\
\cline { 2 - 7 } & $\mathbf{N}$ & Media & D.Típica & N & Media & D.Típica & \\
\hline $\begin{array}{c}\text { Col-Total } \\
\text { precirugía } \\
\text { (mg/dL) }\end{array}$ & 45 & 201,8 & 45,56 & 49 & 201,92 & 44,16 & NS \\
\hline $\begin{array}{c}\text { Col-Total 3 } \\
\text { meses (mg/dL) }\end{array}$ & 44 & $163,43^{\dagger}$ & 31,42 & 45 & $177,61^{\dagger}$ & 39,04 & NS \\
\hline $\begin{array}{c}\text { Col-Total 6 } \\
\text { meses (mg/dL) }\end{array}$ & 39 & $162,82^{\dagger}$ & 27,61 & 41 & $178,80^{\dagger}$ & 35,40 & $<0,05$ \\
\hline $\begin{array}{c}\text { Col-Total 9 } \\
\text { meses (mg/dL) }\end{array}$ & 26 & $153,35^{\dagger}$ & 28,66 & 34 & $176,28^{\dagger}$ & 26,41 & $<0,001$ \\
\hline
\end{tabular}




\begin{tabular}{|c|c|c|c|c|c|c|c|}
\hline & \multicolumn{3}{|c|}{$<42$ años } & \multicolumn{3}{|c|}{$\geq 42$ años } & \multirow{2}{*}{$\mathbf{P}$} \\
\hline & $\mathbf{N}$ & Media & D.Típica & $\mathbf{N}$ & Media & D.Típica & \\
\hline $\begin{array}{c}\text { Col-Total } 12 \\
\text { meses (mg/dL) }\end{array}$ & 39 & $155,31^{\dagger}$ & 22,41 & 46 & $172,07^{\dagger}$ & 30,56 & $<0,05$ \\
\hline $\begin{array}{c}\text { Col-Total } 18 \\
\text { meses (mg/dL) }\end{array}$ & 37 & $161,81^{\dagger}$ & 24,51 & 38 & $175,24^{\dagger}$ & 30,96 & $<0,05$ \\
\hline $\begin{array}{c}\text { Col-Total } 24 \\
\text { meses (mg/dL) }\end{array}$ & 46 & $163^{\dagger}$ & 24,62 & 51 & $182,01^{\dagger}$ & 35,76 & $<0,05$ \\
\hline
\end{tabular}

Tabla 4.11.2.3. Descripción del Colesterol Total (Col-Total) plasmático en las diferentes revisiones evaluadas según el grupo de edad

\subsubsection{HDL-Colesterol}

A continuación, tabla 4.11.2.4, se muestra la evolución del HDLColesterol (HDL-Col), desde la primera consulta hasta los 24 meses postcirugía. Desde la consulta precirugía los valores medios de HDL-Col fluctúan hasta los 6 meses, a partir del cual aumentan significativamente hasta los 24 meses postquirúrgicos. El 25\% de los pacientes desde los 9 meses postquirúrgicos superan los $60 \mathrm{mg} / \mathrm{dL}$ de HDL-Col. Los valores de HDL-Col aumentan significativamente $(P<0,001)$ respecto del valor prequirúrgico desde los 9 meses hasta el último control evaluado.

\begin{tabular}{|c|c|c|c|c|c|c|c|}
\hline & $\begin{array}{l}\text { HDL-Col } \\
\text { precirugía } \\
\text { (mg/dL) }\end{array}$ & $\begin{array}{c}\text { HDL-Col } \\
3 \\
\text { meses } \\
\text { (mg/dL) }\end{array}$ & $\begin{array}{c}\text { HDL-Col } \\
6 \\
\text { meses } \\
\text { (mg/dL) }\end{array}$ & $\begin{array}{c}\text { HDL-Col } \\
9 \\
\text { meses } \\
\text { (mg/dL) }\end{array}$ & $\begin{array}{c}\text { HDL-Col } \\
12 \\
\text { meses } \\
\text { (mg/dL) }\end{array}$ & $\begin{array}{c}\text { HDL-Col } \\
18 \\
\text { meses } \\
\text { (mg/dL) }\end{array}$ & $\begin{array}{c}\text { HDL-Col } \\
24 \\
\text { meses } \\
\text { (mg/dL) }\end{array}$ \\
\hline $\mathbf{N}$ & 83 & 85 & 77 & 58 & 80 & 70 & 90 \\
\hline Media & 49,09 & 45,86 & $49,37^{*}$ & $52,56^{\star^{\dagger \dagger}}$ & $57,08^{\star^{\dagger}}$ & $58,85^{\star^{\dagger}}$ & $61,98^{*^{\dagger}}$ \\
\hline D.Típica & 14,16 & 13,91 & 12,05 & 11,25 & 13,69 & 13,62 & 14,86 \\
\hline Mediana & 46 & 44 & 47 & 51,50 & 55,65 & 56,05 & 62 \\
\hline $\begin{array}{c}\text { Rango } \\
\text { intercuartílico } \\
\text { (P25-P75) }\end{array}$ & $40-57$ & $37-52$ & $41,4-57$ & $44-61$ & $47-65$ & $\begin{array}{c}49,75- \\
67,75\end{array}$ & $51-69,03$ \\
\hline
\end{tabular}

Tabla 4.11.2.4. Descripción del HDL-Colesterol (HDL-Col) plasmático en las diferentes revisiones evaluadas

En todos los controles estudiados los valores medios de HDL-Col están dentro de los valores límite de referencia 40-60 mg/dL (ATP III). En la figura 4.11.2.2 se observa cómo el $24,09 \%$ de los pacientes se encuentra por debajo del valor límite inferior antes de la cirugía, a los 3 meses aumenta, 
siendo el $34,11 \%$ de los pacientes. Sin embargo después de este control el porcentaje de pacientes con valores de HDL-Col inferiores a $40 \mathrm{mg} / \mathrm{dL}$ desciende, observando a los 6 meses al 18,18\% de los pacientes, el 13,79\% a los 9 meses, un 5\% al año de la cirugía y aumentando ligeramente a los 18 meses a un 7,14\% y finalmente a los 24 meses de la cirugía sólo el 3,33\% presentaba valores inferiores al límite.

En cuanto a los pacientes observados por encima de los valores máximos de referencia del HDL-Col $(60 \mathrm{mg} / \mathrm{dL})$ se describe en el control prequirúrgico al 15,66\% de los pacientes, a los 3 meses desciende al 9,41\%, aumentando en los 6 y 9 meses al 16,88\%, 29,31\%, respectivamente. Después de un año desde la cirugía, el 35\% de los pacientes superaba el valor máximo, el $42,85 \%$ a los 18 meses y el 54,44\% y 24 meses respectivamente.

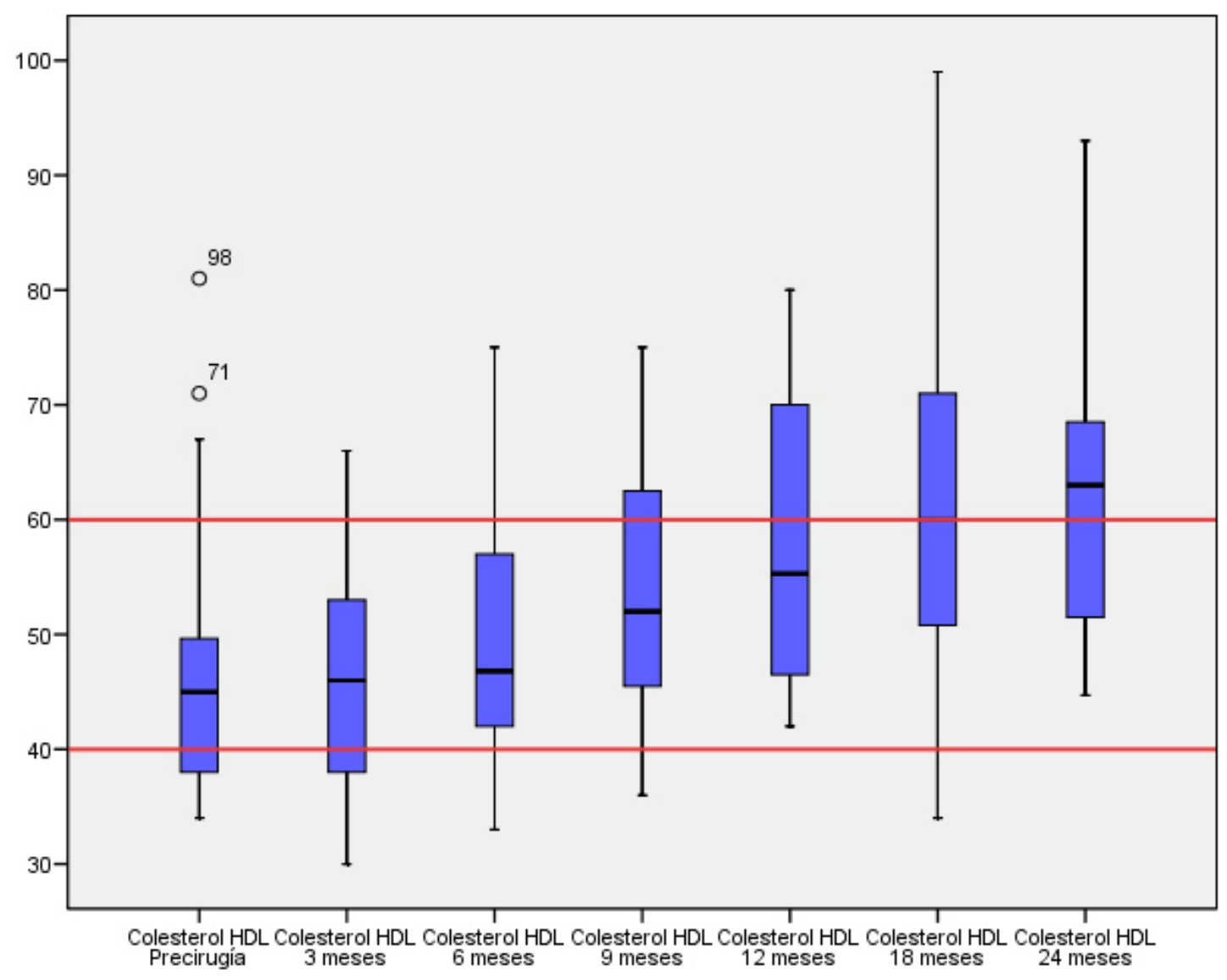

Figura 4.11.2.2. Diagrama de caja del HDL-Colesterol plasmático en los diferentes controles evaluados representando los valores de referencia en el eje de ordenadas 
Al comparar los valores medios de HDL-Col de las diferentes revisiones por sexo, en todos ellos los valores son más elevados en las mujeres siendo esta diferencia estadísticamente significativa en el control precirugía y a los 3, 18 y 24 meses postquirúrgicos. El valor medio de HDL-Col en las mujeres supera el límite máximo desde los 18 meses postcirugía, tabla 4.11.2.5.

\begin{tabular}{|c|c|c|c|c|c|c|c|}
\hline & \multicolumn{3}{|c|}{ Mujer } & \multicolumn{3}{|c|}{ Hombre } & \multirow{2}{*}{$\mathbf{P}$} \\
\hline & $\mathbf{N}$ & Media & D.Típica & $\mathbf{N}$ & Media & D.Típica & \\
\hline $\begin{array}{l}\text { HDL-Col } \\
\text { precirugía } \\
\text { (mg/dL) }\end{array}$ & 57 & 53,40 & 13,89 & 26 & 39,65 & 9,52 & $<0,001$ \\
\hline $\begin{array}{c}\text { HDL-Col } 3 \\
\text { meses } \\
\text { (mg/dL) }\end{array}$ & 61 & $47,73^{\dagger \dagger}$ & 14,68 & 24 & 41,11 & 10,53 & $<0,05$ \\
\hline $\begin{array}{l}\text { HDL-Col } 6 \\
\text { meses } \\
\text { (mg/dL) }\end{array}$ & 53 & 50,24 & 11,19 & 24 & $47,45^{\dagger}$ & 13,82 & NS \\
\hline $\begin{array}{l}\text { HDL-Col } 9 \\
\text { meses } \\
\text { (mg/dL) }\end{array}$ & 38 & 53,89 & 11,25 & 20 & $50,04^{\dagger}$ & 11,09 & NS \\
\hline $\begin{array}{c}\text { HDL-Col } 12 \\
\text { meses } \\
\text { (mg/dL) }\end{array}$ & 59 & $58,24^{\dagger \dagger}$ & 14,17 & 21 & $53,84^{\dagger}$ & 11,99 & NS \\
\hline $\begin{array}{c}\text { HDL-Col } 18 \\
\text { meses } \\
\text { (mg/dL) }\end{array}$ & 51 & $60,91^{\dagger}$ & 13,27 & 19 & $53,31^{\dagger}$ & 13,33 & $<0,05$ \\
\hline $\begin{array}{c}\text { HDL-Col } 24 \\
\text { meses } \\
\text { (mg/dL) }\end{array}$ & 64 & $64,35^{\dagger}$ & 13,72 & 26 & $56,14^{\dagger}$ & 16,17 & $<0,05$ \\
\hline
\end{tabular}

Tabla 4.11.2.5. Descripción del HDL-Colesterol (HDL-Col) plasmático en las diferentes revisiones evaluadas según el sexo

En la tabla 4.11.2.6 se detalla la evolución del HDL-Col medio de las diferentes revisiones según el grupo de edad, siendo en todos los controles mayor en el grupo de los $\geq 42$ años. Esta diferencia es estadísticamente significativa a los 3 y 9 meses postquirúrgicos. En el grupo de mayor edad se describe un valor medio de HDL-Col $>60 \mathrm{mg} / \mathrm{dL}$ desde los 18 meses postquirúrgicos, a diferencia de los $<42$ años, los cuales no obtienen cifras de HDL-Col medio por encima del valor máximo de referencia. 


\begin{tabular}{|c|c|c|c|c|c|c|c|}
\hline & \multicolumn{3}{|c|}{$<42$ años } & \multicolumn{3}{|c|}{$\geq 42$ años } & \multirow{2}{*}{$\mathbf{P}$} \\
\hline & $\mathbf{N}$ & Media & D.Típica & $\mathbf{N}$ & Media & D.Típica & \\
\hline $\begin{array}{l}\text { HDL-Col } \\
\text { precirugía } \\
\text { (mg/dL) }\end{array}$ & 38 & 47,94 & 15,33 & 45 & 50,07 & 13,19 & NS \\
\hline $\begin{array}{c}\text { HDL-Col } 3 \\
\text { meses (mg/dL) }\end{array}$ & 41 & $42,10^{\dagger \dagger}$ & 9,37 & 44 & 49,37 & 16,44 & $<0,05$ \\
\hline $\begin{array}{c}\text { HDL-Col } 6 \\
\text { meses (mg/dL) }\end{array}$ & 37 & 47,07 & 11,15 & 40 & 51,51 & 12,59 & NS \\
\hline $\begin{array}{c}\text { HDL-Col } 9 \\
\text { meses (mg/dL) }\end{array}$ & 25 & 49,39 & 10,62 & 33 & $54,97^{\dagger \dagger}$ & 11,27 & $<0,05$ \\
\hline $\begin{array}{c}\text { HDL-Col } 12 \\
\text { meses (mg/dL) }\end{array}$ & 34 & $54,74^{\dagger \dagger}$ & 12,97 & 46 & $58,82^{\dagger}$ & 14,09 & NS \\
\hline $\begin{array}{c}\text { HDL-Col } 18 \\
\text { meses (mg/dL) }\end{array}$ & 35 & $56,25^{\dagger}$ & 12,34 & 35 & $61,44^{\dagger}$ & 14,51 & NS \\
\hline $\begin{array}{c}\text { HDL-Col } 24 \\
\text { meses (mg/dL) }\end{array}$ & 41 & $59,33^{\dagger}$ & 12,04 & 49 & $64,20^{\dagger}$ & 16,66 & NS \\
\hline
\end{tabular}

Tabla 4.11.2.6. Descripción del HDL-Colesterol (HDL-Col) plasmático en las diferentes revisiones evaluadas según el grupo de edad

\subsubsection{LDL-Colesterol}

En la tabla 4.11.2.7 se describe la evolución del LDL-Colesterol (LDLCol) observando una tendencia descendente de los valores medios hasta el año de la cirugía, desde ese momento aumenta ligeramente a los 18 y 24 meses. En el 75\% de la muestra antes de la cirugía los valores de LDL-Col superaban los 97,20 mg/dL. Los valores de LDL-Col disminuyen significativamente $(\mathrm{P}<0,001)$ en todos los controles desde el $3^{\circ}$ mes, al comparar los resultados con el valor prequirúrgico, siendo a los 12 meses el control donde se observa el valor más bajo.

\begin{tabular}{|c|c|c|c|c|c|c|c|}
\hline & $\begin{array}{l}\text { LDL-Col } \\
\text { precirugía } \\
\text { (mg/dL) }\end{array}$ & $\begin{array}{c}\text { LDL-Col } \\
3 \\
\text { meses } \\
\text { (mg/dL) }\end{array}$ & $\begin{array}{l}\text { LDL-Col } \\
6 \\
\text { meses } \\
\text { (mg/dL) }\end{array}$ & $\begin{array}{c}\text { LDL-Col } \\
9 \\
\text { meses } \\
\text { (mg/dL) }\end{array}$ & $\begin{array}{c}\text { LDL-Col } \\
12 \\
\text { meses } \\
\text { (mg/dL) }\end{array}$ & $\begin{array}{c}\text { LDL-Col } \\
18 \\
\text { meses } \\
\text { (mg/dL) }\end{array}$ & $\begin{array}{c}\text { LDL-Col } \\
24 \\
\text { meses } \\
\text { (mg/dL) }\end{array}$ \\
\hline $\mathbf{N}$ & 81 & 84 & 75 & 57 & 80 & 70 & 87 \\
\hline Media & 126,90 & $105,82^{*^{\dagger}}$ & $102,90^{*^{\dagger}}$ & $98,80^{*^{\dagger}}$ & $91,99^{\dagger}$ & $94,88^{\dagger}$ & $96,28^{*^{\dagger}}$ \\
\hline D.Típica & 39,81 & 35,78 & 29,40 & 24,03 & 24,75 & 25,01 & 26,99 \\
\hline Mediana & 127,80 & 99,90 & 100 & 98 & 90,90 & 91 & 93 \\
\hline $\begin{array}{c}\text { Rango } \\
\text { intercuartílico } \\
\text { (P25-P75) }\end{array}$ & $\begin{array}{l}97,20- \\
149,20\end{array}$ & $\begin{array}{l}83,85- \\
128,90\end{array}$ & $\begin{array}{c}85- \\
120,60\end{array}$ & $\begin{array}{c}79- \\
118,50\end{array}$ & $\begin{array}{l}71,70- \\
110,15\end{array}$ & $\begin{array}{l}78,50- \\
114,35\end{array}$ & $\begin{array}{c}78- \\
113,20\end{array}$ \\
\hline
\end{tabular}

Tabla 4.11.2.7. Descripción del LDL-Colesterol (LDL-Col) plasmático en las diferentes revisiones evaluadas 
Como se muestra en la figura 4.11.2.3, el 74,07\% de los pacientes antes de la cirugía superaban los valores máximos de referencia de LDL-Col $(<100$ $\mathrm{mg} / \mathrm{dL}$. ATP III). Hasta los 12 meses apenas se observa variación en el porcentaje de pacientes con valores superiores al límite siendo en todos ellos aproximadamente el $50 \%$ de los casos. Al año desciende esta cifra al $33,75 \%$ de los casos. En el siguiente control aumenta al $40 \%$ y finalmente a los 2 años se describe un 41,37\% de pacientes con valores de LDL-Col superiores al límite máximo de referencia.

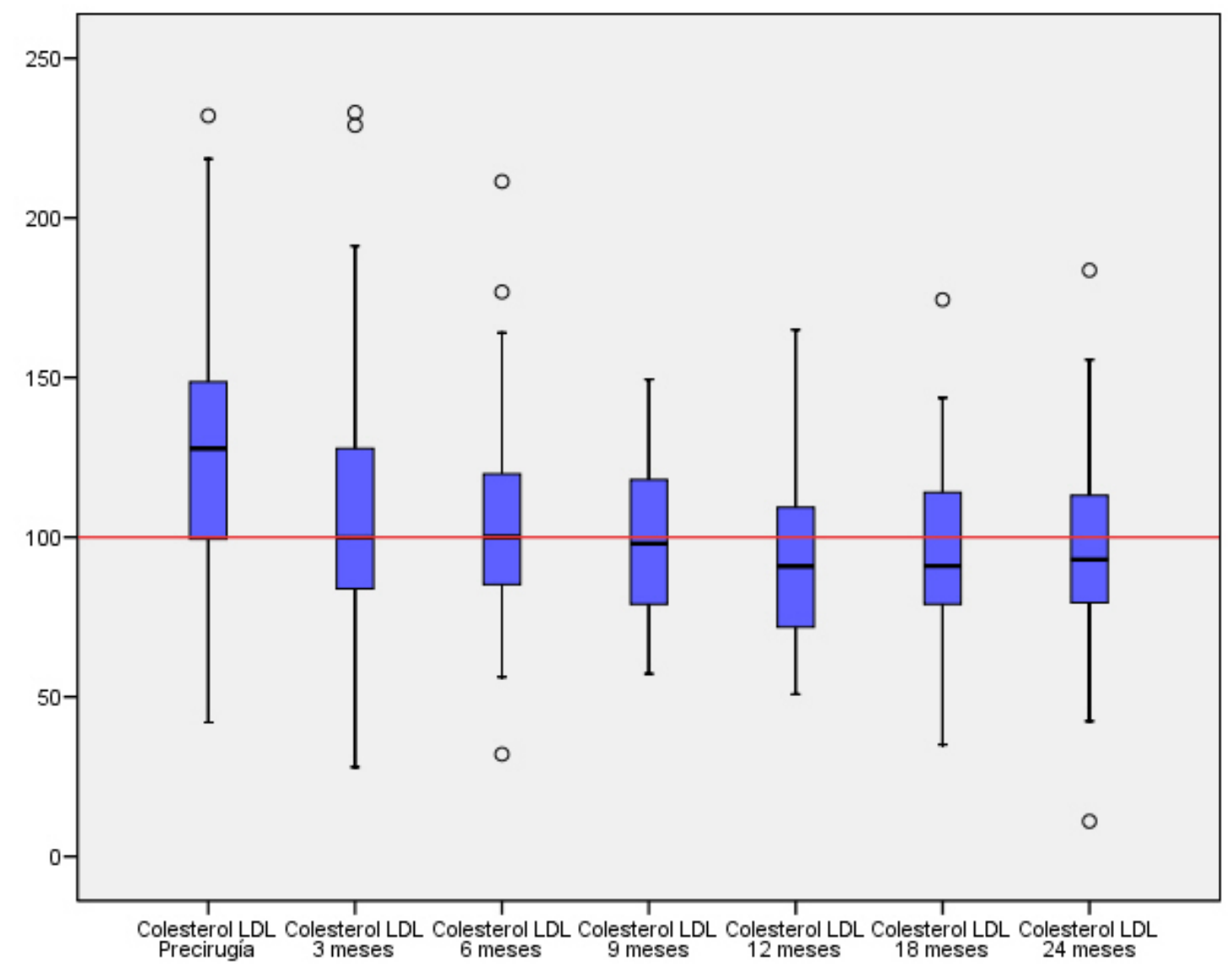

Figura 4.11.2.3. Diagrama de caja del LDL-Colesterol plasmático en los diferentes controles evaluados representando los valores de referencia en el eje de ordenadas

Según el sexo apenas se muestran variaciones de los valores de LDLCol medio, tabla 4.11.2.8, siendo en todos los controles a excepción de los 3 meses superior es en las mujeres. Sin embargo esas diferencias entre ambos sexos sólo son significativas en la revisión de los 6 meses dónde los valores de LDL-Col medios en las mujeres superan en 15,5 mg/dL a los hombres $(P<0,05)$. 


\begin{tabular}{|c|c|c|c|c|c|c|c|}
\hline & \multicolumn{3}{|c|}{ Mujer } & \multicolumn{3}{|c|}{ Hombre } & \multirow{2}{*}{$\mathbf{P}$} \\
\hline & $\mathbf{N}$ & Media & D.Típica & $\mathbf{N}$ & Media & D.Típica & \\
\hline $\begin{array}{l}\text { LDL-Col } \\
\text { precirugía } \\
\text { (mg/dL) }\end{array}$ & 56 & 131,80 & 36,74 & 25 & 115,91 & 44,80 & NS \\
\hline $\begin{array}{c}\text { LDL-Col } 3 \\
\text { meses (mg/dL) }\end{array}$ & 60 & $105,78^{\dagger}$ & 34,89 & 24 & 105,91 & 38,68 & NS \\
\hline $\begin{array}{c}\text { LDL-Col } 6 \\
\text { meses (mg/dL) }\end{array}$ & 52 & $107,65^{\dagger}$ & 29,91 & 23 & $92,15^{\dagger \dagger}$ & 25,65 & $<0,05$ \\
\hline $\begin{array}{c}\text { LDL-Col } 9 \\
\text { meses (mg/dL) }\end{array}$ & 37 & $102,99^{\dagger}$ & 24,14 & 20 & $91,06^{\dagger \dagger}$ & 22,36 & NS \\
\hline $\begin{array}{l}\text { LDL-Col } 12 \\
\text { meses (mg/dL) }\end{array}$ & 59 & $94,10^{\dagger}$ & 25,33 & 21 & $86,06^{\dagger}$ & 22,54 & NS \\
\hline $\begin{array}{l}\text { LDL-Col } 18 \\
\text { meses (mg/dL) }\end{array}$ & 51 & $96,25^{\dagger}$ & 25,95 & 19 & $91,20^{\dagger}$ & 22,52 & NS \\
\hline $\begin{array}{c}\text { LDL-Col } 24 \\
\text { meses (mg/dL) }\end{array}$ & 62 & $98,24^{\dagger}$ & 27,74 & 25 & $91,45^{\dagger}$ & 24,90 & NS \\
\hline
\end{tabular}

Tabla 4.11.2.8. Descripción del LDL-Colesterol (LDL-Col) plasmático en las diferentes revisiones evaluadas según el sexo

Del mismo modo pero agrupados por la edad, como se muestra en la tabla 4.11.2.9, en todos los controles se observan valores medios de LDLCol más elevados en el grupo de los $\geq 42$ años siendo esta diferencia estadísticamente significativa en la revisión de los 9 meses.

\begin{tabular}{|c|c|c|c|c|c|c|c|}
\hline & \multicolumn{3}{|c|}{$<42$ años } & \multicolumn{3}{|c|}{$\geq 42$ años } & \multirow{2}{*}{$\mathbf{P}$} \\
\hline & $\mathbf{N}$ & Media & D.Típica & $\mathbf{N}$ & Media & D.Típica & \\
\hline $\begin{array}{l}\text { LDL-Col } \\
\text { precirugía } \\
\text { (mg/dL) }\end{array}$ & 37 & 126,46 & 40,87 & 44 & 127,26 & 39,36 & NS \\
\hline $\begin{array}{c}\text { LDL-Col } 3 \\
\text { meses (mg/dL) }\end{array}$ & 40 & $101,38^{\dagger}$ & 25,47 & 44 & 109,85 & 42,98 & NS \\
\hline $\begin{array}{c}\text { LDL-Col } 6 \\
\text { meses (mg/dL) }\end{array}$ & 36 & $99,42^{\dagger}$ & 25,49 & 39 & $106,10^{\dagger \dagger}$ & 32,60 & NS \\
\hline $\begin{array}{c}\text { LDL-Col } 9 \\
\text { meses (mg/dL) }\end{array}$ & 24 & $91,33^{\dagger}$ & 24,88 & 33 & $104,24^{\dagger \dagger}$ & 22,20 & $<0,05$ \\
\hline $\begin{array}{l}\text { LDL-Col } 12 \\
\text { meses (mg/dL) }\end{array}$ & 34 & $97,96^{\dagger}$ & 21,36 & 46 & $94,97^{\dagger}$ & 26,82 & NS \\
\hline $\begin{array}{l}\text { LDL-Col } 18 \\
\text { meses (mg/dL) }\end{array}$ & 34 & $91,29^{\dagger}$ & 21,81 & 36 & $98,26^{\dagger}$ & 27,58 & NS \\
\hline $\begin{array}{l}\text { LDL-Col } 24 \\
\text { meses (mg/dL) }\end{array}$ & 40 & $92,11^{\dagger}$ & 20,92 & 47 & $99,84^{\dagger}$ & 31,03 & NS \\
\hline
\end{tabular}

Tabla 4.11.2.9. Descripción del LDL-Colesterol (LDL-Col) plasmático en las diferentes revisiones evaluadas según el grupo de edad 


\subsubsection{Triglicéridos}

Los triglicéridos (TG) completan el perfil lipídico estudiado en los pacientes de la muestra. En la tabla 4.11.2.10 se describe la evolución de los TG en los diferentes controles trimestrales. Desde la consulta previa a la cirugía y en los sucesivos controles postquirúrgicos, los valores medios de TG disminuyen significativamente a excepción de los resultados entre la revisión de los 18 y 24 meses. Todos los controles posteriores a la cirugía registran valores de TG significativamente más bajos $(P<0,001)$ en referencia al valor prequirúrgico.

\begin{tabular}{|c|c|c|c|c|c|c|c|}
\hline & $\begin{array}{c}\text { TG } \\
\text { precirugía } \\
\text { (mg/dL) }\end{array}$ & $\begin{array}{c}\text { TG } \\
3 \\
\text { meses } \\
\text { (mg/dL) }\end{array}$ & $\begin{array}{c}\text { TG } \\
6 \\
\text { meses } \\
\text { (mg/dL) }\end{array}$ & $\begin{array}{c}\text { TG } \\
9 \\
\text { meses } \\
\text { (mg/dL) }\end{array}$ & $\begin{array}{c}\text { TG } \\
12 \\
\text { meses } \\
\text { (mg/dL) }\end{array}$ & $\begin{array}{c}\text { TG } \\
18 \\
\text { meses } \\
\text { (mg/dL) }\end{array}$ & $\begin{array}{c}\text { TG } \\
24 \\
\text { meses } \\
\text { (mg/dL) }\end{array}$ \\
\hline $\mathbf{N}$ & 92 & 88 & 78 & 58 & 84 & 74 & 95 \\
\hline Media & 138,05 & $100,09 *^{\dagger}$ & $88,05^{*^{\dagger}}$ & $83,94^{\dagger}$ & $81,06^{*^{\dagger}}$ & $77,35^{\star^{\dagger}}$ & $76,04^{\dagger}$ \\
\hline D.Típica & 78,45 & 31,03 & 34,49 & 32,76 & 31,58 & 29,54 & 30,34 \\
\hline Mediana & 117,50 & 99,50 & 81,50 & 77,50 & 72,50 & 70 & 68 \\
\hline $\begin{array}{c}\text { Rango } \\
\text { intercuartílico } \\
\text { (P25-P75) }\end{array}$ & $89-159,50$ & 78-118 & $\begin{array}{c}64- \\
101,50\end{array}$ & $\begin{array}{l}61,75- \\
91,50\end{array}$ & $\begin{array}{c}60,25- \\
95,50\end{array}$ & $55-90$ & $57-92$ \\
\hline
\end{tabular}

Tabla 4.11.2.10. Descripción de los triglicéridos (TG) plasmáticos en las diferentes revisiones evaluadas

Según las recomendaciones ATP III, el valor límite de TG se sitúa en $150 \mathrm{mg} / \mathrm{dL}$ como se muestra la figura 4.11.2.4. Antes de la cirugía el 30,43\% de los pacientes superaba el valor límite máximo, a los 3 meses tan solo el 6,81\%, reduciéndose este porcentaje a los 6 meses al 5,1\%. En la revisión de los 9 meses se observa el 6,89\% de los pacientes, 3,57\% al año. Y continuando este descenso, siendo la revisión de los 24 meses en la que se describe el porcentaje más bajo de pacientes con valores de TG superiores al límite $(2,10 \%$ de la muestra). 


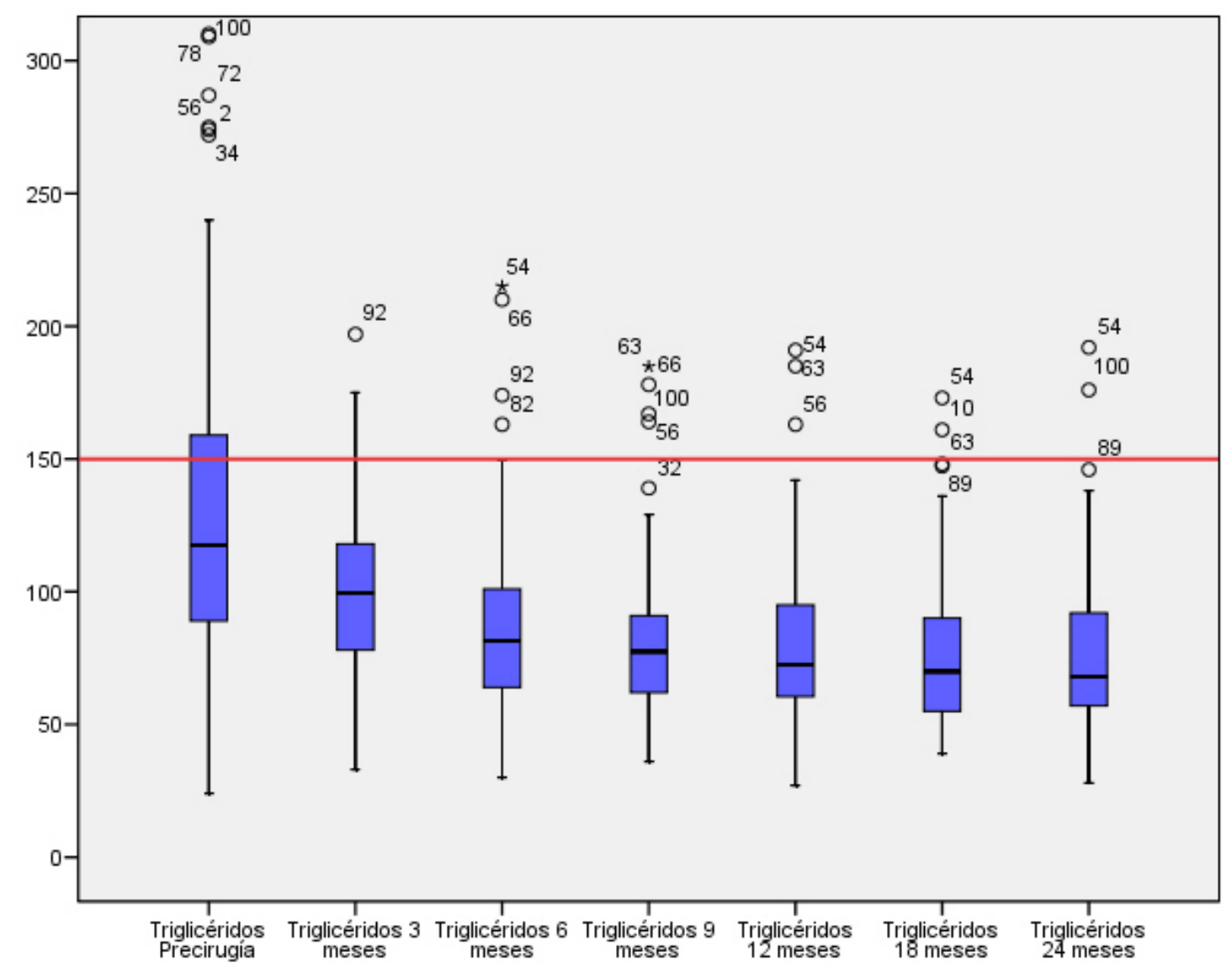

Figura 4.11.2.4. Diagrama de caja de los triglicéridos plasmáticos en los diferentes controles evaluados representando los valores de referencia en el eje de ordenadas

La evolución de los valores medios de TG no se encuentran determinados por el sexo, no mostrando diferencias estadísticamente significativas en ninguna de las revisiones entre hombres y mujeres (tabla 4.11.2.11). Cabe destacar la tendencia descendente desde la precirugía en ambos sexos a excepción del control de los 24 meses en los hombres en los que el valor medio de TG asciende respecto del control anterior, siempre sin superar el valor límite de referencia.

\begin{tabular}{|c|c|c|c|c|c|c|c|}
\hline & \multicolumn{3}{|c|}{ Mujer } & \multicolumn{3}{|c|}{ Hombre } & \multirow{2}{*}{$\mathbf{P}$} \\
\hline & $\mathbf{N}$ & Media & D.Típica & $\mathbf{N}$ & Media & D.Típica & \\
\hline $\begin{array}{l}\text { TG precirugía } \\
\text { (mg/dL) }\end{array}$ & 66 & 132,09 & 76,77 & 26 & 153,18 & 82,17 & NS \\
\hline $\begin{array}{c}\text { TG } 3 \text { meses } \\
\text { (mg/dL) }\end{array}$ & 64 & $102,34^{\dagger \dagger}$ & 29,96 & 24 & $94,08^{\dagger}$ & 33,66 & NS \\
\hline $\begin{array}{c}\text { TG } 6 \text { meses } \\
\text { (mg/dL) }\end{array}$ & 55 & $90,12^{\dagger}$ & 34,07 & 23 & $83,09^{\dagger \dagger}$ & 35,73 & NS \\
\hline $\begin{array}{c}\text { TG } 9 \text { meses } \\
\text { (mg/dL) }\end{array}$ & 38 & $85,80^{\dagger}$ & 35,69 & 20 & $80,41^{\dagger}$ & 26,83 & NS \\
\hline $\begin{array}{l}\text { TG } 12 \text { meses } \\
(\mathrm{mg} / \mathrm{dL})\end{array}$ & 62 & $81,15^{\dagger}$ & 33,31 & 22 & $80,80^{\dagger}$ & 26,79 & NS \\
\hline
\end{tabular}




\begin{tabular}{|c|c|c|c|c|c|c|c|}
\hline & \multicolumn{3}{|c|}{ Mujer } & \multicolumn{3}{|c|}{ Hombre } & \multirow{2}{*}{$\mathbf{P}$} \\
\hline & $\mathbf{N}$ & Media & D.Típica & $\mathbf{N}$ & Media & D.Típica & \\
\hline $\begin{array}{l}\text { TG } 18 \text { meses } \\
\text { (mg/dL) }\end{array}$ & 53 & $76,57^{\dagger}$ & 29,79 & 21 & $79,31^{\dagger}$ & 29,52 & NS \\
\hline $\begin{array}{l}\text { TG } 24 \text { meses } \\
\text { (mg/dL) }\end{array}$ & 67 & $73,87^{\dagger}$ & 27,79 & 28 & $81,25^{\dagger}$ & 35,75 & NS \\
\hline
\end{tabular}

Tabla 4.11.2.11. Descripción de los triglicéridos (TG) plasmáticos en las diferentes revisiones evaluadas según el sexo

Atendiendo al grupo de edad se observa como en todos los controles los valores medios de TG son más elevados en el grupo de los $\geq 42$ años, siendo estas diferencias significativas a los 6, 9, 12, y 24 meses postquirúrgicos. Tabla 4.11.2.12.

\begin{tabular}{|c|c|c|c|c|c|c|c|}
\hline & \multicolumn{3}{|c|}{$<42$ años } & \multicolumn{3}{|c|}{$\geq 42$ años } & \multirow{2}{*}{$\mathbf{P}$} \\
\hline & $\mathbf{N}$ & Media & D.Típica & $\mathbf{N}$ & Media & D.Típica & \\
\hline $\begin{array}{c}\text { TG } \\
\text { precirugía } \\
\text { (mg/dL) }\end{array}$ & 45 & 130,71 & 66,04 & 47 & 145,08 & 88,89 & NS \\
\hline $\begin{array}{c}\text { TG } 3 \text { meses } \\
\text { (mg/dL) }\end{array}$ & 43 & $94,40^{\dagger}$ & 25,15 & 45 & $105,53^{\dagger}$ & 35,19 & NS \\
\hline $\begin{array}{c}\text { TG } 6 \text { meses } \\
\text { (mg/dL) }\end{array}$ & 38 & $79,79^{\dagger}$ & 26,28 & 40 & $95,89^{\dagger}$ & 39,54 & $<0,05$ \\
\hline $\begin{array}{c}\text { TG } 9 \text { meses } \\
\text { (mg/dL) }\end{array}$ & 25 & $69,92^{\dagger}$ & 20,61 & 33 & $94,56^{\dagger}$ & 36,38 & $<0,05$ \\
\hline $\begin{array}{c}\text { TG } 12 \\
\text { meses } \\
\text { (mg/dL) }\end{array}$ & 38 & $70,39^{\dagger}$ & 23,52 & 46 & $89,87^{\dagger}$ & 34,77 & $<0,05$ \\
\hline $\begin{array}{c}\text { TG } 18 \\
\text { meses } \\
(\mathrm{mg} / \mathrm{dL})\end{array}$ & 37 & $70,98^{\dagger}$ & 24,67 & 37 & $83,71^{\dagger}$ & 32,82 & NS \\
\hline $\begin{array}{c}\text { TG } 24 \\
\text { meses } \\
(\mathrm{mg} / \mathrm{dL})\end{array}$ & 45 & $66,94^{\dagger}$ & 21,79 & 50 & $84,24^{\dagger}$ & 34,57 & $<0,05$ \\
\hline & & & $P<0$ & & $2 \operatorname{col} x$ & trol & írgi \\
\hline
\end{tabular}

Tabla 4.11.2.12. Descripción de los triglicéridos (TG) plasmáticos en las diferentes revisiones evaluadas según el grupo de edad

En la figura 4.11.2.5 se muestra una gráfica a página completa de los diferentes parámetros estudiados en el perfil lipídico en cada una de las revisiones, categorizados por grupos de edad y sexo a modo de resumen y vista simultánea de la tendencia de todos los parámetros previamente descritos. 


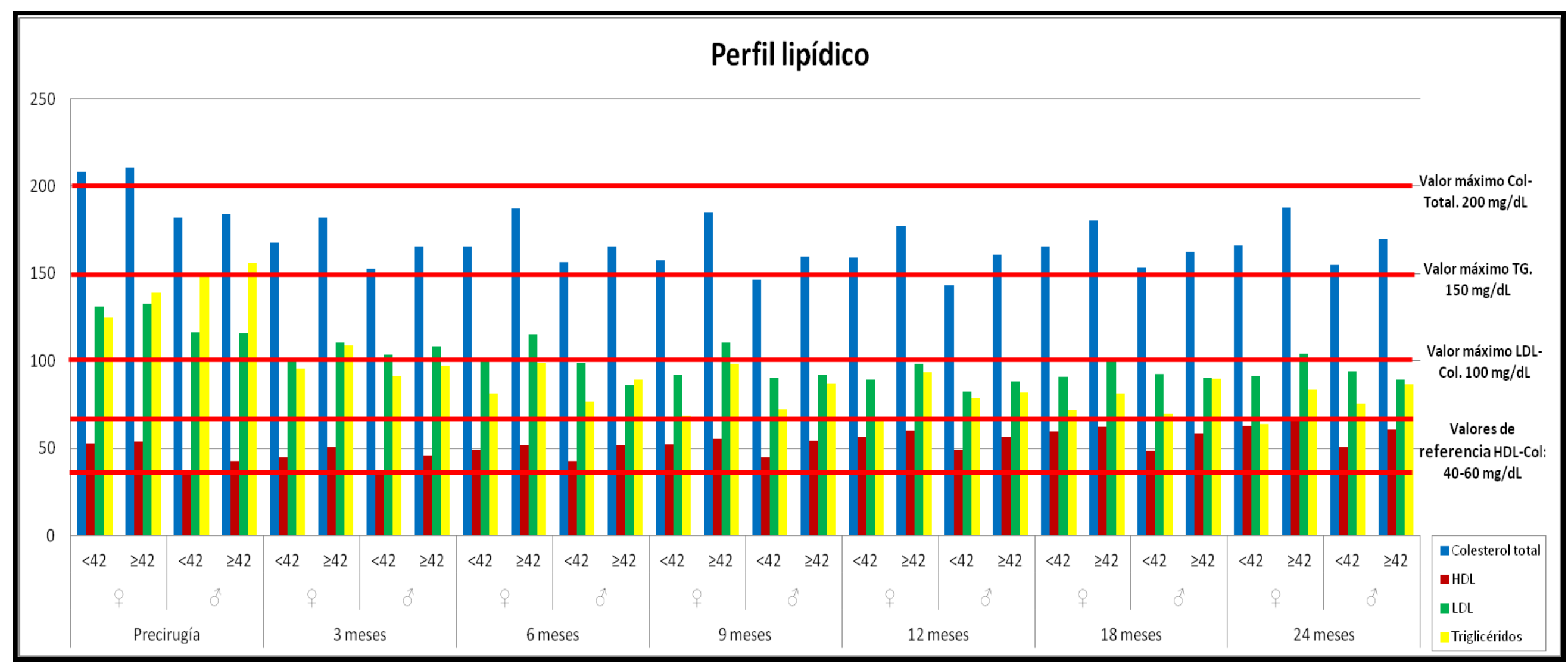

Figura 4.11.2.5. Gráfico de barras del perfil lipídico plasmático en los diferentes controles evaluados según el sexo y el grupo de edad correspondiente en cada uno de ellos 


\subsubsection{Perfil renal}

Las variables utilizadas en la descripción del perfil renal de la muestra fueron: ácido úrico (Ácd.Úrico), urea y creatinina (Creat). La tasa de filtración glomerular no se describe puesto que en todos los pacientes tanto en la primera consulta como en el resto de revisiones posteriores a la intervención siempre fue $>60 \mathrm{~mL} / \mathrm{min}$.

\subsubsection{1. Ácido úrico}

En la consulta inicial se registra el valor medio más elevado del Ácd.Úrico, reduciéndose de manera progresiva en los siguientes controles hasta los 12 meses (tabla 4.11.3.1) dónde se observa el valor medio más bajo. A los 18 meses asciende de manera significativa reduciéndose a los 24 meses, observando en ambas revisiones al 75\% de los pacientes con valores inferiores a 4,90 mg/dL. El Ácd.Úrico de los controles posteriores a la intervención en referencia a los valores precirugía disminuyen de manera significativa $(P<0,05)$.

\begin{tabular}{|c|c|c|c|c|c|c|c|}
\hline & $\begin{array}{c}\text { Ácd. } \\
\text { Úrico } \\
\text { precirugía } \\
\text { (mg/dL) }\end{array}$ & $\begin{array}{l}\text { Ácd. } \\
\text { Úrico } 3 \\
\text { meses } \\
\text { (mg/dL) }\end{array}$ & $\begin{array}{c}\text { Ácd. } \\
\text { Úrico } 6 \\
\text { meses } \\
\text { (mg/dL) }\end{array}$ & $\begin{array}{l}\text { Ácd. } \\
\text { Úrico } 9 \\
\text { meses } \\
\text { (mg/dL) }\end{array}$ & $\begin{array}{l}\text { Ácd. } \\
\text { Úrico } 12 \\
\text { meses } \\
\text { (mg/dL) }\end{array}$ & $\begin{array}{l}\text { Ácd. } \\
\text { Úrico } 18 \\
\text { meses } \\
\text { (mg/dL) }\end{array}$ & $\begin{array}{c}\text { Ácd. } \\
\text { Úrico } 24 \\
\text { meses } \\
\text { (mg/dL) }\end{array}$ \\
\hline $\mathbf{N}$ & 88 & 90 & 76 & 58 & 82 & 71 & 93 \\
\hline Media & 5,82 & $4,66^{*^{\dagger}}$ & $4,27 *^{\dagger}$ & $4,15^{\star^{\dagger}}$ & $3,93^{\dagger}$ & $4,17 *^{\dagger}$ & $4,09^{\dagger}$ \\
\hline D.Típica & 1,65 & 1,35 & 1,24 & 0,94 & 1,09 & 1,21 & 1,13 \\
\hline Mediana & 5,75 & 4,58 & 4,15 & 4,10 & 3,80 & 4 & 4,10 \\
\hline $\begin{array}{c}\text { Rango } \\
\text { intercuartílico } \\
\text { (P25-P75) }\end{array}$ & $4,70-6,90$ & $\begin{array}{l}3,60- \\
5,62\end{array}$ & $\begin{array}{l}3,40- \\
5,07\end{array}$ & $\begin{array}{l}3,47- \\
4,80\end{array}$ & $\begin{array}{l}3,19- \\
4,60\end{array}$ & $\begin{array}{l}3,36- \\
4,90\end{array}$ & $\begin{array}{l}3,40- \\
4,90\end{array}$ \\
\hline \multicolumn{8}{|c|}{$\begin{array}{r}{ }^{*} \mathrm{P}<0,05 \text { comparado con el control anterior } \\
{ }^{\dagger} \mathrm{P}<0,001 \text { comparado con el control prequirúrgico }\end{array}$} \\
\hline
\end{tabular}

Tabla 4.11.3.1. Descripción del ácido úrico (Ácd. Úrico) plasmático en las diferentes revisiones evaluadas

En la figura 4.11.3.1 se muestra la evolución del Ácd. Úrico marcando los valores de referencia en el eje de ordenadas. En la primera consulta el $20,45 \%$ de los pacientes superaba el valor máximo de referencia. Posteriormente desciende a los 3 meses al 3,33\%, y el 1,31\% a los 6 meses. En la revisión de los 9 y 12 meses ningún paciente superaba el valor máximo de referencia. Tan solo el 1,40\% a los 18 meses y el 1,07\% a los 2 años de la cirugía presentaron valores superiores al límite máximo. 


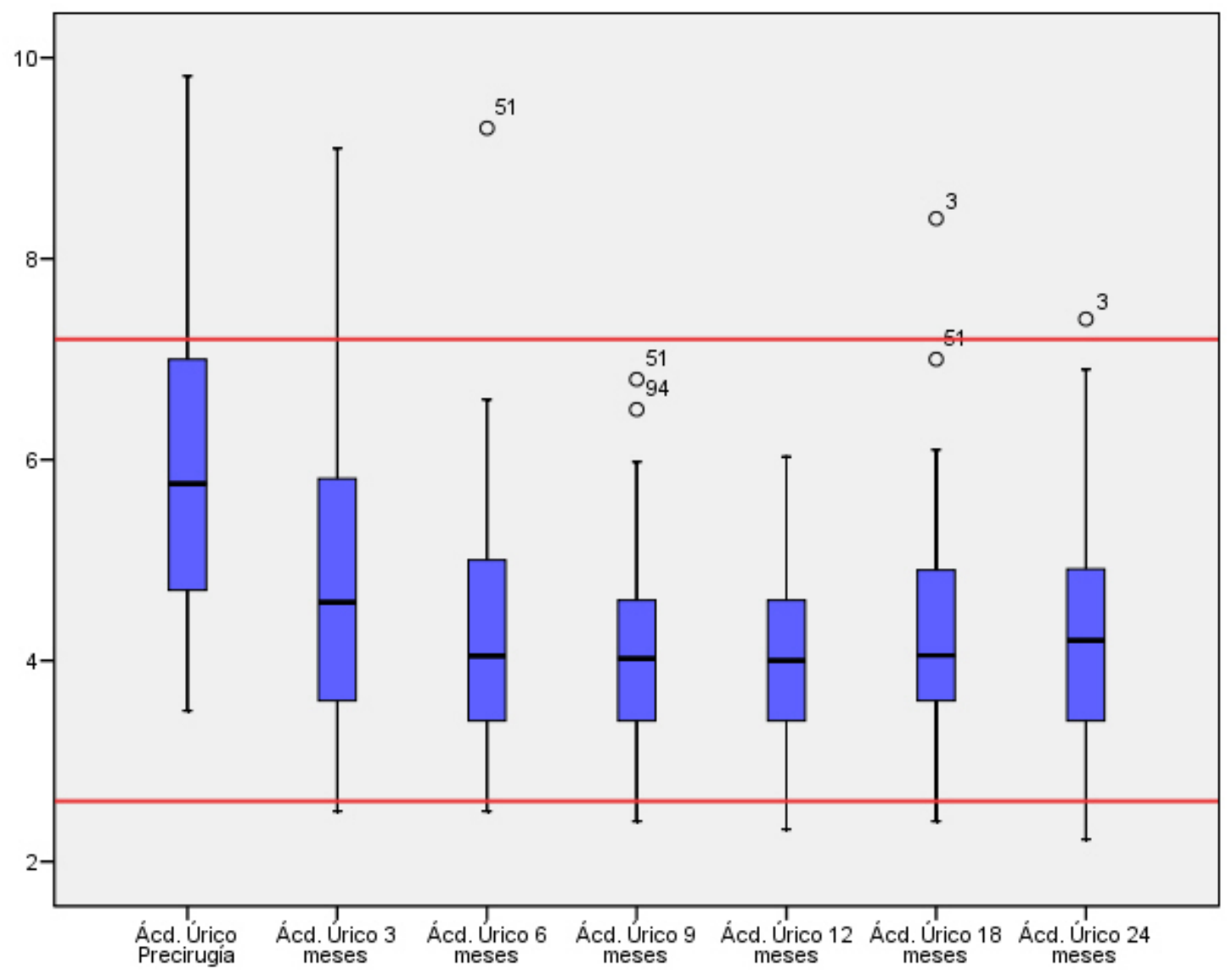

Figura 4.11.3.1. Diagrama de caja del ácido úrico plasmático en los diferentes controles evaluados representando los valores de referencia en el eje de ordenadas

Por sexo, como se describe en la tabla 4.11.3.2, el valor medio del Ácd. Úrico en todos los controles fue más elevado en los hombres que en las mujeres $(P<0,001)$, aunque en ambos sexos la reducción del Ácd. Úrico a 24 meses fue estadísticamente significativa.

\begin{tabular}{|c|c|c|c|c|c|c|c|}
\hline & \multicolumn{3}{|c|}{ Mujer } & \multicolumn{3}{|c|}{ Hombre } & \multirow{2}{*}{$\mathbf{P}$} \\
\hline & $\mathbf{N}$ & Media & D.Típica & $\mathbf{N}$ & Media & D.Típica & \\
\hline $\begin{array}{c}\text { Ácd. Úrico } \\
\text { precirugía } \\
\text { (mg/dL) }\end{array}$ & 62 & 5,29 & 1,39 & 26 & 7,10 & 1,52 & $<0,001$ \\
\hline $\begin{array}{c}\text { Ácd. Úrico } 3 \\
\text { meses (mg/dL) }\end{array}$ & 64 & $4,20^{\dagger}$ & 1,10 & 26 & $5,78^{\dagger}$ & 1,28 & $<0,001$ \\
\hline $\begin{array}{c}\text { Ácd. Úrico } 6 \\
\text { meses (mg/dL) }\end{array}$ & 52 & $3,85^{\dagger}$ & 0,98 & 24 & $5,19^{\dagger}$ & 1,25 & $<0,001$ \\
\hline $\begin{array}{c}\text { Ácd. Úrico } 9 \\
\text { meses (mg/dL) }\end{array}$ & 37 & $3,76^{\dagger}$ & 0,72 & 21 & $4,85^{\dagger}$ & 0,91 & $<0,001$ \\
\hline $\begin{array}{l}\text { Ácd. Úrico } 12 \\
\text { meses (mg/dL) }\end{array}$ & 60 & $3,58^{\dagger}$ & 0,96 & 22 & $4,87^{\dagger}$ & 0,88 & $<0,001$ \\
\hline $\begin{array}{l}\text { Ácd. Úrico } 18 \\
\text { meses (mg/dL) }\end{array}$ & 50 & $3,71^{\dagger}$ & 0,91 & 21 & $5,25^{\dagger}$ & 1,18 & $<0,001$ \\
\hline
\end{tabular}




\begin{tabular}{|c|c|c|c|c|c|c|c|}
\hline & \multicolumn{3}{|c|}{ Mujer } & \multicolumn{3}{|c|}{ Hombre } & \multirow{2}{*}{$\mathbf{P}$} \\
\hline & $\mathbf{N}$ & Media & D.Típica & $\mathbf{N}$ & Media & D.Típica & \\
\hline $\begin{array}{l}\text { Ácd. Úrico } 24 \\
\text { meses (mg/dL) }\end{array}$ & 65 & $3,61^{\dagger}$ & 0,84 & 28 & $5,20^{\dagger}$ & 0,90 & $<0,001$ \\
\hline
\end{tabular}

Tabla 4.11.3.2. Descripción del ácido úrico (Ácd. Úrico) plasmáticos en las diferentes revisiones evaluadas según el sexo

Respecto de la edad no se observan diferencias estadísticamente entre los dos grupos en ninguna de las revisiones evaluadas, tabla 4.11.3.3, aunque el descenso a 24 meses respecto del valor prequirúrgico fue significativo.

\begin{tabular}{|c|c|c|c|c|c|c|c|}
\hline & \multicolumn{3}{|c|}{$<42$ años } & \multicolumn{3}{|c|}{$\geq 42$ años } & \multirow{2}{*}{$\mathbf{P}$} \\
\hline & $\mathbf{N}$ & Media & D.Típica & $\mathbf{N}$ & Media & D.Típica & \\
\hline $\begin{array}{l}\text { Ácd. Úrico } \\
\text { precirugía } \\
\text { (mg/dL) }\end{array}$ & 41 & 5,74 & 1,80 & 47 & 5,88 & 1,51 & NS \\
\hline $\begin{array}{c}\text { Ácd. Úrico } 3 \\
\text { meses (mg/dL) }\end{array}$ & 44 & $4,85^{\dagger \dagger}$ & 1,43 & 46 & $4,48^{\dagger}$ & 1,26 & NS \\
\hline $\begin{array}{c}\text { Ácd. Úrico } 6 \\
\text { meses(mg/dL) }\end{array}$ & 36 & $4,36^{\dagger \dagger}$ & 1,28 & 40 & $4,19^{\dagger}$ & 1,20 & NS \\
\hline $\begin{array}{c}\text { Ácd. Úrico } 9 \\
\text { meses (mg/dL) }\end{array}$ & 24 & $4,39^{\dagger \dagger}$ & 0,97 & 34 & $3,99^{\dagger}$ & 0,90 & NS \\
\hline $\begin{array}{l}\text { Ácd. Úrico } 12 \\
\text { meses (mg/dL) }\end{array}$ & 37 & $3,92^{\dagger \dagger}$ & 1,21 & 45 & $3,93^{\dagger}$ & 1,01 & NS \\
\hline $\begin{array}{l}\text { Ácd. Úrico } 18 \\
\text { meses (mg/dL) }\end{array}$ & 36 & $4,12^{\dagger \dagger}$ & 1,33 & 35 & $4,21^{\dagger}$ & 1,10 & NS \\
\hline $\begin{array}{l}\text { Ácd. Úrico } 24 \\
\text { meses (mg/dL) }\end{array}$ & 43 & $4,08^{\dagger \dagger}$ & 1,30 & 50 & $4,09^{\dagger}$ & 0,96 & NS \\
\hline
\end{tabular}

Tabla 4.11.3.3. Descripción del ácido úrico (Ácd. Úrico) plasmáticos en las diferentes revisiones evaluadas según el grupo de edad

\subsubsection{Urea}

En la tabla 4.11.3.4 se muestra la evolución de los valores medios de la urea plasmática. La disminución de los valores medios de urea entre la consulta precirugía y la revisión de los 24 meses fue significativa $(P<0,001)$, no así al comparar la revisión de los 3 meses con la de los 24 meses postquirúrgicos. 


\begin{tabular}{|c|c|c|c|c|c|c|c|}
\hline & $\begin{array}{c}\text { Urea } \\
\text { precirugía } \\
\text { (mg/dL) }\end{array}$ & $\begin{array}{c}\text { Urea } \\
3 \\
\text { meses } \\
\text { (mg/dL) }\end{array}$ & $\begin{array}{c}\text { Urea } \\
6 \\
\text { meses } \\
\text { (mg/dL) }\end{array}$ & $\begin{array}{c}\text { Urea } \\
9 \\
\text { meses } \\
\text { (mg/dL) }\end{array}$ & $\begin{array}{c}\text { Urea } \\
12 \\
\text { meses } \\
\text { (mg/dL) }\end{array}$ & $\begin{array}{c}\text { Urea } \\
18 \\
\text { meses } \\
\text { (mg/dL) }\end{array}$ & $\begin{array}{c}\text { Urea } \\
24 \\
\text { meses } \\
\text { (mg/dL) }\end{array}$ \\
\hline $\mathbf{N}$ & 80 & 76 & 62 & 49 & 62 & 58 & 76 \\
\hline Media & 33,65 & $25,65^{\dagger}$ & $27,22^{\dagger}$ & $27,35^{\dagger \dagger}$ & $29,33^{\dagger \dagger}$ & $31,01^{\dagger \dagger}$ & $27,48^{\dagger}$ \\
\hline D.Típica & 9,74 & 7,72 & 7,92 & 8,40 & 8,27 & 20,76 & 8,38 \\
\hline Mediana & 33 & 24 & 27 & 28 & 29 & 29,50 & 27 \\
\hline $\begin{array}{c}\text { Rango } \\
\text { intercuartílico } \\
\text { (P25-P75) }\end{array}$ & $26-39$ & $20-31$ & $21-31,50$ & $20-32,5$ & $24-34,25$ & $22,75-33$ & $22-32$ \\
\hline
\end{tabular}

Tabla 4.11.3.4. Descripción de urea plasmática en las diferentes revisiones evaluadas

Del mismo modo que el ácido úrico, los valores de urea posteriores a la cirugía disminuyen significativamente al correlacionarlo con el valor previo a la intervención quirúrgica.

Al mostrar la evolución de la urea respecto a los valores de referencia (10,7-49,2 mg/dL), se observa cómo el $5 \%$ de los pacientes en la consulta previa de la cirugía superaba ese valor máximo. Desde este momento ningún paciente de la muestra se encuentra por encima del valor máximo de referencia hasta los 18 y 24 meses en los que se describe a un solo paciente en cada control. Figura 4.11.3.2. 


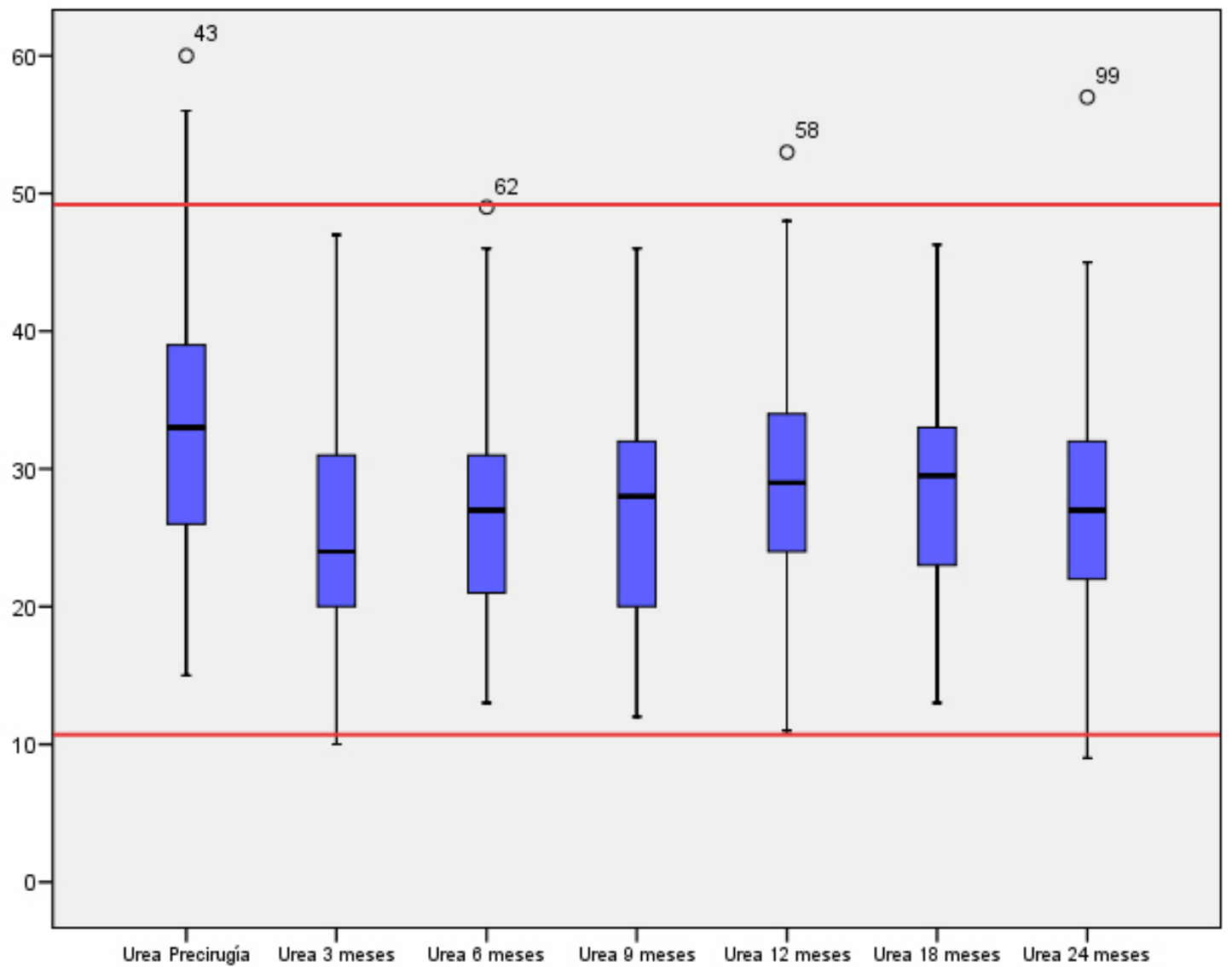

Figura 4.11.3.2. Diagrama de caja de la urea plasmática en los diferentes controles evaluados representando los valores de referencia en el eje de ordenadas

Por sexo, los valores medios de urea plasmática en todos los controles observados siempre fue mayor en los hombres, esta diferencia fue estadísticamente significativa entre ambos sexos a los 9 y 12 meses. Tabla 4.11.3.5.

\begin{tabular}{|c|c|c|c|c|c|c|c|}
\cline { 2 - 7 } \multicolumn{1}{c|}{} & \multicolumn{5}{c|}{ Mujer } & \multicolumn{3}{c|}{ Hombre } & \multirow{2}{*}{ P } \\
\cline { 2 - 7 } & $\mathbf{N}$ & Media & D.Típica & $\mathbf{N}$ & Media & D.Típica & \\
\hline $\begin{array}{c}\text { Urea precirugía } \\
\text { (mg/dL) }\end{array}$ & 58 & 32,62 & 9,11 & 22 & 36,36 & 11,02 & NS \\
\hline $\begin{array}{c}\text { Urea 3 meses } \\
\text { (mg/dL) }\end{array}$ & 55 & $24,82^{\dagger}$ & 6,64 & 21 & 27,84 & 9,86 & $\mathrm{NS}$ \\
\hline $\begin{array}{c}\text { Urea 6 meses } \\
\text { (mg/dL) }\end{array}$ & 43 & $27,19^{\dagger \dagger}$ & 8,06 & 19 & $27,27^{\dagger \dagger}$ & 7,81 & $\mathrm{NS}$ \\
\hline $\begin{array}{c}\text { Urea 9 meses } \\
\text { (mg/dL) }\end{array}$ & 30 & $25,39^{\dagger \dagger}$ & 8,07 & 19 & 30,43 & 8,18 & $<0,05$ \\
\hline $\begin{array}{c}\text { Urea 12 meses } \\
\text { (mg/dL) }\end{array}$ & 43 & $27,91^{\dagger \dagger}$ & 7,61 & 19 & 32,54 & 8,99 & $<0,05$ \\
\hline $\begin{array}{c}\text { Urea 18 meses } \\
\text { (mg/dL) }\end{array}$ & 39 & $27,78^{\dagger \dagger}$ & 6,90 & 19 & 37,65 & 34,56 & $\mathrm{NS}$ \\
\hline
\end{tabular}




\begin{tabular}{|c|c|c|c|c|c|c|c|}
\hline & \multicolumn{3}{|c|}{ Mujer } & \multicolumn{3}{|c|}{ Hombre } & \multirow{2}{*}{$\mathbf{P}$} \\
\hline & $\mathbf{N}$ & Media & D.Típica & $\mathbf{N}$ & Media & D.Típica & \\
\hline $\begin{array}{l}\text { Urea } 24 \text { meses } \\
\text { (mg/dL) }\end{array}$ & 50 & $26,70^{\dagger}$ & 7,76 & 26 & $29^{\dagger \dagger}$ & 9,42 & NS \\
\hline
\end{tabular}

Tabla 4.11.3.5. Descripción de la urea plasmática en las diferentes revisiones evaluadas según el sexo

Tanto en los hombres como en las mujeres no se observaron diferencias significativas en ninguno de las revisiones al compararlas con el control prequirúrgico.

En la tabla 4.11.3.6, se muestra la evolución de la urea por grupos de edad, siendo el valor medio de esta superior en todos los controles evaluados hasta los 18 meses en el grupo de $\geq 42$ años.

A los 24 meses de la cirugía se describe un aumento de la urea significativo en el grupo de mayor edad respecto a los $<42$ años $(P<0,001)$.

\begin{tabular}{|c|c|c|c|c|c|c|c|}
\hline & \multicolumn{3}{|c|}{$<42$ años } & \multicolumn{3}{|c|}{$\geq 42$ años } & \multirow{2}{*}{$\mathbf{P}$} \\
\hline & $\mathbf{N}$ & Media & D.Típica & $\mathbf{N}$ & Media & D.Típica & \\
\hline $\begin{array}{c}\text { Urea } \\
\text { precirugía } \\
\text { (mg/dL) }\end{array}$ & 36 & 31,50 & 7,43 & 44 & 35,41 & 11,06 & NS \\
\hline $\begin{array}{l}\text { Urea } 3 \text { meses } \\
\text { (mg/dL) }\end{array}$ & 40 & $22,99^{\dagger}$ & 6,09 & 36 & $28,61^{\dagger \dagger}$ & 8,32 & $<0,001$ \\
\hline $\begin{array}{l}\text { Urea } 6 \text { meses } \\
\text { (mg/dL) }\end{array}$ & 32 & $24,55^{\dagger \dagger}$ & 6,06 & 30 & $30,06^{\dagger \dagger}$ & 8,75 & $<0,05$ \\
\hline $\begin{array}{l}\text { Urea } 9 \text { meses } \\
(\mathrm{mg} / \mathrm{dL})\end{array}$ & 21 & $24,39^{\dagger \dagger}$ & 7,42 & 28 & 29,56 & 8,54 & $<0,05$ \\
\hline $\begin{array}{l}\text { Urea } 12 \text { meses } \\
\text { (mg/dL) }\end{array}$ & 28 & $27,52^{\dagger \dagger}$ & 6,32 & 34 & 30,81 & 9,41 & NS \\
\hline $\begin{array}{l}\text { Urea } 18 \text { meses } \\
\text { (mg/dL) }\end{array}$ & 32 & 31,34 & 27,35 & 26 & 30,61 & 7,35 & NS \\
\hline $\begin{array}{l}\text { Urea } 24 \text { meses } \\
\text { (mg/dL) }\end{array}$ & 40 & $24,35^{\dagger}$ & 6,91 & 36 & $30,97^{\dagger \dagger}$ & 8,57 & $<0,001$ \\
\hline
\end{tabular}

Tabla 4.11.3.6. Descripción de la urea plasmática en las diferentes revisiones evaluadas según el grupo de edad 


\subsubsection{Creatinina}

A continuación en la tabla 4.11.3.7 se detalla la evolución de la creatinina plasmática (Creat) en las diferentes revisiones, observando una disminución de los valores medios desde la primera consulta siendo esta reducción estadísticamente significativa entre la consulta previa a la cirugía y los 3 meses. Esa disminución de los valores de Creat se puede observar en el resto de controles al compararlos con el valor precirugía $(P<0,001)$.

\begin{tabular}{|c|c|c|c|c|c|c|c|}
\hline & $\begin{array}{c}\text { Creat } \\
\text { precirugía } \\
\text { (mg/dL) }\end{array}$ & $\begin{array}{l}\text { Creat } 3 \\
\text { meses } \\
(\mathrm{mg} / \mathrm{dL})\end{array}$ & $\begin{array}{c}\text { Creat } 6 \\
\text { meses } \\
(\mathrm{mg} / \mathrm{dL})\end{array}$ & $\begin{array}{l}\text { Creat } 9 \\
\text { meses } \\
(\mathrm{mg} / \mathrm{dL})\end{array}$ & $\begin{array}{c}\text { Creat } 12 \\
\text { meses } \\
(\mathrm{mg} / \mathrm{dL})\end{array}$ & $\begin{array}{c}\text { Creat } 18 \\
\text { meses } \\
(\mathrm{mg} / \mathrm{dL})\end{array}$ & $\begin{array}{c}\text { Creat } 24 \\
\text { meses } \\
(\mathrm{mg} / \mathrm{dL})\end{array}$ \\
\hline $\mathbf{N}$ & 89 & 90 & 78 & 57 & 81 & 73 & 95 \\
\hline Media & 0,79 & $0,67^{*^{\dagger}}$ & $0,68^{\dagger}$ & $0,70^{\dagger}$ & $0,66^{\dagger}$ & $0,68^{\dagger}$ & $0,65^{\dagger}$ \\
\hline D.Típica & 0,17 & 0,16 & 0,12 & 0,13 & 0,13 & 0,13 & 0,14 \\
\hline Mediana & 0,77 & 0,65 & 0,67 & 0,69 & 0,66 & 0,67 & 0,63 \\
\hline $\begin{array}{c}\text { Rango } \\
\text { intercuartílico } \\
\text { (P25-P75) }\end{array}$ & $0,68-0,90$ & $\begin{array}{c}0,56- \\
0,78\end{array}$ & $\begin{array}{c}0,59- \\
0,74\end{array}$ & $\begin{array}{c}0,61- \\
0,80\end{array}$ & $\begin{array}{c}0,57- \\
0,74\end{array}$ & $\begin{array}{c}0,58- \\
0,73\end{array}$ & $\begin{array}{c}0,56- \\
0,72\end{array}$ \\
\hline
\end{tabular}

Tabla 4.11.3.7. Descripción de la creatinina (Creat) plasmática en las diferentes revisiones evaluadas

El 2,24\% de los pacientes en la consulta inicial superaban los valores máximo de referencia (figura 4.11.3.3), el 1,1\% a los 3 meses. En el resto de controles ningún paciente superó el valor máximo de referencia. 


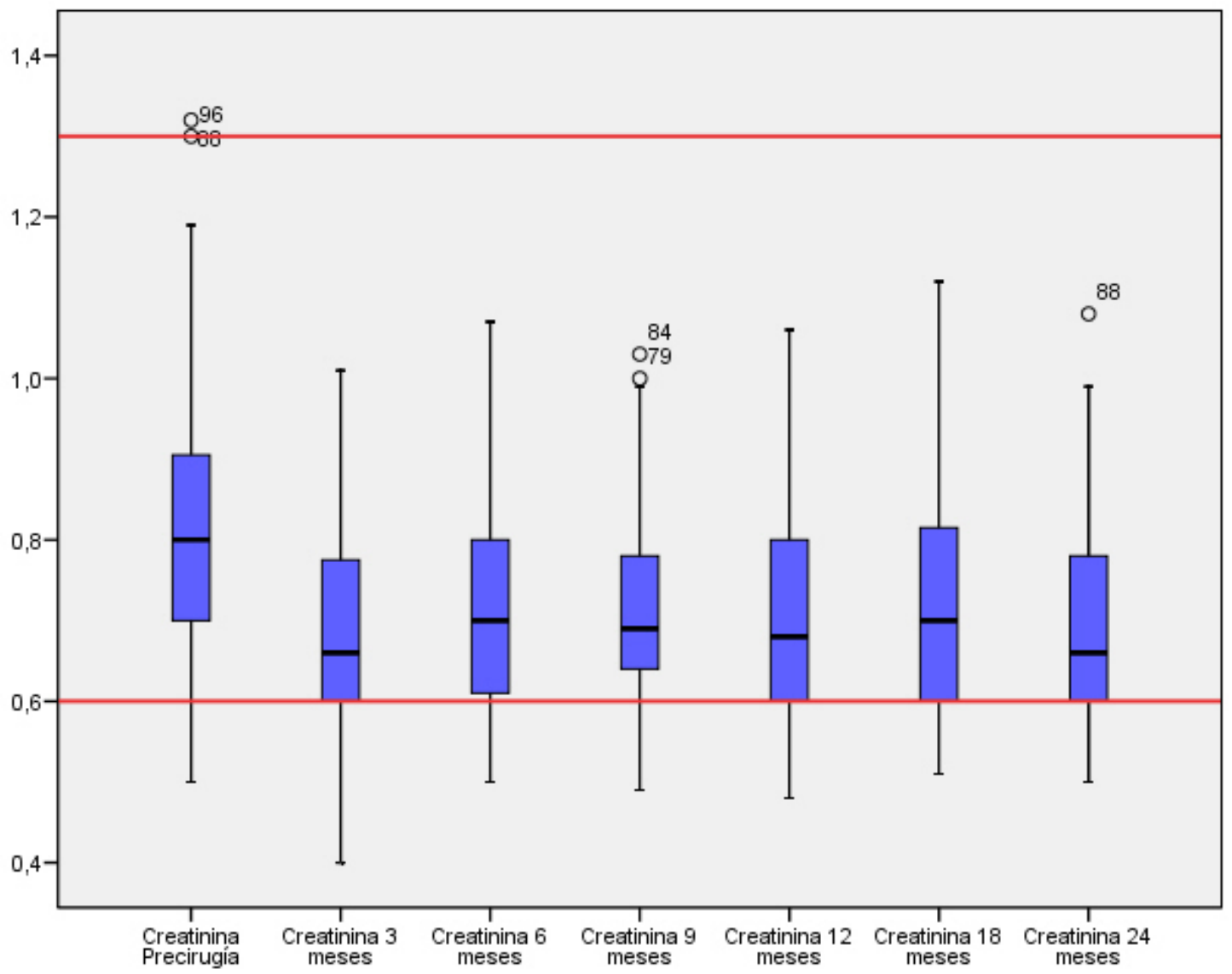

Figura 4.11.3.3. Diagrama de caja de la creatinina plasmática en los diferentes controles evaluados representando los valores de referencia en el eje de ordenadas

En relación al sexo, tabla 4.11.3.8, se observa como los hombres presentan valores significativamente más elevados que las mujeres en todos los controles sin llegar al valor máximo de referencia (1,3 mg/dL).

En los dos grupos se describe una disminución significativa de los valores de Creat entre la precirugía y cada uno de los controles estudiados $(\mathrm{P}<0,001)$.

\begin{tabular}{|c|c|c|c|c|c|c|c|}
\hline & \multicolumn{3}{|c|}{ Mujer } & \multicolumn{3}{|c|}{ Hombre } & \multirow{2}{*}{$\mathbf{P}$} \\
\hline & $\mathbf{N}$ & Media & D.Típica & $\mathbf{N}$ & Media & D.Típica & \\
\hline $\begin{array}{c}\text { Creat precirugía } \\
\text { (mg/dL) }\end{array}$ & 63 & 0,73 & 0,13 & 26 & 0,92 & 0,20 & $<0,001$ \\
\hline $\begin{array}{c}\text { Creat } 3 \text { meses } \\
\text { (mg/dL) }\end{array}$ & 64 & $0,63^{\dagger}$ & 0,12 & 26 & $0,79^{\dagger}$ & 0,18 & $<0,001$ \\
\hline $\begin{array}{l}\text { Creat } 6 \text { meses } \\
(\mathrm{mg} / \mathrm{dL})\end{array}$ & 54 & $0,63^{\dagger}$ & 0,09 & 24 & $0,78^{\dagger}$ & 0,14 & $<0,001$ \\
\hline $\begin{array}{l}\text { Creat } 9 \text { meses } \\
(\mathrm{mg} / \mathrm{dL})\end{array}$ & 35 & $0,64^{\dagger}$ & 0,10 & 22 & $0,81^{\dagger}$ & 0,11 & $<0,001$ \\
\hline
\end{tabular}




\begin{tabular}{|c|c|c|c|c|c|c|c|}
\hline & \multicolumn{3}{|c|}{ Mujer } & \multicolumn{3}{|c|}{ Hombre } & \multirow{2}{*}{$\mathbf{P}$} \\
\hline & $\mathbf{N}$ & Media & D.Típica & $\mathbf{N}$ & Media & D.Típica & \\
\hline $\begin{array}{l}\text { Creat } 12 \text { meses } \\
(\mathrm{mg} / \mathrm{dL})\end{array}$ & 58 & $0,61^{\dagger}$ & 0,09 & 23 & $0,81^{\dagger}$ & 0,12 & $<0,001$ \\
\hline $\begin{array}{l}\text { Creat } 18 \text { meses } \\
(\mathrm{mg} / \mathrm{dL})\end{array}$ & 51 & $0,62^{\dagger}$ & 0,08 & 22 & $0,82^{\dagger}$ & 0,13 & $<0,001$ \\
\hline $\begin{array}{c}\text { Creat } 24 \text { meses } \\
(\mathrm{mg} / \mathrm{dL})\end{array}$ & 67 & $0,59^{\dagger}$ & 0,08 & 28 & $0,80^{\dagger}$ & 0,14 & $<0,001$ \\
\hline
\end{tabular}

Tabla 4.11.3.8. Descripción de la creatinina (Creat) plasmática en las diferentes revisiones evaluadas según el sexo

Por el contrario en la tabla 4.11.3.9 se muestra como por grupos de edad no se evidencian diferencias significativas en los valores de Creat.

De igual modo que por sexo, la disminución de los valores de Creat entre el control postquirúrgico y los posteriores, disminuye de manera significativa en ambos grupos de edad $(P<0,001)$.

\begin{tabular}{|c|c|c|c|c|c|c|c|}
\hline & \multicolumn{3}{|c|}{$<42$ años } & \multicolumn{3}{|c|}{$\geq 42$ años } & \multirow{2}{*}{$\mathbf{P}$} \\
\hline & $\mathbf{N}$ & Media & D.Típica & $\mathbf{N}$ & Media & D.Típica & \\
\hline $\begin{array}{c}\text { Creat precirugía } \\
\text { (mg/dL) }\end{array}$ & 39 & 0,75 & 0,14 & 50 & 0,81 & 0,19 & NS \\
\hline $\begin{array}{l}\text { Creat } 3 \text { meses } \\
(\mathrm{mg} / \mathrm{dL})\end{array}$ & 44 & $0,67^{\dagger}$ & 0,18 & 46 & $0,67^{\dagger}$ & 0,13 & NS \\
\hline $\begin{array}{l}\text { Creat } 6 \text { meses } \\
(\mathrm{mg} / \mathrm{dL})\end{array}$ & 37 & $0,66^{\dagger}$ & 0,12 & 41 & $0,69^{\dagger}$ & 0,13 & NS \\
\hline $\begin{array}{l}\text { Creat } 9 \text { meses } \\
(\mathrm{mg} / \mathrm{dL})\end{array}$ & 23 & $0,72^{\dagger}$ & 0,14 & 34 & $0,69^{\dagger}$ & 0,12 & NS \\
\hline $\begin{array}{l}\text { Creat } 12 \text { meses } \\
\text { (mg/dL) }\end{array}$ & 37 & $0,66^{\dagger}$ & 0,13 & 44 & $0,67^{\dagger}$ & 0,13 & NS \\
\hline $\begin{array}{l}\text { Creat } 18 \text { meses } \\
\text { (mg/dL) }\end{array}$ & 36 & $0,69^{\dagger}$ & 0,13 & 37 & $0,67^{\dagger}$ & 0,13 & NS \\
\hline $\begin{array}{l}\text { Creat } 24 \text { meses } \\
\text { (mg/dL) }\end{array}$ & 47 & $0,65^{\dagger}$ & 0,16 & 48 & $0,65^{\dagger}$ & 0,12 & NS \\
\hline
\end{tabular}

Tabla 4.11.3.9. Descripción de la creatinina (Creat) plasmática en las diferentes revisiones evaluadas según el grupo de edad

En la figura 4.11.3.4, se representa el conjunto de los valores estudiados en el perfil renal, marcando en el eje de ordenadas los valores límite y describiendo los valores medios por sexo y grupo de edad en cada una de las revisiones. 
El ácido úrico se mantiene más elevado en los hombres en todos los controles respecto de las mujeres, observando en la consulta prequirúrgica valores de ácido úrico superiores al límite máximo de referencia en el grupo de hombres $<42$ años.

La urea siempre presenta valores más elevados en el grupo de los $\geq 42$ años independientemente del sexo, excepto a los 18 meses dónde se registran valores más elevados en los varones más jóvenes, sin superar el valor máximo de referencia.

En cuanto a la creatinina, se muestra una tendencia homogénea de los valores medios en los hombres y mujeres indistintamente del grupo de edad. 


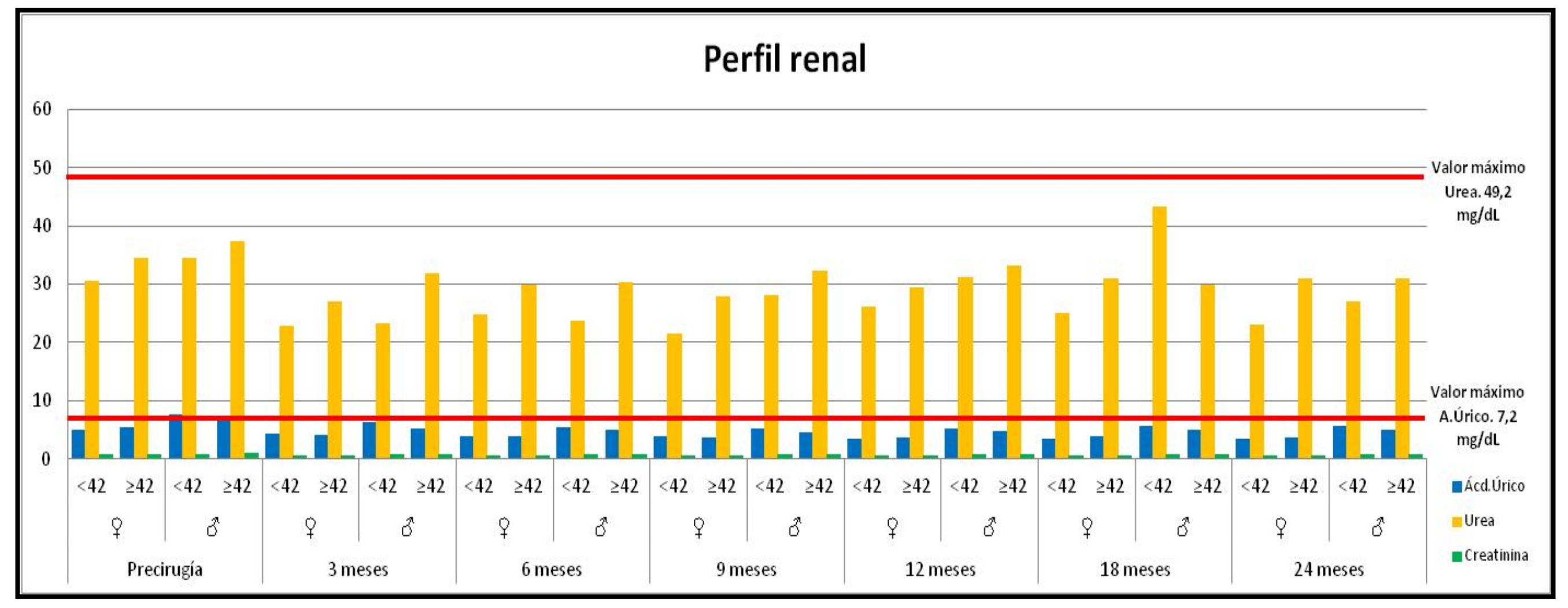

Figura 4.11.3.4. Gráfico de barras del perfil renal plasmático en los diferentes controles evaluados según el sexo y el grupo de edad correspondiente en cada uno de ellos 


\subsubsection{Perfil hepático}

A continuación se describe la evolución de las enzimas hepáticas principales desde la primera consulta hasta los 24 meses después de la cirugía.

\subsubsection{Transaminasa glutámico oxalacética (GOT)}

En la tabla 4.11.4.1 se muestra la evolución de GOT desde la primera consulta y en los posteriores controles trimestrales postquirúrgicos observando una tendencia ascendente de los valores medios hasta los 9 meses de la cirugía, desde el cual disminuye significativamente en el control de los 24 meses.

El valor medio de GOT desde la primera consulta respecto a los 2 años después de la cirugía aumenta significativamente sin llegar en ningún caso al valor límite máximo: $50 \mathrm{U} / \mathrm{L}$.

\begin{tabular}{|c|c|c|c|c|c|c|c|}
\hline & $\begin{array}{c}\text { GOT } \\
\text { precirugía } \\
\text { (U/L) }\end{array}$ & $\begin{array}{c}\text { GOT } \\
3 \\
\text { meses } \\
(\mathrm{U} / \mathrm{L})\end{array}$ & $\begin{array}{c}\text { GOT } \\
6 \\
\text { meses } \\
(\mathrm{U} / \mathrm{L})\end{array}$ & $\begin{array}{c}\text { GOT } \\
9 \\
\text { meses } \\
(\mathrm{U} / \mathrm{L})\end{array}$ & $\begin{array}{c}\text { GOT } \\
12 \\
\text { meses } \\
(\mathrm{U} / \mathrm{L})\end{array}$ & $\begin{array}{c}\text { GOT } \\
18 \\
\text { meses } \\
\text { (U/L) }\end{array}$ & $\begin{array}{c}\text { GOT } \\
24 \\
\text { meses } \\
(U / L)\end{array}$ \\
\hline $\mathbf{N}$ & 88 & 87 & 77 & 58 & 80 & 74 & 94 \\
\hline Media & 25,35 & 30,43 & $32,89^{\dagger \dagger}$ & $34,38^{\star^{\dagger \dagger}}$ & $33,28^{\dagger \dagger}$ & $32,27^{\dagger}$ & $31,27^{\star{ }^{\dagger \dagger}}$ \\
\hline D.Típica & 9,60 & 20,05 & 21,84 & 19,48 & 21,72 & 16,95 & 16,06 \\
\hline Mediana & 23 & 25 & 27 & 28 & 26 & 27,50 & 27,50 \\
\hline $\begin{array}{c}\text { Rango } \\
\text { intercuartílico } \\
\text { (P25-P75) }\end{array}$ & $19-29$ & $20-32$ & $21-36,50$ & $21-41,25$ & $\begin{array}{c}20,25- \\
36,75\end{array}$ & $20-37,25$ & $21-37$ \\
\hline
\end{tabular}

Tabla 4.11.4.1. Descripción de la transaminasa glutámico oxalacética (GOT) en las diferentes revisiones evaluadas

De manera gráfica se muestra ese punto de inflexión desde los 9 meses, figura 4.11.4.1, en la primera consulta el 4,54\% de los pacientes superaba el valor máximo de referencia. Aumentando este porcentaje en el primer trimestre a 11,49\%, disminuyendo a los 6 meses (9,09\%). En el siguiente control vuelve a aumentar siendo superior que en la primera consulta $(15,51 \%)$. Desde este momento el porcentaje de pacientes que superaba el valor máximo de referencia desciende, siendo en los trimestres posteriores del: $12,5 \%, 10,81 \%$ y $10,63 \%$ respectivamente. 


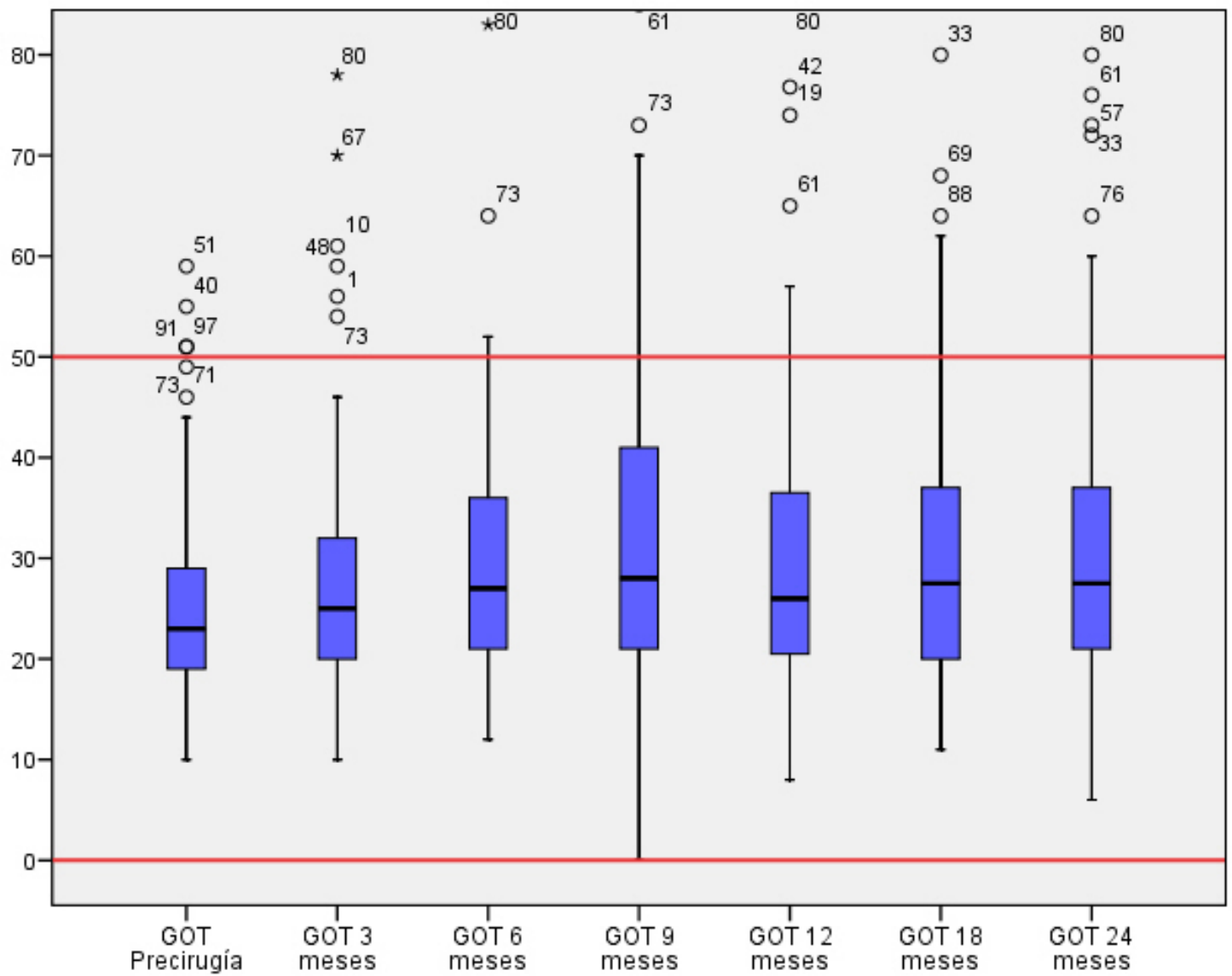

Figura 4.11.4.1. Diagrama de caja de la transaminasa glutámico oxalacética (GOT) plasmática en los diferentes controles evaluados representando los valores de referencia en el eje de ordenadas

Por sexo no se observan diferencias estadísticamente significativas entre los valores medios de GOT a excepción de la consulta prequirúrgica, dónde los hombres presentan valores medios más elevados $(P<0,05)$.

En el grupo de las mujeres desde el control de los 6 meses se describe un cambio significativo en el valor de GOT al compararlo con la precirugía $(P<0,001)$, a diferencia del grupo de los varones.

\begin{tabular}{|c|c|c|c|c|c|c|c|}
\hline & \multicolumn{3}{|c|}{ Mujer } & \multicolumn{3}{|c|}{ Hombre } & \multirow{2}{*}{$\mathbf{P}$} \\
\hline & $\mathbf{N}$ & Media & D.Típica & $\mathbf{N}$ & Media & D.Típica & \\
\hline $\begin{array}{c}\text { GOT precirugía } \\
\text { (U/L) }\end{array}$ & 63 & 23,59 & 9,09 & 25 & 29,77 & 9,62 & $<0,05$ \\
\hline $\begin{array}{c}\text { GOT } 3 \text { meses } \\
\text { (U/L) }\end{array}$ & 61 & 31,13 & 22,25 & 26 & 28,81 & 13,84 & NS \\
\hline $\begin{array}{c}\text { GOT } 6 \text { meses } \\
\text { (U/L) }\end{array}$ & 53 & $30,29^{\dagger}$ & 18,58 & 24 & 38,65 & 27,29 & NS \\
\hline $\begin{array}{c}\text { GOT } 9 \text { meses } \\
\text { (U/L) }\end{array}$ & 36 & $33,89^{\dagger}$ & 18,30 & 22 & 35,19 & 21,69 & NS \\
\hline
\end{tabular}




\begin{tabular}{|c|c|c|c|c|c|c|c|}
\hline & \multicolumn{3}{|c|}{ Mujer } & \multicolumn{3}{|c|}{ Hombre } & \multirow{2}{*}{$\mathbf{P}$} \\
\hline & $\mathbf{N}$ & Media & D.Típica & $\mathbf{N}$ & Media & D.Típica & \\
\hline $\begin{array}{c}\text { GOT } 12 \text { meses } \\
\text { (U/L) }\end{array}$ & 57 & $33,51^{\dagger}$ & 21,89 & 23 & 32,72 & 21,77 & NS \\
\hline $\begin{array}{c}\text { GOT } 18 \text { meses } \\
\text { (U/L) }\end{array}$ & 52 & $31,75^{\dagger}$ & 16,31 & 22 & 33,52 & 18,70 & NS \\
\hline $\begin{array}{c}\text { GOT } 24 \text { meses } \\
\text { (U/L) }\end{array}$ & 65 & $31,41^{\dagger}$ & 16,81 & 29 & 30,95 & 14,49 & NS \\
\hline
\end{tabular}

Tabla 4.11.4.2. Descripción de la transaminasa glutámico oxalacética (GOT) plasmática en las diferentes revisiones evaluadas según el sexo

Respecto a la mediana de edad de la muestra de estudio, tabla 4.11.4.3, en ninguno de los controles se aprecian variaciones significativas de GOT. Los valores en el último control aumentaron significativamente sólo en el grupo de los $<42$ años.

\begin{tabular}{|c|c|c|c|c|c|c|c|}
\hline & \multicolumn{3}{|c|}{$<42$ años } & \multicolumn{3}{|c|}{$\geq 42$ años } & \multirow{2}{*}{$\mathbf{P}$} \\
\hline & $\mathbf{N}$ & Media & D.Típica & $\mathbf{N}$ & Media & D.Típica & \\
\hline $\begin{array}{l}\text { GOT precirugía } \\
\text { (U/L) }\end{array}$ & 42 & 23,37 & 7,68 & 46 & 27,15 & 10,85 & NS \\
\hline $\begin{array}{c}\text { GOT } 3 \text { meses } \\
\text { (U/L) }\end{array}$ & 44 & $29,97^{\dagger \dagger}$ & 16,36 & 43 & 30,91 & 23,43 & NS \\
\hline $\begin{array}{c}\text { GOT } 6 \text { meses } \\
\text { (U/L) }\end{array}$ & 38 & $34,54^{\dagger \dagger}$ & 20,67 & 39 & 31,29 & 23,08 & NS \\
\hline $\begin{array}{c}\text { GOT } 9 \text { meses } \\
\text { (U/L) }\end{array}$ & 26 & $34,85^{\dagger \dagger}$ & 22,57 & 32 & 34 & 16,92 & NS \\
\hline $\begin{array}{c}\text { GOT } 12 \text { meses } \\
\text { (U/L) }\end{array}$ & 36 & $33,61^{\dagger \dagger}$ & 24,08 & 44 & 33,01 & 19,86 & NS \\
\hline $\begin{array}{c}\text { GOT } 18 \text { meses } \\
\text { (U/L) }\end{array}$ & 37 & $31,59^{\dagger \dagger}$ & 19,82 & 37 & 32,96 & 13,73 & NS \\
\hline $\begin{array}{c}\text { GOT } 24 \text { meses } \\
\text { (U/L) }\end{array}$ & 45 & $31,70^{\dagger \dagger}$ & 18,41 & 49 & 30,87 & 13,72 & NS \\
\hline
\end{tabular}

Tabla 4.11.4.3. Descripción de la transaminasa glutámico oxalacética (GOT) plasmática en las diferentes revisiones evaluadas según el grupo de edad

\subsubsection{Transaminasa glutámico-pirúvica (GPT)}

En la tabla 4.11.4.4 se detalla la evolución de GPT, observando fluctuaciones no significativas de los valores medios. La GPT a los 24 meses apenas sufre variación respecto al valor precirugía, commparando cada uno de los valores obtenidos en cada control respecto al prequirúrgico en ninguno se observan diferencias estadísticamente significativas. El 50\% de la muestra en todos los controles presenta valores entre 28-30 U/L 


\begin{tabular}{|c|c|c|c|c|c|c|c|}
\hline & $\begin{array}{c}\text { GPT } \\
\text { precirugía } \\
\text { (U/L) }\end{array}$ & $\begin{array}{c}\text { GPT } \\
3 \\
\text { meses } \\
\text { (U/L) }\end{array}$ & $\begin{array}{c}\text { GPT } \\
6 \\
\text { meses } \\
(U / L)\end{array}$ & $\begin{array}{c}\text { GPT } \\
9 \\
\text { meses } \\
(\mathrm{U} / \mathrm{L})\end{array}$ & $\begin{array}{c}\text { GPT } \\
12 \\
\text { meses } \\
(\mathrm{U} / \mathrm{L})\end{array}$ & $\begin{array}{c}\text { GPT } \\
18 \\
\text { meses } \\
(U / L)\end{array}$ & $\begin{array}{c}\text { GPT } \\
24 \\
\text { meses } \\
\text { (U/L) }\end{array}$ \\
\hline $\mathbf{N}$ & 92 & 88 & 79 & 59 & 84 & 75 & 98 \\
\hline Media & 34,94 & 36,41 & 40,02 & 41,75 & 39,73 & 36,47 & $35,10^{*}$ \\
\hline D.Típica & 20,13 & 26,15 & 29,60 & 30,21 & 26,06 & 19,59 & 21,02 \\
\hline Mediana & 28 & 29 & 29 & 30 & 31,50 & 31 & 30 \\
\hline $\begin{array}{c}\text { Rango } \\
\text { intercuartílico } \\
\text { (P25-P75) }\end{array}$ & $21-41$ & $20,25-42$ & $22-45$ & $22-53$ & $23-46$ & $22-49$ & $20,75-44$ \\
\hline
\end{tabular}

Tabla 4.11.4.4. Descripción de la transaminasa glutámico-pirúvica (GPT) en las diferentes revisiones evaluadas

La evolución de GPT representada con los valores de referencia (figura 4.11.4.2) muestra cómo en la primera consulta el 17,39\% superaba ese límite. El 19,31\% a los 3 meses, 22,78\% a los 6 meses. Ese porcentaje de pacientes que superaban el límite máximo asciende al 25,42\% en los 9 meses, siendo este el punto dónde más pacientes se observa que superaban el valor límite máximo. Al año de la cirugía desciende al 20,23\%, aumentando ligeramente a los 18 meses $(22,66 \%)$ y volviendo a descender a los 24 meses observando al $18,36 \%$ de los pacientes. 


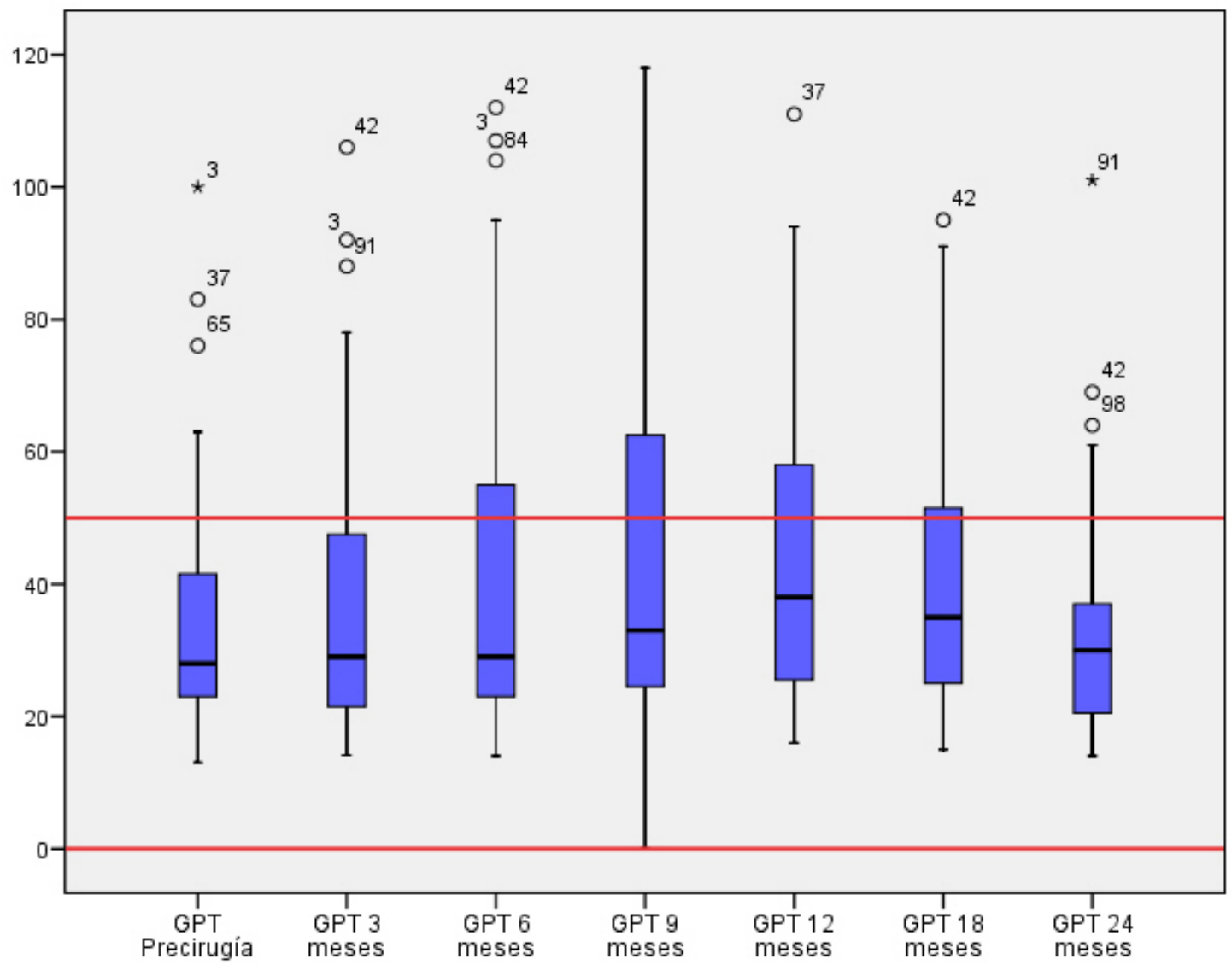

Figura 4.11.4.2. Diagrama de caja de la transaminasa glutámico-pirúvica (GPT) plasmática en los diferentes controles evaluados representando los valores de referencia en el eje de ordenadas

Desde la analítica precirugía hasta los 6 meses los valores medios de GPT son superiores en los hombres, tabla 4.11.4.5, siendo esta diferencia estadísticamente significativa en el control inicial y a los 6 meses. En el resto de las revisiones se muestran variaciones de los valores medios de GPT con ligeras fluctuaciones que no suponen diferencias significativas por ser hombre o mujer.

\begin{tabular}{|c|c|c|c|c|c|c|c|}
\hline & \multicolumn{3}{|c|}{ Mujer } & \multicolumn{3}{|c|}{ Hombre } & \multirow{2}{*}{$\mathbf{P}$} \\
\hline & $\mathbf{N}$ & Media & D.Típica & $\mathbf{N}$ & Media & D.Típica & \\
\hline $\begin{array}{c}\text { GPT precirugía } \\
\text { (U/L) }\end{array}$ & 66 & 29,38 & 15,11 & 26 & 49,06 & 24,35 & $<0,001$ \\
\hline $\begin{array}{c}\text { GPT } 3 \text { meses } \\
\text { (U/L) }\end{array}$ & 63 & 35,50 & 27,01 & 25 & $38,69^{\dagger \dagger}$ & 24,21 & NS \\
\hline $\begin{array}{c}\text { GPT } 6 \text { meses } \\
\text { (U/L) }\end{array}$ & 55 & 35,43 & 25,98 & 24 & 50,54 & 34,94 & $<0,05$ \\
\hline $\begin{array}{c}\text { GPT } 9 \text { meses } \\
\text { (U/L) }\end{array}$ & 37 & $41,92^{\dagger}$ & 31,38 & 22 & 41,46 & 28,84 & NS \\
\hline $\begin{array}{c}\text { GPT } 12 \text { meses } \\
\text { (U/L) }\end{array}$ & 61 & $41,02^{\dagger}$ & 26,46 & 23 & $36,30^{\dagger \dagger}$ & 25,20 & NS \\
\hline
\end{tabular}




\begin{tabular}{|c|c|c|c|c|c|c|c|}
\hline & \multicolumn{3}{|c|}{ Mujer } & \multicolumn{3}{|c|}{ Hombre } & \multirow{2}{*}{$\mathbf{P}$} \\
\hline & $\mathbf{N}$ & Media & D.Típica & $\mathbf{N}$ & Media & D.Típica & \\
\hline $\begin{array}{c}\text { GPT } 18 \text { meses } \\
\text { (U/L) }\end{array}$ & 53 & $35,37^{\dagger \dagger}$ & 19,75 & 22 & 39,12 & 19,38 & NS \\
\hline $\begin{array}{c}\text { GPT } 24 \text { meses } \\
\text { (U/L) }\end{array}$ & 69 & $35,56^{\dagger \dagger}$ & 23,03 & 29 & $34,01^{\dagger \dagger}$ & 15,54 & NS \\
\hline
\end{tabular}

Tabla 4.11.4.5. Descripción de la transaminasa glutámico-pirúvica (GPT) plasmática en las diferentes revisiones evaluadas según el sexo

En cuanto a los grupos de edad, en la tabla 4.11.4.6 se muestra como en ninguno de los controles se describen variaciones significativas entre los $<42$ años y los $\geq 42$ años.

En ninguno de los controles postquirúrgicos observados por grupos de edad se muestran cambios significativos al compararlos con el valor prequirúrgico.

\begin{tabular}{|c|c|c|c|c|c|c|c|}
\hline & \multicolumn{3}{|c|}{$<42$ años } & \multicolumn{3}{|c|}{$\geq 42$ años } & \multirow{2}{*}{$\mathbf{P}$} \\
\hline & $\mathbf{N}$ & Media & D.Típica & $\mathbf{N}$ & Media & D.Típica & \\
\hline $\begin{array}{c}\text { GPT precirugía } \\
\text { (U/L) }\end{array}$ & 44 & 34,82 & 20,99 & 48 & 35,06 & 19,54 & NS \\
\hline $\begin{array}{c}\text { GPT } 3 \text { meses } \\
(\mathrm{U} / \mathrm{L})\end{array}$ & 43 & 39,34 & 24,67 & 45 & 33,60 & 27,47 & NS \\
\hline $\begin{array}{c}\text { GPT } 6 \text { meses } \\
\text { (U/L) }\end{array}$ & 39 & 44,09 & 28,55 & 40 & 36,06 & 30,43 & NS \\
\hline $\begin{array}{c}\text { GPT } 9 \text { meses } \\
\text { (U/L) }\end{array}$ & 26 & 44,20 & 32,53 & 33 & 39,82 & 28,61 & NS \\
\hline $\begin{array}{c}\text { GPT } 12 \text { meses } \\
\text { (U/L) }\end{array}$ & 39 & 41,78 & 29,33 & 45 & 37,96 & 23,05 & NS \\
\hline $\begin{array}{c}\text { GPT } 18 \text { meses } \\
\text { (U/L) }\end{array}$ & 37 & 37,55 & 22,66 & 38 & 35,42 & 16,29 & NS \\
\hline $\begin{array}{c}\text { GPT } 24 \text { meses } \\
\text { (U/L) }\end{array}$ & 47 & 34,67 & 21,24 & 51 & 35,50 & 21,03 & NS \\
\hline
\end{tabular}

Tabla 4.11.4.6. Descripción de la transaminasa glutámico-pirúvica (GPT) plasmática en las diferentes revisiones evaluadas según el grupo de edad

\subsubsection{Transaminasa gamma glutamil transpeptidasa (GGT)}

En la tabla 4.11.4.7 se muestra la evolución de GGT, observando una tendencia descendente desde el control inicial hasta los 24 meses. Aún así las variaciones entre controles son mínimas, siendo a los 24 meses el valor medio más bajo de GGT. Al comparar el valor medio precirugía con la revisión de los 24 meses, el descenso es significativo $(P<0,001)$. Del mismo 
modo ocurre al comparar los valores de GGT del resto de los controles postquirúrgicos con el resultado prequirúrgico, observando una reducción significativa $(P<0,001)$ en cada uno de ellos de GGT.

\begin{tabular}{|c|c|c|c|c|c|c|c|}
\hline & $\begin{array}{c}\text { GGT } \\
\text { precirugía } \\
\text { (U/L) }\end{array}$ & $\begin{array}{c}\text { GGT } \\
3 \\
\text { meses } \\
(U / L)\end{array}$ & $\begin{array}{c}\text { GGT } \\
6 \\
\text { meses } \\
(U / L)\end{array}$ & $\begin{array}{c}\text { GGT } \\
9 \\
\text { meses } \\
(U / L)\end{array}$ & $\begin{array}{c}\text { GGT } \\
12 \\
\text { meses } \\
(U / L)\end{array}$ & $\begin{array}{c}\text { GGT } \\
18 \\
\text { meses } \\
(U / L)\end{array}$ & $\begin{array}{c}\text { GGT } \\
24 \\
\text { meses } \\
(\mathrm{U} / \mathrm{L})\end{array}$ \\
\hline $\mathbf{N}$ & 88 & 87 & 77 & 58 & 84 & 73 & 95 \\
\hline Media & 29,60 & $27,84^{\dagger}$ & $25,23^{\dagger}$ & $25,87^{\dagger}$ & $25,44^{\dagger}$ & $23,81^{\dagger}$ & $22,46^{*^{\dagger}}$ \\
\hline D.Típica & 19,01 & 69,41 & 26,29 & 26,65 & 28,51 & 23,15 & 22,05 \\
\hline Mediana & 23,50 & 15 & 16 & 18,50 & 16 & 15 & 14 \\
\hline $\begin{array}{c}\text { Rango } \\
\text { intercuartílico } \\
\text { (P25-P75) }\end{array}$ & $16-37$ & $10-26$ & $11-27,50$ & $12-27,08$ & $11-27$ & $11-28,50$ & $10-26$ \\
\hline
\end{tabular}

Tabla 4.11.4.7. Descripción de la transaminasa gamma glutamil transpeptidasa (GGT) en las diferentes revisiones evaluadas

Al describir la evolución de GGT en relación a los valores de referencia se observa en la primera consulta un $9,09 \%$ de pacientes que superaban el límite máximo, a los 3 meses el 6,89\%, volviendo a registrarse a los 6 meses el 9,09\% de los pacientes. Desde este momento el porcentaje de pacientes que superaba el valor límite máximo desciende progresivamente hasta registrase un 6,31\% de los pacientes en la revisión de los 24 meses. 


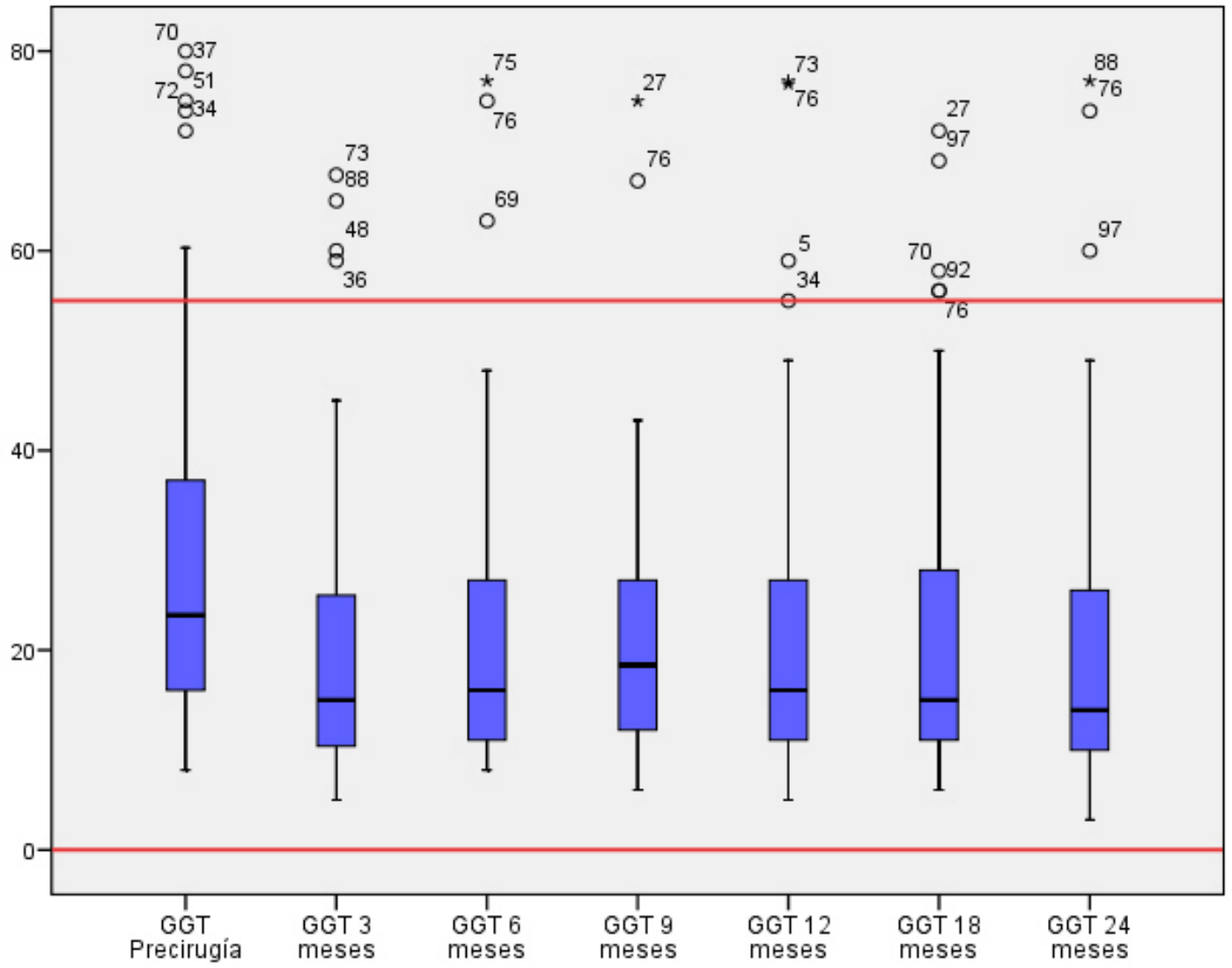

Figura 4.11.4.3. Diagrama de caja de la transaminasa gamma glutamil transpeptidasa (GGT) plasmática en los diferentes controles evaluados representando los valores de referencia en el eje de ordenadas

Respecto al sexo se aprecia un valor medio de GGT superior en los hombres respecto a las mujeres en todos los controles a excepción del control de los 3 meses en el que la diferencia entre valores medios es de $1,52 \mathrm{U} / \mathrm{L}$, mayor en las mujeres.

\begin{tabular}{|c|c|c|c|c|c|c|c|}
\hline & \multicolumn{3}{|c|}{ Mujer } & \multicolumn{3}{|c|}{ Hombre } & \multirow{2}{*}{$\mathbf{P}$} \\
\hline & $\mathbf{N}$ & Media & D.Típica & $\mathbf{N}$ & Media & D.Típica & \\
\hline $\begin{array}{c}\text { GGT precirugía } \\
\text { (U/L) }\end{array}$ & 62 & 26,77 & 20,09 & 26 & 36,34 & 14,36 & $<0,05$ \\
\hline $\begin{array}{c}\text { GGT } 3 \text { meses } \\
\text { (U/L) }\end{array}$ & 62 & $28,28^{\dagger}$ & 81,84 & 25 & $26,76^{\dagger \dagger}$ & 15,58 & NS \\
\hline $\begin{array}{c}\text { GGT } 6 \text { meses } \\
\text { (U/L) }\end{array}$ & 53 & $18,70^{\dagger}$ & 15,90 & 24 & 39,64 & 37,39 & $<0,001$ \\
\hline $\begin{array}{c}\text { GGT } 9 \text { meses } \\
\text { (U/L) }\end{array}$ & 36 & $18,83^{\dagger \dagger}$ & 12,97 & 22 & 37,38 & 37,72 & $<0,05$ \\
\hline $\begin{array}{c}\text { GGT } 12 \text { meses } \\
\text { (U/L) }\end{array}$ & 61 & $20,54^{\dagger}$ & 21,90 & 23 & 38,42 & 38,92 & $<0,05$ \\
\hline $\begin{array}{c}\text { GGT } 18 \text { meses } \\
\text { (U/L) }\end{array}$ & 52 & $17,55^{\dagger}$ & 13,11 & 21 & 39,30 & 33,72 & $<0,001$ \\
\hline
\end{tabular}




\begin{tabular}{|c|c|c|c|c|c|c|c|}
\hline & \multicolumn{3}{|c|}{ Mujer } & \multicolumn{3}{|c|}{ Hombre } & \multirow{2}{*}{$\mathbf{P}$} \\
\hline & $\mathbf{N}$ & Media & D.Típica & $\mathbf{N}$ & Media & D.Típica & \\
\hline $\begin{array}{c}\text { GGT } 24 \text { meses } \\
(\mathrm{U} / \mathrm{L})\end{array}$ & 67 & $18,13^{\dagger}$ & 18,40 & 28 & $32,82^{\dagger \dagger}$ & 26,51 & $<0,05$ \\
\hline
\end{tabular}

Tabla 4.11.4.8. Descripción de la transaminasa gamma glutamil transpeptidasa (GGT) plasmática en las diferentes revisiones evaluadas según el sexo

En relación a la mediana de edad los valores medios de GGT son más elevados en el grupo de mayor edad siendo esta diferencia estadísticamente significativa a los 18 y 24 meses postquirúrgicos $(P<0,05)$. Al igual que las mujeres a los 2 años de la cirugía reduciendo más la GGT (11,58 U/L) a diferencia de los hombres en los que la disminución sobre el valor medio es de $3,38 \mathrm{U} / \mathrm{L}$.

\begin{tabular}{|c|c|c|c|c|c|c|c|}
\hline & \multicolumn{3}{|c|}{$<42$ años } & \multicolumn{3}{|c|}{$\geq 42$ años } & \multirow{2}{*}{$\mathbf{P}$} \\
\hline & $\mathbf{N}$ & Media & D.Típica & $\mathbf{N}$ & Media & D.Típica & \\
\hline $\begin{array}{c}\text { GGT precirugía } \\
\text { (U/L) }\end{array}$ & 42 & 28,08 & 20,58 & 46 & 30,98 & 17,57 & NS \\
\hline $\begin{array}{c}\text { GGT } 3 \text { meses } \\
\text { (U/L) }\end{array}$ & 42 & $18,63^{\dagger}$ & 12,23 & 45 & $36,44^{\dagger \dagger}$ & 95,51 & NS \\
\hline $\begin{array}{c}\text { GGT } 6 \text { meses } \\
\text { (U/L) }\end{array}$ & 38 & $24,19^{\dagger \dagger}$ & 23,61 & 39 & $26,24^{\dagger \dagger}$ & 28,94 & NS \\
\hline $\begin{array}{c}\text { GGT } 9 \text { meses } \\
(U / L)\end{array}$ & 25 & 26,48 & 28,13 & 33 & $25,40^{\dagger \dagger}$ & 25,90 & NS \\
\hline $\begin{array}{c}\text { GGT } 12 \text { meses } \\
\text { (U/L) }\end{array}$ & 39 & $22,62^{\dagger \dagger}$ & 20,58 & 45 & $27,88^{\dagger \dagger}$ & 33,98 & NS \\
\hline $\begin{array}{c}\text { GGT } 18 \text { meses } \\
(\mathrm{U} / \mathrm{L})\end{array}$ & 36 & $18,25^{\dagger}$ & 13,96 & 37 & 29,21 & 28,66 & $<0,05$ \\
\hline $\begin{array}{c}\text { GGT } 24 \text { meses } \\
\text { (U/L) }\end{array}$ & 44 & $16,50^{\dagger}$ & 12,03 & 51 & $27,60^{\dagger \dagger}$ & 27 & $<0,05$ \\
\hline
\end{tabular}

Tabla 4.11.4.9. Descripción de la transaminasa gamma glutamil transpeptidasa (GGT) plasmática en las diferentes revisiones evaluadas según el grupo de edad

\subsubsection{Fosfatasa Alcalina (FA)}

En la tabla 4.11.4.10 se muestra la evolución de FA en las diferentes revisiones evaluadas. La tendencia de los valores medios de FA aumenta hasta los 9 meses, desde aquí desciende en los otros 2 controles trimestrales repuntando a los 24 meses $(118,41 \mathrm{U} / \mathrm{L})$. Al comparar la determinación de FA entre la revisión precirugía y los 2 años posteriores, el 
aumento de FA es significativo $(\mathrm{P}<0,001)$, del mismo modo si correlacionamos los valores de FA entre los 3 meses y los 24 meses postquirúrgicos $(\mathrm{P}<0,001)$. En ningún caso los valores medios de $F A$ superaron los valores de referencia máximos (120 U/L). Tan sólo a los 9 meses postquirúrgicos se superó el valor máximo de referencia en 1,29 U/L.

\begin{tabular}{|c|c|c|c|c|c|c|c|}
\hline & $\begin{array}{c}\text { FA } \\
\text { precirugía } \\
\text { (U/L) }\end{array}$ & $\begin{array}{c}\text { FA } \\
3 \\
\text { meses } \\
(U / L)\end{array}$ & $\begin{array}{c}\text { FA } \\
6 \\
\text { meses } \\
(U / L)\end{array}$ & $\begin{array}{c}\text { FA } \\
9 \\
\text { meses } \\
(U / L)\end{array}$ & $\begin{array}{c}\text { FA } \\
12 \\
\text { meses } \\
(\mathrm{U} / \mathrm{L})\end{array}$ & $\begin{array}{c}\text { FA } \\
18 \\
\text { meses } \\
(U / L)\end{array}$ & $\begin{array}{c}\text { FA } \\
24 \\
\text { meses } \\
(\mathrm{U} / \mathrm{L})\end{array}$ \\
\hline $\mathbf{N}$ & 76 & 79 & 70 & 50 & 67 & 64 & 85 \\
\hline Media & 92,44 & $99,35^{\top \top}$ & $104,90^{\dagger}$ & $121,29^{\dagger}$ & $119,22^{*^{\dagger}}$ & $106,20^{\dagger}$ & $118,41^{\dagger}$ \\
\hline D.Típica & 60 & 71,99 & 71,74 & 117,56 & 106,64 & 42,24 & 61,29 \\
\hline Mediana & 74 & 79 & 104,90 & 96,50 & 94 & 95,50 & 105 \\
\hline $\begin{array}{c}\text { Rango } \\
\text { intercuartílico } \\
\text { (P25-P75) }\end{array}$ & $64-100$ & $66-103$ & $\begin{array}{l}71,50- \\
114,35\end{array}$ & $\begin{array}{l}76,50- \\
117,50\end{array}$ & $75-126$ & $\begin{array}{c}80- \\
116,25\end{array}$ & $\begin{array}{l}81,50- \\
127,50\end{array}$ \\
\hline
\end{tabular}

Tabla 4.11.4.10. Descripción de la Fosfatasa Alcalina (FA) en las diferentes revisiones evaluadas

En la figura 4.11.4.4 se aprecia la evolución de FA en relación con el valor de referencia máximo, superando ese límite antes de la cirugía el $17,10 \%$ de los pacientes, reduciéndose al 15,18\% a los 3 meses. A los 6 meses el $21,42 \%$ de los pacientes superaba el límite de referencia, aumentando hasta el $24 \%$ y $26,85 \%$ a los 9 y 12 meses respectivamente. En la revisión de los 18 meses se reduce ese porcentaje al 23,43\% de los pacientes volviendo a aumentar en el último control, observando el 28,23\% de los pacientes con valores de FA por encima de ese valor límite. 


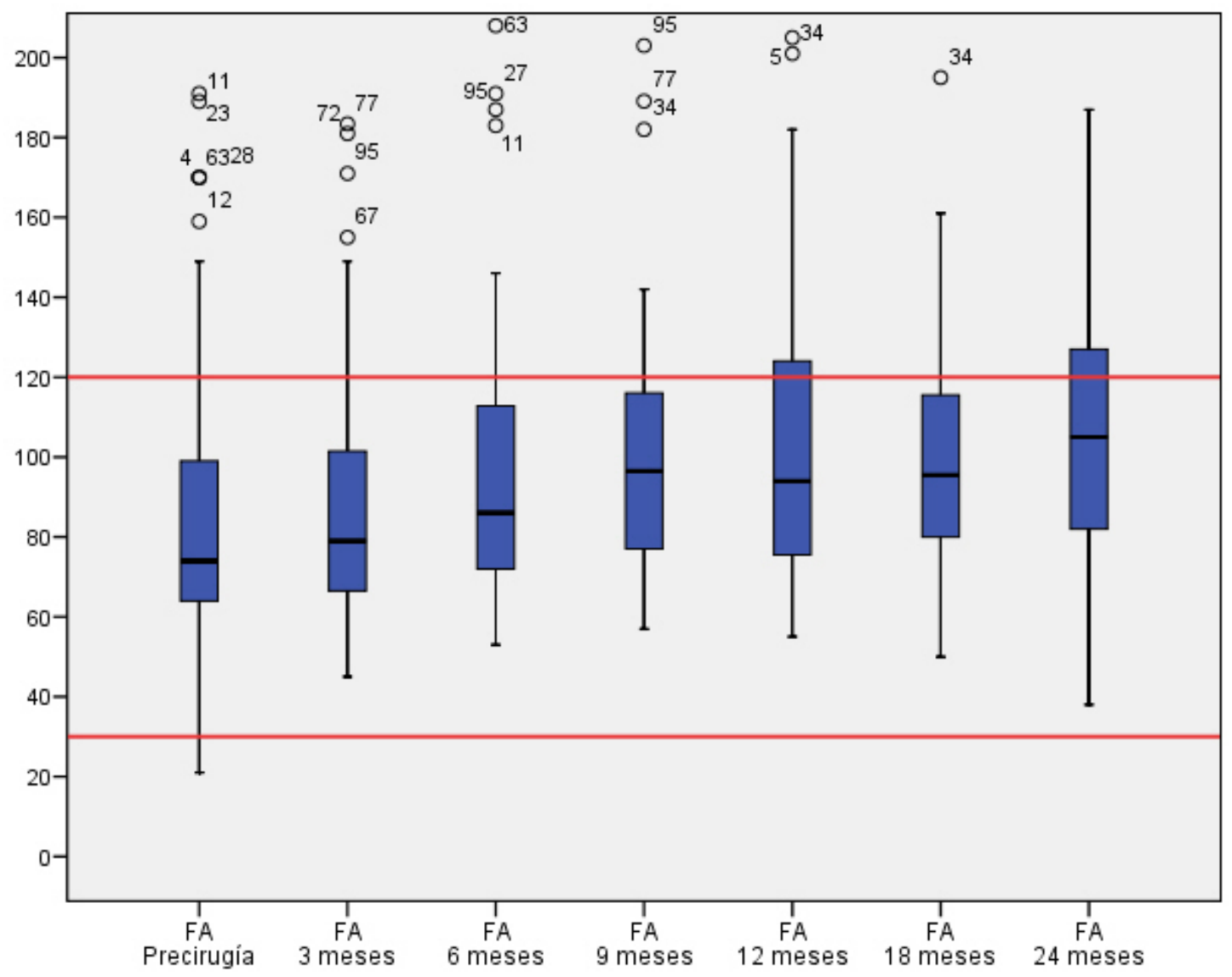

Figura 4.11.4.4. Diagrama de caja de la Fosfatasa Alcalina (FA) plasmática en los diferentes controles evaluados representando los valores de referencia en el eje de ordenadas

Los hombres presentaron valores medios de FA superiores a las mujeres en todos los controles excepto a los 18 meses sin ser en ninguno de ellos esta diferencia estadísticamente significativa. En ambos sexos la FA a 24 meses aumentó respecto del control prequirúrgico, siendo significativo en las mujeres $(P<0,001)$.

\begin{tabular}{|c|c|c|c|c|c|c|c|}
\hline & \multicolumn{3}{|c|}{ Mujer } & \multicolumn{3}{|c|}{ Hombre } & \multirow{2}{*}{$\mathbf{P}$} \\
\hline & $\mathbf{N}$ & Media & D.Típica & $\mathbf{N}$ & Media & D.Típica & \\
\hline $\begin{array}{c}\text { FA } \\
\text { precirugía } \\
\text { (U/L) }\end{array}$ & 58 & 89,91 & 47,02 & 18 & 100,56 & 91,53 & NS \\
\hline $\begin{array}{c}\text { FA } 3 \text { meses } \\
\text { (U/L) }\end{array}$ & 56 & 94,25 & 68,21 & 23 & $111,76^{\dagger}$ & 80,74 & NS \\
\hline $\begin{array}{c}\text { FA } 6 \text { meses } \\
\text { (U/L) }\end{array}$ & 47 & $96,68^{\dagger \dagger}$ & 36,92 & 23 & $121,68^{\dagger}$ & 113,38 & NS \\
\hline $\begin{array}{c}\text { FA } 9 \text { meses } \\
\text { (U/L) }\end{array}$ & 34 & $105,53^{\dagger}$ & 48,97 & 16 & $154,78^{\dagger}$ & 195,23 & NS \\
\hline $\begin{array}{c}\text { FA } 12 \\
\text { meses (U/L) }\end{array}$ & 50 & $108,70^{\dagger}$ & 48,27 & 17 & $150,15^{\dagger}$ & 195,98 & NS \\
\hline
\end{tabular}




\begin{tabular}{|c|c|c|c|c|c|c|c|}
\hline & \multicolumn{3}{|c|}{ Mujer } & \multicolumn{3}{|c|}{ Hombre } & \multirow{2}{*}{$\mathbf{P}$} \\
\hline & $\mathbf{N}$ & Media & D.Típica & $\mathbf{N}$ & Media & D.Típica & \\
\hline $\begin{array}{c}\text { FA } 18 \\
\text { meses (U/L) }\end{array}$ & 44 & $106,98^{\dagger}$ & 44,02 & 20 & 104,50 & 39,06 & NS \\
\hline $\begin{array}{c}\text { FA } 24 \\
\text { meses (U/L) }\end{array}$ & 60 & $117,83^{\dagger}$ & 59,70 & 25 & 119,79 & 66,20 & NS \\
\hline
\end{tabular}

Tabla 4.11.4.11. Descripción de la Fosfatasa Alcalina (FA) plasmática en las diferentes revisiones evaluadas según el sexo

Del mismo modo ocurre al describir la evolución de FA por grupos de edad, siendo mayor los valores medios de FA en el grupo de mayor edad, a excepción del control prequirúrgico y el de los 24 meses. Ninguna de esas diferencias fue estadísticamente significativa, en ambos grupos de edad la FA a 24 meses aumentó significativamente respecto del valor prequirúrgico.

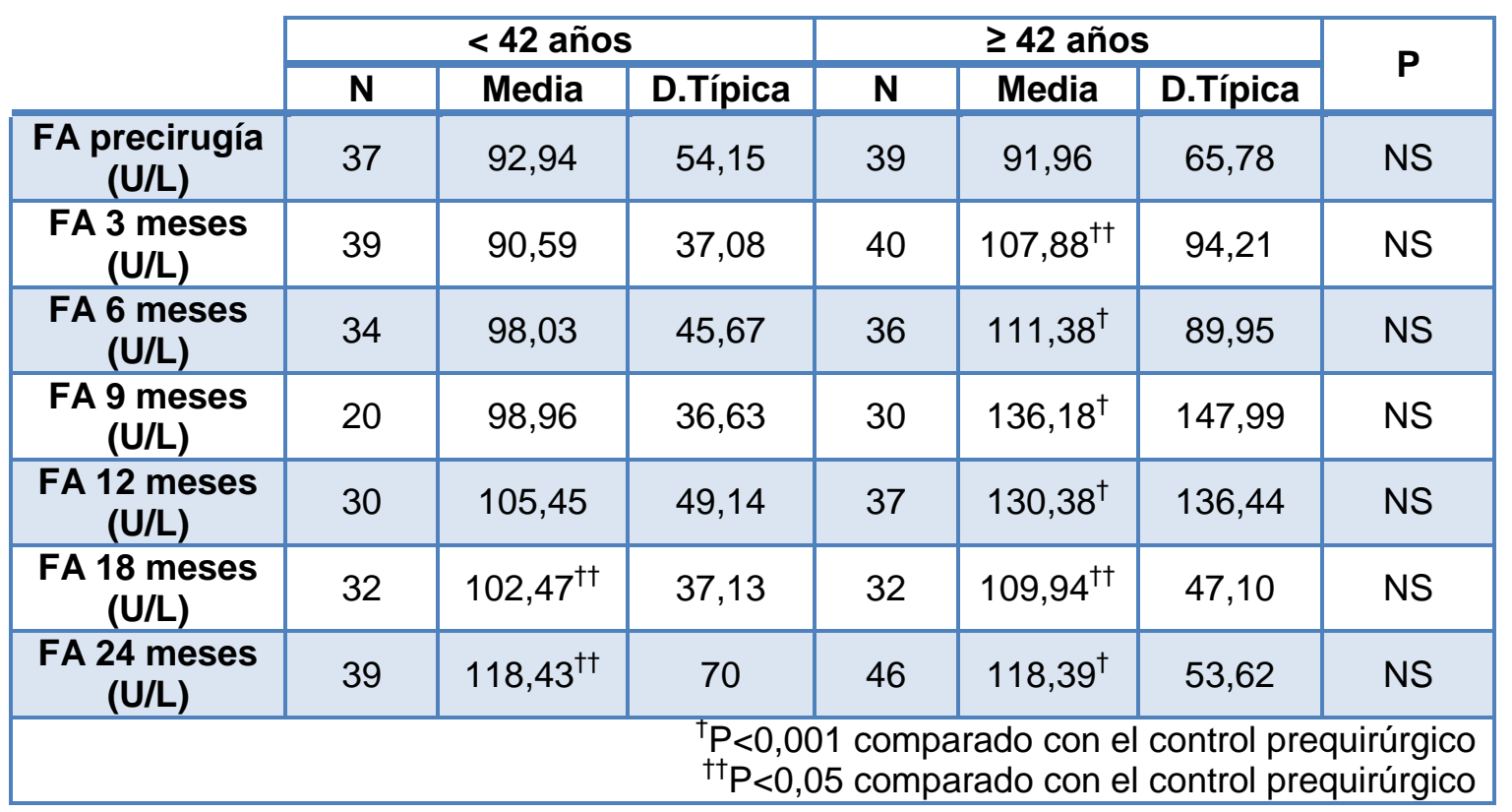

Tabla 4.11.4.12. Descripción de la Fosfatasa Alcalina (FA) plasmática en las diferentes revisiones evaluadas según el grupo de edad

En la figura 4.11.4.4, se muestra a página completa el conjunto de las variables estudiadas en el perfil hepático, agrupando los resultados por sexo y estos a su vez por grupos de edad.

A los 6, 9 y 12 meses son los varones $\geq 42$ años quienes superan los valores límite de referencia de FA, por el contrario a los 24 meses son los 
varones $<42$ años y las mujeres $\geq 42$ años quienes superan el límite máximo.

Los valores de GOT y GGT medios de las mujeres y hombres de cada grupo de edad se encuentran dentro de los valores de referencia a excepción de la GGT de los 18 meses en los varones $\geq 42$ años.

La GPT se muestra por encima del valor límite máximo en los hombres en la $1^{\mathrm{a}}$ consulta en los < 42 años, y del mismo modo en el control de los 3 , 6 y 9 meses postquirúrgicos. A los 12 meses desciende estando al límite del valor máximo de referencia, manteniéndose por debajo del mismo hasta los 24 meses estudiados.

Las mujeres apenas sufren variación en los niveles medios de GPT por grupo de edad. En todos los controles ambos grupos de edad están por debajo del valor máximo de referencia. 


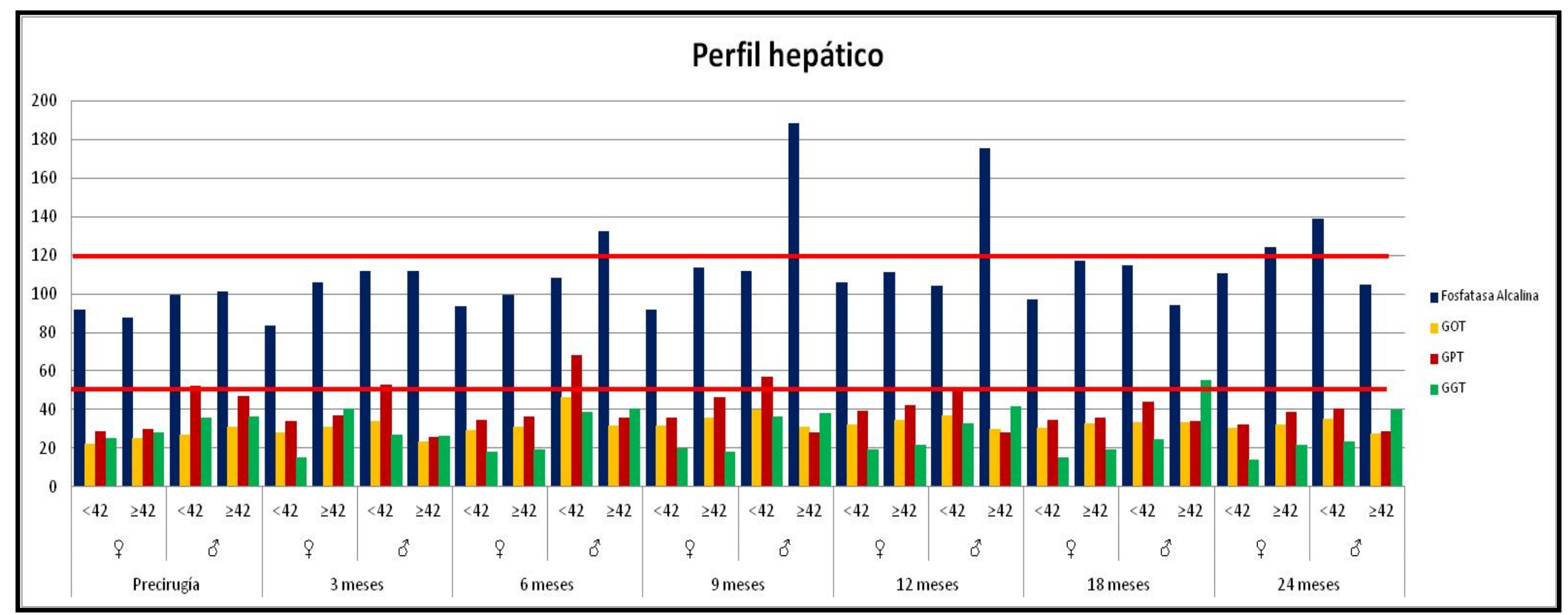

Figura 4.11.4.5. Gráfico de barras del perfil hepático plasmático en los diferentes controles evaluados según el sexo y el grupo de edad correspondiente en cada uno de ellos 


\subsubsection{Vitaminas}

El ácido fólico y la vitamina $B_{12}$ son vitaminas con una estrecha interrelación metabólica en la síntesis de nucleótidos purínicos y pirimidínicos. Sus determinaciones plasmáticas por defecto indican estados carenciales y malnutrición, en el caso de la vitamina $B_{12}$ su déficit causa anemia megaloblástica, siendo una de las complicaciones más frecuentes después de la cirugía bariátrica ${ }^{72}$.

\subsubsection{Vitamina $B_{12}$}

En la tabla 4.11.5.1 se muestra la evolución de la vitamina $\mathrm{B}_{12}$ (Vit $\mathrm{B}_{12}$ ), desde el primer control postquirúrgico evaluado. Los valores medios de Vit $B_{12}$ se mantienen sin apenas variación hasta el control de los 6 meses, desde el cual descienden de manera progresiva hasta los 24 meses sin ser significativo.

Al comparar los resultados de Vit $\mathrm{B}_{12}$ entre el control de los 3 meses con cada uno de los sucesivos hasta los 2 años de seguimiento, se observa una disminución significativa de la Vit $\mathrm{B}_{12}$ desde el año de la cirugía, estando siempre por encima del valor límite inferior de referencia.

\begin{tabular}{|c|c|c|c|c|c|c|}
\hline & $\begin{array}{c}\text { Vit } B_{12} \\
3 \\
\text { meses } \\
(p g / m L)\end{array}$ & $\begin{array}{c}\text { Vit } B_{12} \\
6 \\
\text { meses } \\
(p g / m L)\end{array}$ & $\begin{array}{c}\text { Vit } B_{12} \\
9 \\
\text { meses } \\
(p g / m L)\end{array}$ & $\begin{array}{c}\text { Vit } B_{12} \\
12 \\
\text { meses } \\
(p g / m L)\end{array}$ & $\begin{array}{c}\text { Vit } B_{12} \\
18 \\
\text { meses } \\
(p g / m L)\end{array}$ & $\begin{array}{c}\text { Vit } B_{12} \\
24 \\
\text { meses } \\
(p g / m L)\end{array}$ \\
\hline $\mathbf{N}$ & 85 & 68 & 50 & 77 & 63 & 82 \\
\hline Media & 415,74 & 416,42 & 378,86 & $359,88^{\dagger \dagger}$ & $329,16^{\dagger}$ & $320,89^{\dagger}$ \\
\hline D.Típica & 155,39 & 202,54 & 149,95 & 157,79 & 122,36 & 166,15 \\
\hline Mediana & 383 & 358,50 & 332 & 318 & 287 & 276 \\
\hline $\begin{array}{c}\text { Rango } \\
\text { intercuartílico } \\
\text { (P25-P75) }\end{array}$ & $\begin{array}{c}305,50- \\
504,45\end{array}$ & $\begin{array}{c}291,80- \\
439,45\end{array}$ & $\begin{array}{l}257,75- \\
456,25\end{array}$ & $\begin{array}{c}247,65- \\
415,80\end{array}$ & $\begin{array}{c}240,60- \\
416\end{array}$ & $\begin{array}{l}216,75- \\
378,50\end{array}$ \\
\hline
\end{tabular}

Tabla 4.11.5.1. Descripción de Vitamina $B_{12}\left(\right.$ Vit $\left.B_{12}\right)$ plasmática en las diferentes revisiones evaluadas

A continuación se muestra de manera gráfica (figura 4.11.5.1) la evolución de la Vit $B_{12}$ en relación a los valores máximo de referencia. A los 3 meses de la cirugía el $4,70 \%$ de los pacientes presentaba valores inferiores al límite 
inferior de referencia $(211 \mathrm{pg} / \mathrm{mL})$. En el siguiente control esa cifra desciende al 4,41\%, manteniendo esa tendencia a los 9 meses (4\%). A los 12 meses aumenta observando al 10,38\% de los pacientes, descendiendo a los 18 meses (7,93\%). A diferencia de los 24 meses dónde se observa al 21,95\% de los pacientes con valores de Vit $B_{12}$ por debajo del valor límite de referencia.

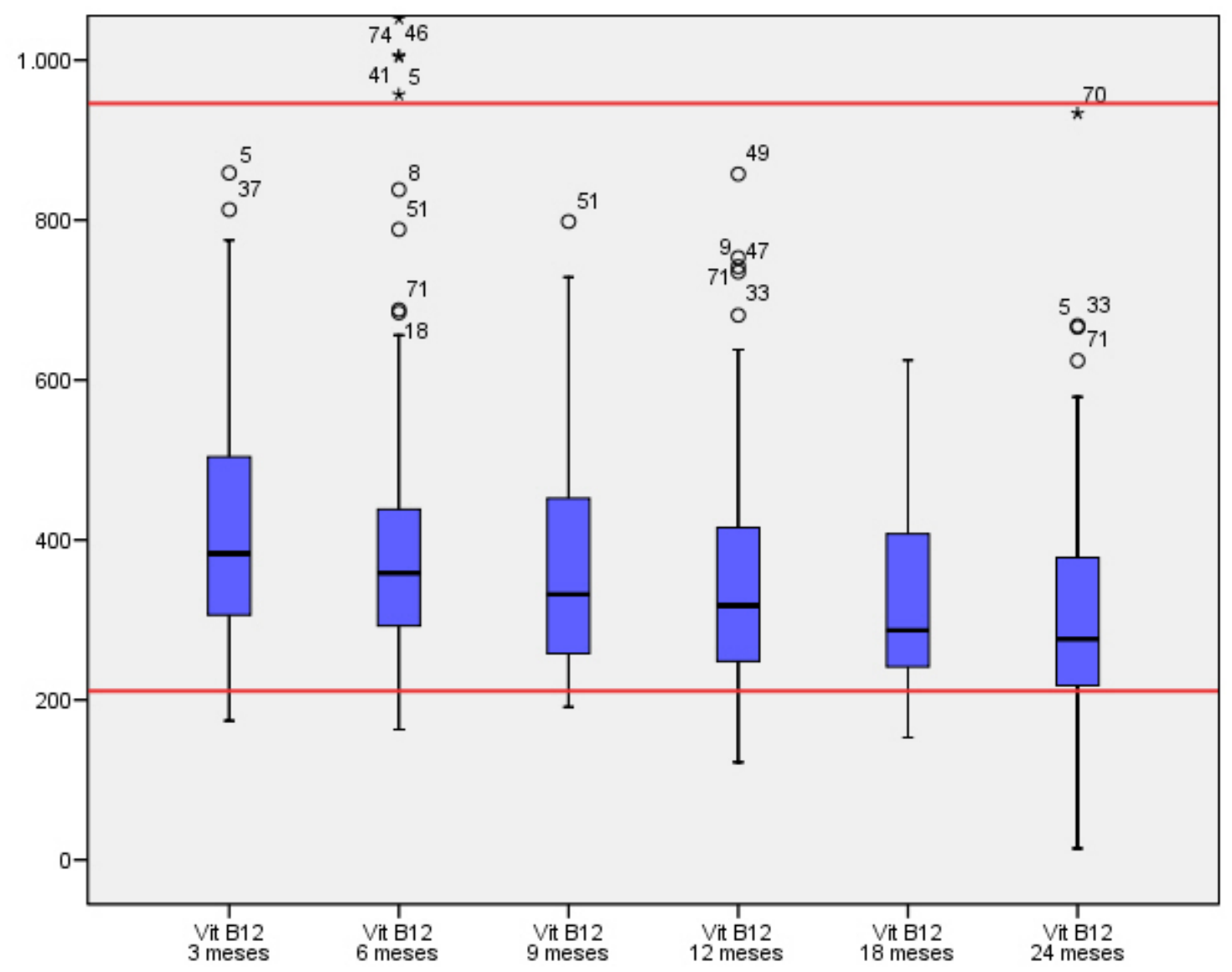

Figura 4.11.5.1. Diagrama de caja de la Vitamina $B_{12}$ (Vit $B_{12}$ ) plasmática en los diferentes controles evaluados representando los valores de referencia en el eje de ordenadas

En relación al sexo, tabla 4.11.5.2, en las mujeres se aprecian valores medios de $V i t B_{12}$ superiores a los varones, siendo esta diferencia significativa en el control de los 3 meses postquirúrgico $(P<0,05)$. En las mujeres, la reducción de Vit $B_{12}$ desciende significativamente desde los 12 meses al correlacionar los resultados con el valor del $3^{\circ}$ mes $(P<0,05)$, en cambio en los hombres se aprecia desde los 18 meses $(P<0,001)$. 


\begin{tabular}{|c|c|c|c|c|c|c|c|}
\hline & \multicolumn{3}{|c|}{ Mujer } & \multicolumn{3}{|c|}{ Hombre } & \multirow{2}{*}{$\mathbf{P}$} \\
\hline & $\mathbf{N}$ & Media & D.Típica & $\mathbf{N}$ & Media & D.Típica & \\
\hline $\begin{array}{c}\text { Vit } B_{12} 3 \text { meses } \\
(\mathrm{pg} / \mathrm{mL})\end{array}$ & 62 & 434,40 & 167,46 & 23 & 365,46 & 104,01 & $<0,05$ \\
\hline $\begin{array}{c}\text { Vit } B_{12} 6 \text { meses } \\
(\mathrm{pg} / \mathrm{mL})\end{array}$ & 47 & 425,52 & 216,54 & 21 & 396,06 & 170,17 & NS \\
\hline $\begin{array}{c}\text { Vit } B_{12} 9 \text { meses } \\
(\mathrm{pg} / \mathrm{mL})\end{array}$ & 32 & 401,64 & 166,57 & 18 & 338,36 & 107,25 & NS \\
\hline $\begin{array}{c}\text { Vit } B_{12} 12 \\
\text { meses (pg/mL) }\end{array}$ & 57 & $367,93^{\dagger \dagger}$ & 171,33 & 20 & 336,94 & 110,97 & NS \\
\hline $\begin{array}{c}\text { Vit } B_{12} 18 \\
\text { meses (pg/mL) }\end{array}$ & 42 & $343,85^{\dagger \dagger}$ & 134,12 & 21 & $299,77^{\dagger}$ & 90,41 & NS \\
\hline $\begin{array}{c}\text { Vit } B_{12} 24 \\
\text { meses (pg/mL) }\end{array}$ & 61 & $331,17^{\dagger \dagger}$ & 184,79 & 21 & $291,04^{\dagger}$ & 90,05 & NS \\
\hline
\end{tabular}

Tabla 4.11.5.2. Descripción de la Vitamina $B_{12}$ (Vit $B_{12}$ ) plasmática en las diferentes revisiones evaluadas según el sexo

Por grupos de edad como se detalla en la tabla 4.11.5.3, los valores medios de Vit $B_{12}$ no muestran una tendencia homogénea y las diferencias entre controles no son significativas. En ambos sexos los valores medios de Vit $B_{12}$ a los 2 años después de la cirugía no son inferiores al valor límite de referencia $(211 \mathrm{pg} / \mathrm{mL})$. En el grupo de menor edad, la disminución de la Vit $B_{12}$ es significativa desde los 9 meses hasta los 2 años de seguimiento $(P<0,05)$, en el grupo de los $\geq 42$ años esa diferencia es significativa a los 24 meses $(P<0,05)$.

\begin{tabular}{|c|c|c|c|c|c|c|c|}
\hline & \multicolumn{3}{|c|}{$<42$ años } & \multicolumn{3}{|c|}{$\geq 42$ años } & \multirow{2}{*}{$\mathbf{P}$} \\
\hline & $\mathbf{N}$ & Media & D.Típica & $\mathbf{N}$ & Media & D.Típica & \\
\hline $\begin{array}{c}\text { Vit } B_{12} 3 \text { meses } \\
(\mathrm{pg} / \mathrm{mL})\end{array}$ & 42 & 424,61 & 148,18 & 43 & 407,09 & 163,41 & NS \\
\hline $\begin{array}{c}\text { Vit } B_{12} 6 \text { meses } \\
(\mathrm{pg} / \mathrm{mL})\end{array}$ & 33 & 427,58 & 199,77 & 35 & 405,89 & 207,47 & NS \\
\hline $\begin{array}{c}\text { Vit } B_{12} 9 \text { meses } \\
(\mathrm{pg} / \mathrm{mL})\end{array}$ & 21 & $364,41^{\dagger \dagger}$ & 115,68 & 29 & 389,33 & 171,82 & NS \\
\hline $\begin{array}{c}\text { Vit } B_{12} 12 \\
\text { meses (pg/mL) }\end{array}$ & 34 & $348,80^{\dagger \dagger}$ & 145,60 & 43 & 368,65 & 167,98 & NS \\
\hline $\begin{array}{c}\text { Vit } B_{12} 18 \\
\text { meses }(p g / m L)\end{array}$ & 30 & $307,87^{\dagger}$ & 99,53 & 33 & 348,51 & 138,63 & NS \\
\hline $\begin{array}{c}\text { Vit } B_{12} 24 \\
\text { meses (pg/mL) }\end{array}$ & 41 & $322,13^{\dagger \dagger}$ & 177,67 & 41 & $319,65^{\dagger \dagger}$ & 155,99 & NS \\
\hline
\end{tabular}

Tabla 4.11.5.3. Descripción de la Vitamina $B_{12}$ (Vit $B_{12}$ ) plasmática en las diferentes revisiones evaluadas según el grupo de edad 


\subsubsection{2. Ácido fólico}

En la tabla 4.11.5.4 se muestra la evolución del ácido fólico plasmático (Ácd. Fol) en las diferentes revisiones evaluadas desde el primer control postquirúrgico. La tendencia de los valores medios es creciente desde la primera revisión postquirúrgica hasta el año de la intervención, describiendo el valor medio más elevado a los 12 meses de la cirugía $(P<0,001)$.

\begin{tabular}{|c|c|c|c|c|c|c|}
\hline & $\begin{array}{c}\text { Ácd. Fol } \\
3 \\
\text { meses } \\
\text { (ng/mL) }\end{array}$ & $\begin{array}{c}\text { Ácd. Fol } \\
6 \\
\text { meses } \\
\text { (ng/mL) }\end{array}$ & $\begin{array}{c}\text { Ácd. Fol } \\
9 \\
\text { meses } \\
(\mathrm{ng} / \mathrm{mL})\end{array}$ & $\begin{array}{c}\text { Ácd. Fol } \\
12 \\
\text { meses } \\
\text { (ng/mL) }\end{array}$ & $\begin{array}{c}\text { Ácd. Fol } \\
18 \\
\text { meses } \\
\text { (ng/mL) }\end{array}$ & $\begin{array}{c}\text { Ácd. Fol } \\
24 \\
\text { meses } \\
\text { (ng/mL) }\end{array}$ \\
\hline $\mathbf{N}$ & 86 & 68 & 51 & 75 & 62 & 81 \\
\hline Media & 6,20 & $8,61^{*^{\dagger}}$ & $9,19^{\dagger}$ & $9,41^{\dagger}$ & $8,23^{\dagger \dagger}$ & $8,03^{\dagger \dagger}$ \\
\hline D.Típica & 3,58 & 4,23 & 4,40 & 4,64 & 4,49 & 4,57 \\
\hline Mediana & 5,35 & 8,25 & 8,91 & 9 & 6,65 & 6,40 \\
\hline $\begin{array}{c}\text { Rango } \\
\text { intercuartílico } \\
\text { (P25-P75) }\end{array}$ & $\begin{array}{l}4,20- \\
7,55\end{array}$ & $\begin{array}{l}5,12- \\
10,53\end{array}$ & $5-12$ & $\begin{array}{l}5,90- \\
12,61\end{array}$ & $\begin{array}{l}4,55- \\
11,80\end{array}$ & $\begin{array}{l}4,90- \\
10,50\end{array}$ \\
\hline \multicolumn{7}{|c|}{$\begin{array}{l}{ }^{*} \mathrm{P}<0,05 \text { comparado con el control anterior } \\
{ }^{\dagger} \mathrm{P}<0,001 \text { comparado con el control } 3^{\circ} \text { mes } \\
{ }^{+\dagger} \mathrm{P}<0,05 \text { comparado con el control } 3^{\circ} \text { mes }\end{array}$} \\
\hline
\end{tabular}

Tabla 4.11.5.4. Descripción del ácido fólico (Ácd. Fol) plasmático en las diferentes revisiones evaluadas

En la figura 4.11.5.2 se representa la evolución del Ácd. Fol conforme a los valores límite de referencia. A los 3 meses de la cirugía el 32,55\% de los pacientes se encontraba con valores de Ácd. Fol por debajo del valor límite de referencia $(4,6 \mathrm{ng} / \mathrm{mL})$. Este porcentaje desciende en las dos siguientes revisiones al 20,58\% y $17,64 \%$ (6 y 9 meses postquirúrgicos respectivamente). En la revisión anual se eleva ligeramente hasta el 18,66\%, continuando con esa tendencia hasta los 18 meses, describiendo un 24,19\% de los pacientes con valores por debajo del límite. En el último control evaluado este porcentaje vuelve a descender mostrando valores inferiores a $4,6 \mathrm{ng} / \mathrm{mL}$ en el $22,22 \%$ de los pacientes. 


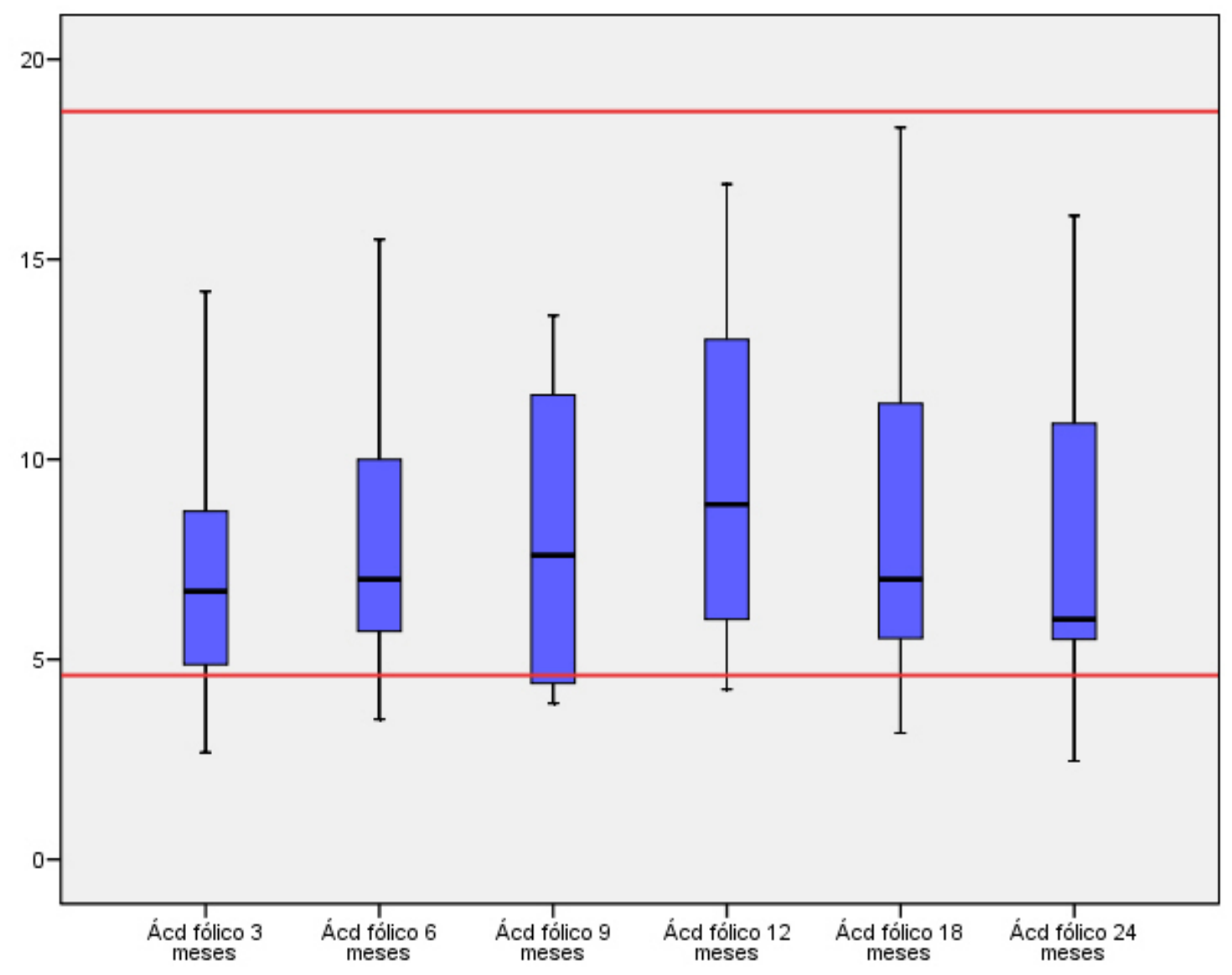

Figura 4.11.5.2. Diagrama de caja de la Ácido fólico plasmático en los diferentes controles evaluados representando los valores de referencia en el eje de ordenadas

Las variaciones del Ácd. Fol en las diferentes revisiones postquirúrgicas no muestran cambios estadísticamente significativos entre hombres y mujeres a excepción de la revisión de los 18 meses (tabla 4.11.5.5). Desde los 9 meses postquirúrgicos hasta los 24 meeses, las cifras de Ácd. Fol son más elevadas en las mujeres a diferencia de los controle de los 3 y 6 meses.

En las mujeres la tendencia del Ácd. Fol medio plasmático aumenta hasta los 12 meses de la cirugía $(P<0,001)$, control desde el que empiezan a descender ligeramente. En los hombres el Ácd. Fol desde el control de los 3 meses aumenta significativamente a los 6 y 9 meses $(P<0,05)$, después disminuye sin representar un cambio significativo en relación a los valores del primer trimestre postquirúrgico. 


\begin{tabular}{|c|c|c|c|c|c|c|c|}
\hline & \multicolumn{3}{|c|}{ Mujer } & \multicolumn{3}{|c|}{ Hombre } & \multirow{2}{*}{$\mathbf{P}$} \\
\hline & $\mathbf{N}$ & Media & D.Típica & $\mathbf{N}$ & Media & D.Típica & \\
\hline $\begin{array}{c}\text { Ácd. Fol } 3 \text { meses } \\
\text { (ng/mL) }\end{array}$ & 63 & 6,07 & 2,53 & 23 & 6,54 & 5,59 & NS \\
\hline $\begin{array}{c}\text { Ácd. Fol } 6 \text { meses } \\
\text { (ng/mL) }\end{array}$ & 47 & $8,30^{\dagger}$ & 3,86 & 21 & $9,32^{\dagger \dagger}$ & 4,98 & NS \\
\hline $\begin{array}{l}\text { Ácd. Fol } 9 \text { meses } \\
\text { (ng/mL) }\end{array}$ & 33 & $9,28^{\dagger}$ & 4,57 & 18 & $9,04^{\dagger \dagger}$ & 4,20 & NS \\
\hline $\begin{array}{l}\text { Ácd. Fol } 12 \text { meses } \\
\text { (ng/mL) }\end{array}$ & 56 & $9,56^{\dagger}$ & 4,67 & 19 & 8,99 & 4,64 & NS \\
\hline $\begin{array}{l}\text { Ácd. Fol } 18 \text { meses } \\
\text { (ng/mL) }\end{array}$ & 41 & $9,03^{\dagger \dagger}$ & 4,69 & 21 & 6,67 & 3,70 & $<0,05$ \\
\hline $\begin{array}{l}\text { Ácd. Fol } 24 \text { meses } \\
\text { (ng/mL) }\end{array}$ & 60 & $8,14^{\dagger \dagger}$ & 4,38 & 21 & 7,71 & 5,17 & NS \\
\hline
\end{tabular}

Tabla 4.11.5.5. Descripción del ácido fólico (Ácd. Fol) plasmático en las diferentes revisiones evaluadas según el sexo

En referencia al grupo de edad, en la tabla 4.11.5.6 se observan valores medios de Ácd. Fol más elevados en los $\geq 42$ años siendo esta diferencia estadísticamente significativa en la revisión de los 3 y 18 meses $(P<0,05)$. En ambos grupos al comparar los valores de Ácd. Fol entre el $3^{\circ}$ mes postquirúrgico y los siguientes controles hasta los 12 meses, se observó un aumento significativo. En los más jóvenes el aumento del Ácd. Fol desde el $3^{\circ}$ mes hasta los 24 meses sí fue significativo $(P<0,05)$ a diferencia de los pacientes $\geq 42$ años.

\begin{tabular}{|c|c|c|c|c|c|c|c|}
\hline & \multicolumn{3}{|c|}{$<42$ años } & \multicolumn{3}{|c|}{$\geq 42$ años } & \multirow{2}{*}{$\mathbf{P}$} \\
\hline & $\mathbf{N}$ & Media & D.Típica & $\mathbf{N}$ & Media & D.Típica & \\
\hline $\begin{array}{c}\text { Ácd. Fol } 3 \text { meses } \\
\text { (ng/mL) }\end{array}$ & 42 & 5,29 & 2,12 & 44 & 7,07 & 4,41 & $<0,05$ \\
\hline $\begin{array}{c}\text { Ácd. Fol } 6 \text { meses } \\
\text { (ng/mL) }\end{array}$ & 33 & $8,09^{\dagger}$ & 3,88 & 35 & $9,11^{\dagger \dagger}$ & 4,52 & NS \\
\hline $\begin{array}{l}\text { Ácd. Fol } 9 \text { meses } \\
\text { (ng/mL) }\end{array}$ & 22 & $8,91^{\dagger}$ & 4,07 & 29 & $9,41^{\dagger \dagger}$ & 4,70 & NS \\
\hline $\begin{array}{l}\text { Ácd. Fol } 12 \text { meses } \\
\text { (ng/mL) }\end{array}$ & 32 & $8,79^{\dagger \dagger}$ & 4,65 & 43 & $9,87^{\dagger \dagger}$ & 4,63 & NS \\
\hline $\begin{array}{l}\text { Ácd. Fol } 18 \text { meses } \\
(\mathrm{ng} / \mathrm{mL})\end{array}$ & 30 & 6,64 & 3,65 & 32 & 9,73 & 4,74 & $<0,05$ \\
\hline $\begin{array}{l}\text { Ácd. Fol } 24 \text { meses } \\
\text { (ng/mL) }\end{array}$ & 42 & $7,46^{\dagger \dagger}$ & 4,24 & 39 & 8,63 & 4,88 & NS \\
\hline
\end{tabular}

Tabla 4.11.5.6. Descripción del ácido fólico (Ac.FOL) plasmático en las diferentes revisiones evaluadas según el grupo de edad 


\subsubsection{Proteínas}

En este perfil plasmático se medirá la evolución de las proteínas totales, albúmina y ferritina, las cuales son variables analíticas afectadas en la cirugía bariátrica principalmente en las de tipo malabsortivo.

\subsubsection{Proteínas totales}

Los valores medios de las proteínas totales (Prot.T) plasmáticas descienden de manera paulatina desde el primer control postquirúrgico hasta el año de la cirugía dónde se describe un ligero aumento que continua hasta el último control evaluado a los 2 años de la intervención (tabla 4.11.6.1). El valor de las Prot.T a los 3 meses de la intervención se reduce de manera significativa $(P<0,05)$, del mismo modo que al comparar el valor inicial antes de la cirugía y el resultado obtenido en cada una de las revisiones posteriores $(P<0,001)$.

\begin{tabular}{|c|c|c|c|c|c|c|c|}
\hline & $\begin{array}{l}\text { Prot.T } \\
\text { precirugía } \\
\text { (g/L) }\end{array}$ & $\begin{array}{c}\text { Prot.T } \\
3 \\
\text { meses } \\
(g / L)\end{array}$ & $\begin{array}{c}\text { Prot.T } \\
6 \\
\text { meses } \\
\text { (g/L) }\end{array}$ & $\begin{array}{c}\text { Prot.T } \\
9 \\
\text { meses } \\
(\mathrm{g} / \mathrm{L})\end{array}$ & $\begin{array}{l}\text { Prot.T } \\
12 \\
\text { meses } \\
(\mathrm{g} / \mathrm{L})\end{array}$ & $\begin{array}{c}\text { Prot.T } \\
18 \\
\text { meses } \\
(\mathrm{g} / \mathrm{L})\end{array}$ & $\begin{array}{c}\text { Prot.T } \\
24 \\
\text { meses } \\
\text { (g/L) }\end{array}$ \\
\hline $\mathbf{N}$ & 67 & 82 & 70 & 51 & 75 & 66 & 79 \\
\hline Media & 7,18 & $6,62^{*^{\dagger}}$ & $6,59^{\dagger}$ & $6,49^{\dagger}$ & $6,55^{\dagger}$ & $6,61^{\dagger}$ & $6,65^{\dagger}$ \\
\hline D.Típica & 0,49 & 0,58 & 0,51 & 0,46 & 0,47 & 0,41 & 0,42 \\
\hline Mediana & 7,10 & 6,60 & 6,60 & 6,52 & 6,68 & 6,70 & 6,70 \\
\hline $\begin{array}{c}\text { Rango } \\
\text { intercuartílico } \\
\text { (P25-P75) }\end{array}$ & $6,80-7,50$ & $\begin{array}{l}6,30- \\
6,90\end{array}$ & $6,20-7$ & $\begin{array}{c}6,10- \\
6,80\end{array}$ & $\begin{array}{c}6,29- \\
6,80\end{array}$ & $\begin{array}{l}6,30- \\
6,90\end{array}$ & $\begin{array}{c}6,40- \\
6,92\end{array}$ \\
\hline \multicolumn{8}{|c|}{$\begin{array}{r}{ }^{*} \mathrm{P}<0,05 \text { comparado con el control anterior } \\
{ }^{\dagger} \mathrm{P}<0,001 \text { comparado con el control prequirúrgico }\end{array}$} \\
\hline
\end{tabular}

Tabla 4.11.6.1. Descripción de las proteínas totales (Prot.T) plasmáticas en las diferentes revisiones evaluadas

Las Prot.T de todos los pacientes evaluados en cada revisión se encuentra por encima del valor límite inferior (4,1 g/L), ninguno incurre en déficit (figura 4.11.6.1). Sin embargo el 95,52\% de los pacientes previamente a la intervención superaba el valor máximo de referencia. Desde el primer control postquirúrgico el porcentaje de pacientes que superaban los $6,3 \mathrm{~g} / \mathrm{L}$ de Prot.T fue descendiendo ligeramente hasta los 12 meses en cada revisión trimestral: $79,26 \%, 72,85 \%, 72,54 \%, 62,66 \%$. Desde ese momento el porcentaje de pacientes que superaba el valor límite máximo de referencia 
subió al 74,24\% y 77,21\% en el control de los 18 y 24 meses respectivamente.

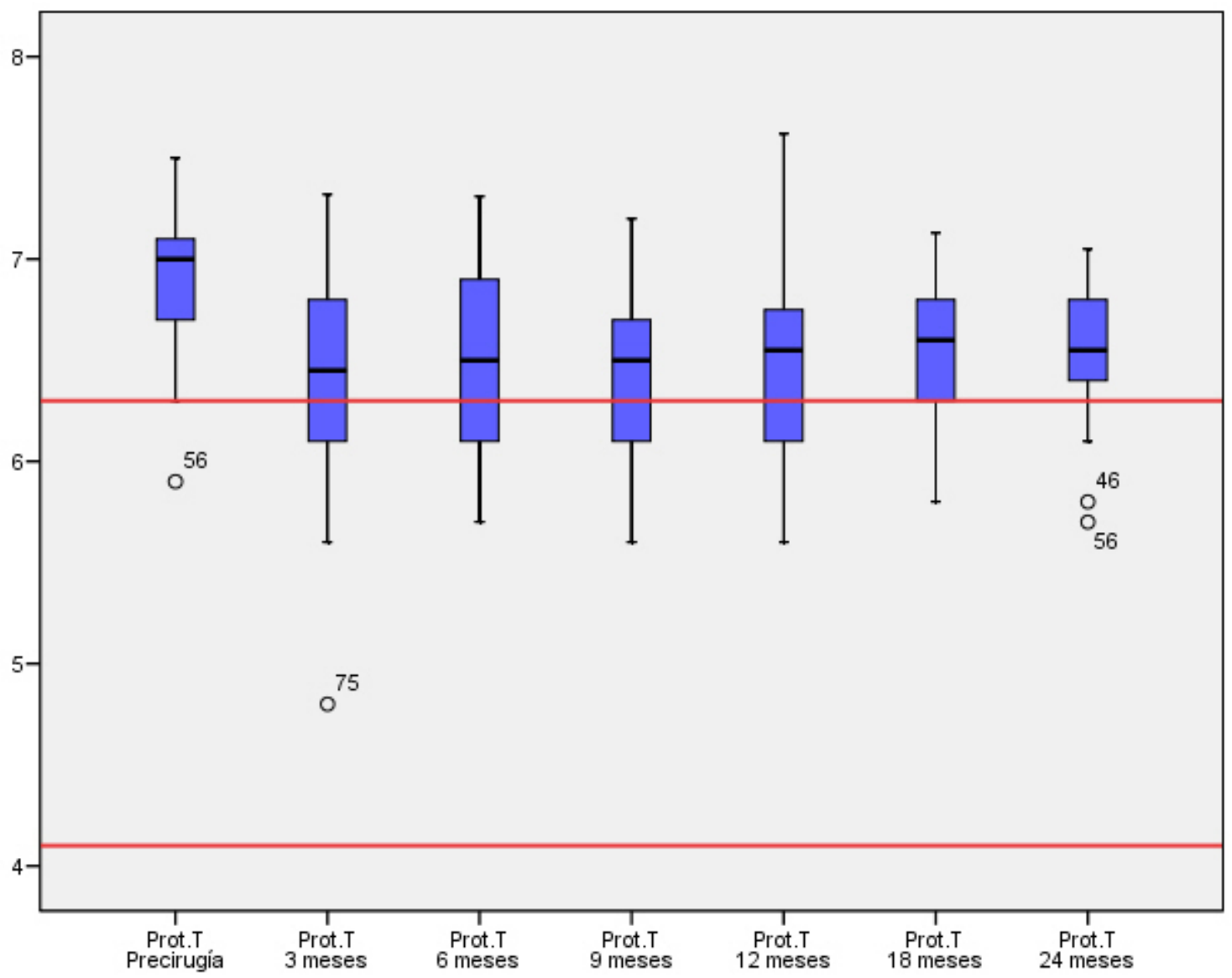

Figura 4.11.6.1. Diagrama de caja de las proteínas totales (Prot.T) plasmáticas en los diferentes controles evaluados representando los valores de referencia en el eje de ordenadas

En la tabla 4.11.6.2 se detalla la evolución de las Prot.T según el sexo sin apreciarse diferencias estadísticamente significativas entre hombres y mujeres. Cabe destacar que el valor medio de Prot.T es superior en los varones en todos los controles a excepción de la revisión de los 12 meses en la que ambos sexos igualan dicho valor. En cada uno de los grupos se describe una disminución del valor de Prot.T en todos los controles al compararlos con el valor prequirúrgico, sin ser inferior al valor límite de referencia. 


\begin{tabular}{|c|c|c|c|c|c|c|c|}
\hline & \multicolumn{3}{|c|}{ Mujer } & \multicolumn{3}{|c|}{ Hombre } & \multirow{2}{*}{$\mathbf{P}$} \\
\hline & $\mathbf{N}$ & Media & D.Típica & $\mathbf{N}$ & Media & D.Típica & \\
\hline $\begin{array}{c}\text { Prot.T precirugía } \\
\text { (g/L) }\end{array}$ & 48 & 7,16 & 0,49 & 19 & 7,21 & 0,50 & NS \\
\hline $\begin{array}{l}\text { Prot.T } 3 \text { meses } \\
\text { (g/L) }\end{array}$ & 59 & $6,59^{\dagger}$ & 0,56 & 23 & $6,71^{\dagger \dagger}$ & 0,65 & NS \\
\hline $\begin{array}{l}\text { Prot.T } 6 \text { meses } \\
\text { (g/L) }\end{array}$ & 47 & $6,54^{\dagger}$ & 0,56 & 23 & $6,67^{\dagger}$ & 0,38 & NS \\
\hline $\begin{array}{l}\text { Prot.T } 9 \text { meses } \\
\text { (g/L) }\end{array}$ & 32 & $6,41^{\dagger}$ & 0,47 & 19 & $6,63^{\dagger \dagger}$ & 0,42 & NS \\
\hline $\begin{array}{c}\text { Prot.T } 12 \text { meses } \\
(\mathrm{g} / \mathrm{L})\end{array}$ & 56 & $6,55^{\dagger}$ & 0,47 & 19 & $6,55^{\dagger}$ & 0,49 & NS \\
\hline $\begin{array}{c}\text { Prot.T } 18 \text { meses } \\
(\mathrm{g} / \mathrm{L})\end{array}$ & 47 & $6,57^{\dagger}$ & 0,43 & 19 & $6,71^{\dagger \dagger}$ & 0,37 & NS \\
\hline $\begin{array}{c}\text { Prot.T } 24 \text { meses } \\
\text { (g/L) }\end{array}$ & 54 & $6,60^{\dagger}$ & 0,44 & 25 & $6,74^{\dagger}$ & 0,38 & NS \\
\hline
\end{tabular}

Tabla 4.11.6.2. Descripción de las proteínas totales (Prot.T) plasmáticas en las diferentes revisiones evaluadas según el sexo

Por grupos de edad la evolución de los valores de Prot.T varía (tabla 4.11.6.3), apreciándose unos valores de Prot.T superiores en el grupo de menos edad siendo esta diferencia significativa a los 3, 12, 18 y 24 meses posteriores a la cirugía. En ambos grupos los valores de Prot.T en cada control al compararlos con el valor prequirúrgico disminuyen de manera significativa sin superar el valor límite inferior de referencia.

\begin{tabular}{|c|c|c|c|c|c|c|c|}
\hline & \multicolumn{3}{|c|}{$<42$ años } & \multicolumn{3}{|c|}{$\geq 42$ años } & \multirow{2}{*}{$\mathbf{P}$} \\
\hline & $\mathbf{N}$ & Media & D.Típica & $\mathbf{N}$ & Media & D.Típica & \\
\hline $\begin{array}{l}\text { Prot.T precirugía } \\
\text { (g/L) }\end{array}$ & 27 & 7,28 & 0,44 & 40 & 7,11 & 0,51 & NS \\
\hline $\begin{array}{c}\text { Prot.T } 3 \text { meses } \\
\text { (g/L) }\end{array}$ & 40 & $6,81^{\dagger \dagger}$ & 0,60 & 42 & $6,44^{\dagger}$ & 0,51 & $<0,001$ \\
\hline $\begin{array}{c}\text { Prot.T } 6 \text { meses } \\
(\mathrm{g} / \mathrm{L})\end{array}$ & 31 & $6,69^{\dagger}$ & 0,57 & 39 & $6,51^{\dagger}$ & 0,45 & NS \\
\hline $\begin{array}{l}\text { Prot.T } 9 \text { meses } \\
\text { (g/L) }\end{array}$ & 20 & $6,55^{\dagger \dagger}$ & 0,54 & 31 & $6,45^{\dagger}$ & 0,40 & NS \\
\hline $\begin{array}{l}\text { Prot.T } 12 \text { meses } \\
\text { (g/L) }\end{array}$ & 32 & $6,71^{\dagger}$ & 0,47 & 43 & $6,43^{\dagger}$ & 0,45 & $<0,05$ \\
\hline $\begin{array}{l}\text { Prot.T } 18 \text { meses } \\
(\mathrm{g} / \mathrm{L})\end{array}$ & 3 & $6,81^{\dagger \dagger}$ & 0,36 & 35 & $6,44^{\dagger}$ & 0,38 & $<0,001$ \\
\hline $\begin{array}{c}\text { Prot.T } 24 \text { meses } \\
\text { (g/L) }\end{array}$ & 38 & $6,77^{\dagger}$ & 0,39 & 41 & $6,53^{\dagger}$ & 0,42 & $<0,05$ \\
\hline
\end{tabular}

Tabla 4.11.6.3. Descripción de las proteínas totales (Prot.T) plasmáticas en las diferentes revisiones evaluadas según el grupo de edad 


\subsubsection{Albúmina}

\subsubsection{Albúmina}

En la tabla 4.11.6.4, se describe la evolución de la albúmina plasmática (Alb). Sólo se dispone de 11 pacientes con determinación de la Alb antes de la cirugía, aún así las variaciones de los valores medios de Alb no muestran cambios estadísticamente significativos entre ninguno de los controles evaluados. Del mismo modo tampoco se aprecian cambios significativos entre los valores de Alb desde el $3^{\circ}$ mes postquirúrgico y los descritos a los 24 meses.

\begin{tabular}{|c|c|c|c|c|c|c|c|}
\cline { 2 - 7 } & $\begin{array}{c}\text { Alb } \\
\text { precirugía } \\
(\mathbf{g} / \mathbf{L})\end{array}$ & $\begin{array}{c}\text { Alb } \\
\mathbf{3} \\
\mathbf{m e s e s} \\
\mathbf{( g / L )}\end{array}$ & $\begin{array}{c}\text { Alb } \\
\mathbf{6} \\
\mathbf{m e s e s} \\
\mathbf{( g / L )}\end{array}$ & $\begin{array}{c}\text { Alb } \\
\mathbf{9} \\
\text { meses } \\
(\mathbf{g} / \mathbf{L})\end{array}$ & $\begin{array}{c}\text { Alb } \\
\mathbf{1 2} \\
\mathbf{m e s e s} \\
\mathbf{( g / L )}\end{array}$ & $\begin{array}{c}\text { Alb } \\
\mathbf{1 8} \\
\mathbf{m e s e s} \\
\mathbf{( g / L )}\end{array}$ & $\begin{array}{c}\text { Alb } \\
\mathbf{2 4} \\
\mathbf{m e s e s} \\
\mathbf{( g / L )}\end{array}$ \\
\hline $\mathbf{N}$ & 11 & 78 & 61 & 43 & 63 & 60 & 72 \\
\hline Media & 4,04 & 4,07 & 4,09 & 4,07 & 4,08 & 4,10 & 4,14 \\
\hline D.Típica & 0,90 & 0,44 & 0,32 & 0,31 & 0,35 & 0,36 & 0,35 \\
\hline Mediana & 4,27 & 4,04 & 4,11 & 4,10 & 4,10 & 4,15 & 4,20 \\
\hline $\begin{array}{c}\text { Rango } \\
\text { intercuartílico } \\
\text { (P25-P75) }\end{array}$ & $3,90-4,60$ & $3,80-$ & $3,94-$ & $3,94-$ & $3,90-$ & $3,88-$ & $3,97-$ \\
4,30 & 4,30 & 4,29 & 4,30 & 4,37 & 4,40 \\
\hline
\end{tabular}

Tabla 4.11.6.4. Descripción de la albúmina (Alb) plasmática en las diferentes revisiones evaluadas

En la figura 4.11.6.2 se representa la evolución de la Alb en los diferentes controles evaluando la tendencia conforme a los valores límite de referencia (3,5-5,2 g/L). Antes de la cirugía el 9,09\% de los pacientes presentaba valores de Alb por debajo del límite, continuando con una tendencia descendente en los siguientes controles trimestrales hasta los 12 meses, dónde se registra el número más bajo: 7,69\%, 6,55\%, 4,65\%, 1,58\%, respectivamente. A los 18 meses se describe un $8,33 \%$ de pacientes, reduciéndose al 2,77\% a los 24 meses.

Entre todas las revisiones evaluadas, sólo se observa a un paciente a los 3 meses postquirúrgicos, por encima del valor límite máximo. 


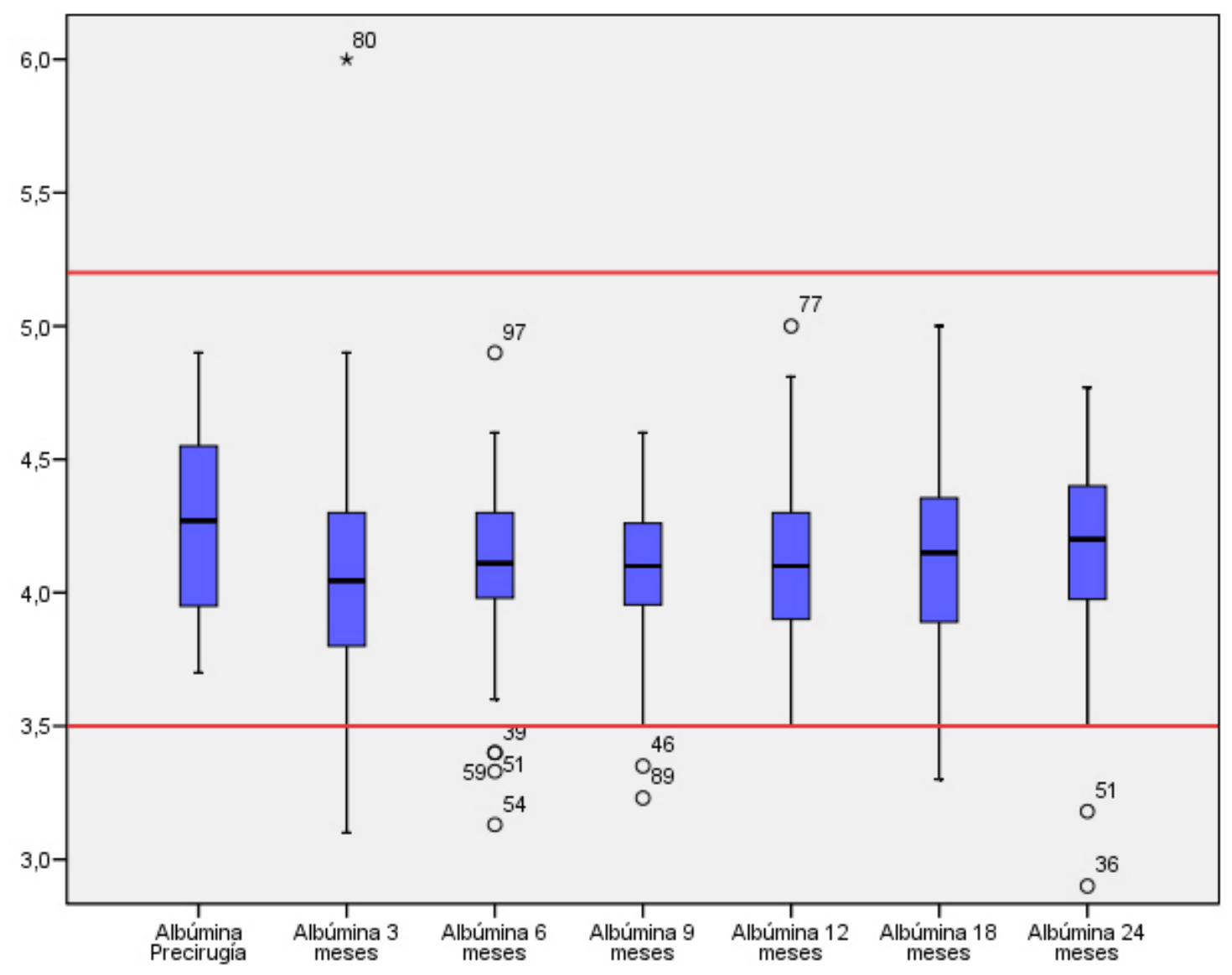

Figura 4.11.6.2. Diagrama de caja de la albúmina plasmática en los diferentes controles evaluados representando los valores de referencia en el eje de ordenadas

En referencia al sexo, como se muestra en la tabla 4.11.6.5, los hombres presentan valores medios de Alb superiores a los de las mujeres siendo esta diferencia estadísticamente significativa en la revisión previa a la cirugía y en los controles posteriores de los 6 y 12 meses. En ninguno de los dos grupos se observan cambios significativos entre el control estudiado en relación al valor prequirúrgico.

\begin{tabular}{|c|c|c|c|c|c|c|c|}
\hline & \multicolumn{3}{|c|}{ Mujer } & \multicolumn{3}{|c|}{ Hombre } & \multirow{2}{*}{$\mathbf{P}$} \\
\hline & $\mathbf{N}$ & Media & D.Típica & $\mathbf{N}$ & Media & D.Típica & \\
\hline $\begin{array}{c}\text { Alb precirugía } \\
(\mathrm{g} / \mathrm{L})\end{array}$ & 7 & 3,67 & 0,95 & 4 & 4,69 & 0,17 & $<0,05$ \\
\hline $\begin{array}{c}\text { Alb } 3 \text { meses } \\
\text { (g/L) }\end{array}$ & 56 & 4,03 & 0,36 & 22 & 4,16 & 0,60 & NS \\
\hline $\begin{array}{c}\text { Alb } 6 \text { meses } \\
\text { (g/L) }\end{array}$ & 40 & 4,03 & 0,31 & 21 & 4,20 & 0,33 & $<0,05$ \\
\hline $\begin{array}{l}\text { Alb } 9 \text { meses } \\
\text { (g/L) }\end{array}$ & 29 & 4,04 & 0,28 & 14 & 4,14 & 0,36 & NS \\
\hline
\end{tabular}




\begin{tabular}{|c|c|c|c|c|c|c|c|}
\hline & \multicolumn{3}{|c|}{ Mujer } & \multicolumn{3}{|c|}{ Hombre } & \multirow{2}{*}{$\mathbf{P}$} \\
\hline & $\mathbf{N}$ & Media & D.Típica & $\mathbf{N}$ & Media & D.Típica & \\
\hline $\begin{array}{c}\text { Alb } 12 \text { meses } \\
(\mathrm{g} / \mathrm{L})\end{array}$ & 48 & 4,03 & 0,34 & 15 & 4,24 & 0,35 & $<0,05$ \\
\hline $\begin{array}{c}\text { Alb } 18 \text { meses } \\
\text { (g/L) }\end{array}$ & 44 & 4,05 & 0,36 & 16 & 4,24 & 0,34 & NS \\
\hline $\begin{array}{c}\text { Alb } 24 \text { meses } \\
\text { (g/L) }\end{array}$ & 50 & 4,10 & 0,36 & 22 & 4,23 & 0,32 & NS \\
\hline
\end{tabular}

Tabla 4.11.6.5. Descripción de la albúmina (Alb) plasmática en las diferentes revisiones evaluadas según el sexo

Por mediana de edad (tabla 4.11.6.6) se observan unos valores medios de Alb más elevados en el grupo de los < 42 años, siendo esta diferencia estadísticamente significativa en el control de los 3 meses postquirúrgicos.

\begin{tabular}{|c|c|c|c|c|c|c|c|}
\cline { 2 - 7 } & \multicolumn{3}{|c|}{$<42$ años } & \multicolumn{3}{c|}{$\geq \mathbf{4 2}$ años } & \multirow{2}{*}{ P } \\
\cline { 2 - 7 } & $\mathbf{N}$ & Media & D.Típica & $\mathbf{N}$ & Media & D.Típica & \\
\hline $\begin{array}{c}\text { Alb precirugía } \\
\text { (g/L) }\end{array}$ & 4 & 4,46 & 0,23 & 7 & 3,80 & 1,07 & NS \\
\hline $\begin{array}{c}\text { Alb 3 meses } \\
\text { (g/L) }\end{array}$ & 37 & 4,22 & 0,46 & 41 & 3,92 & 0,37 & $<0,05$ \\
\hline $\begin{array}{c}\text { Alb 6 meses } \\
\text { (g/L) }\end{array}$ & 28 & 4,11 & 0,26 & 33 & 4,07 & 0,37 & NS \\
\hline $\begin{array}{c}\text { Alb 9 meses } \\
\text { (g/L) }\end{array}$ & 17 & 4,09 & 0,25 & 26 & 4,05 & 0,35 & NS \\
\hline $\begin{array}{c}\text { Alb 12 meses } \\
\text { (g/L) }\end{array}$ & 30 & $4,11^{\dagger \dagger}$ & 0,34 & 33 & 4,05 & 0,36 & NS \\
\hline $\begin{array}{c}\text { Alb 18 meses } \\
\text { (g/L) }\end{array}$ & 31 & 4,17 & 0,37 & 29 & 4,02 & 0,34 & NS \\
\hline $\begin{array}{c}\text { Alb 24 meses } \\
\text { (g/L) }\end{array}$ & 38 & 4,20 & 0,30 & 34 & 4,07 & 0,39 & NS \\
\hline
\end{tabular}

Tabla 4.11.6.6. Descripción de la albúmina (Alb) plasmática en las diferentes revisiones evaluadas según el grupo de edad

A página completa en la figura 4.11.6.3, se muestra la evolución de las proteínas totales y la albúmina plasmática en los hombres y las mujeres respecto a la mediana de edad desde la primera consulta hasta los 2 años de la cirugía, teniendo en cuenta los valores límite de referencia. Los valores medios de Prot.T en los hombres y las mujeres en todos los controles se encuentran por encima del límite máximo de referencia. Ambos sexos independientemente de la edad presentan una misma tendencia en la evolución de las Prot.T. 
Del mismo modo ocurre con los valore de Alb, la tendencia en ambos sexos se comporta de la misma forma independientemente de la mediana de edad. En todos los controles evaluados la Alb plasmática media está dentro de los valores límite de referencia (3,5-5,2 g/L). 


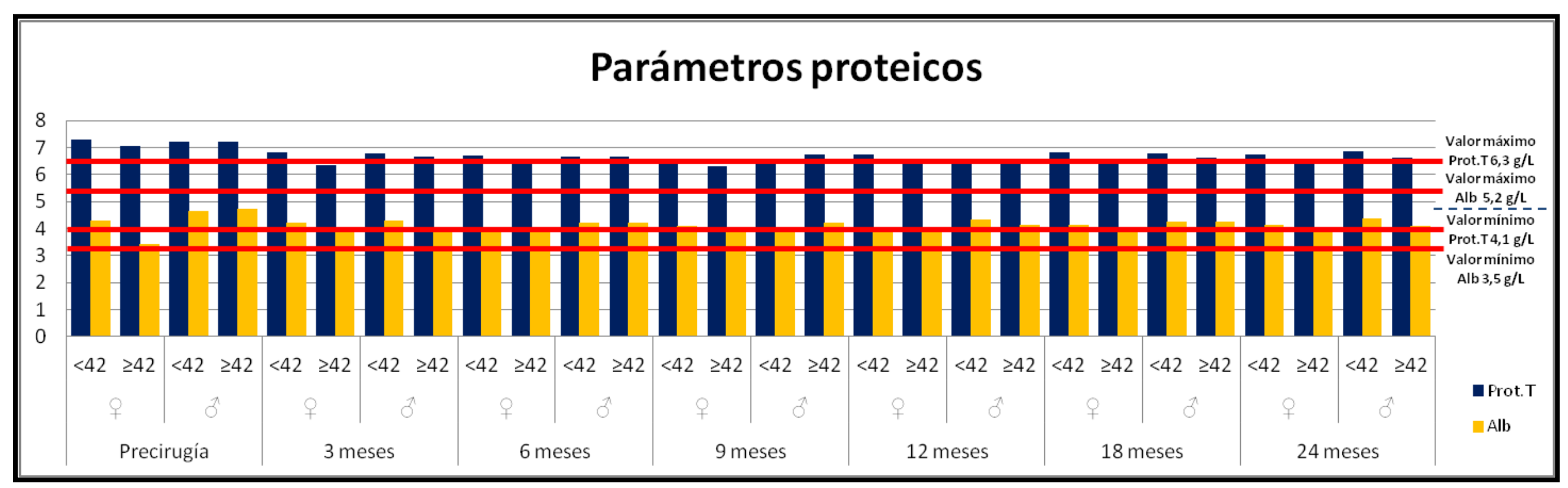

Figura 4.11.6.3. Gráfico de barras de las proteínas totales y la albúmina plasmática en los diferentes controles evaluados según el sexo y el grupo de edad correspondiente en cada uno de ellos 


\subsubsection{Ferritina}

En la tabla 4.11.6.7 se muestra la evolución de la ferritina plasmática en las diferentes revisiones evaluadas, observando un aumento de los valores medios en el primer control postquirúrgico desde el cual disminuye de manera progresiva hasta alcanzar su valor más bajo a los 24 meses de la cirugía. La disminución de la ferritina desde la primera consulta comparado con los valores obtenidos a los 2 años del BAGUA disminuye de manera significativa $(P<0,001)$.

\begin{tabular}{|c|c|c|c|c|c|c|c|}
\hline & $\begin{array}{c}\text { Ferritina } \\
\text { precirugía } \\
\text { (ng/mL) }\end{array}$ & $\begin{array}{c}\text { Ferritina } \\
3 \\
\text { meses } \\
\text { (ng/mL) }\end{array}$ & $\begin{array}{c}\text { Ferritina } \\
6 \\
\text { meses } \\
(\mathrm{ng} / \mathrm{mL})\end{array}$ & $\begin{array}{c}\text { Ferritina } \\
9 \\
\text { meses } \\
\text { (ng/mL) }\end{array}$ & $\begin{array}{c}\text { Ferritina } \\
12 \\
\text { meses } \\
\text { (ng/mL) }\end{array}$ & $\begin{array}{c}\text { Ferritina } \\
18 \\
\text { meses } \\
\text { (ng/mL) }\end{array}$ & $\begin{array}{c}\text { Ferritina } \\
24 \\
\text { meses } \\
\text { (ng/mL) }\end{array}$ \\
\hline $\mathbf{N}$ & 80 & 82 & 71 & 57 & 71 & 70 & 87 \\
\hline Media & 123,34 & $174,12^{*^{\dagger}}$ & $153,96^{\star}$ & $137,07^{\star}$ & 115,38 & $105,48^{\dagger \dagger}$ & $88,64^{\star^{\dagger}}$ \\
\hline D.Típica & 121,22 & 145,94 & 115,72 & 118,11 & 119,40 & 112,01 & 97,68 \\
\hline Mediana & 74,50 & 130,55 & 118,10 & 94 & 58 & 50,85 & 39,50 \\
\hline $\begin{array}{c}\text { Rango } \\
\text { intercuartílico } \\
\text { (P25-P75) }\end{array}$ & $\begin{array}{l}33,13- \\
182,38\end{array}$ & $\begin{array}{l}57,29- \\
253,25\end{array}$ & $\begin{array}{l}63,50- \\
240,86\end{array}$ & $\begin{array}{l}39,25- \\
232,30\end{array}$ & $24-211$ & $\begin{array}{c}12,23- \\
183\end{array}$ & $\begin{array}{c}12- \\
157,75\end{array}$ \\
\hline \multicolumn{8}{|c|}{$\begin{array}{l}{ }^{*} \mathrm{P}<0,05 \text { comparado con el control anterior } \\
01 \text { comparado con el control prequirúrgico }\end{array}$} \\
\hline
\end{tabular}

Tabla 4.11.6.7. Descripción de la ferritina plasmática en las diferentes revisiones evaluadas

En la figura 4.11.6.4 se detalla la evolución de la ferritina en relación a los valores límite de referencia (10-300 ng/mL). Cabe destacar la presencia de los valores más elevados de ferritina en los 3 meses postquirúrgicos. Según el valor límite de referencia inferior el número de pacientes por debajo de 10 $\mathrm{ng} / \mathrm{mL}$ aumenta desde el $6^{\circ}$ mes postquirúrgico; observando a un 8,45\% y un $16,09 \%$ de los pacientes al año y los 2 años de la cirugía respectivamente.

Con un comportamiento totalmente opuesto el porcentaje de pacientes que se encontraban por encima del valor límite máximo, fue mayor en las primeras revisiones $(11,25 \%$ de pacientes en la primera consulta y el $14,63 \%$ a los 3 meses) en comparación con las últimas revisiones evaluadas (5,71\% de pacientes a los 18 meses y el 4,59\% de pacientes a los 24 meses). 


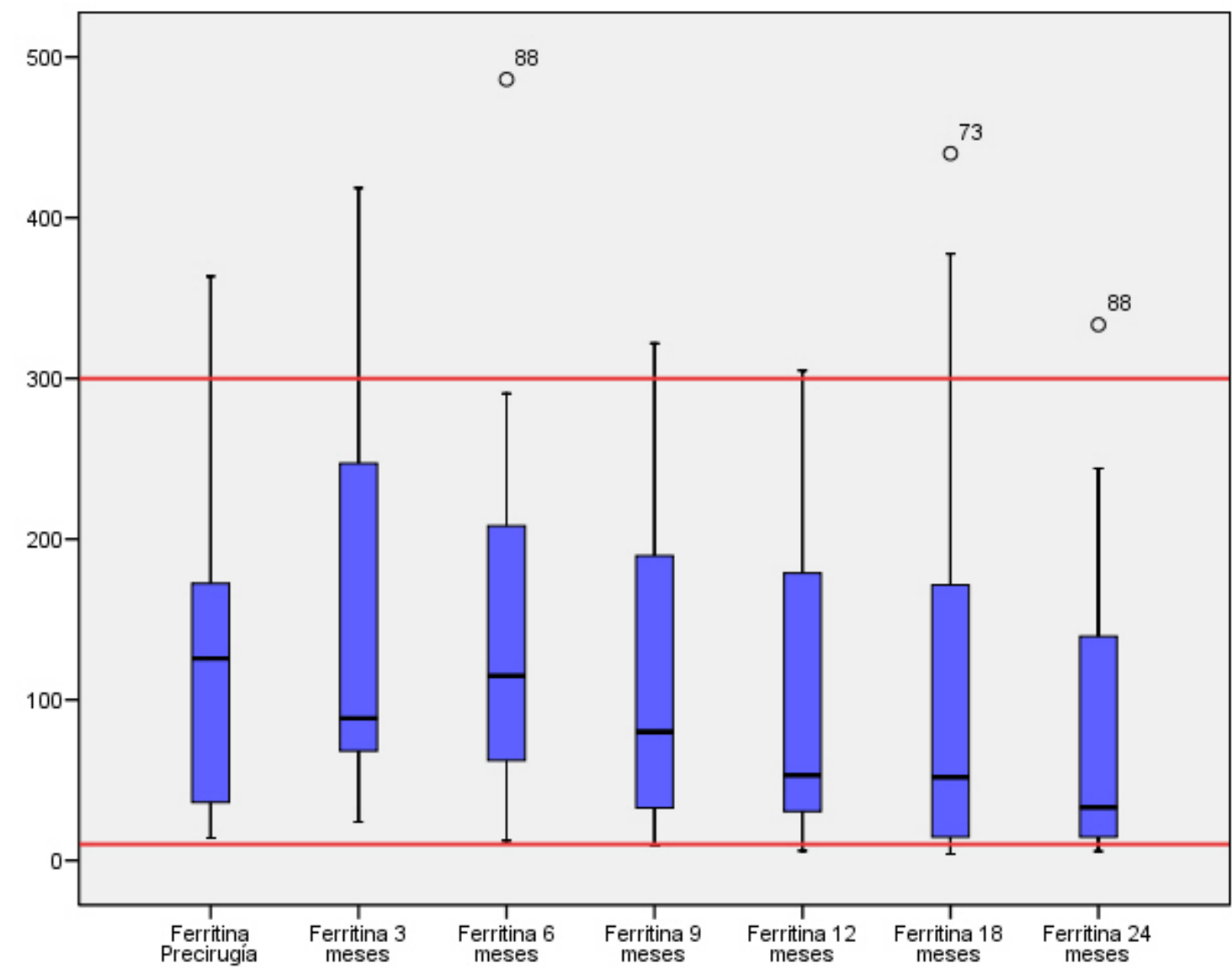

Figura 4.11.6.4. Diagrama de caja de la ferritina plasmática en los diferentes controles evaluados representando los valores de referencia en el eje de ordenadas

Al estudiar el comportamiento de la ferritina en función del sexo, tabla 4.11.6.8, se aprecian unos valores muy superiores en los varones respecto de las mujeres en todos los controles evaluados siendo esta diferencia estadísticamente significativa $(P<0,001)$. Dentro del grupo de las mujeres se observa a los 3 y 6 meses como la ferritina aumenta de manera significativa respecto al control prequirúrgico. Desde los 9 meses empiezan a bajar los niveles de ferritina, siendo a los 24 meses el valor más bajo $(P<0,001)$.

En los varones se describe una disminución significativa de la ferritina en el control de los 12 y 18 meses $(P<0,05)$ y más elevada a los 24 meses con un valor medio de 172,23 ng/mL $(P<0,001)$. 


\begin{tabular}{|c|c|c|c|c|c|c|c|}
\hline & \multicolumn{3}{|c|}{ Mujer } & \multicolumn{3}{|c|}{ Hombre } & \multirow{2}{*}{$\mathbf{P}$} \\
\hline & $\mathbf{N}$ & Media & D.Típica & $\mathbf{N}$ & Media & D.Típica & \\
\hline $\begin{array}{l}\text { Ferritina } \\
\text { precirugía } \\
\text { (ng/mL) }\end{array}$ & 58 & 69,50 & 58,67 & 22 & 265,29 & 129,69 & $<0,001$ \\
\hline $\begin{array}{c}\text { Ferritina } 3 \\
\text { meses }(\mathrm{ng} / \mathrm{mL})\end{array}$ & 59 & $138,10^{\dagger}$ & 139,13 & 23 & 266,53 & 122,40 & $<0,001$ \\
\hline $\begin{array}{c}\text { Ferritina } 6 \\
\text { meses }(\mathrm{ng} / \mathrm{mL})\end{array}$ & 50 & $107,72^{\dagger \dagger}$ & 88,80 & 21 & 264,07 & 97,35 & $<0,001$ \\
\hline $\begin{array}{c}\text { Ferritina } 9 \\
\text { meses }(\mathrm{ng} / \mathrm{mL})\end{array}$ & 38 & 96,01 & 88,91 & 19 & 219,20 & 128,34 & $<0,001$ \\
\hline $\begin{array}{c}\text { Ferritina } 12 \\
\text { meses (ng/mL) }\end{array}$ & 53 & 81,47 & 87,87 & 18 & $215,22^{\dagger \dagger}$ & 144,74 & $<0,001$ \\
\hline $\begin{array}{c}\text { Ferritina } 18 \\
\text { meses (ng/mL) }\end{array}$ & 50 & 68,23 & 82,21 & 20 & $198,58^{\dagger \dagger}$ & 123,94 & $<0,001$ \\
\hline $\begin{array}{c}\text { Ferritina } 24 \\
\text { meses (ng/mL) }\end{array}$ & 64 & $58,60^{\dagger \dagger}$ & 74,15 & 23 & $172,23^{\dagger}$ & 107,81 & $<0,001$ \\
\hline
\end{tabular}

Tabla 4.11.6.8. Descripción de ferritina plasmática en las diferentes revisiones evaluadas según el sexo

Del mismo modo al evaluar la ferritina por grupos de edad, tabla 4.11.6.9, se describen unos valores más elevados en los $\geq 42$ años en todas las series, siendo esta diferencia estadísticamente significativa en la precirugía, 12, 18 y 24 meses postquirúrgicos.

\begin{tabular}{|c|c|c|c|c|c|c|c|}
\hline & \multicolumn{3}{|c|}{$<42$ años } & \multicolumn{3}{|c|}{$\geq 42$ años } & \multirow{2}{*}{$\mathbf{P}$} \\
\hline & $\mathbf{N}$ & Media & D.Típica & $\mathbf{N}$ & Media & D.Típica & \\
\hline $\begin{array}{l}\text { Ferritina } \\
\text { precirugía } \\
\text { (ng/mL) }\end{array}$ & 37 & 86,34 & 92,59 & 43 & 155,18 & 134,33 & $<0,05$ \\
\hline $\begin{array}{c}\text { Ferritina } 3 \\
\text { meses (ng/mL) }\end{array}$ & 39 & $147,61^{\dagger}$ & 113,98 & 43 & $198,17^{\dagger \dagger}$ & 167,56 & NS \\
\hline $\begin{array}{c}\text { Ferritina } 6 \\
\text { meses (ng/mL) }\end{array}$ & 35 & $140,90^{\dagger \dagger}$ & 107,79 & 36 & 166,67 & 123,13 & NS \\
\hline $\begin{array}{c}\text { Ferritina } 9 \\
\text { meses (ng } / \mathrm{mL})\end{array}$ & 25 & 118,96 & 103,23 & 32 & 151,22 & 128,37 & NS \\
\hline $\begin{array}{c}\text { Ferritina } 12 \\
\text { meses (ng } / \mathrm{mL} \text { ) }\end{array}$ & 31 & 68,55 & 91,27 & 40 & 151,67 & 126,84 & $<0,05$ \\
\hline $\begin{array}{c}\text { Ferritina } 18 \\
\text { meses (ng/mL) }\end{array}$ & 35 & $80,28^{\dagger}$ & 106,94 & 35 & 130,67 & 112,78 & $<0,05$ \\
\hline $\begin{array}{c}\text { Ferritina } 24 \\
\text { meses (ng/mL) }\end{array}$ & 42 & $67,89^{\dagger}$ & 92,85 & 45 & $108,01^{\dagger \dagger}$ & 99,10 & $<0,05$ \\
\hline
\end{tabular}

Tabla 4.11.6.9. Descripción de ferritina plasmática en las diferentes revisiones evaluadas según el grupo de edad 
Dentro del grupo del grupo de los $<42$ años, la ferritina aumenta desde la precirugía a los 3 meses $(P<0,001)$, al igual que a los 6 meses $(P<0,05)$.

Desde los 9 meses se inicia el descenso de la ferritina, observando una disminución significativa en el control de los 18 y 24 meses respecto al valor prequirúrgico $(\mathrm{P}<0,001)$.

Los $\geq 42$ años parten con unos valores prequirúrgicos de ferritina más elevados, aumentando a los 3 meses $(P<0,05)$, desde el cual disminuyen, registrando el valor más bajo a los 24 meses respecto al valor inicial $(P<0,05)$. 


\subsubsection{Minerales}

A continuación se describe la evolución de los minerales: hierro, calcio y fósforo, por ser estos de los principales minerales en el cuerpo humano y así poder observar las modificaciones que sufren tras la cirugía de BAGUA, al excluir el paso de los alimentos por el duodeno y yeyuno, dónde se produce mayoritariamente su absorción.

\subsubsection{Hierro}

Los valores medios de hierro plasmático, como se muestra en la tabla 4.11.7.1, disminuyen de manera significativa desde la primera consulta a los 3 meses siendo este control en el que se describe un valor medio de hierro más bajo $(P<0,05)$. A los 6 meses aumenta ligeramente, continuando esta tendencia hasta los 9 meses $(P<0,05)$, a los 12 meses de la cirugía el hierro apenas sufre modificaciones respecto al control anterior, aumentando a los 18 meses de nuevo y cayendo en último control sin variaciones significativas. Al comparar los valores de hierro en la primera consulta con los obtenidos a los 24 meses de la cirugía no se observan cambios significativos.

\begin{tabular}{|c|c|c|c|c|c|c|c|}
\hline & $\begin{array}{c}\text { Hierro } \\
\text { precirugía } \\
(\mu \mathrm{g} / \mathrm{dL})\end{array}$ & $\begin{array}{c}\text { Hierro } \\
3 \\
\text { meses } \\
(\mu g / d L)\end{array}$ & $\begin{array}{c}\text { Hierro } \\
6 \\
\text { meses } \\
(\mu \mathrm{g} / \mathrm{dL})\end{array}$ & $\begin{array}{c}\text { Hierro } \\
9 \\
\text { meses } \\
(\mu \mathrm{g} / \mathrm{dL})\end{array}$ & $\begin{array}{c}\text { Hierro } \\
12 \\
\text { meses } \\
(\mu g / d L)\end{array}$ & $\begin{array}{c}\text { Hierro } \\
18 \\
\text { meses } \\
(\mu \mathrm{g} / \mathrm{dL})\end{array}$ & $\begin{array}{c}\text { Hierro } \\
24 \\
\text { meses } \\
(\mu g / d L)\end{array}$ \\
\hline $\mathbf{N}$ & 85 & 87 & 69 & 58 & 76 & 69 & 86 \\
\hline Media & 81,79 & $70,45^{\star^{\dagger \dagger}}$ & $73,34^{\dagger \dagger}$ & $78,93^{\star}$ & 78,63 & 80,40 & 76,49 \\
\hline D.Típica & 30,53 & 19,58 & 23,55 & 28,35 & 27,30 & 34,95 & 30,49 \\
\hline Mediana & 76 & 72 & 71 & 78 & 77 & 80 & 79,50 \\
\hline $\begin{array}{c}\text { Rango } \\
\text { intercuartílico } \\
\text { (P25-P75) }\end{array}$ & $\begin{array}{l}62,50- \\
98,95\end{array}$ & $58-82$ & $57-90,60$ & $\begin{array}{l}62,75- \\
94,25\end{array}$ & $\begin{array}{l}61,10- \\
93,30\end{array}$ & 61-101 & $54,50-95$ \\
\hline
\end{tabular}

Tabla 4.117.1. Descripción del hierro plasmático en las diferentes revisiones evaluadas

Al estudiar el número de pacientes que se encontraban fuera de los valores límite de referencia del hierro (50-175 $\mu \mathrm{g} / \mathrm{dL})$ por encima de ese valor máximo sólo se observó en la precirugía en un 1,17\% y en el control de los 18 meses en el $1,44 \%$ de los pacientes. 
Por el contrario, como se aprecia en la figura 4.11.7.1, el número de pacientes por debajo del valor límite inferior antes de la cirugía era del $10,58 \%$, aumentando ligeramente a los 3 meses en un 11,49\%, tendencia que continua en ascenso hasta los 9 meses (15,51\%).

Al año de la intervención el número de pacientes por debajo del valor límite inferior desciende en un $13,15 \%$, porcentaje que seguiría creciendo hasta observar a los 24 meses al $20,93 \%$ de los pacientes con valores por debajo del límite inferior de referencia $(50 \mu \mathrm{g} / \mathrm{dL})$.

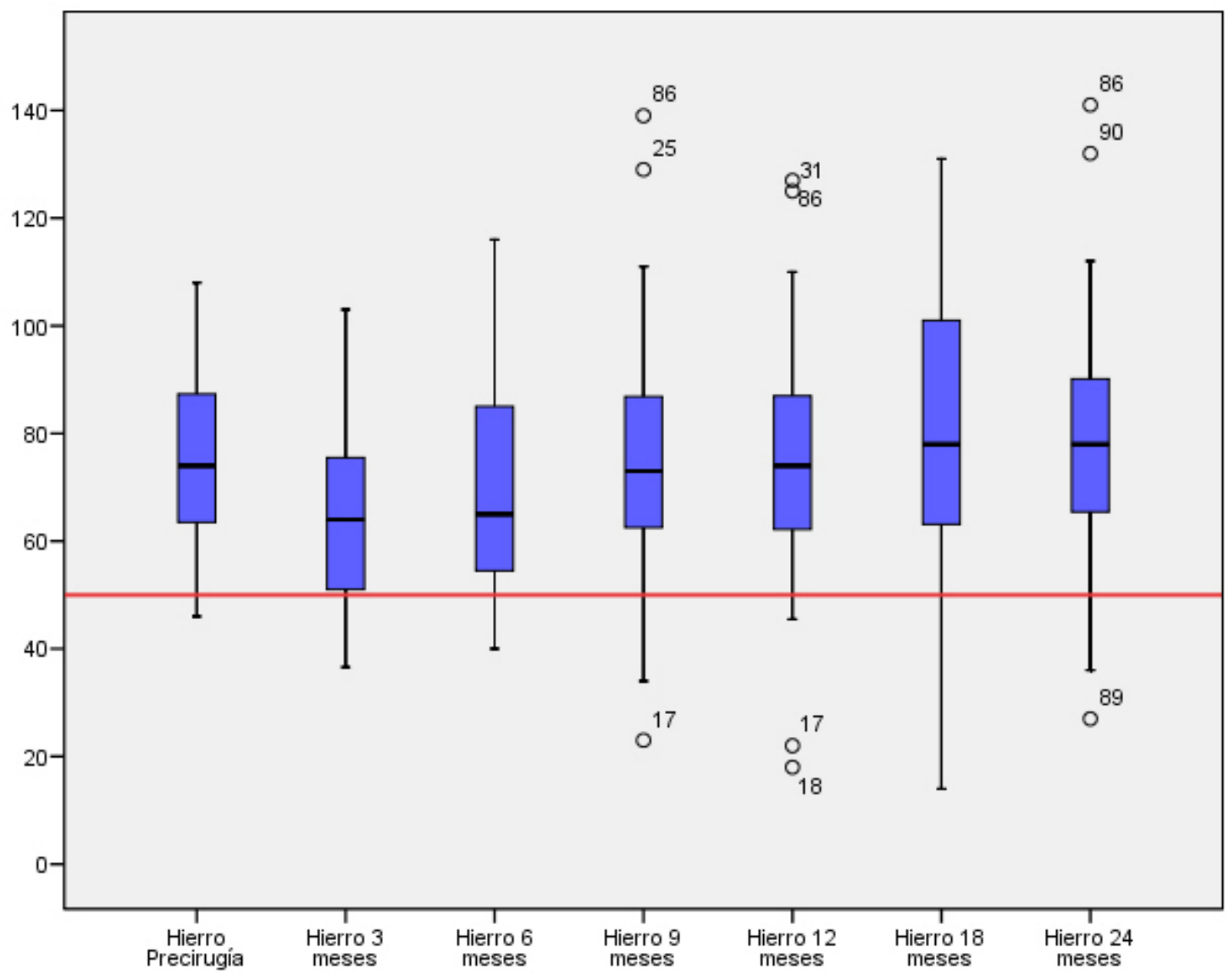

Figura 4.11.7.1. Diagrama de caja del hierro plasmático en los diferentes controles evaluados representando los valores de referencia en el eje de ordenadas

En la tabla 4.11.7.2 se describe la evolución del hierro plasmático en función del sexo, siendo los varones quienes registran valores medios más elevados de hierro es todos los controles siendo esta diferencia estadísticamente significativa a los 6, 12 y 18 meses postquirúrgicos. 
En el grupo de las mujeres la disminución del hierro en relación al valor prequirúrgico es significativa $(P<0,05)$ a los 3 y 6 meses. En los varones por el contrario se observa un aumento significativo del hierro a los 18 meses en relación al valor prequirúrgico $(P<0,05)$, en el resto de controles las variaciones de hierro no son significativas.

\begin{tabular}{|c|c|c|c|c|c|c|c|}
\hline & \multicolumn{3}{|c|}{ Mujer } & \multicolumn{3}{|c|}{ Hombre } & \multirow{2}{*}{$\mathbf{P}$} \\
\hline & $\mathbf{N}$ & Media & D.Típica & $\mathbf{N}$ & Media & D.Típica & \\
\hline $\begin{array}{c}\text { Hierro } \\
\text { precirugía } \\
(\mu \mathrm{g} / \mathrm{dL})\end{array}$ & 62 & 81,15 & 32,58 & 23 & 83,52 & 24,76 & NS \\
\hline $\begin{array}{c}\text { Hierro } 3 \\
\text { meses }(\mu \mathrm{g} / \mathrm{dL})\end{array}$ & 62 & $68,65^{{ }^{\dagger}}$ & 20,79 & 25 & 74,93 & 15,68 & NS \\
\hline $\begin{array}{c}\text { Hierro } 6 \\
\text { meses }(\mu \mathrm{g} / \mathrm{dL})\end{array}$ & 48 & $68,45^{\dagger \dagger}$ & 22,50 & 21 & 84,53 & 22,54 & $<0,001$ \\
\hline $\begin{array}{c}\text { Hierro } 9 \\
\text { meses }(\mu \mathrm{g} / \mathrm{dL})\end{array}$ & 38 & 75,19 & 27,27 & 20 & 86,04 & 29,70 & NS \\
\hline $\begin{array}{c}\text { Hierro } 12 \\
\text { meses }(\mu \mathrm{g} / \mathrm{dL})\end{array}$ & 56 & 76,02 & 27,63 & 20 & 85,92 & 25,62 & NS \\
\hline $\begin{array}{c}\text { Hierro } 18 \\
\text { meses }(\mu \mathrm{g} / \mathrm{dL})\end{array}$ & 49 & 75,48 & 35,59 & 20 & $92,46^{\dagger \dagger}$ & 30,93 & $<0,05$ \\
\hline $\begin{array}{c}\text { Hierro } 24 \\
\text { meses }(\mu \mathrm{g} / \mathrm{dL})\end{array}$ & 62 & 70,72 & 29,07 & 24 & 91,42 & 29,53 & $<0,05$ \\
\hline
\end{tabular}

Tabla 4.11.7.2. Descripción del hierro plasmático en las diferentes revisiones evaluadas según el sexo

Al observar las variaciones del hierro plasmático en los dos grupos de edad, tabla 4.11.7.3, se aprecia en la consulta previa a la cirugía un valor más elevado de manera significativa en el grupo de mayor edad. Todo lo contrario ocurre en el inmediato control postquirúrgico en el que el grupo de los $<42$ años presentan valores de hierro más elevados $(P<0,05)$.

En los siguientes controles hasta los 24 meses postquirúrgicos estudiados, los valores de hierro son superiores en el grupo de mayor edad respecto a los < 42 años, sin ser esta una diferencia significativa estadísticamente. Dentro del grupo de los $\geq 42$ años sólo se observa una disminución significativa en los valores de hierro comparados con el control prequirúrgico a los 3 y 6 meses. 


\begin{tabular}{|c|c|c|c|c|c|c|c|}
\hline & \multicolumn{3}{|c|}{$<42$ años } & \multicolumn{3}{|c|}{$\geq 42$ años } & \multirow{2}{*}{$\mathbf{P}$} \\
\hline & $\mathbf{N}$ & Media & D.Típica & $\mathbf{N}$ & Media & D.Típica & \\
\hline $\begin{array}{c}\text { Hierro } \\
\text { precirugía } \\
(\mu \mathrm{g} / \mathrm{dL})\end{array}$ & 40 & 74,87 & 34,17 & 45 & 87,95 & 25,75 & $<0,05$ \\
\hline $\begin{array}{c}\text { Hierro } 3 \\
\text { meses }(\mu \mathrm{g} / \mathrm{dL})\end{array}$ & 41 & 75,17 & 19,61 & 46 & $66,25^{\dagger}$ & 18,76 & $<0,05$ \\
\hline $\begin{array}{c}\text { Hierro } 6 \\
\text { meses }(\mu \mathrm{g} / \mathrm{dL})\end{array}$ & 35 & 72,54 & 27,42 & 34 & $74,16^{\dagger \dagger}$ & 19,16 & NS \\
\hline $\begin{array}{c}\text { Hierro } 9 \\
\text { meses }(\mu \mathrm{g} / \mathrm{dL})\end{array}$ & 25 & 78,40 & 31,12 & 33 & 79,34 & 26,55 & NS \\
\hline $\begin{array}{c}\text { Hierro } 12 \\
\text { meses }(\mu \mathrm{g} / \mathrm{dL})\end{array}$ & 33 & 74,07 & 30,07 & 43 & 82,13 & 24,77 & NS \\
\hline $\begin{array}{c}\text { Hierro } 18 \\
\text { meses }(\mu \mathrm{g} / \mathrm{dL})\end{array}$ & 35 & 75,08 & 39,99 & 34 & 85,88 & 28,44 & NS \\
\hline $\begin{array}{c}\text { Hierro } 24 \\
\text { meses }(\mu \mathrm{g} / \mathrm{dL})\end{array}$ & 43 & 73,02 & 29,35 & 43 & 79,97 & 31,55 & NS \\
\hline
\end{tabular}

Tabla 4.11.7.3. Descripción del hierro plasmático en las diferentes revisiones evaluadas según el grupo de edad

\subsubsection{Calcio}

Los valores medios de calcio plasmáticos se expresan en la tabla 4.11.7.4, apreciando una disminución de los valores medios desde la primera consulta hasta los 2 años posteriores a la cirugía.

El calcio plasmático medio desde la primera consulta respecto a los resultados a los 18 y 24 meses de la cirugía experimentó un descenso significativo $(P<0,05)$.

\begin{tabular}{|c|c|c|c|c|c|c|c|}
\hline & $\begin{array}{c}\text { Calcio } \\
\text { precirugía } \\
\text { (mg/dL) }\end{array}$ & $\begin{array}{c}\text { Calcio } \\
3 \\
\text { meses } \\
\text { (mg/dL) }\end{array}$ & $\begin{array}{c}\text { Calcio } \\
6 \\
\text { meses } \\
\text { (mg/dL) }\end{array}$ & $\begin{array}{c}\text { Calcio } \\
9 \\
\text { meses } \\
\text { (mg/dL) }\end{array}$ & $\begin{array}{c}\text { Calcio } \\
12 \\
\text { meses } \\
\text { (mg/dL) }\end{array}$ & $\begin{array}{c}\text { Calcio } \\
18 \\
\text { meses } \\
\text { (mg/dL) }\end{array}$ & $\begin{array}{c}\text { Calcio } \\
24 \\
\text { meses } \\
\text { (mg/dL) }\end{array}$ \\
\hline $\mathbf{N}$ & 22 & 85 & 68 & 49 & 74 & 66 & 88 \\
\hline Media & 9,41 & 9,25 & 9,19 & 9,13 & 9,15 & $9,14^{\dagger \dagger}$ & $9,19^{\dagger \dagger}$ \\
\hline D.Típica & 0,55 & 0,69 & 0,79 & 0,48 & 0,44 & 0,45 & 0,51 \\
\hline Mediana & 9,43 & 9,28 & 9,21 & 9,10 & 9,20 & 9,10 & 9,15 \\
\hline $\begin{array}{c}\text { Rango } \\
\text { intercuartílico } \\
\text { (P25-P75) }\end{array}$ & $8,98-9,80$ & $\begin{array}{l}9,05- \\
9,50\end{array}$ & $9-9,51$ & $\begin{array}{c}8,90- \\
9,45\end{array}$ & $\begin{array}{l}8,83- \\
9,40\end{array}$ & $\begin{array}{c}8,80- \\
9,50\end{array}$ & $\begin{array}{c}8,82- \\
9,46\end{array}$ \\
\hline
\end{tabular}

Tabla 4.11.7.4. Descripción calcio plasmático en las diferentes revisiones evaluadas 
En la figura 4.11.7.2, se representa en un diagrama de cajas la evolución del calcio plasmático en referencia a los límites de referencia (8,6-10,2 mg/dL) expresados en el eje de ordenadas. No se observan variaciones significativas del porcentaje de pacientes que se encontraba con valores de calcio por debajo del límite inferior de referencia, siendo en la consulta previa el 4,54\% de los pacientes, en el control de los 9 meses el 8,16\% y descendiendo este valor en los controles sucesivos hasta registrar al 5,68\% de pacientes por debajo del límite de referencia inferior a los 24 meses de la cirugía.

Por el contrario, por encima del valor límite de referencia sólo se describieron pacientes en el control previo a la cirugía $(4,54 \%$ de los pacientes), a los 9 meses (2,04\% de los pacientes) y a los 24 meses $(2,27 \%$ de los pacientes).

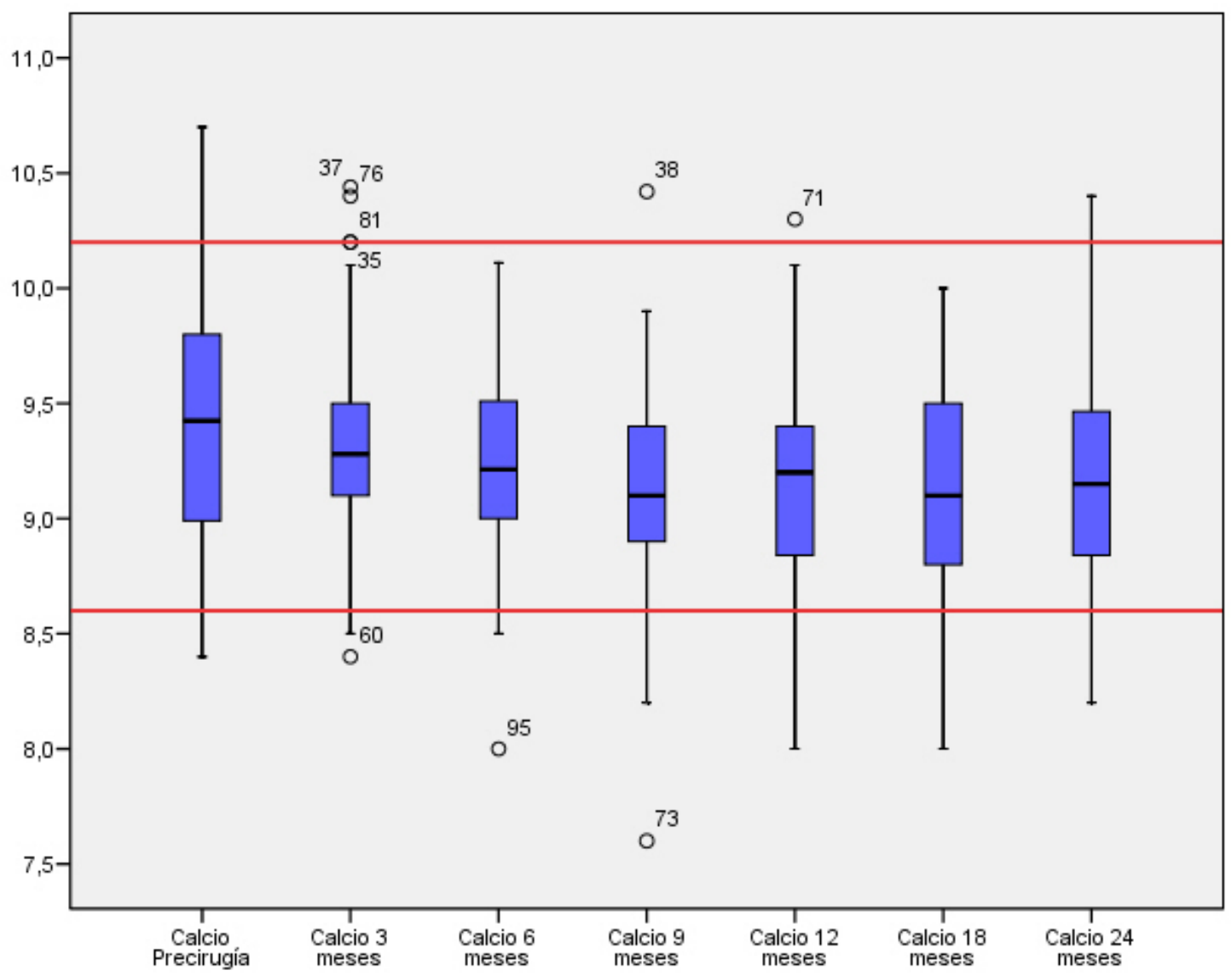

Figura 4.11.7.2. Diagrama de caja del calcio plasmático en los diferentes controles evaluados representando los valores de referencia en el eje de ordenadas 
La evolución del calcio por sexos, tabla 4.11.7.5, muestra como los hombres en todos los controles estudiados presentan valores más elevados que las mujeres sin ser esta diferencia estadísticamente significativa. Del mismo modo, las variaciones del calcio en hombres y en mujeres respecto al valor prequirúrgico no se modificaron significativamente.

\begin{tabular}{|c|c|c|c|c|c|c|c|}
\hline & \multicolumn{3}{|c|}{ Mujer } & \multicolumn{3}{|c|}{ Hombre } & \multirow{2}{*}{$\mathbf{P}$} \\
\hline & $\mathbf{N}$ & Media & D.Típica & $\mathbf{N}$ & Media & D.Típica & \\
\hline $\begin{array}{c}\text { Calcio } \\
\text { precirugía } \\
(\mathrm{mg} / \mathrm{dL})\end{array}$ & 14 & 9,38 & 0,57 & 8 & 9,46 & 0,54 & NS \\
\hline $\begin{array}{c}\text { Calcio } 3 \\
\text { meses (mg/dL) }\end{array}$ & 61 & 9,18 & 0,75 & 24 & 9,41 & 0,46 & NS \\
\hline $\begin{array}{c}\text { Calcio } 6 \\
\text { meses (mg/dL) }\end{array}$ & 46 & 9,10 & 0,89 & 22 & 9,36 & 0,46 & NS \\
\hline $\begin{array}{c}\text { Calcio } 9 \\
\text { meses (mg/dL) }\end{array}$ & 32 & 9,12 & 0,47 & 17 & 9,15 & 0,52 & NS \\
\hline $\begin{array}{c}\text { Calcio } 12 \\
\text { meses (mg/dL) }\end{array}$ & 54 & 9,11 & 0,46 & 20 & 9,27 & 0,35 & NS \\
\hline $\begin{array}{c}\text { Calcio } 18 \\
\text { meses (mg/dL) }\end{array}$ & 46 & 9,10 & 0,43 & 20 & 9,21 & 0,51 & NS \\
\hline $\begin{array}{c}\text { Calcio } 24 \\
\text { meses (mg/dL) }\end{array}$ & 61 & 9,12 & 0,47 & 27 & 9,35 & 0,56 & NS \\
\hline
\end{tabular}

Tabla 4.11.7.5. Descripción del calcio plasmático en las diferentes revisiones evaluadas según el sexo

Por grupos de edad, tabla 4.11.7.6, los valores medios de calcio prácticamente no varían entre los dos grupos. En los < 42 años desde los 12 meses de la cirugía hasta los 24 meses, la reducción en el valor de calcio respecto a la precirugía si fue significativo $(P<0,05)$.

\begin{tabular}{|c|c|c|c|c|c|c|c|}
\cline { 2 - 7 } \multicolumn{1}{c|}{} & \multicolumn{3}{c|}{$<\mathbf{4 2}$ años } & \multicolumn{3}{c|}{$\geq \mathbf{4 2}$ años } & \multirow{2}{*}{$\mathbf{P}$} \\
\cline { 2 - 7 } & $\mathbf{N}$ & Media & D.Típica & $\mathbf{N}$ & Media & D.Típica & \\
\hline $\begin{array}{c}\text { Calcio } \\
\text { precirugía } \\
\text { (mg/dL) }\end{array}$ & 12 & 9,55 & 0,49 & 10 & 9,24 & 0,60 & NS \\
\hline $\begin{array}{c}\text { Calcio 3 meses } \\
\text { (mg/dL) }\end{array}$ & 42 & 9,24 & 0,89 & 43 & 9,26 & 0,42 & NS \\
\hline $\begin{array}{c}\text { Calcio 6 meses } \\
\text { (mg/dL) }\end{array}$ & 33 & 9,18 & 1,04 & 35 & 9,19 & 0,46 & NS \\
\hline $\begin{array}{c}\text { Calcio 9 meses } \\
\text { (mg/dL) }\end{array}$ & 21 & 8,99 & 0,50 & 28 & 9,24 & 0,45 & NS \\
\hline $\begin{array}{c}\text { Calcio 12 } \\
\text { meses (mg/dL) }\end{array}$ & 33 & $9,18^{\dagger \dagger}$ & 0,42 & 41 & 9,13 & 0,45 & NS \\
\hline
\end{tabular}




\begin{tabular}{|c|c|c|c|c|c|c|c|}
\hline & \multicolumn{3}{|c|}{$<42$ años } & \multicolumn{3}{|c|}{$\geq 42$ años } & \multirow{2}{*}{$\mathbf{P}$} \\
\hline & $\mathbf{N}$ & Media & D.Típica & $\mathbf{N}$ & Media & D.Típica & \\
\hline $\begin{array}{c}\text { Calcio } 18 \\
\text { meses (mg/dL) }\end{array}$ & 32 & $9,16^{\dagger \dagger}$ & 0,50 & 34 & 9,11 & 0,41 & NS \\
\hline $\begin{array}{c}\text { Calcio } 24 \\
\text { meses }(\mathrm{mg} / \mathrm{dL})\end{array}$ & 43 & $9,25^{\dagger \dagger}$ & 0,52 & 45 & 9,14 & 0,50 & NS \\
\hline
\end{tabular}

Tabla 4.11.7.6. Descripción del calcio plasmático en las diferentes revisiones evaluadas según el grupo de edad

\subsubsection{Fósforo}

Como se muestra en la tabla 4.11.7.7, la evolución del fósforo plasmático en los diferentes controles evaluados desde la primera consulta hasta los 24 meses de la cirugía no experimenta cambios significativos.

\begin{tabular}{|c|c|c|c|c|c|c|c|}
\cline { 2 - 8 } & $\begin{array}{c}\text { Fósforo } \\
\text { precirugía } \\
\text { (mg/dL) }\end{array}$ & $\begin{array}{c}\text { Fósforo } \\
\mathbf{3} \\
\mathbf{m e s e s} \\
(\mathbf{m g} / \mathbf{d L})\end{array}$ & $\begin{array}{c}\text { Fósforo } \\
\mathbf{6} \\
\mathbf{m e s e s} \\
(\mathbf{m g} / \mathbf{d L})\end{array}$ & $\begin{array}{c}\text { Fósforo } \\
\mathbf{9} \\
\mathbf{m e s e s} \\
(\mathbf{m g} / \mathbf{d L})\end{array}$ & $\begin{array}{c}\text { Fósforo } \\
\mathbf{1 2} \\
\mathbf{m e s e s} \\
(\mathbf{m g} / \mathbf{d L})\end{array}$ & $\begin{array}{c}\text { Fósforo } \\
\mathbf{1 8} \\
\mathbf{m e s e s} \\
(\mathbf{m g} / \mathbf{d L})\end{array}$ & $\begin{array}{c}\text { Fósforo } \\
\mathbf{2 4} \\
\mathbf{m e s e s} \\
(\mathbf{m g} / \mathbf{d L})\end{array}$ \\
\hline $\mathbf{N}$ & 14 & 79 & 64 & 41 & 65 & 61 & 77 \\
\hline Media & 3,58 & 3,83 & 4,04 & 4,02 & 4,11 & 3,89 & 3,83 \\
\hline D.Típica & 0,51 & 0,73 & 0,77 & 0,83 & 0,53 & 0,55 & 0,64 \\
\hline Mediana & 3,45 & 3,70 & 4 & 3,90 & 4,10 & 3,90 & 3,80 \\
\hline $\begin{array}{c}\text { Rango } \\
\text { intercuartílico } \\
\text { (P25-P75) }\end{array}$ & $3,10-3,97$ & $3,50-$ & $3,70-$ & $3,48-$ & $3,75-$ & $3,45-$ & $3,45-$ \\
4,96 & 4,30 & 4,45 & 4,50 & 4,30 & 4,20 \\
\hline
\end{tabular}

Tabla 4.11.7.7. Descripción fósforo plasmático en las diferentes revisiones evaluadas

En relación a los límites de referencia del fósforo en sangre (2,3-4,2 $\mathrm{mg} / \mathrm{dL}$ ), no se observa a ningún paciente por debajo del valor límite inferior en ninguno de los controles.

Por el contrario el número de pacientes que superaba el valor límite máximo fue en la primera consulta del 14,28\%, aumentando progresivamente hasta los 9 meses (29,26\%). Al año de la intervención el 27,69\% de los pacientes superaba el valor límite máximo, manteniéndose a los 18 meses y reduciendo este ligeramente en el último control estudiado $(20,77 \%$ de los pacientes). 


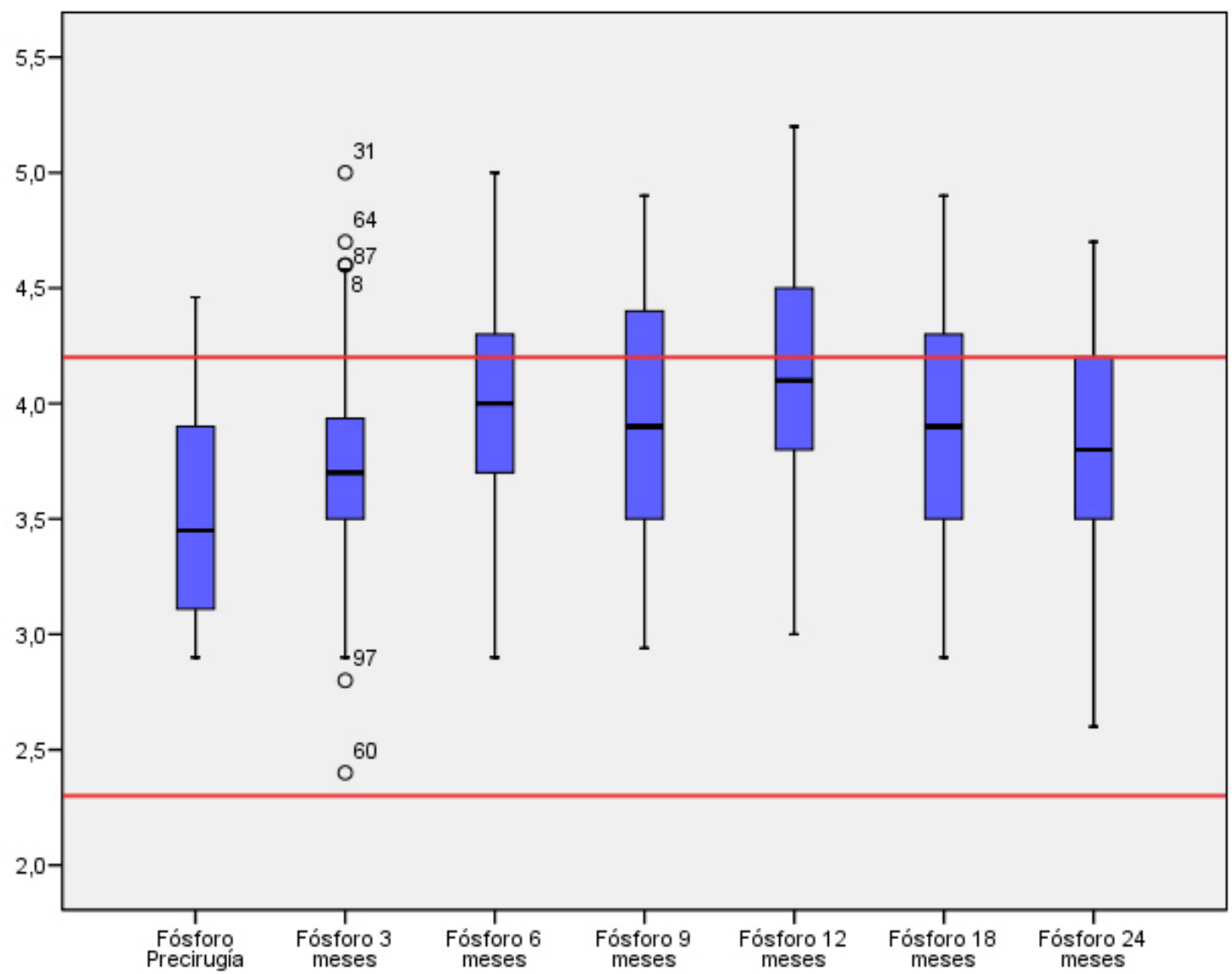

Figura 4.11.7.3. Diagrama de caja del fósforo plasmático en los diferentes controles evaluados representando los valores de referencia en el eje de ordenadas

En todos los controles evaluados, son las mujeres quienes presentan valores medios de fósforo en sangre más elevados (tabla 4.11.7.8), siendo esta diferencia estadísticamente significativa a los 6, 18 y 24 meses postquirúrgicos. En ambos grupos ninguno de los valores de fósforo comparado con el valor medio prequirúrgico muestra diferencias estadísticamente significativas.

\begin{tabular}{|c|c|c|c|c|c|c|c|}
\hline & \multicolumn{3}{|c|}{ Mujer } & \multicolumn{3}{|c|}{ Hombre } & \multirow{2}{*}{$\mathbf{P}$} \\
\hline & $\mathbf{N}$ & Media & D.Típica & $\mathbf{N}$ & Media & D.Típica & \\
\hline $\begin{array}{l}\text { Fósforo precirugía } \\
\text { (mg/dL) }\end{array}$ & 9 & 3,60 & 0,50 & 5 & 3,54 & 0,58 & NS \\
\hline $\begin{array}{c}\text { Fósforo o } 3 \text { meses } \\
\text { (mg/dL) }\end{array}$ & 56 & 3,88 & 0,82 & 23 & 3,67 & 0,44 & NS \\
\hline $\begin{array}{l}\text { Fósforo } 6 \text { meses } \\
\text { (mg/dL) }\end{array}$ & 43 & 4,17 & 0,84 & 21 & 3,78 & 0,56 & $<0,05$ \\
\hline $\begin{array}{l}\text { Fósforo } 9 \text { meses } \\
(\mathrm{mg} / \mathrm{dL})\end{array}$ & 28 & 4,10 & 0,94 & 13 & 3,86 & 0,52 & NS \\
\hline $\begin{array}{c}\text { Fósforo } 12 \text { meses } \\
\text { (mg/dL) }\end{array}$ & 46 & 4,18 & 0,52 & 19 & 3,93 & 0,53 & NS \\
\hline
\end{tabular}




\begin{tabular}{|c|c|c|c|c|c|c|c|}
\hline & \multicolumn{3}{|c|}{ Mujer } & \multicolumn{3}{|c|}{ Hombre } & \multirow{2}{*}{$\mathbf{P}$} \\
\hline & $\mathbf{N}$ & Media & D.Típica & $\mathbf{N}$ & Media & D.Típica & \\
\hline $\begin{array}{l}\text { Fósforo } 18 \text { meses } \\
(\mathrm{mg} / \mathrm{dL})\end{array}$ & 43 & 4,03 & 0,51 & 18 & 3,56 & 0,50 & $<0,05$ \\
\hline $\begin{array}{l}\text { Fósforo } 24 \text { meses } \\
\text { (mg/dL) }\end{array}$ & 53 & 3,95 & 0,68 & 24 & 3,55 & 0,41 & $<0,05$ \\
\hline
\end{tabular}

Tabla 4.11.7.8. Descripción del fósforo plasmático en las diferentes revisiones evaluadas según el sexo

Por grupos de edad, tabla 4.11.7.9, es el grupo de los $<42$ años quienes describen valores medios más elevados de fósforo en sangre hasta los 9 meses, siendo este el único control en el que el fósforo es más elevado en el grupo de mayor edad. A partir del año de la cirugía hasta los 24 meses postquirúrgicos evaluados, son los < 42 años quienes presentan valores de fósforo más elevados siendo esta diferencia estadísticamente significativa a los 12 meses.

En ambos grupos de edad, ninguno de los valores de fósforo comparado con el valor medio prequirúrgico se vio modificado de manera significativa.

\begin{tabular}{|c|c|c|c|c|c|c|c|}
\hline & \multicolumn{3}{|c|}{$<42$ años } & \multicolumn{3}{|c|}{$\geq 42$ años } & \multirow{2}{*}{$\mathbf{P}$} \\
\hline & $\mathbf{N}$ & Media & D.Típica & $\mathbf{N}$ & Media & D.Típica & \\
\hline $\begin{array}{l}\text { Fósforo precirugía } \\
\text { (mg/dL) }\end{array}$ & 7 & 3,85 & 0,54 & 7 & 3,31 & 0,32 & NS \\
\hline $\begin{array}{c}\text { Fósforo } 3 \\
\text { meses(mg/dL) }\end{array}$ & 39 & 3,98 & 0,89 & 40 & 3,66 & 0,50 & NS \\
\hline $\begin{array}{l}\text { Fósforo } 6 \text { meses } \\
(\mathrm{mg} / \mathrm{dL})\end{array}$ & 32 & 4,12 & 0,92 & 32 & 3,96 & 0,59 & NS \\
\hline $\begin{array}{l}\text { Fósforo } 9 \text { meses } \\
(\mathrm{mg} / \mathrm{dL})\end{array}$ & 18 & 3,94 & 0,52 & 23 & 4,09 & 1,01 & NS \\
\hline $\begin{array}{l}\text { Fósforo } 12 \text { meses } \\
\text { (mg/dL) }\end{array}$ & 30 & 4,30 & 0,37 & 35 & 3,94 & 0,60 & $<0,05$ \\
\hline $\begin{array}{l}\text { Fósforo } 18 \text { meses } \\
\text { (mg/dL) }\end{array}$ & 29 & 3,94 & 0,53 & 32 & 3,84 & 0,56 & NS \\
\hline $\begin{array}{l}\text { Fósforo } 24 \text { meses } \\
\text { (mg/dL) }\end{array}$ & 40 & 3,93 & 0,74 & 37 & 3,72 & 0,50 & NS \\
\hline
\end{tabular}

Tabla 4.11.7.9. Descripción del fósforo plasmático en las diferentes revisiones evaluadas según el grupo de edad 


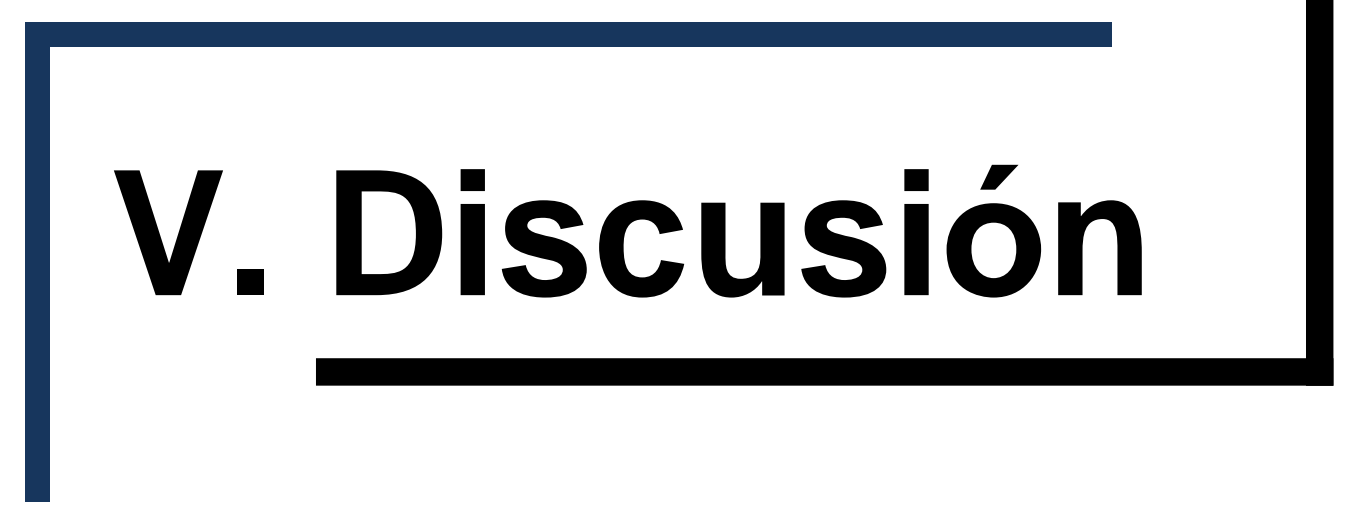


A continuación, se abordan las características generales de los pacientes del estudio ReCiMB comparados con otras técnicas de carácter mixto como el bypass gástrico en Y Roux (BGYR), pues en la bibliografía científica actual las publicaciones que describen el mini bypass gástrico (MBG) con la modalidad BAGUA son muy limitadas. El metaanálisis de MBG publicado por Kamal.K et al $^{128}$ en el año 2013, describe diferentes series de pacientes estadounidenses con la excepción del estudio español de Carbajo et al $^{129}$, siendo una restricción a la hora de comparar los resultados obtenidos y aún más cuando el origen de los pacientes es un centro médico privado y todos ellos son de nacionalidad española.

En la actualidad el BGYR contiua siendo la técnica más utilizada de carácter restrictivo-malabsortivo y de la que existe un mayor número de publicaciones, aunque presenta complicaciones recurrentes a largo plazo ${ }^{130}$ y menor efectividad en la pérdida de peso que otras técnicas emergentes mínimamente invasivas ${ }^{131}$, como BAGUA, que consigue mejorar los resultados en pérdida de peso y supone una ventaja adicional por su mayor seguridad y ante la muy remota necesidad de requerirlo, por la reversibilidad de la cirugía ${ }^{132,133}$. 


\subsection{Características de la muestra}

\subsubsection{Características generales de la muestra}

\subsubsection{Sexo y edad}

En la tabla 5.1 se presentan los datos de la muestra estudiada comparados con el resto de publicaciones descritas en el metaanálisis "mini bypass gástrico (MBG)"128.

La muestra estudiada está constituida por 100 pacientes con predominio del sexo femenino (71\%) y una edad media de 42,61 $\pm 11,33$ años. Aunque los resultados de los distintos estudios varían por el número de participantes y el seguimiento postquirúrgico, en líneas generales al igual que nuestro trabajo se observa un mayor número de mujeres intervenidas, sin embargo la edad media es menor en todos ellos.

\begin{tabular}{|c|c|c|c|c|c|}
\hline $\begin{array}{l}\text { Estudios } \\
\text { analizados }\end{array}$ & $\begin{array}{l}\text { Periodo de } \\
\text { estudio }\end{array}$ & $\begin{array}{c}\text { Número } \\
\text { de } \\
\text { pacientes }\end{array}$ & $\begin{array}{l}\text { Edad } \\
\text { media }\end{array}$ & Mujeres & Hombres \\
\hline & & $\mathbf{N}$ & (años) & N (\%) & N (\%) \\
\hline Lee et $\mathrm{al}^{134}$ & $\begin{array}{c}\text { Oct 2001-Sep } \\
2010\end{array}$ & 1163 & 32,3 & $850(73,08 \%)$ & $313(26,91 \%)$ \\
\hline Wang et $\mathrm{al}^{135}$ & $\begin{array}{c}\text { Oct } 2001-O c t \\
2004\end{array}$ & 423 & 30,8 & $336(79,43 \%)$ & $87(20,56 \%)$ \\
\hline $\begin{array}{l}\text { Peraglie et } \\
\mathrm{al}^{136}\end{array}$ & - & 16 & 40 & $14(87,5 \%)$ & $2(12,5 \%)$ \\
\hline $\begin{array}{l}\text { Chakhto ura } \\
\text { et } \mathrm{al}^{137}\end{array}$ & $\begin{array}{c}\text { Oct } 2006-\text { Nov } \\
2007\end{array}$ & 100 & 40,9 & 77 (77\%) & $23(23 \%)$ \\
\hline Piazza et al ${ }^{138}$ & $\begin{array}{l}\text { Oct 2008- } \\
\text { May } 2011\end{array}$ & 197 & 37,9 & $147(74,61 \%)$ & $50(25,38 \%)$ \\
\hline $\begin{array}{l}\text { Carbajo et } \\
\text { al }^{123}\end{array}$ & $\begin{array}{l}\text { Jul 2002-Jun } \\
2004\end{array}$ & 209 & 41 & $172(82,29 \%)$ & $37(17,70 \%)$ \\
\hline $\begin{array}{l}\text { Rutledge et } \\
\mathrm{al}^{133}\end{array}$ & $\begin{array}{l}\text { Sept 1997- } \\
\text { Feb } 2004\end{array}$ & 2410 & 39 & $2049(85,02 \%)$ & $361(14,97 \%)$ \\
\hline Noun et $\mathrm{al}^{139}$ & $\begin{array}{c}\text { Oct } 2004-O c t \\
2006\end{array}$ & 126 & 35 & $80(63,49 \%)$ & $44(34,92 \%)$ \\
\hline Noun et $\mathrm{al}^{140}$ & $\begin{array}{l}\text { Nov 2005- } \\
\text { Ene } 2011\end{array}$ & 1000 & 33,15 & $661(66,1 \%)$ & $339(33,9 \%)$ \\
\hline ReCiMB & $\begin{array}{c}\text { Ene 2010-Dic } \\
2012\end{array}$ & 100 & 42,61 & 71 (71\%) & 29 (29\%) \\
\hline
\end{tabular}

Tabla 5.1. Características generales de las publicaciones del metaanálisis "mini bypass gástrico"128 y el estudio ReCiMB 
Estas características generales también se observan en otras publicaciones de cirugía bariátrica representativas en las que se comparan diferentes técnicas quirúrgicas como el trabajo publicado por Sjöström et $\mathrm{al}^{141}$ sobre la población de Suecia (SOS) en el que describe la evolución de:

a)Banda gástrica ajustable. $\mathrm{N}=376$.

b)Gastroplastia vertical anillada. $\mathrm{N}=1369$.

c)Bypass gástrico. $\mathrm{N}=265$.

El estudio SOS está formado por $70,6 \%$ de mujeres y $29,4 \%$ de hombres, edad media de 46,1 años. A diferencia de los trabajos comparados anteriormente, aquí la edad media descrita es superior a la observada en nuestro trabajo.

En el último metaanálisis del año 2014 de Buchwald ${ }^{142}$ en el que se describe los resultados de BGYR publicados desde el año 1990 hasta el 2013 no se aprecian grandes diferencias puesto que describe un 79\% de mujeres, 21\% de hombres y una edad media de 38,7 años.

\subsubsection{Procedencia de los pacientes}

Los pacientes de nuestra muestra son mayoritariamente del País Vasco (35\%). Aunque el CTO se encuentra situado en Valladolid, de esta Comunidad Autónoma proceden el 9\%. Esta heterogeneidad de los pacientes puede ser debida al coste de la cirugía el cual es financiado íntegramente por el paciente, a diferencia de los estudios en series de pacientes captados en la asistencia sanitaria pública de cada Servicio Regional de Salud.

\subsubsection{Características socioeconómicas}

En la recogida de los datos sobre la actividad profesional desempeñada por los pacientes de nuestra muestra se utilizó la clasificación nacional de ocupaciones desarrollada por el Servicio Nacional de Aprendizaje y Dirección de Empleo dependiente del Ministerio de Trabajo y Seguridad Social (Anexo III). No hemos encontrado ninguna publicación de pacientes intervenidos de cirugía bariátrica que especifique detalladamente la ocupación profesional como la propuesta en el estudio ReCiMB. 
La última publicación de pacientes intervenidos de bypass que analiza el nivel socioeconómico, corresponde a la revisión de Allison. A et $\mathrm{al}^{143}$, en la que se estudia las características de los pacientes intervenidos de BGYR con 5 años de seguimiento postquirúrgico con nacionalidades diferentes. En total describen 663 pacientes (74,4\% Europeos-Americanos) con asistencia sanitaria privada en el $86,4 \%$ de los casos, un $10 \%$ con educación superior y tan sólo un 10,7\% de pacientes con una ocupación profesional en el sector de la administración y dirección. En el estudio ReCiMB, la ocupación profesional más recurrente en el $26 \%$ de los casos es el sector que contiene: arte, cultura, recreación y deporte. Seguido del $25 \%$ de los pacientes que pertenecían al sector finanzas y administración.

El estudio europeo del realizado por la administración pública del Servicio Nacional de Salud Británico ${ }^{144}$ en 2006 a través de la encuesta (HSE), determinó las características de los pacientes obesos candidatos a cirugía bariátrica entre las que destacan el bajo nivel de cualificación (35,7\%), trabajos de manufacturación en el 49,5\% a diferencia del sector de gestión y administración en el $26,7 \%$ de los casos. Estos últimos obtienen cifras comparables a las de nuestro estudio en el sector finanzas y administración.

Nuestro estudio presenta un mayor número de pacientes con ocupaciones profesionales de mayor cualificación y esto puede ser debido a la financiación privada de la cirugía a diferencia del Servicio Nacional de Salud Británico, que es público.

\subsubsection{Inicio de la obesidad}

Se estudiaron cuáles fueron las circunstancias desencadenantes de la ganancia ponderal según la percepción personal de cada paciente. Mayoritariamente se observó en los hombres un inicio en la etapa de la adolescencia.

Las mujeres con hijos (67,6\% de las mujeres de la muestra) identificaron el embarazo como la etapa en la que se inició el aumento de peso que dio 
origen a la obesidad actual, el resto de mujeres $(32,4 \%)$ señalaron la etapa de la infancia y adolescencia.

Dentro de los estudios de cohortes en los que se analiza el desarrollo de la obesidad durante y después de la gestación, destaca el trabajo de Fraser et $\mathrm{al}^{145}$ en el que las mujeres con una ganancia exagerada de peso durante el embarazo mantuvieron dicho peso hasta en un $15 \%$ de los casos, quedando afectadas con las disfunciones propias de la obesidad para el resto de su vida. Oken et al ${ }^{146}$, demostraron como el $16 \%$ de las mujeres obesas durante la gestación mantuvieron gran parte del peso adquirido durante el embarazo varios años después.

\subsubsection{Catalogación de la muestra estudiada según IMC. Criterio SEEDO}

Los pacientes de la muestra previamente a la cirugía fueron catalogados según el grado de obesidad (criterios SEEDO): 10\% obesidad tipo I, 33\% obesidad tipo II, 42\% obesidad tipo III y el 15\% restante presentó una obesidad tipo IV. IFSO determina los criterios de los pacientes candidatos en función del grado de obesidad y comorbilidades asociadas, especificando la posibilidad de cirugía en pacientes con IMC $\geq 30<35$ que cumplan con los requisitos de un mal control glucémico asociado a otras comorbilidades mayores no controladas adecuadamente, o que formen parte de protocolos controlados por especialistas basados en cambios en el estilo de vida y tratamiento farmacológico habitual ${ }^{147}$.

Los 10 pacientes intervenidos de BAGUA con obesidad tipo I, mantenían un seguimiento y control de las comorbilidades asociadas por su médico especialista previamente a cirugía en su lugar de origen, con el que se mantuvo un seguimiento postquirúrgico combinado con CTO Valladolid para evitar confusiones en las pautas y mejorar la adherencia del paciente.

De los trabajos publicados de pacientes intervenidos de cirugía bariátrica desde un IMC 30, destacan los de O'Brien, Dixon, Lee y Schauer recogidos en la revisión de 2014 de Busetto et $\mathrm{al}^{148}$, con resultados comparables a los de nuestro estudio en el cuál la mayoría de los pacientes eran obesos mórbidos, seguido del grupo de obesidad tipo II. 


\subsubsection{Hábitos en la conducta alimentaria}

Antes de la cirugía se determinaron los hábitos alimentarios basados en los criterios de evaluación exigidos por IFSO a los Centros integrantes, en el que se incluye a golosos, picoteadores, comilones y comilones emocionales. Los pacientes de nuestro estudio se distribuyeron en: $73 \%$ golosos, $77 \%$ picoteadores, 90\% comilones y 36\% comilones emocionales. El $41 \%$ de los pacientes presentó de manera simultánea 3 de esas conductas.

En España, el equipo de la Unidad de Obesidad del Hospital General Universitario de Elche ${ }^{149}$, publicó las conductas alimentarias preoperatorias de los pacientes intervenidos posteriormente de manga gástrica siguiendo las recomendaciones de IFSO, describiendo al 100\% de los pacientes como comilones o grandes comedores, el 44\% presentaba un patrón picoteador y el $40 \%$ reconoció una ingesta abundante de dulces, cifras dispares comparadas con las obtenidas en nuestra muestra aunque en ambos estudios el patrón más recurrente fue el de comilón o gran comedor. 


\subsubsection{Antecedentes clínicos de la muestra}

Entre los antecedentes clínicos de la muestra estudiada destaca por encima de todos, la presencia de insuficiencia respiratoria en el 99\% de los pacientes, seguido de problemas osteoarticulares (88\%), esteatosis hepática (81\%) y SAOS (81\%). A diferencia del resto de estudios, en nuestro trabajo se detallan las comorbilidades iniciales en función del sexo y la edad según se describe en el punto 4.2 de los resultados.

En el trabajo de Noun et $\mathrm{al}^{140}$, con una serie de 1000 pacientes se observó en el 26,5\% la presencia de comorbilidades entre las que destacó: 19\% DM, 24,6\% dislipemia, 23\% HTA, 17,8\% apnea, 22\% problemas osteoarticulares y $21 \%$ con reflujo gastroesofágico. En nuestra serie de pacientes el porcentaje de DM era prácticamente el mismo (18\%), sin embargo el porcentaje de dislipemia era más elevado (68\%), así como el porcentaje de hipertensos (37\%), SAOS (81\%), artropatías (88\%), y enfermedad de reflujo gastroesofágico (53\%).

Kular et $\mathrm{al}^{150}$, en la publicación sobre una serie de 1054 pacientes intervenidos de MBG con seguimiento a 6 años, muestra resultados muy dispares. Con una elevada prevalencia de comorbilidades iniciales entre sus pacientes, describiendo dificultad respiratoria en el $84,3 \%$ de los casos, seguido del $83,3 \%$ de esteatosis hepática, HTA en el 72\%, DM en el 64\%, dislipemia en el $62 \%$. Resultados más elevados en todas las comorbilidades descritas comparadas con los pacientes de nuestra muestra.

En el conjunto de antecedentes clínicos prequirúrgicos, los resultados de nuestros pacientes comparten las mismas comorbilidades iniciales que otros estudios nacionales como el publicado por el Hospital Universitario de Valencia de pacientes intervenidos de cruce duodenal ${ }^{151}$ en los que se describe un 48\% de hipertensos, 32,27\% de artropatías, 28,8\% dislipemia, $27,8 \%$ diabéticos, $19,2 \%$ SAOS. Insuficiencia venosa de miembros inferiores en el $16,3 \%$, cifra muy por debajo del $40 \%$ de nuestra muestra. Del mismo modo ocurre con el síndrome depresión/ansiedad en el 25,9\%, a diferencia del $39 \%$ de los pacientes incluidos en nuestro estudio, al igual que la 
presencia de reflujo gastroesofágico el cuál se observó en el 6,7\% de la muestra, en comparación con el 53\% de los casos de nuestro estudio.

El Departamento de Cirugía de la Universidad de St Luke ${ }^{152}$, centro acreditado estadounidense por el Metabolic and Bariatric Surgery Accreditation and Quality Improvement Program (MBSAQIP), publicó las comorbilidades iniciales de una serie de 158 pacientes intervenidos de bypass gástrico en $\mathrm{Y}$ de Roux: 28,5\% DM, 53,2\% hipertensos, 31\% dislipemia, 35,4\% SAOS. Cifras más elevadas que las de la muestra de nuestro estudio en el número de diabéticos (18\%) e hipertensos (37\%) y no así en las otras dos comorbilidades descritas: dislipemia (68\%) y SAOS (81\%).

La apnea del sueño es una de las comorbilidades descritas que no sigue una tendencia similar entre las series de pacientes estudiadas sometidos a cirugía bariátrica, esta situación puede explicarse porque aproximadamente el $80 \%$ de los pacientes con SAOS no son diagnosticados previamente ${ }^{153}$.

Los factores etiológicos que se asocian a la presencia del hígado graso no alcohólico se clasifican en primarios, aquellos que están relacionados con la obesidad, diabetes tipo 2 y dislipidemia ${ }^{154}$. El $81 \%$ de los pacientes previamente a la cirugía de BAGUA fueron diagnosticados de esteatosis hepática a través de ecografía, cifras similares a las descritas en la Tesis de Ferrer $\mathrm{M}^{155}$, el cual analiza la función hepática de los pacientes intervenidos en el Hospital público de Torrecárdenas mediante derivación biliopancreática de 78 sujetos, con un $88,15 \%$ de casos de esteatosis hepática.

Inicialmente en la historia clínica se determinó la presencia de 18 pacientes con DM tipo 2, de los cuales 8 estaban en tratamiento con antidiabéticos orales, 2 con insulina y 2 con la combinación de ambos. Al realizar la bioquímica prequirúrgica, aplicando los criterios ADA 2015 se describieron $31,9 \%$ pacientes prediabéticos y $13,8 \%$ diabéticos.

En el metaanálisis de Sjöström ${ }^{141}$ el 25,8\% de los casos presentaba diabetes, al igual que los demás metaanálisis consultados no se contempla 
en la precirugía una clasificación de los pacientes entre los que son diabéticos y prediabéticos, como sí hemos tenido en cuenta en esta Tesis. 


\subsubsection{Antecedentes quirúrgicos de la muestra}

Actualmente no se conoce ninguna serie de pacientes publicada en la que se analice el impacto de las cirugías previas en la evolución de los pacientes sometidos a cirugía de MBG de una sola anastomosis. La mayoría de los autores se limitan a la descripción de las comorbilidades previas más relevantes y su evolución tras la cirugía, aunque especifican que la cirugía abdominal anterior y especialmente en la realización de una segunda intervención bariátrica (reconversión) son factores a tener en cuenta pues influyen negativamente en la aparición de complicaciones postquirúrgicas.

Los centros integrantes del EAC-BS registran los antecedentes quirúrgicos abdominales previos a la cirugía bariátrica pero esos datos no son de carácter público. Carbajo et al $^{123}$ describe en su estudio un 18,18\% de los casos con cirugías previas que generan adherencias, cifras prácticamente idénticas al 18\% de pacientes con cirugía abdominal previa en esta Tesis: apendicetomía (13\%) y colecistectomía (5\%). Esta última es comparable al $8 \%$ de pacientes con colecistectomía anterior a la cirugía descrita en el trabajo de Chakhtoura et $\mathrm{al}^{137}$.

Otras cirugías que son susceptibles de generar adherencias, son aquellas que impliquen incisión quirúrgica de la pared abdominal anterior, como las cirugías ginecológicas entre las que IFSO aconseja registrar, observando al $12 \%$ de la muestra de nuestro estudio. Resultados que no han podido compararse por no encontrar ningún estudio que aborde este aspecto.

En nuestro estudio ningún paciente presentó cirugías bariátricas anteriores y no se llevó a cabo ninguna reconversión. Por el contrario Carbajo et al $^{123}$ sí describe un $1,91 \%$ de los casos en los que la cirugía de BAGUA fue una reconversión. Noun et $\mathrm{al}^{140}$, describe un $7,7 \%$ de casos de reconversión.

Los resultados publicados por la Unidad Funcional de Obesidad del Hospital Clinic de Barcelona ${ }^{156}$, centro participante del EAC-BS, tras aplicar cirugía bariátrica en 203 pacientes muestra un 3,5\% de los casos con 
cirugías bariátricas anteriores. En este mismo estudio describen un 32,7\% de pacientes con cirugías abdominales previas, resultados ligeramente más elevados, si tenemos en cuenta a los pacientes de nuestro estudio con cirugías anteriores que impliquen incisión de la pared abdominal anterior (30\%). 


\subsection{Hábitos tóxicos}

En la primera consulta se determinó según las recomendaciones de IFSO el consumo de alcohol y de tabaco, una limitación para describir la evolución de estos hábitos fue no registrar el consumo en los controles postoperatorios.

\subsubsection{Hábito tabáquico}

Son pocos los estudios que describen el consumo de tabaco en pacientes intervenidos de bypass gástrico y ninguno de ellos específicamente del MBG. Los metaanálisis publicados asocian el aumento de las complicaciones quirúrgicas con el consumo de tabaco y todos coinciden que aquellos pacientes que se sometan a una cirugía y no hayan abandonado el tabaco 2 meses antes, las complicaciones postoperatorias aumentan y los resultados quirúrgicos empeoran ${ }^{159}$.

En la muestra ReCiMB, se observó un consumo de tabaco previo a la cirugía bariátrica en el $24 \%$ de los pacientes, cifras ligeramente superiores a las publicadas por el trabajo más reciente y con más pacientes intervenidos de BGYR ( $n=899)$ por el Centro de Obesidad e Investigación de Filadelfia ${ }^{160}$ el cual describe un $19 \%$ de fumadores antes de la cirugía. Destacan la reducción del número de cigarrillos consumidos en el día a los 6 y 12 meses postquirúrgicos, en ese mismo estudio el $81 \%$ era no fumador, resultados más elevados que los de nuestros pacientes en los que se observó a un $76 \%$, de los que el $23 \%$ eran ex-fumadores.

El Centro de Filadelfia ${ }^{160}$ describió un mayor descenso en el consumo de cigarrillos postquirúrgicos entre las personas de mayor edad. En nuestra muestra, antes de la cirugía no se observaron diferencias significativas en el consumo de tabaco en función del sexo o la edad.

\subsubsection{Consumo de alcohol}

Del mismo modo que con el consumo de tabaco, IFSO sólo indica registrar el consumo de alcohol antes de la intervención quirúrgica pero no en el postoperatorio. 
El 2013 la Sociedad Americana de Cirugía Metabólica y Bariátrica $\left(\right.$ ASMBS) ${ }^{161,162}$, recomendaba abstenerse del consumo de alcohol a todos los paciente sometidos a bypass gástrico debido a las alteraciones en el metabolismo provocadas por el alcohol y por ser un factor potencial en el desarrollo de deficiencias vitamínicas y favorecer el aumento de peso. En nuestra muestra antes de la intervención se describe un $79 \%$ de no bebedores activos y un $21 \%$ de bebedores activos, de los cuales el $15 \%$ bebía con carácter semanal, $3 \%$ a diario y otro 3\% con carácter mensual.

El estudio de la prevalencia del abuso de alcohol tras cirugía bariátrica publicado en 2015 sobre una muestra de 97 pacientes intervenidos en $\mathrm{Y}$ de Roux $^{163}$, describe cifras mucho más elevadas a las obtenidas en nuestro estudio: $21,1 \%$ de pacientes consumidores de alcohol antes de la intervención, siendo un 4,5\% de los casos bebedores a diario y un 6,3\% mensual. Estos valores fueron estudiados a 24 meses postquirúrgicos, describiendo un descenso del $15,5 \%$ de los pacientes bebedores.

Por el contrario, los estudios prospectivos de King et a $\left.\right|^{164}$ y Conason. A et $\mathrm{al}^{165}$ sobre el consumo de alcohol en pacientes intervenidos de cirugía bariátrica reflejan un aumento del consumo de alcohol postcirugía.

King et $\mathrm{al}^{164}$, muestra los resultados obtenidos en pacientes sometidos a cirugía bariátrica en 10 centros hospitalarios estadounidenses mostrando inicialmente un $62,3 \%$ de los pacientes con trastornos por el consumo de alcohol, cifra que se aumenta en un $2 \%$ a los dos años de la cirugía. Los hombres, más jóvenes, con menos recursos sociales que bebían y fumaban previamente a la cirugía tenían más riesgo de trastornos por consumo de alcohol.

Conason.A et $\mathrm{al}^{165}$ afirman que los pacientes sometidos a BGYR el consumo de alcohol aumentó en un 1,9\% a diferencia de las otras técnicas bariátricas evaluadas. 


\subsection{Preparación dietético-nutricional previa a la cirugía}

El tratamiento nutricional preoperatorio tiene como fin primordial la reducción del hígado graso como también de la grasa abdominal, con el objeto de disminuir, tanto el tiempo operatorio como las complicaciones quirúrgicas. A la vez que se incide en la modificación del hábito alimentario, repercutiendo en un mayor éxito de pérdida ponderal a largo plazo ${ }^{166,167}$.

Aunque la evidencia científica no ha determinado la necesidad de rechazar a un paciente candidato a cirugía bariátrica que cumpla los criterios de inclusión recomendados, pero que no haya sido capaz de reducir su peso en la fase preoperatoria ${ }^{168}$, nuestro equipo quirúrgico sí establece un peso objetivo marcado para el momento de la cirugía, basado en una reducción entre el $10-12 \%$ del peso inicial según la situación clínica del paciente. No obstante el porcentaje se modifica a criterio del cirujano en función del riesgo quirúrgico basado fundamentalmente en las comorbilidades asociadas y el tipo de obesidad abdominal, aplicándose una reducción mayor en los hombres, el grupo de mayor edad y en los pacientes con un grado de obesidad mayor como se especifica en el apartado 4.5 de los resultados. Ese grado de cumplimiento del peso objetivo, fue mayoritario, siendo favorable en el $74 \%$ de los casos, ninguno de los pacientes que no cumplieron el objetivo fue excluido de la cirugía de BAGUA.

Benjaminov et $\mathrm{al}^{169}$, demostraron mediante estudios tomográficos que con una dieta muy baja en carbohidratos durante 4 semanas se conseguía reducir el contenido graso del hígado y el tamaño del volumen hepático, especialmente del lóbulo izquierdo, en el periodo preoperatorio. Por el contrario, Nomura et $\mathrm{al}^{170}$, ya en 1987 , comunicaron que con una dieta baja en calorías se reducía significativamente el tamaño del hígado.

A nuestros pacientes no se les realizaron pruebas de imagen posterior a la dieta de preparación prequirúrgica como el caso de Nomura et $\mathrm{al}^{170}$, pero la disminución del volumen hepático y de la grasa abdominal favoreció el acto quirúrgico no observándose ninguna complicación quirúrgica como se señala en el apartado 4.6 de los resultados. 
Para alcanzar ese objetivo de pérdida ponderal considerado como seguro para la realización del acto quirúrgico y evitar posibles complicaciones, en los pacientes de nuestro estudio se aplicó una preparación dietético-nutricional de 20 días de duración en la que se utilizaron durante 12 días una dieta hiperproteica pura a razón de 800 kcal/día, (Vegefast-Complet ${ }^{\circledR}$; Vegenat, España), y dieta líquida absoluta durante los ocho días previos a la cirugía ${ }^{122}$.

Lewis et $\mathrm{al}^{167}$, describieron la utilización de este tipo de preparados, específicamente Optifast ${ }^{\circledR}$ durante 6 semanas a razón de entre 400-800 kcal/día, en pacientes que iban a someterse a banda gástrica ajustable.

Los resultados porcentuales de reducción ponderal sobre el peso inicial en el trabajo de Lewis muestran cifras del 15,1\%, nosotros obtuvimos una media de $11,33 \%$, con una preparación menos restrictiva.

Aunque el tiempo medio desde la primera consulta hasta el momento de la cirugía fue de 94,27 días, sólo se llevó a cabo el protocolo en los últimos 20 días antes de la intervención quirúrgica. Puede que nuestros buenos resultados sin ser tan restrictivos en el protocolo de dieta prequirúrgica, se deban al control nutricional ejercido vía mail y telefónico sobre los pacientes.

Lim et $\mathrm{al}^{171}$, en la guía de buenas prácticas de cirugía bariátrica señalaron la necesidad de una pérdida de peso preoperatoria del $5 \%$ al $10 \%$, específicamente en pacientes con un IMC > 50 o comorbilidades asociadas a la obesidad. Utilizando fórmulas preparadas 102 veces al día, comprobando que era una estrategia eficaz para la pérdida de peso preoperatoria, obteniendo una pérdida de peso exitosa a razón de 450-900 g/semana. En los pacientes ReCiMB, la reducción de peso semanal fue de $1100 \mathrm{~g} /$ semana, cifra superior a la descrita por Lim et $\mathrm{al}^{171}$. Del mismo modo, el porcentaje de pérdida de peso preoperatorio fue superior en nuestro estudio, cumpliendo así con el objetivo de reducción porcentual prequirúrgico $(11,33 \%)$. 


\subsection{Características específicas de la cirugía}

El número de cirugías bariátricas a nivel mundial ha aumentado considerablemente desde el año 2003, según la última versión publicada del "Bariatric surgery worldwide $2013 " 172$ en la que se describe un aumento del 11\% en Europa, siendo la manga gástrica la que ha aumentado más notablemente en el último trienio sin disponer de datos de su efectividad a medio y largo plazo en el control del peso. En esta publicación se muestra el BGYR como la técnica más empleada en Europa en el último trienio (38\%), seguida muy de cerca de la manga gástrica (37\%). No describe la tendencia en los últimos años de la cirugía de mini bypass la cual representa el 4,90\% de todas las técnicas evaluadas en Europa.

Las características quirúrgicas de las últimas series de pacientes intervenidos de MBG se detallan en la tabla 5.2 comparándolas con las obtenidas de nuestra muestra.

\begin{tabular}{|c|c|c|c|c|c|}
\hline \multirow{3}{*}{$\begin{array}{l}\text { Estudios } \\
\text { analizados }\end{array}$} & \multirow{2}{*}{$\begin{array}{c}\text { Longitud } \\
\text { asa bilio- } \\
\text { pancreática }\end{array}$} & \multirow{2}{*}{$\begin{array}{l}\text { Duración } \\
\text { cirugía }\end{array}$} & \multirow{2}{*}{$\begin{array}{c}\text { Estancia } \\
\text { hospitalaria }\end{array}$} & \multicolumn{2}{|c|}{ Complicaciones } \\
\hline & & & & Menores & Mayores \\
\hline & $(\mathrm{cm})$ & (minutos) & (días) & N (\%) & N (\%) \\
\hline Lee et $\mathrm{al}^{134}$ & $200-300$ & 115,3 & 3,7 & $\begin{array}{c}78 \\
(6,7 \%)\end{array}$ & $\begin{array}{c}21 \\
(1,8 \%)\end{array}$ \\
\hline $\begin{array}{l}\text { Wang et } \\
\mathrm{al}^{135}\end{array}$ & - & 130,8 & 5 & $\begin{array}{c}18 \\
(4,3 \%)\end{array}$ & $\begin{array}{c}7 \\
(1,7 \%)\end{array}$ \\
\hline $\begin{array}{l}\text { Peraglie et } \\
\mathrm{al}^{136}\end{array}$ & 200 & 78 & 1,2 & - & $\begin{array}{c}0 \\
(0 \%)\end{array}$ \\
\hline $\begin{array}{l}\text { Chakhto ura } \\
\text { et } \mathrm{al}^{137}\end{array}$ & 200 & 129 & 8,5 & - & $\begin{array}{c}7 \\
(7 \%)\end{array}$ \\
\hline $\begin{array}{l}\text { Piazza et } \\
\mathrm{al}^{138}\end{array}$ & $180-240$ & 120 & 5 & - & $\begin{array}{c}8 \\
(4 \%)\end{array}$ \\
\hline $\begin{array}{l}\text { Carbajo et } \\
\text { al }^{123}\end{array}$ & 200 & 93 & - & $\begin{array}{c}12 \\
(5,74 \%)\end{array}$ & $\begin{array}{c}2 \\
(0,9 \%)\end{array}$ \\
\hline $\begin{array}{l}\text { Rutledge et } \\
\mathrm{al}^{133}\end{array}$ & 200 & 37,5 & 1 & $\begin{array}{c}142 \\
(5,9 \%)\end{array}$ & $\begin{array}{c}2 \\
(0,08 \%)\end{array}$ \\
\hline Noun et $\mathrm{al}^{139}$ & - & 144 & 3,3 & $\begin{array}{c}6 \\
(4,7 \%)\end{array}$ & $\begin{array}{c}0 \\
(0 \%)\end{array}$ \\
\hline Noun et $\mathrm{al}^{140}$ & 150 & 89 & 1,8 & $\begin{array}{c}34 \\
(3,4 \%)\end{array}$ & $\begin{array}{c}0 \\
(0 \%)\end{array}$ \\
\hline ReCiMB & 274 & 94,60 & 1 & $\begin{array}{c}0 \\
(0 \%)\end{array}$ & $\begin{array}{c}0 \\
(0 \%)\end{array}$ \\
\hline
\end{tabular}

Tabla 5.2. Características quirúrgicas de las publicaciones del metaanálisis "mini bypass gástrico" ${ }^{\text {"128 }}$ y el estudio ReCiMB 
La longitud del asa biliopancreática es muy variable entre los diferentes cirujanos y justifican esa longitud por el tipo de obesidad del paciente, edad y grado de obesidad $^{134}$.

En la muestra ReCiMB, la media del asa biliopancreática $(274,95 \mathrm{~cm})$ se encontraba entre las longitudes propuestas por los diferentes autores del metaanálisis y más elevada que la descrita en el trabajo anterior de Carbajo et $\mathrm{al}^{123}$. Esa longitud del asa biliopancreática fue significativamente más elevada en los hombres, siendo estos los pacientes con un IMC inicial medio más elevado que las mujeres, dando respuesta a la justificación de Noun et $\mathrm{al}^{140}$, los cuales describen un aumento de esa longitud del asa biliopancreática o malabsortiva en $10 \mathrm{~cm}$ por cada punto de IMC $>40$ antes de la cirugía.

Aprovechando el acto quirúrgico, en los pacientes de nuestra muestra se realizó una reducción de la hernia hiatal al 55\% y colecistectomía al 12\% (todas ellas mujeres), los estudios publicados de mini bypass no describen la presencia de cirugía combinada.

Escalona et $\mathrm{al}^{173}$ describen la combinación de la colecistectomía junto con el BGYR en una muestra de 1311 pacientes, siendo el 10,9\% de los pacientes a los que se les realizó la técnica combinada, cifras muy similares a las propuestas en nuestro trabajo (12\%). También afirman que entre el 15 $20 \%$ de los pacientes de riesgo tienen colelitiasis y más del $90 \%$ son asintomáticos, es por ello que aplicando la colecistectomía en pacientes litiásicos se disminuye este riesgo y, por lo tanto, la necesidad de la evaluación endoscópica ${ }^{174,175}$.

Escalona et $\mathrm{al}^{173}$, muestran un mayor tiempo de duración de la cirugía cuando se combina con la colecistectomía (129,8 minutos) al igual que la estancia hospitalaria (4 días). Los pacientes intervenidos de BAGUA a los que se les realizó colecistectomía simultánea también fue mayor el tiempo quirúrgico (121,58 minutos) respecto a los que no (94,60 minutos). Por el contrario el tiempo de hospitalización de los pacientes de nuestra muestra en el 98\% de los casos fue de 24 horas independientemente de la combinación con colecistectomía. 
Como se muestra en la tabla 5.6, el tiempo medio de duración de la cirugía de MBG más reducida fue descrito por Rutledge et al $^{133}(37,5$ minutos), seguido de Peraglie et $\mathrm{al}^{136}$ (78 minutos) y Noun et $\mathrm{al}^{140}$ (89 minutos). Carbajo et $\mathrm{al}^{123}$ en la muestra de 209 pacientes describieron un tiempo de cirugía prácticamente igual al descrito en la serie de pacientes de la Tesis (93 minutos y 94,60 minutos respectivamente).

El tiempo de estancia hospitalaria más bajo fue de 24 horas de hospitalización, descrito por Carbajo et $\mathrm{al}^{123}$ y Rutledge et $\mathrm{al}^{133}$, el cuál es el mismo que el observado en los pacientes de nuestra muestra.

Kular et al $^{150}$, describen una duración media de la cirugía de 52 minutos, con una hospitalización de 2,5 días de media. Lacy et $\mathrm{al}^{156}$, muestran una duración media de la cirugía de 131 minutos, con una estancia hospitalaria también más elevada que la de nuestro estudio con 3,8 días de hospitalización.

En cuanto a la presencia de complicaciones menores y/o mayores asociadas a la intervención; en nuestra muestra no se observó ninguna, a diferencia de la mayoría de los estudios publicados de mini bypass gástrico como se detalla en la tabla 5.2, en la que el porcentaje de complicaciones menores está comprendido entre el 3,4-6,7\%.

Kular et al $^{150}$ también describieron complicaciones tempranas en el 5,9\% de los casos, como los estudios de Lee et $\mathrm{al}^{134,135}$.

La mortalidad asociada a la cirugía en todos los estudios de la tabla 5.6 es menor del $1 \%$, como recomienda Fobi et $\mathrm{al}^{176}$ y Baltasar et $\mathrm{al}^{177}$ para considerar la cirugía como segura e idónea.

Noun et $\mathrm{al}^{139,140}$ son los únicos que muestran una mortalidad del $0 \%$ al igual que la descrita en nuestro trabajo. Se observa un aumento de la mortalidad en aquellos estudios en los que el número de cirugías de reconversión es mayor, como en la serie de Carbajo et $\mathrm{al}^{123}$ con un $0,9 \%$ de mortalidad, seguida de Piazza et $\mathrm{al}^{138}(0,5 \%)$ y Lee et $\mathrm{al}^{134}(0,17 \%)$. 


\subsection{Valoración antropométrica}

En el siguiente apartado se abordarán las variables estudiadas en el punto 4.7 de los resultados comparando la evolución ponderal, IMC, perímetro de cintura y cadera de los pacientes de nuestra muestra con seguimiento a 2 años con el resto de estudios relevantes de MBG, BGYR y otras técnicas emergentes como la manga gástrica. También se valorará el riesgo de padecer comorbilidades mayores asociadas a su IMC en cada una de las revisiones postquirúrgicas.

\subsubsection{Evolución de la pérdida ponderal}

La calidad de cualquier técnica quirúrgica bariátrica está definida, tanto por la reducción del sobrepeso como por su mantenimiento posterior, por la resolución o mejoría de las comorbilidades asociadas y por la inexistencia de secuelas $^{125}$. Para una correcta expresión de la pérdida de peso corporal y poder comparar los resultados de forma precisa, los cirujanos bariátricos de la diferentes sociedades internacionales acordaron utilizar el porcentaje de sobrepeso perdido (PSP) y los cambios en el IMC expresados como porcentaje del IMC perdido (PIMCP) o porcentaje del exceso del IMC perdido $(\mathrm{PEIMCP})^{178}$, aunque en nuestro trabajo también se determinó la pérdida ponderal entre cada una de las revisiones expresada en valores absolutos de peso e IMC.

Siguiendo las recomendaciones de IFSO, estudiamos la evolución del peso en términos absolutos de manera trimestral hasta los 12 meses postquirúrgicos, y desde aquí hasta los 24 meses de manera semestral, a diferencia de la mayoría de los trabajos en los que durante el primer año no registran los 6 controles de peso.

El peso inicial de nuestra muestra $(116,75 \pm 22,19 \mathrm{Kg})$ fue ligeramente más bajo que en el resto de estudios del metaanálisis "mini bypass gástrico"128, como Noun et al ${ }^{140}(121,6 \pm 23,8 \mathrm{Kg})$, Chakhtoura et al ${ }^{137}(131 \pm$ $23,1 \mathrm{Kg})$.

La evolución del peso sigue la misma tendencia descendente que en el resto de publicaciones, observando a los 12 meses postquirúrgicos el peso 
medio más bajo $(68,56 \pm 13,10 \mathrm{Kg})$, al igual que Chakhtoura et al ${ }^{137}(89,8 \pm$ $18,4 \mathrm{Kg}$ ). En cambio Noun et $\mathrm{al}^{140}$ muestran el peso medio más bajo en el control de los 18 meses postquirúrgicos $(79,3 \pm 14,4 \mathrm{Kg})$.

Lee et $\mathrm{al}^{179}$ anteriormente, compararon la efectividad de la pérdida ponderal entre el MBG y el BGYR entre dos submuestras de pacientes con edades homogéneas, siendo mayor el peso inicial de los pacientes intervenidos con la técnica $Y$ de Roux $(119,1 \pm 17 \mathrm{Kg} .115,5 \pm 17,5 \mathrm{Kg})$, y observando el peso medio más bajo a los 2 años postquirúrgicos. El peso inicial descrito de los pacientes sometidos a MBG es el más próximo al obtenido en nuestro trabajo $(116,75 \pm 22,19 \mathrm{Kg})$.

Del mismo modo ocurre al comparar la evolución del peso con los resultados obtenidos con otras técnicas bariátricas, Sjöström ${ }^{141}$ en el estudio (SOS) describe entre los 12 y 24 meses postquirúrgicos la etapa de mayor pérdida ponderal, siendo de mayor a menor: el bypass gástrico (32 kg), gastroplastia vertical anillada $(25 \mathrm{Kg})$ y banda gástrica ajustable $(20 \mathrm{Kg})$. En nuestra muestra a los 12 meses la pérdida de peso fue de $48 \mathrm{Kg}$, resultados más elevados que en ninguna de las otras técnicas descritas.

Otra de las formas de expresar en términos relativos el peso es mediante el PSP, modelo que es defendido por las sociedades de cirujanos bariátricos por su utilidad en la comprensión del éxito o fracaso de la técnica en función del peso logrado. Por el contrario es criticado por otro sector médico que reportan las pérdidas de peso en términos absolutos ${ }^{180}$.

Nuestros resultados en el PSP siguen una tendencia ascendente hasta los 12 meses postquirúrgicos, siendo el valor máximo alcanzado (89,70 \pm 16,57\%). Ninguno de los autores del metaanálisis de "mini bypass gástrico"128 describen un valor de PSP tan elevado al año de la intervención, siendo Rutledge et $\mathrm{al}^{133}$ el más próximo (89\%), seguido de Carbajo et al ${ }^{123}$ (75\%) y Noun et $\mathrm{al}^{140}(69,9 \%)$.

Van De Laar et $\mathrm{al}^{180}$, muestran una serie de pacientes intervenidos de BGYR con seguimiento a 2 años, obteniendo los mejores resultados a los 24 meses de la cirugía con un PSP de $77,3 \pm 22,8 \%$, a diferencia de los 
pacientes de nuestro estudio en los que se describió un resultado más elevado $(88,10 \pm 16,99 \%)$.

Incluso teniendo en cuenta un peso inicial más bajo que el nuestro, como describen Bindal et $\mathrm{al}^{181}(109 \pm 29,5 \mathrm{Kg})$, de una muestra de pacientes intervenidos de BGYR, los resultados del PSP a 12 y 24 meses $(53,8 \%$, $60,7 \%$ ) fueron más bajos que los descritos en los pacientes intervenidos de BAGUA.

Respecto a la influencia de la edad en la pérdida de peso de los pacientes de la muestra estudiada, no observamos diferencias estadísticamente significativas entre los dos grupos de edad aunque el PSP fue más elevado en el grupo de los < 42 años $(91,08 \pm 17,22 \%$. 85,35 \pm $16,45 \%)$. El metaanálisis publicado por Lynch et $\mathrm{al}^{182}$ sobre la efectividad de la cirugía bariátrica en personas mayores de 55 años (tabla 5.3), muestran al igual que nosotros, mejores resultados en los pacientes más jóvenes e intervenidos de BGYR respecto a los de banda gástrica ajustable (BGA). Ninguno de los autores del metaanálisis describió un PSP superior al obtenido en los pacientes de BAGUA a 12 meses, aunque el IMC prequirúrgico era más elevado en el resto de trabajos.

\begin{tabular}{|c|c|c|c|}
\hline Estudios analizados & Técnica & $\begin{array}{c}\text { IMC } \\
\text { prequirúrgico }\end{array}$ & $\begin{array}{l}\text { PSP } 12 \\
\text { meses }\end{array}$ \\
\hline & & $\left(\mathrm{Kg} / \mathrm{m}^{2}\right)$ & $(\%)$ \\
\hline Fazylov.R et $\mathrm{al}^{183}$ & BGYR & 47 & 70 \\
\hline Papasavas P.K et al ${ }^{184}$ & BGYR & 50,2 & 64 \\
\hline Sosa J.L et al ${ }^{185}$ & BGYR & 48,5 & 65 \\
\hline Willkomm C.M et $\mathrm{al}^{186}$ & BGYR & 45 & 75 \\
\hline Frutos M.D et $\mathrm{al}^{187}$ & BGA & 48,1 & 58 \\
\hline Mittermair et $\mathrm{al}^{188}$ & BGA & 44,3 & 32 \\
\hline ReCiMB & BAGUA & $42,61 \pm 6,66$ & $89,70 \pm 16,57$ \\
\hline
\end{tabular}

Tabla 5.3. Resultados de PSP del metaanálisis publicado por Lynch et al ${ }^{182}$, comparados con el estudio ReCiMB

El PSP observado a los 12 y 24 meses postquirúrgicos de los pacientes de la Tesis fue más elevado en las mujeres respecto de los hombres sin ser esa diferencia significativa, al igual que en el resto de publicaciones en las que el peso inicial de los hombres fue superior $(132,23 \pm 22,13 \%$. 110,43 \pm 
18,99\%). En ninguna de las publicaciones consultadas en la discusión se describe la variación ponderal en función del sexo, lo cual puede estar justificado por el elevado número de mujeres descritas, constituyendo en todos más del $63 \%$ de la muestra ${ }^{128}$.

Otras de las formas utilizadas para expresar la variación ponderal en valores absolutos es mediante el IMC, como se muestra en la tabla 5.4 que recoge los estudios del metaanálisis "mini bypass gástrico (MBG)"128.

\begin{tabular}{|c|c|c|c|c|}
\hline $\begin{array}{l}\text { Estudios } \\
\text { analizados }\end{array}$ & $\begin{array}{c}\text { IMC } \\
\text { inicial } \\
\left(\mathrm{Kg} / \mathrm{m}^{2}\right)\end{array}$ & $\begin{array}{c}\text { IMC } 6 \\
\text { meses } \\
\left(\mathrm{Kg} / \mathrm{m}^{2}\right)\end{array}$ & $\begin{array}{c}\text { IMC } 12 \\
\text { meses } \\
\left(\mathrm{Kg} / \mathrm{m}^{2}\right)\end{array}$ & $\begin{array}{l}\text { IMC 24 } \\
\text { meses } \\
\left(\mathrm{Kg} / \mathrm{m}^{2}\right)\end{array}$ \\
\hline Lee et $\mathrm{al}^{134}$ & 41,1 & - & - & - \\
\hline Wang et al ${ }^{135}$ & 44,2 & - & 29,2 & 28,4 \\
\hline Peraglie et al $^{136}$ & 62,4 & - & - & - \\
\hline $\begin{array}{l}\text { Chakhto ura et } \\
\mathrm{al}^{137}\end{array}$ & 46,9 & 35,1 & 31,9 & - \\
\hline Piazza et al $^{138}$ & 52,9 & 34,2 & 39,4 & 30,3 \\
\hline Carbajo et al ${ }^{123}$ & 48 & - & - & - \\
\hline $\begin{array}{l}\text { Rutledge et } \\
\mathrm{al}^{133}\end{array}$ & 46 & - & - & - \\
\hline Noun et $\mathbf{a l}^{139}$ & 44 & - & - & - \\
\hline Noun et $\mathrm{al}^{140}$ & 42,5 & - & 28,3 & - \\
\hline ReCiMB & $\begin{array}{c}42,61 \pm \\
6,66\end{array}$ & $\begin{array}{c}26,99 \pm \\
4,15\end{array}$ & $\begin{array}{c}25,08 \pm \\
3,59\end{array}$ & $\begin{array}{c}25,33 \pm \\
3,35\end{array}$ \\
\hline
\end{tabular}

Tabla 5.4. Evolución del IMC publicaciones del metaanálisis "mini bypass gástrico"128 y el estudio ReCiMB

En todos los estudios del metaanálisis ${ }^{128}$, el IMC inicial fue mayor al observado en nuestra muestra excepto en el trabajo de Lee et al $^{134}$ y Noun et $\mathrm{al}^{140}$. Solamente Wang et $\mathrm{al}^{135}$ y Piazza et $\mathrm{al}^{138}$ describen la evolución del IMC a 24 meses, siendo este el control con un menor IMC medio a diferencia de los pacientes de nuestra muestra que fue a los 12 meses.

Según criterios SEEDO, en el ReCiMB a partir de los 6 meses postquirúrgicos no se observaron pacientes con obesidad mórbida y/o extrema. A diferencia de Søvik.T et $\mathrm{al}^{189}$, en el que describen la modificación del IMC tras la cirugía bariátrica de BGYR y el cruce duodenal, mostrando al $26 \%$ de los pacientes intervenidos de BGYR a 2 años con un IMC $\geq 40$ y ninguno de los intervenidos de cruce duodenal, siendo en esta última el IMC inicial de los pacientes más elevado. En nuestro estudio, tras la preparación 
dietético-nutricional prequirúrgica los pacientes con obesidad extrema en el momento de la cirugía dejaron de serlo. Se evidencian pacientes con normopeso desde los 3 meses, siendo a los 24 meses de la cirugía el control con un mayor número de pacientes normopesos (48\% de los casos). Ninguno de los estudios consultados mostraron pacientes con normopeso a los 24 meses postquirúrgicos.

La expresión de la variación del IMC en términos relativos se realizó mediante la determinación del PIMCP y el PEIMCP, ambas determinaciones en los pacientes evaluados en esta Tesis alcanzaron su máximo valor a los 12 meses postquirúrgicos, coincidiendo con el control de máxima pérdida ponderal, mientras que en la mayoría de las publicaciones consultadas que a continuación se muestran, expresan los resultados en términos relativos del peso y no del IMC.

Aunque hemos descrito que ambas formas muestran en cada control evaluado los mismos cambios significativos respecto al control inicial, obteniendo el mejor resultado a los 12 meses postquirúrgicos, del mismo modo al comparar los resultados por sexo y mediana de edad.

En la Tesis Doctoral de Suárez Llanos, 2013 ${ }^{190}$; se muestra la evolución de 97 pacientes intervenidos de BGYR en el Hospital General Universitario Gregorio Marañón con seguimiento a 24 meses. El peso inicial fue superior al de nuestro estudio $(139,3 \pm 20,5 \mathrm{Kg} \cdot 116,75 \pm 22,19 \mathrm{Kg})$ y la mayor pérdida ponderal expresada en PSP se observó a los 24 meses (61,1 \pm 21,4\%) a diferencia del PEIMCP que fue a los 18 meses $(71,5 \pm 17,5 \%)$. Nuestros resultados en el PEIMCP fueron más elevados, apreciando la mayor pérdida ponderal a los 12 meses de la cirugía $(104,82 \pm 23,57 \%)$.

En el trabajo de Contreras et $\mathrm{al}^{191}$, describen una correlación entre el efecto de la edad sobre la evolución del PEIMCP en pacientes intervenidos de BGYR y manga gástrica al año de la cirugía, mostrando una correlación significativa entre los pacientes con $\geq 45$ años, en los que el PEIMCP no fue tan positivo. Los pacientes descritos por Contreras et $\mathrm{al}^{191}$ tienen un IMC inicial más bajo que los pacientes de nuestro estudio, tabla 5.5, y en ambas 
técnicas los resultados a 12 meses del PEIMCP fue menor que los pacientes intervenidos de BAGUA.

\begin{tabular}{|c|c|c|c|}
\hline \multirow{2}{*}{ Estudio analizado } & \multirow{2}{*}{$\begin{array}{l}\text { Grupo de } \\
\text { edad }\end{array}$} & IMC inicial & $\begin{array}{c}\text { PEIMCP } 12 \\
\text { meses }\end{array}$ \\
\hline & & $\left(\mathrm{Kg} / \mathrm{m}^{2}\right)$ & (\%) \\
\hline \multirow{2}{*}{ Contreras et $\mathrm{al}^{134}$} & $<45$ años & $40,7 \pm 6,7$ & $91 \pm 26,6$ \\
\hline & $\geq 45$ años & $41,6 \pm 6,8$ & $83,6 \pm 27$ \\
\hline \multirow{2}{*}{ ReCiMB } & $<42$ años & $42,64 \pm 7,16$ & $106,19 \pm 26,04$ \\
\hline & $\geq 42$ años & $42,58 \pm 6,22$ & $103,58 \pm 21,33$ \\
\hline
\end{tabular}

Tabla 5.5. PEIMCP a 12 meses por grupos de edad comparando los resultados del estudio de Contreras et al ${ }^{134}$ y ReCiMB

Los pacientes ReCiMB no presentaron diferencias significativas respecto a la mediana de edad, aunque en todos los controles desde los 3 meses postquirúrgicos se observó un PEIMCP mayor en el grupo de pacientes más jóvenes como describen Contreras et $\mathrm{al}^{134}$ a los 12 meses de la cirugía.

Chevallier et al $^{192}$ detallan la evolución ponderal de una muestra de pacientes intervenidos de bypass gástrico de una anastomosis con un peso inicial de $127 \mathrm{Kg}$, en la que se aprecia el PEIMCP más elevado a los 24 meses de la cirugía en el grupo de pacientes más jóvenes (< 40 años 80,1 \pm $19,3 \% ; \geq 40$ años $74,7 \pm 28,7 \%$ ), sin ser esa diferencia significativa estadísticamente, al igual que los resultados observados en nuestro trabajo (< 42 años $108 \pm 28,80 \%$; $\geq 42$ años $99,91 \pm 22,46 \%$ ).

No existe un criterio unánime en la elección óptima para la expresión de la pérdida ponderal en los pacientes intervenidos de cirugía bariátrica, por ello se describió la evolución ponderal en términos absolutos y relativos. En la actualidad se utiliza la propuesta de Larrad et al $^{125}$ (basándose en la correlación estadística entre el PSP y el PEIMCP) la valoración de la pérdida de peso mediante el PEIMCP, calculado preferentemente según la formulación propuesta por Cigaina ${ }^{193}$, concepto este último (PEIMCP) al que se recurrió en el estudio de los pacientes ReCiMB para catalogar los resultados como excelentes, buenos y fracasos como se detalla en el punto 4.7.c de los resultados. 
Todos los pacientes de ReCiMB, desde los 6 meses de la cirugía presentaron resultados entre buenos y excelentes y ningún fracaso. Contreras et al ${ }^{134}$ describió a los 12 meses de la cirugía al 2,6\% de los pacientes $<45$ años con un PEIMCP $<50 \%$, considerado como fracaso, a diferencia del grupo de $\geq 45$ años en el que el porcentaje de fracasos fue mucho mayor (14,9\%). En nuestro estudio no se observaron diferencias significativas en relación al grupo de edad, aunque desde el $6^{\circ}$ mes de la cirugía el porcentaje de excelentes fue más elevado en el grupo de edad más joven. Del mismo modo se observa un mayor porcentaje de excelentes entre las mujeres respecto a los hombres sin ser esa diferencia significativa.

La Sociedad Americana de Cirugía Bariátrica y Metabólica (ASMBS) defiende expresar la pérdida ponderal en términos relativos, aceptando la utilización del PSP para el peso y el PEIMCP para el IMC como medidas de resultado de la cirugía ${ }^{194}$. Algunos cirujanos defienden su uso como un estándar que determina el éxito de la técnica y el cuál es fácil de comparar con el resto de cirugías, por la falta de consenso en los objetivos del peso ideal postquirúrgico ${ }^{195}$.

No obstante, otros autores critican la utilización del PSP y PEIMCP como medio de estandarización de los objetivos ponderales de las cirugías bariátricas, demostrando que los pacientes con un IMC prequirúrgico más elevado tienen peores resultados postquirúrgicos de $\mathrm{PSP}^{196}$, como ocurre con los hombres de nuestra muestra que parten con un peso inicial más elevado y obtienen un PSP y PEIMCP más bajo que las mujeres. Sin tener en cuenta por otra parte la asociación entre obesidad y SM en el que el PSP por sí solo no es capaz de expresar la mejora metabólica, y es necesario recurrir a la determinación de otros parámetros como el perímetro de cintura $^{55}$.

\subsubsection{Evolución del patrón de distribución de la grasa abdominal}

Es necesario estudiar la distribución de la grasa en el individuo, pues su localización, especialmente la abdominal ${ }^{19,21}$, influye en la determinación del riesgo cardiovascular. Por eso se utilizan las determinaciones del perímetro de cintura e índice cintura/cadera entre otros y no sólo el IMC, pues han 
demostrado una asociación positiva relacionada con un mayor riesgo cardiovascular $^{197}$, siendo fáciles de utilizar y llevar a cabo. Los límites máximos que la IDF y el ATP III aconsejan no sobrepasar están definidos por un perímetro de cintura en el hombre de $102 \mathrm{~cm}$ y $88 \mathrm{~cm}$ en la mujer ${ }^{58}$, siendo estos los valores adoptados en nuestro trabajo para definir la obesidad abdominal.

\section{- Perímetro de cintura}

En los pacientes ReCiMB, se observó un descenso en la evolución del perímetro de cintura postquirúrgico. En las mujeres, desde los 9 meses postquirúrgicos el perímetro de cintura se encuentra por debajo de $88 \mathrm{~cm}$, en los hombres desde los 6 meses el perímetro de cintura es menor de $102 \mathrm{~cm}$. El valor más bajo se observó en las mujeres a los 18 meses y en los hombres a los 12 meses, coincidiendo con el control postquirúrgico en el que se registró un peso e IMC medio más bajo en ambos sexos.

En el metaanálisis de $\mathrm{MBG}^{128}$, ningún autor muestra la evolución de los perímetros de cintura y cadera de los pacientes intervenidos. Kular et $\mathrm{al}^{150}$ describen un perímetro de cintura medio inicial más bajo que el de nuestros pacientes $(118,2 \pm 15,7 \mathrm{~cm} .128,49 \pm 15,33 \mathrm{~cm})$, siendo el IMC inicial más elevado que el de nuestra muestra $(43,2 \pm 7,4.42,61 \pm 6,66)$.

Del mismo modo ocurre al comparar los resultados de las mujeres ReCiMB con las mujeres descritas por lannelli. A et $\mathrm{al}^{198}$, intervenidas de BGYR, las cuales antes de la cirugía presentaban un perímetro de cintura más bajo $(117,8 \pm 11,7 \mathrm{~cm}$. 124,44 $\pm 14,26 \mathrm{~cm})$ con un peso prequirúrgico más elevado $(116,35 \pm 15,5 \mathrm{Kg}$. 110,43 \pm 18,99 cm).

Al año de la cirugía, las mujeres de nuestro estudio y las descritas por lannelli. $\mathrm{A}$ et $\mathrm{al}^{198}$ descienden el perímetro de cintura, observando el valor más bajo en nuestros pacientes $(83,21 \pm 10,15 \mathrm{~cm} .88,1 \pm 12,1 \mathrm{~cm})$, cumpliendo las recomendaciones IDF y ATP $\mathrm{III}^{58}$.

Por grupos de edad, en los pacientes < 42 años de nuestro estudio se evidenciaron valores más bajos en el perímetro de cintura sin ser esa diferencia significativa, Ebrahimi-Mameghani et $\mathrm{al}^{199}$, comprobaron dicha 
asociación a largo plazo postquirúrgico (9 años), mostrando un aumento de $5,46 \mathrm{~cm}$ al año en los pacientes de mayor edad a diferencia de los más jóvenes en el que el aumento fue de $3,74 \mathrm{~cm}$.

\section{- Perímetro de cadera}

La evolución del perímetro de cadera no sigue la misma tendencia que la cintura, observando en ambos sexos los valores medios más bajos a los 24 meses de la cirugía. Stevens et $\mathrm{al}^{200}$, describen una asociación positiva entre los hombres y los pacientes de mayor edad con valores del perímetro de cintura más elevado al igual que en nuestro estudio. Afirman la presencia de valores más elevados en el perímetro de la cadera en función del IMC, a diferencia de lo que ocurre en los pacientes ReCiMB en los que el perímetro de cadera desciende progresivamente hasta alcanzar el valor más bajo a los 2 años de la intervención, a diferencia del IMC el cual se obtiene a los 12 meses de la cirugía.

Jastrzębska et $\mathrm{al}^{201}$ reunieron una muestra compuesta por 18 pacientes intervenidos de BGYR y 32 de manga gástrica, mostrando una interacción positiva en el descenso de peso, IMC, y perímetro de cintura y cadera a 6 meses postquirúrgicos diferenciado entre hombres y mujeres comparable a los resultados obtenidos con nuestros pacientes como se detalla en la tabla 5.6.

\begin{tabular}{|c|c|c|c|c|c|}
\hline \multirow{2}{*}{\multicolumn{2}{|c|}{ Variables }} & \multicolumn{2}{|c|}{ Jastrzębska et al ${ }^{201}$} & \multicolumn{2}{|c|}{ ReCiMB } \\
\hline & & \multirow{2}{*}{$\begin{array}{c}\text { Mujeres } \\
120,66 \pm 21,24\end{array}$} & \multirow{2}{*}{$\begin{array}{c}\text { Hombres } \\
142,83 \pm 28,41\end{array}$} & \multirow{2}{*}{$\begin{array}{c}\text { Mujeres } \\
110,43 \pm 18,99\end{array}$} & \multirow{2}{*}{$\begin{array}{c}\text { Hombres } \\
132,23 \pm 22,13\end{array}$} \\
\hline \multirow{3}{*}{$\begin{array}{c}\text { Peso } \\
(\mathrm{Kg})\end{array}$} & Precirugía & & & & \\
\hline & 3 meses & $102,30 \pm 20,71$ & $118,13 \pm 23,92$ & $78,33 \pm 14,42$ & $89,44 \pm 14,45$ \\
\hline & 6 meses & $92,89 \pm 19,70$ & $111,43 \pm 27,44$ & $70,11 \pm 11,83$ & $84,86 \pm 14,50$ \\
\hline \multirow{3}{*}{$\begin{array}{c}\mathrm{IMC} \\
\left(\mathrm{Kg} / \mathrm{m}^{2}\right)\end{array}$} & Precirugía & $44,55 \pm 9,73$ & $47,75 \pm 9,78$ & $42,32 \pm 6,75$ & $43,31 \pm 6,49$ \\
\hline & 3 meses & $37,90 \pm 9,37$ & $38,85 \pm 8,12$ & $30,08 \pm 5,29$ & $29,01 \pm 4,37$ \\
\hline & 6 meses & $34,92 \pm 9,21$ & $36,7 \pm 9,48$ & $26,80 \pm 4,15$ & $27,51 \pm 4,20$ \\
\hline \multirow{3}{*}{$\begin{array}{l}\text { Perímetro } \\
\text { cintura } \\
\text { (cm) }\end{array}$} & Precirugía & $130,96 \pm 20,48$ & $146,33 \pm 17,96$ & $124,44 \pm 14,26$ & $138,41 \pm 13,37$ \\
\hline & 3 meses & $117,53 \pm 23,07$ & $128,42 \pm 14,63$ & $94,48 \pm 16,29$ & $102,41 \pm 13,35$ \\
\hline & 6 meses & $110,53 \pm 23,04$ & $122,67 \pm 19,51$ & $89,84 \pm 10,49$ & $98,05 \pm 10,73$ \\
\hline \multirow{3}{*}{$\begin{array}{c}\text { Perímetro } \\
\text { cadera } \\
\text { (cm) }\end{array}$} & Precirugía & $137,46 \pm 14,53$ & $137,08 \pm 17,90$ & $123,06 \pm 26,63$ & $124,34 \pm 21,80$ \\
\hline & 3 meses & $125,50 \pm 12,88$ & $125,5 \pm 17,02$ & $111,38 \pm 13,06$ & $108,63 \pm 15,69$ \\
\hline & 6 meses & $120,26 \pm 13,09$ & $120,67 \pm 19,33$ & $105,39 \pm 10,11$ & $104,50 \pm 8,12$ \\
\hline
\end{tabular}

Tabla 5.6. Comparativo de las variables: peso, IMC, perímetro de cintura y cadera de los pacientes del estudio de Jastrzębska et al ${ }^{201}$ y el estudio ReCiMB 
A los 6 meses de la cirugía se observó que en ninguno de los 2 estudios, los pacientes alcanzaban el normopeso, ni la exclusión de riesgo cardiovascular asociado al perímetro de la cintura según indicaciones de IDF y ATP III ${ }^{58}$, a excepción de los hombres del estudio ReCiMB.

\section{- Riesgo cardiovascular y distribución de la grasa}

El paciente con obesidad abdominal tiene una predisposición a sufrir eventos cardiovasculares y es por ello es una necesidad estimar su evolución en los pacientes intervenidos de MBG, para ello utilizamos el IMC y el perímetro de cintura, definiendo la obesidad abdominal según los criterios ATP $1 \mathrm{II}^{58}$. El riesgo cardiovascular en las personas obesas no sigue una distribución normal y es necesario realizar una correcta identificación del riesgo en cada persona de manera individualizada, como se detalla en el metaanálisis de Vest et $\mathrm{al}^{202}$ describiendo una reducción del riesgo cardiovascular en los pacientes obesos intervenidos de cirugía bariátrica.

Existe una correlación positiva de los diferentes indicadores antropométricos asociados al aumento de eventos cardiovasculares adversos, como describen Puig et $\mathrm{al}^{203}$ en más de 2000 pacientes del registro de REDINSCOR (Red Española de Insuficiencia Cardiaca), mostrando en ambos sexos el perímetro de cintura como el indicador más preciso. Puig et $\mathrm{al}^{203}$, coinciden con la SEEDO, en no emplear sólo el perímetro de cintura o IMC, pues conlleva limitaciones para realizar una correcta identificación de los pacientes con riesgo cardiovascular y estudiar la evolución del mismo, siendo necesario utilizar los dos valores combinados para predecir de manera más fiable el pronóstico de los pacientes. Por este motivo se empleó en cada control postquirúrgico la categorización del IMC (sobrepeso y obesidad grados I, II y III) y el aumento del perímetro de cintura (> $102 \mathrm{~cm}$ en el varón y > $88 \mathrm{~cm}$ en la mujer) como indicadores de riesgo relativo (comparado con el peso y perímetro de cintura normal), como se puede ver de manera detallada en el punto 4.8 de los resultados. 


\subsection{Evaluación de la adaptación alimentaria postquirúrgica}

La dieta postcirugía de los pacientes intervenidos de cirugía bariátrica debe de proporcionar todos los nutrientes, aportando por lo menos las cantidades mínimas recomendadas, teniendo en cuenta que los pacientes después de un procedimiento de tipo mixto ven reducida la cantidad de las tomas así como la absorción de nutrientes ${ }^{204}$. Es necesario un seguimiento dietético-nutricional posterior a la cirugía con la finalidad de conseguir una óptima reeducación alimentaria del paciente, mediante una adecuada progresión alimentaria junto con una apropiada suplementación en proteínas, vitaminas y minerales que permita una evolución favorable del peso, evitando carencias nutricionales y fortaleciendo los hábitos alimentarios y estilos de vida saludables ${ }^{204,205}$.

CTO lleva a cabo un protocolo de reeducación alimentaria postquirúrgico en el cual se valoró la respuesta de los pacientes en cada control postquirúrgico respecto a su autovaloración de la adaptación alimentaria y las dificultades observadas en el proceso. El control de la progresión alimentaria se llevó a cabo por el equipo nutricional de CTO, mediante control telefónico semanal hasta la primera evaluación postquirúrgica de los 3 meses con resultados analíticos y registro (ANEXO II). El protocolo establecido por CTO, se completa con una duración entre 3-6 meses; con el inicio de la administración de líquidos, seguido de una dieta líquida completa rica en proteínas y baja en grasas, seguido de una dieta triturada hasta alcanzar una dieta normal.

Esta pauta alimentaria con ligeras variaciones es compartida por otras Unidades bariátricas como describe Rubio.MA et $\mathrm{al}^{205}$, con el objetivo de minimizar las carencias nutricionales propias de la cirugía y favorecer la reeducación alimentaria. La mayoría de los pacientes desde el primer control postquirúrgico realizan entre 4-5 comidas diarias, observando a un gran número que manifiesta picotear entre horas evitando la sensación de plenitud, como señala Parkes. $E^{206}$ en la utilización de una correcta pauta alimentaria postquirúrgica en la que es necesaria evitar irritar y sobrecargar el reservorio gástrico, prescindiendo de comidas que den lugar a plenitud e 
irritación gástrica y aumentando el tiempo dedicado a la comida entre otras, para poder alcanzar un mayor éxito en la pérdida de peso y reducir los efectos adversos de una inadecuada adaptación alimentaria.

Para valorar cómo percibieron los pacientes el periodo de adaptación alimentaria y siguiendo los criterios establecidos por IFSO, los pacientes aunque con una tasa de respuesta muy baja, mayoritariamente expresaron su adaptación entre buena y óptima desde los 6 meses, señalando las carnes seguido de los cereales y la leche, los alimentos peor tolerados en todos los controles postquirúrgicos evaluados como se detalla en el capítulo 4.9 de los resultados. Estos mismos alimentos son descritos por Rubio.MA et $\mathrm{al}^{205}$ como los peor tolerados, mostrando un 51\% de los casos con intolerancia a la carne, 35\% arroz y $16 \%$ a la leche, es por ello que muchos pacientes tienden a una sobrealimentación debido a una mayor tolerancia de alimentos grasos siendo más fácil recurrir a ellos antes que tratar de adaptarse a una nueva situación ${ }^{207}$.

Los efectos adversos más frecuentes de una mala adaptación alimentaria son los vómitos, reflujo gastroesofágico (RGE) y diarrea ${ }^{207}$, y aunque la tasa de respuesta fue baja, se apreció que los vómitos y RGE eran más frecuentes en la etapa inicial de la adaptación alimentaria postquirúrgica. El mal olor de las deposiciones es característico en estos pacientes debido a la mala digestión y malabsorción de los alimentos.

Las náuseas y vómitos suelen aparecer tras comer demasiado deprisa 0 una masticación insuficiente de los alimentos o al ingerir cantidades superiores a las del nuevo reservorio gástrico, observando con más frecuencia estos efectos adversos en cirugías restrictivas y mixtas ${ }^{205}$. En cambio la diarrea, suele aparecer tras la derivación biliopancreática y procesos mixtos más agresivos como el cruce duodenal ${ }^{205,207}$.

La sobrealimentación es otro de los efectos postquirúrgicos a controlar, pues es frecuente observar cómo los pacientes recurren a los alimentos grasos pues les resulta más fácil de digerir como son el chocolate, helados, dulces, frutos secos, etc ${ }^{205}$. Esta situación puede ser debida a una alteración 
conductual, cambios emocionales que deben de ser vigilados de cerca para evitar el fracaso de la cirugía y reconducir al paciente en hábitos saludables en su alimentación, haciéndole partícipe de control nutricional para así mejorar la adherencia terapéutica.

Estos efectos adversos influyen de manera negativa en la calidad de vida de los pacientes siendo necesario un control de las carencias nutricionales que estos puedan ocasionar, como el propuesto por IFSO y llevado a cabo en CTO con el objetivo de minimizar esos efectos adversos y mejorar el proceso de modificación de la conducta alimentaria. 


\subsection{Actividad física postquirúrgica}

Aunque no se llevó a cabo una determinación de la actividad física inicial de los pacientes posteriormente intervenidos de BAGUA, cumpliendo con las recomendaciones del EAC-BS se pretendió valorar el nivel de actividad física en los controles evaluados postquirúrgicos. La tasa de respuesta a la pregunta de valoración de la actividad física no fue muy elevada pero se observa un aumento desde el primer control postquirúrgico evaluado hasta los 2 años de la cirugía, respondiendo mayoritariamente realizar ejercicio 2 veces a la semana o a diario.

Esta tendencia del abandono del sedentarismo y el aumento de la actividad física en los 2 primeros años postquirúrgicos fue descrita por King et $\mathrm{al}^{208}$ en su estudio de la actividad física de 473 pacientes intervenidos de cirugía bariátrica (69,6\% BGYR), mostraron como el nivel de sedentarismo desciende en el primer año a la vez que el nivel de actividad física aumenta significativamente, manteniéndose estable el nivel de sedentarismo a 3 años a diferencia de la intensidad de actividad física que se reduce.

Estos mismos resultados son compartidos por la serie descrita por Reid et $\mathrm{al}^{209}$, los cuales describen el nivel de actividad física a largo plazo mediante el ActivPAL ${ }^{\mathrm{TM}} 3$ de 89 pacientes, en la que muestran una actividad física insuficiente y un alto nivel de sedentarismo en relación a los estándares de las guías de salud.

Aunque nuestros resultados a 2 años en cuanto al nivel de actividad física son positivos, es necesario ser consecuentes en las recomendaciones pautadas en los pacientes para garantizar un óptimo control del peso y estilo de vida saludable a largo plazo. 


\subsection{Evolución de los valores bioquímicos plasmáticos}

\subsubsection{Glucemia}

En todos los estudios consultados desde el momento quirúrgico se aprecia un descenso del valor medio de la glucemia, el cual está acompañado de la reducción ponderal de los pacientes. Buchwald et a ${ }^{129}$ en su metaanálisis describen una resolución de la DM en el 98,9\% de los pacientes intervenidos de derivación biliopancreática, el 83,7\% en el bypass gástrico y por último la manga gástrica con el 71,6\%.

En nuestro estudio el valor medio más bajo no coincide con el control de mayor pérdida de peso, como muestra Milone et $\mathrm{al}^{210}$ en 31 pacientes intervenidos de MBG y manga gástrica con seguimiento a 12 meses, describiendo una remisión de la DB del 87,5\%, siendo mayor la efectividad de la reducción de la glucemia en los pacientes de MBG. En comparación, nuestros resultados a 12 meses son ligeramente más bajos con un 82,61\% de resolución de la DM.

En la mayoría de las publicaciones no expresan los resultados de diabetes conforme a las recomendaciones de la SECO ( $<100 \mathrm{mg} / \mathrm{dL}$ ). Nosotros observamos a 24 meses, una remisión parcial en el 95,41\% de los casos y una remisión total en el $81,84 \%$, cifras muy superiores a las descritas por Brethauer et $\mathrm{al}^{211}$ en una muestra de 217 pacientes con DM intervenidos de diferentes técnicas bariátricas con una resolución total y parcial del $24 \%$ y $26 \%$ respectivamente a 6 años. Estas grandes diferencias pueden ser debidas a las características de la muestra inicial, pues en la de Brethauer et $\mathrm{al}^{211}$, todos los pacientes seleccionados eran DM y el tipo de cirugías puede justificar una menor efectividad en la reducción de la glucemia.

En las series de pacientes intervenidos exclusivamente de MBG, todos muestran una tendencia descendente de la glucemia postquirúrgica con cifras de remisión superiores al $70 \%$. Kular et al ${ }^{150}$ describen una remisión del $93,2 \%$ a 6 años y una mejoría en el 98\% de los casos, en nuestros pacientes el $100 \%$ mejoraron el nivel medio de glucemia prequirúrgica pero 
no podemos comparar los resultados de remisión con Kular et al ${ }^{150}$ pues utilizan la determinación de la HbA1c exclusivamente y no de la glucemia, observando en nuestro caso una remisión del 84,79\%. A diferencia de Kim et $\mathrm{al}^{212}$, que describen una resolución de la DM a corto plazo del $70 \%$ en una muestra de pacientes diabéticos, con un valor medio de glucemia alcanzado de $144 \mathrm{mg} / \mathrm{dL}$.

En nuestro trabajo los diabéticos prequirúrgicos resolvieron la DM en el $84,79 \%$ de los casos a 2 años de seguimiento, prácticamente igual que los descritos a 26 meses por Chevallier et $\mathrm{al}^{192}$ en el 85,7\%. En estos dos estudios, las cifras son comparables a los resultados a medio plazo, propuestos por Rutledge et $\mathrm{al}^{133}$ y Bruzzi et $\mathrm{al}^{213}$, con una mejoría del $83 \%$ y del $82 \%$ respectivamente.

Apreciamos una peor evolución de los valores medios de glucemia en los hombres y en los pacientes $\geq 42$ años, aunque no se han podido comparar con los estudios propuestos en la discusión, porque no catalogan los resultados en función del sexo y la edad, siendo en todos más del 63\% de los pacientes mujeres.

\subsubsection{Perfil lipídico}

La evolución de todos los valores en sangre correspondientes al perfil lipídico estudiados en nuestros pacientes mejoran después de la cirugía significativamente, con las implicaciones en la disminución del riesgo cardiovascular que supone la normalización de los valores lipídicos ${ }^{201,203}$.

Milone et $\mathrm{al}^{214}$, estudiaron la evolución del perfil lipídico a 12 meses en una muestra de 160 pacientes intervenidos de cirugía bariátrica de los cuales 74 MBG y el resto manga gástrica. Aún siendo el IMC inicial de los 74 pacientes superior al de nuestro estudio $\left(47,3 \pm 3,88 \mathrm{Kg} / \mathrm{m}^{2} .42,61 \pm 6,66\right.$ $\mathrm{Kg} / \mathrm{m}^{2}$ ), los valores iniciales de las diferentes variables del perfil lipídico no se presentan igual, siendo el Col-Total, LDL-Col y HDL-Col más elevados en nuestros pacientes como se describe en la tabla 5.7. 


\begin{tabular}{lcccc}
\hline \multicolumn{1}{c}{$\begin{array}{c}\text { Estudio } \\
\text { analizado }\end{array}$} & Col-Total & LDL-Col & HDL-Col & TG \\
\cline { 2 - 5 } & $(\mathbf{m g} / \mathrm{dL})$ & $(\mathrm{mg} / \mathrm{dL})$ & $(\mathrm{mg} / \mathrm{dL})$ & $(\mathrm{mg} / \mathrm{dL})$ \\
\hline Milone et $\mathbf{a l}^{2 \mathbf{1 4}}$ & $187,8 \pm 50,6$ & $113,3 \pm 22,9$ & $40,1 \pm 8,47$ & $170,8 \pm 91,5$ \\
\hline ReCiMB & $201,86 \pm 44,60$ & $126,90 \pm 39,81$ & $49,09 \pm 14,16$ & $138,05 \pm 78,45$
\end{tabular}

Tabla 5.7. Valores prequirúrgicos del perfil lipídico plasmático del estudio de Milone et al ${ }^{214} y$ el estudio ReCiMB

Milone et $\mathrm{al}^{214}$, describen una reducción significativa del Col-Total, LDL y TG, con un aumento del HDL a los 6 y 12 meses respecto al valor prequirúrgico, como en nuestros pacientes. Al compararlos con los resultados obtenidos en los pacientes intervenidos de manga gástrica, los cambios no fueron tan positivos, pero defienden que la técnica no es la única responsable de los cambios en el perfil lipídico, sino también la modificación de la conducta alimentaria y la disminución ponderal sufrida por los pacientes, siendo comparables del mismo modo los resultados obtenidos por el BGYR ${ }^{134}$. Concluyendo que no pueden identificar los determinantes de la normalización y mejora del perfil lipídico en los pacientes intervenidos de cirugía bariátrica estudiados debido a los complejos mecanismos que intervienen en el metabolismo del perfil lipídico que aún son desconocidos $^{214}$.

En MBG, Kular et $\mathrm{al}^{150}$ describen una remisión de la hiperlipidemia del 91\% de los casos intervenidos a 6 años, cifras comparables a la remisión de los valores de TG en nuestro estudio en un $91,12 \%$ de los casos a 24 meses postquirúrgicos. Piazza el $\mathrm{al}^{138}$, reporta una resolución de la dislipemia en el $70 \%$ de los casos. Es necesario especificar cuál es la variable del perfil lipídico y el criterio utilizado para reportar los resultados pues como se observa en nuestro estudio a 24 meses, el mayor porcentaje de remisión de la dislipemia corresponde a los TG (91,12\%), seguido del Col-Total $(68,36 \%)$ y el LDL-Col $(44,14 \%)$ según los criterios ATP III. Los valores de HDL-Col se normalizaron en el $86,17 \%$ de los casos con un HDL-Col prequirúrgico $<40$ $\mathrm{mg} / \mathrm{dL}$.

Søvik et $\mathrm{al}^{189}$, muestran la evolución de 60 pacientes sometidos a cruce duodenal (29) y BGYR (31) a 2 años, observando una mejora significativa del perfil lipídico a 24 meses en ambas series. La evolución de las variables 
se detalla en la tabla 5.8, con unos valores iniciales más elevados en nuestros pacientes, a excepción de los TG, que los descritos por Søvik et $\mathrm{al}^{189}$, mostrando una tendencia similar en ambos estudios a 24 meses.

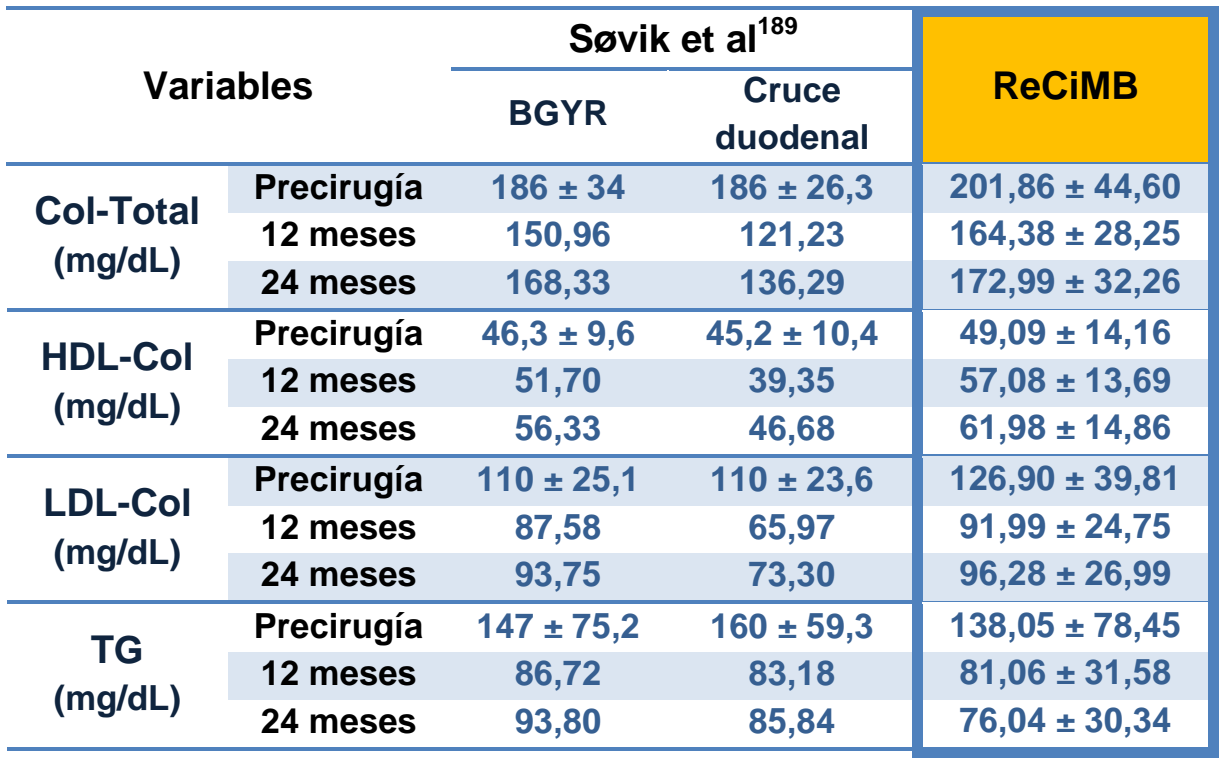

Tabla 5.8. Evolución del perfil lipídico plasmático del estudio de Søvik et al ${ }^{189}$ y el estudio ReCiMB

Søvik et $\mathrm{al}^{189}$, sugieren que los resultados positivos sobre el perfil lipídico son ocasionados por la reducción ponderal, reduciendo así el riesgo cardiovascular de los pacientes sometidos al procedimiento quirúrgico, como se detalla en el metaanálisis en los que se redujo el LDL-Col en 38,6 mg/dL, consiguiendo reducir en un 19\% la mortalidad coronaria a 5 años.

En los estudios publicados de MBG no se muestran las diferencias por sexo y grupos de edad en cuanto a las variaciones postquirúrgicas del perfil lipídico. Las mujeres intervenidas de BAGUA parten con unos valores medios prequirúrgicos de Col-Total, LDL-Col y HDL-Col más elevados que los varones a diferencia de los TG, independientemente ambos sexos mejoran significativamente los resultados a 24 meses. Por grupos de edad los $\geq 42$ años parten con unos valores del perfil lipídico ligeramente más elevados, y aunque los resultados a 24 meses son positivos, no alcanzan las cifras del grupo de pacientes más joven. 


\subsubsection{Perfil renal}

Varios estudios basados en la población $\mathrm{n}^{215,216}$ han demostrado que la obesidad es un factor de riesgo independiente para el desarrollo de la enfermedad renal crónica. Fox ${ }^{215}$, estudió en la población de Framingham a 2738 individuos sin evidencia de enfermedad renal crónica durante una media de 18,5 años, evidenciando que aquellos con un IMC >30 aumentaron las probabilidades de desarrollar enfermedad renal en un $23 \%$. En un estudio de cohorte retrospectivo de 320252 individuos estadounidenses, Hsu et $a^{216}$ encontraron una asociación positiva entre el aumento del IMC y el riesgo de desarrollar enfermedad renal terminal.

Aunque en el metaanálisis de MBG no se describe la evolución postquirúrgica del perfil renal de los pacientes intervenidos ${ }^{128}$, otros autores muestran un descenso de los parámetros renales e incluso una mejora y estabilización de la enfermedad renal crónica a través de la cirugía bariátrica debido a la pérdida ponderal inducida ${ }^{217}$.

En nuestro trabajo como se detalla en el apartado 4.12.3 de los resultados, el perfil renal disminuye significativamente desde el $3^{\circ}$ mes postquirúrgico hasta los 24 meses, en todas las variables descritas. Getty et $\mathrm{al}^{218}$ analizaron la evolución del perfil renal en 37 pacientes sometidos a BGYR a 6 meses de seguimiento, mostrando la misma tendencia que en nuestros pacientes, aunque con una creatinina precirugía de 0,83 $\pm 0,21$ $\mathrm{mg} / \mathrm{dL}$, más elevada que en nuestro trabajo $(0,79 \pm 0,17 \mathrm{mg} / \mathrm{dL})$. A 6 meses de seguimiento, los resultados de Getty et al ${ }^{218}$ fueron más elevados que en nuestros pacientes $(0,72 \pm 0,16 \mathrm{mg} / \mathrm{dL} .0,68 \pm 0,12 \mathrm{mg} / \mathrm{dL})$.

Con un seguimiento de la función renal de 233 pacientes intervenidos de cirugía bariátrica a 12 meses de seguimiento, Hou et $a^{219}$ clasificaron a los pacientes en función de su tasa de filtración glomerular (TFG) observando que 127 de ellos con una TFG normal (125-90 $\mathrm{mL} / \mathrm{min})$ empeoraban ligeramente al año de la cirugía: creatinina $(0,75 \pm 0,1 \mathrm{mg} / \mathrm{dL} \rightarrow 0,78 \pm 0,7$ $\mathrm{mg} / \mathrm{dL})$ y ácido úrico $(6,6 \pm 1,8 \mathrm{mg} / \mathrm{dL} \rightarrow 7,4 \pm 10,8 \mathrm{mg} / \mathrm{dL})$. Por el contrario este mismo estudio en los pacientes con una TFG inicial entre $89-60 \mathrm{~mL} / \mathrm{min}$ la evolución del perfil renal fue positiva, observando una reducción media de 
creatinina $(0,9 \pm 0,1 \mathrm{mg} / \mathrm{dL} \rightarrow 0,8 \pm 0,1 \mathrm{mg} / \mathrm{dL})$ y ácido úrico $(7,4 \pm 1,9$ $\mathrm{mg} / \mathrm{dL} \rightarrow 6,4 \pm 1,9 \mathrm{mg} / \mathrm{dL})$. Nuestros resultados se asemejan a este último grupo de pacientes descrito por Hou et $\mathrm{al}^{219}$, aunque la disminución de la creatinina $(0,79 \pm 0,17 \mathrm{mg} / \mathrm{dL} \rightarrow 0,66 \pm 0,13 \mathrm{mg} / \mathrm{dL})$ y del ácido úrico $(5,82 \pm$ $1,65 \mathrm{mg} / \mathrm{dL} \rightarrow 3,93 \pm 1,09 \mathrm{mg} / \mathrm{dL}$ ) si fue significativa en ambos casos $(\mathrm{P}<0,001)$.

Reid et $\mathrm{al}^{220}$, evaluaron la función renal tras cirugía bariátrica (manga gástrica y BGYR) en 158 pacientes, corroborando nuestros resultados al mostrar una reducción significativa $(P<0,001)$ a 12 meses de creatinina $(0,72$ $\pm 0,1 \mathrm{mg} / \mathrm{dL} \rightarrow 0,67 \pm 0,1 \mathrm{mg} / \mathrm{dL})$.

De los estudios evaluados en la descripción del perfil renal postquirúrgico ninguno mostró resultados a 24 meses, a diferencia de nuestro estudio en el que se pudo observar el descenso significativo de creatinina $(P<0,001)$ de todos los valores del perfil renal en cada una de las revisiones respecto al valor precirugía.

\subsubsection{Perfil hepático}

Los niveles de transaminasas en el paciente obeso están comúnmente elevados y se asocian a una progresión de la enfermedad hepática crónica $^{52,53}$. La efectividad en reducción ponderal de los pacientes sometidos a tratamiento quirúrgico consigue reducir los niveles de transaminasas postquirúrgicos y también la prevalencia del hígado graso no alcohólico ${ }^{52,221}$, además de la presencia de esteatosis hepática no alcohólica, considerándose la manifestación hepática del síndrome metabólico ${ }^{54}$ junto con la resistencia a la insulina como mecanismo fisiopatológico común ${ }^{221}$.

Por el contrario en nuestro estudio la evolución de las transaminasas postcirugía a 2 años, aumentaron significativamente: GOT (25,35 \pm 9,60 $\mathrm{U} / \mathrm{L} \rightarrow 31,27 \pm 16,06 \mathrm{U} / \mathrm{L})$ y $F A,(92,44 \pm 60 \mathrm{U} / \mathrm{L} \rightarrow 118,41 \pm 61,29 \mathrm{U} / \mathrm{L})$. A diferencia de la GGT la cual disminuye significativamente $(29,60 \pm 19,01$ $U / L \rightarrow 22,46 \pm 22,05 U / L) P<0,001$. Es necesario especificar que aunque se aprecia ese aumento generalizado de las transaminasas, el valore límite 
máximo fue superado a 2 años por: el 10,63\% de GOT, un 18,36\% de GPT, el $6,37 \%$ de GGT, y el $28,23 \%$ de FA.

El aumento de las transaminasas puede estar condicionado a la elevación de los parámetros inflamatorios y hormonales perioperatorios y la gran pérdida ponderal en un periodo de tiempo tan corto por un aumento de la movilización de adipocitos ${ }^{222}$, contribuyendo finalmente a la lipotoxicidad propia de la esteatohepatitis ${ }^{223}$.

Estudios realizados sobre el paciente obeso intervenido de cirugía bariátrica ${ }^{224}$ muestran una reducción de las transaminasas y el hígado graso no alcohólico asociado a la pérdida ponderal, obteniendo una reducción a 2 años de la GPT y GOT (-14 U/L. -5 U/L, respectivamente). A más largo plazo los resultados a 10 años, muestran un descenso de la GPT menor (-11 U/L), a diferencia de la GOT que aumentó (+2,5 U/L). Los efectos a más largo plazo fueron peores probablemente debido a la reganancia ponderal de los pacientes después de 10 años de la cirugía, mostrando una correlación positiva entre el aumento de peso y la elevación de las transaminasas (GPT: $r=0,500, P<0,001$; GOT: $r=0,289, P<0,001$ ) y 10 años (GOT: $r=0,357$, $P<0,001 ; A S T: r=0,160, P<0,001)^{224}$.

En referencia al sexo, en todas las variables del perfil hepático estudiadas se observaron valores más elevados prequirúrgicos en los varones, como detalla Xourafas et al ${ }^{225}$ en una revisión de 756 pacientes intervenidos de cirugía bariátrica (BGYR=512. Banda gástrica ajustable=244) a 3 años, mostrando unos valores de GPT prequirúrgicos: $27 \pm 27,5 \mathrm{U} / \mathrm{L}$ en las mujeres y $41 \pm 33,2 \mathrm{U} / \mathrm{L}$ en los hombres. Valores similares a los descritos en nuestros pacientes, siendo en la mujer 29,38 $\pm 15,11 \mathrm{U} / \mathrm{L}$ y en el hombre $49,06 \pm 24,35 \mathrm{U} / \mathrm{L}$. Xourafas et $\mathrm{al}^{225}$ muestran un descenso significativo de los valores de GPT a 3 años a diferencia de nuestros resultados, sin observar diferencias entre los pacientes intervenidos de BGYR $(19,8 \pm 10$ U/L) y banda gástrica ajustable (19,1 $\pm 9,1 \mathrm{U} / \mathrm{L})$.

Por grupos de edad no se observaron variaciones significativas entre nuestros pacientes en ninguna variable del perfil hepático a excepción de la GGT en los 18 y 24 meses postquirúrgicos en los que el valor fue más 
elevado en el grupo de los $\geq 42$ años $(P<0,05)$. Del mismo modo que Xourafas et $\mathrm{al}^{225}$ que no encontraron variaciones significativas al estudiar la GPT en los pacientes con más de 50 años.

\subsubsection{Proteínas}

El déficit de proteínas es la deficiencia nutricional más común entre los macronutrientes en las técnicas bariátricas malabsortivas, especialmente BGYR y $\mathrm{DBP}^{226}$. El componente malabsortivo de la cirugía no sólo es el causante, y también está asociado con otros componentes que disminuyen la ingesta de alimentos como anorexia, vómitos, diarrea, intolerancia a los alimentos o alcoholismo ${ }^{227}$.

\section{- Proteínas totales (Prot.T)}

Las Prot.T de nuestros pacientes disminuyeron de manera progresiva hasta los 12 meses, donde se observa un cambio en la tendencia manteniéndose el ascenso de los valores hasta el último control evaluado, aún así no se apreció a ningún paciente por debajo de los valores normales en los diferentes controles.

Por el contrario los estudios que reportan datos de evolución de Prot.T muestran unas deficiencias entre 7,7-11,9\% en técnicas puramente malabsortivas ${ }^{228,229}$, reduciendo estas tasas al 3\% al reducir la longitud del asa malabsortiva con la implicación de una menor pérdida ponderal como ya describió Scopinaro ${ }^{112}$.

Gobato et $\mathrm{al}^{228}$, muestra un descenso significativo de los niveles de Prot. $T$ a 6 meses $(7,37 \pm 0,44 \mathrm{~g} / \mathrm{L} \rightarrow 7,02 \pm 0,37 \mathrm{~g} / \mathrm{L})$, al igual que nuestros resultados $(7,18 \pm 0,49 \mathrm{~g} / \mathrm{L} \rightarrow 6,59 \pm 0,51 \mathrm{~g} / \mathrm{L})$ aunque el punto de partida era ligeramente más bajo. Superando los 2 años postquirúrgicos el porcentaje de deficiencias proteicas disminuye al 7\% a 8 años reportados tras cirugía puramente malabsortivas ${ }^{229,230}$. 


\section{- Albúmina (Alb)}

Las variaciones de la Alb después de la cirugía fueron mínimas en nuestro estudio, aumentando desde los 12 meses postquirúrgicos como se muestra en el punto 4.11.6.2 de los resultados. No es muy común observar deficiencias de Alb y en las publicaciones suelen reportar deficiencias a 2 y 10 años entre el $13 \%$ y $27,9 \%$, respectivamente ${ }^{231}$.

Antes de la cirugía el 9,09\% de los pacientes de nuestro estudio presentaba deficiencias de Alb que fueron fluctuando hasta observar a los 24 meses el $2,77 \%$. Los diferentes estudios consultados coinciden con un intervalo de deficiencias de Alb previas a la cirugía que varían entre el 1$15 \%{ }^{230,232,233}$, que mejoran reportando un $7 \%$ en diferentes periodos postquirúrgicos que abarcan desde los 6 meses hasta los 24 meses como en nuestro estudio.

\section{- Ferritina}

Los niveles de ferritina tras las cirugías de tipo malabsortivo se encuentran disminuidos ${ }^{129}$, por causas anatómicas debido a la exclusión del paso de los alimentos por el primer tercio del intestino delgado. Las implicaciones de la ferritina como proteína responsable del almacenamiento de hierro plasmático y sus deficiencias en la aparición de anemia ferropénica deben completarse con un estudio del metabolismo del hierro, analizando conjuntamente los valores plasmáticos de: hierro, ferritina, índice de saturación de la transferrina y hemoglobina ${ }^{234}$.

Los valores de ferritina en nuestro estudio disminuyeron de manera progresiva, con un descenso significativo a 2 años postquirúrgicos, observando una deficiencia de ferritina en el $16,09 \%$ de los pacientes en el último control evaluado. Las deficiencias de ferritina en los diferentes estudios consultados a corto y medio plazo son muy variables como se aprecia en el estudio de Gobato et $\mathrm{al}^{228}$, que muestran unas deficiencias en el $8,33 \%$ de los pacientes a 6 meses, o Billeter et al ${ }^{235}$ en un $50 \%$ a 24 meses.

Bugianesi et $\mathrm{al}^{236}$ describen un $21,1 \%$ de pacientes con hiperferritinemia diagnosticados de hígado graso no alcohólico sin tratamiento quirúrgico, 
demostrando la presencia de fibrosis severa en los pacientes de mayor edad, mujeres, hipertransaminemia e hiperferritinemia. Es por ello que niveles alterados antes de la cirugía podrían ser considerados como un marcador pronóstico sobre el efecto en las comorbilidades propias del SM en los pacientes candidatos a cirugía bariátrica.

\subsubsection{Micronutrientes}

\subsubsection{Vitaminas}

El componente malabsortivo de la cirugía implica una reducción en la absorción de nutrientes que es necesario controlar de manera individualizada en cada paciente y puede agravarse sin el cumplimiento del protocolo postquirúrgico ${ }^{15,237}$, en el que se incluye la suplementación vitamínica durante el primer año. A continuación se abordan las vitaminas más representativas con riesgo carencial después de la cirugía.

\section{- Vitamina $B_{12}\left(\right.$ Vit $\left.B_{12}\right)$}

La deficiencia de Vit $B_{12}$ se ha observado con frecuencia después de la cirugía bariátrica ${ }^{231}$, especialmente en las técnicas mixtas, y puede ocurrir como resultado de varios factores: la reducción en la producción de ácido clorhídrico gástrico, intolerancia a los alimentos ricos en Vit $\mathrm{B}_{12}$ como las carnes rojas, o la disminución de pepsina necesaria para la liberación de la Vit $\mathrm{B}_{12}$ presente en los alimentos proteicos ${ }^{226,231}$. Por otra parte, la producción de factor intrínseco en las células parietales del estómago está alterada por la reducción del compartimento gástrico, favoreciendo la aparición de la anemia perniciosa ${ }^{226}$.

El descenso en los valores de Vit $B_{12}$ en nuestros pacientes fue significativo desde el año de la cirugía hasta los 2 años evaluados, observando una deficiencia de $V$ it $B_{12}$ en el 10,38\% y 21,95\% de los pacientes a 1 y 2 años respectivamente. Estos resultados son favorables respecto a la mayoría de los estudios de BGYR que describen unas 
deficiencias entre el 33-40\% al año de la cirugía ${ }^{238,239}$ y entre el 8-37\% en los 4 años posteriores ${ }^{239}$.

Vargas-Ruiz et $\mathrm{al}^{240}$ describen un 6,6\% y un 16,6\% de pacientes con deficiencias de $V i t B_{12}$, a 1 y 2 años postcirugía, respectivamente. Aunque presenta una prevalencia menor de la deficiencia de Vit $B_{12}$ que la de nuestro estudio, los valores medios postquirúrgicos fueron más bajos, como se detalla en la tabla 5.9.

\begin{tabular}{|c|c|c|c|}
\hline \multirow{2}{*}{$\begin{array}{l}\text { Estudio } \\
\text { analizado }\end{array}$} & \multicolumn{3}{|c|}{ Vit $B_{12}(p g / m L)$} \\
\hline & 6 meses & 1 año & 2 años \\
\hline $\begin{array}{c}\text { Vargas- } \\
\text { Ruiz et al }{ }^{240}\end{array}$ & $232 \pm 148$ & $180 \pm 75$ & $125 \pm 28$ \\
\hline ReCiMB & $416,42 \pm 202,54$ & $359,88 \pm 157,79$ & $320,89 \pm 166,15$ \\
\hline
\end{tabular}

Tabla 5.9. Evolución de la Vit $B_{12}$ en el estudio de Vargas-Ruiz et al ${ }^{240}$ y el estudio ReCiMB

\section{- Ácido fólico (Ácd.Fol)}

El almacenamiento de Ácd.Fol puede agotarse pocos meses después de la cirugía bariátrica en ausencia de una óptima suplementación o ingesta adecuada de alimentos como las verduras de color verde oscuro, frutas, pollo o hígado ${ }^{237}$. Y aunque las deficiencias de esta vitamina son menos frecuentes que las de Vit $B_{12}$, si son apreciables después de las técnicas bariátricas, específicamente de las malabsortivas, reportando entre el 9-18\% de los casos a 2 años de seguimiento ${ }^{240}$.

El Ácd.Fol de los pacientes de nuestro estudio, aumentó en los controles postquirúrgicos hasta el año de la cirugía coincidiendo con la supresión de la suplementación multivitamínica. Al año de la cirugía, el 18,66\% de los pacientes presentaba deficiencias de Ácd.Fol, resultados similares a los descritos por Aarts et $\mathrm{al}^{238}$, con una deficiencia de Ácd.Fol del 16,7\%.

En valores absolutos la tendencia del Ácd.Fol en el estudio de VargasRuiz et $\mathrm{al}^{240}$ experimenta un aumento progresivo hasta los 2 años postquirúrgicos, coincidiendo con el periodo de suplementación al igual que en nuestro estudio, tabla 5.10. 


\begin{tabular}{cccc}
\hline Estudio & \multicolumn{3}{c}{ Ácd.Fol $(\mathrm{ng} / \mathrm{mL})$} \\
\cline { 2 - 4 } analizado & $\mathbf{6}$ meses & $\mathbf{1}$ año & 2 años \\
\hline $\begin{array}{c}\text { Vargas- } \\
\text { Ruiz et al }\end{array}$ (40 $^{\text {Ryyy}}$ & $11,2 \pm 6,2$ & $11,1 \pm 5,2$ & $12,9 \pm 5,9$ \\
\hline ReCiMB & $8,61 \pm 4,23$ & $9,41 \pm 4,64$ & $8,03 \pm 4,57$
\end{tabular}

Tabla 5.10. Evolución de Ácd.Fol en el estudio de Vargas-Ruiz et al ${ }^{240}$ y el estudio ReCiMB

Cabe destacar la presencia de niveles alterados de homocisteína después de la cirugía bariátrica tanto en procedimientos restrictivos y malabsortivos, actuando no sólo como indicador de las deficiencias de Vit $\mathrm{B}_{12}$ y Ácd.Fol sino también como marcador de riesgo cardiovascular y neurológico ${ }^{241}$. Sería por ello necesario para una correcta evaluación de las deficiencias de Vit $B_{12}$ y Ácd.Fol determinar los niveles séricos de homocisteína en los pacientes.

\subsubsection{Minerales}

La cirugía bariátrica como ya se ha explicado anteriormente, puede incurrir en deficiencias nutricionales por un aporte inadecuado de alimentos en la dieta, secundario al descenso de la ingesta, y anatómicamente por la exclusión de duodeno y yeyuno, por ser lugares de absorción de minerales como el hierro, calcio y fósforo entre otros, siendo estos los evaluados en nuestros pacientes. Las publicaciones de MBG consultadas ${ }^{128}$ no especifican ni las cantidades de los nutrientes que disminuyen, ni en el tiempo que transcurre postcirugía ${ }^{133,135,139}$, mostrando resultados de malnutrición aproximadamente en el $39,1 \%$ de los casos postquirúrgicos ${ }^{128}$.

\section{- Hierro}

Los valores de hierro después de la cirugía disminuyeron ligeramente a 24 meses $(81,79 \pm 30,53 \mu \mathrm{g} / \mathrm{dL} \rightarrow 76,49 \pm 30,49 \mu \mathrm{g} / \mathrm{dL})$, con la misma tendencia que en el trabajo de Vargas et $\mathrm{al}^{240}(66,3 \pm 26 \mu \mathrm{g} / \mathrm{dL} \rightarrow 38 \pm 22,7$ $\mu \mathrm{g} / \mathrm{dL})$, con un descenso que continua hasta los 3 años de seguimiento $(31,7$ $\pm 18 \mu \mathrm{g} / \mathrm{dL}$ ). Cabe señalar que el 13,15\% de los pacientes ReCiMB antes de la cirugía presentaba deficiencias de hierro. 
Las diferentes publicaciones de BGYR $229,230,232$ presentan deficiencias de hierro sérico entre 1 y 8 años de seguimiento, en el 14-50,2\% de los pacientes intervenidos. Nuestros resultados a 24 meses se encuentran en ese intervalo, describiendo un $20,93 \%$.

Antes de la cirugía de BAGUA, no se observaron variaciones significativas entre los valores de hierro en los hombres y mujeres, por el contrario a los 24 meses los varones aumentaron los niveles de hierro a diferencia de las mujeres.

En cambio, Worm et al ${ }^{242}$ en una muestra de 835 pacientes intervenidos de BGYR con seguimiento a 24 meses (tabla 5.11), describe un aumento significativo del hierro sérico, en ambos sexos aunque más elevado en los varones.

\begin{tabular}{lcc|cc}
\hline \multirow{2}{*}{$\begin{array}{c}\text { Estudio } \\
\text { analizado }\end{array}$} & \multicolumn{4}{c}{ Hierro sérico $(\boldsymbol{\mu g} / \mathbf{d L})$} \\
\cline { 2 - 5 } & \multicolumn{2}{c}{ Precirugía } & \multicolumn{2}{c}{ 24 meses } \\
\cline { 2 - 5 } & Hombres & Mujeres & Hombres & Mujeres \\
\hline Worm et al $\mathbf{2 4 2}^{24,}$ & $92,62 \pm 2,23$ & $78,12 \pm 1,67$ & $104,9 \pm 3,9$ & $81,46 \pm 2,23$ \\
\hline ReCiMB & $83,52 \pm 24,76$ & $81,15 \pm 32,58$ & $91,42 \pm 29,53$ & $70,72 \pm 29,07$
\end{tabular}

Tabla 5.11. Evolución de hierro sérico en el estudio de Worm et al ${ }^{242}$ y el estudio ReCiMB

\section{- Calcio}

Al igual que el hierro, este mineral se absorbe preferentemente en duodeno y yeyuno proximal por lo que la cirugía bariátrica compromete la absorción del mismo y aumenta el riesgo de presentar deficiencias. Para poder estudiar el metabolismo del calcio, es necesario conocer los niveles de vitamina $D$, pues con bajos niveles de la misma, la absorción del calcio en la dieta disminuye ${ }^{243}$.

Sin embargo no siempre se aprecia una disminución del calcio sérico, pues aumentan los niveles de la hormona paratiroidea, permitiendo su absorción por un mecanismo de difusión pasiva ${ }^{243,244}$. Especialmente en la técnicas malabsortivas, la dificultad de absorción de la vitamina $D$ contribuye a que la homeostasis del calcio y el metabolismo mineral óseo se vea comprometido ${ }^{244}$. 
En nuestro estudio, estas determinaciones no pudieron llevarse a cabo pues no se disponía inicialmente de las suficientes muestras de vitamina D y PTH sanguíneas de los pacientes intervenidos de BAGUA con seguimiento a 24 meses, siendo una de las causas el elevado sobrecoste de la analítica a cargo de los pacientes y la no inclusión de IFSO en la hoja de revisión postquirúrgica la determinación de deficiencias de vitamina D.

Los valores de calcio sérico iniciales descendieron significativamente a los 2 años postquirúrgicos $(9,41 \pm 0,55 \mathrm{mg} / \mathrm{dL} \rightarrow 9,19 \pm 0,51 \mathrm{mg} / \mathrm{dL})$, siendo comparables a los resultados obtenidos por Casagrande et $\mathrm{al}^{245}$ a sólo 1 año de seguimiento, en pacientes intervenidos de BGYR $(9,3 \pm 0,5 \mathrm{mg} / \mathrm{dL} \rightarrow 9,20$ $\pm 0,4 \mathrm{mg} / \mathrm{dL}$ ). A los 2 años de la cirugía en nuestros pacientes se observó una deficiencia de calcio sérico en el 5,68\%, siendo estas cifras más elevadas que las reportadas por otros estudios a largo plazo ${ }^{230,231}$ en los que no superan el $2,2 \%$.

Es necesario garantizar el aporte de calcio, pues en los pacientes con cirugía malabsortiva la absorción se encuentra disminuida entre otras causas a la ingesta insuficiente de lácteos y la intolerancia adquirida a la lactosa, como se detalla en el 4.9.3 de los resultados. Por ello es fundamental un óptimo control postquirúrgico con la finalidad de evitar estados carenciales e inadaptaciones alimentarias

\section{- Fósforo}

La concentración de fósforo en la sangre está determinada por un equilibrio entre la absorción del fósforo de la dieta en el intestino, el almacenamiento en los huesos, y la eliminación a través de la orina, y en la regulación del mismo está implicada la hormona PTH. Es por ello que en los estudios consultados, se muestra el metabolismo del calcio fósforo junto con la determinación de PTH y vitamina $D^{242,243}$. Aunque carecemos de las determinaciones de PTH y vitamina D, la evolución del fósforo sanguíneo de nuestros pacientes no mostró cambios significativos en el seguimiento postquirúrgico a 2 años en ninguno de los controles evaluados, al igual que otros estudios en pacientes intervenidos de cirugía bariátrica ${ }^{246,247}$. El déficit en los niveles de fósforo suelen ser infrecuentes y se asocian 
fundamentalmente a la deficiencia de vitamina $D$, la cual estimula su absorción, o a la ingesta de etanol ${ }^{247}$.

\subsection{Limitaciones del estudio e implicaciones de futuro}

La principal limitación de este trabajo fue la falta de aleatorización de la muestra de los pacientes analizados y la pérdida en el seguimiento postquirúrgico. Aunque se intentó limitar la pérdida de datos mediante un control postquirúrgico en el que se les hace entrega a cada paciente de la ficha de valoración de cada control trimestral, junto con la petición de la analítica con los marcadores necesarios, y todo ello reforzado por un control telefónico del equipo médico-nutricional, se observó una pérdida de pacientes a partir de los 6 meses postquirúrgicos. Los parámetros bioquímicos que no pudieron evaluarse en este trabajo, y sí estaban en la petición analítica, junto con las revisiones presenciales a las que un elevado porcentaje de pacientes no acudían, puede ser debido al coste añadido que supone al paciente y posiblemente por la falta de concienciación del mismo con su control postquirúrgico.

No obstante, estas limitaciones fueron asumibles para responder al propósito de este trabajo, describiendo las características generales del paciente candidato a cirugía de MBG y la evolución a 2 años del peso, adaptación alimentaria y parámetros bioquímicos.

Es necesario continuar estudiando la evolución de los pacientes analizados para poder observar los cambios a largo plazo, de hecho IFSO actualmente exige el seguimiento postquirúrgico hasta los 5 años en todos los Centros acreditados, al igual que mejorar la participación e implicación de los pacientes en su proceso de adaptación posterior a la cirugía. 


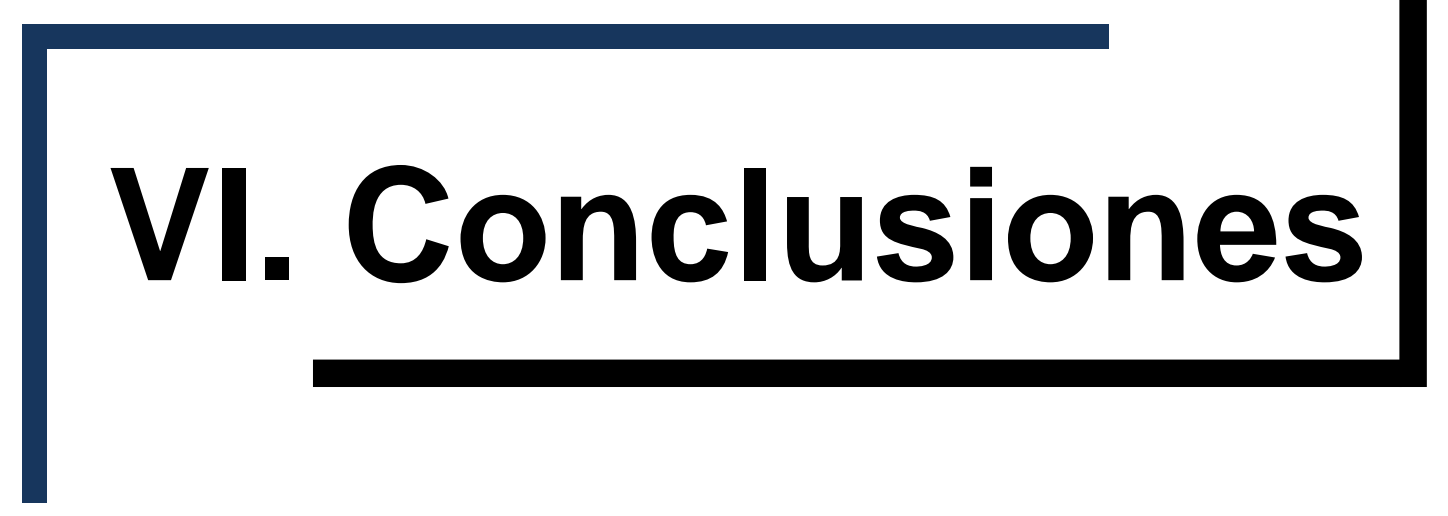


La cirugía de BAGUA ha permitido una reducción de peso efectiva en todos los pacientes, mejorando las comorbilidades asociadas y los parámetros metabólicos alterados durante los 2 años de seguimiento evaluados.

1. Los pacientes del estudio ReCiMB se caracterizan por un predominio del sexo femenino, con una edad media de 42 años.

Previamente a la cirugía se detectaron:

a) Comorbilidades asociadas en todos los pacientes, principalmente: insuficiencia respiratoria (99\%), problemas osteoarticulares (88\%), esteatosis hepática (81\%), dislipemia (68\%), hipertensión (37\%) y diabetes (18\%).

b) El modelo de conducta alimentaria en la mayoría se asociaba a un patrón de consumo comilón (90\%), picoteador (77\%), goloso (73\%) y comilón emocional (36\%).

c) La presencia de un hábito tóxico que evidencia un $24 \%$ de pacientes fumadores y un $21 \%$ de bebedores activos.

2. La preparación prequirúrgica se basó en una reducción ponderal entre el $11-12 \%$ del peso inicial, con la finalidad de disminuir los riesgos quirúrgicos y favorecer hábitos alimentarios saludables, logrando ese objetivo ponderal en el $74 \%$ de los pacientes.

3. Todos los pacientes evaluados disminuyen peso de manera significativa, alcanzando la mayor pérdida a los 12 meses, obteniendo un resultado excelente en el Porcentaje de Sobrepeso Perdido y Porcentaje de Exceso de Índice de Masa Corporal Perdido según los criterios evaluados desde el primer control postquirúrgico.

4. Se resolvieron todos los casos de obesidad mórbida y extrema iniciales, apreciando un $48 \%$ de pacientes con normopeso a los 24 meses de la cirugía.

5. La adaptación alimentaria postquirúrgica según la valoración de los pacientes fue considerada entre buena y óptima, siendo la carne, lácteos 
y cereales los alimentos peor tolerados. La incidencia de vómitos, reflujo gastroesofágico y diarrea no superó el 15\% a los 2 años de la cirugía.

6. Los parámetros bioquímicos evaluados muestran una tendencia a alcanzar los valores normales de referencia desde los 3 meses postquirúrgicos.

a) La glucemia disminuye en todos los controles postquirúrgicos, observando una remisión parcial de la diabetes en el $95,41 \%$ de los casos y una remisión total en el $81,84 \%$ a los 2 años de seguimiento.

b) Los parámetros evaluados en el perfil lipídico y renal, mejoran significativamente.

c) En el perfil hepático las transaminasas aumentan, a excepción de la GGT.

7. Los parámetros nutricionales estudiados en la bioquímica descienden debido al componente malabsortivo de la técnica y por la disminución en la ingesta de alimentos, a excepción de la albúmina, ácido fólico y fósforo.

8. Sería recomendable abordar un seguimiento postquirúrgico más prolongado y completo, que permita una mayor adherencia de los pacientes, para mejorar la consolidación de hábitos alimentarios saludables de manera permanente. 


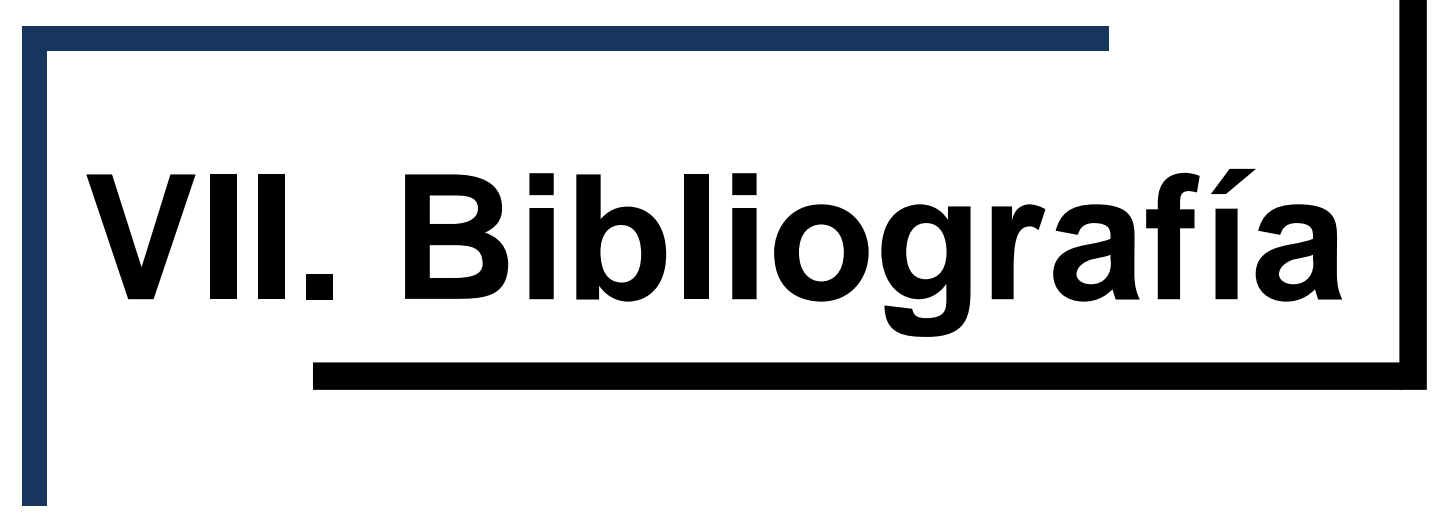


1. Franco Sassi. Obesity and the Economics of Prevention: Fit not Fat [Libro en Internet]. OECD; 2010 [acceso 19 de agosto de 2014]. Disponible en: http://www.oecd-ilibrary.org/social-issues-migration-health/obesity-andthe-economics-of-prevention_9789264084865-en

2. Brown PJ, Konner M. An anthropological perspective on obesity. Ann N Y Acad Sci. 1987; 499: 29-46.

3. Bray GA. Obesity: Historical development of scientific and cultural ideas. Int J Obes Relat Metab Disord. 1990: 14: 909-926.

4. Bray GA. The Battle of the Bulge. Pittsburgh; Dorrance Publishing; 2007.

5. Bray GA. Obesity and the Metabolic Syndrome. Totowa; NJ: Humana Press; 2007.

6. Brown PJ. Cultural perspectives on the etiology and treatment of obesity. Neva York; Raven Press; 1993.

7. Stunkard AJ, LaFleur WR, Wadden TA. Stigmatization of obesity in medieval times: Asia and Europe. Int J Obes Relat Metab Disord. 1998; 22: 1141-1144.

8. Vague J. La différentiation sexuelle, facteur déterminant des formes de l'obésité. Presse Med. 1947; 55: 339-340.

9. Marañón G. Gordos y flacos. 3. ${ }^{a}$ ed. Madrid; Espasa Calpe; 1936.

10. Powers PS. Social and cultural factors in obesity. Baltimore; Williams and Wilkins Co; 1980.

11. Zhang $\mathrm{Y}$, Proenca R, Maffei M, Barone M, Leopold L, Friedman JM. Positional cloning of the mouse obese gene and its human homologue. Nature. 1994; 372: 425-432.

12. Foz M. La Declaración de Milán. Med Clin (Barc). 1999; 113: 494-495.

13. World Health Organization. The challenge of obesity in the WHO European Region and the strategies for response. Geneva: WHO Library Cataloguing-in-Publication; 2007. 
14. Barbany M, Foz M. Obesidad: concepto, clasificación y diagnóstico. Anales del Sistema Sanitario de Navarra. 2002; 25: 7-16.

15. Salas-Salvadó J, Rubio MA, Barbany M, Moreno B, y Grupo Colaborativo de SEEDO. Consenso SEEDO 2007 para la evaluación del sobrepeso y la obesidad y el establecimiento de criterios de intervención terapéutica. Med Clin (Barc). 2007; 125: 184-196.

16. Bray G, Bouchard C, James WPT. Definitions and proposed current classifications of obesity. New York; Marcel Dekker; 1998.

17. González CA, Pera G, Agudo A, Amiano P, Barricarte A, Beguiristain JM, et al. Factores asociados a la acumulación de grasa abdominal estimada mediante índices antropométricos. Med Clin (Barc). 2000; 114(11):401406.

18. Fernandez-Real JM, Vayreda M, Casamitjana R, Saez M, Ricart W. Índice de masa corporal (IMC) y porcentaje de masa grasa. Med Clin (Barc). 2001; 117(18): 681-684.

19. WHO Technical Report Series 894 Obesity: Preventing and Managing The Global Epidemic. World Health Organization. Geneva; 2000.

20. Janssen I, Heymsfield S, Allison D, Kotler D, Ross R. Body mass index and waist circumference independently contribute to the prediction of nonabdominal, abdominal subcutaneous and visceral fat. Am J Clin Nutr. 2002; 75: 683-688.

21. Lean ME, Han TS, Morrison CE. Waist circumference as a measure for indicating need for weight management. BMJ. 1995; 311: 158-61.

22. Martí A, Moreno-Aliaga MJ, Ochoa MC, Marrades P, Santos JL, Martínez JA. Genética de la obesidad en humanos: rumbos de investigación. Rev Esp Obes. 2004; 2(6):351-362.

23. Farooqi SJ, Rahilly S. Genetics of obesity in humanans. Endocr Rev. 2006; 27: 710-718. 
24. Martínez-González MA, Martínez JA, Hu FB, Gibney MJ, Kearney J. Physical inactivity, sedentary lifestyle and obesity in the European Union. Int J Obes Relat Metab Disord. 1999; 23(11):1192-1201.

25. Monteiro CA, Moura EC, Conde WL, Popkin BM. Socioeconomic status and obesity in adult populations of developing countries: a review. Bull World Health Organ. 2004; 82(12): 940-946.

26. Wee CC, McCarthy EP, Davis RB, Phillips RS. Physician counseling about exercise. JAMA. 1999; 282(16):1583-1588.

27. Jorm AF, Korten AE, Christensen H, Jacomb PA, Rodgers B, Parslow RA. Association of obesity with anxiety, depression and emotional well-being: a community survey. Aust N Z J Public Health. 2003; 27(4):434-440.

28. Berman WH, Berman ER, Heymsfield S, Fauci M, Ackerman S. The effect of psychiatric disorders on weight loss in obesity clinic patients. Behavioral Medicine. 1993; 18: 167-172.

29. Vidal O, Cordido F, Martínez F, Jorge S. "Clasificación y clínica de las obesidades". En: La Obesidad. Monografía de la Sociedad Española de Endocrinología. Soriguer Escofet F. Ediciones Díaz de Santos. Madrid; 1994: 3-17.

30. Chagnon YC, Borecki IB, Perusse L, Roy S, Lacaille M, Chagnon M, et al. Genome-wide search for genes related to the fat-free body mass in the Quebec family study. Metabolism. 2000; 49(2): 203-207.

31. Coady SA, Jaquish CE, Fabsitz RR, Larson MG, Cupples LA, Myers RH. Genetic variability of adult body mass index: a longitudinal assessment in Framingham studies. Obes Res. 2002; 10(7): 675-681.

32. Lee JH, Reed DR, Price RA. Familial risk ratios for extreme obesity: implications for mapping human obesity genes. Int J Obes Relat Metab Disord. 1997; 21(10): 935-940. 
33. Redman LM, Heilbronn LK, Martin CK, Alfonso A, Smith SR, Ravussin E. Effect of calorie restriction with or without exercise on body composition and fat distribution. J Clin Endocrinol Metab. 2007; 92(3): 865-872.

34. Palou A, Bonet ML, Pico C, Rodriguez AM. Nutrigenómica y obesidad. Rev Med Univ Navarra. 2004; 48(2): 36-48.

35. Ruderman NB, Saha AK, Kraegen EW. Minireview: malonyl CoA, AMPactivated protein kinase, and adiposity. Endocrinology. 2003; 144(12): 5166-5171.

36. Minokoshi Y, Kim YB, Peroni OD, Fryer LG, Muller C, Carling D, et al. Leptin stimulates fatty-acid oxidation by activating AMP-activated protein kinase. Nature. 2002; 415(6869): 339-343.

37. Warne JP. Tumour necrosis factor alpha: a key regulator of adipose tissue mass. J Endocrinol. 2003; 177(3): 351- 355.

38. Duplus E, Glorian M, Forest C. Fatty acid regulation of gene transcription. J Biol Chem. 2000; 275(40): 30749- 30752.

39. Mallo F, Casanueva FF, Diéguez C. "Modelos animales y experimentales de obesidad". En: Soriguer Escofet F. La Obesidad. Monografía de la Sociedad Española de Endocrinología. Madrid: Ediciones Díaz de Santos; 1994. 119-128.

40. Orera Clemente MA. "Aspectos genéticos de la obesidad". En: Moreno B, Monereo S, Álvarez J. Obesidad. La epidemia del siglo XXI. $2^{\mathrm{a}}$ ed. Madrid: Ediciones Díaz de Santos; 2000. 70-99.

41. Frayling TM, Timpson NJ, Weedon MN, Zeggini E, Freathy RM, Lindgren $\mathrm{CM}$, et al. A common variant in the FTO gene is associated with body mass index and predisposes to childhood and adult obesity. Science. 2007; 316: 889-894.

42. Smemo S, Tena JJ, Kim KH, Gamazon ER, Sakabe NJ, Gómez Marín C, et al. Obesity-associated variants within FTO form long-range functional connections with IRX3. Nature. 2014; 507: 371-375. 
43. Raney BJ, Cline MS, Rosenbloom KR, Dreszer TR, Learned K, Barber GP, et al. ENCODE whole-genome data in the UCSC genome browser "ENCODE whole-genome data in the UCSC genome browser: 2011 update. Nucleic Acids Res. 2011; 39: 871-875.

44. OECD Better Life Index. Acceso 30 de agosto de 2014. Disponible en: ww.oecdbetterlifeindex.org/topics/health/.

45. Finucane MM, Stevens GA, Cowan MJ, Danaei G, Lin JK, Paciorek CJ, et al. National, regional, and global trends in body-mass index since 1980: systematic analysis of health examination surveys and epidemiological studies with 960 country-years and 9,1 million participants. Lancet. 2011; 377 (9765): 557-567.

46. Canoy D, Buchan I. Challenges in obesity epidemiology. Obesity Rev. 2007; 8 (1): 1-11.

47. World Obesity Federation [Sede web]. Inglaterra: Federación Mundial de la Obesidad; 2014 [Acceso 1 de septiembre de 2014]. Disponible en: http://www.worldobesity.org/

48. Flegal KM, Carroll MD, Kit BK, Ogden CL. Prevalence of obesity and trends in the distribution of body mass index among US adults, 19992010. JAMA. 2012; 307 (5): 491-497.

49. Guh DP, Zhang W, Bansback N, Amarsi Z, Birmingham CL, Anis AH. The incidence of comorbidities related to obesity and overweight: a systematic review and metaanalysis. BMC public health. 2009; 9: 88.

50. Caterson I, Hubbard V, Bray GA, Grunstein R, Hansen B, Hong Y, et al. Prevention Conference VII. Obesity, a worldwide epidemic related to heart disease and stroke. Group III: worldwide comorbidities of obesity. Circulation. 2004; 110: 476-483.

51. Wajchenberg, B.L. Beta-cell failure in diabetes and preservation by clinical treatment. Endocr Rev. 2007; 28 (2): 187-218. 
52. Neuschwander-Tetri BA, Caldwell SH. Nonalcoholic steatohepatitis: summary of an AASLD Single Topic Conference. Hepatology. 2003; 37(5): 1202-1219.

53. Dowman JK, Tomlinson JW, Newsome PN. Pathogenesis of nonalcoholic fatty liver disease. QJM. 2009; 103(2): 71-83.

54. Wree A. Obesity affects the liver the link between adipocytes and hepatocytes. Digestion. 2011; 83(1-2): 124-133.

55. Alberti KG, Zimmet PZ. Definition, diagnosis and classification of diabetes mellitus and its complications. Part 1: diagnosis and classification of diabetes mellitus provisional report of a WHO consultation. Diabet Med. 1998; 15(7): 539-553.

56. Expert Panel on Detection, Evaluation, and Treatment of High Blood Cholesterol In Adults. Executive Summary of The Third Report of The National Cholesterol Education Program (NCEP) Expert Panel on Detection, Evaluation, And Treatment of High Blood Cholesterol In Adults (Adult Treatment Panel III). JAMA. 2001; 285(19): 2486-2497.

57. Alberti KG, Zimmet PZ, Shaw J. The metabolic syndrome: a new worldwide definition. Lancet. 2005; 366(9491): 1059-1062.

58. Alberti KG, et al. Harmonizing the metabolic syndrome: a joint interim statement of the International Diabetes Federation Task Force on Epidemiology and Prevention; National Heart, Lung, and Blood Institute; American Heart Association; World Heart Federation; International Atherosclerosis Society; and International Association for the Study of Obesity. Circulation. 2009; 120(16): 1640-1645.

59. Luengo E, Ordoñez B, Bergua C. Obesidad, dislipemia y síndrome metabólico. Rev Esp Cardiol. 2005; 5 (Suppl): D21-29.

60. Kenchaiah S, Evans JC, Levy D. Obesity and the risk of heart failure. N Engl. 2002; 347: 305-313. 
61. Poirier P, Giles TD, Bray GA, Hong Y, Stern JS, Pi-Sunyer FX, Eckel RH; American Heart Association. Obesity and cardiovascular disease: pathophysiology, evaluation, and effect of weight loss: an update of the 1997 American Heart Association Scientific Statement on Obesity and Heart Disease from the Obesity Committee of the Council on Nutrition, Physical Activity, and Metabolism. Circulation 2006; 113 (6): 898-918.

62. Sironi AM, et al. Visceral fat in hypertension: influence on insulin resistance and beta-cell function. Hypertension. 2004; 44(2): 127-33.

63. Brown CD, et al. Body mass index and the prevalence of hypertension and dyslipidemia. Obes Res. 2000; 8(9): 605-619.

64. Pérez de Llano LA. Efectos de la obesidad sobre el aparato respiratorio. Pneuma. 2007; 7: 19-26.

65. Lucas $P$, Rodriguez JM, Miguel J. La vía aérea durante el sueño: fisiología y fisiopatología. En: Álvarez-Sala J, González N. Trastornos respiratorios del sueño. $1^{\mathrm{a}}$ ed. Madrid: Ergon; 2004. p. 45-57.

66. Ruhl CE, Everhart JE. Overweight, but not high dietary fat intake, increases risk of gastroesophageal reflux disease hospitalization: the NHANES I Epidemiologic Follow-up Study. First National Health and Nutrition Examination Survey. Ann Epidemiol. 1999; 9: 424-435.

67. Sise A, Friedenberg FK. A comprehensive review of gastroesophageal reflux disease and obesity. Obes Rev. 2008; 9(3): 194-203.

68. Friedenberg FK, et al. The association between gastroesophageal reflux disease and obesity. Am J Gastroenterol. 2008; 103(8): 2111-2122.

69. Dittrick GW, et al. Gallbladder pathology in morbid obesity. Obes Surg. 2005; 15(2): 238-242.

70. Castillo L, Lopez JC, Villa AR, Gonzalez-Barranco J. Menstrual cycle length disorders in 18 to 40 years old obese women. Nutrition. 2003; 19(4): 317-320. 
71. Ramlau-Hansen $\mathrm{CH}$, Thulstrup AM, Nohr EA, Bonde JP, Sorensen TI, Olsen J. Subfecundity in overweight and obese couples. Hum Reprod. 2007; 22(6): 1634-1637.

72. Forga L, Petrina E, Barberia JJ. Complications of obesity. An Sist Sanit Navar. 2002; 25 Suppl 1: 117-126.

73. McCartney CR, Blank SK, Prendergast KA, Chhabra S, Eagleson CA, Helm KD, et al. Obesity and Sex Steroid Changes Across Puberty: Evidence for Marked Hyperandrogenemia in Pre- and Early Pubertal Obese Girls. J Clin Endocrinol Metab. 2007; 92(2): 430-436.

74. Anandacoomarasamy $\mathrm{A}$, et al. The impact of obesity on the musculoskeletal system. Int J Obes. 2008; 32(2): 211-222.

75. Arthritis related statistics 2006. National Center for Chronic Disease Prevention and Health Promotion. Division of Adult and Community Health, Health Care and Aging Studies Branch. 2006.

76. Bergstrom A, et al. Overweight as an avoidable cause of cancer in Europe. Int J Cancer. 2001; 91(3): 421-430.

77. Simon GE, Von Korff M, Saunders K, Miglioretti DL, Crane PK, Van Belle $\mathrm{G}$, et al. Association between obesity and psychiatric disorders in the US adult population. Arch Gen Psychiatry. 2006; 63(7): 824-830.

78. Williams J, Wake M, Hesketh K, Maher E, Waters E. Health-related quality of life of overweight and obese children. JAMA. 2005; 293(1): 70-76.

79. Ministerio de Sanidad y Consumo. Agencia Española de Seguridad Alimentaria y Nutrición. Estrategia NAOS; 2005 [acceso 18 de noviembre de 2014]. Disponible en: http://www.naos.aesan.msssi.gob.es/naos/estrategia/que_es/

80. Corio R, Gadea P, Gutiérrez R, Díaz M, Matilla C, Monereo S. Estrategia SEMERGEN, SEEDO y SEEN para la prevención y el tratamiento del 
sobrepeso y la obesidad en Atención Primaria. Semergen. 2007; 33: 463465.

81. Tsigos C, Hainer V, Basdevant A, Finer N, Fried M, Mathus-Vliegen E, et al. Management of obesity in adults: European clinical practice guidelines. Obes Facts. 2008; 1: 106-116.

82. Scottish Intercollegiate Guidelines Network. A guideline developers'handbook [monografía en Internet]. Edinburgh: SIGN; 2001 [acceso 19 de noviembre de 2014]. Disponible en: http://www.sign.ac.uk/guidelines/fulltext/50/index.html

83. Sjöström L, Lindroos AK, Peltonen M, Torgerson J, Bouchard C, Carlsson B, et al and the Swedish Obese Subjects Study Scientific Group.Lifestyle, diabetes, and cardiovascular risk factors 10 years after bariatric surgery. $\mathrm{N}$ Engl J Med 2004; 351: 2683-2693.

84. North American Association for the Study of Obesity. National Heart, Lung, and Blood Institute. National Institutes of Health. The practical guide identification, evaluation, and treatment of overweight and Obesity in Adults. NIH; 2000.

85. U.S. Department of Agriculture and U.S. Department of Health and Human Services. Dietary Guidelines for Americans, 2010. 7th Edition, Washington DC: U.S. Government Printing Office; 2010.

86. Gargallo M, Breton I, Basulto J, Quiles J, Formiguera X, Salas-Salvadó J, et al. Recomendaciones nutricionales basadas en la evidencia para la prevención y el tratamiento del sobrepeso y la obesidad en adultos (Consenso FESNAD-SEEDO). La dieta en el tratamiento de la obesidad (III/III). Nutr Hosp. 2012; 27(3): 833-864.

87. Hall KD. What is the Required Energy Deficit per unit Weight Loss? Int J Obes. 2008; 32: 573-576. 
88. Vilchez FJ, Campos C, Amaya MJ, Sánchez P, Pereira JL. Las dietas de muy bajo valor calórico (DMBVC) en el manejo clínico de la obesidad mórbida. Nutr Hosp. 2013; 28(2): 275-285.

89. Rubio MA, Moreno C. Dietas de muy bajo contenido calórico: adaptación a nuevas recomendaciones. Rev Esp Obes. 2004; 2: 91-98.

90. Leidy HJ, Tang M, Armstrong CL, Martin CB, Campbell WW. The effects of consuming frequent, higher protein meals on appetite and satiety during weight loss in overweight/obese men. Obesity. 2011; 19: 818-824.

91. Huang SC, Freitas TC, Amiel E, Everts B, Pearce EL, Lok JB, Pearce EJ. Fatty acid oxidation is essential for egg production by the parasitic flatworm Schistosoma mansoni. PLoS Pathog. 2012; 8(10): e1002996.

92. Mastellos N, Gunn LH, Felix LM, Car J, Majeed A. Transtheoretical model stages of change for dietary and physical exercise modification in weight loss management for overweight and obese adults. Cochrane Database Syst. Rev. 2014 Feb 5; (2): CD008066.

93. Ismail I, Keating SE, Baker MK, Johnson NA. A systematic review and meta-analysis of the effect of aerobic vs: resistance exercise training on visceral fat. Obes reviews. 2012; 13: 68-91.

94. Kissane NA, Pratt JS. Medical and surgical treatment of obesity. Best Pract Res Clin Anaesthesiol. 2011; 25(1): 11-25.

95. Rivera G, Bocanegra A, Acosta RI, De la Garza M, Flores G. Tratamiento de la obesidad; nuevas perspectivas. Rev Mex C Farm. 2007; 38(2):4856.

96. Hainer V, Hainerova IA. Do we need anti-obesity drugs? Diabetes Metab Res Rev. 2012; 28(Suppl): 28-20.

97. Garfield AS, Heisler K. Pharmacological targeting of the serotonergic system for the treatment of obesity. Journal of Physiology. 2009; 587(1): 49-60. 
98. Rucker D, Padwal R, Li SK, Curioni C, Lau DC. Long term pharmacotherapy for obesity and overweight: updated meta-analysis. British Medical Journal. 2007; 335(7631): 1194-1199.

99. Van Gaal L, Pi-Sunyer X, Despr'es JP, McCarthy C, Scheen A. Efficacy and safety of rimonabant for improvement of multiple cardiometabolic risk factors in overweight/obese patients: pooled 1-year data from the Rimonabant in Obesity (RIO) program. Diabetes care. 2008; 31(Suppl2): 229-240.

100. Padwal RS, Majumdar SR. Drug treatments for obesity: orlistat, sibutramine, and rimonabant. The Lancet. 2007; 369(9555): 71-77.

101. Torgerson JS, Hauptman J, Boldrin MN, Sjöström L. XENical in the Prevention of Diabetes in Obese Subjects (XENDOS) Study: a randomized study of orlistat as an adjunct to lifestyle changes for the prevention of type 2 diabetes in obese patients. Diabetes Care. 2004; 27(1): 155-161.

102. Plodkowski RA, Nguyen Q, Sundaram U, Nguyen L, Chau DL, St Jeor S. Bupropion and naltrexone: a review of their use individually and in combination for the treatment of obesity. Expert Opinion on Pharmacotherapy. 2009; 10(6): 1069-1081.

103. Velasco JL, Martín de la Torre E. Nutrición y metabolismo de los trastornos de la conducta alimentaria. Barcelona: Glosa; 2004.

104. Decaluwé V, Braet C. Prevalence of binge-eating disorder in obese children and adolescents seeking weight-loss treatment. Int J Obes Relat Metab Disord. 2003; 27: 404-409.

105. Sociedad Española para el Estudio de la Obesidad (SEEDO). Recomendaciones de la SECO para la práctica de la cirugía bariátrica (Declaración de Salamanca). Cir Esp. 2004; 75(5):312-314.

106. Noel PH, Puga JA. Management of overweight and obese adults. BMJ. 2002; 325: 757-761. 
107. Buchwald H. Consensus Conference Statement: Bariatric surgery for morbid obesity: health implications for patients, health professionals, and third-party payers. J Am Coll Surg. 2005; 200: 593-604.

108. Buchwald H, Oien DM. Metabolic/Bariatric Surgery Worldwide 2011. Obes Surg. 2013; 23: 427-436.

109. Arribas D, Aguilella V, Elia M, Artigas C, Martínez M. Resultados a largo plazo de la gastroplastia vertical con banda en el tratamiento quirúrgico de la obesidad mórbida. Complicaciones específicas de la técnica quirúrgica. Cir Esp. 2001; 70: 227-230.

110. Bowne WB, Julliard $K$, Castro AE, et al. Laparoscopic gastric bypass is superior to adjustable gastric band in super morbidly obese patients: a prospective, comparative analysis. Arch Surg. 2006; 141: 683-689.

111. Lee CM, Cirangle PT, Jossart GH. Vertical gastrectomy for morbid obesity in 216 patients: report of two-years results. Surg Endosc. 2007; 21(10): 1810-1816.

112. Scopinaro N, Adami GF, Marinari GM, et al. Biliopancreatic diversion. World J Surg. 1998; 22: 936-946.

113. Hess DS, Hess DW. Biliopancreatic dversion with a duodenal switch. Obes Surg. 1998; 8: 267-282.

114. Marceau P, Hould FS, Simard S, et al. Biliopancreatic diversion with duodenal switch. World J Surg. 1998; 22: 947-954.

115. Higa KD, Ho T, Boone KB. Laparoscopic Roux-en-Y gastric bypass: technique and 3-year follow-up. J Laparoendosc Adv Surg Tech A. 2001; 11: 377-382.

116. Schneider BE, Villegas L, Blackburn GL, et al. Laparoscopic gastric bypass surgery: outcomes. J Laparoendosc Adv Surg Tech A. 2003; 13: 247-255.

117. Fisher BL, Atkinson JD, Cottam D. Incidence of gastroenterostomy stenosis in laparoscopic Roux-en-Y gastric bypass using 21- or 25-mm 
circular stapler: a randomized prospective blinded study. Surg Obes Relat Dis. 2007 ; 3: 176-179.

118. Gaggiotti G, Tack J, Garrido AB, Palau M, Cappelluti G, Di Matteo F. Adjustable totally implantable intragastric prosthesis (ATIIP).Endosgast for treatment of morbid obesity: one-year follow-up of a multicenter prospective clinical survey. Obes Surg. 2007; 17: 949-56.

119. Fogel R, De Fogel J, Bonilla $Y$ et al. Clinical experience of transoral suturing for an endoluminal vertical gastroplasty: 1-year follow-up in 64 patients. Gastrointest Endosc. 2008; 68: 51-58.

120. Rodríguez-Grunert L, Galvao Neto MP, Alamo M, Ramos AC, Baez PB, Tarnoff M. First human experience with endoscopically delivered and retrieved duodenal-jejunal bypass sleeve. Surg Obes Relat Dis. 2008; 4: 55-59.

121. De Luca M, Segato G, Busetto L, Favretti F et al. Progress in Implantable Gastric Stimulation: Summary of results of the European Multi.center study. Obes Surg. 2004; 14: 33-39.

122. Carbajo MA, Castro MJ, Kleinfinger S, Gomez-Arenas S, Ortiz-Solorzano J, Wellman R, et al. Effects of a balanced energy and high protein formula diet (Vegestart complet ${ }^{\circledR}$ ) vs. low-calorie regular diet in morbid obese patients prior to bariatric surgery (laparoscopic single anastomosis gastric bypass): A prospective, double-blind randomized study. Nutr Hosp. 2010; 25(6): 939-948.

123. Carbajo MA, Garcia-Caballero M, Osorio D et al. One anastomosis gastric bypass by laparoscopy: Results of the first 209 patients. Obes Surg. 2005; 15: 398-404.

124. Carbajo MA, Ortiz-Solorzano J, Garcia Lanza C, Perez M, Guadalupe O, Castro MJ. Laparoscopic one anastomosis gastric bypass (LOAGB) assisted by robotic arm: Technique and outcomes in1126 patients. Asociacion Mexicana de Cirugia Endoscopica. 2008; 9(1): 6-13. 
125. Larrad A, Sánchez-Cabezudo C. Indicadores de calidad en cirugía bariátrica y criterios de éxito a largo plazo. Cir Esp. 2004; 75(3): 301-304.

126. Lorenzo C, Williams K, Hunt JK, Haffner SM. The National Cholesterol Education Program-Adult Treatment Panel III, International Diabetes Federation, and World Health Organization Definitions of the Metabolic Syndrome as Predictors of Incident Cardiovascular Disease and Diabetes. Diabetes Care. 2007; 30: 8-13.

127. Molarius A, Seidell JC. Selection of anthropometric indicators for classification of abdominal fatness--a critical review. Int J Obes Relat Metab Disord. 1998; 22: 719-727.

128. Mahawar KK, Jennings N, Brown J, Gupta A, Balupuri S, Small PK. "Mini" gastric bypass: Systematic review of a controversial procedure. Obes Surg. 2013; 23(11): 1890-1898.

129. Carbajo M, García-Caballero M, Toledano M, et al. One-anastomosis gastric bypass by laparoscopy: results of the first 209 patients. Obes Surg. 2005; 15(3): 398-404.

130. Schauer $P$, Ikramuddin S. Outcomes after laparoscopic Roux-en-Y gastric bypass for morbid obesity. Ann Surg. 2000; 232: 515-529.

131. Moszkowicz D, Arienzo R, Khettab I, et al. Sleeve gastrectomy severe complications: is it always a reasonable surgical option? Obes Surg. 2013; 23(5): 676-686.

132. Rutledge R. The mini-gastric bypass: experience with first 1,274 cases. Obes Surg. 2001; 11: 270-280.

133. Rutledge $\mathrm{R}$, Walsh $\mathrm{W}$. Continued excellent results with the minigastric bypass: six year study in 2,410 patients. Obes Surg. 2005; 15(9): 13041308.

134. Lee WJ, Ser KH, Lee YC, et al. Laparoscopic Roux-en-Y vs. minigastric bypass for the treatment of morbid obesity: a 10-year experience. Obes Surg. 2012; 22(12): 1827-1834. 
135. Wang W, Wei PL, Lee YC, et al. Short-term results of laparoscopic minigastric bypass. Obes Surg. 2005; 15(5): 648-654.

136. Peraglie C. Laparoscopic mini-gastric bypass (LMGB) in the supersuper obese: outcomes in 16 patients. Obes Surg. 2008; 18(9): 1126-1129.

137. Chakhtoura G, Zinzindohoué F, Ghanem Y, et al. Primary results of laparoscopic mini-gastric bypass in a French obesity-surgery specialized university hospital. Obes Surg. 2008; 18(9): 1130-1133.

138. Piazza L, Ferrara F, Leanza S, et al. A laparoscopic mini-gastric bypass: short-term single-institute experience. Updates Surg. 2011; 63(4): 239242.

139. Noun R, Riachi E, Zeidan S, et al. Mini-gastric bypass by minilaparotomy: a cost-effective alternative in the laparoscopic era. Obes Surg. 2007; 17(11): 1482-1486.

140. Noun R, Skaff J, Riachi E, et al. One thousand consecutive minigastric bypass: short- and long-term outcome. Obes Surg. 2012; 22(5): 697-703.

141. Sjöström L. Review of the key results from the Swedish Obese Subjects (SOS) trial - a prospective controlled intervention study of bariatric surgery. J Intern Med. 2013; 273(3): 219-234.

142. Buchwald H, Buchwald JN, McGlennon TW. Systematic review and metaanalysis of medium-term outcomes after banded Roux-en-Y gastric bypass. Obes Surg. 2014; 24(9): 1536-1551.

143. Gullick AA, Graham LA, Richman J, Kakade M, Stahl R, Grams J. Association of Race and Socioeconomic Status with Outcomes Following Laparoscopic Roux-en-Y Gastric Bypass. Obes Surg. 2015; 25(4): 705711.

144. Ahmad A, Laverty AA, Aasheim E, Majeed A, Millett C, Saxena S. Eligibility for bariatric surgery among adults in England: analysis of a national cross-sectional survey. JRSM. 2014; 7; (5): 1. 
145. Fraser A, Tilling K, MacDonald-Wallis C, Sattar N, Brion M, Benfield L, et al. Association of maternal weight gain in pregnancy with offspring obesity and metabolic and vascular traits in childhood. Circulation. 2010; 121(23): 2557-2564.

146. Oken E, Kleinman KP, Belfort MB, Hammitt JK, Gillman MW. Associations of gestational weight gain with short and larger term maternal and child health outcomes. Am J Epidemiol. 2009; 170: 173-180.

147. Mechanick JI, Youdim A, Jones DB, Garvey WT, Hurley DL, McMahon $\mathrm{MM}$, et al. Clinical practice guidelines for the perioperative nutritional, metabolic, and nonsurgical support of the bariatric surgery patient-2013 update: Cosponsored by American association of clinical endocrinologists, the obesity society, and American society for metabolic \& bariatric surgery. Obesity. 2013; 21(Suppl. 1): S1-S27.

148. Busetto L, Dixon J, De Luca M, Shikora S, Pories W, Angrisani L. Bariatric surgery in class I obesity: A position statement from the international federation for the surgery of obesity and metabolic disorders (IFSO). Obes Surg. 2014; 24(4): 487-519.

149. Ruiz-Tovar J, Boix E, Bonete JM, Martínez R, Zubiaga L, Díez M, et al. Effect of preoperative eating patterns and preoperative weight loss on the short- and mid-term weight loss results of sleeve gastrectomy. Cir Esp. 2015; 93(4): 241-247.

150. Kular KS, Manchanda N, Rutledge R. A 6-year experience with 1,054 mini-gastric bypasses - First study from Indian subcontinent. Obes Surg. 2014; 24(9): 1430-1435.

151. Vázquez A, Montalva E, De Tursi IC. Valoración de la evolución de las comorbilidades de la obesidad mórbida tras tratamiento quirúrgico mediante la técnica del cruce duodenal. Nutr. Hosp. 2007; 22: 596-601.

152. El Chaar M, Claros L, Ezeji GC, Miletics M, Stoltzfus J. Improving outcome of bariatric surgery: Best practices in an accredited surgical center. Obes Surg. 2014; 24(7): 1057-1063. 
153. Finkel KJ, Searleman AC, Tymkew H, Tanaka CY, Saager L, Safer-Zadeh E, et al. Prevalence of undiagnosed obstructive sleep apnea among adult surgical patients in an academic medical center. Sleep Med. 2009; 10(7): 753-758.

154. Masuoka HC, Chalasani N. Nonalcoholic fatty liver disease: Anemerging threat to obese and diabetic individuals. Ann NY AcadSci. 2013; 1281:106-22.

155. Márquez Ferrer M. Influencia de la cirugía bariátrica en el hígado graso no alcohólico. Evaluación histológica [tesis doctoral]. Granada: Editorial de la Universidad de Granada; 2008.

156. Lacy AM, Delgado S. Controversias en cirugía laparoscópica de la obesidad. Contraindicaciones y límites de la cirugía laparoscópica. Cir Esp. 2004; 75(5): 287-289.

157. Lent MR, Hayes SM, Wood GC, Napolitano MA, Argyropoulos G, Gerhard GS, et al. Smoking and alcohol use in gastric bypass patients. Eating Behav. 2013; 14(4): 460-463.

158. De Araujo Burgos MGP, Cabral PC, Maio R, Oliveira BMPM, Dias MSO, De Figueiredo Melim DB, et al. Prevalence of Alcohol Abuse Before and After Bariatric Surgery Associated With Nutritional and Lifestyle Factors: A Study Involving a Portuguese Population. Obes Surg. 2015.

159. Myers K, Hajek P, Hinds C, McRobbie H. Stopping smoking shortly before surgery and postoperative complications: A systematic review and metaanalysis. Arch Intern Med. 2011; 171(11): 983-989.

160. Lent MR, Hayes SM, Wood GC, Napolitano MA, Argyropoulos G, Gerhard GS, et al. Smoking and alcohol use in gastric bypass patients. Eating Behav. 2013; 14(4): 460-463.

161. Mechanick JI, Youdim A, Jones DB, Timothy Garvey W, Hurley DL, Molly McMahon $\mathrm{M}$, et al. Clinical practice guidelines for the perioperative nutritional, metabolic, and nonsurgical support of the bariatric surgery patient - 2013 update: Cosponsored by American Association of Clinical 
Endocrinologists, the Obesity Society, and American Society for Metabolic \& Bariatric Surgery. Surg Obes Relat Dis. 2013; 9(2): 159-191.

162. Odom J, Zalesin KC, Washington TL, Miller WW, Hakmeh B, Zaremba DL, et al. Behavioral predictors of weight regain after bariatric surgery. Obes Surg. 2010; 20(3): 349-356.

163. De Araujo Burgos MGP, Cabral PC, Maio R, Oliveira BMPM, Dias MSO, De Figueiredo Melim DB, et al. Prevalence of Alcohol Abuse Before and After Bariatric Surgery Associated With Nutritional and Lifestyle Factors: A Study Involving a Portuguese Population. Obes Surg. 2015; 25(9):17161722.

164. King WC, Chen J-, Mitchell JE, Kalarchian MA, Steffen KJ, Engel SG, et al. Prevalence of alcohol use disorders before and after bariatric surgery. JAMA. 2012; 307(23): 2516-2525.

165. Conason A TJ, Hsu CH, Puma L, Knafo D, Geliebter A. Substance use following bariatric weight loss surgery. JAMA Surg. 2013; 148(2): 145-150.

166. Cassie S, Menezes C, Birch D, Shi X, Karmali S. Effect of preoperative weight loss in bariatric surgical patients: A systematic review. Surg Obes Relat Dis. 2011; 7: 760-768.

167. Lewis M, Phillips M, Slavotinek J, Kow L, Thompson C, Toouli J. Change in liver size and fat content after treatment with Optifast ${ }^{\circledR}$ very low calorie diet. Obes Surg. 2006; 16: 697-701.

168. Martínez-Ramos D, Salvador-Sanchis JL, Escrig-Sos J. Preoperative weight loss in bariatric surgery candidate patients. Evidence based recommendations. Cir Esp. 2012; 90(3):147-155.

169. Benjaminov O, Beglaibter N, Gindy L, Spivak H, Singer P, Wienberg M, et al. The effect of a low-carbohydrate diet on the nonalcoholic fatty liver in morbidly obese patients before bariatric surgery. Surg Endosc. 2007; 21: 1423-1427. 
170. Nomura F, Ohnishi K, Ochiai T, Okuda K. Obesity-related nonalcoholic fatty liver: CT features and follow-up studies after low-calorie diet. Radiology. 1987; 162: 845-847.

171. Lim RB, Blackburn GL, Jones DB. Benchmarking Best Practices in Weight Loss Surgery. Curr Probl Surg. 2010; 47(2): 79-174.

172. Angrisani L, Santonicola A, lovino P, Formisano G, Buchwald H, Scopinaro N. Bariatric Surgery Worldwide 2013. Obes Surg. 2015.

173. Escalona A, Boza C, Muñoz R, Pérez G, Rayo S, Crovari F, et al. Routine preoperative ultrasonography and selective cholecystectomy in laparoscopic roux-en-Y gastric bypass. Why not? Obes Surg. 2008; 18(1): 47-51.

174. Venneman NG, van Erpecum KJ. Gallstone disease: primary and secondary prevention. Best Pract Res Clin Gastroenterol 2006; 20(6): 1063-1073.

175. Rutledge $D$, Jones $D$, Rege R. Consequences of delay in surgical treatment of biliary disease. Am J Surg 2000; 180(6): 466-469.

176. Fobi MAL, Lee $\mathrm{H}$. The surgical technique of the Fobi-Pouch operation for obesity (The transected silastic vertical gastric bypass). Obes Surg. 1998; 8(3): 283-288.

177. Baltasar A, Bou R, Del Río J, Bengochea M, Escrivá C, Miró J et al. Cirugía bariátrica: resultados a largo plazo de la gastroplastia vertical anillada ¿Una esperanza frustrada? Cir Esp. 1997; 62: 175-179.

178. Deitel M, Greenstein RJ. Recommendations for reporting weigth loss. Obes Surg 2003; 13: 159-160.

179. Lee W, Yu P, Wang W, Chen T, Wei P, Huang M. Laparoscopic Roux-en$Y$ versus mini-gastric bypass for the treatment of morbid obesity: $A$ prospective randomized controlled clinical trial. Ann Surg. 2005; 242(1): 20-28. 
180. Van De Laar A, De Caluwé L, Dillemans B. Relative outcome measures for bariatric surgery. Evidence against excess weight loss and excess body mass index loss from a series of laparoscopic Roux-en-Y gastric bypass patients. Obes Surg. 2011; 21(6): 763-767.

181. Bindal V, Gonzalez-Heredia R, Elli EF. Outcomes of Robot-Assisted Rouxen-Y Gastric Bypass as a Reoperative Bariatric Procedure. Obes Surg. 2015; 25(10): 1810-1815.

182. Lynch J, Belgaumkar A. Bariatric surgery is effective and safe in patients over 55: A systematic review and meta-analysis. Obes Surg. 2012; 22(9):1507-1516.

183. Fazylov R, Soto E, Merola S. Laparoscopic Roux-en-Y gastric bypass in morbidly obese patients > or $=55$ years old. Obes Surg. 2008; 18(6): 656659.

184. Papasavas PK, Gagné DJ, Kelly J, et al. Laparoscopic Roux-En-Y gastric bypass is a safe and effective operation for the treatment of morbid obesity in patients older than 55 years. Obes Surg. 2004; 14(8): 10561061.

185. Sosa JL, Pombo H, Pallavicini H, et al. Laparoscopic gastric bypass beyond age 60. Obes Surg. 2004; 14(10): 1398-1401.

186. Willkomm CM, Fisher TL, Barnes GS, et al. Surgical weight loss > 65 years old: is it worth the risk? Surg Obes Relat Dis. 2010; 6(5): 491-496.

187. Frutos MD, Luján J, Hernández Q, et al. Results of laparoscopic gastric bypass in patients $>$ or $=55$ years old. Obes Surg. 2006; 16(4): 461-464.

188. Mittermair RP, Aigner F, Obermüller S. Results and complications after Swedish adjustable gastric banding in older patients. Obes Surg. 2008; 18(12): 1558-1562.

189. Søvik TT, Aasheim ET, Taha O, My Engström RN, Fagerland MW, Björkman S, et al. Weight loss, cardiovascular risk factors, and quality of 
life after gastric bypass and duodenal switch: A randomized trial. Ann Intern Med. 2011; 155(5): 281-291.

190. Suárez Llanos J.P. Comparación del déficit nutricional tras bypass gástrico vs. derivación biliopancreática [tesis doctoral]. Madrid: Servicio de publicaciones de la Universidad Complutense de Madrid; 2013.

191. Contreras J.E, Santander C, Court I, Bravo J. Correlation Between Age and Weight Loss after Bariatric Surgery. Obes Surg. 2010; 23:1286-1289.

192. Chevallier JM, Arman GA, Guenzi M, Rau C, Bruzzi M, Beaupel N, et al. One Thousand Single Anastomosis (Omega Loop) Gastric Bypasses to Treat Morbid Obesity in a 7-Year Period: Outcomes Show Few Complications and Good Efficacy. Obes Surg. 2015; 25(6):951-958.

193. Cigaina V. Gastric pacing as therapy for morbid obesity: preliminary results. Obes Surg 2002; 12(Suppl.): 12-16.

194. Dixon JB, McPhail T, O'Brien PE. Minimal reporting requirements for weight loss: current methods not ideal. Obes Surg. 2005; 15(7): 10341039.

195. Van De Laar A. Bariatric outcomes longitudinal database (BOLD) suggests excess weight loss and excess BMI loss to be inappropriate outcome measures, demonstrating better alternatives. Obes Surg. 2012; 22(12): 1843-1847.

196. Biron S, Hould F, Lebel S, et al. Twenty years of biliopancreatic diversion: what is the goal of the surgery? Obes Surg. $2004 ; 14: 160-164$.

197. Lee CMY, Huxley RR, Wildman RP, Woodward M. Indices of abdominal obesity are better discriminators of cardiovascular risk factors than BMI: a meta-analysis. J Clin Epidemiol 2008; 61: 646-653.

198. Iannelli A, Martini F, Rodolphe A, Schneck A, Gual P, Tran A, et al. Body composition, anthropometrics, energy expenditure, systemic inflammation, inpremenopausal women 1 year after laparoscopic Roux-en-Y gastric 
bypass. Surgical Endoscopy and Other Interventional Techniques. 2014; 28(2): 500-507.

199. Ebrahimi-Mameghani M, Scott JA, Der G, Lean ME, Burns CM. Changes in weight and waist circumference over 9 years in a Scottish population. Eur J Clin Nutr. 2008; 62: 1208-1214.

200. Stevens J, Katz EG, Huxley RR. Associations between gender, age and waist circumference. Eur J Clin Nutr. 2010; 64(1): 6-15.

201. Jastrzębska-Mierzyńska M, Ostrowska L, Hady HR, Dadan J, Konarzewska-Duchnowska $\mathrm{E}$. The impact of bariatric surgery on nutritional status of patients. Videosurgery Miniinv 2015; 10 (1): 115-124.

202. Vest AR, Heneghan HM, Agarwal S, Schauer PR, Young JB. Bariatric surgery and cardiovascular outcomes: A systematic review. Heart. 2012; 98(24): 1763-1777.

203. Puig T, Ferrero-Gregori A, Roig E, Vazquez R, Gonzalez-Juanatey JR, Pascual-Figal D, et al. Prognostic value of body mass index and waist circumference in patients with chronic heart failure (Spanish REDINSCOR registry). Rev Esp Cardiol. 2014; 67(2): 101-106.

204. Formiguera Sala X. Dieta postcirugía bariátrica. En: Salas Salvado J, Bonada i Sanjaume A, Trallero Casañas R, Saló i Sola M. Nutrición y Dietética Clínica. Barcelona: Doyma; 2000. 178-179.

205. Rubio MA, Salas-Salvadó J, Moreno C. Pautas alimentarias postcirugía bariátrica. En: Rubio MA, editor. Manual de obesidad mórbida. Madrid: Editorial Médica Panamericana; 2006. p. 301-308.

206. Parkes E. Nutritional management of patients after bariatric surgery. Am J Med Sci 2006; 331: 207-213.

207. Rubio MA, Moreno C. Nutritional implications of bariatric surgery on the gastrointestinal tract. Nutricion Hospitalaria. 2007; 22(Suppl. 2): 124-134.

208. King WC, Chen J-, Bond DS, Belle SH, Courcoulas AP, Patterson EJ, et al. Objective assessment of changes in physical activity and sedentary 
behavior: Pre- through 3 years post-bariatric surgery. Obesity. 2015; 23(6): 1143-1150.

209. Reid RER, Carver TE, Andersen KM, Court O, Andersen RE. Physical Activity and Sedentary Behavior in Bariatric Patients Long-Term PostSurgery. Obes Surg. 2015; 25(6): 1073-1077.

210. Milone M, Di Minno MND, Leongito M, Maietta $\mathrm{P}$, Bianco $\mathrm{P}$, Taffuri $\mathrm{C}$, et al. Bariatric surgery and diabetes remission: Sleeve gastrectomy or minigastric bypass? World Journal of Gastroenterology. 2013; 19(39): 65906597.

211. Brethauer SA, Aminian A, Romero-Talamás H, Batayyah E, Mackey J, Kennedy $\mathrm{L}$, et al. Can diabetes be surgically cured? Long-term metabolic effects of bariatric surgery in obese patients with type 2 diabetes mellitus. Ann Surg. 2013; 258(4): 628-636.

212. Kim Z, Hur KY. Laparoscopic mini-gastric bypass for type 2 diabetes: The preliminary report. World J Surg. 2011; 35(3): 631-636.

213. Bruzzi M, Rau C, Voron T, Guenzi M, Berger A, Chevallier J-. Single anastomosis or mini-gastric bypass: Long-term results and quality of life after a 5-year follow-up. Surg Obes Relat Dis. 2015; 11(2): 321-327.

214. Milone $M$, Lupoli $R$, Maietta $P$, Di Minno A, Bianco $P$, Ambrosino $P$, et al. Lipid profile changes in patients undergoing bariatric surgery: $A$ comparative study between sleeve gastrectomy and mini-gastric bypass. Int J Surg. 2015; 14: 28-32.

215. Fox CS. Predictors of new-onset kidney disease in a community based population. JAMA. 2004; 291(7):844-850.

216. Hsu CY, Iribarren C, McCulloch CE, et al. Risk factors for endstage renal disease: 25-year follow-up. Arch Intern Med. 2009; 169(4): 342-350.

217. Alexander JW, Goodman HR, Hawver LR, et al. Improvement and stabilization of chronic kidney disease after gastric bypass. Surg Obes Relat Dis. 2009; 5: 237-241. 
218. Getty JLZ, Hamdallah IN, Shamseddeen HN, Wu J, Low RK, Craig J, et al. Changes in renal function following Roux-en-Y gastric bypass: $A$ prospective study. Obes Surg. 2012; 22(7): 1055-1059.

219. Hou C, Shyu R, Lee W, Ser K, Lee Y, Chen S. Improved renal function 12 months after bariatric surgery. Surg Obes Relat Dis. 2013; 9(2): 202-206.

220. Reid TJ, Saeed S, McCoy S, Osewa AA, Persaud A, Ahmed L. The effect of bariatric surgery on renal function. Surg Obes Relat Dis. 2014; 10(5): 808-813.

221. Aller R, Izaola O, Ruiz-Rebollo L, Pacheco D, de Luis DA. Predictive factors of non-alcoholic steatohepatitis: Relationship with metabolic syndrome. Nutr Hosp. 2015; 31(6): 2496-2502.

222. Sagredo S, Brahm J, Uribe M, Codoceo V, Smok G. Acute liver failure after bariatric surgery. A case report and literature review. Gastroenterol Hepatol. 2013; 36(2): 76-80.

223. Cusi K. Role of obesity and lipotoxicity in the development of nonalcoholic steatohepatitis: pathophysiology and clinical implications. Gastroenterology. 2012; 142: 711-725.

224. Burza MA, Romeo S, Kotronen A, Svensson P, Sjöholm K, Torgerson JS, et al. Long-Term Effect of Bariatric Surgery on Liver Enzymes in the Swedish Obese Subjects (SOS) Study. PLoS ONE. 2013; 8(3).

225. Xourafas D, Ardestani A, Ashley SW, Tavakkoli A. Impact of weight-loss surgery and diabetes status on serum ALT levels. Obes Surg. 2012; 22(10): 1540-1547.

226. Ponsky TA, Brody F, Pucci E. Alterations in gastrointestinal physiology after Roux-en-Y gastric bypass. J Am Coll Surg 2005; 201(1): 125-131.

227. Aills L, Blankenship J, Buffington C, Furtado M, Parrott J. ASMBS Allied Health Nutritional Guidelines for the Surgical Weight Loss Patient. Surg Obes Relat Dis 2008; 4(5 Suppl): S73-108. 
228. Gobato RC, Chaves DFS, Chaim EA. Micronutrient and physiologic parameters before and 6 months after RYGB. Surg Obes Relat Dis. 2014; 10(5): 944-951.

229. Toh SY, Zarshenas N, Jorgensen J. Prevalence of nutrient deficiencies in bariatric patients. Nutrition 2009; 25: 1150-1156.

230. Dalcanale L, Oliveira CPMS, Faintuch J, et al. Long-term nutritional outcome after bypass. Obes Surg 2010; 20: 181-187.

231. Ho T, et al. Long-term results after laparoscopic roux-en-Y gastric bypass: 10-year follow-up. Surg Obes Relat Dis 2009; 5: Abstract PL-211.

232. Flancbaum L, Belsley S, Drake V, Colarusso T, Tayler E. Preoperative nutritional status of patients undergoing Roux-en-Y gastric bypass for morbid obesity. J Gastrointest Surg 2006; 10: 1033-1037.

233. Ernst B, Thurnheer M, Schmid SM, Schultes B. Evidence for the necessity to systematically assess micronutrient status prior to bariatric surgery. Obes Surg 2009; 19: 66-73.

234. Bermejo F, García-López S. A guide to diagnosis of iron deficiency and iron deficiency anemia in digestive diseases. World J Gastroenterol. 2009; 15: 4638-4643.

235. Billeter AT, Probst P, Fischer L, Senft J, Kenngott HG, Schulte T, et al. Risk of Malnutrition, Trace Metal, and Vitamin Deficiency Post Roux-en-Y Gastric Bypass - a Prospective Study of 20 Patients with BMI $<35 \mathrm{~kg} / \mathrm{m} 2$.

236. Bugianesi E, Manzini P, D'Antico S, et al. Relative contribution of iron burden, HFE mutations, and insulin resistance to fibrosis in non alcoholic fatty liver. Hepatology 2004; 39: 179-187.

237. Heber D, Greenway FL, Kaplan LM, Livingston E, Salvador J, Still C, Endocrine Society. Endocrine and Nutritional management of the postbariatric surgery patient: an Endocrine Society Clinical Practice Guideline. J Clin Endocrinol Metab. 2010; 95(11): 4823-4843. 
238. Aarts EO, van Wageningen B, Janssen IM, Berends FJ. Prevalence of anemia and related deficiencies in the first year following laparoscopic gastric bypass for morbid obesity. J Obes. 2012; 2012: 193705.

239. Cable CT, Colbert CY, Showalter T, et al. Prevalence of anemia after RouX-en-Y gastric bypass surgery: what is the right number? Surg Obes Relat Dis. 2011; 7: 134-139.

240. Vargas-Ruiz AG, Hernandez-Rivera G, Herrera MF. Prevalence of iron, folate, and B12 deficiency anemia after laparoscopic RouX-en-Y gastric bypass. Obes Surg. 2008; 18: 288-293.

241. Wald DS, Bestwick JP, Wald NJ. Homocysteine as a cause of ischemic heart disease: The door remains open. Clin Chem. 2012; 58(10): 14881490.

242. Worm D, Madsbad S, Kristiansen VB, Naver L, Hansen DL. Changes in Hematology and Calcium Metabolism After Gastric Bypass Surgery a 2Year Follow-Up Study. Obes Surg. 2015.

243. Slater G, Ren C, Siegel N, Williams T, Barr D, Wolfe B, et al. Serum fatsoluble vitamin deficiency and abnormal calcium metabolism after malabsorptive bariatric surgery. J Gastrointest Surg. 2004; 8(1): 48-55.

244. Bloomberg RD, Fleishman A, Nalle JE, Herron DM, Kini S. Nutritional Deficiencies following Bariatric Surgery: What Have We Learned? Obes Surg 2005; 15: 145-154.

245. Casagrande DS, Repetto G, Mottin CC, Shah J, Pietrobon R, Worni M, et al. Changes in bone mineral density in women following 1-year gastric bypass surgery. Obes Surg. 2012; 22(8): 1287-1292.

246. De Luis DA, Pacheco D, Izaola O, Terroba MC, Cuellar L, Cabezas G. Micronutrient status in morbidly obese women before bariatric surgery. Surg Obes Relat Dis. 2013; 9(2): 323-327. 
247. Saif T, Strain GW, Dakin G, Gagner M, Costa R, Pomp A. Evaluation of nutrient status after laparoscopic sleeve gastrectomy 1, 3, and 5 years after surgery. Surg Obes Relat Dis. 2012; 8(5): 542-547. 


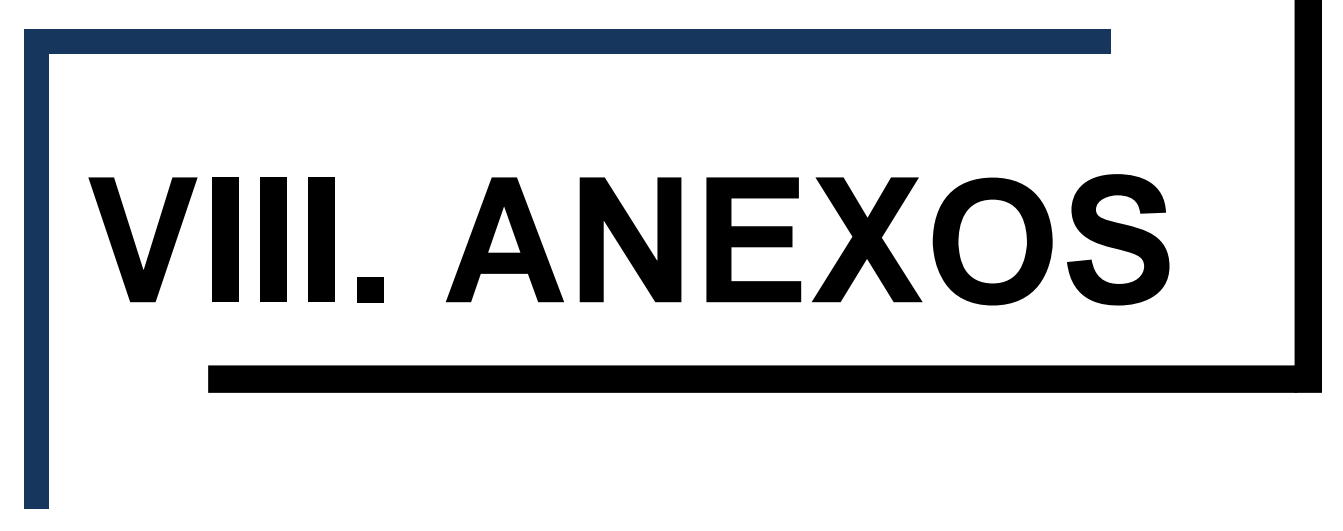




\section{ANEXO I}

Los Centros de Excelencia de Cirugía de la Obesidad acreditados por el European Council of Bariatric Surgery (Consejo Europeo de Cirugía Bariátrica) han establecido una base de datos europea en la que el tratamiento de los datos es absolutamente anónimo y confidencial, con carácter científico y estadístico por la que dichos centros están obligados a incluir a sus pacientes operados.

En este sentido autorizo al Centro de Excelencia para el Estudio $Y$ Tratamiento de la Obesidad de Valladolid, para la realización de dicho trabajo en el Registro del European Acreditation Council of Bariatric Surgery (EAC-BS)

Valladolid, a .de del $201 \ldots$

Fdo:

D.N.I: 


\section{ANEXO II}

\section{FICHA DE CONTROL POSTQUIRÚRGICO}

> FECHA RECOGIDA DATOS:

> NOMBRE:

$>$ APELLI DOS:

$>$ MAI L:

> TELÉFONO CONTACTO:

> CORREO ELECTRÓNICO:

\section{DATOS:}

- PESO ACTUAL:

- PERímetro de CI NTURA actual:

- PeRímetro de CADERA ACTUAL:

- NÚMERO DE COMIDAS AL DÍA:

- PICOTEA (SI/NO):

- tolerAnCia del ali MENTO (Reflejar con un círculo) : REGULAR...BUENA...ÓPTIMA... OBSERVACIONES:

- VÓMITOS (SI/NO):

- NÚMERO DE DEPOSICIONES DIARIAS:

- EjeRCICIO fÍsICO A LA SEMANA (REFLejar CON UN CÍRCULO) :

NUNCA...1 VEZ/SEMANA...2 VECES/SEMANA...DIARIO

- TRATAMIENTO FARMACOLÓGICO (INDICAR) : ........... 


\section{ANEXO III}

\section{MINISTERIO DE TRABAJO Y SEGURIDAD SOCIAL - SERVICIO NACIONAL DE APRENDIZAJE DIRECCIÓN DE EMPLEO - DIVISIÓN DE ESTUDIOS OCUPACIONALES CLASIFICACIÓN NACIONAL DE OCUPACIONES}

\begin{tabular}{|c|c|}
\hline & 1. FINANZAS Y ADMINISTRACIÓN \\
\hline \multirow{2}{*}{$\begin{array}{l}0 \text { Ocupación de } \\
\text { Dirección }\end{array}$} & $\begin{array}{l}\text { ÁREA OCUPACIONAL } 00 \\
\text { 001 ALTA DIRECCIÓN PÚBLICA Y PRIVADA }\end{array}$ \\
\hline & $\begin{array}{l}101 \text { Gerentes de servicios administrativos } \\
102 \text { Gerentes de servicios financieros y comerciales } \\
103 \text { Gerentes de servicios de comunicación }\end{array}$ \\
\hline $\begin{array}{l}\text { Nivel de } \\
\text { Preparación A }\end{array}$ & $\begin{array}{l}\text { Área ocupacional } 11 \\
\text { OCUPACIONES PROFESIONALES EN } \\
\text { ADMINISTRACIÓN Y FINANZAS } \\
111 \text { Contadores, auditores y profesionales en inversión } \\
112 \text { Profesionales en recursos humanos y organización de las } \\
\text { empresas }\end{array}$ \\
\hline $\begin{array}{l}\text { Nivel de } \\
\text { Preparación B }\end{array}$ & $\begin{array}{l}\text { Área Ocupacional } 12 \\
\text { OCUPACIONES ADMINISTRATIVAS } \\
121 \text { Jefes administrativos } \\
122 \text { Asistentes administrativos } \\
123 \text { Ocupaciones administrativas de finanzas y seguros } \\
124 \text { Secretarías, relatores y transcriptores }\end{array}$ \\
\hline $\begin{array}{l}\text { Nivel de } \\
\text { Preparación C }\end{array}$ & $\begin{array}{l}\text { Área Ocupacional } 13 \\
\text { OFICINISTAS Y AUXILIARES } \\
131 \text { Oficinistas en general } \\
132 \text { Operadores de equipo de oficina } \\
133 \text { Oficinistas de finanzas y seguros } \\
134 \text { Oficinistas de apoyo administrativo } \\
135 \text { Oficinistas de biblioteca, publicaciones, información y afines } \\
136 \text { Ocupaciones de distribución de correo y mensajería } \\
137 \text { Ocupaciones de registro, programación y distribución }\end{array}$ \\
\hline \multicolumn{2}{|c|}{ 2. CIENCIAS NATURALES, APLICADAS Y RELACIONADAS } \\
\hline \multirow{2}{*}{$\begin{array}{l}0 \text { Ocupación de } \\
\text { Dirección }\end{array}$} & $\begin{array}{l}\text { ÁREA OCUPACIONAL } 00 \\
\text { O01 ALTA DIRECCIÓN PÚBLICA Y PRIVADA }\end{array}$ \\
\hline & $\begin{array}{l}201 \text { Gerentes de ingeniería, arquitectura, ciencias y sistemas de } \\
\text { información }\end{array}$ \\
\hline $\begin{array}{l}\text { Nivel de } \\
\text { Preparación A }\end{array}$ & $\begin{array}{l}\text { Área Ocupacional } 21 \\
\text { OCUPACIONES PROFESIONALES EN CIENCIAS } \\
\text { NATURALES Y APLICADAS } \\
211 \text { Profesionales en ciencias físicas y químicas }\end{array}$ \\
\hline
\end{tabular}




\begin{tabular}{|c|c|}
\hline & $\begin{array}{l}212 \text { Profesionales en ciencias biológicas } \\
213 \text { Ingenieros civiles, mecánicos, eléctricos y químicos } \\
214 \text { Otros ingenieros } \\
215 \text { Arquitectos y urbanistas } \\
216 \text { Matemáticos, analistas y programadores de sistemas. }\end{array}$ \\
\hline $\begin{array}{l}\text { Ár } \\
\mathbf{O} \\
\mathbf{C I} \\
22 \\
22 \\
22 \\
22 \\
22 \\
\text { ca } \\
22 \\
22\end{array}$ & $\begin{array}{l}\text { Área Ocupacional } 22 \\
\text { OCUPACIONES TÉCNICAS RELACIONADAS CON LAS } \\
\text { CIENCIAS NATURALES Y APLICADAS } \\
221 \text { Ocupaciones técnicas en ciencias físicas } \\
222 \text { Ocupaciones técnicas en ciencias biológicas } \\
223 \text { Ocupaciones téc. en ingeniería civil, mecánica e industrial } \\
224 \text { Ocupaciones técnicas en ingeniería eléctrica y electrónica } \\
225 \text { Ocupaciones técnicas en arquitectura, dibujo, agrimensura y } \\
\text { cartografía } \\
226 \text { Inspectores de normas técnicas y funcionarios de regulación } \\
227 \text { Oficiales y controladores de transporte }\end{array}$ \\
\hline \multicolumn{2}{|r|}{ 3. SALUD } \\
\hline \multirow{2}{*}{$\begin{array}{l}0 \text { Ocupación de } \\
\text { Dirección }\end{array}$} & $\begin{array}{l}\text { ÁREA OCUPACIONAL } 00 \\
\text { 001 ALTA DIRECCIÓN PÚBLICA Y PRIVADA }\end{array}$ \\
\hline & 301 Gerentes de servicios a la salud \\
\hline Nivel de Preparación A & $\begin{array}{l}\text { Área Ocupacional } 31 \\
\text { OCUPACIONES PROFESIONALES EN SALUD } \\
311 \text { Médicos, odontólogos y veterinarios } \\
312 \text { Optómetras y otros profesionales del tratamiento de la } \\
\text { salud } \\
\text { 313 Farmacéuticos, dietistas y nutricionistas } \\
\text { 314 Profesionales en terapia y valoración } \\
315 \text { Enfermeras licenciadas }\end{array}$ \\
\hline Nivel de Preparación B & $\begin{array}{l}\text { Área Ocupacional } 32 \\
\text { OCUPACIONES TÉCNICAS EN SALUD } \\
321 \text { Tecnólogos y técnicos en salud } \\
322 \text { Otras ocupaciones técnicas en cuidados de la salud }\end{array}$ \\
\hline Nivel de Preparación C & $\begin{array}{l}\text { Área Ocupacional } 33 \\
\text { OCUPACIONES AUXILIARES EN SERVICIOS DE LA } \\
\text { SALUD } \\
\text { 331 Auxiliares en servicios de la salud }\end{array}$ \\
\hline \multicolumn{2}{|c|}{$\begin{array}{l}\text { 4. CIENCIAS SOCIALES, EDUCACIÓN, ADMINISTRACIÓN PÚBLICA Y } \\
\text { RELIGIÓN }\end{array}$} \\
\hline \multirow{2}{*}{$\begin{array}{l}0 \text { Ocupación de } \\
\text { Dirección }\end{array}$} & $\begin{array}{l}\text { ÁREA OCUPACIONAL } 00 \\
\text { 001 ALTA DIRECCIÓN PÚBLICA Y PRIVADA }\end{array}$ \\
\hline & $\begin{array}{l}401 \text { Gerentes de administración pública } \\
402 \text { Gerentes de educación, servicios sociales y comunitarios }\end{array}$ \\
\hline $\begin{array}{l}\text { Nivel de Preparación } \\
\text { A }\end{array}$ & $\begin{array}{l}\text { Área Ocupacional } 41 \\
\text { OCUPACIONES PROFESIONALES EN CIENCIAS } \\
\text { SOCIALES, EDUCACIÓN, ADMINISTRACIÓN }\end{array}$ \\
\hline
\end{tabular}




\begin{tabular}{|c|c|}
\hline & $\begin{array}{l}\text { PÚBLICA Y RELIGIÓN } \\
411 \text { Jueces y abogados } \\
412 \text { Profesores y asistentes de educación superior } \\
413 \text { Instructores de formación profesional y vocacional } \\
414 \text { Profesores y consejeros pedagógicos, educación media y } \\
\text { básica. } \\
415 \text { Psicólogos, trabajadores sociales y clérigos } \\
416 \text { Investigadores y consultores de políticas y programas } \\
\text { oficiales }\end{array}$ \\
\hline $\begin{array}{l}\text { Nivel de Preparación } \\
\text { B }\end{array}$ & $\begin{array}{l}\text { Área Ocupacional } 42 \\
\text { OCUPACIONES DE NIVEL MEDIO EN SERVICIO } \\
\text { SOCIAL, EDUCACIÓN Y RELIGIÓN } \\
421 \text { Ocupaciones de nivel medio en servicio social, educación y } \\
\text { religión }\end{array}$ \\
\hline \multicolumn{2}{|r|}{ 5. ARTE, CULTURA, RECREACIÓN Y DEPORTE } \\
\hline \multirow{2}{*}{$\begin{array}{l}0 \text { Ocupación de } \\
\text { Dirección }\end{array}$} & $\begin{array}{l}\text { ÁREA OCUPACIONAL } 00 \\
\text { 001 ALTA DIRECCIÓN PÚBLICA Y PRIVADA }\end{array}$ \\
\hline & 501 Gerentes de arte, cultura, recreación y deporte \\
\hline $\begin{array}{l}\text { Nivel de Preparación } \\
\text { A }\end{array}$ & $\begin{array}{l}\text { Área Ocupacional } 51 \\
\text { OCUPACIONES PROFESIONALES EN ARTE Y } \\
\text { CULTURA } \\
511 \text { Bibliotecarios, archivistas y restauradores } \\
512 \text { Escritores, traductores y profesionales de relaciones públicas } \\
513 \text { Artistas, creativos y escénicos }\end{array}$ \\
\hline $\begin{array}{l}\text { Nivel de Preparación } \\
\text { B }\end{array}$ & $\begin{array}{l}\text { Área Ocupacional } 52 \\
\text { OCUPACIONES TÉCNICAS Y ESPECIALIZADAS EN } \\
\text { ARTE, CULTURA, RECREACIÓN Y DEPORTE } \\
521 \text { Ocupaciones técnicas en museos y galerías } \\
522 \text { Fotógrafos y aplicaciones técnicas en arte gráfico, cine, } \\
\text { radio, TV y artes escénicas } \\
523 \text { Locutores y otros artistas del espectáculo } \\
524 \text { Diseñadores y artesanos } \\
525 \text { Deportistas, entrenadores, árbitros y ocupaciones } \\
\text { relacionadas }\end{array}$ \\
\hline \multicolumn{2}{|r|}{ 6. VENTAS Y SERVICIOS } \\
\hline \multirow[b]{2}{*}{$\begin{array}{l}0 \text { Ocupación de } \\
\text { Dirección }\end{array}$} & $\begin{array}{l}\text { ÁREA OCUPACIONAL } 00 \\
\text { 001 ALTA DIRECCIÓN PÚBLICA Y PRIVADA }\end{array}$ \\
\hline & $\begin{array}{l}601 \text { Gerentes de ventas, mercadeo y publicidad } \\
602 \text { Gerentes de comercio al por menor } \\
603 \text { Gerentes de servicios de alimentos y alojamiento } \\
604 \text { Oficiales de servicios de protección y defensa } \\
605 \text { Gerentes de otros servicios }\end{array}$ \\
\hline \multicolumn{2}{|l|}{$\begin{array}{l}\text { Nivel de Preparación } \\
\text { A }\end{array}$} \\
\hline Nivel de & Área Ocupacional 62 \\
\hline
\end{tabular}




\begin{tabular}{|c|c|}
\hline B & $\begin{array}{l}\text { OCUPACIONES TÉCNICAS EN VENTAS Y SERVICIOS } \\
621 \text { Superiores y administradores de ventas y servicios } \\
622 \text { Superiores y técnicos de los servicios de protección y } \\
\text { defensa } \\
623 \text { Ocupaciones técnicas en ventas y compradores } \\
624 \text { Chefs }\end{array}$ \\
\hline $\begin{array}{l}\text { Nivel de Preparación } \\
\text { C }\end{array}$ & $\begin{array}{l}\text { Área Ocupacional } 63 \\
\text { OCUPACIONES INTERMEDIAS EN VENTAS Y } \\
\text { SERVICIOS } \\
\text { 631 Representantes de ventas } \\
632 \text { Dependientes de comercios y servicios } \\
633 \text { Ocupaciones de servicios a pasajeros } \\
634 \text { Guías de turismo y recreación } \\
635 \text { Ocupaciones de servicios de alimentos y bebidas } \\
636 \text { Ocupaciones de servicios de protección } \\
637 \text { Ocupaciones de servicios personales }\end{array}$ \\
\hline $\begin{array}{l}\text { Nivel de Preparación } \\
\text { D }\end{array}$ & $\begin{array}{l}\text { Area Ocupacional } 66 \\
\text { OCUPACIONES ELEMENTALES EN VENTAS Y } \\
\text { SERVICIOS } \\
661 \text { Ocupaciones auxiliares en ventas } \\
662 \text { Auxiliares de cafetería } \\
663 \text { Aseadores } \\
664 \text { Auxiliares de servicios }\end{array}$ \\
\hline \multicolumn{2}{|r|}{ 7. EXPLOTACIÓN PRIMARIA Y EXTRACTIVA } \\
\hline \multirow{2}{*}{$\begin{array}{l}0 \text { Ocupación de } \\
\text { Dirección }\end{array}$} & $\begin{array}{l}\text { ÁREA OCUPACIONAL } 00 \\
\text { O01 ALTA DIRECCIÓN PÚBLICA Y PRIVADA }\end{array}$ \\
\hline & 701 Gerentes de producción primaria y extractiva \\
\hline \multicolumn{2}{|l|}{$\begin{array}{l}\text { Nivel de Preparación } \\
\text { A }\end{array}$} \\
\hline $\begin{array}{l}\text { Nivel de Preparación } \\
\text { B }\end{array}$ & $\begin{array}{l}\text { Área Ocupacional } 72 \\
\text { OCUPACIONES TÉCNICAS DE LA ACTIVIDAD } \\
\text { PRIMARIA Y EXTRACTIVA } \\
721 \text { Supervisores de minería, petróleo y gas } \\
722 \text { Supervisores de agricultura, pecuario y silvicultura } \\
723 \text { Ocupaciones técnicas de la explotación minera y perforación } \\
\text { de petróleo y gas } \\
724 \text { Contratistas y administradores en agricultura, ganadería y } \\
\text { acuicultura } \\
725 \text { Expertos en pesca }\end{array}$ \\
\hline $\begin{array}{l}\text { Nivel de Preparación } \\
\text { C }\end{array}$ & $\begin{array}{l}\text { Área Ocupacional } 73 \\
\text { OCUPACIONES INTERMEDIAS DE LA ACTIVIDAD } \\
\text { PRIMARIA Y EXTRACTIVA } \\
731 \text { Trabajadores de mantenimiento de minas y pozos de petróleo } \\
\text { y gas } \\
732 \text { Trabajadores forestales y de silvicultura } \\
733 \text { Trabajadores agropecuarios }\end{array}$ \\
\hline
\end{tabular}




\begin{tabular}{|l|l|}
\hline \multicolumn{1}{|l|}{} & 734 Trabajadores de pesca \\
\hline Nivel de Preparación & $\begin{array}{l}\text { Área Ocupacional 76 } \\
\text { OBREROS DE LA ACTIVIDAD PRIMARIA }\end{array}$ \\
\hline & \begin{tabular}{l} 
761 Obreros producción primaria y extractiva \\
\hline
\end{tabular} \\
\hline
\end{tabular}

8. OFICIOS, OPERADORES DE EQUIPO Y TRANSPORTE

\begin{tabular}{|l|l|}
\hline $\begin{array}{l}\text { 0 Ocupación de } \\
\text { Dirección }\end{array}$ & $\begin{array}{l}\text { ÁREA OCUPACIONAL 00 } \\
\text { O01 ALTA DIRECCIÓN PÚBLICA Y PRIVADA }\end{array}$ \\
\hline \begin{tabular}{l|l|} 
Nivel de Preparación \\
A
\end{tabular} & $\begin{array}{l}\text { 801 Gerente de construcción y transporte } \\
\text { 802 Gerentes de operación y mantenimiento de instalaciones }\end{array}$ \\
\hline $\begin{array}{ll}\text { Nivel de Preparación } \\
\text { B }\end{array}$ & $\begin{array}{l}\text { Área Ocupacional 82 } \\
\text { CONTRATISTAS Y SUPERVISORES DE OFICIOS Y Y }\end{array}$ \\
& $\begin{array}{l}\text { OPEADORES DE EQUIPO Y TRANSPORTE } \\
\text { 821 Supervisores y contratistas de oficios y operación de equipos } \\
\text { 822 Supervisores de operaciones de transporte ferroviario y } \\
\text { automotor }\end{array}$ \\
\hline & $\begin{array}{l}\text { Área Ocupacional 83, 84 y 85 } \\
\text { OFICIOS Y OPERADORES DE EQUIPO Y TRANSPORTE }\end{array}$ \\
\hline
\end{tabular}

831 Troquelistas y ajustadores de máquinas herramientas

832 Ocupaciones en electricidad y telecomunicaciones

833 Plomeros e instaladores de tubería

834 Ocupaciones de moldeo y montaje de estructuras metálicas

835 Carpinteros y ebanistas 836 Oficiales de construcción

837 Otras ocupaciones de la construcción

841 Mecánicos de maquinaria y equipo pesado

842 Mecánicos de vehículo automotor

Nivel de Preparación

843 Otros mecánicos

C

844 Tapiceros, sastres, marroquineros, joyeros y ocupaciones

relacionadas

845 Operadores de máquinas estacionarias y plantas de energía

846 Operadores de grúa, perforadoras y pegadoras

847 Operadores de equipo pesado

848 Otros trabajadores de reparación e instalación

851 Maquinista y ocupaciones de operación de transporte

ferroviario

852 Conductores de vehículo automotor

853 Otros operadores de equipo de transporte de pasajeros y

carga

854 Operarios portuarios y de transporte de materiales

\section{Área Ocupacional 86}

OBREROS Y AYUDANTES DE LA CONSTRUCCIÓN Y

Nivel de Preparación D
861 Ayudantes y obreros de construcción y otros oficios
862 Trabajadores del mantenimiento de obras públicas y otros trabajadores 


\section{PROCESAMIENTO, FABRICACIÓN Y ENSAMBLE DE BIENES}

\begin{tabular}{|l|}
\hline $\begin{array}{l}\text { 0 Ocupación de } \\
\text { Dirección }\end{array}$ \\
\hline $\begin{array}{l}\text { Nivel de Preparación } \\
\text { A }\end{array}$ \\
\hline
\end{tabular}

ÁREA OCUPACIONAL 00 O01 ALTA DIRECCIÓN PÚBLICA Y PRIVADA

901 Gerentes de Fabricación y Procesamiento de Bienes

A

\section{Área Ocupaciones 92}

SUPERVISORES Y OCUPACIONES TÉCNICAS EN

Nivel de Preparación PROCESAMIENTO Y FABRICACIÓN DE BIENES

B

921 Supervisores de procesamiento

922 Supervisores de fabricación y ensamble

923 Operadores de control y central, procesamiento y fabricación

\section{Área Ocupacional 93, 94}

OPERARIOS DE MÁQUINAS DE PROCESAMIENTO Y

FABRICACIÓN Y ENSAMBLADORES

931 Operarios de máquinas y trabajadores relacionados, procesamiento de metales y minerales

932 Operarios de máquinas y trabajadores relacionados, elaboración de productos químicos, plástico y caucho

933 Operarios de máquinas y trabajadores relacionados con el procesamiento de la madera y producción de pulpa y papel

Nivel de Preparación 934 Operarios de máquinas y trabajadores relacionados con la C

fabricación de textiles

935 Operarios de máquinas y trabajadores relacionados con la manufactura de productos de tela, piel y cuero

936 Operarios de máquinas y trabajadores relacionados con el procesamiento de alimentos, bebidas y tabaco.

937 Operarios de máquinas de impresión y de artes gráficas

938 Ensambladores de productos mecánicos, eléctricos y

electrónicos

939 Otros ensambladores y ocupaciones relacionadas

941 Operarios de máquinas para trabajar la madera y el metal

\section{Área Ocupacional 96}

Nivel de Preparación

D

\section{OBREROS DE PROCESAMIENTO, FABRICACIÓN Y}

SUMINISTRO DE SERVICIOS

961 Obreros de fabricación y procesamiento 
